\title{
BOUGAINVILLE before the conflict
}





\section{BOUGAINVILLE before the conflict}

EDITED BY

ANTHONY J REGAN AND HELGA M GRIFFIN

\section{ANU}

eView 


\section{ANU}

\section{eView}

Published by ANU eView

The Australian National University

Acton ACT 2601, Australia

Email: enquiries.eview@anu.edu.au

This title is also available online at http://eview.anu.edu.au

National Library of Australia Cataloguing-in-Publication entry

Title: Bougainville before the conflict / edited by Anthony J Regan and Helga M Griffin.

ISBN:

9781921934230 (paperback) 9781921934247 (ebook)

Subjects: $\quad$ Bougainville Island (Papua New Guinea)--History.

Bougainville Island (Papua New Guinea)--Politics and

government.

Bougainville Island (Papua New Guinea)--Social conditions.

Other Creators/Contributors:

Regan, A. J. (Anthony J.), editor.

Griffin, Helga, 1935- editor.

Dewey Number: 995.92

All rights reserved. No part of this publication may be reproduced, stored in a retrieval system or transmitted in any form or by any means, electronic, mechanical, photocopying or otherwise, without the prior permission of the publisher.

Cover image: Village in the mountains (unidentified) taken in 1908. Style matches Koromira sleeping houses on piles on the left as recorded by Frizzi in 1911. [Thurnwald 1912, Volume 1: Tableau VII, Figure 126].

Printed by Griffin Press

Previous edition (C) 2005 Pandanus Books, Research School of Pacific and Asian Studies,

The Australian National University

This edition (C) 2015 ANU eView

This book can be purchased from http://eview.anu.edu.au 


\section{CONTENTS}

List of Illustrations, Maps and Figures viii

Acknowledgments xiv

A Note for Readers

Introduction $\quad x x$

THE PLACE AND THE PEOPLE

Bougainville’s Early History: An Archaeological Perspective 1

Matthew Spriggs

$\begin{array}{ll}\text { The Geology of Bougainville } & 20\end{array}$

Hugh L. Davies

$\begin{array}{ll}\text { The Languages of Bougainville } & 31\end{array}$

Darell Tryon

An Introduction to Bougainville Cultures $\quad 47$ Eugene Ogan

Why do the People of Bougainville Look Unique? Some Conclusions 57

from Biological Anthropology and Genetics

Jonathan Friedlaender

THE COLONIAL PERIOD TO WORLD WAR II

Origins of Bougainville's Boundaries $\quad 72$

James Griffin

German Colonial Rule in the Northern Solomons 77

Peter Sack

$\begin{array}{ll}\text { The Pacification of Southern Bougainville, 1900-30 } & 108\end{array}$

Hugh Laracy

'Imperium in Imperio'? The Catholic Church in Bougainville 125 Hugh Laracy

1914: Changing the Guard at Kieta 136

Hugh Laracy

Between the Waitman's Wars: 1914-42 141

Peter Elder

$\begin{array}{lr}\text { Bougainville in World War II } & 168\end{array}$

Hank Nelson 


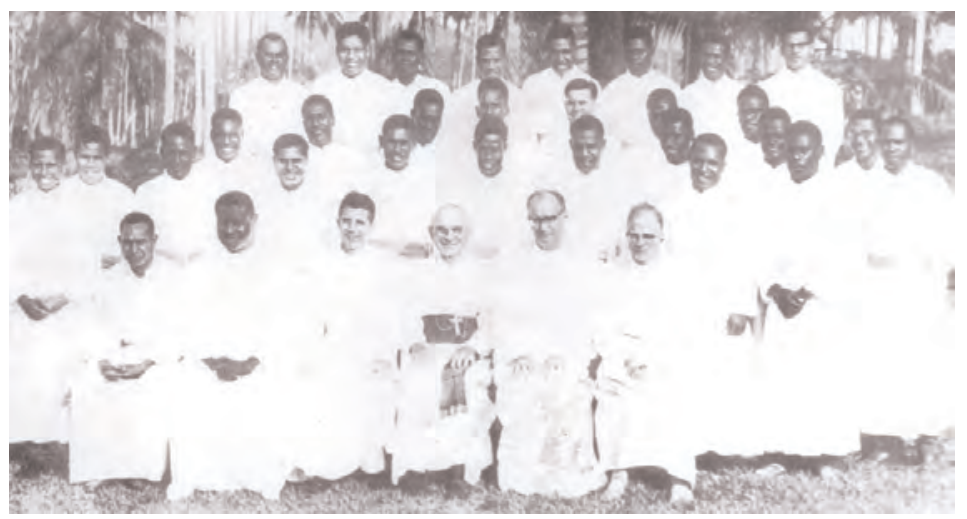

Seminarians from Papua New Guinea and Bougainville, 1964

[Aerts, 1994. By courtesy of Hugh Laracy, Auckland]

Sources on Pre-mining Bougainville

Helga M. Griffin

ECONOMIC AND SOCIAL CHANGE POST-WORLD WAR II

Post-War Reconstruction in Bougainville: Plantations,

Smallholders and Indigenous Capital

Scott MacWilliam

Post-1960s Cocoa and Copra Production in Bougainville Joachim Lumanni

The Panguna Mine

Don Vernon

Torau Response to Change

Melchior Togolo

Movements Towards Secession 1964-76

James Griffin

Shaping Leadership through Bougainville Indigenous Values and

Catholic Seminary Training — a Personal Journey John Lawrence Momis

The Bougainville Catholic Church and 'Indigenisation' Elizabeth Ibua Momis

PERSPECTIVES ON PARTICULAR BOUGAINVILLE SOCIETIES Buin Social Structure 


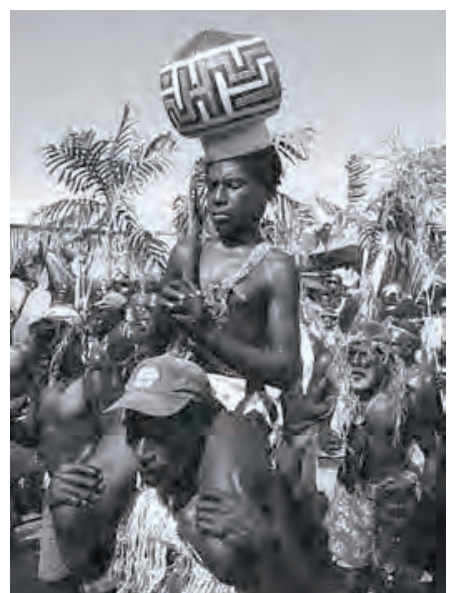

Boy in Upe hat carried aloft by elder during ceremony for the signing of the Bougainville Peace Agreement in Arawa, 30/08/2001.

[Papua New Guinea Post Courier Pictorial Archives 31/08/2001.

Photograph by Gorethy Kenneth]

We are Born Chiefs: Chiefly Identity and Power in Haku, Buka Island Bill Sagir

Land for Agriculture — Silent Women: Mens' Voices Roselyne Kenneth

Snapshots from Nasioi, 1963-2000

Eugene Ogan

Nagovisi Then and Now, 1963-2000 Jill Nash

Vignettes of Mogoroi Village, Buin, 1971-2004 Jared Keil

TOWARDS UNDERSTANDING THE ORIGINS OF THE CONFLICT Identities Among Bougainvilleans Anthony J. Regan

Nagovisi Villages as a Window on Bougainville in 1988 James Tanis

Historical Chronology 


\section{LIST OF ILLUSTRATIONS, MAPS AND FIGURES}

Village in the mountains

Cover image

Bougainvillean seminarians

Boy in Upe hat

vii

Men at Kieta in government hats

'Australia's Shame'

Buin people demonstrating panpipes

$\mathrm{xi}$

Bukas in traditional Muns

A family scene under a Nasioi house

Women dancing with fans

xvi

Key map for Bougainville

xxiv

Shards of Lapita pottery from Anir Island, north of Nissan

xxxviii

The distribution of Lapita culture sites in the Western Pacific, dating to between 3,300 and 2,700 years ago

The location of 'Greater Bougainville'

'Greater Bougainville' in its regional context

Archaeological sites on Nissan Island mentioned in the text

Seafloor topography

Simplified topographic map of Bougainville and Buka Islands

Geological map

Map of shallow earthquakes

The languages of Bougainville

Papuan and Austronesian language areas

The Oceanic subgroup of Austronesian languages 
Location of the North-West Solomonic group of Oceanic languages 36

The North-West Solomonic language group: genetic tree 36

Skin colour in Island Melanesia 59

Skin reflectance values for Bougainville, New Ireland, and New Britain $\quad 59$

Comparison of Bougainville skin reflectance $\quad 60$

Hair colour readings in Island Melanesia 61

Frequency distribution of mtDNA haplogroup B 66

Frequency distribution of two very old indigenous mtDNA haplogroups $\quad 67$

Frequency distribution of three mtDNA haplogroups (VII, X, and XII) 67

Bougainville marital migration rates 69

Boundary between Bougainville and Shortland Island and Fauro Islands 75

The Anglo-German Declaration of 1886

Plantations in 1948-1968 154

Bougainville cocoa production 1978/79-1998/99 246

Bougainville copra production 1985-1998 248

Smallholder cocoa production on Bougainville: 1962/63-1998/99 255

Domestic and world cocoa price trends: 1974-1999 255

Copra Prices in Papua New Guinea 1970-2000 256

The Panguna mine c. 1972

Relationship between sub-clans/settlements in Nakaripa Clan 349

Groupings within language groups 2005

Electoral boundaries 1972

Boy initiates in 1911 with their characteristic Upe head covers 566 


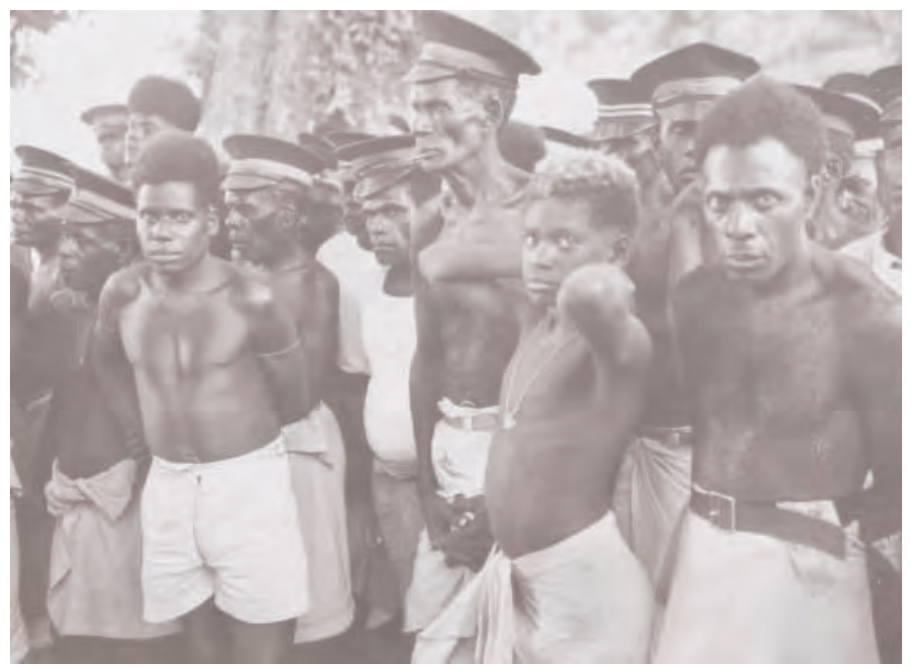

Men at Kieta in government hats listening in 1956 to a petition to be sent to the United Nations.

[Australian Information Service.

National Library of Australia Pictorial Archives]

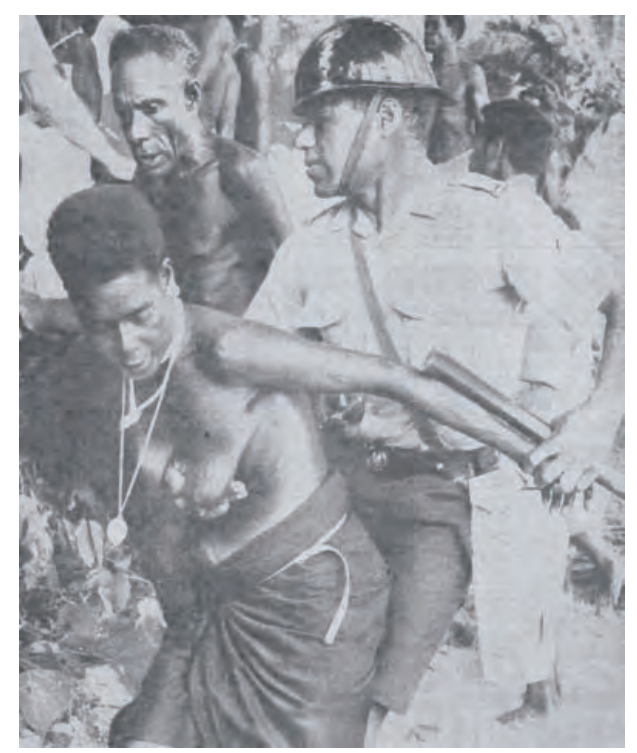

'Australia's Shame'. Rorovana woman with survey peg being tackled by police in early August 1969. $\mathrm{Mel}$ Togolo has identified the male villager behind her as being Mele, a clan leader from Rorovana 2. [Sydney Sun, 6 August 1969]. 


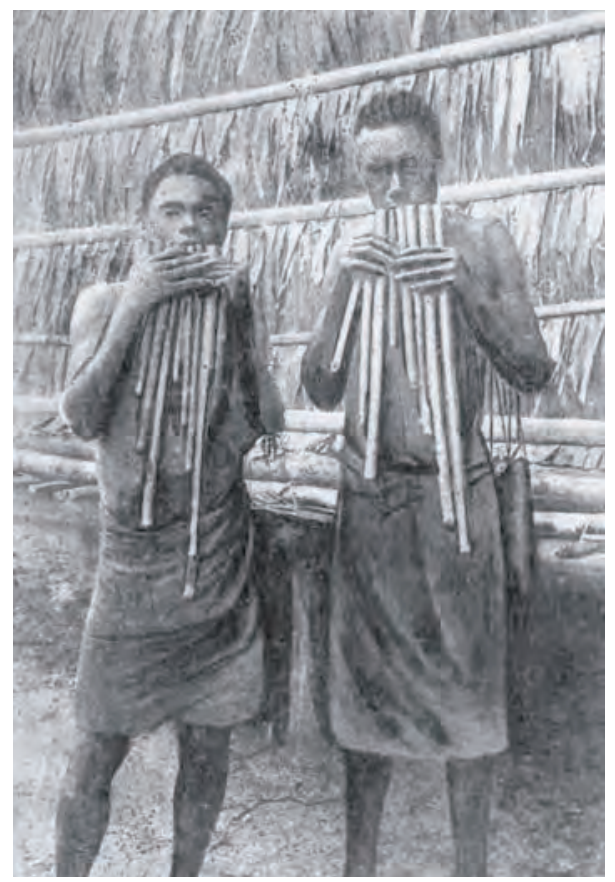

Buin people demonstrating panpipes 1908.

[Thurnwald, R., 1912: Tableau XIII, Figure 150]

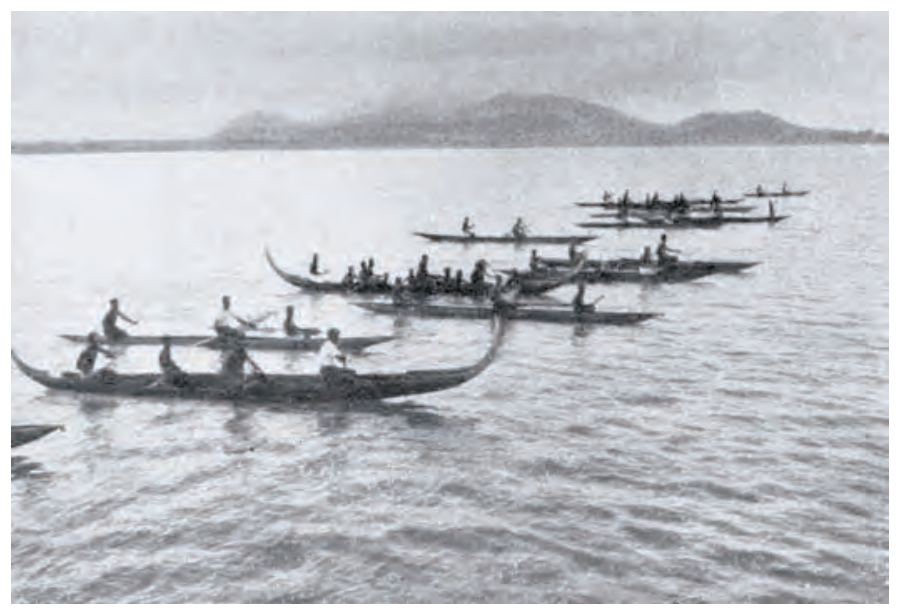

Where 161 years before their warriors protested against Louis de Bougainville's intrusion, in 1929 Bukas in traditional Muns (special canoes) jubilantly welcome the Catholic Bishop-elect, Thomas Wade. [McHardy, 1935: opposite p. 46]. 


\section{ACKNOWLEDGMENTS}

number of individuals and organisations provided practical assistance, advice,
support or encouragement that contributed to the preparation and publication of this book. We thank them for their contributions.

The genesis of this book was in a conference on the theme 'Bougainville Change and Identities, Division and Integration', from 10 to 12 August 2000, organised by the State, Society and Governance in Melanesia (SSGM) Project in the Research School of Pacific and Asian Studies (RSPAS) at The Australian National University (ANU), Canberra, Australia. The Convenor of the SSGM Project, David Hegarty, and its then Executive Officer, Monica Wehner, both played invaluable roles in organisation of the conference. Successors in the role of SSGM Executive Officer, Jeannette Regan and Sue Rider, assisted with organi-sation of transcriptions of some taped sessions of the conference, and provided efficient liaison with authors in various parts of the globe. Jean Bourke assisted with the transcription of some presentations and discussions.

All the maps in this book were drawn and edited by Kay Dancey, Cartographic Coordinator of Geospatial and Cartographic Services of RSPAS, ANU, and we are grateful for her efficient and professional support. Staff of the Map Room at the National Library of Australia copied two maps in our possession for Kay's reference.

There were few unpublished original pictures with historical relevance on Bougainville in the archives that we searched in Sydney and Canberra, and so we have instead included some previously published pictures. Staff of the Pictorial Unit of the Australian National Library copied pictures from its archives, including images from the Australian newspaper. Darren Boyd of the RSPAS's Photography Unit copied photos of historic interest from the following publications: Richard Thurnwald's [1912] Volumes on Buin; Ernst Frizzi's [1914] essay on central Bougainville and Buin; Emmet McHardy's [1935] publication; and the pamphlet [1994] edited by Theo Aerts (kindly loaned by Hugh Laracy of 
Auckland). Glenn Summerhayes kindly shared with us his fieldwork photos of Lapita pottery shards from the Feni Islands north-west of Buka.

Mary Gosling and other staff from the Petherick Room in the National Library of Australia assisted us in tracing rare books and unusual references.

Financial support for the holding of the 2000 Conference and for editorial and associated costs was provided by the SSGM Project and the Australian Agency for International Development (AusAID). Some funds needed to make the book available at a reasonable cost and to a wider audience in Bougainville were provided by Riotinto Minerals (PNG) Ltd.

We are grateful to those who either read and commented on the whole manuscript or advised us on particular chapters or on some details of fact: Raymond Apthorpe, David Hegarty, Herbert Girschik, James Griffin, Roselyne Kenneth, Hugh Laracy, Ron May, Douglas Oliver, Simon Pentanu, Mel Togolo, Marcelline Tunim and Mary Walta.

Special thanks goes to staff of Pandanus Books — to Ian Templeman, Justine Molony and Emily Brissenden. Their cheerful tolerance, energetic professionalism and calm support helped to see through a complex undertaking that depended on the collaboration of participants in different countries.

We are especially grateful to the authors of the chapters in this book who participated without remuneration and who continued to believe in the value of this project in spite of the considerable time taken to reach publication, as well as obstacles related to geographic remoteness and their own commitments.

We thank Mary Walta for helping us compile the Glossary and for careful reading of the page proofs and James Griffin for assistance with the index.

AJR and HMG 


\section{A NOTE FOR READERS}

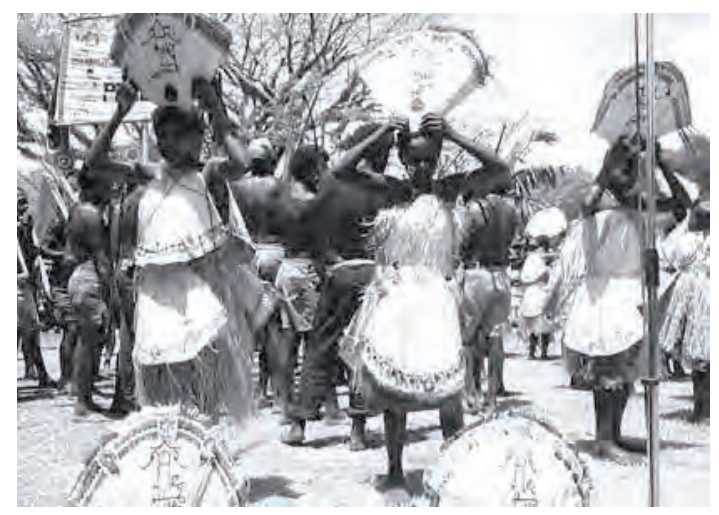

Women dancing with fans during ceremony for the signing of the Bougainville Peace Agreement in Arawa, 30/08/2001.

[Papua New Guinea Post Courier Pictorial Archives 31/08/2001. Photograph by Gorethy Kenneth]

\section{USE OF NAMES}

A number of names and expressions of various kinds used in connection with Bougainville tend to cause confusion. To make detailed explanations of the issues each time one of the names or expressions in question is used in an essay in this book would add unnecessary and repetitive detail, and could even run the risk of causing further confusion. Instead, we propose to, at this point, identify and explain some of the sources of confusion, and indicate the approaches to choices of names taken, in terms of editorial policy, in the following essays.

\section{Papua, New Guinea, Territory of Papua and New Guinea, and Papua New Guinea}

The areas that now comprise the territory of the Independent State of Papua New Guinea have, at various points in time, been controlled by differing authorities and assigned varying names (aspects of the issues involved are discussed by Griffin ['Origins of Papua New Guinea's Boundaries', this volume]). In particular, until World War II, the two main parts of what is now Papua New Guinea existed as the separate territories of New Guinea and Papua. After World War II they retained separate legal status, but were administered together as the Territory of Papua and New Guinea. In 1971 the official name was changed to Papua New Guinea and was maintained at independence in 1975. 
Chapters in this book discuss aspects of the history of Bougainville that occurred at particular points in Papua New Guinea's history, and if complete accuracy in use of names were to be required, there would need to be frequent changes in the name or names used. In the interests of simplicity, our editing approach has been for the name 'Papua New Guinea' to be used, even when discussing things that occurred before 1975. Exceptions have been made, however, where there are particular reasons for use of the name that actually applied at the time.

\section{Bougainville and North Solomons}

The island of Bougainville was named after the French explorer, Louis de Bougainville. Under the Australian colonial regime, that name was also applied to the Administrative District — from 1975 Province — of Bougainville. The use of the name for the district/province has been a source of confusion in two main ways. The first involves the fact that the district or province includes not just the island of Bougainville, but also the island of Buka, a number of mainly small islands associated with Buka and Bougainville, and a number of groups of atolls some distance from Bougainville and Buka. Hence there can sometimes be uncertainty whether a reference to 'Bougainville' is intended to include all islands and atolls in the district/province, or just the main island of Bougainville. Such confusion is sometimes compounded by apparently inconsistent use of the expressions 'in Bougainville' and 'on Bougainville'. We have sought to reduce uncertainty by clarifying whether it is just Bougainville Island that is being discussed, or the larger geographic entity that includes that island, and also by minimizing use of the expressions 'in Bougainville' and 'on Bougainville'. Where they are used, the latter expression refers only to the main island, while the former refers to the district or province that includes that island among others.

The second source of confusion concerns the fact that the names 'Northern Solomons' or 'North Solomons' are often used to refer to the district or province of Bougainville. There is sometimes argument about what is the correct name, an issue that we have needed to consider in order to ensure consistency in the use of names in the various chapters in this book.

The origins of the use of the name 'Northern Solomons' go back at least to the period of German colonial rule [Sack, this volume], when use of that name reflected the geographical location of what later became known as Bougainville (district or province) at the northern end of the Solomon Islands chain. It continued to be known as Northern Solomons for some people long after the Australians renamed the district 'Bougainville'.

When Papua New Guinea became independent in September 1975, a law was passed defining the boundaries and the names of the country's 19 provinces 
- the Organic Law on Provincial Boundaries. It specified that the name for what had been the colonial district of Bougainville would from then be 'Bougainville Province'. That law has never been amended in that regard, though it will no longer apply in Bougainville from June 2005 (as discussed further, below).

In 1977, a Bougainville Constituent Assembly, authorized by the Organic Law on Provincial Government (a law passed by the Papua New Guinea National Parliament) made a constitution - the Constitution of North Solomons Province for the provincial government then being established for Bougainville. In relation to the names of Bougainville and its provincial government, that Constitution provided that:

1. For the purposes of that constitution and of provincial laws, 'the Bougainville Province as established under the National Constitution, by whatever name it may be known for the purposes of the National Constitutional Laws, shall be known as "North Solomons"'; and

2. For the same purposes, the 'provincial government established for North Solomons ... shall be known as the "Provincial Government of North Solomons"',

(sections 1 and 2 of the Constitution of North Solomons Provincial Government.)

The aim here was to assert the distinctiveness of Bougainville and Bougainvilleans within Papua New Guinea by emphasising geographic, historic and cultural links with neighbouring Solomon Islands.

The clearly expressed wish of the representatives of Bougainville in the Bougainville Constituent Assembly for Bougainville and its government to be known by a name different from that officially designated in the Organic Law on Provincial Boundaries should perhaps have led to a change of the 'official' name through amendment of that law. While there was some discussion of that possibility in the late 1970s, it did not occur. It was not seen as a major issue in Bougainville. The fact that the choice of the name as expressed in the Constitution of the North Solomons Provincial Government had been made by the representatives of the people of Bougainville (or North Solomons) was seen as the key issue.

From the late 1970s, Bougainville became widely known as 'North Solomons'. The name was (and still is) used on maps, in Papua New Guinea newspapers, in books and articles, and in day-to-day conversation. As a result, many people still believe that North Solomons is the official name of Bougainville.

As for the provincial government, rather than being called the Provincial Government of North Solomons, as defined in the Constitution of North Solomons 
Provincial Government, it was commonly referred to as the North Solomons Provincial Government. That name continued to be used until 1995.

The situation in relation to use of the name North Solomons began to change from the late 1980s, with a reversion to use of the name Bougainville for the province. From an early period, the conflict that began in Bougainville in November 1988 was known both in Bougainville and in the rest of Papua New Guinea as the 'Bougainville crisis'. The group seeking secession called themselves the Bougainville Revolutionary Army, and later established an associated government body, called the Bougainville Interim Government. Then in April 1995, after almost five years of a National Government imposed suspension of the North Solomons Provincial Government arising from the conflict in Bougainville, the suspension was lifted by the National Government. But under amendments to the Constitution of North Solomons Provincial Government made at that time, the name of the provincial government was changed to the Bougainville Transitional Government. The decision to cease using the name 'North Solomons' was made because by 1995, after some seven years of the 'Bougainville crisis', the name 'Bougainville' had now become widely recognized both in Papua New Guinea and internationally, and the issue of seeking to assert distinctiveness through association with Solomon Islands no longer seemed so pressing (Theodore Miriung, personal communication, June 1995).

Use of the name 'Bougainville' continued to be preferred after the Bougainville Transitional Government was replaced in 1999 by the Bougainville Interim Provincial Government. That body is expected to be replaced from June 2005 by an elected Autonomous Bougainville Government, which will be established under amendments to the Papua New Guinea Constitution that give effect to the Bougainville Peace Agreement of August 2001. Under section 282 of the Papua New Guinea Constitution the people of Bougainville are empowered to make a constitution for their new government. Among other things, that constitution can make provision for 'the naming of Bougainville, the Bougainville Government and institutions of the Bougainville Constitution or Bougainville Government'. Under the Constitution of the Autonomous Region of Bougainville adopted by the Bougainville Constituent Assembly in November 2004 and endorsed by the Papua New Guinea Cabinet (National Executive Council) in December 2005, provision is made for Bougainville to be known 'formally as the Autonomous Region of Bougainville', but otherwise to be known simply as 'Bougainville' (section 1(2)). The name for the government is specified as the Autonomous Bougainville Government (section 2).

As a result of the combined effect of section 282 of the Papua New Guinea Constitution and section 1(2) of the Constitution of the Autonomous Region of 
Bougainville, the provisions of the Organic Law on Provincial Boundaries in relation to the name of Bougainville will no longer apply there when the full provisions of the new Bougainville Constitution begin to apply in full. As provided in the enactment clauses in the Preamble to the Constitution of the Autonomous Region of Bougainville, this will occur upon the completion of the elections for the Autonomous Bougainville Government, expected to be in June 2005.

Hence, even though this book is primarily about Bougainville before the conflict (or the crisis), and so in large part covers a period during which the name widely used was 'North Solomons', various chapters also cover periods when the name 'Bougainville' was used. It would tend to cause confusion if discussion were to constantly swap between names depending on the period being discussed. Instead, as a matter of editorial approach, we have decided that the name 'Bougainville' should be used to refer to the district or province, unless there is some special reason for using the name 'Northern Solomons' or 'North Solomons' (as, for example, in the chapter by Sack entitled 'German Colonial Rule in Northern Solomons'), because it deals with a period of history when the name 'Northern Solomons' was in official use.

Finally, we have used the name North Solomons Provincial Government rather than the legally correct Provincial Government of North Solomons, as the former has always been the name in common usage for the provincial government for Bougainville established in 1977.

\section{Names of Companies Involved in Exploration and Mining}

There is sometimes confusion about the names and acronyms of companies involved in mining exploration, mining operation and shareholding in exploration and mining companies involved in Bougainville. Among the companies involved were Rio Tinto Zinc Corporation Ltd, Conzinc Riotinto of Australia Ltd, Conzinc Riotinto Australia Exploration Ltd, New Broken Hill Consolidated Ltd, Bougainville Copper Pty Ltd, Bougainville Mining Ltd, and Bougainville Copper Ltd.

Conzinc Riotinto of Australia Ltd (CRA) — the product of previous company mergers — was established in 1962. In April 1965 the London-based Rio Tinto Zinc Corporation Limited (RTZ) owned 85 per cent of Australia-based CRA.

When it was decided that CRA would undertake a systematic search for copper deposits in the Southwest Pacific, New Broken Hill Consolidated Ltd (NBHC) joined it as a junior partner. This partnership launched the exploration of Bougainville in the form of an entity named Conzinc Riotinto Australia Exploration Ltd (CRAE), with a two thirds interest held by CRA and a one third 
interest held by NBHC. After CRAE's explorations turned up promising prospects at Panguna in Bougainville, evaluation was handed over in 1967 to Bougainville Copper Pty Ltd (BCPL).

The Australian colonial Administration took a 20 per cent equity interest in BCPL in 1970. The remaining 80 per cent owned by CRA and NBHC was held by their subsidiary, the holding company, Bougainville Mining Limited (BML).

In $1971 \mathrm{BML}$ offered a proportion of its shares to members of the public in Papua New Guinea and Australia. A share education programmed was conducted in Papua New Guinea in early 1971. One million shares were offered in Papua New Guinea of which 900,000 were taken up by Papua New Guinea indigenous organisations and individuals.

After commencement of mining in 1972 the operating company was registered, in the same year, in Papua New Guinea as a public company and renamed Bougainville Copper Ltd (BCL).

For the most part, as a matter of editorial policy, we have limited references to the two main entities involved, namely Conzinc Riotinto of Australia Ltd (CRA) and Bougainville Copper Ltd (BCL), unless there has been some specific reason to make reference to another corporate entity involved in exploration or mining related activities.

\section{Names for Areas and Languages of Bougainville}

A variety of names are used by both Bougainvilleans and outside observers and academic commentators to identify particular areas of Bougainville, and also languages, language groups and other groups and communities in Bougainville. Examples of the various names that linguists (and their Bougainvillean informants) use in relation to the numerous languages of Bougainville can be seen in the discussion in Tryon [this volume]. For example, the language spoken by the people of the Buin area, in south Bougainville is variously named as Buin, Telei, Terei and Rugara. In the Nagovisi area of southwestern Bougainville, the area is known to some as Nagovis and to others as Nagovisi, and the language spoken by the people of that area is sometimes referred to as Nagovisi and sometimes as Sibbe [Tryon, this volume], and by others as Tobee or Sibee [Tanis, this volume]. Part of the reason for such differences is probably related to the many small groupings within, and even straddling, language groups, which have been more important in the lives of most people than language groups (especially in the case of larger language groups), certainly until recently [Tanis, and Regan, both this volume]. Further, in some cases, at least, it seems that there were no names for what linguists recognise as languages that were commonly accepted by all groups of speakers of those languages [Regan, this volume]. Some of the localised groupings that people belong 
to are distinguished, in part at least, by differences in dialect or pronunciation, differences which are reflected in local names for both the group in question and the local language variant that they speak [Tanis, and Regan, both this volume]. A further factor is changes over time, so that what was once generally known as the Motuna language, spoken by the people of Siwai (or Siuai), also in southwestern Bougainville, is now often referred to as Siwai [Tryon, this volume].

As a result of this immense diversity in names used, there are no hard and fast rules about names of areas, language groups and other groups. As far as possible, we have aimed to ensure a degree of consistency in use of such names by authors in this volume. At the same time, however, authors sometimes have particular reasons for choice of name, and this helps to explain variations within and between chapters.

\section{Crisis and Conflict}

When violent actions against the property of Bougainville Copper Ltd began in November 1988, the situation was soon being described as the 'Bougainville crisis'. This expression continued to be used in discussion of the situation for many years, and is still in common usage. On the other hand, as the period of the violence began to stretch out, it gradually became referred to by other people as the 'Bougainville conflict'. Because both expressions are in common use, we have left it to each author which of them (if any) they prefer to use.

\section{ON SOURCES}

Only those sources to which authors have referred in their chapters make up the general bibliography which does not include unreferenced background reading. Sources are listed alphabetically (whether published or unpublished) under the names of their authors or the agencies that were responsible for their creation. Other articles from journals and newspapers or general archival material is listed later.

\section{STYLE}

\section{Acronyms}

Acronyms are used when names or titles consisting of more than one word (e.g. in organisations, institutions and companies) appear more than once in a chapter. They are then cited in brackets immediately when the name or title appears for the first time. After that, they appear simply in abbreviation and are also recorded in the separate List of Abbreviations. 


\section{Glosses}

All non-English words are listed and translated in the Glossary. 


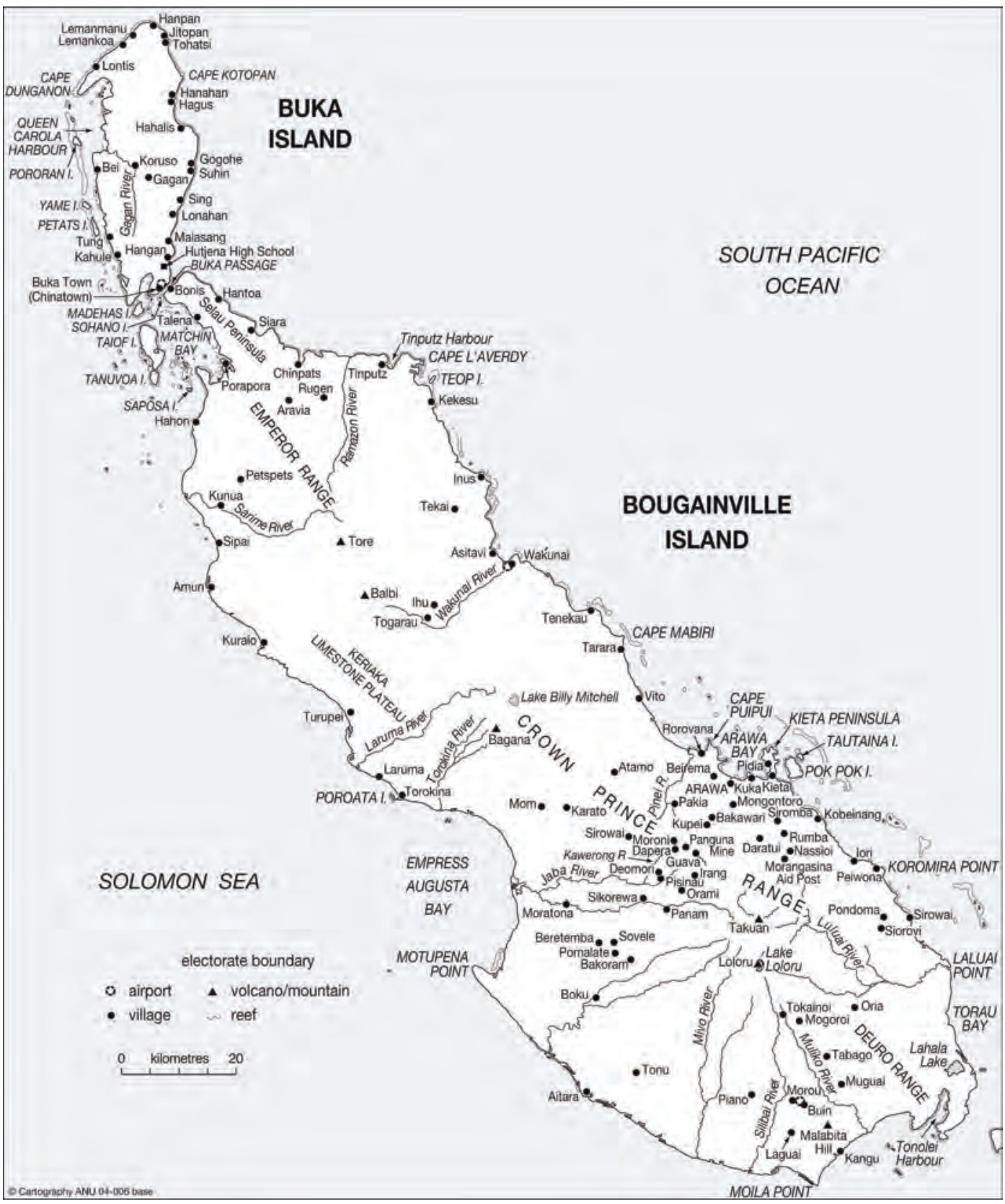




\title{
INTRODUCTION
}

\author{
by Helga M. Griffin and Anthony J. Regan
}

ne of the most beautiful group of islands of the south-west Pacific, with
a population estimated to be less than 200,000 in 2005, and a human occupation of almost 30,000 years, Bougainville has had a remarkable history. Apart from one significant known wave of migration about 3,000 years ago, Bougainville and the nearby islands to its south and east - where peoples of similar language, culture, and appearance live — remained in virtual isolation until European interventions in the 19 th century.

Bougainville attracted European interest because of its beauty, the aggressive fighting qualities of some of its coastal groups in early contact with Europeans, its potential as a labour recruitment area, its status as what Douglas Oliver [1991: 3] has referred to as 'the black spot in an island world of brown skins' in the Pacific Ocean, and its cultural diversity. It is only on Bougainville and nearby parts of the Solomon Islands that Pacific people of such dark skin colour live, while its linguistic and cultural diversity was unusual in so small an area. Although there is a high central mountain chain, the obstacles to interaction between groups would seem less formidable than in many other parts of Melanesia.

Apart from the concentration of dark skin colour and the high degree of diversity that continued to attract the attention of observers, in particular ethnographers and prehistorians, until the 1960s there seemed to be little unique about Bougainville. Like the rest of Melanesia, it constituted a patchwork of almost autonomous stateless societies, the boundaries of which were determined by geographic features, language and custom, and made cohesive by behaviour based on a principle of balanced reciprocity. From the late 1960s, however, Bougainville became the subject of much greater scrutiny - from academic as well as other observers - for two main reasons. The first involved the struggle of some of its people to resist the imposition by the colonial regime and a large multi-national mining company of a huge open-cut copper and gold mine at Panguna, in the rugged mountains of central Bougainville. The second was the struggle by 
Bougainvilleans to assert a common identity and to seek a new political status in independence from, or a special autonomous political status within, Papua New Guinea.

From 1988, tragic developments have attracted wider interest of outside observers and have generated considerable introspection among many Bougainvilleans. There was a nine-year destructive secessionist war against Papua New Guinea from late 1988. It aroused bitter internal conflicts among Bougainvilleans. The conflict caused or contributed to probably thousands of deaths, mainly of Bougainvilleans, before agreement was reached (first among Bougainvilleans themselves, and then with Papua New Guinea) to stop the fighting. The collective decision by Bougainvilleans to end the conflict was the most important basis for what has become one of the world's most remarkable peace processes. Something that began in 1997 — despite its inherent fragility - continues to develop at the time of writing (early 2005).

Questions have arisen from these developments. When did the belief in one Bougainvillean identity emerge and how has it been shaped? Why has Bougainville been the only Melanesian area where a bitter and protracted civil war on such a scale has occurred? There have, of course, been rumblings by one or another group of people in the larger South-West Pacific region expressing a desire to secede from the colonially established nation state they inhabit. No others have been as persistent as Bougainvilleans in their pursuit of political independence. We therefore must ask, was Bougainville somehow inherently different in the combination of its micro-cultures? Or was it just another slice of Melanesia, a microcosm that reflected the ethnic diversity of Papua New Guinea and the wider region? If so, did Bougainville's historical circumstances contribute?

The following questions need to be asked and, if possible, answered:

- Why did what appeared to start as a localised landowner dispute escalate so rapidly into a widespread secessionist rebellion?

- Why did that rebellion also develop a second dimension of bitter conflict among Bougainvillean groups?

- How was it that Bougainvilleans were able to agree to end the conflict in 1997 ?

- How, after bitter internal conflict over an extended period, have they been able to reconcile and work together again? Is there a common element inherent in their cultures or in their colonial experience, or in a combination of both, that has facilitated what has occurred during the peace process? Is the success, (to date, at least) of the Bougainville peace process rooted in the specific cultural and political circumstances of Bougainville, or are there more general lessons to be drawn from the Bougainvillean experience? 
This book does not seek to provide definitive answers to all of these questions. Rather, it seeks to shed light on the situation of Bougainville and its peoples before the conflict began, and to understand how that situation developed in such a relatively short period of European contact.

The origins of this book lie in a three-day conference held in Canberra, Australia, in August 2000, organised by the State, Society and Governance in Melanesia Project in the Research School of Pacific and Asian Studies, at The Australian National University. Anchored in core papers delivered at that conference, the book grew, however, with the expansion of the essays and with the recruitment of other pieces to fill some of the obvious gaps.

Unfortunately, the task of filling all gaps has been too great. In large part this is because research and reflection on many aspects of Bougainville's experience is still sketchy and incomplete. While Helga Griffin's essay plots some of the gaps in published records of Bougainville's early history, many more exist, for all periods and for all fields of knowledge. There is much more to be done.

The chapters are organised into five main groups. The first, under the title of The Place and the People, begins with a chapter on Bougainville's prehistory by Matthew Spriggs who surveys the evidence for the long period of human occupation of Bougainville, and their long isolation from the rest of the world. The chapters in this group also include an outline of Bougainville's geological origins by Hugh Davies. One focus of some of the chapters is the exploration of longasked questions associated with the reasons for Bougainville being the Pacific's 'black spot' and the diversity amongst its people. Jonathan Friedlaender examines the reasons for the apparently unique appearance, in the Pacific, of Bougainvilleans, while the Spriggs' material on the long isolation of the population of Bougainville contributes to the evidence and explanations about, among other things, the unique appearance of Bougainvilleans which Friedlaender suggests is related to genetic chacteristics studied by him and his colleagues during almost 40 years of medical anthropological research. In this group are also chapters about how Bougainvillean groups both resemble each other and differ in terms of both language (Darrell Tryon) and culture (Eugene Ogan).

The extent of diversity among Bougainvillean societies both before the colonial era, and continuing to the present, is also explored in the fourth group of chapters, entitled Perspectives on Particular Bougainville Societies. Those chapters include two studies of the matrilineal Haku people of Buka Island, one by Roselyne Kenneth, a Haku anthropologist, and the other by Bill Sagir, a Papua New Guinean anthropologist, married in Haku where he conducted the fieldwork for his Ph.D. thesis. By contrast, Jared Keil writes about the social structure in Buin — the main area of patrilineal societies in mainly matrilineal Bougainville. 
Three separate reports are also included in this group about the observations made during repeated visits to dispersed locations in Bougainville by Ogan (the Nasioi), Jill Nash (the Nagovisi) and Keil (the Telei).

Perspectives on Bougainville's diversity also emerge from chapters in other groups, notably those by Melchior Togolo, in the third group, on Economic and Social Change Post-World War II and James Tanis and Anthony Regan in the fifth group, Towards Understanding the Origins of the Conflict. Both Togolo and Tanis focus on the experiences of the particular Bougainvillean communities in which they grew up, the Torau and the Nagovisi respectively, while Anthony Regan's exploration of the complex web of identities to which the average Bougainvillean may adhere is based on new research.

Many arguments about the closely interrelated factors that may have contributed to the conflict in Bougainville have been advanced already in a wide range of publications, many of which are considered, in one way or another, in chapters in this book. They include:

i) the destructive impact of the Panguna mine on social and physical environments;

ii) colonialism's erosive and disturbing impositions (both secular and religious),

a) its centralised political and supposedly legal control over traditionally self-governing communities;

b) its denigration of indigenous values and practices;

c) its forging of unnatural boundaries;

d) its contribution to Bougainville's identity as a people apart from those of the rest of Papua New Guinea;

iii) the Bougainvilleans' perception that their material and physical welfare had been neglected by central governments before the mine brought wealth to the region;

iv) disruptions and transformations wrought by the plantation economy;

v) increasing tensions within and between Bougainvillean groups due to growing economic inequality generated by monopolistic and capitalist enterprises as well as the uneven impacts of widespread small-holder cash crop activity in conflict with a traditional egalitarian ethic concerning the distribution of wealth;

vi) the emergence of an educated and articulate church-educated Bougainvillean elite leadership;

vii) the modern construction of a distinct Bougainvillean identity - a people apart;

viii) the development, in response to the impacts of colonialism and economic change, of a Bougainvillean passion for self-determination and willingness to shed blood in its cause; 
ix) the refusal of central government to stage a referendum on the question of Bougainville independence.

Some of the chapters present new perspectives on these issues, while others raise new issues.

Chapters referring to the origins of the conflict include those in the third group - Economic and Social Change Post-World War II - and the fifth - Towards Understanding the Origins of the Conflict. In the third group, the chapters by Scott Macwilliam and Joachim Lumanni illustrate different aspects of the reasons for unequal economic development, the first dealing with the beginnings of signifi-cant inequality in economic status in the immediate post-war years, and the second dealing with inequality emerging from patterns of small-holder cash crop activity. The chapters by Don Vernon and Togolo grapple with different aspects of the impacts of the Panguna mine. Togolo states that the impacts on Bougainvillean communities of mining activity and the distribution of land rents and compensa-tion by the mining company were much more diverse than has previously been realised. The separate chapters by Elizabeth Ibua Momis and John Momis (both from Buin) reveal the powerful impacts of the Catholic Church on Bougainvillean leadership and ideology. The first chapter in the fifth group, that by Tanis, discusses the perspectives of the people of his own community on many of the issues identified in the previous paragraph, and others, and the contributions that they made to the situation in 1988. The chapter by Regan raises questions about whether the complex web of distinct identities associated with groups among Bougainvilleans may have influenced conflict among Bougainvilleans during the period 1988 to 1997.

Of course, Bougainvilleans have never been passive victims of change. While we can identify the factors listed above as amongst those likely to have played roles in the origins or development of conflict, at the same time there were many Bougainvilleans who welcomed and took advantage of innovations and opportunities. The chapters by John Momis and Togolo imply and state that, as individuals, they have not been mere victims of circumstances. Without loss of loyalty to custom, they can state that they have valued the opportunity to receive an education, to broaden their view of the world, to exercise skill in a profession, to communicate beyond their communal territories, to meet foreigners on equal terms, to speculate on acculturated notions of social justice, to be constructive in inter-ethnic relations and to show a remarkable capacity to practice reconciliation. The capacity of the Bougainvillean's for reconciliation after a decade of bloodshed, argues Elizabeth Momis, is an internalised talent with roots both in indigenous tradition and in Catholic theology. Its strength, she argues, comes from this symbiosis. 
In the various arguments about the negative influences of the outside world on Bougainville, the mine seems to receive most attention. Its insensitive intrusion into quasi-sacred territory and its displacement of habitations and food gardens were matched by other devastating impacts: social, legal, physical, environmental, cultural and economic. The problems caused by the distribution of occupation fees and compensation among mine-lease landholders was only one of many destructive influences. Together, the colonial Administration and the mine developer violated principles of both local culture and of justice in their disregard of traditional notions of rights to land; their failure to take proper account of the complex interests of the many people concerned, including those of women, who had significant roles in the matrilineal societies in the mine lease areas; the failure, for a long time, to provide adequate compensation to the landowners of minelease areas; and, failure to control either environmental degradation or the influx of foreigners who disregarded local standards of behaviour, ethics, and custom. The speed at which change occurred outpaced the capacity of people to control, or even to react, to it to their best advantage.

Obviously, change was not new to Bougainvillean societies. Before the colonial era, a range of factors - including natural disasters such as volcanic eruptions (noted by Davies and discussed by Spriggs) — resulted in great upheavals, probably including frequent and reasonably large-scale migrations (as discussed by Regan). Then, there had been the imposition of foreign colonial administrations; the arrival of Christianity; the impacts of two major wars; 'modern' technology; a cash economy; foreign languages and a radically new 'education' to master; new attitudes to health; an exotic spirituality to grasp; problems associated with consumerism; and, the possibility of working or studying abroad. All these forces for change had to be accommodated, modified or rejected. Chapters in the second, third, fourth and fifth groups give insights into the forces at work in relation to change. The chapters in the second group, The Colonial Period to World War II, include James Griffin's discussion of Bougainville's boundaries; an essay on German colonial rule by Peter Sack; chapters on the 'pacification' of Southern Bougainville, the Catholic Church and the Australian take-over from German colonial control in Kieta by Hugh Laracy; Peter Elder's contribution on plantations, colonial Administration, missions and anthropologists between the two World Wars; and, a chapter on Bougainville during World War II by Hank Nelson. This is followed by a group of chapters dealing with aspects of economic and social change after World War II. All of the chapters in the fourth group concentrate, in one way or another, on the ways in which particular Bougainvillean societies have responded to change. The essays by Togolo, Tanis and Regan also address this aspect of development. 
In particular, Togolo examines the impacts of change through the perspective of the history of his own resilient Torau community while Sagir writes of the 'staying power' and adaptability of Haku 'chiefs'. Kenneth adds a perspective on the impacts of economic change on land and on the roles of women of rank in Haku, and reveals hidden dangers in an inherited system of ranked positions that is governed by oral tradition.

Although the peoples of Bougainville managed change in various ways, the problems associated with the modern mine probably drove other simmering grievances to the surface in such a way as to affect eventually the whole province, as is illustrated by the two chapters in the fifth group, especially that by Tanis. Where people had previously managed to live with drastic change, both the mine and the remote Papua New Guinea Government were readily blamed for a wide range of ills, many of which were as much aspects of wider economic and social change arising from what is now often called 'globalisation' as things readily attributable to government or the mine.

Lummani, Togolo and Tanis all make it clear that there were other forces at work than just the mine. They all show that destabilisation of Bougainville's traditionally cohesive communities had already begun with the introduction of a plantation economy which changed the nature of its fluid, shared, clan-based use of land and rotational agriculture. Cultivation of cash crops was not limited to the colonial plantation sector. It was originally 'encouraged' by colonial governments to ensure that communities joined the cash economy (initially in part by requiring them to pay personal tax — 'head tax' — as a contribution to the costs of government services). But, especially from the 1960s, as people sought more income by planting more cocoa trees, not only did land available for subsistence gardening reduce, but the land available for cash-crop plantations was also increasingly inequitably distributed. A situation of 'haves' versus 'have-nots' was emerging in the 1980s, accompanied by a mounting sense of grievance. Lummani traces the statistics collected for permanent smallholder plantations on Bougainville and warns of the consequences for social stability of ongoing land clearance in a situation of diminishing access to land. He cautions against unthinking and easy solutions that try to combat land degradation. At the same time, it is clear from Togolo that the impacts of change and of economic inequality have been far from uniform among groups of Bougainvilleans. He argues that his people have welcomed much that the outside world has had to offer while at the same time retaining considerable cohesion. The picture that Tanis paints of the Nagovisi is somewhat different. He indicates that some communities sought to withdraw from contact with the state and the mine, some made compromises, and some sought to take advantage of the situation. 
The dominant influence of the Catholic Church with its attempts to stem artificial birth control and traditional methods of controlling human fertility, probably combined with many other factors (such as improved health services) to contribute to a post World War II population explosion that, in turn, influenced a situation in which sustainable access to land for subsistence agriculture for the whole community was under threat in some areas. Other parts of what was German New Guinea also had both a plantation economy that began under the Germans and an extensive small-holder plantation sector. Has the impact of either or both kinds of plantations in Bougainville been greater? Tanis suggests that, at least in the Panguna mine's Lower Tailings Lease area in Nagovisi, the flow of cash in land rents and compensation payments in the 1970s and 1980s for the leased land was an additional factor contributing to inequality. It was to the advantage of rent and compensation recipients to seize opportunities to build their own (permanent) cocoa estates complete with separate roads, trucks, mills and fermenteries. Individualistic capitalism rapidly replaced the previously highly egalitarian distribution of resources among these communities. MacWilliam makes similar points about how a number of factors combined in the period immediately after World War II to enable development of the beginnings of a class of nouveau riche Bougainvilleans. He sees continuities between the figures emerging in the 1950s and the elite elements that in the 1980s were running not only landowner businesses but also the majority North Solomons Provincial Government owned Bougainville Development Corporation.

The possibility of secession in Bougainville (see the chapter in the third group by James Griffin) was perhaps a dormant strand of psychological energy a human expression of the volcanic landscape. As already discussed, precolonial Bougainville was a mosaic of separate societies of immense diversity, and the processes by which a single Bougainvillean identity emerged has fascinated many observers since the late 1960s.

That identity emerged under colonialism, which played an important part in the development of the view that all Bougainvilleans were one (for some purposes, at least), For example, people from all parts of Bougainville, including the large island of Buka, who worked for the colonists elsewhere in what is now Papua New Guinea, were all commonly described as 'Bukas' until well after World War II (indeed, the word 'Buka' was also used to describe the baskets made only in Siwai and Buin, as far from Buka as it is possible to be in Buka and Bougainville islands!). The first colonial administration drew a map making Bougainville one region (see the chapters by Griffin on Papua New Guinea's boundaries and by Sack on German colonial rule in Bougainville). It had three administration depots and several government posts, from which law and order was supervised and from 
which taxes were collected. Christian churches, linked much more to the Solomon Islands, south and east of Bougainville than to the rest of Papua New Guinea, mainly to the north and west, preached that all people are of equal worth. The same rules of the dominant Catholic church applied to each person no matter where they came from. It preached peace and freedom of inter-communal movement, which, in the early period, the colonial administration sometimes ensured by gun boats and punitive expeditions. (Laracy's chapter on the 'Pacification of Southern Bougainville' provides eye-witness accounts of some impacts of such expeditions.) The colonial administration also tried to erase much of the physical separatism of traditional societies, among other things building roads and establishing organisations such as local governments and co-operative societies that incorporated disparate groups, in the process also contributing to the emergence of new identities amongst Bougainvilleans.

The German Administration frequently employed the distinctive appearing, healthy, strong Bougainvilleans in other parts of German New Guinea often in occupations demanding trustworthiness and dependability. These and other factors probably helped to establish a sense that they were special, a 'chosen' people with, presumably, a sense of destiny. By the 1960s or earlier, Bougainvilleans viewed themselves as a people apart, geographically and culturally more linked to the Western Solomons than to the Bismarck Archipelago, and least of all to far away Papua New Guinea (a point emphasised by Tanis, which echoes Bougainville's prehistoric reality, as analysed by Spriggs). In contradistinction to the 'red skins' of people from other parts of Papua New Guinea, Bougainvilleans have also viewed themselves as distinctive due to what they see as their uniquely dark and prized colour [Thurnwald, H., 1937: 3, 133], a view supported by the research of Friedlaender's team. Skin colour had long been a positive thing for Bougainvilleans - except perhaps in dealing with Europeans [Nash and Ogan 1990].

Pride in their own region, as well as an ability to articulate its concerns and grievances, were enhanced when Bougainvillean men entered Catholic seminaries and developed a vision for the future. John and Elizabeth Momis stress the importance of the social justice vision they imbibed both from indigenous and Catholic sources. There was a Bougainvillean rhetoric in the 1970s and 1980s which claimed for its people superior ethical standards when compared with what they saw as the more 'primitive', generally less well educated people from elsewhere in Papua New Guinea, large numbers of whom had come to Bougainville to work for first the plantations and later the mine.

While Bougainvillean identity was undoubtedly a reality from at least the 1960 s, it did not replace the many identities associated with other groups that Bougainvilleans belong to. Regan seeks not only to 'map' these, but also argues 
that the uneven pattern of colonial development in Bougainville created inequality between groups, contributing to a situation where it was a relatively small step for groups within Bougainville to feel threatened by one another, a phenomenon that may be part of the explanation for the conflict that occurred amongst Bougainvilleans between 1988 and 1997.

It is obvious that colonialism, secular and religious, had a crucial hand in the complex situation that had developed in Bougainville by the 1980s. It drew political boundaries both within Papua New Guinea generally and Bougainville, which brought into play a foreign system of governance from afar administered by visiting executive agents (the kiaps — government field officers - and other officers) to enforce new ways, legal, political, economic, and more. The establishment of peace by force where 'necessary', was crucial, in the process ignoring community-based social and economic maps in the frames of which traditional cultures regulated social, economic, and ritual interactions. Pressure was applied (with limited success) to replace a significant customary basis for social order — fear of magic and sorcery - by the fear of hell and by new promises about the final rewards of good living. But the churches also brought education and health services that the foreign administrations could ill afford, especially to a district so far away.

This interplay in local communities between the old and the new, between stabilising and unsettling influences, and ambivalent local responses, sometimes involving accommodation and compromise, and at others involving rejection of being either neglected or dominated by a central government, are not unique to Bougainville. But, Bougainville is, for all its diversity, a small place which by the 1960s was developing an unusually (for Papua New Guinea) educated and 'visionary' leadership, at a time when not only was the prospect of decolonisation of Papua New Guinea opening new possibilities in relation to Bougainville's future political status but also the Panguna mine, in particular, was forcing the pace of change. These are some of the circumstances that perhaps impelled Bougainvilleans to give their problems more immediate scrutiny than was the case elsewhere in Papua New Guinea, or Melanesia generally. Despite their diversity and differences, Bougainvilleans may thus have more readily achieved coherent and unified responses. Despite its formidable mountain range, a considerable proportion of the people of Bougainville were probably linked in various ways by church and other networks that enabled them to be receptive to organisational tactics that brought disparate groups together.

Globilisation of any kind can readily create fear that people will lose control of their own destiny and be overwhelmed by uncontrollable forces. The creation of a shared identity for Bougainvilleans is probably in part related to their efforts 
to manage the impacts of the outside world. But at the same time, long-held identities within Bougainville remain, and there is a strong emphasis on a return to kastomary ways and traditional authority.

We are at least confident that the contributions to this book shed light on the questions arising from the conflict and the remarkable processes that led to the building of peace and actual reconciliation. Investigation of the conflict and the peace process, which occurred during the 17 years subsequent to 1988 , is beyond the scope of this book. Much has happened in that period that has changed Bougainville. It would have been difficult in the extreme for the contributors to this volume to have speculated about the linkages between issues relevant to the period before 1988 on the one hand, and those arising in relation to the period of conflict between 1988 and 1997, the ending of conflict in 1997 and the development of a peace process from then to 2005 .

On the other hand, there seems to us little doubt that a deeper understanding of how Bougainvilleans had reached a situation where the conflict could have emerged in late 1988 should also some shed light on the developments from that point. We can be clear, for example, about the strength of resentment by Bougainvilleans towards the impacts of the mine and of the way a remote national government was dealing with them. The evidence is there, too, of the growth of inequality among Bougainvilleans, the strength of communal identities and of a sense of threat from 'outsiders' in Bougainville. Understanding of those two sets of factors alone provides insights into the broad contours of the Bougainville conflict itself.

By helping us to understand Bougainville better, all of the chapters should provide at least some insights into the ending of the conflict and the success of the peace process. Some of the chapters do more than that. The chapters on individual societies shed considerable light on the resilience of Bougainvillean communities, something that was clearly essential to the way in which the pressures of nine years of war and the strains of a difficult peace process have been managed. The amazing effectiveness of reconciliation in Bougainville after years of bloodshed and civil disturbance attests to both the continuing resilience of customary values of Bougainville's small scale communities and, as Elizabeth Momis stresses, the positive messages of peace in well-grounded Christian indoctrination.

In this book, we have tried to bring together a range of research and reflections, some previously unpublished. Some of the contributions are 'distillations' of work that scholars have published elsewhere but which, in most cases, are not readily available, least of all to Bougainvilleans, including those who have received a formal education. We hope this publication will be of interest to all those seeking to understand Bougainville better, especially Bougainvilleans themselves. 



\section{THE PLACE}

AND THE PEOPLE 


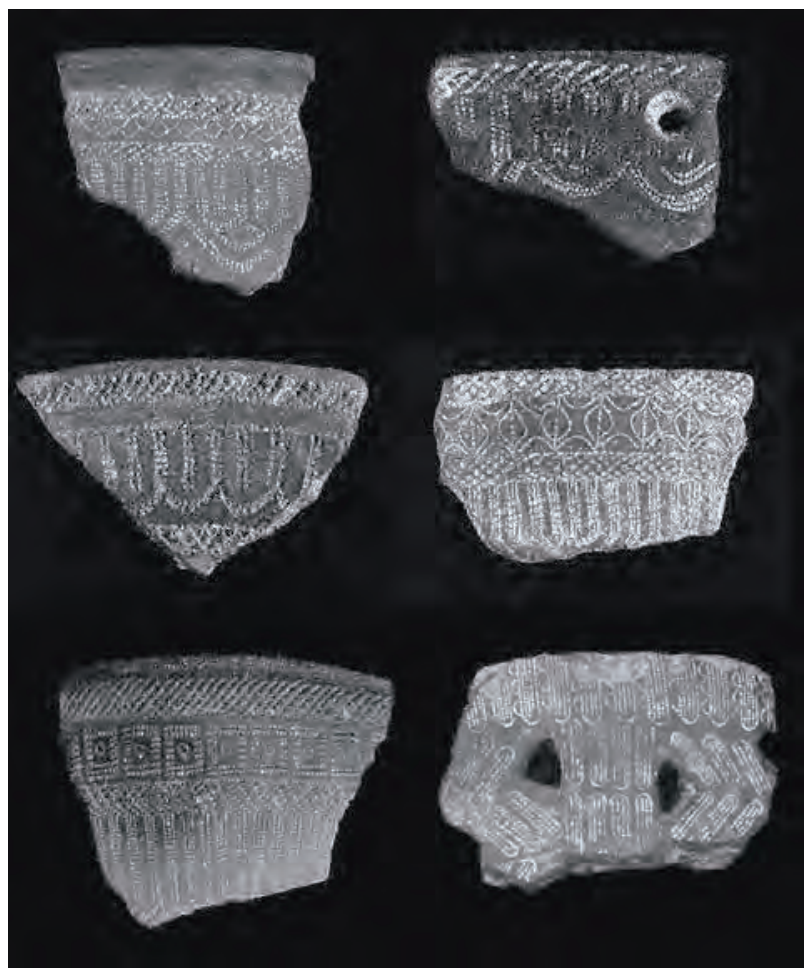

Figure 1: Shards of Lapita pottery from Anir Island, north of Nissan.

[Photographs from the archaeological research archives of Dr Glenn Summerhayes, ANU.] 


\title{
BOUGAINVILLE'S EARLY HISTORY: AN ARCHAEOLOGICAL PERSPECTIVE
}

by Matthew Spriggs

\begin{abstract}
whole new vista on Bougainville's past was opened up in 1988 by the publiAcation of Stephen Wickler's dates for his excavations at Kilu Cave near Malasang Village on Buka. A series of radiocarbon dates, back to nearly 29,000 years ago, extended the known history of the main Solomons chain by almost 10 times [Wickler and Spriggs 1988]. Previously, the earliest dated sites for the Solomon archipelago were about 3,000 years old, relating to colonisation by agricultural, Austronesian-speaking populations who made and used a very distinctively decorated pottery called Lapita. Assemblages of Lapita pottery include red-slipped pots of various shapes and sizes, sometimes decorated using dentate (tooth-like) stamps to produce elaborate patterns [Figure 1] such as representations of a human face. This pottery is found at many sites between the Bismarcks and Samoa, dating to this time period, and to the south and east of the Bismarcks [Map 1]. It was generally thought to represent the first colonisation of the Pacific islands by humans. This is still the case for Vanuatu, New Caledonia, Fiji, Tonga and Samoa. But the dates for Kilu demonstrated a much longer human history for the Solomons chain.

A longer than 3,000 year history had, in fact, been predicted for the Solomons chain, particularly for Bougainville, prior to 1988 on the basis of the presence of non-Austronesian or Papuan languages and because of the distinctive skin colour and genetic patterns of the Bougainvilleans and other western Solomons populations. The non-Austronesian languages were distributed on Bougainville, as they are on the island of New Guinea, in the interior and south of the island, with Austronesian languages occurring mainly along the coastal fringes and thus appearing to represent the languages of later arrivals [see Tryon, this volume]. The genetic diversity of Bougainvilleans, symbolised by their extremely dark skin colour, was thought by biological anthropologists to have required an
\end{abstract}




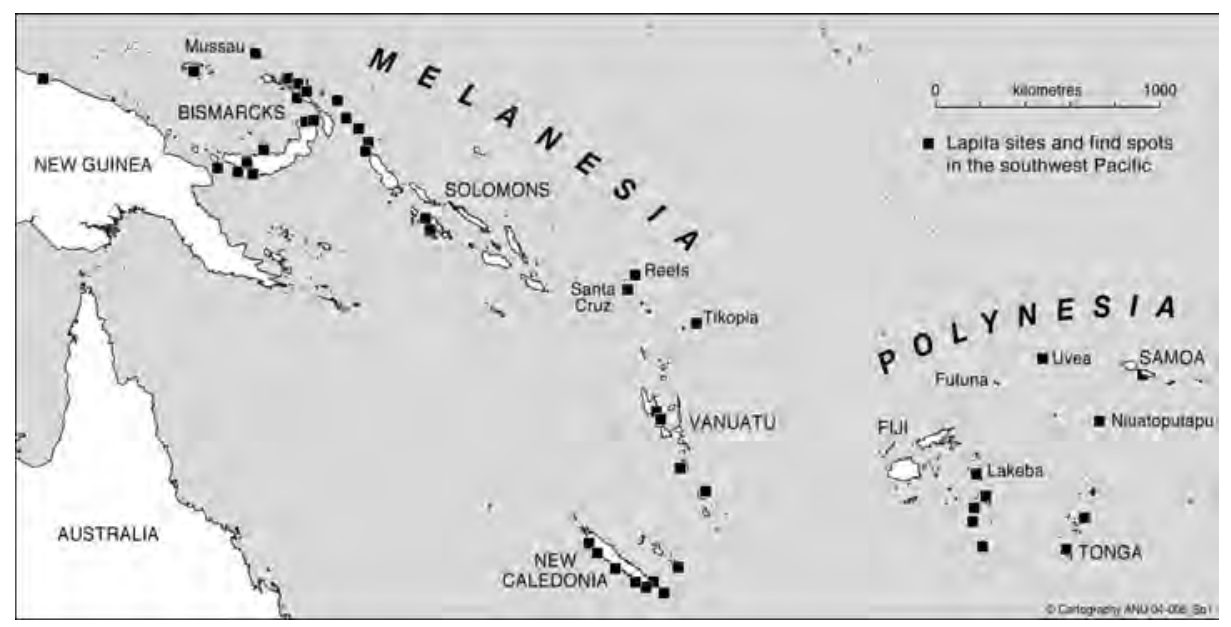

Map 1: The distribution of Lapita Culture sites in the Western Pacific, dating to between 3,300 and 2,700 years ago [Adapted from Spriggs 1997: Figure 4.2].

extremely long time-period of occupation of the region, certainly a lot longer than 3,000 years [see Friedlaender 1987, and this volume].

The Kilu Cave excavation confirmed these predictions and gave us a glimpse of what the lifestyle of early Solomon Islands populations was like. Just as the Kilu results were first being published, the Bougainville 'crisis' was beginning and so no further archaeological research has taken place since the late 1980s. In 1992 I published an outline archaeological and linguistic history of the northern Solomons, and its history was placed in an Island Melanesia-wide context in my 1997 book, The Island Melanesians [Spriggs 1992a, 1997]. This updated summary draws upon those works, and the references contained therein, and on Wickler's revised and published PhD thesis [Wickler 2003]. Detailed bibliographic references can be found in those publications.

\section{EARLY SETTLERS}

For the majority of Bougainville's known history it was not an island as we now know it, but part of a much larger land mass that we can call 'Greater Bougainville', which stretched at one time from the northern tip of Buka down along what is now the Solomon Islands to Nggela, in sight of modern Honiara [Map 2]. Included within this much larger island were Buka, Bougainville, Shortland Islands, Choiseul, Santa Isabel and Nggela in the Florida Group. At 46,400 square kilometres at its greatest extent, Greater Bougainville was bigger 


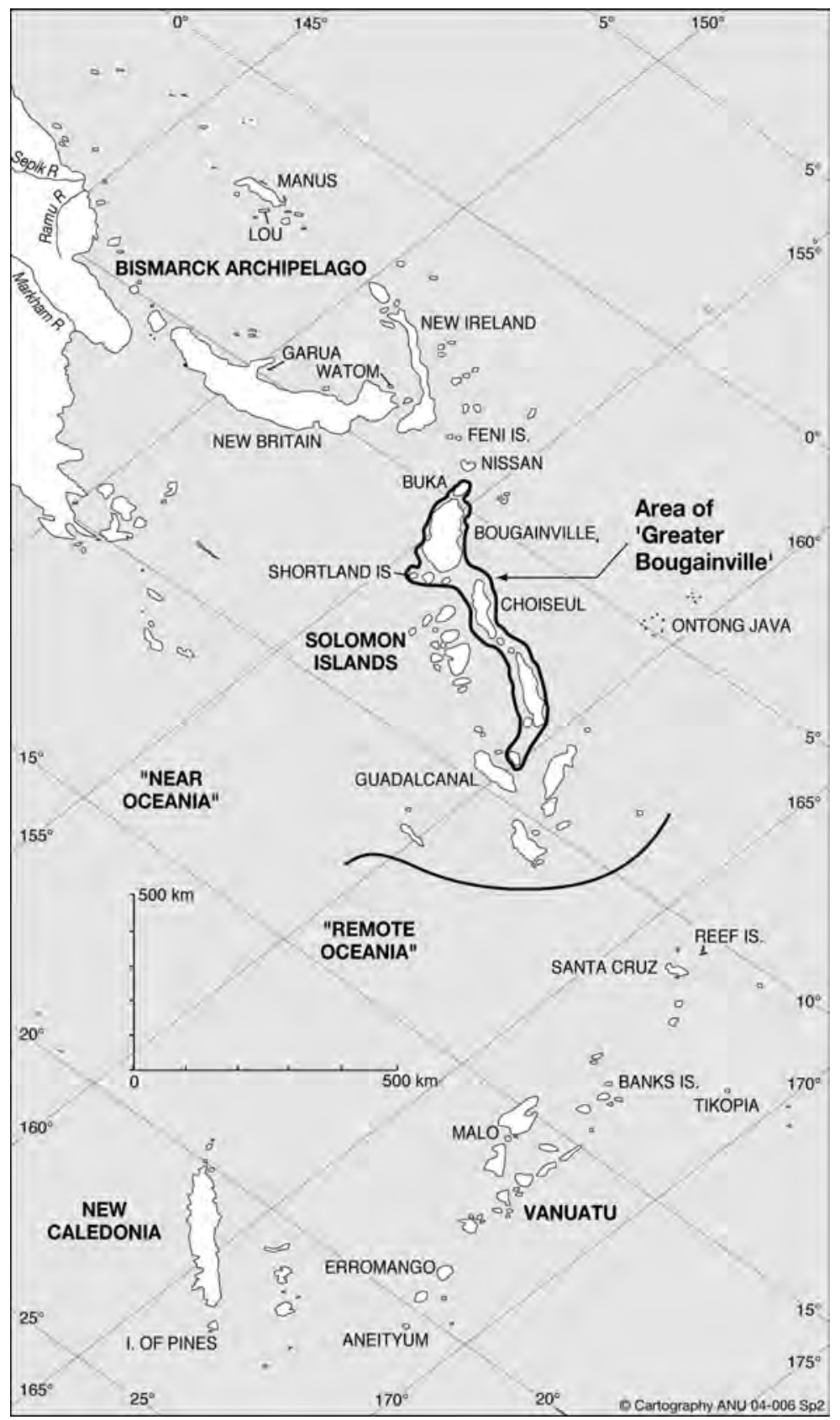

Map 2: The location of 'Greater Bougainville'.

Comment: At times of lower sea level during the coldest period of the last Ice Age (28,000 to 18,000 years ago), present-day Buka, Bougainville, Shortland Islands, Choiseul, Isabel and Nggela were joined as a single large land-mass. [Base map by Ian Faulkner.] 
even than the extent of New Britain to its north during the Pleistocene or Ice Age. This would have been the situation from before 29,000 years ago to somewhere around 10,000 years ago when the melting of the wide-spread ice sheets raised global sea levels towards their present heights and ushered in the geological period called the Holocene. Geographically, Bougainville still remains the largest of the Solomon Islands, even with its now much reduced land area. A century of political division between Bougainville and the rest of the Solomons chain should thus not be allowed to obscure these longer-term connections.

Although Kilu Cave is the earliest site currently known in the entire Solomons chain, this does not necessarily make it the earliest site occupied by humans in the region. From the Bismarck Archipelago to the north, the obvious immediate origin for its first colonists, there are sites dating back 35,000 to 40,000 years [discussed in Spriggs 1997: Ch. 2]. Sites on mainland New Guinea - itself joined to Australia for much of its history — go back even earlier, and the human settlement of the Australia-New Guinea continent is now generally believed to go back 50,000 to 60,000 years [see Jones and Spriggs 2002 for a recent overview].

We do not yet know whether there was any appreciable gap between the settlement of New Guinea and the islands to the immediate east. Sea gaps to New Britain and New Ireland were no greater than those which would have had to be crossed in the first place from the Asian mainland to reach New Guinea and Australia by some of the earliest of all modern humans to leave the African homeland. They would have followed the coastlines of the Middle East, India and South-East Asia as far as present-day Bali, before island-hopping comparatively short distances across the Islands of Wallacea to make landfall on the Australia-New Guinea continent. Following the northern coasts of New Guinea there was no greater sea crossing to reach New Britain and then New Ireland [see Map 3]. But the sea gap to Buka is considerably greater and the island of destination is not in sight when one sets off. This may have delayed discovery of the Solomons, or it may be simply that we have not yet found the earliest sites there.

Kilu is a cave at the base of a 30-metre high limestone cliff, some 65 metres from the sea and currently about 8 metres above the high tide mark. It consists of a large, dry front shelter where excavation took place and a damper small cave chamber behind. The main shelter is 33 metres by 17 metres and well lit. A three by one metre trench was excavated through 2.2 metres of archaeological deposit resting on bedrock [Wickler 1990, 2001]. The bottom portion of the fine silt deposits dated to between 28,700 and 20,100 years ago, about 75 centimetres being built up over this 8,000 year period. Cave use during this time seems to represent only very sporadic low-intensity use. The stone tools consist of small flakes that were probably obtained locally, some at least from river cobbles. 


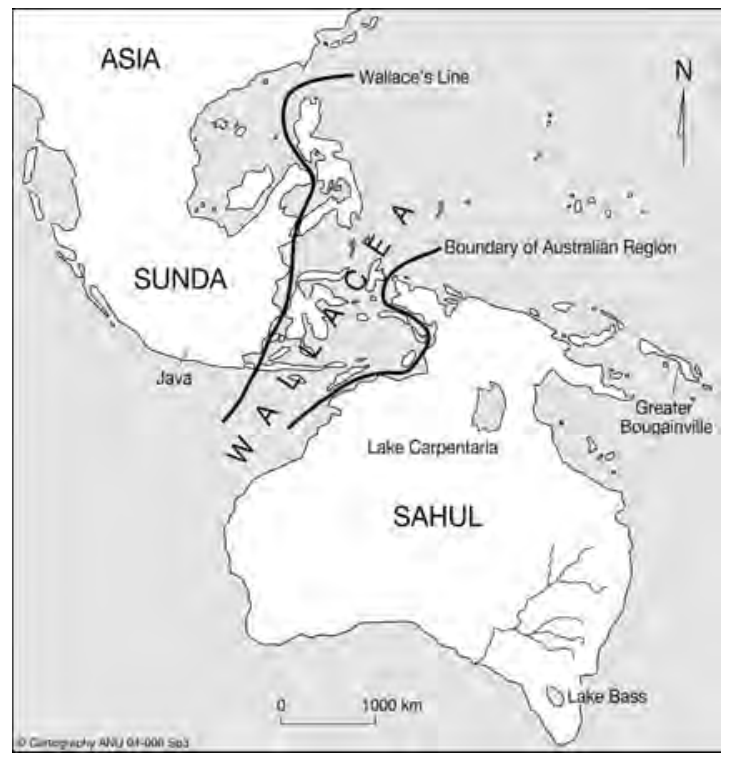

Map 3: 'Greater Bougainville'

in its regional context.

Comment: Its earliest

inhabitants had moved

out of Sunda, the southern

extension of Asia, crossed

the islands of Wallacea to the

continent of Sahul (Australia

and New Guinea) and then

made subsequent sea crossings

to reach Bougainville by 29,000

years ago at the latest [After

Thorne and Raymond 1989].

These rather ad-hoc tools were examined by Tom Loy (then of the Australian National University) for residues of material adhering to them which could give clues as to the function of the tools, a relatively new technique in which Loy is one of the pioneers. A sample of 47 tools was examined under the microscope, from both early (pre-20,000 year-old) and later, Holocene levels. Of these some 27 had evidence of use in the form of a polish on the tool edge, or starch grains and other plant material stuck to the tool surface. Seventeen of the tools from Pleistocene levels had starch grains identifiable to genus, 14 from Colocasia taro and three from Alocasia taro. They were probably used to cut and scrape raw taro in preparation for cooking [Loy, Spriggs and Wickler 1992].

It has always been accepted that plants must have played an important role in early economies but until recently it has not been possible to identify what plants were actually involved. Archaeologists were limited to the elements of the economy that were more obviously present in that site, such as bones and shells. Had we been limited to these in our consideration of Kilu, then the interpretation of its archaeological record might have pointed to a reef-focused, coastal economy. Yet the Kilu evidence suggests a real emphasis on plants which we know later formed the agricultural staples of the region. Colocasia taro was probably naturally distributed throughout the Bismarcks and Solomons. The source of the taro may have been the local stream or areas of natural swamp. It is unknown what level of management there was of this resource. The distribution throughout the deposit of tools with residue on them might suggest a regular supply was available that would seem to require some degree of cultivation. 
A dense shell midden and marine fish bones show that the adjacent coast was not neglected, but high visibility and bulk of shells does not equate with dominance in the diet. Kilu also produced a great quantity of bones from land animals. Five species of endemic Solomon Island rats were found, including two new species - the noble Solomys spriggsarum and the much smaller and less noble Melomys spechti [Flannery and Wickler 1990]. These would have formed a rich forest source of protein. Bats and a range of reptiles including a large skink, a varanid or monitor lizard and snakes were also part of what seems to have been a very varied diet. Nearly all the bones found appear to have resulted from human meals rather than other predators such as owls, while the range of body parts present shows that whole animals were brought to the site and butchered and eaten there.

Between about 20,000 and 10,000 years ago the Kilu site was abandoned, and we as yet have no other sites that bridge the gap in the Solomons. This abandonment may have resulted from changes in sea level that dropped to a maximum 130 metres below its present level during the coldest part of the Ice Age. The site may have been isolated at the top of a substantial cliff with no access to the coast at this time. Kilu was reoccupied at about 10,400-10,000 years ago, and a series of dates continues to about 5,450-5,300 years ago [Wickler 2003]. The upper 30 centimetres of the deposit is partly disturbed, showing some ephemeral use of the site in the last 2,500 years. The Holocene levels (meaning those of the last 10,000 years) include large hearths, but the significance of this is unclear as no charcoal at all had survived in the Pleistocene or Ice Age levels. The stone tools continue to be simple flakes, and residue analysis showed that their function in processing root crops also stayed the same. A decline in quantity and increase in breakage of bone in the top 60 centimetres of the deposit suggests a decrease in intensity in site use before its abandonment sometime around 5,000 years ago.

\section{5,000 TO 2,500 YEARS AGO: A TIME OF CHANGE}

It is at about this time that we first find evidence of human use of other sites in the northern Solomons. Nissan Island, between New Ireland and the Feni Group and Buka, represents a stepping-stone island between the Bismarcks and the Solomons. Archaeological investigations there took place between 1985 and 1987 [Spriggs 1991; see Map 4]. The cave of Lebang Takoroi on Nissan has produced early dates for pre-pottery levels between 6,100 and 3,800 years ago, and two other nonpottery sites on the island (Lebang Tatale and Lebang Halika) have produced dates contemporary or overlapping with the earliest Lapita sites in the Bismarck archipelago. Takoroi is the only habitable cave on the inner, lagoon side of Nissan and has been above the reach of the sea for many thousands of years longer. 


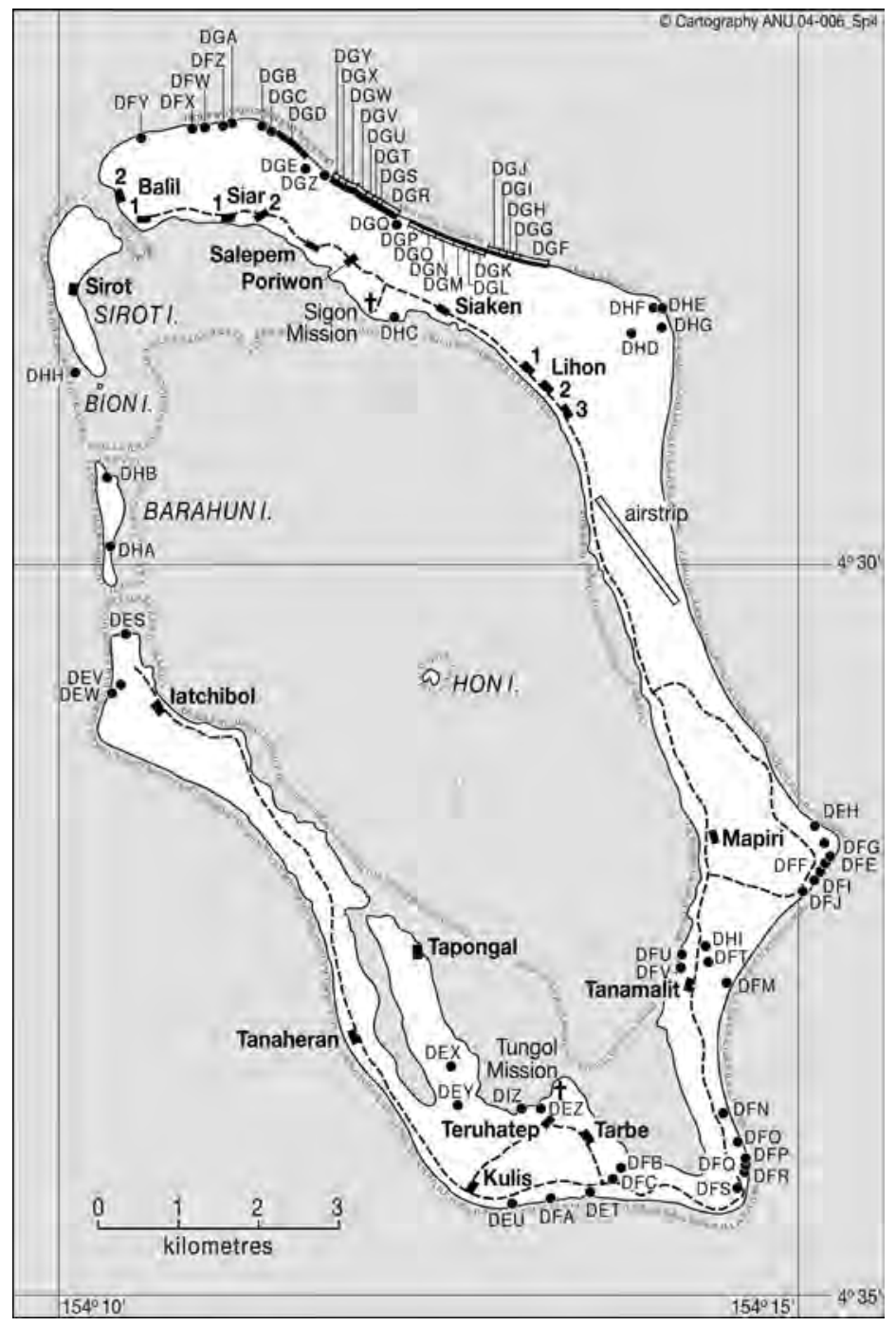

Map 4: Archaeological sites on Nissan Island mentioned in the text. DES is Tarmon, DFF is Lebang Halika, DFV is Takoroi, DGD is the Yomining complex and DGW is Tatale [Map from Spriggs 1991].

Occupation evidence was sparse in Takoroi and the deposits were disturbed by much later use in some parts. Stone artefacts of obsidian from Talasea and Mopir on New Britain occurred throughout the pre-pottery levels, a result of longdistance exchange. The possum Phalanger orientalis also appears to have been present from the base of the site, an introduction from New Ireland. The only identifiable plant remains were of coconut. At Tatale occupation of the shelter 
began on a pumice beach deposit suggesting that it had not long been out of the reach of wave action when first occupied. It is now some 155 metres from the inner edge of the reef. The top two metres contain a pottery sequence going back about 2,500 years, while the lowest 1.3 metres was without pottery. A single flake of New Britain obsidian came from the lower deposit, but shell midden was common and the charcoal samples contained Canarium or galip nut (probably more than one species), and tentatively-identified Pangium, Sterculia, Metroxylon (sago), and Terminalia. The age of the lower deposit is somewhere between 4,600 and 3,400 years ago.

Lebang Halika, also on Nissan, is more firmly dated. Its lower pre-pottery deposit covers the period from 3,650 to 3,200 years ago and so it overlaps with the earliest Bismarcks Lapita sites. Above this is a partially disturbed Lapita deposit. There appears to be no hiatus in occupation and the difference is that pottery and obsidian occur only in the upper levels. The obsidian is about equally distributed between the Talasea and Admiralty Islands (Manus) sources. Artefacts in the preLapita levels included Tridacna shell adzes, polished shell knife fragments, an incomplete Trochus shell fishhook and other pieces of cut shell. There were significantly greater quantities of fish and animal bone in the lower levels. Marine shell quantity declines by half in Lapita levels.

Various nut tree species were identified from the lower deposit: confident identifications of Canarium indicum and coconut, and less confident ones of other Canarium species, Sterculia, Dracontomelon, Spondias, Thespesia, Burckella, Areca and a tree fern. Artefacts associated with Lapita levels include Tridacna adze fragments, a bone point, a Trochus armring fragment, a human tooth pendant, a polished shell knife fragment and other pieces of worked shell. The fish are all common reef-dwellers in both periods, and phalangers and bats also go right through. Pig occurs in the earlier levels, but only as isolated teeth and it is more abundant in Lapita levels. The introduced Polynesian rat, Rattus exulans is found only in the Lapita levels.

On Buka, the site of Palandraku has a pre-pottery deposit dating to about 5,000 years ago, beginning at about the time Kilu goes out of use [Wickler 1990, 2003]. It is located about 200 metres north of Kilu at the base of a 10-metre high limestone cliff about 50 metres from the sea and five metres above it. It is a wet cave with chambers extending back into the cliff and may at one time have been part of an underground river system. Remains of an earth oven occurred in the 5,000 year-old levels. The stone artefacts within the cave were similar to those from Kilu. Various worked shell pieces made up the rest of the artefacts, including a shell bead and a Trochus armring fragment. The pottery style dates the base of the upper levels to about 2,500 years ago. As well as a wider range of shell ornaments, 
the later component included pig and phalanger which were previously absent. Two obsidian flakes from Manus also occurred in the 2,500 year-old levels.

Lebang Halika on Nissan produced a range of shell artefacts, including pearlshell knives or scrapers that are typical of Lapita assemblages, and contains a small amount of pig bone and a wide range of fruit and nut tree species, presumably domesticated. The assemblage is quite different from that in the earlier Takoroi (also on Nissan) site which has no shell assemblage, no pig, no plant remains except Cocos. Takoroi contains significant quantities of New Britain obsidian, whereas there was only a single piece in early Tatale and none in the Halika deposits.

One possibility is that Halika represents a pioneer phase of Lapita settlement, resulting from an exploratory probe beyond the confines of the earliest Lapita settlements in the Bismarcks. The Feni Islands, the location of several early Lapita settlements [Summerhayes 2001a and 2001b], are visible from Nissan and occasional visits from there might be expected early in the process of agricultural colonisation. It is not at all clear that Nissan was permanently inhabited prior to Lapita times. Without an agricultural base it is unlikely that it could have supported more than occasional fishing groups. Perhaps such groups interacted with their new Lapita neighbours from Feni to bring Lapita-associated artefacts to Lebang Halika?

Lapita represents a fully agricultural lifestyle which accompanies the first introduction of domestic pigs, dogs and chickens, and the commensal Polynesian rat to the New Guinea and Island Melanesian regions. There is a lot of debate about how much of the Lapita phenomenon represents an intrusion from Island South-East Asia and how much of this culture developed in the Bismarcks [Kirch 1997; Jones and Spriggs 2002]. The domestic animals, the use of pottery and some other artefacts, and the Austronesian languages that were introduced at this time, certainly represent intrusive elements from South-East Asia. The process must certainly have included in-migration of populations into the region as well. Ultimately the Lapita expansion, either directly or indirectly, resulted from the development of agriculture in southern China many thousands of years earlier. While in the Bismarcks and northern Solomons Lapita culture was added to what was already a rich cultural mix, in lands beyond the main Solomons it represents the first colonisation of what had previously been the empty islands of Vanuatu, New Caledonia, Fiji and Polynesia. Lapita is a culture that ties together regions we now call 'Melanesia' and 'Polynesia'.

That there are early Lapita sites in the Feni Group has already been mentioned. On Nissan a similar Early Lapita occupation is confined on current evidence to rockshelter use at Lebang Halika and Yomining. As there is no workable 
clay on this raised atoll, all of the pottery must have been imported. The Feni Islands or other islands further to the north are thought to be the source for this early phase of pottery use some 3,200 years ago.

A somewhat later Western Lapita assemblage was found on the reef flat at Tarmon, at one of the reef passages through to the central lagoon of Nissan, and dates to some period after 3,000 years ago. This may be the remains of a stilt house occupation or a settlement on a now disappeared sand cay. Pottery and other artefacts are found on the reef in an area of some 5,000 square metres. The pottery in this site comes from Buka to the south, the mountains of which are visible on the horizon some 60 kilometres away. The Lapita phase at Tarmon appears to have been short lived.

Pottery from the Nissan rockshelters continued to come from a northern source, even after the distinctive dentate stamped decoration disappeared about 2,700 to 2,500 years ago. The later pottery of the Yomining phase is predominantly plain with occasional incision and notched rims. Nissan is the easternmost island on which Early Western Lapita pottery is found. Dates for Lapita sites on Buka to the south-east begin a few centuries later than those from the Bismarcks, suggestive of a short pause before the rapid dispersal as far as New Caledonia, Fiji and Western Polynesia.

These Lapita assemblages on Buka and adjacent islands are very similar in their pottery to the Tarmon site on Nissan, and also in their locations. Lapita sites occur at Kessa, near the northern end of Buka, and on Sohano Island at its southern tip [Wickler 1990, 2003]. They represent stilt house occupations on sandy reef flats. The site at Kessa is an artefact scatter in a band some 40 metres wide and 300 metres long in the central portion of a reef flat currently some 100 to 200 metres in width. The Sohano site covers some 30,000 square metres of a similar reef area, but most material was in spatially distinct concentrations of pottery, volcanic oven stones and stone artefacts. Later settlement was restricted to the present beach and inner reef area where there were very few decorated sherds found.

Taken together with the Tarmon site on Nissan, these sites can be ordered in time based on the percentage and type of decoration, even though no directly datable materials remain. Kessa is the earliest, Tarmon on Nissan next and finally Sohano. It is suggested by Wickler that the Sohano Island assemblage continues to about 2,200 years ago, here based on dated pottery of the Sohano style which follows on from the more identifiably Lapita assemblages on Buka. The sites appear to represent quite late manifestations of a Western Lapita style and its ultimate transition to incised and applied relief motifs.

Other artefacts surviving at these reef sites include small oval-sectioned polished stone adzes, grindstones, abraders and obsidian flakes. Palandraku and 
Kilu Caves contain plain pottery of the immediately post-Lapita 'Buka' style. At Kilu it is found in the disturbed upper layers of the site, but at Palandraku there is a thin in-situ deposit representing reoccupation of the cave after a long period of abandonment. Pig and possum make their earliest definite appearance on Buka at this site, associated with the Buka style pottery.

A pattern of apparent extinctions of birds and endemic mammals occurred on Buka with the advent of the Lapita culture. The contrast is essentially between pre- and post-Lapita assemblages as most of the Lapita sites on Buka are open reef flat sites and faunal remains are not preserved. The pre-Lapita deposits at Kilu contained a range of bird taxa larger than those presently found on the island [Wickler 2003]. Included in these were a rail much larger than any living species (found only in the Pleistocene deposit) and three pigeons from the early to midHolocene levels which are significantly bigger than the largest species currently found in the Buka area. The endemic rats Solomys spriggsarum and Melomys spechti also last occur in mid-Holocene levels at Kilu. The Lapita or immediately postLapita period clearly saw the extinction of several endemic animal species.

Pig first occurs on Buka in late Lapita levels at Palandraku Cave along with possum, but it becomes the dominant species in middens from the Sohano period onwards. Dog first appears in Sohano period deposits as does a single specimen of wallaby (Thylogale browni), presumably introduced from New Ireland as a captive animal rather than forming part of a breeding population [Flannery et al. 1988].

\section{FROM 2,500 TO 500 YEARS AGO}

The post-Lapita Yomining phase on Nissan consists of a predominantly plain pottery with occasional incised decoration. It continues until perhaps 750 years ago, after which late Hangan style pottery from Buka begins to be imported. Because the Yomining assemblage is quite different from the Sohano style pottery of Buka, dating to about 2,200 to 1,400 years ago, a source to the north on New Ireland or one of the islands off its east coast must be assumed. The material culture and fauna are similar to that from Lapita sites [Spriggs 1991].

On Buka the Sohano and subsequent Hangan (1,400-700 years ago) phases with their variety of incised and applied relief styles appear to represent a continuous development from late Lapita assemblages there. The post-Lapita sequences of Buka were first studied by Specht [1969], and he gave names to the various phases and styles discussed here. Particularly from the Hangan phase onwards there is an emphasis on the use of shell artefacts such as adzes, trolling lure shanks, bivalve scrapers and a range of ornaments still in use in the recent past and to some extent even today [Blackwood 1935; Krause 1906]. The use of flaked 
stone was minimal during this period although small quantities of Admiralty Islands obsidian continued to be imported [Wickler 2003]. Over time there was a tendency for the number of pottery producing centres in the Buka area to decline until, by European contact, there were just three adjacent specialist potting villages in operation.

Surface finds of Sohano and Hangan pottery have been found on the Bougainville mainland along the east coast as far south as the vicinity of Teop Island. The earliest dated site on Bougainville itself is the Sivu rockshelter on the Kieta Peninsula of central Bougainville near Pidia village. From this and other central Bougainville sites a continuous ceramic and cultural sequence spanning the last 1,500 years has been recovered, involving three successive styles of pottery: Sivu, Asio and Pidia, the last identical to pottery still made in the area into the 1980s. Sivu pottery is a thin, plain lip, calcareous-tempered pottery. It was followed about 1,000 years ago by a thin ware with notched lips and narrow line incision (Asio style). This overlaps with the generally plain untempered thick ware with plain or notched lips found today which has an antiquity of about 300 years. Associated with the two earlier styles were portable nut-cracking stones, a Tridacna shell adze, shell money beads, a Conus shell ring, bat tooth beads and a bone point.

At Manetai, north of Arawa, stone tools including a distinctive knife form were found and are almost certainly from the same source as surface finds from the inland Nagovisi area some 30 kilometres to the south [Nash and Mitchell 1973]. By at least 1,500 years ago, and perhaps earlier still, a regional culture appears to have developed in the centre and south of Bougainville.

An exactly parallel pottery sequence, at least for its 'Early' and 'Middle' periods down to about 300 years ago, comes from the Shortland Islands off the southern end of Bougainville [Irwin 1972], is replicated in Buin in south Bougainville [Terrell 1976], and is also likely from Choiseul on evidence from surface collections [Miller 1979]. The Early period in the Shortlands is estimated to have lasted from about 1,500 to 1,000 years ago and produced a thin, plain pottery. Middle period pottery from 1,000 to 300 years ago consisted of incised and applied relief ware, paralleled in the earliest Buin assemblages. Shortland Island pottery of this period was found in Buin, and occasionally vice versa. Late period ware of the historic period involved applied relief and carved-paddle impressions, whereas on Buin the style changed from thick paint (which is sometimes found as imports with Shortlands Middle period ware) to thin painted decoration.

Explosive volcanic activity almost certainly had a significant effect on the lives of the inhabitants of mainland Bougainville. We have evidence of at least four volcanic centres that have been active in the past 3,000 years: Balbi, Bagana, Billy 
Mitchell and Loloru [Rogerson et al. 1989]. There is oral history concerning the eruption of Balbi in the last few hundred years although geologists currently believe it last erupted significantly some 1,000 years ago. Bagana is active at present and Billy Mitchell has exploded twice in the last thousand years, about 950 and 300 years ago. Dates for activity of Loloru continue throughout the early to mid-Holocene period to about 3,000 years ago and there is presently fumarole activity at the site.

The airfall ash deposits from the eruption of Billy Mitchell 950 years ago covered most of the northern half of the island of Bougainville to depths between 10 and 60 centimetres and those from the later eruption affected the centre-north of the island with depths of 10 to 40 centimetres being deposited over a smaller area. In addition a pyroclastic flow from this later eruption covers an area of some 300 square kilometres east from Billy Mitchell to the coast. Even at the coast some 20 kilometres from the source this flow is still some tens of metres thick. Its volume is approximately 10 cubic kilometres [Rogerson et al. 1989: 70-4]. It is significant that when European plantation development started at the end of the 19th century the area from Numanuma to Mabiri was largely deserted. On the basis of stories told to me at Manetai, it would seem that the current inhabitants have either moved in from the north or over the mountains from the west, mainly during the last 100 years.

\section{THE LAST 500 YEARS}

Late Malasang and Mararing style (500 to 100 years old) pottery from Buka has been found at surface sites at the southern tip of New Ireland and in the Feni Group, but quantities are small. It is only when one moves south again from Feni to Nissan that pottery from this period appears on sites in any quantity, this stepping-stone island being a major destination for pottery from Buka. At European contact Buka had three contiguous pottery making villages, and there were several centres in central Bougainville and more in the south of the island. Given the rapid development of styles, surface sites of at least the last 1,000 years from Nissan south to the Shortlands can be dated generally to within a couple of hundred years by visual inspection of the decorated pottery.

For Nissan, the impression gained from surface collections [Kaplan 1976 and my own work] is of a continuing expansion of the number and size of settlements through to European contact and then a substantial decline before the population boom of the last hundred years. The same appears true for Buka, for the Paubake area near Buin Town in southern Bougainville studied by Terrell [1976] and for the Shortland Islands [Irwin 1973]. 
On Nissan the shift in pottery source from a northern New Ireland source to Buka occurs at the time that late Hangan pottery was being made on Buka [Spriggs 1991]. Sites on Nissan from that period (the radiocarbon dates we have commence about 750 years ago) witness the first occurrence of pelagic fish such as tuna and bonito. These are today caught in the open sea by trolling and it is tempting to see that technology first being applied on Nissan at this time and being introduced from the south where trolling hooks are known from the Sohano period (2,200 to 1,400 years ago) onwards. Moray eels disappear in the Nissan sites at the same time, interpreted as the beginnings of a food taboo which is still in force today in some Nissan villages. Hangan pottery from Buka is succeeded about 700 years ago by the Malasang style, followed about 200 years later by the Mararing style which is usually found together with Recent style pottery [see Wickler 2003].

There was clearly an overlap in production on Buka of these two styles as Mararing is rarely found in excavation or on surface sites without the Recent style also being present, whereas there are other later sites with only Recent style pottery. This developed into the pottery that was still made into the 1960s. The first evidence of the use of caves for burial occurs on Nissan during the Malasang phase and this and the following Mararing/Recent phase provide clear continuity with Nissan society as recorded in the late 19th and early 20th century [Krause 1906]. Indeed such continuity is seen too in the smaller sample of late Hangan material from the island and noted as well for Buka by Specht [1969].

Admiralty Islands obsidian continued to reach Nissan in small amounts into the historic period, and in the top levels of some of the cave sites there appears to be a resurgence of the use of Talasea obsidian. It is tempting to see this as a result of increased contacts between New Britain and the northern Solomons in the German colonial period of the late 19th century. The amount of obsidian coming into Nissan declined over time after the higher quantities of the Yomining phase. Another interesting trend from the Hangan period on is a marked rise in the density of shell midden deposited in the excavated sites. Rising population presumably necessitated the greater exploitation of such resources. Cave burial is common in the Mararing/Recent phase on Nissan with extended, flexed and secondary interments being found.

The last record of the import of obsidian to Buka occurs in the Malasang phase and it was not known there ethnographically, although other items from the Bismarcks came in via Nissan in historic times [Specht 1974; Spriggs 1991: Table 1]. The expansion of trade in Buka pots north to the edge of the Bismarcks, beginning in the Malasang phase, is matched by expansion south along the Bougainville coast. Mararing pottery is known from surface sites as far south as Numanuma, 
although this latter region is within the area of major impact of the last eruption of Billy Mitchell volcano that would have buried any earlier evidence. Further north on Teop Island an interesting overlap is found in the recent past between Buka-made pottery of late Malasang (approximately 650 to 500 years old) and later styles and Pidia style pottery traded up from central Bougainville [Black 1977].

Contact between the Buka and central Bougainville pottery-producing areas is attested by the adoption on Buka in the Mararing phase of pointed base vessels, typical of more southerly parts of Bougainville from earlier times. Another innovation in vessel form in the Mararing phase is spouted bowls called kepa which were used in recent times to heat coconut oil.

I have identified a Mararing sherd among a collection from the Polynesian outlier island of Ontong Java in Solomon Islands reported by Miller [1979]. Here the transport route may have been from Buka to the Carterets (Kilinailau) and then south down the chain of Polynesian-speaking island communities to the east of Bougainville. The Carteret Islanders today speak a Buka language, but their oral traditions tell of the conquest of the island from a previous Polynesian population. The men were killed and the women taken as wives by the conquerors according to the story.

The central and southern Bougainville pottery styles and their connections further south in the Solomons have been discussed earlier. Terrell's [1976] archaeological survey in the non-Austronesian-speaking Buin area of south Bougainville also examined the many stone arrangements called tsigoro, single upright stones and so-called 'megaliths' or stone tables made up of large boulders or capstones propped up on small stones. The stone arrangements, sometimes circles or ovals, are associated in tradition with cremation sites of traditional leaders, while the stone tables are said to have been for food display during feasts. The stone tables often occur in lines and would have required a lot of labour to build as some of the capstones are extremely large. They would not need to have been carried any great distances however as such stones are common within the alluvium making up the Buin Plain [Terrell 1978a]. Terrell suggests the tables are prestige symbols, likening them to the large timber slit gongs commissioned by traditional leaders in southern Bougainville and carried to their club houses with great pomp and feasting by up to 200 followers.

What Terrell found in Buin was that the burial practices of the recent past seemed to have only a shallow time depth. Earlier they had been more complex, including cremation burial in pottery urns within winged rectangular stone arrangements at about 950 to 650 years ago. This and other earlier burial types were paralleled in the historically recorded burial practices of the Austronesian- 
speaking Shortland Islanders to the immediate south of Bougainville. Given that he found no pottery, indeed no sites, earlier than 1,000 years old in Buin, Terrell considered that pottery making and the parallel forms of burial rite were introductions from the Shortland Islands at that time.

One would need to find earlier sites in Buin without these features to confirm this hypothesis, but contact between more hierarchically organised Austronesian Shortland Islanders and non-Austronesian Buin speakers may explain the hierarchical nature of Buin society at European contact compared to other southern Bougainville groups. These were apparently less exposed to contact with Austronesian communities. The 'feudal' nature of Buin society when first described by outsiders would have come about either from elite dominance by chiefs of Shortland's origin or by 'mimicry', exposure to the aristocratic notions of Shortland's neighbours [Terrell 1986: 222-40].

The stone monuments are interesting in the light of the contrast between Buin and neighbouring Siwai as recorded by early twentieth century ethnographers, and the possible effects of European intrusion into the region in influencing the development of 'big man' societies there and levelling the social organisation of previously more hierarchical societies [see Terrell 1978a, 1986: 222-40]. Bougainville has provided the world with one of its great anthropological stereotypes, the 'big man' society. This concept was developed by Sahlins [1963] and Service [1975] on the basis of Douglas Oliver's [1955] ethnography of the Siwai of southern Bougainville as observed during the late 1930s. It has led to a gross ethnographic oversimplification of Melanesia as having 'big man' societies, contrasted with Polynesia having chiefly societies.

The major ethnographer of the neighbouring Buin, Richard Thurnwald, noted that between his two visits 1908-09 and 1933-34 there had been an important levelling of social distance between the chiefs and commoners. $\mathrm{He}$ attributed this to European colonial and mission pacification [Thurnwald, R., 1936b]. The Siwai have no earlier ethnography equivalent to Thurnwald's 1908-09 observations and it is possible that the 'big man' system is here a transformation under colonialism of a more hereditary, hierarchical state of affairs. No archaeology has been carried out yet in Siwai but the results of such work could provide a significant commentary on the genesis of classic 'big man' systems.

The archaeological evidence, while it may not necessarily support the idea of an elite group of Shortland Islanders invading and subjugating the Buins, does suggest that the feudal nature of Buin society was breaking down during the early stages of European contact, with a simplification of burial rite and the cessation of construction of megalithic monuments [Terrell 1978a]. In contrast, the opportunity of contact was seized in the Shortlands. Guns were obtained and head-hunting 
raids were carried out to extend the power and renown of local leaders. Some equivalent archaeology in the Siwai area would provide the critical evidence necessary to judge whether a previously more hierarchical society existed there too prior to European contact.

Terrell's work shows that there has been interaction between non-Austronesian and Austronesian groups in the Bougainville Straits area for at least 1,000 years, and my own central Bougainville work would extend this back at least another 600 years. Although Terrell would seem to favour exchange connections as the primary mode of contact, there is evidence of actual migration of Austronesians in the recent past from the Shortlands to southern and central Bougainville and their subsequent assimilation. This pattern could have a significant time depth to it.

The nature of this sort of interaction can be examined using the oral history associated with Austronesian Torau-speaking groups who settled ultimately at three villages on the central Bougainville coast within the last 150 years [Terrell and Irwin 1972]. Refugees from war, they tried to establish themselves unsuccessfully at various points on the coast before reaching present day Rorovana, Vito and Tarara. It is probably not a coincidence that their successful settlements were within the area devastated perhaps one or two hundred years earlier by the last Billy Mitchell eruption and perhaps not at that time yet resettled in any great numbers by mainland groups.

Uruava is a recently extinct language group in the Arawa area which represents an earlier arriving enclave of Austronesians. This language was recorded just before a language shift to the local non-Austronesian Nasioi language had been completed and all trace of their Austronesian origins had disappeared. The Torau and Uruava communities were potters. Other potting groups along the central Bougainville coast in the Kieta area are all Nasioi speaking today, but there are clues that some of these communities represent recently assimilated Austronesian groups. Pottery making techniques are identical to those used on Austronesianspeaking Choiseul Island, visible from the Bougainville coast, and as far as we can tell, also to those formerly used in the Shortlands. Indeed the pottery makers of Pidia village on the Kieta peninsula claim to have originally come from Fauro in the Shortlands although there is no trace today of the Fauro language in their speech. Potters at Rumba Village claim that their craft was originally learned from a Torau woman [Ogan 1970b].

As discussed above, the Buin archaeological record might also represent some actual migration rather than just influence via exchange, with subsequent assimilation and language switch as groups moved behind the swampland barrier between the narrow coastal fringe and the Buin plain. Siwai pottery making is interesting in this context and suggests a different process of introduction. In Buin pottery 
was traditionally made mainly by women, whereas in Siwai it was made only by men, a situation unique in Island Melanesia as far as I can tell. No ancestral Shortland origin is indicated in any direct sense here. Siwai men (unlike their womenfolk) were able to travel widely across group boundaries as part of exchange partnerships. They were thus able to observe and then bring back to their own communities the art of pottery making, elevating it to an activity quite different in its social status than it was in Buin or indeed elsewhere in Island Melanesia. Oliver [1955: 297, 346] reports that potting was an extremely remunerative activity for those men skilled at it.

The first European to set eyes on the Solomons was Alvaro de Mendana in 1568 and the name he gave to the archipelago has stuck. The first Europeans to visit the northern Solomons were the Dutch explorers Corneliszoon Schouten and Jacob Le Maire, who skirted Takuu and Nissan in 1616. They were followed by another Dutch expedition, that of Abel Tasman, in 1643. Takuu and Nissan were again seen and contact made with canoes from these islands. The Takuu Islanders were described as 'tawny' in appearance and the Nissans as 'entirely and quite naked, their body very black, the hair curly like kaffirs, but not so woolly, nor their noses so flat: some had white rings of (so it appeared) bone round their arms [Tridacna shell armrings], some were on the face striped with lime' [Sharp 1968: 201]. There is no further record of contact with Europeans for over 100 years.

Then came the British explorer Carteret, who reached and named the island group of that name in 1767. From his description of the population there as 'black woolly headed Negroes' [Wallis 1965: 178], it seems clear that Halia speakers from Buka had already replaced the Polynesians recorded in oral traditions as the earlier inhabitants. Carteret was the first European to see Buka Island and then passed Nissan. The French explorer, Louis Antoine de Bougainville was next. In 1768 he sailed along the east coast of the island that still bears his name. He also named Buka Island, after the word called out repeatedly from canoes that came off from that island. It is from this period onwards that we have historical sources for the northern Solomons beyond those provided by archaeology, oral traditions and linguistics.

\section{CONCLUSION}

The Northern Solomons were first settled prior to 29,000 years ago by hunting and gathering populations. A second major infusion of migrants occurred around 3,000 years ago, linked to the Lapita expansion from the Bismarcks (and perhaps ultimately South-East Asia) out as far as Tonga and Samoa. The initial migrants spoke languages ancestral to the non-Austronesian languages of Bougainville, and 
those of 3,000 years ago spoke languages ancestral to the Austronesian languages of the region.

Subsequently there have been 3,000 years of mixing, both genetic and cultural, such that language is no longer correlated with either genetics or culture in any direct or simplistic way [see Oliver 1943, 1949: 12-13]. Doubtless over that 3,000 years - and probably before as well - there were further migrants washing up on northern Solomon shores. Some of these may have come from nearby islands, such as the Shortlands, while occasional drift voyagers may have come from much further afield [see Spriggs 1997: 189-12]. Among these would have been the Polynesian ancestors of the atoll dwellers of Nuguria, Nukumanu and Takuu, coming from far to the east in a back-migration some time within the last 2,000 years.

There has also been trade and exchange both to the north via Nissan and to the south via Choiseul and the Shortlands. The 'borders' to north and south of Bougainville and Buka have never been closed, except perhaps during the period soon after initial settlement until the Lapita period or just before. Contact is of course easier to the south than to the north, given distances and sea conditions. Indeed, as mentioned near the beginning of this chapter, at times of lower sea level and during most of its history 'Greater Bougainville' extended as an island to the vicinity of Honiara. Seeing Bougainville as the 'Northern Solomons' thus makes some sense. If we labelled it the 'Southern Bismarcks' we would be doing much more violence to its geography, history and culture [see Spriggs 1992b]. 


\title{
THE GEOLOGY OF BOUGAINVILLE*
}

\author{
by Hugh L. Davies
}

B ougainville and Buka islands and the other islands of the Solomons chain rise from a north-west-trending submarine ridge that is bounded on both sides by deep sea trenches [Map 1]. The islands are constructed almost entirely of volcanic rocks with a mixing of the other kinds of sediments that one would expect to develop around a volcanic island, such as reef limestones.

Construction of the islands began 45 million years ago when volcanic rocks were first erupted on the seafloor along the line of the present Solomon Islands ridge. In time the initial cycle of volcanic activity died off and another began, and then another. In this way the Solomon Islands ridge was built up until sufficient volcanic rock had accumulated to rise above sea level and form the islands. The process has continued to the present day as can be seen in the presence of active and dormant volcanoes on Bougainville, and in the south-western Solomon Islands.

On Bougainville, the older volcanic rocks are exposed in the Crown Prince Range in the centre of the island and south-eastward from the centre, and in the Deuro Range in the extreme south-east [Map 2]. The rocks are a mixture of lavas, volcanic breccias and volcanic sediments and have ages that range from 45 million years down to 4 million years. On Buka Island the equivalent volcanic rocks are exposed on the west coast in the Parkinson Range, and in the smaller islands south of Buka. On Buka the volcanic rocks are generally finer grained than those exposed on Bougainville and have been dated at 30-20 million years.

Included amongst the older volcanic rocks on Bougainville are bodies of coarser-grained 'intrusive' rocks, mainly granodiorite and diorite. These were once the reservoirs of molten rock, or chambers of magma, that fed each volcano. As each phase of volcanic activity slowed, the molten rock cooled slowly, allowing crystals to grow - hence the coarser-grained nature of the rock. It is these coarsergrained intrusive rocks that sometimes contain copper and gold mineralisation, as was the case at Panguna. The copper and gold reserves at Ok Tedi, Frieda River and Wafi on the New Guinea mainland are of similar style. This style of 


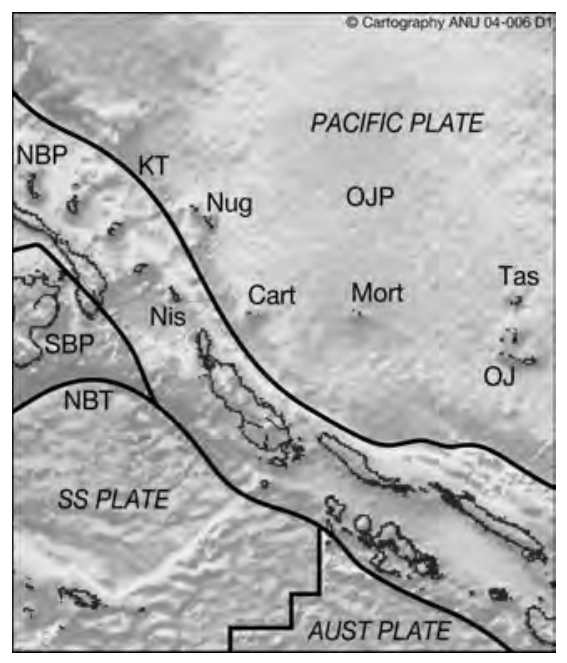

Map 1: Seafloor topography

[from Smith and Sandwell 1997] The map shows seafloor relief and plate boundaries of the area around Bougainville Island. The plates are PP Pacific Plate, SBP South Bismarck Plate, SSP Solomon Sea Plate, OJP Ontong Java Plateau and AP Australian Plate. The Solomon Islands ridge is on the Pacific Plate. Other abbreviations are: KT Kilinailau Trench, NBT New Britain, Nug Nuguria, Cart Carteret, Nis Nissan and Green, Mort Mortlock, Tas Tasman, and OJ Ontong Java islands and atolls.

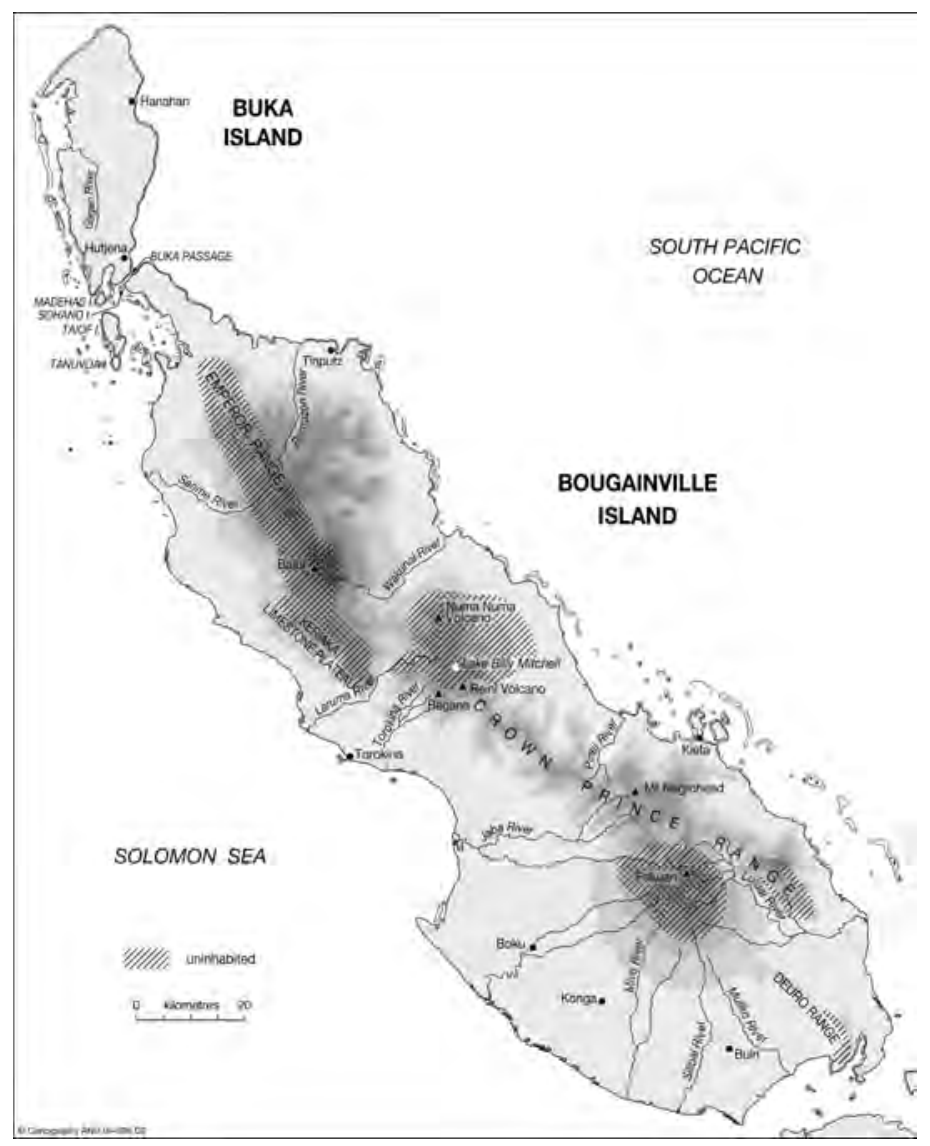

Map 2. Simplified topographic map of Bougainville and Buka Islands [from Blake and Miezitis 1967] 
mineralisation is referred to as porphyry copper because the host rocks normally have a porphyritic texture, meaning that large crystals are set in a finer groundmass.

Associated with the volcanic and intrusive rocks are sedimentary rocks. These include the Early Miocene (about 20 million years) shallow water limestone that forms the Keriaka Plateau south-west of Balbi volcano [Maps 2 and 3] and the raised coral reef that covers much of the surface of Buka Island and northernmost Bougainville. The raised reef is much younger - probably tens or hundreds of thousands of years old. The raised reef stands at about 90 metres above sea level at the northern end of the island and about three metres above sea level at the southern end.

\section{REGIONAL SETTING AND EVOLUTION}

Papua New Guinea, the Solomon Islands and Vanuatu are on a plate boundary. Along this boundary two great plates of the earth's outer layer, or lithosphere, are competing for the same space. This is the reason for the high level of earthquake and volcanic activity.

The Pacific Plate [Map 1] is moving to the west-north-west at a rate of 11 centimetres per year, and the Australian Plate is moving north at seven centimetres per year. The net result is that the two plates converge towards each other at 11 centimetres per year on an azimuth of 070 degrees (east-north-east).

The plate boundary is in fact made up of a series of small plates. One comprises the rocks that make up the floor of the Solomon Sea, another comprises the rocks beneath the south Bismarck Sea and includes New Britain and the Huon Peninsula, and another the rocks beneath the north Bismarck Sea (including Manus and all but the southern tip of New Ireland [Map 1]). The ridge that includes Buka and Bougainville may be part of the Pacific Plate.

Where two plates converge they must either push each other upwards to form a mountain range, as is the case in the centre of the island of New Guinea, or one plate may slide beneath the other. Where one plate slides beneath the other a deep sea trench develops at the plate boundary and volcanoes develop on the upper plate. The process of one plate sliding under another is called subduction and the resulting volcanic activity is called a volcanic arc (because typically the volcanoes lie along an arc when plotted in map view).

\section{Bougainville and Buka}

Bougainville and Buka have grown by two main stages of subduction and volcanic arc activity. The first stage started in the Eocene, about 45 million years ago, when the Pacific Plate was subducted beneath the Australian Plate along the line of the 


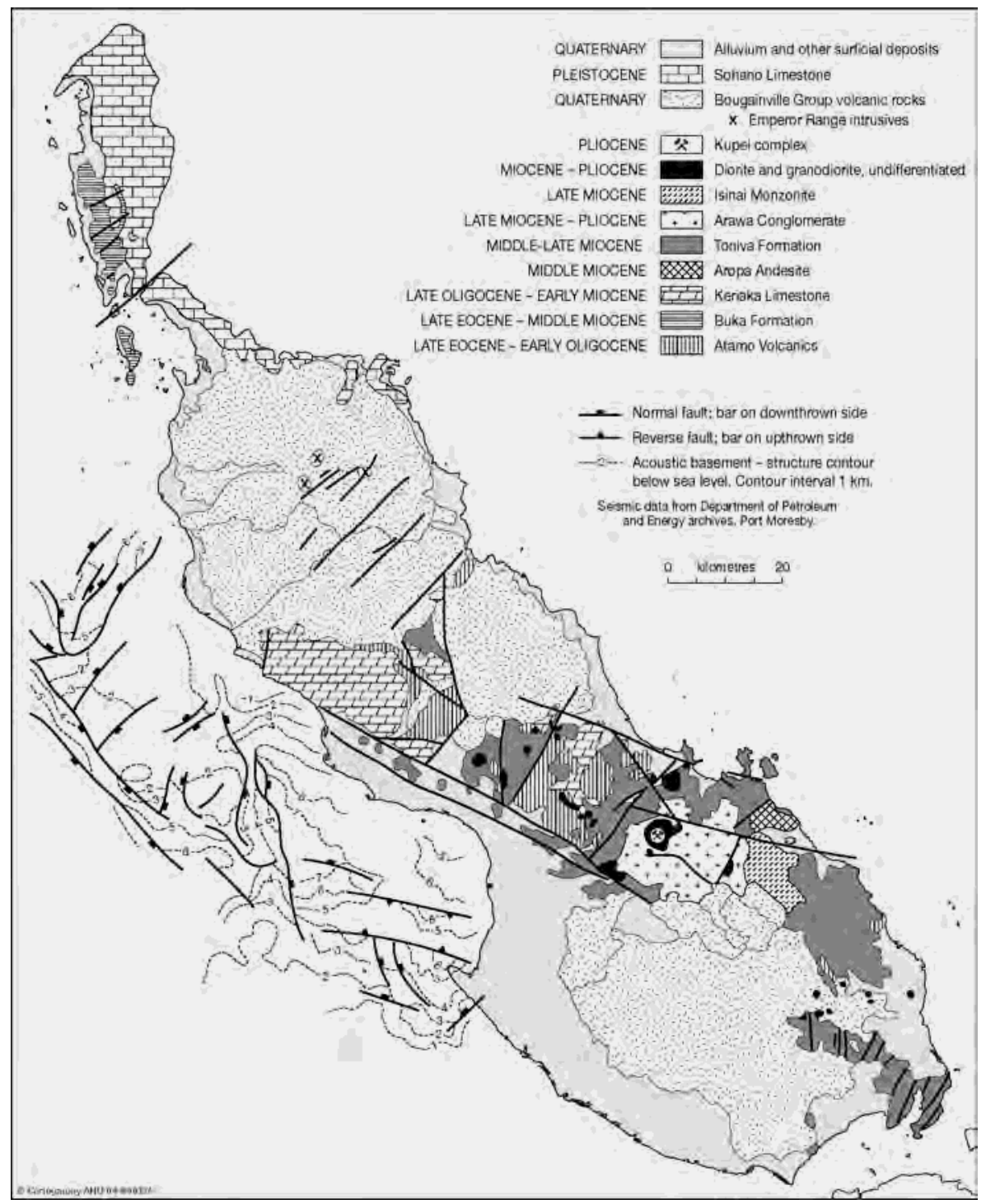

Map 3. Geological map [from Rogerson et al. 1989]

Kilinailau Trench. The second began about 10 million years ago when the Australian Plate was subducted beneath the Pacific Plate along the line of the New Britain - Bougainville - Makira Trench [Map 1]. The first event marked the birth of Bougainville and Buka as a pile of volcanic rocks on the ocean floor. 
The Kilinailau Trench ceased to be active about 10 million years ago when the steady north-westward motion of the Pacific Plate brought the thick oceanic crust of the Ontong Java Plateau into the Kilinailau Trench [Map 1]. The thick crust caused a problem because thick crust is not readily subducted. One could say it was a severe case of indigestion, or of biting off more than one could chew. The shortening of the crust could no longer be accommodated at the Kilinailau Trench and so a new trench formed, this time on the south-western side of the islands, allowing the Australian plate to be subducted beneath the Pacific Plate. This second stage of subduction yielded the more recent volcanic rocks on Bougainville Island, and has culminated in the development of Balbi, Bagana and Loloru volcanoes.

\section{The Other Islands and Atolls}

The Green Islands - Nissan and Pinipel — are atolls comprising coral and sand with a maximum elevation of 26 metres above sea level. They lie on the same submarine ridge as do Bougainville and Buka - a ridge that can be traced northnorthwest to Feni Island and beyond [Map 1]. The ridge is probably made up of the same mixture of older and younger volcanic rocks and associated sediments that are exposed on Bougainville and Buka.

The Nuguria, Carteret (Kilinailau), Mortlock (Takuu) and Tasman (Nukumanu) islands have a completely different geologic setting. These islands are bumps on the surface of Earth's greatest submarine plateau, the Ontong Java Plateau (named for Ontong Java Atoll). The Ontong Java Plateau, one of the marvels of nature, stands 2,500 metres higher than the surrounding seafloor and extends for more than 1,000 kilometres in every direction. The plateau formed about 100 million years ago by the outpouring of great quantities of basalt on the seafloor. The islands, in turn, are on volcanic pedestals that rise 1,500 metres above the surface of the plateau, or 2,000 metres in the case of Nuguria. At the surface they comprise coral and sand. According to the published maps the highest points in the Nuguria, Carteret and Mortlock islands are one metre above sea level, and in the Tasman Islands, three metres.

\section{DETAILS OF THE GEOLOGY OF BOUGAINVILLE AND BUKA}

Major studies of the geology of Bougainville and Buka islands were conducted in 1965 [Blake and Miezitis 1967] and 1987-88 [Rogerson et al. 1989]. The 1987-88 program was part of a larger aid-funded campaign by the National Government and the Federal Republic of Germany that included airborne geophysical surveys in 1986; ground geophysics (following up on the airborne 
anomalies) in 1987 and 1988; synthetic aperture radar imaging of the entire island at various scales; a volcanic hazards investigation; a program to promote small-scale alluvial mining; and a public relations program that aimed to explain the other activities, and to assess people's attitudes towards these activities. The ultimate aim was perhaps to pave the way for a resumption of mineral exploration in the province.

The geological mapping in 1987-88 was hampered by limited access to some parts of central and southern Bougainville, where landowners discouraged entry of the teams. Despite this, the program was successful in making refinements to the earlier mapping. In particular, where Blake and Miezitis [1967] had grouped all of the basement volcanic rocks into one rock unit (Kieta Volcanics, of uncertain age, probably Oligocene), the later workers were able to divide the volcanics into a number of constituent rock units, and to determine the age of most of these.

They defined an older unit (Atomo Volcanics) that contained microfossils that proved a Middle to Late Eocene age (in the range 50-40 million years [Map 3]). Overlying the Atomo Volcanics were two major units, the Toniva Formation and Arawa Conglomerate. These occupy much of the area previously mapped as Kieta Volcanics including the area adjacent to the Panguna minesite. These rocks are considerably younger than the Atamo Volcanics at around 15-10 million years. The succession of rock units was summarised by Rogerson et al. [1989].

All of the intrusive rocks have ages between 8 million and 1 million years (potassium-argon ages reported by Page and McDougall [1972] and Rogerson et al. [1989]) and thus were generated in the most recent volcanic cycle, after the New Britain - Bougainville - Makira Trench became active.

Geologists engaged in the 1987-88 field surveys also collected minus80-mesh sieved stream sediment samples for chemical analysis. This is a standard method of mineral exploration and can lead to identification of areas where there is an anomalous concentration of metal in rock or soil, and hence in stream sediments. The geochemical survey defined a number of areas that were anomalous for gold or copper. Most were within a $10 \mathrm{~km}$ radius of the Panguna Mine [see map in Rogerson et al. 1989].

As part of the same program, 10,000 line kilometres of airborne geophysical surveys were flown by the German Government Bundesanstalt fur Geowissenschaften und Rohstoffe (Federal Institute for Geology and Raw Materials) (BGR) in 1986, using a large helicopter equipped to measure the magnetic field, electromagnetics and radiometrics. Fieldwork by ground parties in 1987 and 1988 investigated all anomalies using magnetic, induced polarity, electromagnetic and radiometric methods. Results of this work were not summarised by Rogerson et al. [1989] but 
are available from the Department of Mining in Port Moresby. Geophysical and geological investigations of the waters offshore from Bougainville and Buka in 1984 were reported by Vedder and Bruns [1989].

\section{Mineral and Energy Resources}

In 1930 lode gold was found at Kupei on the north-eastern side of the Crown Prince Range, and subsequently at Pumkuna (Panguna) and Moroni on the southwestern slopes. These deposits were worked on a small scale until World War II. Small scale alluvial gold mining resumed after the war at Atomo, Karato and other localities [Blake and Miezitis 1967].

The potential for an ore body at the site of the Panguna Mine [Clark 1990] was recognised in 1961, and was tested by drilling in 1964. Mining started in April 1972 and ceased due to civil unrest in 1989. The mine is discussed further below. Other gold or copper-gold deposits may remain to be discovered in the areas defined by the 1987-88 geochemical survey. The most likely areas are within a $10 \mathrm{~km}$ radius of Panguna. The Bougainville Basin, to the west of the island, was tested for petroleum with one unsuccessful wildcat well, LEEtoile-1, in 1975 [Rogerson et al. 1989]. Thermal areas associated with the major volcanoes have the potential to provide geothermal energy.

\section{About Porphyry Copper Deposits}

Porphyry copper ore was first recognised and mined in the western United States in the early 1900s. The ore is by its nature very low grade (usually less than 1 per cent copper) and can be mined profitably only if it is present in great volume. For this reason porphyry copper deposits are also referred to as bulk low-grade copper deposits.

In order to profitably mine ore of such low grade there must be economies of scale, hence the use of giant power shovels, ore trucks that can carry tens or even hundreds of tonnes of ore, and an efficient milling and ore processing plant. The mining method is usually by open cut, rather than underground, and large volumes of waste material must be disposed of each day.

The wastes that are generated are of two types: waste rock, which is the barren rock that must be removed in order to gain access to the ore; and mill tailings, which are the fine sands that remain once the ore has been crushed and the copper-bearing sulphide minerals extracted. In a stable and dry environment the tailings can be stored in a tailings dam, allowed to dry out, and then rehabilitated with vegetation. In locations where there is high rainfall and the likelihood of earthquake activity, tailing dams are a less attractive option, because of the risk that the dam might fail catastrophically. 


\section{THE PANGUNA MINE}

Jack Errol Thompson, the resident geologist in Port Moresby for the Territory Administration, visited Kupei and Panguna in 1961 with the object of checking the potential for porphyry copper mineralisation. He was aware that miners in the Kupei-Panguna area in the 1930s had reported copper mineralisation associated with gold in quartz veins in igneous rocks. He confirmed and reported the nature of the mineralisation [Thompson 1962; Davies 1992].

Geologists with Conzinc Riotinto of Australia were aware of developments in the Philippines, where porphyry copper had been discovered recently and mines were being developed, took note of the report, redirected their exploration effort from Queensland, and applied for prospecting rights to the Kupei-Panguna area in 1963. In three months of operations in 1964 the company defined a sizeable copper anomaly in surface soils, suggesting the presence of mineralisation at depth. In the following years the mineralised zone was confirmed by drilling and tunnelling, a major orebody was defined, and an initial agreement on terms and conditions for development was negotiated with Government (the Australian Administration) in 1967.

A feasibility study for the development of a major mine was completed by 1969 and Bougainville Copper Ltd (BCL), a company with shares held by Conzinc Riotinto of Australia Ltd (53.6 per cent), the Papua New Guinea government (19.1 per cent), and public shareholders (27.3 per cent), started mining in April 1972. The mine came on stream at a time of high metal prices with the result that good profits were made in the early years. The Papua New Guinea government was concerned at the loss of revenue due to tax concessions in the original agreement, and renegotiated the agreement in 1974. This was widely hailed as a landmark event in dealings between a government and a multinational corporation.

The mine operated profitably until closure in 1989. A resource of 496 million tonnes of copper-gold ore averaging 0.42 per cent copper and 0.55 grams per tonne gold remains in the ground. The total amount of mineable ore that remains, if we include lower grade ore that is suitable for upgrading, is 691 million tonnes of 0.40 per cent copper and 0.46 grams per tonne gold [Bougainville Copper Limited Annual Report for 1989].

When in full production ore was mined at a rate of 130,000 tonnes per day and waste rock at a rate of 115,000 tonnes per day. Shortly before the mine was closed, production of ore had been increased to 143,000 tonnes per day by the installation of a fourth ball mill. The ore was concentrated at the mine using conventional crushing, grinding and flotation. This increased copper content 
from 0.44 per cent to 30.1 per cent, gold from 0.50 grams per tonne to 31.0 grams per tonne, and silver from 1.41 grams per tonne to 91.2 grams per tonne (average figures for the first five months of 1989, from BCL Annual Report for 1989). The slurry of concentrate was then pumped to Loloho on the east coast where it was filtered, dried and exported by ship. Waste rock was dumped in valleys near the mine, and mill tailings (the fine sediment that remains after the ore has been crushed and the sulphides extracted) were released into Kawerong Creek and thence into the Jaba River.

The mine brought major economic benefits to Papua New Guinea. The value of the metals produced from the time when the mine opened in 1972 until closure in May 1989 was K5.1 billion, which represents about 44 per cent of Papau New Guinea's exports over that period. During the same period contributions to the Government in the form of dividends, taxes and royalties totalled K1.033 billion, which represents about 17 per cent of all the revenue that was generated internally within Papua New Guinea (data from BCL Annual Report for 1989). Beyond this the company's activity spurred the growth of local businesses to provide goods and services to the mine. Another important contribution by the mine was an excellent training program for apprentices and others.

At the same time the mining operation had negative effects on the physical environment, as noted by Chambers [1985] and Hughes and Sullivan [1992]. For one thing, no environmental impact study was carried out prior to mine development. The disposal of mine tailings was an ongoing problem. The constant flood of tailings filled the channel of the Jaba River to a depth of 30 metres and overflowed on to the flood plain for a width of one kilometre. At the coast, the tailing sands accumulated to form a delta of 900-1000 hectares, and the fine fraction was carried seaward in suspension to settle on the floor of the bay.

The tailings were rich in copper (800-1,000 ppm) and other chemicals and had the effect of destroying all aquatic life in the Jaba River and its floodplain [Hughes and Sullivan, 1992]. At the time that the mine closed, in 1989, a pipeline to carry tailings from the mill to the sea was under construction with the intention that there would be no further release of tailings into the river system, and that the Jaba River and flood plain would be rehabilitated. (See Vernon, this volume, for further discussion of environmental impacts of the mine.)

\section{NATURAL HAZARDS}

Bougainville and Buka islands are at risk from earthquakes, tsunamis and volcanic activity. The islands lie immediately east of a zone of very intense, shallow earthquake activity [Map 4]. In fact, the seismic activity in the triangular area between 
Bougainville and New Britain is the highest in Papua New Guinea and is the equal of the most active areas in the world [Everingham et al. 1977]. Any structures in the islands are required to meet strict building codes for earthquake safety.

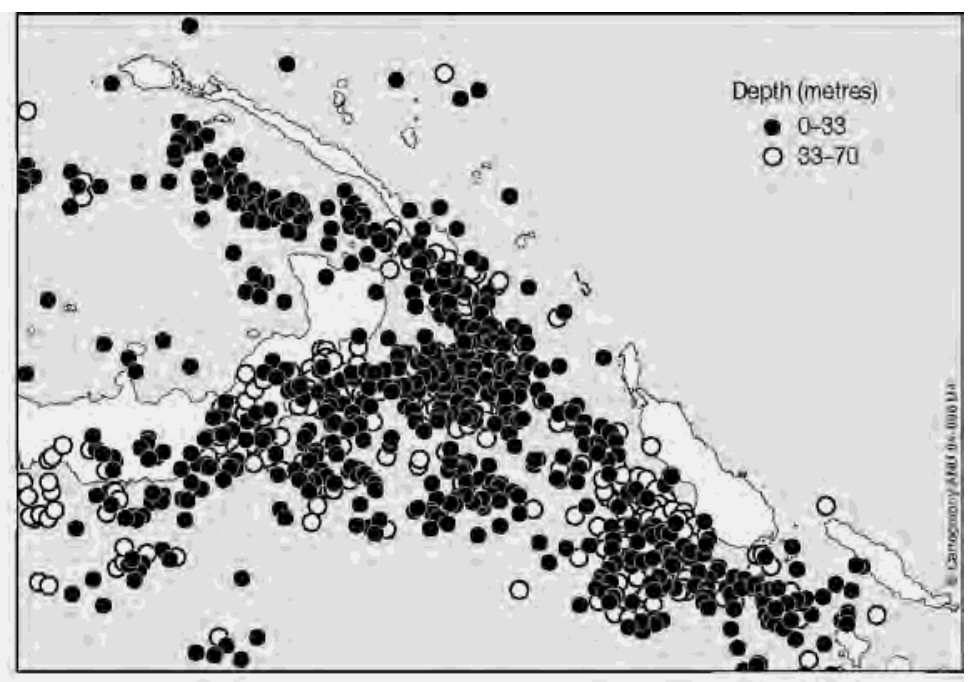

Map 4. Map of shallow earthquakes [United States Geological Survey http:/neic.usgs.gov.] Comment: The map shows the intense concentration of shallow earthquakes in the triangular area between Bougainville-Buka and New Britain. Earthquakes of magnitude five or greater that occurred at depths less than 50 kilometres in the last 30 years are shown.

The coastline of Bougainville is attacked periodically by near-source and farsource tsunamis. A near-source tsunami is one that originates from a local earthquake. An example is the tsunami of July 1975 that severely damaged the telephone exchange at Torokina [Everingham et al. 1977]. A far-source tsunami originates from a distant earthquake. An example is the November 1952 tsunami that damaged the Marist Brothers' school at Kieta. This tsunami originated from a major earthquake near the coast of Kamchatka in the north Pacific [Everingham 1977]. The Pacific Tsunami Warning System now provides emailed warnings of far-source tsunamis but there is currently no means of providing warnings of nearsource tsunamis. This is because the arrival of the tsunami follows too soon after the earthquake - a pause of only 10-20 minutes typically. Because there is a high risk of tsunamis on all coasts, dwellings should not be built near sea level, and major infrastructure, such as schools, hospitals, power stations, police headquarters 
and communications facilities should be located on high ground or at a distance of at least 800 metres from the shoreline.

Great volcanoes form much of the land surface of Bougainville, from Balbi in the north to Taroka and Loloru in the south. Balbi erupted some time in the interval 1800-1850 AD, generating pyroclastic flows (fast moving clouds of hot gas, dust and rock fragments) and causing some deaths. The volcano is potentially active and is likely to again produce pyroclastic flows when it erupts. At present there are active solfataras (vents emitting sulphurus vapours) in the summit area (at 2,715 metres above sea level) and hot springs on the upper slopes [Blake and Miezitis, 1967]. Another major volcano that probably has erupted within the last several hundred years, and is considered potentially active, is Loloru $(1,887$ metres). Loloru also has solfataras in the summit area and hot springs on the slopes [Blake and Miezitis, 1967].

The only volcano that is currently active is Bagana (1,730 metres), a massive symmetrical lava cone largely constructed by an accumulation of viscous andesitic lava flows. Eruptive activity at Bagana is almost continuous and is characterised by emission of ash and non-explosive effusion of viscous lava. Explosive activity at times produces pyroclastic flows. Future pyroclastic flows could threaten any settlements close to the foot of the volcano.

The lake at the summit of Loloru volcano and and the crater lake of Billy Mitchell volcano (thought to be extinct; lake level 1,000 metres above sea level) are a potential source of catastrophic mudflows, in the event that the lake walls were breached by volcanic or earthquake activity.

\section{Endnotes}

* I thank Mary Walta and Herbert Girschik for critical comment that considerably improved this chapter. 


\title{
THE LANGUAGES OF BOUGAINVILLE
}

\author{
by Darrell Tryon
}

卫

he Bougainville Province of Papua New Guinea consists of the following islands to the east of the Papua New Guinea mainland: Bougainville, Buka and adjacent islands, and the offshore island groups including the Nissan (Green Island), Nuguria (Fead), Takuu (Mortlock), Nukumanu (Tasman) and Tulun (Carteret) islands [Hanson et al. 2001: 282].

The languages of Bougainville belong to two major language families, the Austronesian Family and the Papuan, or non-Austronesian, language group. The Austronesian and Papuan languages are not genetically related, that is, they have different origins, and, as will be discussed below, very different chronologies. The Austronesian languages are located in the northern part of the Buka-Bougainville land mass, and in coastal pockets further south, as well as on the small islands to the north and east, [Map 1]. The Papuan languages form a geographical continuum covering the central and southern sections of Bougainville (minus the Austronesian enclaves).

The term 'language' is used in a number of different ways. Commonly it is used as a marker of political identity - in this sense each social unit has its own language or dialect in Bougainville Province, approximately 50 in all. In technical terms, there are currently 16 Austronesian languages and nine Papuan languages spoken in the Bougainville Province today. What distinguishes a 'language' from a 'dialect'? Linguists say that if two modes of speech are mutually intelligible, then they are said to constitute dialects of a single language. If they are not mutually intelligible, then they are considered to constitute separate languages. To a certain extent, then, these distinctions are subjective. What follows is a brief introduction to Austronesian and Papuan languages and language families, its purpose being to situate the languages of the Bougainville Province within these parameters. 


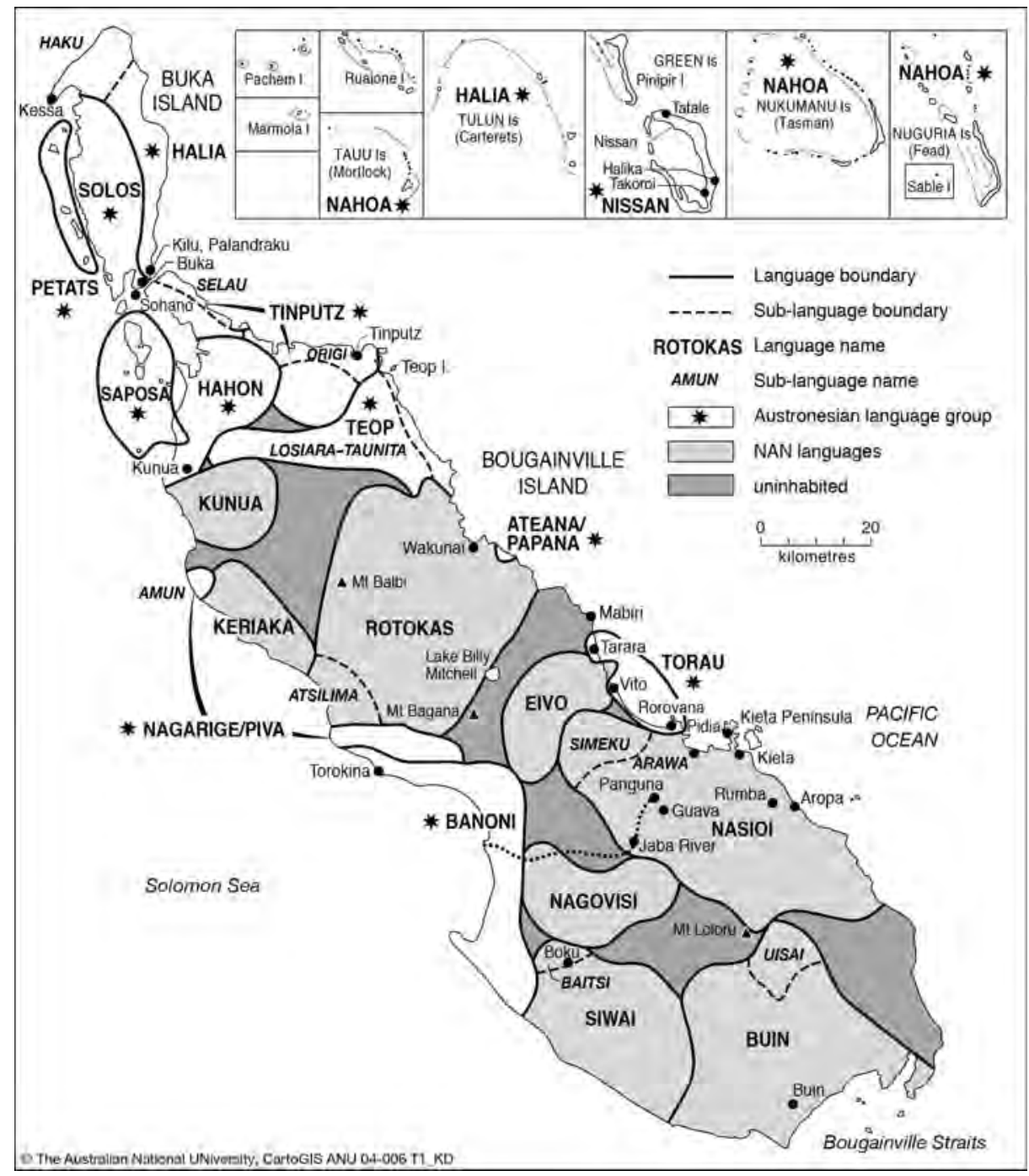

Map 1: The languages of Bougainville

\section{DISTINGUISHING AUSTRONESIAN AND PAPUAN LANGUAGES}

What is meant by the terms 'Papuan' and 'non-Austronesian'? First, the term 'nonAustronesian' was coined to describe those languages which are found mainly in greater New Guinea, but which are not members of the Austronesian language family, which is easily distinguished by its relatively uniform basic grammatical 
features and lexicon [for further details see Tryon, ed. 1995]. The so-called Papuan, or 'non-Austronesian' languages are generally considered to be much more complex, morphologically and syntactically, (and difficult to learn for speakers of Austronesian languages) and are immediately recognisable as not being Austronesian [Foley 1986]. However, the term 'non-Austronesian' is totally inadequate, as all of the languages of the world outside the Austronesian family could have this label applied to them. The term 'Papuan' is not much better, in that there is a geographical area in Papua New Guinea called Papua. This area is home to both Austronesian and 'non-Austronesian' languages. However, as no better term has been devised until now, the term Papuan has become the preferred label for those 'nonAustronesian' languages found in greater New Guinea and environs.

\section{THE AUSTRONESIAN LANGUAGES}

The Austronesian languages present on Bougainville are all members of the great Oceanic subgroup of Austronesian [Map 2], represented in family tree form in Figure 1 below. In fact, the Austronesian languages are believed to have originated in southern China about 6,000 years ago and from there, migrating first to Taiwan and later moving to the Philippines, Indonesia, Madagascar, Singapore, Malaysia and parts of mainland South-East Asia (Vietnam and Cambodia) [Tryon, ed. 1995]. From island South-East Asia they moved along the north coast of the island of New Guinea and settled in the New Britain/New Ireland area about 4,000 years ago [Spriggs 1997]. This was the cradle of the famous Lapita culture from where the Austronesian peopling of Island Melanesia began some 500 years later. The archaeological evidence indicates that the first Austronesian language speakers would have reached the Bougainville area roughly 3,000 years ago [see Spriggs, this volume].

This is considerably later than the first Papuan language speaking communities, which have been present in the Buka-Bougainville area for almost 30,000 years. ${ }^{1}$ It is self-evident that there was major and intensive contact between the Austronesian newcomers and the older established Papuans (see below).

So where do the Austronesian languages of the Bougainville area fit into the Melanesian scheme of things? We have seen that they are all members of the Oceanic subgroup, a huge subgroup which has as its members almost half of the Austronesian family [Map 2]. Within Oceanic, the Bougainville area languages are members of the Western Oceanic subgroup, which comprises all the Austronesian languages of Papua New Guinea and the Western Solomons [Figure 1].

Within the Western Oceanic subgroup, the Austronesian languages of Bougainville are members of a group known as the Meso-Melanesian cluster [Map 3]. 


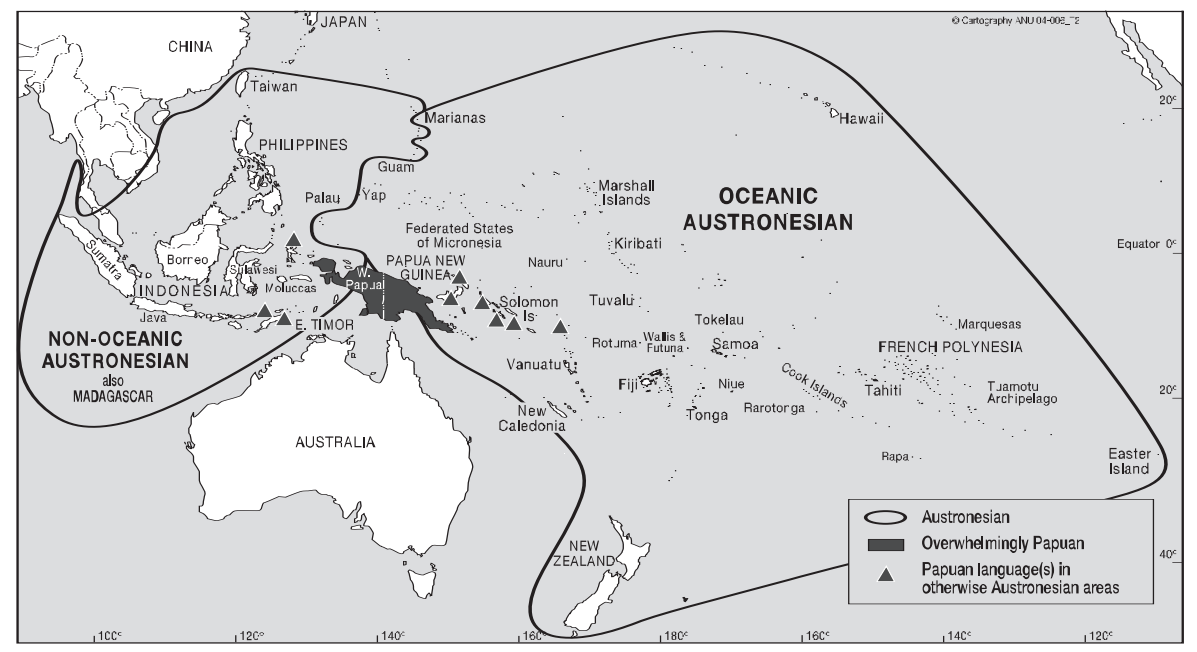

Map 2: Papuan and Austronesian language areas

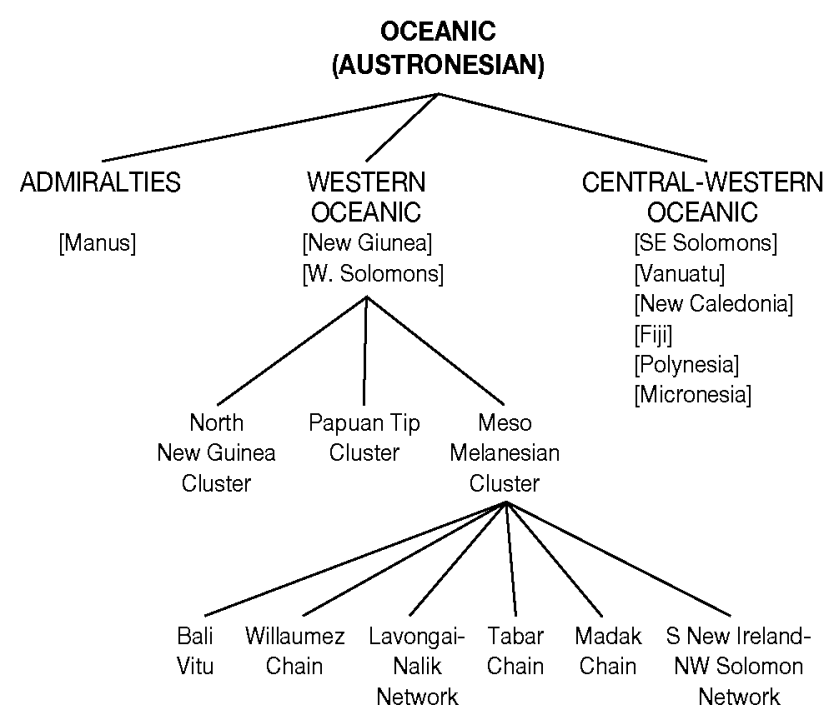

Figure 1: The Oceanic subgroup of Austronesian languages 


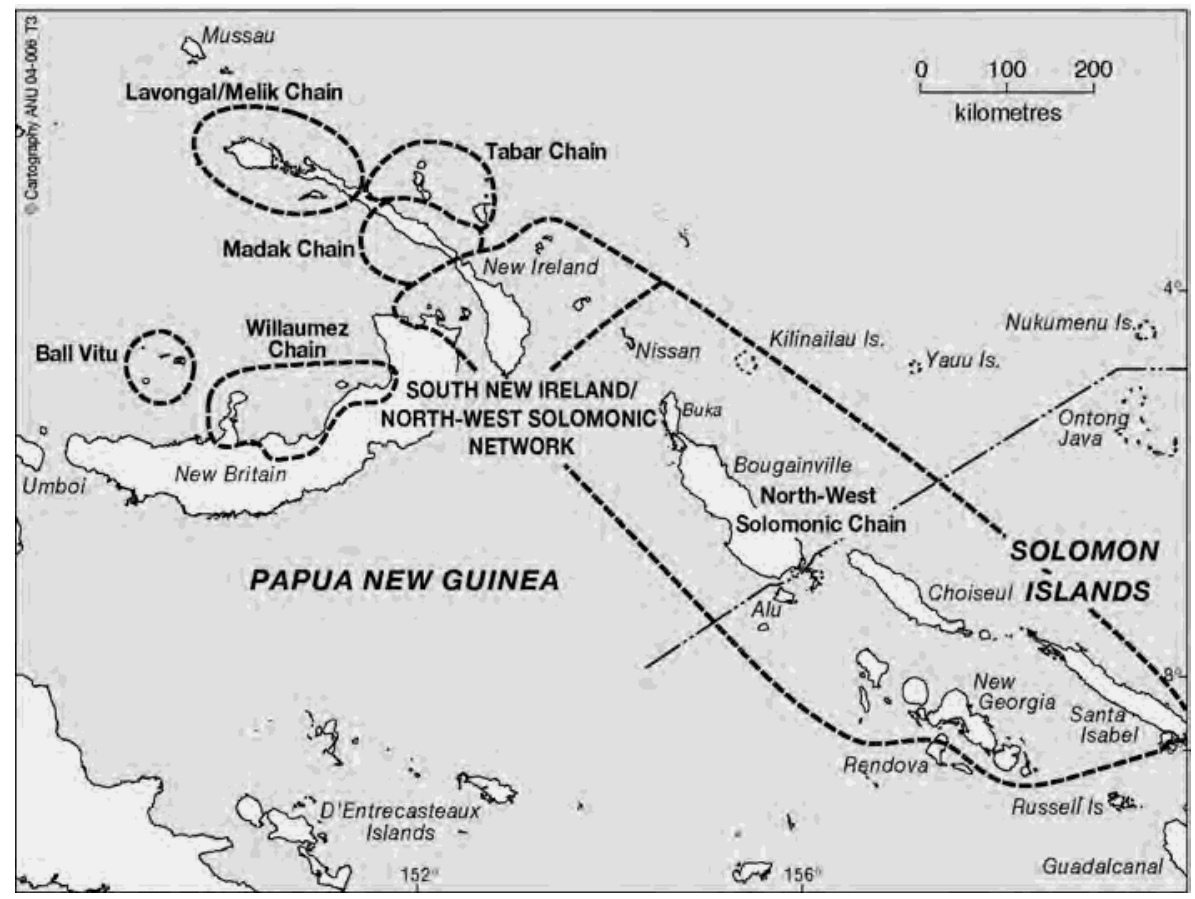

Map 3: Location of the Meso-Melanesian cluster and its subgroups

This grouping includes most of the Austronesian languages of New Ireland (the Lavongai-Nalik Chain, Tabar Chain, Madak Chain), and the north coast of New Britain (Bali-Vitu, Willaumez Chain), as well as the languages of the South New Ireland-North-West Solomonic Network.

In terms of the languages of Bougainville, it is the South New IrelandNorth-West Solomonic Network which is the defining subgroup. Within this, the most closely related languages are members of the North-West Solomonic group (see Map 4). It can be seen from this map that this group takes in all of the Austronesian languages of Buka and Bougainville and Nissan to the north-west, as well as the languages of the Western Solomons (the Shortland Islands, Choiseul, New Georgia and Santa Isabel, with the exception of Bughotu, on the eastern extremity of Santa Isabel. ${ }^{2}$

The inter-relationships of the Austronesian languages of Bougainville, and their further links to the languages of the North-West Solomonic chain, are set out in Figure 2. This figure shows that Petats and Halia (and its dialects) are closely related, as are Saposa (and the Taiof dialect) and Hahon, Tinputz and Teop. Piva is most closely related to its neighbour Banoni. On East Bougainville there is a strong link between Torau and Uruava (now extinct), ${ }^{3}$ and Mono-Alu in the Shortlands [Ross 1988: 217]. 


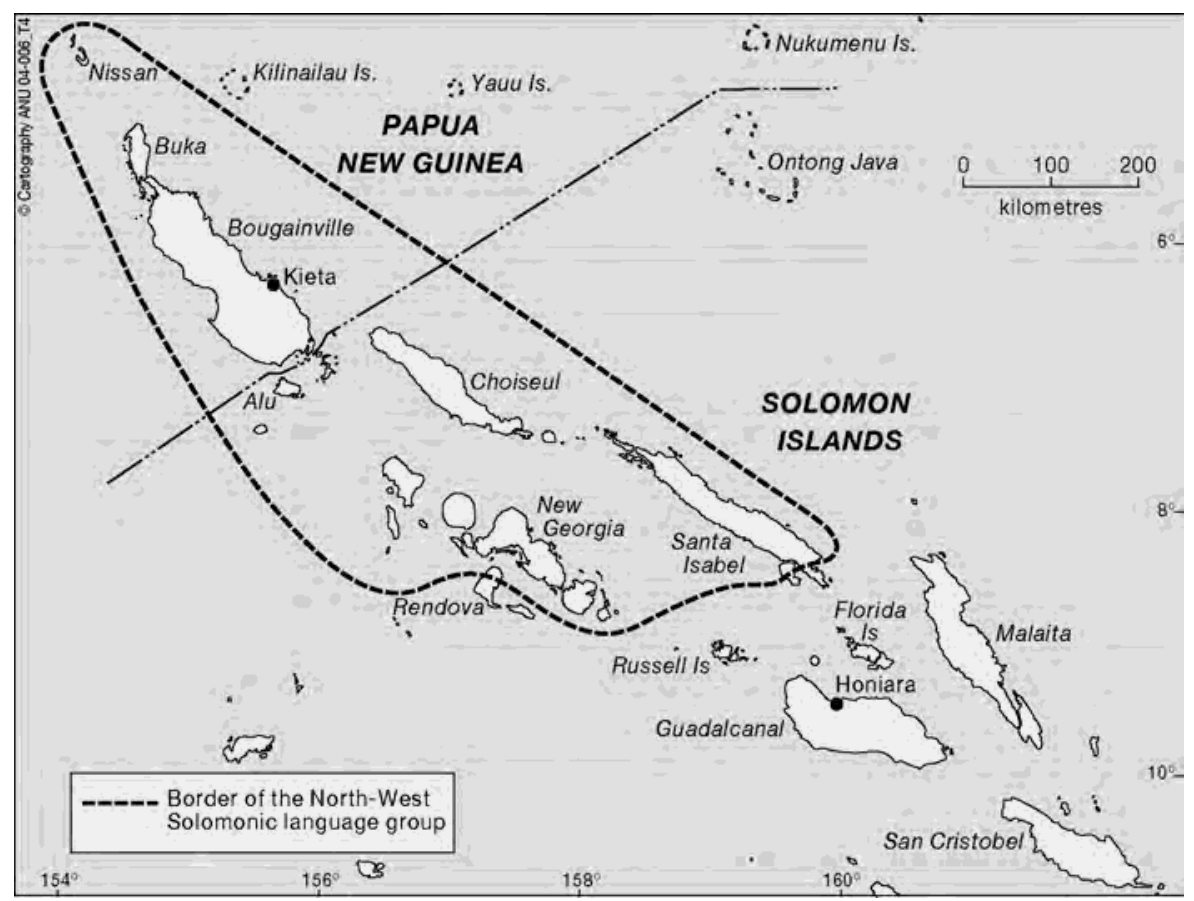

Map 4: Location of the North-West Solomonic group of Oceanic languages

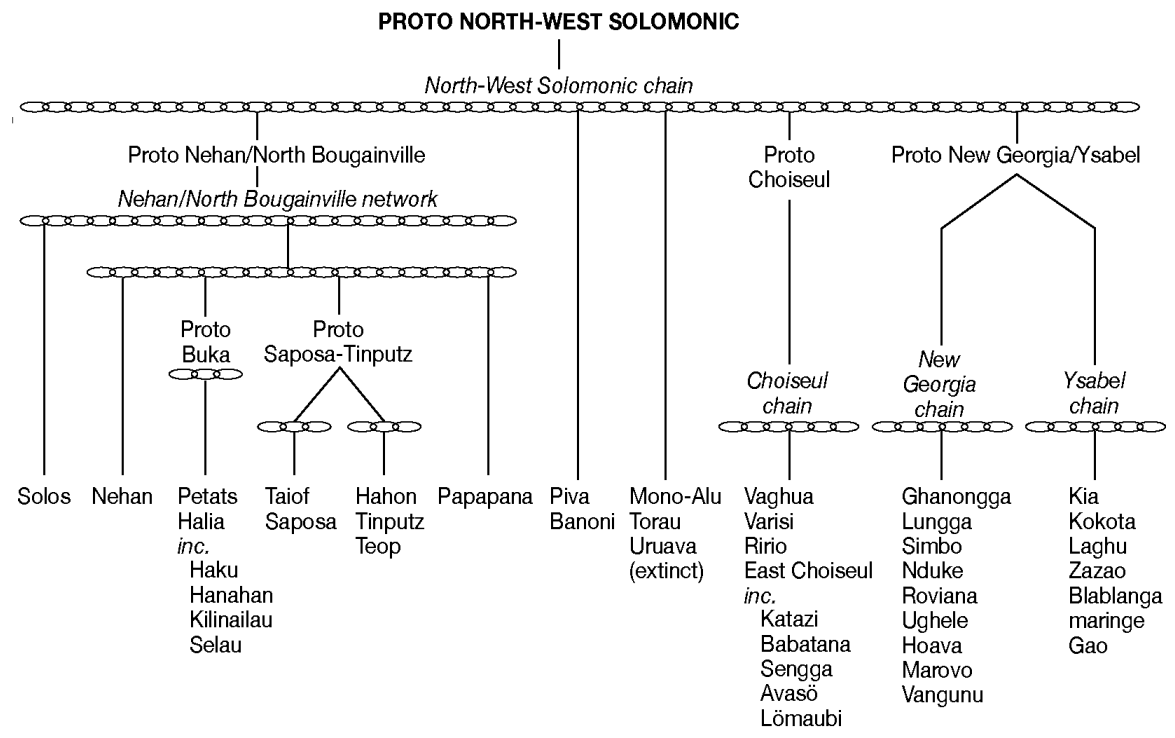

Figure 2: The North-West Solomonic language group: genetic tree 
In terms of linguistics, then, there are 16 extant Austronesian languages spoken in Bougainville Province. These include Nehan (Green Island-Nissan), together with three Polynesian Outlier languages, namely Takuu (Mortlock Island), Nuguria (Fead), and Nukumanu (Tasman Island). The languages, locations and approximate numbers of speakers are as follows:

\begin{tabular}{lllr}
\multicolumn{2}{l}{ Language } & Location & No. of Speakers ${ }^{4}$ \\
\hline 1. & Halia & Kilinailau (Carteret Is), & $20,000[1994]^{5}$ \\
2. & Haku & NE Buka, NE Bougainville & \\
3. & Solos & NE Buka & $5,000[1982]$ \\
4. & Petats & C \& SW Buka & $3,200[1977]$ \\
& & Petats, Pororan, Hitau, & $2,000[1975]$ \\
5. & Saposa (Taiof) & Matsungan Is (off W Buka) & \\
& & Saposa and Taiof I & $1,400[1998]$ \\
6. & Hahon (Hanon) & (SW of Buka) & \\
7. & Piva & NW Bougainville & $1,300[1977]$ \\
8. & Banoni & W Bougainville & $550[1977]$ \\
9. & Tinputz (Vadoo) & SW Bougainville & $1,000[1977]$ \\
10. & Teop & NE Bougainville & $3,900[1991]$ \\
11. & Papapana & NE Bougainville & $5,000[1991]$ \\
12. & Torau (Rorovana) & E Bougainville & $150[1977]$ \\
13. & Uruava & SE Bougainville & $605[1963]$ \\
14. & Nehan (Green Is-Nissan) & N Bougainville & EXTINCT \\
15. & Takuu & Mortlock Islands & $7,000[1995]$ \\
16. & Nukumanu & Tasman Islands & $250[1981]$ \\
17. & Nuguria & Nukuria Atoll & $200[1981]$ \\
\hline & & & $200[1981]$ \\
\hline
\end{tabular}

\section{Previous Classifications}

There have been a number of surveys of the languages of Bougainville carried out over the past forty years, principally Allen and Hurd [1963], Wurm and Hattori [1981-83], Wassmann [1995] ${ }^{6}$ and Ethnologue (Grimes ed.) [2000]. The listing above takes previous surveys into account, but is also based on native speakers' evaluations of differences between the surveys, especially with regard to variant names and the differentiation of 'language' versus 'dialect'. Before discussing these, it is useful to tabulate the results of previous surveys as follows: 


\begin{tabular}{|c|c|c|c|c|c|}
\hline & Language & Variant Name & Dialects & Sub-dialects & Sub-language ${ }^{7}$ \\
\hline $\mathrm{AH}^{8}$ & Halia & $\begin{array}{l}\text { Hanahan, } \\
\text { Tulon, }\end{array}$ & $\begin{array}{l}\text { Halia, Haku, } \\
\text { Hangan } \\
\text { Tasi }\end{array}$ & & Selau \\
\hline WH & Halia & & $\begin{array}{l}\text { Haku, Hanahan, } \\
\text { Selau, Carteret }\end{array}$ & & \\
\hline ET $^{9}$ & Halia & Tasi & $\begin{array}{l}\text { Hanahan, Hangan, } \\
\text { Touloun, Selau }\end{array}$ & & \\
\hline DT & Halia & & & & \\
\hline ET & Hakö & & Lontes & & \\
\hline DT & $\mathrm{Haku}^{10}$ & & & & \\
\hline $\mathrm{AH}$ & Solos & & & & \\
\hline WH & Solos & & & & \\
\hline ET & Solos & & & & \\
\hline DT & Solos & & & & \\
\hline $\mathrm{AH}$ & Petats & & $\begin{array}{l}\text { Petats, Hitau-Poro } \\
\text { Matsungan }\end{array}$ & ran, & \\
\hline WH & Petats & & & & \\
\hline ET & Petats & & $\begin{array}{l}\text { Hitau-Pororan, } \\
\text { Matsungan, Sumuo }\end{array}$ & & \\
\hline DT & Petats & & & & \\
\hline $\mathrm{AH}$ & Saposa & & Saposa, Taiof & & \\
\hline WH & Saposa & & Saposa, Taiof & & \\
\hline ET & Saposa & & Saposa, Taiof & & \\
\hline DT & Saposa & Taiof & & & \\
\hline $\mathrm{AH}$ & Hahon & & $\begin{array}{l}\text { Hahon, Kurur, } \\
\text { Ratsua, Aravia }\end{array}$ & & \\
\hline WH & Hahon & & & & \\
\hline ET & Hahon & & $\begin{array}{l}\text { Kurur, Ratsua, } \\
\text { Aravia }\end{array}$ & & \\
\hline DT & Hahon & & & & \\
\hline $\mathrm{AH}$ & Tinputz & Wasoi & $\begin{array}{l}\text { Tinputz, } \\
\text { Pokpapa }\end{array}$ & $\begin{array}{l}\text { Dios (Tsibatabai), } \\
\text { Chundawan }\end{array}$ & Orig \\
\hline WH & Timputz & & & & \\
\hline ET & Tinputz & $\begin{array}{l}\text { Vasuii, Vasui, } \\
\text { Wasoi, Timputs }\end{array}$ & $\begin{array}{l}\text { Vasui, Vavouhpoa', } \\
\text { Vaene', Vado-Vaen } \\
\text { Vapopeo', Vapopeo } \\
\text { Rausaura, Vado }\end{array}$ & & \\
\hline DT & Tinputz & Vaadoo & & & \\
\hline $\mathrm{AH}$ & Teop & & $\begin{array}{l}\text { Teop, } \\
\text { Wainanana }\end{array}$ & $\begin{array}{l}\text { Losiara, } \\
\text { Taunita, } \\
\text { Melilup, } \\
\text { Petspets }\end{array}$ & $\begin{array}{l}\text { Losiara- } \\
\text { Taunita }\end{array}$ \\
\hline WH & Teop & & & & \\
\hline ET & Teop & & $\begin{array}{l}\text { Wainanana, } \\
\text { Losiara (Raosiara), } \\
\text { Koopei (Kopei) }\end{array}$ & & \\
\hline DT & Teop & & & & \\
\hline $\mathrm{AH}$ & Papapana & & & & \\
\hline
\end{tabular}




\begin{tabular}{|c|c|c|c|c|c|}
\hline (tomen & Language & Variant Name & Dialects & Sub-dialects & Sub-language 7 \\
\hline WH & Papapa & & & & \\
\hline ET & Papapana & & & & \\
\hline DT & Papapana & & & & \\
\hline $\mathrm{AH}$ & Nagarige & Piva & Nagarige & Amun & \\
\hline WH & Piva & & & & \\
\hline ET & Piva & Nagarige & Amun & & \\
\hline DT & Piva & & & & \\
\hline $\mathrm{AH}$ & Banoni & Tsonari & & & \\
\hline WH & Banoni & & & & \\
\hline ET & Banoni & Tsunari & & & \\
\hline DT & Banoni & & & & \\
\hline $\mathrm{AH}$ & Torau & & & & \\
\hline WH & Torau & & & & \\
\hline ET & Torau & Rorovana & & & \\
\hline DT & Torau & Rorovana & & & \\
\hline WH & Uruava & & & & \\
\hline ET & Uruava & & & & \\
\hline DT & Uruava $^{11}$ & & & & \\
\hline $\mathrm{AH}$ & Nissan & & Nissan, Pinipel & & \\
\hline WH & Nehan & Nissan & & & \\
\hline ET & Nehan & Nissan, Nihan & Nehan, Pinipel & & \\
\hline DT & Nehan & Nissan & & & \\
\hline $\mathrm{AH}$ & Nahoa $^{12}$ & Taku & $\begin{array}{l}\text { Mortlock, Tasman, } \\
\text { Nuguria-Fead }\end{array}$ & & \\
\hline WH & Takuu & & & & \\
\hline ET & Takuu & $\begin{array}{l}\text { Tauu, Taku, Tau, } \\
\text { Mortlock }\end{array}$ & & & \\
\hline DT & Takuu & & & & \\
\hline $\mathrm{AH}$ & Nahoa & Taku & $\begin{array}{l}\text { Mortlock, Tasman, } \\
\text { Nuguria-Fead }\end{array}$ & & \\
\hline WH & Nukumanu & & & & \\
\hline ET & Nukumanu & Tasman & & & \\
\hline DT & Nukumanu & & & & \\
\hline $\mathrm{AH}$ & Nahoa & Taku & $\begin{array}{l}\text { Mortlock, Tasman, } \\
\text { Nuguria-Fead }\end{array}$ & & \\
\hline WH & Nuguria & & & & \\
\hline ET & Nuguria & $\begin{array}{l}\text { Nukuria, Nahoa, } \\
\text { Fead }\end{array}$ & & & \\
\hline DT & Nuguria & & & & \\
\hline
\end{tabular}

\section{THE PAPUAN LANGUAGES}

The Papuan or non-Austronesian languages, which number some 750, are mainly spoken across the mountainous interior of the great island of New Guinea. In Map 2, they are indicated in solid black. Austronesian languages are spoken mainly in the coastal regions. Papuan languages are also spoken to the west of 
New Guinea in the northern half of Halmahera, on Pantar and Alor, and in parts of Timor. To the east of New Guinea, Papuan languages are spoken in parts of New Britain and New Ireland, Bougainville, and in parts of the Solomon Islands as far south-east as the Santa Cruz group.

It has not been demonstrated that all of the Papuan languages are genetically related. However, thanks to the pioneering work of Wurm and his team during the 1960s [Wurm, ed. 1975], and since that time through the work of an increasing number of scholars, especially Ross [1996] and Pawley [1998], it has been demonstrated that a large number of the Papuan languages, up to 500, are in all likelihood members of a single language group, best known as the Trans New Guinea Phylum, or Trans New Guinea Family. Pawley sums up the situation as follows:

It now seems certain that there is a valid genetic group which includes many of the groups of Papuan languages assigned by Wurm, Voorhoeve and McElhanon [1975] to the TNG Phylum. The core of this group consists of many small subgroups spoken in the central mountain ranges of New Guinea, starting east of the Bird's Head and extending to Southeast Papua, together with the Asmat-Kamoro and Awyu-Dumut groups of the southwest lowlands and two large groups of northeast New Guinea: the Madang group (with about 100 languages), and the Finisterre-Huon group (about 70 languages) — some 400 languages in all [Pawley 1998: 683].

While this is a major grouping, the remainder of the Papuan languages have been classified into a number of small phyla, up to 50, each with a membership of 20 to 30 languages. None of these phyla have been demonstrated to be related to one another, and none have been shown to belong to the very extensive Trans New Guinea Phylum. Given the extreme antiquity of the populations speaking the languages in these phyla, this situation is not really surprising. ${ }^{13}$

There are eight Papuan or non-Austronesian languages spoken on Bougainville as follows:

\begin{tabular}{lllr} 
& Language & Location & No. of Speakers \\
\hline 1. & Kunua (Konua) & W Bougainville & $3,500[1998]$ \\
2. & Rotokas & C Bougainville & $4,320[1981]$ \\
3. & Keriaka & W Bougainville & $1,000[1981]$ \\
4. & Eivo & C Bougainville & $1,200[1981]$ \\
5. & Nasioi (Kieta) & SE Bougainville & $10,000[1990]$ \\
6. & Nagovisi & SW Bougainville & $5,000[1975]$ \\
7. & Siwai (Motuna) & SW Bougainville & $6,600[1981]$ \\
8. & Buin (Telei) & S Bougainville & $30,500[1998]$ \\
\hline
\end{tabular}


Variant language and dialect names recorded in previous surveys [Allen and Hurd 1963; Wurm and Hattori 1981-83; Ethnologue 2000] include the following:

\begin{tabular}{|c|c|c|c|c|c|}
\hline & Language & Variant Name & Dialects & Sub-dialects & Sub-language \\
\hline $\mathrm{AH}$ & Kunua & & & & \\
\hline WH & Konua & & & & \\
\hline ET & Rapoisi & Kunua, Konua & & & \\
\hline DT & Kunua & Konua & & & \\
\hline $\mathrm{AH}$ & Keriaka & & & & \\
\hline WH & Keriaka & & & & \\
\hline ET & Kereaka & Keriaka & & & \\
\hline DT & Keriaka & & & & \\
\hline $\mathrm{AH}$ & Rotokas & & $\begin{array}{l}\text { Rotokas, } \\
\text { Pipipaia, Aita, }\end{array}$ & Atsilima & \\
\hline WH & Rotokas & & Atsilima & & \\
\hline ET & Rotokas & & $\begin{array}{l}\text { Pipipaia, Aita, } \\
\text { Atsilima }\end{array}$ & & \\
\hline DT & Rotokas & & & & \\
\hline $\mathrm{AH}$ & Eivo & & & & \\
\hline WH & Eivo & & & & \\
\hline ET & Eivo & & & & \\
\hline $\mathrm{DT}$ & Eivo & & & & \\
\hline $\mathrm{AH}$ & Nasioi & & $\begin{array}{l}\text { Nasioi, Pakia- } \\
\text { Sieronji, Koromira, } \\
\text { Lantanai, } \\
\text { Oune, Orami } \\
\text { Simek }\end{array}$ & $\begin{array}{l}\text { Mainoki } \\
\text { Korpei }\end{array}$ & Simeku \\
\hline $\begin{array}{l}\text { WH } \\
\text { ET }\end{array}$ & $\begin{array}{l}\text { Nasioi } \\
\text { Naasioi }\end{array}$ & Nasioi, & $\begin{array}{l}\text { Simek } \\
\text { Naasioi, Kongara, }\end{array}$ & & \\
\hline ET & & $\begin{array}{l}\text { Nasioi, } \\
\text { Kieta, } \\
\text { Kieta Talk, } \\
\text { Aunge }\end{array}$ & $\begin{array}{l}\text { Naasioi, Kongara, } \\
\text { Orami (Guava), } \\
\text { Pakia-Sideronsi }\end{array}$ & & \\
\hline DT & Nasioi & Kieta & & & \\
\hline $\mathrm{AH}$ & Nagovisi & Sibbe & & & \\
\hline WH & Nagovisi & & & & \\
\hline ET & $\begin{array}{l}\text { Nagovisi } \\
\text { Sibbe }\end{array}$ & Nagovis, & & & \\
\hline DT & Nagovisi & & & & \\
\hline $\mathrm{AH}$ & Siwai & Motuna & Siwai & & $\begin{array}{l}\text { Baitsi } \\
\text { (Sigisigero) }\end{array}$ \\
\hline WH & Siwai & Motuna & Baitsi & & \\
\hline ET & Siwai & Motuna & Baitsi (Sigisigero) & & \\
\hline DT & Siwai & Motuna & & & \\
\hline $\mathrm{AH}$ & Buin & $\begin{array}{l}\text { Telei, } \\
\text { Rugara }\end{array}$ & Buin & & Uitai \\
\hline WH & Buin & Uisai & & & \\
\hline ET & Buin & $\begin{array}{l}\text { Telei, Terei, } \\
\text { Rugara }\end{array}$ & & & \\
\hline DT & Buin Telei & & & & \\
\hline
\end{tabular}


Ethnologue [2000] also lists the following Papuan languages not listed elsewhere:

\begin{tabular}{lllr} 
& Language & Location & No. of Speakers \\
\hline ET & Uisai & Buin District & 2,500 speakers [SIL 1991] \\
ET & Lantanai & Kieta District & 300 speakers [SIL 1990] \\
ET & Koromira & Kieta District & 1,562 speakers [SIL 1990] \\
ET & Oune & Kieta District & 1,900 speakers [SIL 1990] \\
ET & Simeku & Kieta District & 1,898 speakers [SIL 1980] \\
\hline
\end{tabular}

Usiai is considered to be a dialect of Buin, while Lantanai, Koromira, Oune and Simeku are perhaps best considered to constitute dialects of Nasioi.

\section{PAPUAN LANGUAGES OF BOUGAINVILLE}

In terms of the Bougainville area, what is the position of the relationships of the Papuan languages spoken there? Wurm [1975] posited the existence of an East Papuan Phylum, extending from New Britain and Rossel Island in the Louisiade Archipelago eastwards across the Solomon Islands chain to the Reef Islands and Santa Cruz group in the far south-east of the Solomons. The groupings posited by Wurm are as follows:

a. Yele-Solomons-New Britain Super-Stock:

$\begin{array}{ll}\text { Central Solomons Family } & \text { Bilua (Vella Lavella) } \\ & \text { Baniata (Rendova) } \\ & \text { Lavukaleve (Russell Is) } \\ & \text { Savosavo (Savo) } \\ & \text { Kazukuru (New Georgia) } \\ & \text { Guliluli (New Gerogia) } \\ \text { Kazukuru Family }{ }^{14} & \text { Doriri (New Georgia) } \\ & \text { Yele (Rossel Island) } \\ \text { Bele Isolate } & \text { Baining (New Britain) } \\ \text { Baining-Taulil Family } & \text { Taulil (New Britain) } \\ & \text { Butam (New Britain, extinct) } \\ & \text { Sulka (New Britain) } \\ & \text { Kol (New Britain) } \\ & \text { Wasi (New Britain) } \\ & \text { Anem (New Britain) } \\ & \text { Kuot (New Ireland) }\end{array}$


b. Bougainville Sub-Phylum Level Superstock:

$\begin{array}{ll}\text { East Bougainville Stock } & \text { Nasioi } \\ & \text { Nagovisi } \\ & \text { Buin } \\ & \text { Siwai } \\ \text { West Bougainville Stock } & \text { Rotokas } \\ & \text { Eivo } \\ & \text { Konua } \\ & \text { Keriaka } \\ & \text { Reefs } \\ \text { Reef Islands-Santa Cruz } & \text { Löndäi } \\ & \text { Nea } \\ & \text { Nanggu }\end{array}$

While the existence of an East Papuan Phylum, based on quite fragmentary evidence, has never found formal acceptance, the groupings of the Papuan languages spoken on Bougainville proposed by Wurm [1975] are very much in agreement with the groupings reached by Ross [2000], based on a historical study of Bougainville pronominal systems, as follows:

$\begin{array}{ll}\text { North Bougainville } & \text { Rotokas } \\ & \text { Kunua } \\ & (\text { Keriaka) })^{15} \\ & \text { (Eivo) } \\ \text { South Bougainville } & \text { Nasioi } \\ & \text { Nagovisi } \\ & \text { Buin (Telei) } \\ & \text { Motuna (Siwai) }\end{array}$

Ross [2000] considers that these two Papuan language groups are unrelated, ${ }^{16}$ even though today they are geographically contiguous. Spriggs [1997] reports that in traditional times, however, the two groups were separated by a large area of volcanic activity.

Pronouns are usually reliable indicators of relationships between two languages, as they are not normally subject to borrowing. They have been used, in fact, to demonstrate the existence of the Trans New Guinea Phylum. When this test was applied to the putative East New Guinea Phylum, as many as eight distinct groups emerged. While this may appear strange, perhaps it suggests that if these groupings are genetically related, then the relationship may be of much 
greater antiquity than the Trans New Guinea Phylum case, which is associated with the development of agriculture in the New Guinea Highlands about 6,000 years ago [Pawley 1998].

While it is known that the Austronesians came to Bougainville about 3,000 BP, much less is known about the Papuan speakers, except that there has been human occupation on the island for approximately 30,000 years. As far as the spread of the Papuan-speaking population is concerned, we know that New Britain, New Ireland and 'Greater Bougainville' [Spriggs, this volume] were separate islands right through the Pleistocene period, which indicates that the 'East Papuans' did not reach their destinations on foot. Prior to the arrival of the Austronesians, we can assume that, based on present-day Papuan language distributions, the area as far east as the central Solomons was peopled by Papuan-speaking populations. These Papuan languages were later displaced by Austronesian speakers.

Evidence from the 20th century includes the three extinct Papuan languages spoken on New Georgia (Kazukuru, Guliguli, Doriri), evidently displaced by Austronesian languages, for which we have linguistic evidence. ${ }^{17}$ In New Britain and New Ireland we have other evidence of intense Papuan/Austronesian contact. There are high numbers of roots in the Austronesian languages of this area today, which are not of Austronesian origin. Ross [1994] suggests that Madak, an Austronesian language of New Ireland adjacent to Kuot, a Papuan language, shows evidence that it may be the result of an incomplete shift by its speakers from a Papuan language to an Austronesian one. On the other hand, the Reefs-Santa Cruz languages of the south-east Solomon Islands look as if they are Papuan-type languages possibly carried to their present location by Austronesian speakers [see Wurm 1978; Lincoln 1978].

At present we have no idea whether the present-day Papuan speakers on Bougainville descend directly from an original Papuan settlement, perhaps around 29,000 years ago. Most of the Papuan languages seem to have been in contact with one another, however, as evidenced by the presence of gender systems. ${ }^{18}$

\section{CONCLUSION}

Bougainville's linguistic composition is a complex one, in that it has about equal numbers of speakers of Austronesian and Papuan languages. However, based on the current classification, there are approximately twice as many Austronesian as opposed to Papuan languages spoken in the province. The linguistic evidence leads us to the conclusion that there has been considerable contact and interaction between the two language groups over a long period, throughout the whole New Britain-New Ireland-Bougainville-Western Solomons area. 
In terms of reconstructing the early history and prehistory of the region, the picture is complicated by the fact that populations may change languages over time. Papuan speakers may for various sociological and technological reasons adopt an Austronesian language, as in the case of Madak in New Ireland, mentioned above. Or the shift may be in the opposite direction, as in the case of the Reefs-Santa Cruz area. In fact there are a few languages on the mainland of Papua New Guinea, for example Maisin, in the Oro Province, where contact and interaction has been so intense that it is practically impossible to determine whether the present language is Austronesian or Papuan.

The whole Bougainville region is typical of the symbiotic relationship which exists between Papuan and Austronesian languages, particularly in Papua New Guinea. The intensity and varying nature of these interactions have produced an areal linguistic diversity without parallel. For what characterises the region is not just the great number of different languages and societies, but the extraordinary diversity within that number, due primarily to intensive contact over a very long period [Lynch 1981; Pawley 1981]. 


\section{Endnotes}

1. Wickler and Spriggs [1988] record a date of nearly 29,000 for the Kilu Cave on Buka.

2. With the exception of the Polynesian Outlier languages, see below.

3. Uruava was formerly spoken on south-east Bougainville, between Rorovana and Kieta.

4. See Grimes, Barbara ed. [2000] Ethnologue. Dallas: SIL International.

5. Because of the 'crisis' in Bougainville, up to date census figures for individual languages are not as yet available.

6. The information in this publication, while valuable historically, is covered by Allen and Hurd [1963], so is not reproduced here.

7. The term 'sub-language' is used by Allen and Hurd 'to classify a speech which is more distant than a dialect and yet not far enough removed to be considered a separate language' [1963: 2].

8. AH [Allen and Hurd 1963]; WH [Wurm and Hattori 1981-83]; ET [Ethnologue 2000]; DT [Darrell Tryon].

9. See Grimes, Barbara ed. [2000] Ethnologue. Dallas: SIL International.

10. Both Ethnologue [2000] and the present writer consider that Haku constitutes a separate language from Halia. Ruth Spriggs (personal communication) confirms this assessment, based on mutual intelligibility.

11. See endnote 1.

12. Allen and Hurd [1963] classify Takuu, Nukumanu and Nuguria as dialects of Nahoa. All other commentators treat them as separate languages. All three are Polynesian Outlier languages. Polynesian Outlier languages are Polynesian languages situated outside Triangle Polynesia (in Melanesia and Micronesia), mainly as a result of drift voyaging from central Polynesia, and therefore much later than the original Austronesian colonisation of Island Melanesia.

13. Spriggs [1997: 39, 47] gives the following archaeological dates: Papua New Guinea Highlands (55,000 BP), New Britain and New Ireland $(35,000)$, Buka $(29,000)$, Guadalcanal $(22,000)$.

14. All of these languages became extinct early in the 20th century

15. Square brackets indicate a tentative assignment to this group.

16. That is, they cannot be demonstrated to be related to any other language group. They are certainly not Austronesian, but may ultimately be shown to be genetically related to some other Papuan language group.

17. Waterhouse [1931].

18. Nouns in these languages are classified as either masculine or feminine, indicated by suffixation. 


\title{
AN INTRODUCTION TO BOUGAINVILLE CULTURES ${ }^{1}$
}

\author{
by Eugene Ogan
}

\begin{abstract}
A lthough there has been much written about Bougainville during the past three decades, most especially since 'the Conflict', drawing together all the strands of prehistory, history and ethnology to present a composite picture of the people who live in Bougainville (including Buka but not all the outlying islands) remains a daunting task. What follows cannot pretend to be definitive, but rather is offered to provide a suitable background for the more detailed papers included in this volume.

Some general, preliminary comments should be made. 'Cultures' — broadly defined as the life ways of people - are dynamic, not static. People are both the active agents of their culture, and the subjects of the cultural framework in which they live. Cultures change constantly, albeit at different rates. In the case of Bougainville, where people settled about 29,000 years ago, culture change has taken place at an ever-increasing pace, especially since sustained contact with the west began in the late 19th century.

Matthew Spriggs [1997, and this volume], who has carried out first-hand archaeological research on Bougainville, Buka and Nissan, makes clear how complex is the prehistory of the area. He notes that Bougainville and other Melanesian islands represent 'something of a hybrid population', resulting in 'a creolized set of cultures' [1997: 11-12]. In other words, for centuries the area has been characterised by population movements, language shifts, and transmission of cultural traits across what are now political boundaries. Thus the notion that Bougainville cultures are either homogeneous or fixed in time forever cannot be sustained from historical or anthropological perspectives.

Within this complexity, however, current scholarship agrees on certain points. The south-west Pacific, including Island Melanesia, was settled thousands of years ago by people originally moving westward out of South-East Asia.
\end{abstract}


Though dates can never be precise and are always subject to revision, a site on Buka dates back to the Pleistocene (or Ice Age), at about 29,000 years ago [Wickler 1990; Wickler and Spriggs 1988]. There is evidence here that Colocasia taro was already available to these early inhabitants. Language will be discussed in greater detail elsewhere [Tryon, this volume], but it should be noted here that these settlers are believed to have spoken non-Austronesian (NAN, or Papuan) languages. Thus they may well have been the ancestors of people who today speak the related south Bougainville languages Nasioi, Nagovisi (or Sibbe), Buin (or Terei, or Rugara), and Siwai (or Motuna), and the other Papuan languages farther north, Kunua, Keriaka, Rotokas, and Eivo [see Allen and Hurd 1963].

Some 3,000 years ago a new population entered Buka and Bougainville. These people brought a new kind of pottery (called by modern scholars Lapita see Spriggs, this volume) and a rather different way of life. This lifestyle included a better developed agriculture, the domestication of pig, dog and chicken, and larger villages. The newer settlers almost certainly spoke completely different languages - those classed as Austronesian — from the earlier inhabitants. As Spriggs [1997: 71] puts it, 'That the most widespread archaeological phenomenon in the South-East Asia-Pacific region and the most widespread language group in the same area are intimately linked seems hard to deny.' These people were presumably the ancestors of present-day Teop, Hahon, Tinputz, Halia, Solos, Petats, Saposa, Nissan, Nahoa and Banoni. Speakers of another Austronesian language, Torau, arrived in a later migration from the south [Terrell and Irwin 1972].

Though there were now two different groups of settlers in BougainvilleBuka, there was plenty of opportunity during the next millennia for both groups to influence each other culturally, so that certain common patterns had emerged by the time of European contact. Furthermore, these influences went beyond the Bougainville area to include islands to the north and, especially, south. Canoe voyages for such purposes as exchange or raiding across the Bougainville Strait began at least one thousand years ago. A trade in pottery linked Buka to other groups [Specht 1974]. In short, one should not underestimate the complexity of a cultural history that, though not recorded in writing, took place across modern political boundaries for centuries.

A cautionary note is required before commenting further on Bougainville cultures. Anthropologists have often erred when writing their descriptions by portraying peoples' lives as if in a timeless 'ethnographic present'. Misunderstandings thus produced are often resented by younger generations who justifiably say 'My people don't live like that'. In the case of Bougainville, some of the earliest scientific observers were well aware that significant change, sometimes viewed as 
'the loss of tradition', had already taken place [Parkinson 1999: xxxiii; Thurnwald, H., 1934: 151; Blackwood 1935: xxiii: and Thurnwald, R., [1934b: 119]. Thurnwald, in particular, noted changes that he observed between a first visit in 1908-09 and a second in 1934. Any cultural description must be anchored in history, though surveys like the present one have the disadvantage of drawing upon individual accounts that may have been written at different times. What follows is anchored in the first half of the 20th century, whether based on first-hand observation or material carefully collected from elders who lived during the pre-World War II era.

As both academics [for example, Oliver 1989: 255] and older Bougainvilleans [Mauro-Miraku n.d. 2, 18, 62] point out, World War II brought radical social and cultural change to the south-west Pacific. For Bougainvilleans, that included Japanese invasion, and subsequent bombing and reconquest by Allied forces. In less than five years, outsiders moved into Bougainville on a heretofore unprecedented scale [see Nelson, this volume] and villagers were forced to develop strategies adapting to each new incursion. Thus any discussion of islanders' lives must treat the war and its effects as distinguishing sharply different historical periods.

\section{COMPARISONS AND CONTRASTS}

Because Bougainvillean cultures are characterised by both common patterns and noteworthy variation, what follows is organised around these two dimensions. (It should be underscored that a description of pre-war cultural variation does not reflect negatively on the remarkable political unity that Bougainvilleans have forged over the past decade.) More general comparisons and contrasts are followed by two specific examples to add depth to the survey.

\section{Similarities}

During the first half of the 20th century, most people on Bougainville and Buka:

- lived in settlements small in size, at least in comparison with such other New Guinea societies as those found in the East Sepik. As noted by Spriggs [1997], when Austronesian speakers arrived, they brought a pattern of living in larger villages than those of their Papuan predecessors.

- were typical Melanesian swidden horticulturalists, raising root crops (particularly taro before the plant blight of the 1940s) and pigs. Depending on environmental conditions, this subsistence pattern was supplemented by fishing, hunting and foraging.

- recognised descent through females as an important principle of social organisation. Based on this principle, people formed groups of different sizes and with different functions, variously called by anthropologists clans, 
lineages, or sibs. The importance of matrilineal descent sets Bougainvilleans apart from many other New Guinea populations and is reflected in many symbolic forms. In recent years, matrilineality has become a potent political symbol, reflecting women's participation in peacemaking.

- believed in a variety of spirit beings, especially spirits of the dead. Spirits of the dead were believed to take an active role in the lives of the living, with the ability to reward the dutiful or punish transgressors. Other supernatural creatures might be described in Western terms as goblins or nature spirits.

- assigned rights to land and other resources on the basis of a variety of social principles. These included descent, personal or ego-oriented kinship, residence or locality, and exchange. The last especially involved exchanges of both people and property at marriage. Despite the importance of descent, actual cases of land disputes might be settled on the basis of one of the other factors.

\section{Differences}

There were, in addition to these common features, some important dimensions along which cultures varied. These included:

- ecology. Those living on large Melanesian islands have always distinguished between 'bush' and 'saltwater' people, and Bougainvilleans were no exception. However, the island also encompassed several different ecological niches, each permitting slightly different adaptations. Nasioi speakers probably enjoyed a more varied environment than many other groups, stretching from the coast to the mountains and allowing for the exchange of produce with other Nasioi, without going beyond the borders of their own language. Some environments provided greater return for the labour involved. These more productive areas permitted more elaborate exchanges within the community and thus allowed for more differentiation of status among individuals. Still larger surplus production created the opportunity for wider exchanges with more distant communities, as noted below.

- contact with other language groups. People residing in the interior of Bougainville (generally Papuan speakers) had little opportunity for direct contact with anyone but their immediate neighbors [see Allen and Hurd n.d.: 39]. On the other hand, residents of Buka, Nissan and north Bougainville formed what some anthropologists call an 'areal culture' in which marriage and trade crossed language boundaries and permitted the formation of larger political units. Through Nissan, Buka was even linked with New Ireland [Specht 1974]. In the south, Austronesian-speaking Alu Islanders first raided, then traded and exchanged marriage partners with the Papuanspeaking Buin [Keil 1975]. 
- kinship. Cross-cousin marriage, in which two kin groups regularly intermarry, seems particularly associated with southern Papuan speakers [Oliver 1949: 13], especially Nagovisi and Nasioi. As these people regularly emphasise [for example, Mauro-Miraku n.d.: 15-16], this arrangement tends to reduce the likelihood of land disputes, since opponents are likely to share close kin. This was especially true in pre-World War II days, when marriages were likely to be contracted within a limited locality.

- the importance of matrilineal descent varied considerably. As Nash [1974 and 1981] demonstrates, Nagovisi probably represent one end of a continuum - certainly for the south Bougainville Papuan group. Nagovisi clearly stress the power of the matrilineage in all aspects of life. The senior female member of that group controlled land and shell valuables, and represented her lineage in the village community. Among Buin speakers, on the other hand, matrilineal descent only regulated marriage, by specifying that one should marry outside the matrisib. It was patrilineal descent that carried weight in governing rank and access to land [Keil 1975, and this volume].

- rank and leadership. This is a particularly thorny issue, especially in recent times when, as White [1992] points out, a 'discourse of chiefs' prevails in much of the south-west Pacific [for Bougainville, see Regan 2000]. Oliver's [1955] detailed analysis of 'big man' leadership among the Siwai of the 1930s was over-generalised by later anthropologists to draw an artificial polarity separating 'big men' from Chiefs. Terrell [1978a], in discussing a debate between Oliver and Thurnwald over chieftainship in Buin, can be said to have begun a line of argument to which today most anthropologists would subscribe: that a rigid dichotomy between such categories as 'Chief versus Big Man' or 'ascribed versus achieved status' obscures as much as it illuminates [see Douglas 1998: 31].

The general remarks above need to be supplemented by more ethnographic substance. Longer descriptions of Nasioi and Tinputz follow, as examples of a Papuan speaking southern group and an Austronesian speaking northern group. Nasioi material is based primarily on my own fieldwork, carried out intermittently over a period of 41 years. The description of Tinputz culture is based primarily on Blackwood [1935].

\section{NASIOI}

The Nasioi language is most closely related to Nagovisi (Sibbe) and forms, with Siwai (Motuna) and Buin (Telei), the south Bougainville Papuan stock. According to Allen and Hurd's [1963] survey, there were more speakers of Nasioi (with its 
dialects) than any other language in the Bougainville District. These people occupied a variety of ecological niches. They spanned the coastal areas through fertile valleys and up into the high hills. This meant that there was some variation in subsistence patterns. Those living in the valleys had access to more and different products, and could act as middlemen in exchanges between coast and hills. Hill dwellers in what is now called Kongara could not raise coconuts or sago, and so were dependent on their fellows residing at lower altitudes for these items. Villagers on the coast not only had more contact with Austronesian speakers, who reportedly taught them pottery making, but also had access to all the products of the sea. Some Nasioi had more contact with Buin speakers, others with Nagovisi, still others with Austronesian speakers both coastal and inland, specifically Banoni. Exchanges and occasional intermarriage thus took place across both ecological and linguistic boundaries.

Despite these environmentally conditioned differences, Nasioi possessed a relatively uniform culture which can be seen as one variant of a south Bougainville Papuan pattern. Their settlements, whether coastal or inland, were small, with often no more than a few households. People lived in houses raised on posts, usually occupied by husband, wife and children. There seems never to have been any real shortage of land for subsistence. People moved freely, whether to develop new gardens, to avoid disputes with others, or to flee an area that had developed a reputation for sorcery or other supernatural malaise.

One aspect of social organisation was most stable: every Nasioi belonged to a named matrilineal descent group, usually glossed by anthropologists as a clan. Not all members of a clan lived together but were dispersed throughout the entire Nasioi territory. Only those clan members who lived together cooperated on everyday tasks. Ideally, one should marry outside one's clan. Clan membership was one principle through which important land rights were inherited. Bilateral crosscousin marriage (marrying one's father's sister's child who was also one's mother's brother's child) produced long-lasting affinal relationships between two clans. Kongara informants in 1966-67 were emphatic in connecting that practice to other forms of balanced exchange, thereby keeping land and shell valuables within a limited span of kin and geography. Residence rules specified that a newlywed couple should set up housekeeping in the bride's village.

All of these factors helped to create a society that was characterised more by equality than hierarchy. Women had status complementary, rather than subordinate, to that of men. Their role as gardeners, producing the bulk of village subsistence, was highly valued, as was their place in maintaining continuity of the clan. Maternal symbolism characterised Nasioi discourse; the epitome of any quality (like industry) was phrased as 'the mother of (work)'. Social interaction 
was built around an ideal of balance. Thus, Nasioi contrasted their balanced exchange of food and valuables at marriage with the institution of bride price, of which they had heard from other groups. (One Nasioi even said 'What we really did was exchange people', a neat description of what anthropologists call bilateral cross-cousin marriage.)

Nasioi leaders, called oboring (pl. obontu), can thus be fairly described as 'big men', though compared to Siwai described by Oliver [1955] they were rather small fry. Villagers described the important qualities of an oboring as those of generosity, industry, and knowledge. He was certainly supposed to give large feasts to establish and reinforce his status, but these were smaller in scale than elsewhere in the south, and the road to his status was open to others, not simply determined by heredity. He had to rally followers to amass the food for these feasts and, if his demands became too onerous, the followers would simply move away. (Though modern-day Nasioi may have overemphasised their peaceful nature, large-scale conflicts of the kind reported as having occurred in the New Guinea Highlands do seem to have been rare, as one might expect from the existence of adequate supply of garden land.) Another check on an oboring's power lay in the fear that sorcery could be carried out as a leveling mechanism against an overweening individual. Fear of sorcery was generally a form of social control against all forms of transgression.

As noted below, by the time of my fieldwork missionisation had overlain earlier religious practices, but basic attitudes forming a world view showed continuity with the past. Most notable was a belief that all good things came from the spirits of the dead. It was these spirits who had to be propitiated with offerings of special food like pork, opossum or canarium almonds if children and pigs were to thrive, gardens to flourish and success to be achieved in hunting. As older Nasioi said 'If you didn't give them food, you would be the one to starve'. Ancestral spirits provided special abilities like healing to the living. Other beings with whom the living had to contend might be described as nature spirits or bush ogres, such as a fearsome water creature described as part eel, part crocodile, or hairy goblins with a taste for human flesh. Before missionisation, the dead were cremated on a funeral pyre.

Parkinson [1999: 212] said that a line could be drawn that separated headhunting in the south from cannibalism in the north. Although Nasioi in the 1960s would happily agree that this distinction held true for their northern neighbours, they did not discuss head-hunting as one of their own practices. However, they certainly spoke of a time when the dead were cremated and lower jawbones displayed in houses. It is not hard to imagine that such displays were sometimes of enemies slain in battle.

Although the foregoing sketch has of necessity been brief, it does provide the opportunity for the comparison with a different group, which follows. 


\section{TINPUTZ}

Tinputz is an Austronesian language most closely related to Teop and Hahon, with which it forms a family. At the time of Allen and Hurd's survey, there were fewer than 1,500 speakers of Tinputz (including dialects). However, this figure may be misleading in view of the close physical proximity of Tinputz speakers to the other members of their language family, forming a greater concentration of related languages.

The Tinputz are fairly classed as a 'saltwater' people, oriented toward the sea. Taro and other root crops area are cultivated in the lowland and foothills, but villagers exploit maritime resources as well. Fishing for bonito on the open sea and in the lagoon is an important activity for men, while women operate near the shore, fishing with nets and gathering shellfish. This part of Buka is relatively densely populated. Kurtatchi, the village in which Blackwood lived, contained 27 dwellings plus a special house for adolescent boys, with a total of 107 individuals. These houses were built directly on the ground. Before pacification under Western government, villages might move because of warfare, or if sites were seen to be threatened by sorcery.

Matrilineal descent prevailed in Tinputz, forming lineages which were localised. Villagers also recognised a larger matrilineal unit, the clan that spread over all Tinputz territory, though clan ties are less strong than those of the lineage, especially since pacification has eliminated the need to rally members of the larger clan for warfare. Throughout the area, two clans are recognised as most important. They are called Naboin and Nakarib. However, Blackwood is at pains to say these are not moieties, or halves of a two-section social structure, since other, smaller clans exist and may vie for status in particular localities.

Within lineage and clan, strict matrilineality prevails; every child belongs to the lineage and clan of the mother. People are supposed to marry outside their clan, though this rule is not always strictly observed. In each village there is one lineage that takes precedence over all others. The clan to which the lineage belongs is considered the most important, and is generally the most numerous in the village. The head of this lineage is called tsunaun which Blackwood glosses as 'person of rank' or 'person of importance'. The title is strictly hereditary in the female line.

By the time of Blackwood's fieldwork, the authority of tsunaun had been affected by both pacification and government-appointed leaders. However, there was no question about the privileged status afforded the position and the deference shown by commoners. Every event in a tsunaun's life, however minor, was marked by elaborate ceremonies. Both men and women could be tsunaun though 
males exercised more authority over lineage and village matters. Normally a tsunaun's spouse would be of the same status.

On the other hand, tsunaun were not necessarily possessed of more property nor did they enjoy a lifestyle that was, in material terms, much different from that of commoners. Though male tsunaun usually had more than one wife, commoners might also have as many as they could provide for. When special group ceremonies occurred that called for large feasts, he contributed as much as he could but others were expected to provide food as well. Therefore, while a tsunaun definitely possessed higher status and prestige than an oboring, there were nonetheless limits on his power and authority.

Since parallel cousins (mother's sister's children and father's brother's children) were called by the same terms as siblings, marriage between them was forbidden. In addition, marriage between cross-cousins (mother's brother's or father's sister's children) was regarded unfavourably. A couple was typically betrothed as children, the boy's father making initial arrangements with the girl's mother. Exchanges of food took place between the couple's mothers, but more important was the payment of bride-price. This was in the form of strings of currency made of porpoise or flying-fox teeth. The currency was amassed by the boy's mother and her lineage, though the boy's father might be called on to help. A much larger amount of currency was required for a girl who was tsunaun. Initially, the couple lived in the groom's village, even in his mother's house until one was built for the newlyweds. After that, there was a certain freedom of choice of residence, though the couple would always spend a certain amount of time in the village which was the home of the other partner.

A distinctive feature of Tinputz ritual life (shared by related Austronesian groups in North Bougainville) was the wearing of the upi. This conical headgear was prescribed for boys from about the age of nine into early manhood. Following a period of seclusion while the boys' hair grew there were several further stages, each involving feasting and exchanges. During this entire time boys lived in a special house. Avoidance of women while the boys are wearing the upi was strictly observed; a boy was not even allowed to enter his own mother's house. Upi wearers also underwent severe dietary restriction. The removal of the hats was marked with a major ceremony.

Spirits of the dead (urar) were thought to live in Mt Balbi. Although they could bring benefits, the living generally feared them. The same term was applied to spirits who had never been alive. Before western contact the dead were buried at sea, and this is still prescribed for tsunaun, though burial of commoners may take place on land today. Distinct from urar were bush goblins who were typically described as small in stature and usually seen as mischievous but not fearsome. 
However much modern-day Tinputz might like to deny the practice, it seems clear that cannibalism was part of earlier life. The practice was generally performed in response to an insult or as punishment, or as a necessary part of certain ceremonies, rather than out of a desire for human flesh. The victims were typically enemies taken in war and, as a result, pacification meant the end of cannibalism.

\section{CONCLUSION}

This survey, albeit brief, nonetheless makes some significant points. Bougainvilleans have a legitimate case for claiming that they are unique in the south-west Pacific, though not merely on the oft-cited basis of physical appearance (see Friedlaender, this volume). The diversity of their languages and traditional cultures within the space of two large and some small islands is uncommon. The difference between Austronesian and Papuan languages, which as noted by Spriggs in this volume goes back millennia, remains. However, this is but part of a complex story of population movement and cultural transmission that extends over thousands of years.

What is still more distinctive is their 20th century history. They have seen plantation agriculture dominating a colonial economy, followed by a war not of their making that was fought on their own soil, next the largest mining operation in Papua New Guinea at the time, and most recently an armed conflict of international significance that has on occasion divided Bougainvilleans themselves. The resilience they have shown in adapting to these rapidly changing circumstances can be fairly described as heroic. At the dawn of the 21 st century, this characteristic offers the possibility of an even brighter future.

\section{Endnotes}

1. More than a half-century ago, Douglas Oliver [1949] published a survey of Bougainville cultures, based upon first-hand observation and reviews of published literature. Since that date, ethnographic and historical material have notably increased, and I tried to take advantage of both Oliver's still insightful work and more recent scholarship in writing a similar article more than 40 years later [Ogan 1992]. The present offering grows out of these. 


\title{
WHY DO THE PEOPLE OF BOUGAINVILLE LOOK UNIQUE?
}

\section{SOME CONCLUSIONS FROM BIOLOGICAL ANTHROPOLOGY AND GENETICS*}

\author{
by Jonathan Friedlaender
}

ne of the great puzzles of Bougainville is why its people are so distinctive in
appearance from most other people in the region, particularly why they are
so black. Did some Africans somehow move into this area thousands of years ago?
Or were these people descendants of the 'original' inhabitants of the entire region,
who were all black-skinned? Another explanation was that they simply had lived
there, under the tropical sun, long enough to develop their jet-black colour inde-
pendently from other black-skinned groups. I have been told by more than one
Seventh-Day Adventist from Bougainville that there are also Biblical interpreta-
tions suggesting they are descendants of Ham that wandered into this part of
Island Melanesia. I have had this question of the origins of Bougainvilleans in my
mind for a very long time. Beginning in 1966, I have been involved in studies of
questions relating to the health and biology of people in Bougainville, as well as
on nearby islands. As a graduate student, I took part in The Harvard Solomon
Islands Expedition, which was led by Douglas Oliver and Albert Damon from
1966 to 1972 that surveyed Aropa Valley Nasioi, Nagovisi, and Aita as well as
groups on Malaita, Ontong Java, and Ulawa [Friedlaender 1987]. Over the
following decades, I have led expeditions back to Bougainville, Malaita, and
Ontong Java, and expanded the coverage to New Ireland, Lavongai, and New
Britain, but Bougainville always served as the reference and centrepiece. On
Bougainville, I focused on the region on the east central coast with the greatest
language diversity - from the Aita and Rotokas region near Wakunai and Asitavi,
down through the Eivo, Simeku, and North Nasioi region to old Uruava Village 
(Arawa) and Rorovana [Friedlaender 1975]. This included north and south Papuan-speaking groups, as well as some Austronesian speakers. We later surveyed villages in the Solos and Halia areas of Buka, some Siwai, and most recently, a few Saposa and Teop Austronesian groups in the north. The total number of people included in these surveys on Bougainville, one way or another, is roughly 2,000. At this point, there are some fairly clear conclusions I can offer on the causes of the distinctive appearance of the people of Bougainville, and also on some related issues. These will be presented as a series of questions and answers.

\section{How Uniquely Black are Bougainville People, and is Anyone Else in the Region as Black?}

The science of skin colour evaluation has become considerably more exact in the last decade, so that this is an issue we can answer directly, largely due to the work of Heather Norton [Norton et al. 2004; 2005]. The short answer is that a systematic study of skin colour (using the DermaSpectrometer instrument, which measures the amount of dark pigment, or melanin, in one's skin) ${ }^{1}$ confirms a number of facts. Compared with the people of New Ireland, New Britain, and New Guinea, Bougainvilleans are remarkably black-skinned judged by their average 'melanin index' readings [Map 1]. There is only a little overlap in the distributions of Bougainville skin colour with these others [see Figure 1]. The next darkest group in our surveys comes from Lavongai (New Hanover) and northern New Ireland. New Britain people are considerably lighter. New Guinea peoples are lighter still. In other words, there is a gradual shift or gradient in skin colour moving from New Guinea east to Bougainville. While we have not systematically surveyed people from the Shortlands and Western District of Solomon Islands, a few individual readings on people from there, and from impressionistic visits to Gizo, suggest to me that the people there would also join this most black group - once referred to by Douglas Oliver as 'The Black Spot of the Pacific' [Oliver 1991: 3]. Peoples further to the south and east, including Guadalcanal, Malaita, Santa Cruz, and Vanuatu, are all considerably lighter, to judge from our earlier, less technically proficient, surveys.

In broader comparisons, Bougainville people are, on average, darker as a group than African-Americans [Figure 2 - see Norton et al. 2004]. They are in fact blacker than most Africans. We do not know of any darker groups. The major qualification here is that systematic surveys of skin colour readings with the sophisticated DermaSpectrometer instrument have not been taken widely in a variety of populations in Africa or Australia. 


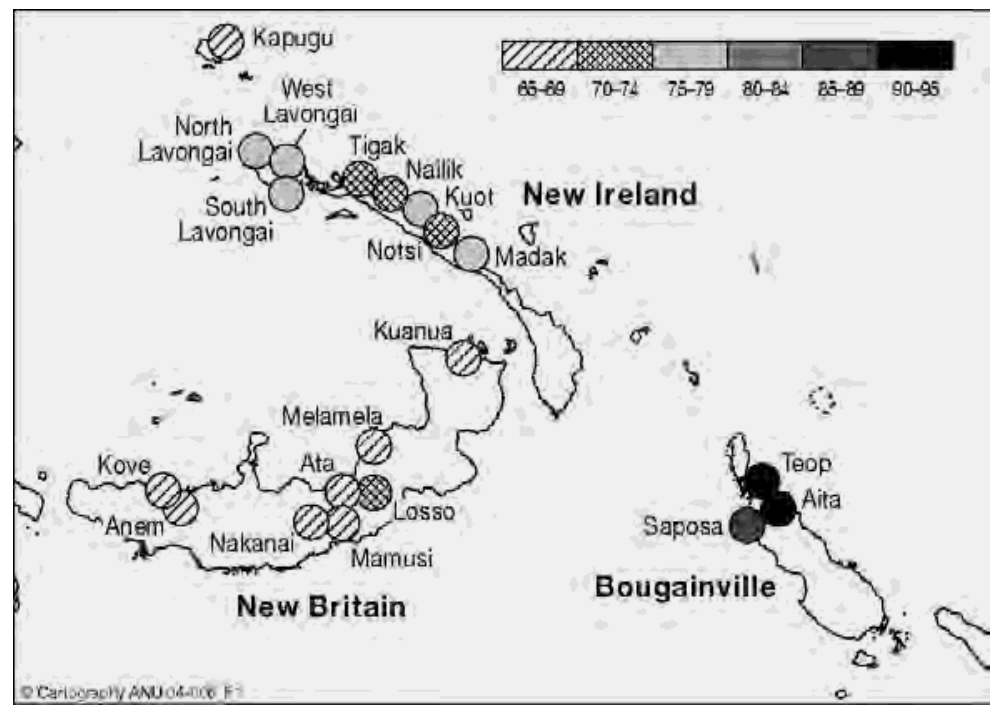

Map 1. Skin colour in Island Melanesia. Average M index readings for selected populations.

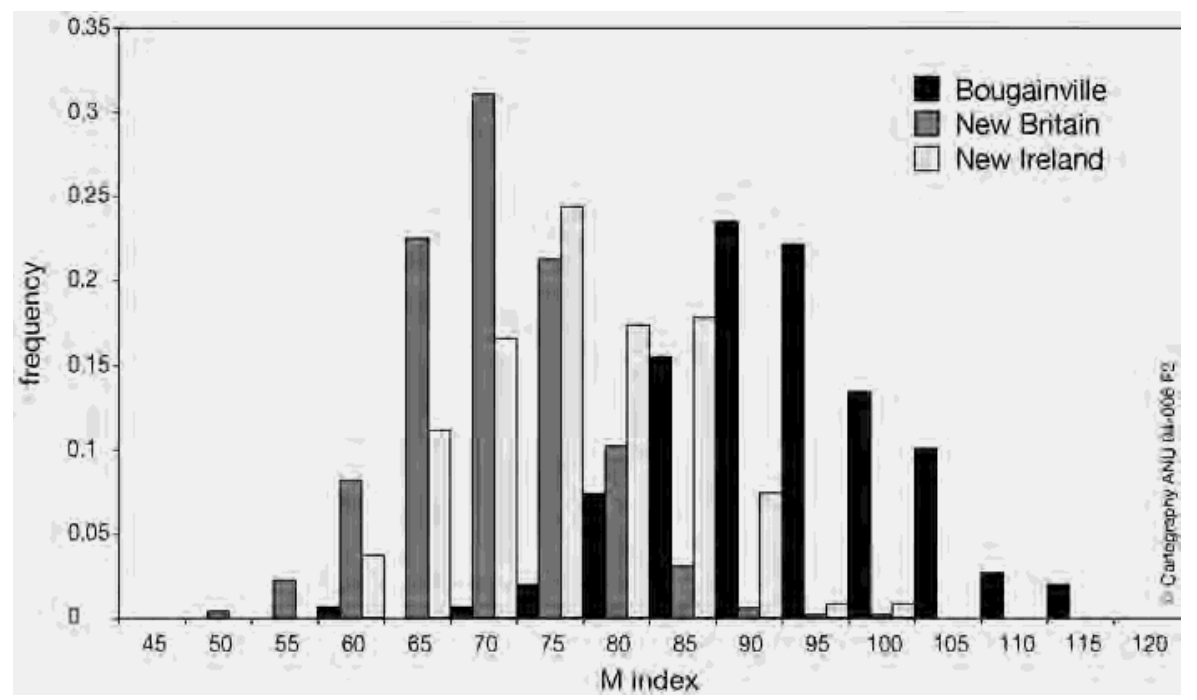

Figure 1. Distribution of $M$ index skin reflectance values for Bougainville, New Ireland, and New Britain. 


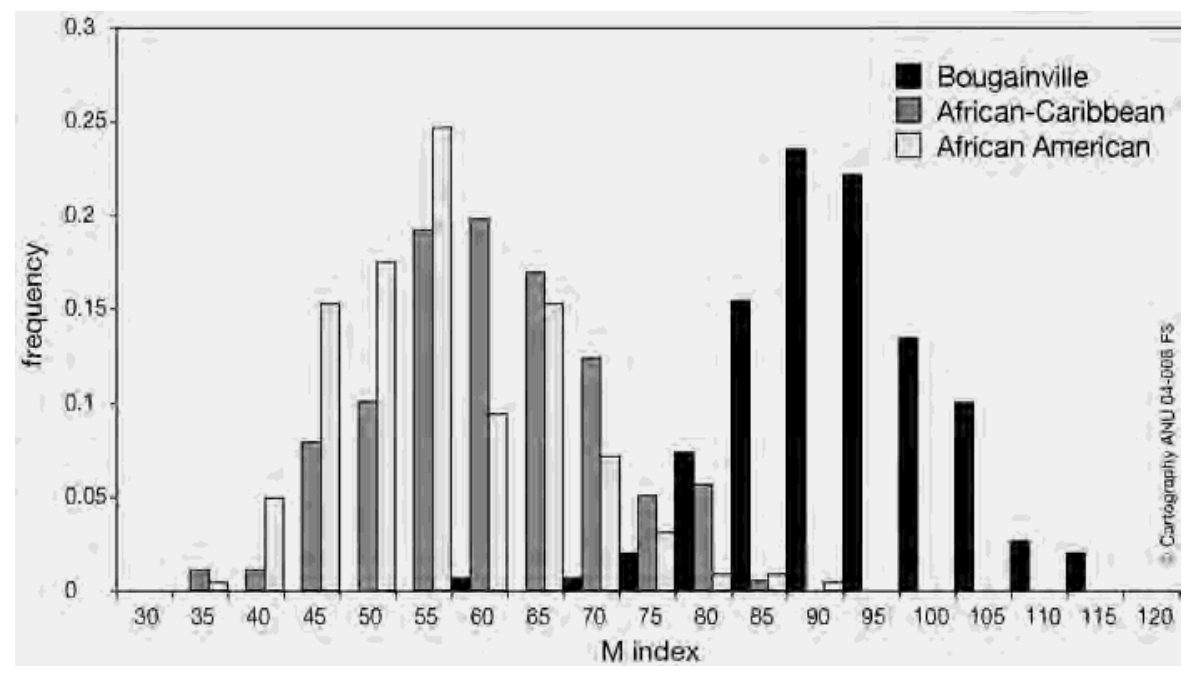

Figure 2. Comparison of Bougainville skin reflectance values with selected other heavily pigmented populations.

\section{Are Some Bougainvilleans Blacker than Others?}

Many people have told me over the years that south-Bougainville groups, particularly the Siwai and Buins, were blacker than groups from other parts of the island. The DermaSpectromter readings do not reveal any significant distinctions among the groups we have surveyed, although this only includes a few Siwai and no Buins. Our skin pigmentation survey concentrated on north Bougainville, and although some people there told me the Aita were lighter than their neighbours, we did not find any difference. Austronesian-speaking groups in north Bougainville and Buka do not differ from the Aita in skin colour.

What did show up as an internal Bougainville distinction is that Aita people have significantly lighter hair pigmentation readings than the Austronesianspeaking groups of north Bougainville that were covered in the survey. The Aita hair values are lighter than any we took in New Britain and Lavongai, as well, but some inland Papuan-speaking groups on those islands (Anem, inland Nakanai, and west Lavongai) are almost as light as the Aita [Map 2]. This is an intriguing finding, which could be interpreted to mean that early Papuan settlers had lighter hair colour than later Austronesian migrants, but this has to be reconciled with other regions in Island Melanesia where light-coloured hair is present, particularly the Austronesian-speaking people of north Malaita. 


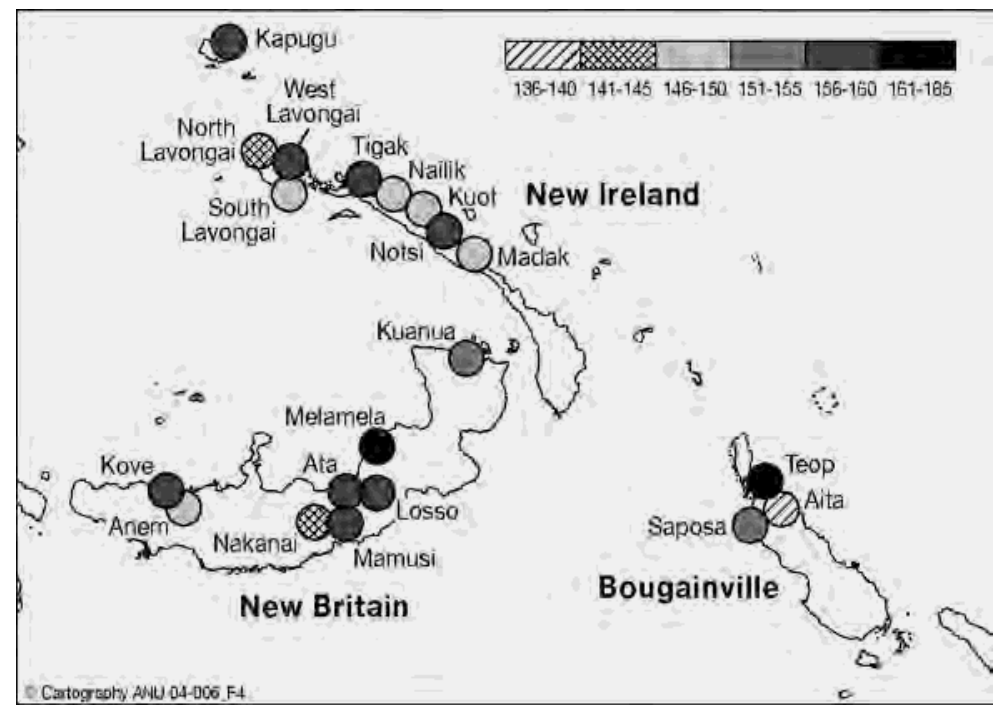

Map 2. Hair colour readings in Island Melanesia. Average $M$ readings for selected populations.

\section{Does this Uniform Black Skin Colour Across Bougainville (and Nearby Regions of Western District) Mean that People there are all Very Much Alike in all their Genes and Biology?}

The answer is, surprisingly, no. Besides the clear differences between Bougainville peoples and those from New Ireland, New Britain and elsewhere in the region, our studies have revealed that the people of Bougainville are genetically remarkably heterogeneous from one section of the island to the next. I do not know of any other area as small as Bougainville that has as much long-standing native biological variation that has developed over many thousands of years. New Britain comes close, but it is almost three times the size of Bougainville. The biological differences within Bougainville tend to follow distinctions of language as well as of neighbourhood. People who speak the same language and are from the same region of Bougainville are likely to be more similar than people from different areas. While this may seem to be a ridiculously obvious statement, the fact that there are so many distinctions among the different groups in such a small island is remarkable and, to my knowledge, is not matched outside Melanesia. 


\section{SUMMARY OF FINDINGS ON THE MANY BIOLOGICAL DIFFERENCES IDENTIFIED}

A number of biological differences distinguish north and south-Bougainville populations that parallel the linguistic divide between north and southBougainville Papuan languages. The Aita, Eivo, Rotokas and to a lesser extent the north Bougainville and Buka Austronesian speakers cluster together, often contrasting with the Nasioi, Nagovisi, and Siwai from the south, along with the Austronesian Torau-speaking Rorovana. For example, with regard to the shape of the head and body, northern mountaineers have broader chests and faces than the smaller and leaner southerners, who tend to have longer and narrower noses and faces, and also longer heads [Friedlaender 1975; Rhoads 1987]. Northern Austronesian-speaking peoples, including those from Buka, tend to be big, but with long heads similar to south-Bougainville Papuan groups. It may be, however, that their large size is due to better nutrition rather than heredity.

Finger and palm print patterns are often revealing about population relationships, and they reinforce the distinctiveness of Bougainville Papuan speakers, particularly the southern Nasioi and Nagovisi [Friedlaender 1975; Froehlich 1987]. They have simple finger and palm prints for a Pacific population, meaning that the ridges on their fingertips and hands form fewer swirling and looping patterns. Prints from other Bougainville groups are less distinctive from other regional groups, and particularly cannot be distinguished from those of Austronesianspeaking groups from Island Melanesia, New Guinea, and Micronesia. Prints from New Guinea Papuan groups and Australian Aborigines all tend to be considerably more complex, but in different ways. As detailed in Froehlich [1987], some groups tend to have more swirling and looping patterns on the thumb pad and tip (New Guinea Papuans), others tend to have more loops and swirls on their middle three fingertips (Australian Aborigines), and others have more print complexity generally (Polynesians). Again, the important conclusion is that Bougainville groups are highly diverse in these characteristics, but taken together, Bougainvilleans constitute a centre of biological distinctiveness in the region.

Tooth sizes and shapes also vary widely among Bougainville groups, but these differences do not form readily interpretable patterns. The Bougainville people with the smallest teeth are the Rotokas from the northern mountains [Harris and Bailit 1987], and south-Bougainville Papuan groups cluster tightly together in a number of other tooth characteristics. A particular dental characteristic called the shovel-shaped incisor, which is commonplace in people with a North Asian or Native American heritage, has an unusual distribution in Bougainville. It is low in frequency in South Pacific native populations from 
Australia to Indonesia and Polynesia. In Bougainville, it is also generally low, except for the Aita and Rotokas, who have moderate frequencies [Dobrich 2004]. This is probably just another example of how variable different Bougainville groups can be, rather than indicating some distant relationship of these groups with North Asians and Native Americans. As a general comparison, Bougainville tooth sizes are about the same as other Island Melanesians, and are intermediate between the large Australian Aboriginal values and smaller South-East Asian or Polynesian averages.

\section{Blood Genetics}

Researchers in human genetics are especially preoccupied with the analysis of blood samples. At first, this was because particular parts of the blood (especially protein molecules on the surface of the red blood cells as well as other proteins floating in the clear blood plasma) varied among people due to very simple distinctions in their inheritance. There is a direct connection between each of these aspects of the blood and a specific gene a person inherits from each parent. The best known example of this sort of variation involves the $\mathrm{ABO}$ blood types, so important in compatible blood transfusion. Very specific differences in a particular protein determine a person's ABO blood type (people can be either types A, $\mathrm{B}, \mathrm{AB}$, or $\mathrm{O}$ ). These differences are the results of distinctions between people at one particular gene (there are tens of thousands of genes in each human, and for the most part, we inherit one of each kind from each parent, making a pair of each kind). For example, a person with type $\mathrm{O}$ blood will have a pair of $\mathrm{O}$ genes, one from the mother and one from the father. A person with type $A B$, with a different kind of protein, has inherited an A gene from one parent and a B gene from the other — and so on.

The important point for questions of population history is that these sorts of characteristics (unlike head shape, finger ridge counts, tooth size, and so on) directly tell us about a particular genetic difference among people and populations. Of course, the $\mathrm{ABO}$ gene is only one gene out of thousands, so it offers only a very small window on the total picture, but it is unambiguous.

For example, my earliest studies in the east-central region of Bougainville showed that everyone in the Eivo and Simkeu region was type $\mathrm{O}$ - there were no genes for A or B in people from that entire region, while A was present and fairly common in both the south and north [Friedlaender 1975]. This was the first clear suggestion we had that there were clear genetic distinctions among different groups in Bougainville. Subsequently, our group has analysed many more populations in the island and region, and analysed different genes - the gene that determines the $\mathrm{Rh}$ factor, genes that determine various anemia deficiencies, and 
a number of unknown effect [Friedlaender and Steinberg 1970; Friedlaender 1971a and 1971b; Friedlaender, et al. 1971; Friedlaender 1975; Rhoads and Friedlaender 1975; Sokal and Friedlaender 1982; Rhoads 1987; Kamboh, et al. 1994; Jobes, et al. 1999; Ryschkewitch, et al. 2000; Cann, et al. 2002; Yanagihara, et al. 2002; Robledo et al. 2003].

The conclusions we drew from these earlier genetic studies largely confirmed and complemented the findings from the skin colour, fingerprints, teeth, and head and body shape studies. Early on, we found one variant that changed in frequency from north to south Bougainville in a very regular and dramatic fashion [Friedlaender and Steinberg 1970]. This is the Kv1 (or Inv) gene, which shifts from a frequency of over 0.80 in the Aita down to a low of 0.32 in the south. A few other gene distributions showed similar patterns, emphasising the variation within Bougainville groups along the lines of language and region. We did not find any gene variants that were entirely restricted just to Bougainville or the region, but there were many variants that were especially common there, or in different parts of the island. In larger world-wide comparisons, these differences, taken together, suggest Bougainville populations have a long separate history from New Guineans, Australian Aborigines, and Asians. There are some clear links to some other Island Melanesian and central Pacific groups (Micronesians and Polynesians), but indications of a long and in some ways separate history remain.

\section{Mitochondrial Genetics - Recent Developments}

We have been fortunate that recently developed techniques of genetic (DNA) analysis now allow a reuse of some blood samples extending back to the first expeditions of our group in 1966. The most interesting new finding concerns variation in an unusual set of genes that occur in the mitochondrion, a part of the cell which is inherited only through the mother's lineage. This is possible because, unlike other DNA (that exists in the paired maternal and paternal chromosomes in the nucleus), the mitochondria are outside the nucleus of each cell, including each egg, but are not in the parts of the father's sperm that are joined with the egg at fertilisation. This means that men (who have mitochondria identical to their mothers and sisters) cannot pass these on to their own children. Mitochondrial variation therefore reflects past marriage and migration patterns of women only. While this is something of a disadvantage and presents only 'half the picture', the major advantage is that mitochondria very rapidly accumulate new variants, or mutations, and scientists have figured out a way to tell which variants are new and which are older. Newer ones that may have appeared only a few hundred years ago should have only spread to a few people in a small region — perhaps even a single village. They 
should also be inherited in only one or two combinations, called haplotypes, with other variants. Older mutations would be expected to be more widely distributed among different peoples, and should occur in a variety of combinations with other, newer, mitochondrial variants [see Friedlaender et al. 2005].

\section{NEW CONCLUSIONS}

New conclusions from the mitochondria studies are still coming in, but some are already clear. Bougainville populations had been heavily (though unevenly) influenced by off-island migrations to an unexpected extent [Merriwether, et al. 1999], specifically from Austronesian sources. These influences are most apparent in south Bougainville, and may account for the north-south gradient in a number of other characters that we had previously attributed to the Papuan language distinctions within the island. This is because one particular missing section of nine letters within the DNA of the mitochondria (mtDNA), in combination with three other specific mtDNA variants, that has been tied to Austronesian-speaking groups, including many Micronesians and Polynesians, is common in south Bougainville, and this would seem to represent Austronesian influence [Map 3].

Two other mtDNA combinations, referred to as the $\mathrm{P}$ and $\mathrm{Q}$ variants or haplogroups, occur in the general region, particularly the interiors of New Guinea, and appear to be very old [Map 4]. P is also found among Australian Aborigines, and $\mathrm{Q}$ has been detected as far west as Indonesia and Malaysia, but only in very low frequencies there. In Island Melanesia, Q occurs in some eastern sections of New Britain and in north Bougainville groups such as the Aita, Rotokas, Eivo, and Simeku. P is found in much lower frequency in the region, notably in north Bougainville Papuans and Vanuatu and New Caledonia.

Some other mtDNA variants are more restricted to specific regions within Island Melanesia and have not been found elsewhere, including New Guinea [Friedlaender et al. 2005]. Their relationships are very distant and old, and indicate just how long people have lived in Island Melanesia. Some apparently have their origins in either East New Britain (Tolai or Baining), or West New Britain (Ata and Kol) but are missing in Bougainville [See Figure 3].

One particularly interesting variant combination, which we call Haplogroup VII [defined by Gentz et al. 2000, and also presented in Map 4], is most common in north and central Papuan-speaking Bougainville populations, with highest frequencies among the Rotokas of north Bougainville. Outside Bougainville, we have not detected it, except for one Solomon Islander. We have not yet been able to link this variant with any others in the region, including Australia, Indonesia, 


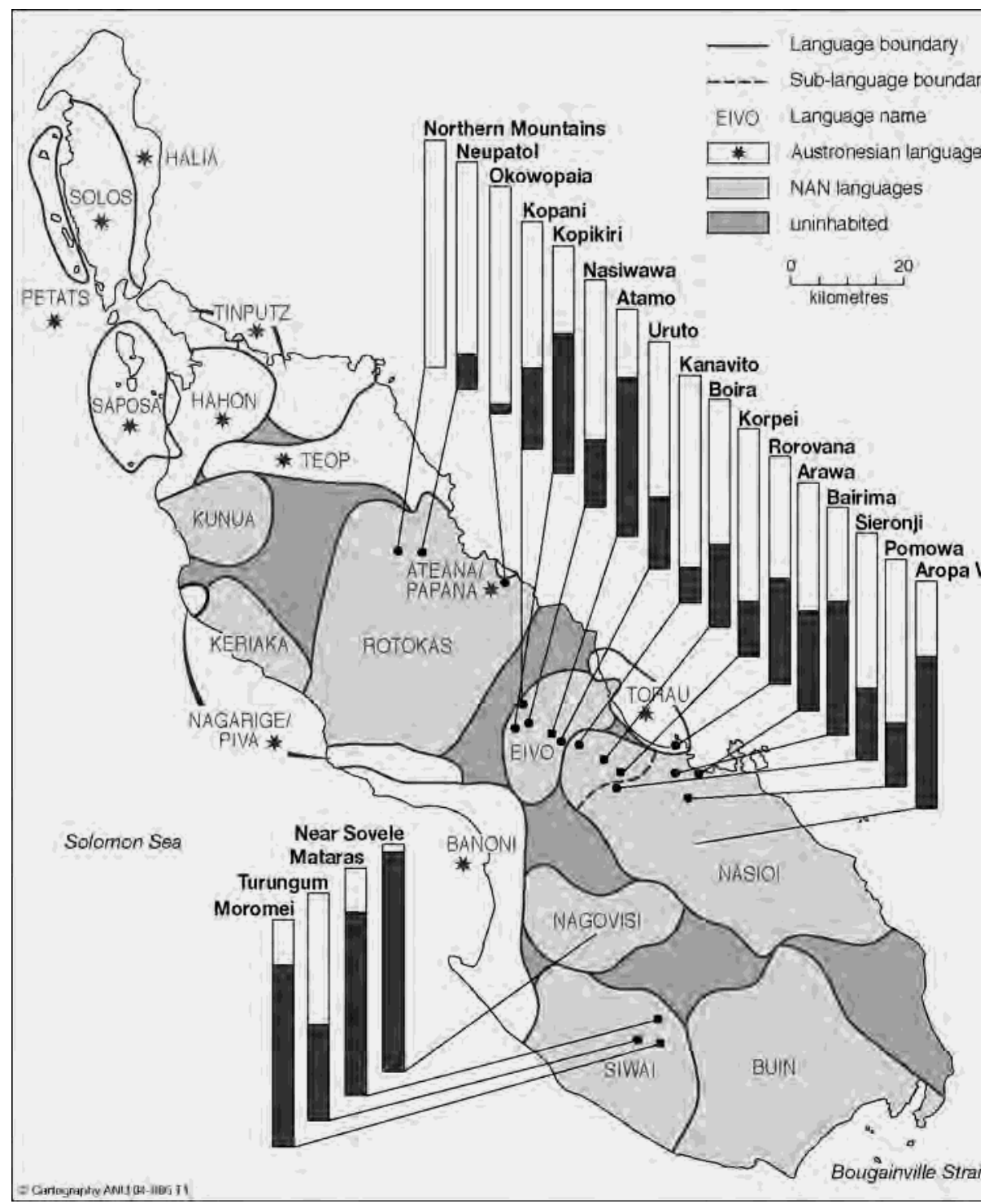

Map 3. Frequency distribution of $m t D N A$ haplogroup $B$ in surveyed Bougainville villages. This variant was apparently introduced by Austronesian-speaking migrants. Note the high frequency of the variant in the south, and its absence in the north mountains. 


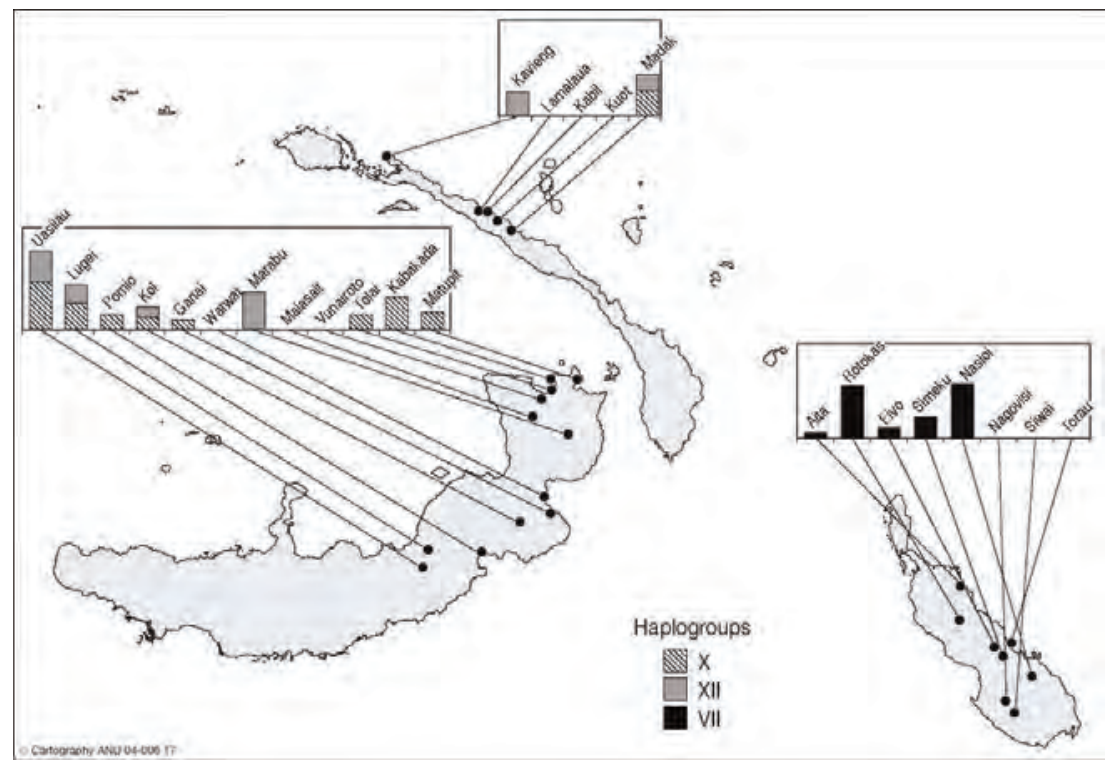

Map 4. Frequency distribution of two very old indigenous $m t D N A$ haplogroups (P and Q) in the south-west Pacific. These occur throughout the region, but are rare elsewhere. ' $N$ ' values at top indicate the number of tested samples.

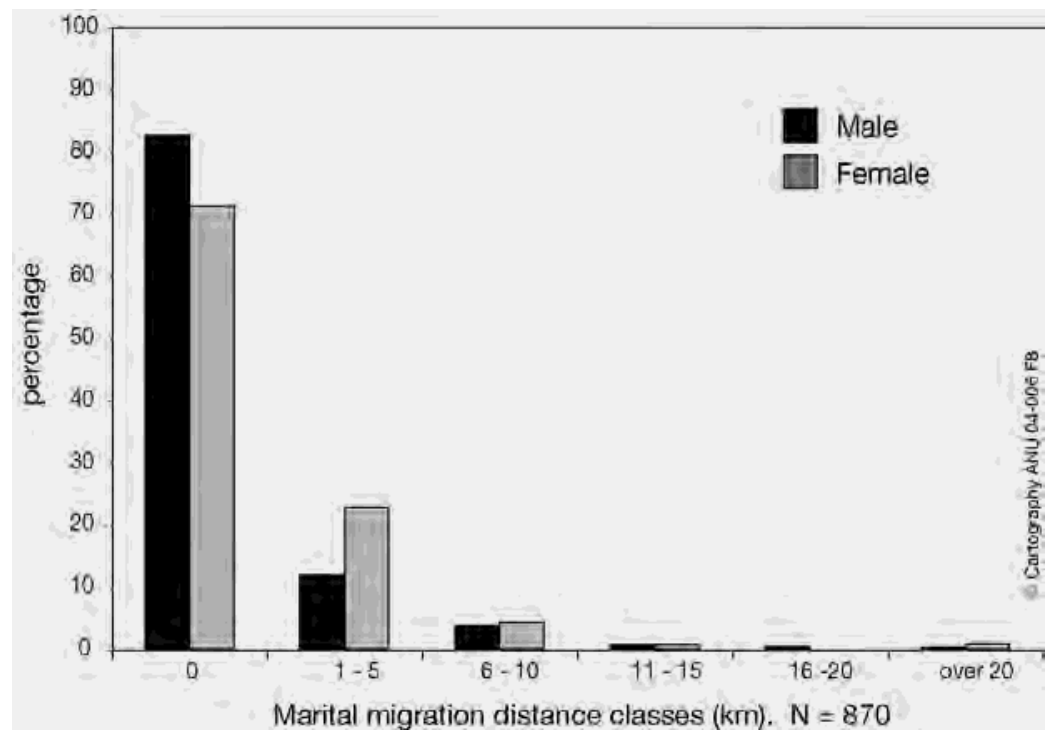

Figure 3. Frequency distribution of three mtDNA haplogroups (VII, X, and XII) that are essentially limited in their distributions to sections of Island Melanesia. Note haplogroup VII is apparently limited to north Bougainville. 
South-East Asia, or East Asia, for that matter. It presents a major question and may well hold the key to questions of ultimate relationships of Bougainville populations to those in India and Africa. It is clearly very old.

The most important finding of our genetic study to date is the extraordinary mtDNA diversity in Island Melanesia, with specific and separate centres in New Britain and Bougainville. The geographically patterned heterogeneity certainly recalls the unresolved relationships of Papuan languages in the same region. As with languages, the more remote regions of the largest Melanesian islands retain the oldest genetic signature.

\section{WHY IS THERE AS MUCH GENETIC VARIATION AMONG DIFFERENT BOUGAINVILLE GROUPS?}

The exceptional internal variation on Bougainville has more than one cause. Bougainville has been inhabited for a very long time, allowing many new genetic variants to develop there. The population was never large. This was at least partially the result of extremely high rates of malaria. Settlement was very unevenly distributed across the island, which meant that the different small groups would tend to diverge genetically over time. People tended to marry very close to home, which meant that once genetic distinctions developed, they had an excellent chance of being maintained in that same village or neighbourhood, and did not spread widely. And finally, there clearly have been some major later migration influences from external sources, particularly from Austronesian-speaking groups in the last thousand years or so. The same forces have acted in similar ways to make for differences among New Britain populations, and also those from New Guinea. Smaller island populations in the region are far more homogeneous.

The limited rate of marriages among people from different villages is especially interesting and deserves more comment. By asking married people from one place where they were born, one can plot the numbers of married people born in the same village (zero kilometres from their marital residences); those born a short distance away (one to five kilometres from their residences), and so on for those who have moved from further and further away [see Figure 4]. The figures for people living in Bougainville villages away from the coast, during the period 1966 to 2003 , did not change appreciably, and were very different from what one finds in urban areas worldwide, where most married people have moved substantial distances from their birthplaces. Basically the same profile existed for men and women. This is undoubtedly a key reason for the genetic variation from one section of Bougainville to the next. Even with the disruptive effects of World War II, the pattern of marital migration in Bougainville was very restricted in the 


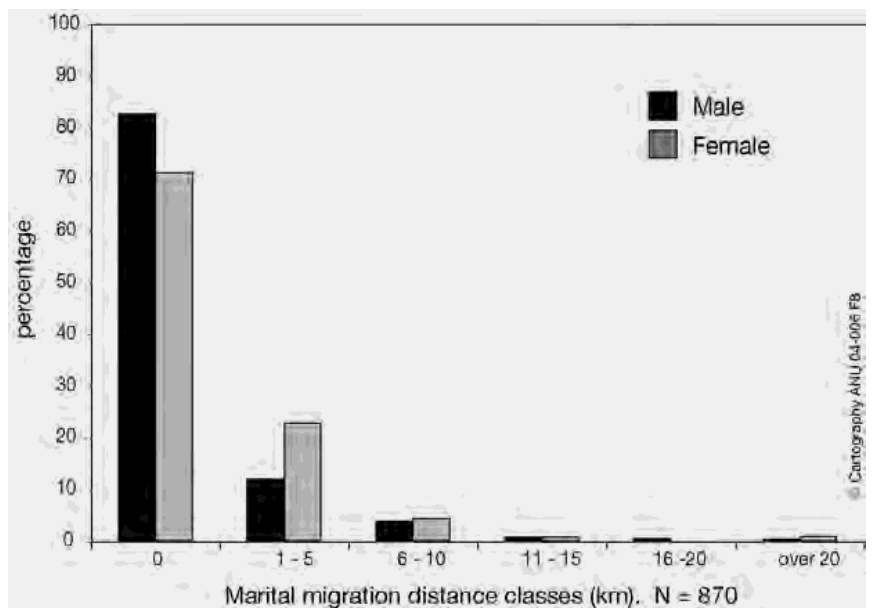

Figure 4. Bougainville marital migration rates.

inland regions, with almost everyone setting up marital residences only a kilometre or two from their birthplaces [Friedlaender 1975: 78]. This pattern very likely characterised earlier periods as well, especially prior to the colonial era. People were afraid to move far because of pervasive feuding, head-hunting, and the fear of malevolent ancestral spirits. We have found the same restricted marital migration rates in inland New Britain, as well.

However, during my visit in 2003 to north coastal Bougainville (the Saposa, Buka, and Teop regions), I found that the marital migration pattern there was different. Many more people had moved from one place to the next by the time they settled down to have families. If this was true in earlier generations, one would expect genetic variation to be more evenly spread out and consistent from one beach location to the next, as opposed to the inland regions. This may also explain why big islands such as Bougainville and New Britain have a great deal of internal genetic diversity, while smaller islands without large mountainous interiors such as New Ireland, are more homogeneous.

In sum, because Bougainville has been settled for so long, and because the inhabitants were relatively few and isolated from one another for most of the time since first settlement, a number of genetic differences have developed within the island's population, as well as between Bougainville and other islands in the region. While most of the differences are only in degree, a few variants are apparently restricted in their distributions to Bougainville or even to particular sections of the island. 


\section{Endnotes}

* This paper represents a summary of a large body of work and participation by many people over 30 years. It relied from the beginning on the goodwill and support of the people of Bougainville, including many co-workers, friends, and assistants as well as the many hundreds of participants. Scientific collaborators have been acknowledged in references, but special thanks go to George Koki, Andrew Merriwether, Heather Norton, and Daniel Hrdy. Much of the research was performed in affiliation with the Papua New Guinea Institute for Medical Research in Goroka, and was supported by the United States National Science Foundation, Wenner-Gren Foundation for Anthropological Research, and the National Geographic Society, as well as Temple University, the United States National Institutes of Health, and the University of Michigan.

1. Skin and hair pigmentation were taken using a DermaSpectrometer (Cortex Technology, Hadsund, Denmark), a narrow band reflectance spectrophotometer. Details are provided in Norton et al. 2004 and 2005. The DermaSpectrometer measures the primary colour-giving elements of the skin, hemoglobin (red) and melanin (brown). The reflectance of narrow-band light in the red spectrum results in an estimate of the melanin content of an individual's skin, using the following equation:

$M=\log 10(1 / \%$ red reflectance), where $M=$ Melanin Index.

Conversely, erythema, or redness of the skin, is calculated by subtracting the absorbance due to melanin from the absorbance of the green filter:

$\mathrm{E}=\log 10(1 / \%$ green reflectance $)-\log 10(1 / \%$ red reflectance $)$, where $\mathrm{E}=$ erythema.

The $\mathrm{M}$ index, as computed by the DermaSpectrometer, is useful in studies of pigmentation variation because it measures the amount of skin pigmentation that is due primarily to the effects of melanin, without any confounding effects from hemoglobin. The upper inner arm was selected as the measurement site because it is a region of the body that is generally unexposed to UVR, allowing for a more accurate measurement of constitutive rather than facultative skin pigmentation. Three measurements were also taken of the hair at the crown. 


$$
\begin{gathered}
\text { THE COLONIAL } \\
\text { PERIOD TO } \\
\text { WORLD WAR II }
\end{gathered}
$$




\title{
ORIGINS OF \\ BOUGAINVILLE'S BOUNDARIES*
}

\author{
by James Griffin
}

$\mathrm{T}$

here has been an entrenched view among educated Bougainvilleans that their province was once under British control and became part of a trade-off between Great Britain and Germany. As will be seen, this did not happen. This misapprehension, however, is a reminder that many people are unaware of the origins of Papua New Guinea's boundaries.

The earliest flag raising in Melanesia was probably by the Spaniard, Ortiz de Retes in 1545 at the mouth of the Santa Augustin River (Mamberamu), north coast of (West) New Guinea. In the Solomon Islands this was done by another Spaniard in 1567, Alvaro de Mendana, who named the islands after the biblical king because he thought it would be a land of fabled gold. He visited the larger islands of Ysabel, Malaita, Makira and Guadalcanal. In 1595 he returned to try to establish a colony - at Santa Cruz - because he could not find where he had been before. Mendana died there but, in any case, the colony had to be aborted. Soon after, Luis de Torres raised the Spanish flag again at Mailu, south-east Papua, before sailing through the strait between Papua New Guinea and Australia that bears his name.

The first boundary on a map of Melanesia was drawn by the Dutch who were in present day Indonesia, then the Spice Islands, from the early 17 th century. They made no attempt to annex the western part of the island of New Guinea until 1828 when British activity in northern Australia spurred them on to claim territory up to the 141 st meridian (the present border). It was enough that the sultanate of Tidore, which was part of the Dutch protectorate, claimed the coastal islands off the Bird's Head (Vogelkopf). This was regarded as an adequate buffer against foreign interests. In 1848 the Dutch, by a secret decree, extended Tidore's rule to the 141 st meridian in the south. This was eventually accepted and a convention of 1895 incorporated the Fly River bulge into the border between British and Dutch New Guinea. 
In 1872-3 agitation by the Australian colonies led to the annexation of the Torres Strait islands just north of Cape York, including Thursday Island. This was ultimately extended right up to the boundary - within a couple of hundred yards, actually — of the Papuan coast in 1879. Originally, Australian maps included even the mudflats of Kawa, Matakawa and Kussa [Van der Veur 1966: 23 (map of Torres Strait)] but, in negotiating the border settlement with an independent Papua New Guinea in 1977-8, the Australian government decided that the borders were untenable and took pains to demonstrate that there had been no intention to annex those mudflats in 1878. Queensland in particular, but the Australian states generally were very concerned about the possibility of some other European power, particularly Germany, annexing part of New Guinea. In April 1883, the Queensland government sent its Thursday Island magistrate up to Port Moresby to raise the flag. This action was repudiated by the British government. An Australian inter-colonial conference, in late 1883, asked London to proclaim a sort of Monroe Doctrine over the Pacific. Lord Derby who was the colonial secretary rather pompously said, 'Great Britain has black subjects enough, thank you,' and he referred to the Australian colonists, as 'raving'. He said, 'It's mere raving.' He ignored them. He was burnt in effigy in at least one of the capital cities in Australia [Whittaker et al 1975: 475].

Meanwhile Germany, which had appeared uninterested in colonies having none at all until 1884 — had, by the end of 1885, colonies in Togoland, the Cameroons, South West Africa (now Namibia), and part of New Guinea and the Marshall Islands. There were more to come, but even then Berlin wanted to avoid territorial sovereignty because of the costs that were involved, and because of the complications that this made for the government in its dealings with the German parliament. Domestic policy was the paramount thing in Chancellor Bismarck's mind. When he realised that colonisation could be achieved satisfactorily through establishing company rule under royal charter, which would administer and meet expenses, his opposition to the acquisition of colonies diminished.

German trading in the Pacific had begun in 1857 with the famous Godeffroy and Sons in Samoa. It traded in coconut oil and marine products, and eventually set up plantations, trading posts and shipping facilities from Tahiti to the Marianas. In 1876 Godeffroy established a base in the Duke of York Islands off the Gazelle Peninsula. Hernsheim and Company was there at much the same time. A major interest was procuring labourers for plantations in Samoa. By 1883, when the Queensland sugar industry began providing keen competition for Melanesian recruits, Bismarck consented to German colonisation in New Guinea.

Great Britain was much more concerned with good diplomatic relations with Germany than annexing another colony. Its diplomacy was globally rather 
than regionally focussed. There was, at the time, friction with France over British control of Egypt, and the British did not want to antagonise Germany in such a way as to make it an ally of France. However, during 1884, the Australian colonies became more and more alarmed that Germany had designs on New Guinea. (It is important to note that politically, there was no Australia at the time. Federation did not occur until 1901 and until that year Australia consisted of six separate colonial states.) This alarm, however, did not impress people in London who insisted that there was no reason to believe that the Germans were interested in New Guinea; and, indeed, they said they had assurances from Berlin that this was not so. It is possible that the British were not being quite honest (that, in fact, they were deceiving the colonies) and that, while they would object to Germany annexing, for example, the Papuan coast - the south coast - they felt that German interests on the north-eastern coast and in the Bismarck Archipelago were quite legitimate. Finally, under cover of what looked like a routine voyage, the Germans, on 2 November 1884, arrived in Rabaul and proclaimed a protectorate, subsequently also raising flags at Madang, Finschhafen and Manus. The news of this reached London only in mid-December, six weeks later. However, a British squadron had already been despatched to Port Moresby to proclaim a protectorate there on 6 November and to raise flags at some ten points along the coast.

There were protests at Germany's actions, but an amicable settlement was reached in April 1885 with British control extending up to the Waria River, taking over the rest of the north-east coast to the tail of the island and the whole of the southern coast. These became the old boundaries of Papua and New Guinea. British New Guinea was acquired by Australia from Great Britain in 1906 and renamed Papua. Imaginary lines were drawn through the centre of the island to designate respective sovereignties. Fortunately what had been German New Guinea and Papua came under the same colonial power before the Highlands was explored, when it would have become clear that the lines would have divided substantial populations.

While the western boundaries between Dutch New Guinea on the one hand, and both German New Guinea and British New Guinea on the other, had been set in the mid-19th century at the 141st meridian, the eastern extreme of German New Guinea was not defined because the status of the Solomons Archipelago was not defined in 1884. It was after the flag raisings of 1884 that further negotiations took place as to the status of the Solomons Archipelago. In 1886 two Anglo-German declarations divided the Solomons so that Buka and Bougainville, the Shortlands, Choiseul, Isabel, Ontong Java and part of the Floridas came under German protection [see Map 1]. The rest was not taken over as the British Solomon Islands Protectorate until 1893. So, Bougainville and Buka were never 


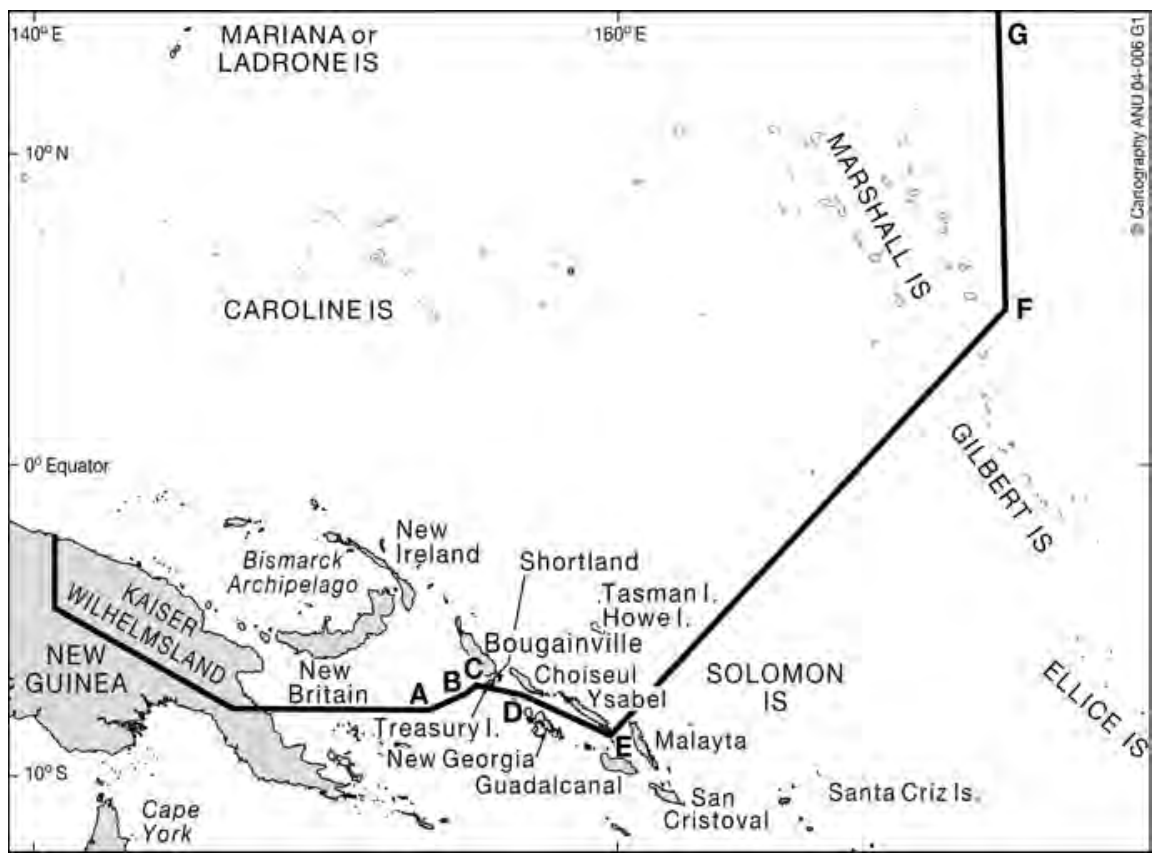

Map 1. Boundary between Bougainville and Shortland Island and Fauro Islands

under the control of the British. In 1899-1900 there was another Anglo-German convention, particularly dealing with the sovereignty of Western Samoa and, as a result of a multi-faceted agreement, the German protected area (Schutzgebiet), [Sack, this volume] was moved back south of Bougainville to what is the boundary of Papua New Guinea today. This change included the Shortlands, Choiseul, Isabel, Ontong Java and related island fragments in what was the British Solomon Islands Protectorate and is now the Republic of the Solomon Islands. Precise lines of demarcation were decided by two conventions of 1904 [see Map 2]. If any people have a grievance about being 'horse-traded' by the colonial powers, it was really those who lived between the demarcation lines of 1886 and 1904, such as the Choiseuls, the Shortlanders and the Isabels, not the Bougainvilleans.

With World War I in 1914, Australia moved very quickly to take over German colonies, up as far as the equator, because the Japanese were concerned to take over the Micronesian colonies of Germany. That 'conquest' was then ratified under the Treaty of Versailles, so that in 1921 Australia was granted virtual sovereignty, with some reservations, through what was called a C-class mandate by the League of Nations. With World War II, the divided administrations of New Guinea and Papua were combined into one and that was ratified as the Territory of Papua and New Guinea in 1949 by the United Nations. These are the boundaries of Papua New Guinea today. 


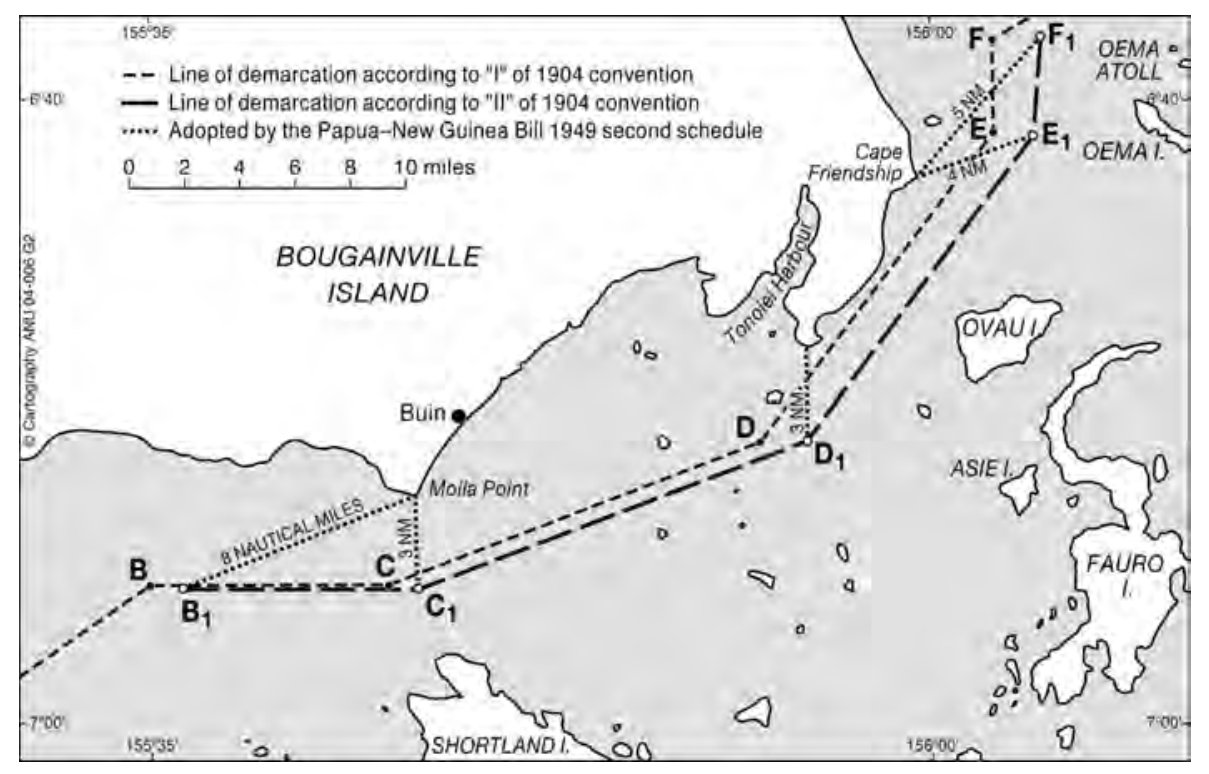

Map 2. The Anglo-German Declaration of 1886.

\section{Endnote}

* The following much used source covers this topic: Van der Veur, [1966], from which the maps are also taken. See also Whittaker et al. 1975: 492-3 for the Second Anglo-German Declaration of 1886. 


\title{
GERMAN COLONIAL RULE IN THE NORTHERN SOLOMONS
}

\author{
by Peter Sack
}

\section{ANNEXATION AND BOUNDARY}

On 10 April 1886 Germany and Great Britain signed a 'Declaration relating to the demarcation of the German and British spheres of influence in the Western Pacific'. It defined a 'conventional line' which cut the Solomon Islands roughly in half. Great Britain agreed not to interfere with the extension of German influence west and north of the line and Germany did the same in favour of Great Britain for the area south and east of it. ${ }^{1}$ This declaration gave the two powers a free hand in relation to each other to make territorial acquisitions in their respective spheres.

The German government acted promptly. It did so at the urging of the Neu Guinea Kompagnie - which was governing Kaiser Wilhelmsland, the northeastern quarter of the main island of New Guinea, and the Bismarck Archipelago under an imperial charter - because the company was concerned that other interested parties had begun to make strategic land acquisitions in the northern Solomons. ${ }^{2}$ On 28 October 1886 the commander of SMS Adler declared all islands in the Solomons north of the line of demarcation - namely Buka, Bougainville, the Shortlands, Choiseul and Ysabel, as well as the smaller islands to the east ${ }^{3}$ - to be a German 'Schutzgebiet $t^{4} \mathrm{He}$ also prohibited, for the time being, the acquisition of land from 'the natives' and the supply of arms, ammunition and liquor to them.

On 13 December the emperor granted the Neu Guinea Kompagnie a charter to govern the Northern Solomons in accordance with the arrangements made in its earlier charter for Kaiser Wilhelmsland and the Bismarck Archipelago.

A major change in the borders of the German part of the Solomons took place as a result of an agreement between Germany and Great Britain 14 November 1899. In this agreement Germany ceded all islands south and south-east of 
Bougainville - namely Choiseul, Ysabel, the Shortlands and the Lord Howe Islands - to Great Britain as part of a compensation package for renouncing her claims to the western section of the Samoan Islands, which became German.

German colonial rule in the Northern Solomons was effectively terminated in September 1914 when the acting governor of German New Guinea capitulated to the Australian Naval and Military Expeditionary Force. In short, German colonial rule in the Northern Solomons lasted for just under 30 years but covered, before the end of 1899, an area which was about twice as large as afterwards.

\section{THE LEGISLATIVE AND ADMINISTRATIVE FRAMEWORK}

As the Northern Solomons had been administered as a part of German New Guinea we need to understand the legislative and administrative framework of this colony in order to appreciate how colonial rule was exercised in this particular area. $^{5}$

\section{The Legislative Framework}

German colonial law was characterised by a combination of two basic distinctions: a 'personal' distinction between 'natives' and 'non-natives'; 6 and a 'substantive' distinction between civil, criminal and procedural law on the one hand and, broadly speaking, administrative law on the other.

For non-natives the metropolitan German/Prussian civil, criminal and procedural law was introduced by the 1886 Protectorates Act, although certain modifications were permitted. By contrast the colonial authorities were given full legislative and administrative discretion in relation to natives.

The most important consequence of these arrangements was that the colonial authorities could only avoid the development of a dual system of justice one for non-natives and another one for natives - by also placing natives forthwith under the introduced metropolitan law, which was legally possible but, for the time being, obviously impractical. ${ }^{7}$ As a result, a distinctly colonial law applying to non-natives as well as natives could only develop in the field of administrative law which thereby acquired an unusually dominant position and produced a specifically colonial form of government.

Although the colonial authorities were free to create a separate system of civil, criminal and procedural law for natives, they were reluctant to do so. Instead they tolerated the continuation of customary law on the assumption that they could replace it with colonial law when and where that became politically desirable and administratively achievable. 
The first legislative move in this field was the enactment of a native penal ordinance. It was not designed as a criminal code addressed to natives but as a procedural code addressed to the colonial authorities. It established station courts, empowered them to punish natives for actions which constituted a serious offence under the German Criminal Code - or which had been declared to be illegal by a colonial police ordinance - and prescribed the procedures the courts had to follow in the exercise of their powers. ${ }^{8}$ This Native Penal Ordinance was supplemented by an ordinance regulating the disciplinary punishment of coloured labourers. ${ }^{9}$ It too was designed as a procedural code addressed to the colonial authorities, since it treated such disciplinary punishments as extraordinary extensions of the penal powers of the state, rather than as the exercise of a quasi-parental, disciplinary power of employers, so that they could only be administered by government officials. ${ }^{10}$

While the authorities hesitated to regulate the substantive civil law of German New Guinea's native population directly, it was affected in various ways by legislation primarily addressed to non-natives. ${ }^{11}$ Land and labour law were two important areas where this happened.

As regards land law the exercise was straight forward because the colonial authorities were empowered by the Protectorates Act to modify the metropolitan civil law it introduced for non-natives. To do so for German New Guinea was essential because the Neu Guinea Kompagnie had been granted a land acquisition monopoly which clashed with the metropolitan freedom of contract principle. ${ }^{12}$ An imperial land ordinance therefore declared that the introduced land law did not apply to the acquisition of native and ownerless land by non-natives. ${ }^{13}$ Instead the acquisition of such land was treated as an administrative process. The colonial law provided that, irrespective of custom, natives could alienate their land but that, contrary to metropolitan law, they had no freedom to contract with parties of their choice. But nor had non-natives. Instead the colonial authorities were empowered to issue administrative instructions to their officials for the exercise of the company's monopoly. ${ }^{14}$ The acquisition process culminated in a public certificate by its Administration which could not be challenged in court on the basis that the instructions had not been followed. Although the company issued general conditions for the transfer of land to settlers, settlers were not given a legal right to acquire land, even if they agreed to be bound by these conditions.

The freedom of contract principle also caused problems with the employment of natives by non-natives. According to the introduced metropolitan law, non-natives were free to employ any native they chose under any conditions that a native was willing to accept - a state of affairs the colonial authorities were unwilling to tolerate. However they could not bring the labour market under their 
control by proclaiming a labour ordinance which declared the introduced civil law to be inapplicable to the employment of natives, since such a modification was not permitted under the Protectorates Act. The authorities therefore had to introduce such a control gradually and indirectly. The first step was a prohibition to 'export' natives as labourers from German New Guinea. This prohibition was then extended to cover the transport of natives as labourers across the sea from one part of the colony to another. However an exemption was made for non-natives who obtained an official recruiting licence. This licence was made subject to the fulfillment of various conditions - a backdoor which could be used to stipulate employment conditions: minimum wages, maximum working hours, adequate food rations and so on.

This 'licensing approach' became a central instrument of colonial government. By proclaiming a general prohibition the colonial authorities gained a flexible administrative control over the field in question. In addition it gave them a de facto monopoly for its economic exploitation, apparently permitting them to manage valuable resources in their own, fiscal interest. ${ }^{15}$ The Neu Guinea Kompagnie's land acquisition monopoly — which, instead of being relinquished, in 1899 was inherited by the Fiskus of German New Guinea, the colonial state in its property owning capacity — is only the most conspicuous example.

One of the first ordinances of the company's administrator restricted most potentially lucrative commercial activities, with the exception of agriculture and the trade in coconuts and copra with natives, to individuals and firms who had obtained an official licence. By the end of German colonial rule the authorities had established a comprehensive mining monopoly for the Fiskus which covered the entire colony. ${ }^{16}$ The licensing approach was even used to modify prohibitions which had been introduced to protect public safety, such as the prohibition on supplying natives with arms, explosives and liquor. Initially this prohibition was exclusively addressed to non-natives. Although a non-native committed an offence when supplying a native with a gun, it took over 20 years before the possession of guns by natives was proclaimed to be a criminal offence. Similarly, it was at first only non-natives who were given the opportunity to obtain a licence to supply natives, although it later became possible for natives to apply themselves for such licences. Even the 'desertion' of a native labourer was only formally declared to be a criminal offence in a 1914 draft labour ordinance, ${ }^{17}$ whereas the relevant legislation had, again from the start, defined various criminal offences by non-native recruiters and employers. ${ }^{18}$

These examples illustrate how far administrative law, usually equipped with penal teeth, had superimposed itself on civil law. Two aspects of this process require special attention: Firstly, its main focus was the relations between non- 
natives and natives. In other words, a dual system of justice which neatly kept non-natives and natives apart was in practice neither possible nor desirable. Secondly, the process affected non-natives as much as natives. To be sure, German colonial law contained significant racial elements but we misunderstand it fundamentally if we see it as privileging non-natives and discriminating against natives. Instead it treated non-natives as well as natives, insofar as the latter became incorporated into the colonial enterprise, as colonial subjects, rather than as citizens. Colonial government was not the government of people but was concerned with the economic development of a territory by the efficient management of its resources, including its - replaceable — human resources. ${ }^{19}$

Finally a look at the direct administrative relations between the colonial authorities and the indigenous population. They remained throughout subject to wide executive discretion. An imperial ordinance regulating the coercive and penal powers of the authorities ${ }^{20}$ applied to natives only if this was specifically ordered by the governor - a step which was not taken in German New Guinea. Whereas this too would have been legally possible, the Colonial Service Act was also not applied to the 'native organs of the administration' - the government chiefs and their assistants (luluai and tultul) — or to native policemen. Native policemen were legally treated as ordinary labourers. Neither their official powers nor their official duties were legally defined. The institution of 'government chiefs' had no legislative basis whatever, although some of their official powers and duties were specified in public notices, administrative instructions and even formal legislation (such as the Roads Ordinance). The compulsory 'public services' the indigenous population had to render were also the product of administrative practice. Only an administrative instruction told officials how they were supposed to exercise their discretion, without imposing judicially enforceable duties on the natives or of legally limiting the services which could be demanded from them.

This legislative reluctance reflected the view that government chiefs and compulsory labour were foreign bodies in a modern system of government which had to make way as soon as possible to normal practices, such as the payment of taxes and the government by salaried officials who were fully integrated into the administrative hierarchy to which alone they owed their loyalty.

A 'punitive expedition' - the use of military force against the indigenous population - was the most 'abnormal' administrative instrument. Yet it was employed right until the end of German colonial rule. ${ }^{21}$ Naturally it too was not given a legislative basis, since such an expedition was seen as warlike in character and thus outside the scope of a 'normal' domestic legal system. However, even punitive expeditions did not take place in a legal vacuum and their role in the colonial scheme of things changed significantly. 
Whereas they were initially a defensive device, carried out to punish natives for attacks on non-natives, they became part of an increasingly proactive pacification campaign, aimed at establishing law and order among the indigenous population. Put differently, punitive expeditions were losing their punitive character. They were no longer concerned with criminal justice but with public peace. They did not respond to crimes already committed - even if they were triggered by such crimes - but to continuing unlawful states of affairs which challenged the authority of the colonial state, in particular its claim to be the only legitimate user of physical force within its territory. While themselves distinctly abnormal, punitive expeditions came to be perceived as sometimes unavoidable constructive steps on the path to administrative normality. However, in order to achieve their purpose, they had to be followed up by peaceful patrols, by the appointment of government chiefs and, eventually, by the establishment of a permanent government station in the area. Yet 'pacification', was in itself not an administrative goal either. Even the rule of law was merely seen as a precondition which permitted the colonial state to focus on its central task: the economic development of its territory.

Still, law and order were from the start crucial elements of the colonial enterprise. The legislative framework, which gave it its unique shape, acquired a growing practical importance. It determined what was actually happening in German New Guinea to a point where the history of this colony becomes unintelligible if colonial law is disregarded.

\section{The Administrative Framework}

Administratively the history of German New Guinea can be divided into two sections of almost equal length: the period of company rule between 1886 and 1899 and the period of imperial government between 1899 and 1914. Under the Neu Guinea Kompagnie the Administration in the colony was headed by an Administrator who was also the chief justice and in charge of the supreme court. German New Guinea was divided into two judicial districts: Kaiser Wilhelmsland and the Bismarck Archipelago. In each, a district court under an imperial judge was established. It had full civil and criminal jurisdiction over non-natives. The imperial judges had no general administrative duties but they were also placed in charge of the station courts which were created to exercise the criminal jurisdiction over natives. The local administration was in the hands of the managers of the company's main stations, who were also responsible for their economic activities.

In 1889, the company's imperial charters were temporarily suspended and its administrator was replaced - in his administrative and judicial capacity 22 by an imperial commissioner. The imperial commissioner was supported by two senior imperial officials. An imperial chancellor was posted to the Bismarck 
Archipelago who took over the judicial functions of the imperial judge and the administrative functions of the company's station manager. In Kaiser Wilhelmsland, where he resided, the imperial commissioner was supported by a secretary who was placed in charge of the district court and station court. ${ }^{23}$

In 1892 a company administrator again took over. But the original arrangements were not completely restored, since the imperial judge, who replaced the imperial chancellor in the Bismarck Archipelago, was an imperial official rather than a company employee. Moreover, in 1895 the administrative functions of the company's station manager were also transferred to him. During the last phase of company rule a full-time imperial judge was finally appointed for Kaiser Wilhelmsland as well but, in contrast to his colleague in the Bismarck Archipelago, he was employed by the company and had no general administrative duties. 24

When an imperial governor arrived in 1899 his seat was moved to the Bismarck Archipelago. The imperial judge in Kaiser Wilhelmsland became an imperial official and took over the local Administration. The imperial judge in the Bismarck Archipelago retained his administrative responsibilities. Both judicial districts became primarily administrative districts and the imperial judges turned into district commissioners for whom their judicial functions were merely a sideline.

The position became more complex when additional local administrations were established. Instead of placing these government stations - as sub-district offices - under the district commissioners, they were placed directly under the governor. ${ }^{25}$ On the other hand, in their capacity as district judges, the district commissioners remained responsible for the exercise of the judicial jurisdiction over non-natives in their entire — unchanged — judicial districts. However, the district judges routinely authorised district officers to exercise much of this jurisdiction within their smaller administrative districts. Moreover, the office of chief justice was separated from that of governor, and while the former office was given to another senior executive, a full-time district judge was again appointed for the Bismarck Archipelago, so that the district commissioner there no longer had judicial functions in relation to non-natives, although he, rather than the district judge, remained responsible for the local station court.

How did this changing administrative framework impact on the Northern Solomons? They were treated as part of the Bismarck Archipelago. They were at first judicially placed under the imperial judge and administratively under the company's station manager there. Between 1889 and 1892 they came in both respects under the imperial chancellor. He was replaced by an imperial judge who subsequently also assumed administrative responsibilities. This arrangement continued under the imperial government represented by the imperial district judge/district commissioner - until a government station was opened in Kieta in 1905. Hence it took 
almost 20 years before German colonial rule acquired a permanent local base in the area and this local presence lasted for less than ten years.

The government station for the Northern Solomons was placed directly under the governor and became responsible for the entire local administration of its district, as well as the administration of criminal justice in relation to its native population. $^{26}$

Since the development of specialised administrative services was, even at the end of German colonial rule, still in its infancy the range of the station's administrative responsibilities was extraordinarily wide. It was responsible for land and labour matters, for public works, for health and education, for the collection of taxes and the customs duties and, generally, for the maintenance of law and order.

Some of these responsibilities were, at least initially, largely theoretical. For example, even by 1914 there was no government school in the district, the construction of a native hospital had only just begun and that of a European hospital was still a long way off, although a government doctor had been posted to Kieta in 1913. The station even had to wait several years before it was supplied with a sea-going vessel so that its field of action had remained rather limited. ${ }^{27}$

Nonetheless the workload was considerable and the personnel to carry it out was minimal. The district officer was supported by a police sergeant, a medical assistant, 50 native policemen and a smaller number of native labourers and tradesmen. Still, this was a vast improvement compared with earlier days. The imperial judge, who was nominally in charge of the local administration of the entire Bismarck Archipelago and the Northern Solomons, only had a part-time native police force of about half that size at his disposal in 1896 . He had to rely on transport by naval or commercial vessels if he wanted to venture further from his seat in the Gazelle Peninsula than his feet, a horse, or a rowing boat could carry him. For about two thirds of the period of German administration of the Northern Solomons, the exercise of colonial rule was therefore bound to have been less than rudimentary. On the other hand, as we shall see, this makes life easy for historians because they only have to deal with fleeting visits.

\section{THE EXERCISE OF GERMAN COLONIAL RULE IN THE NORTHERN SOLOMONS}

\section{Fleeting Visits: 1886 to 1905}

Two years of company rule had passed before acting administrator Kraetke arrived on the first official tour of inspection in the Northern Solomons in November 1888. But then he came in style, on two company steamers, the Isabel and Samoa, 
accompanied not only by Imperial Judge Schmiele and Count Pfeil, the company's manager in the Bismarck Archipelago, but also by Hugo Zöller, a visiting German journalist, Friedrich Eich of the Rhenish Mission, which was considering the Northern Solomons as a field of activity, and Richard Parkinson, the local expert, who had been recruiting labourers in the area for several years.

In light of the available information, Kraetke had decided that the west coast of Buka, the east coast of Bougainville and the Shortland Islands were the most promising locations for a government station, the establishment of which the company had announced in its first annual report. First Kraetke ruled out Carola Harbour on Buka because the suitable small islands in it were all densely populated and its shores were all fringed with mangroves. Then he ruled out the Shortland Islands, the populous domain of the legendary King Gorai, ${ }^{28}$ because many reefs and small islands made an approach dangerous. By contrast Numa Numa Bay at the centre of Bougainville's east coast was uninhabited, but it too was dotted with treacherous reefs. Another bay further north, near Cape Laverdie, was the comparatively best choice. However, Kraetke was far from enthusiastic and nothing happened [Nachrichten aus Kaiser Wilhelmsland (NKW) 1889: 22].

Schmiele, who had been appointed administrator in 1892, paid another official visit to the Northern Solomons in 1893, this time focusing on Choiseul and Ysabel. Due to its sparse population and rugged terrain the latter offered no prospects for either plantations or labour recruiting. The same applied to much of Choiseul. Buka, on the other hand, was so densely populated that there was no room for large scale plantation enterprises. Schmiele regarded Bougainville with its vast stretches of fertile, flat land as a 'true pearl' — but then good plantation land was readily available in less remote parts of German New Guinea. Besides, the warlike character of the Solomon Islanders would make it necessary to supply settlers with much larger 'means of protection' than in the Bismarck Archipelago or Kaiser Wilhelmsland. Yet away from their homes these warriors became excellent labourers and reliable policemen. Since trading opportunities were also very limited - Schmiele was told that the entire copra production in the German Solomons in 1892 had been just 70 tonnes - the best policy was to use the area as a labour reservoir for plantations in the two existing centres: Blanche Bay in the Bismarck Archipelago and Astolabe Bay in Kaiser Wilhelmsland [NKW 1893: 48-56].

An expedition by Imperial Judge Hahl to the Northern Solomons in 1896 was of a different kind. Its immediate reason was a report that the four New Ireland labourers of a Chinese trader of the Forsayth firm, who had been killed in 1894 in Buka Passage, were still held captive by the people responsible for the killing. Hahl embarked with his native police troops — which he had managed to 
boost to 38 men and which was battle-hardened by recent expeditions to New Ireland - on the Forsayth schooner Three Cheers, together with Richard Parkinson, who was recruiting labourers for the firm. Hahl landed with his troops and marched on the village where the captives were said to be held. He was met by the fighting men arranged in military formation outside the village. He demanded the release of the prisoners. When the response was a derisive: 'If you want them, come and get them', Hahl ordered his troop to advance, whereupon the enemy scattered with 'bloodcurdling yells'. But there was a happy end. No fighting ensued. The four prisoners were brought and greeted their release with 'howls of joy'. The locals accompanied Hahl to the Three Cheers and received presents from Parkinson. 'Dating from this incident, we enjoyed lasting good relations with the natives round Buka Strait and these districts later became the best recruiting area for soldiers' [Hahl 1980: 21-2].

The climax of Hahl's expedition had been an earlier march of the troop across Buka from Carola Harbour to Hanahan, the home village of six of Hahl's policemen. The reception was friendly, but Hahl's men warned him that neighbouring villages were planning an attack. Since Hahl 'was anxious to avoid all fighting in this important recruiting area' he marched north along the coast the next morning in the hope of intercepting the Three Cheers, for which, according to plan, he was supposed to have waited in Hanahan. In the village of Jultupan, the home of another of his policemen, Hahl struck trouble. Although the man called on his fellow-villagers to remain quiet, the troops were showered with spears from the surrounding bush. Hahl's men immediately opened fire, but Hahl ordered a halt, because he suspected a misunderstanding - and so it turned out to be. Recognising six Hanahan, their sworn enemies, among Hahl's troop, the Jultupan had feared attack. There was no more fighting but the situation remained tense. Hahl was glad when the Three Cheers came into sight and could be alerted. The retreat was hardly dignified, since Hahl and his men had to swim through the heavy surf, carrying all their gear, before the boats of the schooner could pick them up [Hahl 1980: 21-2].

The first action taken by the new imperial government was a punitive expedition. It responded to the killing of the European captain of the schooner Sea Ghost and one of its crew members in Tinputz Bay in north-eastern Bougainville in 1898. ${ }^{29}$ Imperial Judge and Acting Governor Schnee, frustrated by the lack of action by the Neu Guinea Kompagnie, requisitioned captain Dunbar of S.M.S. Moewe and embarked with 20 native policemen. During the night of 21 April 1899 at 1.00 a.m. the Moewe arrived in Tinputz Bay. The combined landing forces set out for the shore at $4.20 \mathrm{a}$.m. As usual the approach took longer than expected. The sun had risen before the implicated and now deserted villages were 
reached. By 9.00 a.m. the landing forces had returned to the Moewe, without having suffered or inflicted any casualties. In the afternoon the native police troop was again landed, moved inland and 'succeeded' in killing one native. As Schnee and Dunbar decided that the punishment inflicted — which included the removal of all valuables from the villages and the burning of one of them - had been insufficient, the police troop was landed secretly during the night under the command of two native corporals - at least one of them from Buka. The Moewe steamed demonstratively out of the bay as a signal that the punishment had come to an end. The police were picked up the next morning, having killed seven warriors. The police had all been armed with bows and arrows - none of the firearms taken from the Sea Ghost had been used [Schnee 1904: 144-9].

Schnee concluded in 1904 that although the measures taken had run counter to European ideas of a just punishment they had been absolutely necessary - and they had been successful: indeed no further murderous attacks on whites have occurred on Bougainville during the years following the punishment of the Tinputz people'. ${ }^{30}$ This last statement is correct but how much does it mean? Firstly, murderous attacks on whites on Bougainville in earlier years had been rare. ${ }^{31}$ Secondly, European activity in the Northern Solomons between 1898 and 1904 had still been very limited. Thirdly, as detailed below, in the next year a white man was killed in Buin.

The 'proper' start of Imperial Administration in the Northern Solomons was a tour of inspection by Imperial Governor von Bennigsen in 1900 on the new government steamer Stephan - the first designated government vessel in the by now 15 year old history of German New Guinea. Unfortunately, the Stephan turned out to be quite unsuitable and had to be sold at a considerable loss. One of its major drawbacks was a reason why Benningsen, after a brief visit to the Shortlands, headed to Tulagi, the seat of the resident commissioner of the British Solomons. The Stephan could only carry enough coal for a five day journey and Bennigsen wanted to obtain permission to establish a coaling depot at the station of the trader Tindal in the — by now British — Shortland Islands because at the time no suitable commercial enterprise operated in Bougainville or Buka. ${ }^{32}$

The permission was granted and Bennigsen proceeded to inspect the outlying islands east of Bougainville and Buka — which were all worked by Queen Emma's Forsayth firm. First the Stephan called on Ontong Java, now also British, where the Forsayth trader collected about 200 tonnes of copra annually. Next came Nukumanu which was registered as Queen Emma's property. It produced currently around 40 tonnes but the firm expected to increase production to between 150 and 200 tonnes by concentrating the native population on the largest island and planting up the rest with coconut palms. The Mortlock 
Islands (Takuu, or Tauu) were registered for a relative of Queen Emma. Frau Altmann produced 50 tonnes with imported labourers, because the indigenous population had shrunk to 15 heads, but she too hoped to lift production substantially by further plantings. Although inhabited by about 1,300 people the Nissan Islands were registered as Queen Emma's property as well and produced between 120 and 150 tonnes of copra. ${ }^{33}$ The population of Nuguria was much smaller, but the group already produced an average of 150 tonnes and a further increase was expected when the largest island had been planted up with coconut palms [Deutsches Kolonialblatt (DKB) 1901: 113-17].34

An earlier highlight of Bennigsen's trip had been a visit to the headquarters of the Marist mission in the Shortland Islands. The mission now found itself cut off from its most promising mission field in Bougainville by an international border, but Bennigsen was anxious to encourage it to extend its activities northward. He was especially impressed by its agricultural activities. He therefore subsequently authorised the mission to acquire 500 hectares at Kieta to establish a commercial plantation — the first on Bougainville.

With the Marist mission, a new actor had arrived on the scene that came to play an unusually important part in the colonial history of the Northern Solomons, because the mission had for a considerable time no serious local competition. ${ }^{35}$ Yet its impact on the exercise of German colonial rule was minimal. Mission and government operated side by side, without serious tensions but also without close cooperation. Moreover, the respective geographical focus of activities was different. Whereas the mission was initially most interested in southern Bougainville, the Administration was more concerned with its east coast and Buka. For some years, the mission was largely left to its own devices - and its start was by no means trouble-free. The Annual Report for 1901 complained that in 'the absence of a [government] vessel, it was impossible to make contact with the Fathers of the Order of Mary (Marists) ... in the southern section of Bougainville'. The same complaint was voiced more strongly the following year, when it had 'been impossible to intervene after the Marist mission was driven out of its station at Kieta by the natives' [Sack and Clark, trans. and eds. 1979].

Hahl, who had succeeded Benningsen as governor, visited the Northern Solomons on the new government steamer Seestern in October 1903. Hahl wanted to recruit replacements for the native policemen and government labourers he was returning, establish peaceful contacts with the native population and inspect the stations of the Marist mission. ${ }^{36}$ Hahl's experiences in southern Bougainville were mixed. He had no hostile encounters, but his recruiting attempts in Buin and inland of Kieta were unsuccessful because of feuds among the villagers. ${ }^{37}$ By contrast, Hahl's impressions of the conditions on Buka and the 
Buka Passage were entirely positive. ${ }^{38} \mathrm{Hahl}$ was struck by the changes since his expedition as imperial judge in 1897.39

Whereas his troop had to be ready for combat at all times when crossing the island then, he had now been able to visit even the feared Tsolos in the interior unarmed. Apart from a single hill tribe, the Buka had made peace with each other, although fighting could break out again at any time. The establishment of two government stations - one on Buka and the other on Bougainville — was an urgent requirement. They could back the peaceful elements among the population and gradually open the way to the coast for the people living in the interior. An increase in the native population, the number of recruits and the volume of trade would be the result [DKB 1904: 61-4].

Hahl returned in September 1905 to establish 'a permanent station in this area'. ${ }^{40} \mathrm{He}$ no longer saw a need to establish a government station on Buka because conditions had become peaceful under the influence of the young men who had, almost without exception, worked for Europeans, especially the numerous ex-policemen in the districts around Hanahan and Buka Passage. 'Whenever I landed there, I found the men were standing in military formation under the command of former non-commissioned officers, anxious to show that they had retained their discipline and their loyalty' [DKB 1906: 44-6].

By contrast the feuding on Bougainville had continued unabated. 'As it was our first task to establish public peace here and to persuade the people to engage in trade and to enter employment, it seemed obvious that the site selected [for the government station] should be located on this island.' Not surprisingly the 'safe harbour' of Kieta was chosen. Hahl selected an elevated peninsula on its northern side and preparations for the erection of the essential buildings was immediately begun.

Hahl also visited the new Marist station in Buin. In its vicinity 'the trader' McConville had recently been killed, as it turned out by his own boat crew but at the instigation of two local chiefs. Hahl marched inland with his troop but gave orders to shoot only when attacked. As a result four men whom the troop surprised escaped and no arrests were made. Only one of the chiefly houses was burned before the troop returned to the coast. Here Hahl was informed that the Kikili had recently killed two people from a neighbouring village 'without any reason'. In order to prevent the outbreak of a general feud, Hahl decided to intervene. When the troop reached the village, it was deserted. Hahl ordered the burning of half its houses as a warning to the chiefs Garuai, Seka, Beku and Kessi.

It was left to Secretary Merz to report on Hahl's tour of inspection in July 1907. Merz was impressed by the progress made by the government station. Despite the difficult terrain, it had managed to construct a road as far as the 
Zia River with the help of mountain dwellers who had been regarded as absolutely unapproachable cannibals a few months earlier. Conditions in Buin were less satisfactory. The Marist mission had been forced to call for government protection some time earlier. But after a speedy intervention by the district officer the situation had calmed down and the native policemen who had been temporarily posted as a guard at the mission station could be withdrawn.

However, by now Hahl had other concerns. One of his excursions had the purpose of examining the agricultural potential of the area around Kieta. The Aropa Valley proved to be most promising. It offered more than 6,000 hectares of flat land with deep soil, ideally suited for the cultivation of rubber. ${ }^{41}$

During the same tour of inspection Hahl's search for suitable agricultural land continued in southern New Ireland. It is significant that Merz added in this context that the people there were eager to work on a plantation nearby because labourers who stayed close to their homes could visit relatives, take part in the festivities of their villages and still receive the same wages as if they went abroad. In other words, the future favoured planters who were prepared to go to areas where they could find labourers locally rather than those who wanted to settle near the established plantation centres and had to rely on bringing in labourers from elsewhere. The signal was clear; the government was ready to encourage new plantations outside the Gazelle Peninsula and Northern New Ireland, in particular in the Northern Solomons and Southern New Ireland - where a government station had been established in 1904 [DKB 1907: 382-5].42

Hahl's last tour of inspection in the old style took place in July 1908. In April District Officer Doellinger had carried out several expeditions to the Crown Prince Range because the coastal people had appealed for the station's help against attacks by the mountain dwellers. The 'success' of these expeditions encouraged Hahl to attempt the first crossing of Bougainville. He teamed up with the visiting geographer Dr Sapper and with 20 native policemen and 30 carriers. 43 There were no hostile encounters during the six days it took to reach Jaba, north of Empress Augusta Bay, but the results were hardly spectacular and the long crossing of the marshy plains on the western side of the island had been 'arduous and tedious work'. In Jaba the expedition was picked up by the Seestern and taken to Buin. There conditions were comparatively peaceful and Dr Thurnwald was carrying out anthropological fieldwork among the still very unapproachable natives.

When Hahl marched north along the east coast with Doellinger, from Taurawa River to Kieta, he was struck by the 'wonderful stands of timber in the virgin forest'. They consisted predominantly of Maniltoa grandiflora, 'a tree containing good serviceable hardwood', and Hahl estimated that the area traversed offered over one million cubic metres of felling timber [DKB 1908: 1056-7]. 
But economic development rarely took take place overnight in German New Guinea. Another four years passed before experts were sent out from Germany to examine the forestry resources of the colony — with sobering results. More importantly for our purposes, Hahl's tour demonstrated that the exercise of German colonial rule in the Northern Solomons was by now firmly in the hands of the station in Kieta under District Officer Doellinger who, disregarding his absences on leave, remained in charge of the station until the end of German colonial rule.

The problem we now have to face is that the exercise of this rule can no longer be adequately represented by a few episodes. With the establishment of a government station the history of colonial rule in the Northern Solomons changed fundamentally. Rare and fleeting visits were replaced by numerous activities which became increasingly repetitive and routinised.

While it makes historical sense to describe the few tours of inspection by Governor Hahl and his predecessors as unique events which illustrate how much, or how little, had changed between them, it is pointless to try to capture the history of German colonial rule between 1905 and 1914 by describing the thousands of administrative acts of the Kieta station as unique events. Whether we like it or not this history was becoming rapidly a history of numbers which can only be adequately represented by a series of detailed statistical tables. To do so is not a hopeless task because modern, bureaucratic governments do record the necessary quantitative or quantifiable information. The problem with the Northern Solomons is rather that the most important source of this information - the records of the Kieta station — are no longer available. 44

Still, with the help of other, less specific sources it is possible to reconstruct at least some parts of the picture. In addition, the exercise of governmental powers was not arbitrary. It took place within an increasingly tightly structured normative and organisational framework, so that a quantitative approach could and should be combined with a structural approach. 45

What makes the picture more complex but also more colourful is that this framework was not static but still developing and that its shape varied considerably, even at the end of German colonial rule, in geographical as well as substantive terms. But without further ado, let us see what can be done by looking at the field of labour recruiting, the first colonial activity which became routinised in the Northern Solomons, long before the Kieta station was established.

\section{Routinised Local Administration: 1906-1914 \\ Labour Recruiting: a Case Study}

The history of labour recruiting illustrates particularly well why a quantitative and structural approach becomes necessary and possible. During the period of German 
colonial rule several thousand persons were recruited as 'labourers' 46 in the Northern Solomons, so that it is plainly impractical to present the history of this activity by telling the stories of all these recruiting episodes. We can only paint a realistic overall picture if we treat this history essentially as a history of numbers: How many persons were recruited? When, where and how were they recruited? Where and as what were they employed? How many of them deserted, died or renewed their contracts? For the history of labour recruiting the individual recruiting episodes lose their historical significance as unique events and become manifestations of 'types' of cases. ${ }^{47}$

The more sophisticated the 'typology' of cases we are able to distinguish, the more illuminating the picture will be. The simplest version would show no more than the total number of persons recruited in the Northern Solomons in any given year. But we may be able to go considerably further by compiling a table which shows, for example, how many men in particular areas - say Hanahan on Buka — were recruited as policemen in 1907 and where and for how long they served. How far we can in practice move along this path depends on what kind of records were kept, on how reliable they are and on which of them are still available. Before facing these issues, however, we should consider the structural aspect of the picture.

The recruitment - and employment — of natives as labourers was one of the most extensively regulated fields in German New Guinea. These regulations constituted recruitment as a type of activity. But they did so normatively, rather than factually. They set out how recruitment was supposed to take place, although, of course, on the assumption that recruitment would regularly take place in accordance with the rules. Secondly, the regulations established the control mechanisms which were meant to assure that recruiters followed the rules and provided for punishments for 'untypical' — and that is to say illegal — behaviour on their part. Seen from the perspective of German colonial rule, the history of labour recruiting in the Northern Solomons was indeed essentially a combination of norms and numbers. 48

The same applies, in principle, to most other colonial activities: the acquisition and the economic development of land, the construction of roads, the collection of taxes and even the history of punitive expeditions. In fact, it applies to the history of all 'routinised' activities: for example the history of traditional warfare in the Northern Solomons. Historiographically speaking the crucial difference is the records relating to such activities which were - or were not produced. It is the production of increasingly systematic records of their activities by modern bureaucratic governments which enables historians to adopt a quantitative and structural approach to their history. It also obliges them to adopt this 
approach, because the production of these records is an essential part of the operation of modern governments. They cannot function effectively without these records, so that a historian who is not prepared to consider them seriously cannot hope to provide a realistic picture of this operation. ${ }^{49}$

The next question is whether the available records are sufficient for a quantitative approach to the history of labour recruiting in the Northern Solomons. As mentioned before the first problem here is that the most important set of records - those kept by the Kieta station - no longer survive. If they did historians would be confronted by a tedious task but one that would promise rich rewards at the end. Since they do not, and since there exists no other set of records which could offer by itself a satisfactory overall picture, historians have to look at a multitude of sources for bits of relevant information which will often be anecdotal, of dubious reliability and may not add up to anything worthwhile.

The beginning of such a journey may still appear to be reassuringly easy. For example Stewart Firth provides in his $1973 \mathrm{PhD}$ thesis on the recruitment and employment of labourers in the German Pacific a convenient table showing the 'Number of Labourers recruited on Indenture in Buka and Bougainville, 1908, 1910-1913' [Firth 1973: 174].50

\begin{tabular}{lrrrrr} 
Year & 1908 & 1910 & 1911 & 1912 & 1913 \\
\hline Buka & 378 & 388 & 566 & 353 & 540 \\
Bougainville & 541 & 492 & 557 & 627 & 772 \\
Total & 919 & 880 & 1,123 & 980 & 1,312 \\
\hline
\end{tabular}

These figures show that the number of recruits grew more slowly from 1908 onwards than one might have expected. ${ }^{51}$ That the proportion of recruits contributed by the Northern Solomons to the total pool declined in relation to other parts of German New Guinea is less surprising. According to an earlier table by Firth [Firth 1973: 163] it shrank from 20 to 12 per cent. It is remarkable, however, that the proportion of Buka recruits - as compared with those from Bougainville — was still almost the same as in 1908, although one would think that the pacification efforts of the Kieta station had opened substantial new recruiting areas on Bougainville.

The recruitment figures in the Gazette of German New Guinea, the Amtsblatt $[\mathrm{AB}]$, are more detailed, although the amount of detail varies and although neither the figures for 1909 nor those for 1911 were published. 52 Thus the 1912 figures — but only they — distinguish between the coast and the inte- 
rior of Bougainville and show — as another surprise - that the interior had supplied more than twice the number of recruits than the coast (423 compared with 204) [ $A B$ 1913: 57]. The figures for 1910 go a step further in a different direction by showing how many of the persons recruited on Bougainville and Buka were, respectively, employed in the Bismarck Archipelago and Kaiser Wilhelmsland: only one of the Bougainville recruits but 26 of those from Buka made it to the New Guinea mainland [AB 1911: 271]. Unfortunately this is again the only year for which this distinction is made. ${ }^{53}$ Even the 1910 figures do not tell us how many of the recruits were employed in the Northern Solomons themselves - or as what they were employed. 54

Judging by the annual report of the Kieta station for 1913/14 [Sack and Clark 1980], the records that provide this information were obviously kept, although not all of them appear to have been very precise. Thus this report informs us that the number of plantation labourers employed in its district had increased from about 700 to approximately 1,070 in the course of 1913. By contrast, it states that of the 865 new recruits processed in 1913 by the station, 815 came from the district [Sack and Clark eds and trans. 1980: 71]. It would therefore appear that only 533 of the 1,348 persons recruited in the Northern Solomons in $1913^{55}$ went to employment outside the district, that 815 of the approximately 1,070 plantation labourers employed within the district were recent local recruits and that less than 300 of the 700 labourers employed on its plantations a year earlier were still serving at that time.

But can we make such calculations with confidence? Can we be sure, for example, that the report means only plantation labourers when it refers to 'plantation labourers' or does it mean the entire native labour force, including policemen, domestic servants and people employed by traders and recruiters? Does the figure of 1,070 cover only plantation labourers recruited in accordance with the labour ordinance or also locally recruited piece and day workers? 56 How many of them were employed in the Northern Solomons in 1913? A dozen or hundreds? Is the 'terminology' used in 1913 the same as that used in previous years and is the same kind of information available for 1913 available for the entire period during which the Kieta station operated - if we search long enough?

Our task becomes harder still when we turn to the 'atypical', illegal cases of recruiting, involving the use of force, intimidation and deception. No statistical information relating specifically to these cases was published. The closest counterpart to the recruitment statistics are the court statistics for non-natives. They include information on the conviction (and acquittal) of non-natives for criminal offences committed during recruiting but they do not identify these cases as a discrete category. Nor do they identify the locations where the offences in 
question were committed. The same applies to the published penal statistics for natives. They too include convictions of natives for recruiting offences but do not identify them as a discrete category. The case files of the station court in Kieta, which would have been primarily responsible for dealing with recruiting offences by natives, are no longer available. Some of the case files of the district court for the Bismarck Archipelago and the Northern Solomons do survive, but it appears that none of the survivors covers the prosecution of a non-native for recruiting offences in the Northern Solomons.

It is likely that the Kieta station kept some kinds of records of complaints made in recruitment matters by recruits or third parties. There may have even been a special file in which all relevant documents were collected. But if so, this file has disappeared.

What can we do under these circumstances? It would seem that a systematic quantitative and structural approach is impractical and that we have to look at alternatives. It may be helpful in this context to consider how others have dealt with the history of labour recruiting in the Northern Solomons. Let us look at the accounts of two very different authors. First Richard Parkinson, who had recruited labourers in this area since the early 1880s. In his magnum opus, Dreissig Jahre in der Südsee (Thirty Years in the South Seas) [1907], he contrasts the state of affairs before the German annexation with that reached at the time of his writing, which was completed in 1906, that is to say about a year after the establishment of the Kieta Station.

Whereas pre-annexation recruiting had frequently been no more than kidnapping, 'outrages' by white recruiters were now rare exceptions. Although Parkinson attributes this change primarily to the supervision of recruiting by the authorities, he identifies another significant reason: In the course of time recruitment had become a well known institution to all natives. They knew what was expected of them, that they would be transported to a foreign place, had to work and would be returned home after a certain time enriched by their wages. Hundreds of their fellow countrymen already had this experience, had returned and talked about it. The natives were even well informed about the reputation of the various places of work for which they were recruited. If the reputation was good, he would have no difficulty filling his ship with recruits, if it was bad, a recruiter would have a hard time. In particular, if only a few people had returned from a certain place and the few who did had reported the death of many of their fellow countrymen, it was impossible to sign up new recruits for this place [Parkinson 1907: 474-7]. 57

By contrast, some 60 years later, the historian Stewart Firth makes the following point: 
By the nature of the recruiting business the use of force and intimidation, though not as widespread as in the days of wholesale kidnapping, was inevitable [Firth 1973: 179].

Firth does not explain why he believed that 'the nature of the recruiting business' made the use of force and intimidation inevitable. It is clear, however, that he was primarily interested in new recruiting areas whereas Parkinson described the position in Buka and coastal north-eastern Bougainville, his own stamping ground, where recruitment had by 1906 long become a familiar institution. ${ }^{58}$ Moreover, conditions changed significantly after 1906 as a result of the accelerating economic development of the colony. Although it was obviously in Parkinson's personal interest to paint a picture which was as rosy as possible, his assessment of the position in 1906 in the Northern Solomons is probably reasonably accurate. Can the same be said about Firth's assessment, if it is seen as description of the state of affairs which prevailed during the last years of German colonial rule throughout the colony when the established recruiting areas were no longer able to satisfy the growing demand for labourers, when the plantation sector was no longer dominated by a few large, established firms which did their own recruiting and a different group of recruiters emerged; free-lance operators, who were eager to venture into new areas to obtain recruits for smaller enterprises on whom Firth focused his interest.

Besides recruiters employed by the large companies there was a class of professional self-employed recruiters who received cash for each recruit delivered to an employer. In 1905 the government was said to pay $£ 4$ (80 marks) and other employers $\mathfrak{E 5}$ (100 marks) per head. When the professional recruiters first entered Kaiser Wilhelmsland in about 1908, a government official complained that they produced only 'the most enraged confusion' among New Guineans, presumably because they employed more violent methods than New Guinea Company recruiters with a permanent interest in the villagers' willingness to enlist. The recruiter who knocked out a chieftain's front teeth in anger at getting no men was no exception, as shown by the ruthless recruiting of the Forsayth company and the D.H.P.G. (Deutsche Handels und Plantagen Gesellschaft: German Trade and Plantation Company) in the last few years of German rule, when convictions for recruiting crimes increased. Nor was it anything but normal for armed black recruiters to be sent unaccompanied into inland villagers while the whites waited in the boat or on the beach. As a New Guinean revealingly testified to the Kavieng district officer in a recruiting case, the 'other boys carried weapons as usual'. There were even cases of New Guinean recruiters being sent into the bush for months at a time [Firth 1973: 179]. 
Is this picture in fact representative? How many recruiters assaulted chiefs because they got no men? Were the recruiting practices of the Forsayth firm and the $D H P G^{59}$ generally 'ruthless' during the last few years of German colonial rule or did the ruthlessness manifest itself in a few instances in particular areas? By how much did the number of convictions for recruiting crimes increase between, say, 1906 and 1913? Did New Guinean recruiters routinely threaten the local people with their guns? More broadly: How many of the over 10,000 persons recruited in 1913 in German New Guinea were recruited by using force, deception or intimidation? Fifty, 500 or 5,000? And, more specifically: Did the use of force and intimidation again become widespread in the Northern Solomons or did the orderly conditions described by Parkinson persist?

As far as I can see none of the 'minimalist' illustrations used by Firth are set in the Northern Solomons. Indeed, it appears that not a single case of recruiting 'outrages' during the last years of German rule in this area is featured in the 'labour matters' files of the colonial office, Firth's main sources of information. ${ }^{60}$ This does not mean, of course, that all recruits in the Northern Solomons were obtained in accordance with the regulations, but I think we can say with confidence that the assessment of Firth is at least not representative for this part of German New Guinea. ${ }^{61}$ On the other hand, I should present the two 'cases' in my collection in which concerns about recruiting practices in the Northern Solomons after 1906 were raised.

On 7 December 1912 the Hamburger Echo, a metropolitan newspaper, discussed in detail an article by an unnamed author published in another German newspaper. ${ }^{62}$ The author of that article had reported that during his stay on Bougainville the government station in Kieta had supplied a professional recruiter with armed native policemen to capture 20 recruits, mostly Nasioi, who had run away from him before officially signing up at the station. But the author went further, claiming generally that professional recruiters were little better than slave traders who sold their recruits 'against their will for 100 to 150 marks per head' to planters and implying that the authorities did nothing to stop this unacceptable practice. As usual if we look closely at such accounts the position becomes more equivocal - and the author provides enough detail about the particular case to do some probing.

The recruiter in question had been the trader H. from New Britain, a notorious drunkard who had used his connections to win over the 20 recruits with promises and, perhaps, small presents. The recruits had run away when the people at the beach had told them what sort of a person $\mathrm{H}$. was. $\mathrm{H}$. had approached the station because he did not want to lose at least 100 marks per head he was expecting. But even with the assistance of the native policemen $\mathrm{H}$. did not succeed in capturing his recruits. 
This anticlimax did not stop the author of the article from using this case as a hook on which to hang his entire argument, in the course of which he misrepresented the legal position of the authorities as well as recruiters.

Firstly, an administrative appeals decision by Governor Hahl confirmed that the authorities could force a recruit, once he had signed on with a recruiter, or had accepted a payment from him, to appear before them in order to examine the validity of the contract [National Archives of Australia 53/83, Item B201]. Secondly, recruiters did not sign on recruits on their own behalf but for a particular employer who had to be named in the employment contract, which indeed required the approval of the authorities (see section 9 of the 1909 Recruitment Ordinance [AB 1909: 38-41]). In other words, it is unlikely that the authorities acted illegally by providing $\mathrm{H}$. with police assistance - unless the 20 recruits had been persuaded by mere promises to follow $\mathrm{H}$. to the coast, which is improbable. Similarly, the author is wrong in maintaining that recruiters could sell their recruits 'against their will' to the highest bidder.

Again, this does not mean that the behaviour of $\mathrm{H}$. or other professional recruiters in the Northern Solomons during the last years of German colonial rule was always above board, but as it stands, this case contributes little to our understanding of recruiting practices and the author's interpretation merely confuses the issues.

Do we do better with a letter written by Pater Flaus in Buka on 4 August 1913, published in the mission journal Kreuz und Charitas [1913/14: 190-1]? According to Flaus the labour shortage had become so desperate that even young boys were recruited, including students whose parents had signed a 'school contract' in which they agreed to send their child — against a payment - to a mission school. Each steamer brought more whites who tried to obtain recruits for their new plantations. If boys not older than 11 or 12 left the mission school for a few days it was almost certain that he would fall prey to one of these recruiters.

What did the authorities do? The mission had to wait a year or two for an official response to its complaints about these 'abductions'. When it finally arrived it would usually state that the boy had turned 14 in the meantime so that an approval of his recruitment by his parents was no longer required. If the boy was still not old enough, to keep up appearances, the parents would now be asked if they retrospectively approved the recruitment or if they demanded that the boy be returned to the mission school. Their answer would usually favour the recruiter who could give them enough presents. Besides, by then, the relatives expected the boy to return soon with a chest full of trade goods. ${ }^{63}$

The purpose of this tale of woe was to call upon Catholics in Germany to give generous financial support to the mission, to enable it to compete financially 
with the recruiters. Whereas three years before, Flaus had received 3,000 marks to maintain his school, in 1913-14, the mission had been forced to cut the support to 800 marks, a mere 13 marks per student.

It is easy to share the frustration of Pater Flaus, but is the information he provided to support his call for donations convincing? To start with, it would appear that his students were not 'abducted' but went willingly. Nor is it clear that their parents were not aware of their signing up. This does not mean that the recruitment of boys as young as 11 or 12 was not nonetheless objectionable, but was it illegal and how often did it happen? How many of Flaus' young students were recruited? How often did the mission complain and how often did the authorities respond in the manner described? Could boys normally only be recruited after they had turned 14 , but was it legal to recruit younger boys with their parents' consent? Although section 12 of the 1909 Recruitment Ordinance [AB 1909: 38-41] permitted the recruitment of all healthy persons whose bodies were 'sufficiently developed' and said nothing about the need for parental consent, it is difficult to believe that Flaus made up the whole 'story'. But even if we accept that his account reflects a practice adopted by the authorities, it is just as difficult to believe that Flaus would have been able to identify a significant number of cases in which the authorities responded one or two years after the mission had complained about the 'abduction' of one of its students in the manner described - although it is again quite possible that at least one case falling into each of the two categories had actually occurred. Furthermore, Flaus only addressed what may have been a small part of a much larger problem: How many 'under-age' boys were recruited in the Northern Solomons who did not belong to the presumably small minority who attended mission schools?

It is plain that the increasing labour shortage would have encouraged recruiters to sign up boys who were physically not fully developed but still capable of performing lighter duties. What was the response of the authorities to this trend? Here we have to remind ourselves that it was unlikely at the time that the precise age of a recruit could be established, so that the authorities had no choice but to rely on the vague criterion of physical maturity used in the Recruitment Ordinance. 64

To ascertain the response of the authorities to this likely trend we would therefore have to investigate whether or not they refused to approve the employment contracts of an increasing number of recruits on the basis that they had not reached the sufficient stage of maturity required by the Recruitment Ordinance. This brings us back to the crucial point. A critical examination of the letter of Pater Flaus demonstrates once again that the history of labour recruiting in the Northern Solomons is essentially a matter of norms and numbers and that the 
uncritical presentation of dubious, anecdotal information merely confuses the picture.

This raises an even broader question: what is the task of historians and, more specifically, academic historiographers? Is it their task to improve their audience's intellectual understanding of the slice of history they are dealing with? Is it their task to entertain their audience or to empower it politically and ideologically, especially if they are dealing with colonial history and see the current indigenous population of the former colony in question as their most important audience? Do historians primarily serve their audience or do they have overriding, professional obligations?

For historians of German colonial rule in the Northern Solomons who believe that it is their task to 'empower' the people of this province, the issues I have raised are immaterial because the factuality of their accounts no longer seems to matter. But do historians do the people of the Northern Solomons a favour by offering them an account of their past based on an uncritical selection of information which looks appropriate because it highlights the dark sides of colonialism or because it shows their ancestors not as helpless victims but as quite capable of manipulating the colonial forces to their own advantage? To be sure, the people of the Northern Solomons are entitled to construct their own versions of their history. Indeed reclaiming their past, instead of relying on what outsiders tell them about it, may well be an important part of the decolonisation process, but I doubt that it will assist this process in the long run if this reclamation consists of collecting information people like to hear and discarding information which is ideologically counterproductive or narratively unrewarding. Facing the facts is just as crucial if we are looking at the past as if we are looking at the present or towards the future.

As the history of labour recruiting in the Northern Solomons shows, establishing the 'facts' which have shaped the past is not an easy task. It requires a great deal of time - as well as money — and the results may still be disappointing. It is plain that this task cannot be carried out for this paper. But what I can offer is a highly superficial and therefore reasonably safe overview of the economic development of the Northern Solomons - the centrepiece German colonial rule.

\section{Economic Development: An Overview.}

The economic development of the Northern Solomons made a slow start. When a government station was established in 1905, Buka and Bougainville were still treated as a labour reservoir. Leaving aside the small islands to the east - which were worked by Queen Emma and her clan and presumably gradually planted up with coconuts along commercial lines - the only substantial plantation was that 
of the Marist Mission. There was apparently not a single permanent trading post manned by a non-native on the large islands. The Kieta station concentrated on pacifying the east coast of Bougainville, opening the way to the interior for recruiting and trade. Military force was frequently used during this initial phase to break down resistance. As soon as possible, a regime of compulsory labour for the Administration was introduced and primarily used for the construction of roads, which were wide enough for the transportation of produce. However, it took until 1908 before the first fully commercial plantation was established by the Bismarck Archipel Gesellschaft at Aropa. ${ }^{65}$ The New Britain Corporation followed two years later with its Toiemonapu plantation - but then economic development took off. By 1911, ten commercial enterprises were operating in the Northern Solomons and during the next three years a rush of mainly British-Australian capital followed.

In April 1913, land acquisitions made or approved to be made by British-Australian interests amounted to over 10,000 hectares. The biggest fish was Choiseul Plantations Ltd with Burns, Philp \& Co Ltd a major shareholder. It had already acquired 1,000 hectares on the west coast of Bougainville, and permission to acquire another 4,000 hectares had been granted. In addition the company was negotiating with the German firm which had taken over Queen Emma's empire about the private sale of part of its undeveloped land holdings on Bougainville - some 4,500 hectares. In early 1914 an even bigger fish appeared in the pond. The chairman of Lever Brothers had approached Governor Hahl to discuss the acquisition of large areas of plantation land — as much as possible for speedy development. After initial misgivings, Hahl welcomed this massive investment of foreign capital mainly because of the threatening labour shortage in German New Guinea. With Lever Brothers and other powerful parties as his allies he hoped to gain easier access to the international labour market, in particular India, should the need arise.

But German interests also made themselves felt. In 1913 the Hernsheim firm maintained five trading branches staffed by Europeans in the Northern Solomons: in Kieta, Buin, Petatz, Arawa and Enus. The firm employed 11 native sub-traders and its former employee Gustav Sturm had established himself on Buka and employed eight sub-traders. The Forsayth firm was still concentrating on the small islands, but Carl Dierke - a former employee and the son-in-law of Richard Parkinson - had started a plantation in north-eastern Bougainville and employed two Chinese and four natives as traders. Phoebe Calder, another member of Queen Emma's clan, who owned the Mortlock Islands, had obtained permission to acquire 100 hectares near Kieta where her daughter had settled as the wife of the government doctor, Bruno Kröning. Captain William Hamilton, 
who had been involved in pearl-fishing in the Admiralty Islands more than a decade earlier, and was now based in the British Solomons, was among the other four individuals who had been given permission to acquire plantation land on Bougainville and Buka.

The accelerated economic development affected a number of areas, not always positively. Because its consequences preoccupied the station, the construction of roads made little progress in 1913 and the building of the native hospital in Kieta was delayed by several months. Only the wharf in Kieta was extended and could now comfortably berth the North German Lloyd steamer Sumatra which connected the Northern Solomons with Rabaul at three-monthly intervals. However, shipping was now mainly oriented southward to Faisi, in the British Solomons, the closest harbour, to which Burns Philp maintained a six-weekly service. From there most European enterprises trans-shipped their goods on their own small vessels - with the result that the customs office in Kieta had to deal with almost 150 smaller vessels in 1913 - a great deal more than any other harbour in German New Guinea. During that year imports from Australia rose by about 150 per cent and receipts from customs duties by 50 per cent. ${ }^{66}$

Apart from the still troublesome Buin area in the south-west and the remote interior, Bougainville had been largely pacified. The same applied to Buka and the smaller islands. By 1913 about 220 kilometres of roads had been built, running around Buka and on from the northern tip of Bougainville along its east coast with a gap south of Numa Numa - past Kieta to Toiemonapu. The head tax had already replaced corvée (unpaid) labour in the small islands, on Buka and along the east and north coast of Bougainville. Most communities were taxed at the base rate of five marks for each tax payer but about 20 wealthier communities already had to pay 10 marks at the end of German colonial rule. The revenue from the head tax had risen from less than 4,000 marks in 1908 to almost 28,000 marks in 1913, close to half of the total revenue collected in Kieta. On the other hand we do well to remember that this means that the head tax was still collected from only about 4,000 individuals.

Numbers generally were still quite small. Thus, the total non-native population in the Northern Solomons on 1 January 1914 consisted of just 74 persons, of whom one third were members of the Marist Mission. The total increase during the last year had been less than 10 per cent but the number of British and British colonial individuals had more than doubled to 17 persons. Even greater had been the influx of 20 'foreign natives' as the big companies had posted Chinese and Malay traders all over the district.

In 1913 alone, over 5,000 hectares of land for plantations had been acquired but only an additional 500 hectares had been planted up. Still, the number of 
native plantation labourers employed in the district had increased from about 700 to over 1,000 . Most of the new recruits had been obtained locally (815 out of 865). Since the Northern Solomons had yielded a total of 1,348 recruits in 1913 it would appear that now less than 40 per cent of them were exported to other parts of German New Guinea.

Although the export of produce from the Northern Solomons remained comparatively insignificant since most of the plantations still had to become productive, there is no question that the economic development of the district would have been rapid - if the evolution had continued undisturbed. This is reflected in the last development plan for German New Guinea which envisaged an elevation of the government station to the level of a separate district office, with a corresponding increase in staff.

How this hypothetical future would have taken shape is, of course, impossible to say. It is, for example, unlikely that German New Guinea and, in particular, the Northern Solomons would have become a second Fiji, flooded by thousands of Indian plantation labourers even if World War I had not taken place. Yet it is probably safe to say, that the advent of an Australian administration did not speed up development, economically and in other fields, but rather slowed it down and that it did so far beyond the period of military occupation. 


\section{Endnotes}

1. The line started at the eastern end of the border on the main island of New Guinea agreed upon between Britain and Germany in 1885.

2. This referred primarily to 'Queen Emma' (Emma Forsayth) who claimed to have acquired 100,000 hectares in the Northern Solomons, mostly before the annexation. Subsequent negotiations by the colonial authorities reduced these claims dramatically.

3. Despite its close links with the Shortlands, Mono was excluded from the German sphere because the British Navy had established a coaling depot on the island — which was, however, abandoned not long afterwards.

4. Schutzgebiet (protected area) was a new term coined to indicate that what was being created was neither a Kolonie (colony) nor a Protektorat (protectorate). Although the establishment of a Schutzgebiet did involve the assumption of full sovereignty over the territory in question, the commander of SMS Adler was instructed that no treaties of cession with 'the natives' were required. The term Schutzgebiet reflected Bismarck's plan to have these 'colonial' territories administered by private, commercial companies at their expense under imperial charters of protection. However, the designation Schutzgebiet was retained when these territories came under direct imperial administration and thus became ordinary colonies in all but name.

5. For a detailed discussion of this framework see Sack 2001.

6. The legal definition of 'native' included not only the indigenous population - 'natives' as opposed to 'foreigners' - but also 'members of other coloured tribes' (in particular Malays and Chinese). Similarly, the category of 'non-natives' included the subjects of all (civilised, white) states, without singling out German nationals for preferential treatment.

7. It was out of the question, for example, to place the indigenous population under the metropolitan German family law.

8. Twenty years later the station courts were given the positive discretion to punish any behaviour they regarded as deserving punishment — a fundamental departure from the metropolitan nulla poena sine lege principle, according to which actions could only be punished after they had been declared to be punishable by law.

9. Whereas the Native Penal Ordinance permitted no corporal punishments the Disciplinary Ordinance did.

10. After 1899 it became legally possible to licence private employers to carry out such punishments as agents of the government.

11. The most ambitious foray was an attempt to regulate the marriage law of the Tolai. It was spectacularly unsuccessful and the relevant ordinance was soon ignored.

12. It was assumed that the transfer of land to settlers would become the company's primary source of revenue.

13. It also applied to native land which remained the property of natives only in exceptional cases.

14. Once owned by non-natives land could be freely bought and sold.

15. It took until the end of German colonial rule before the colonial office acknowledged that it was legally inadmissible to use police regulations for fiscal purposes.

16. All these monopolies clashed with legal 'freedoms' enjoyed by German citizens at home: the freedom to engage in commercial activities, the freedom to mine and the freedom to appropriate ownerless objects.

17. By then 'deserters' had been punished administratively and even judicially for years. The latter had become legally admissable when an amendment of the Native Penal Ordinance authorised the station courts to punish natives for any kind of behaviour they considered as deserving punishment (see endnote 8). 
18. In addition non-native recruiters and employers were subject to the general criminal law and thus could be punished for assault and other offences.

19. Thus not only 'coloured' labourers imported from abroad but all non-native settlers (including German nationals) — who were, of course, all imports — could be deported.

20. The ordinance provided for strict procedures, including a right of appeal, in the metropolitan mould.

21. Another such instrument was the temporary administrative banishment of troublesome natives from their home areas.

22. A general manager was appointed by the company who was responsible for its commercial activities.

23. The company's station managers retained some administrative functions, especially in labour matters.

24. The relevant legislation gave the imperial judges and the chairmen of the station courts unusual executive powers by making them responsible for the investigation of crimes as well as for the execution of judgements.

25. At the end of German colonial rule a hierarchy of local administrations had developed as a matter of administrative practice, in which the most junior were no longer placed directly under the governor but under a district commissioner.

26. The administration of justice in relation to non-natives remained the responsibility of the district court for the Bismarck Archipelago, although the usual transfer of authority to the district officer occurred.

27. The last group of outlying islands were only added in 1913 to its administrative district.

28. See Sack [2004]

29. One of the killers had subsequently signed up as a labourer and was arrested, tried and executed in Herbertshöhe.

30. All translations from the German sources are the author's, unless otherwise indicated.

31. According to Schnee's table only two whites had been killed on Bougainville before 1898: Captain Ferguson in 1879 and the Hernsheim trader Louis Numa in 1895. The outlying islands worked by the Forsayth firm were a different matter: two killings occurred on Nuguria in 1890 and 1892 (in addition to two in the 1880s) and two traders based in Nissan were killed, one in 1889 and one in 1893, the former together with his wife and child [Schnee 1904: 79-85].

32. According to the 1899-1900 report, apart from the two stations maintained by Tindal, the McDonalds and Atkinson in the Shortlands, only the Forsayth firm operated trading stations in the outlying islands.

33. Although Bennigsen did not visit Kilinailau — also the registered property of Queen Emma - it was obvious that her much larger, unregistered claims to land on Buka and, in particular, Bougainville, needed to be sorted out. An agreement was reached which reduced her claims from 100,000 to an approved 10,000 hectares.

34. Bennigsen also visited Buka to obtain new recruits for his overstretched police force with limited success, since only about 10 'good boys' signed up.

35. Throughout the period of German colonial rule no other mission society became active in the Northern Solomons; the Marists had operated there for over five years before a government station was established and the first 'secular' commercial plantation started operating as late as 1908 .

36. Hahl also went to Tulagi to obtain permission to visit the mission's headquarters in the Shortlands without having to call on the British resident commissioner first. 
37. For the same reason the Tsiworoi people, inland of Toboroi, refused to guide Hahl further into the mountains.

38. Still, there had been tense moments; an ex-policeman returning to Matsungan with his wife and a large store of goods had to be protected from the 'rapacity and bloodthirstiness' of his own people and, labourers returning to Torotzian Island, who were reluctant to disembark because 200 armed warriors had gathered at the beach, had to be ordered to leave the boats immediately or to return with them to the Seestern. But both episodes ended well: the goods taken from the ex-policemen were returned and after they had been recognised the labourers were greeted with great enthusiasm.

39. It is indicative of the stage developments had reached that a chief, Haon of Gagald, returned to Buka on the Seestern from a private visit to Gagald labourers in the Gazelle Peninsula.

40. It would appear that Hahl had been told by the colonial office that for financial reasons two government stations in the Northern Solomons were out of the question.

41. Rubber was seen as the most powerful weapon in the administration's diversification battle, since German New Guinea still relied predominantly on the export of copra.

42. Kaiser Wilhelmsland was a different matter: in 1907 the government had little hope of agricultural development taking off. A few years earlier it had looked as if even Northern New Ireland would be unable to attract commercial plantation enterprises, although it produced a substantial part of the trade copra exported from German New Guinea which, in 1907, still outstripped plantation copra.

43. Editors' Note: Accompanying them was also Professor George Dorsey [Dorsey 1909: 526-43] from the Chicago Field Museum who described the coast to coast crossing, although his part in it appears not to have been cited in German official records of the expedition.

44. It would appear that they did not survive the military occupation during World War I.

45. Government action was, of course, also shaped by a number of other factors; for example, economic and ideological ones.

46. As already pointed out all persons recruited under the recruitment regulations were technically 'labourers', irrespective of whether they served as plantation labourers, boat crews, native policemen and so on.

47. Seen as parts of other histories — such as the life history of a particular recruit — these recruiting episodes may well retain their significance as unique events.

48. In order to fully appreciate the normative aspect of the picture we would need detailed information about the changing relevant regulations - which goes far beyond the scope of this paper.

49. It is equally important to understand that traditional forms of socio-political organisation can no longer function effectively in accordance with their own structural logic if their operation is systematically recorded.

50. The fact that the figures for 1909 are not included already indicates that even at this most general level the task is not straightforward. I should also point out that the table does not show — and does not purport to show — the total number of labourers recruited in the Northern Solomons. Firstly, it only includes 'indentured' labourers — which presumably means labourers recruited in accordance with the relevant recruitment ordinance. Locally recruited labourers who were not transported across the sea, in particular piece and day workers, are apparently not included. Apparently also not included are labourers recruited on the outlying islands (Nissan etc.) which were administratively incorporated into the Kieta district between 1908 and 1913 .

51. According to Thurnwald [1910b: 618] it had been 565 in 1905. 
52. The publication of the Amtsblatt started in 1909.

53. By contrast all three sets of published figures show how many of the recruits died or deserted in the course of the year of recruitment. Let me just say that the death rates differed significantly: from 5.7 per cent among the recruits from the Bougainville interior in 1912 to less than 1 per cent among the Buka recruits in 1910. It appears that dysentery epidemics were a major factor and that some of them had started in the Northern Solomons and were spread by recruits from this area to other parts of German New Guinea.

54. Were the 26 Buka, for example, sent to Kaiser Wilhelmsland to serve as policemen?

55. This figure includes 36 persons recruited in the outlying islands.

56. I did not examine if and when such labourers were included in the labour statistics.

57. This is my summary of Parkinson's account which is now readily available in an English translation.

58. Parkinson, too, came close to seeing 'illegal' recruiting practices in new recruiting areas in his case the Northern Solomons in the 1870s and early 1880s — as inevitable, because the recruiters could not communicate with the local people, because the latter did not know what was expected of them and because they had often experienced or heard about previous acts of kidnapping [Parkinson 1907: 474].

59. The DHPG - the German Trading and Plantation Company — had a privilege to recruit labourers for its plantations in Samoa.

60. These files do not give an overall picture of recruiting in German New Guinea but focus on problems which were brought to the attention of the colonial office and required action by it.

61. I am not maintaining that no serious recruiting 'outrages' occurred during the last years of German colonial rule. The question which concerns me is whether such cases were 'typical' or whether they were exceptions - and how the authorities responded to them. Their response to one of the cases referred to by Firth was that Governor Hahl closed the area between Cape Gloucester and Montagu Harbour in south New Britain for any further recruiting 'across the sea' on 5 September 1912 [ $A B$ 1912: 189].

This measure is certainly open to different interpretations. One could argue that the 'outrages' to which Hahl was responding were merely the tip of an iceberg and that it was only the attention they were attracting in Germany that finally forced the governor to act by such a public gesture. But is such an argument convincing in the absence of solid quantitative evidence? Or are we indeed confronted by rare exceptions to which the authorities reacted promptly and vigorously? Is the fact that Hahl opened the Kilenge area again for recruiting a year later [see $A B$ 1913: 218] proof that he was engaged in a cynical exercise? Or did he genuinely believe that the situation had sufficiently settled down for orderly recruiting to resume?

62. My guess is that the author, who had carried out a 'study trip' to the Pacific, was the anthropologist Friedrich Burger.

63. Earlier Flaus dismissed the trade goods with which a labourer returned as a 'few trifles'.

64. Did Pater Flaus know the birth date of any of his ' 11 or 12 year old' students in 1913 ?

65. It was to give rubber a prominent place in its planting program.

66. Kieta had acquired a customs agency in 1910 and a quarantine facility for the direct import of livestock from Australia in 1914. 


\title{
THE PACIFICATION OF SOUTHERN BOUGAINVILLE, 1900-30
}

\author{
by Hugh Laracy
}

n few parts of Papua New Guinea has involvement with the larger world been
much harsher or more forcibly and persistently experienced than on the island
of Bougainville, in what became the (now) Bougainville Province of that country. There, where the fact of separation has long sustained a smouldering sentiment of separatism, the desire for secession flared into open warfare from 1988 to 2000 [Laracy 1991; Regan 1998]. This latter conflict, in which the national government was the immediate enemy, is but the most explicit and recent expression of what for Bougainville has been an often painful engagement with external forces at various times during the 20th century.

Precedents for much of the horror and discomfort of the war of secession were also visited upon the people of Bougainville (including neighbouring Buka) during World War II. The Japanese occupation began there in March 1942 and, despite some efforts to ingratiate the islanders, the newcomers quickly displayed a marked capacity for ruthlessness [Laracy 1976: 110-17; O’Reilly and Sédès 1949: 163-208; Worsley 1968: 124-32; Nelson, this volume]. The hegemony of their regime was dented by the American landing at Torokina in November 1943, and was further eroded by the grand-standing intensification of the conflict by the Australian forces after they replaced the Americans in December 1944 [Charlton 1983; Medcalf 1986; Nelson, this volume]. But the Japanese still occupied much of the island when hostilities ended in August 1945. Even then, life remained notably difficult for the local people during the next five years.

Prior to these dramatic and destructive events the people of Bougainville, though, were abundantly familiar with the violence that accompanied the advance of an imperial power seeking to exercise political control over them. Nowhere was this more so than on the extensive plain that stretches across the southern part of the island. Fortunately for historical enquiry, the events of the so-called process of 
pacification that this entailed, whereby public disorder was suppressed so that the government's writ was allowed to run unimpeded, were observed and reported on in considerable detail by missionaries who were long resident in the area and were familiar with the people and places concerned.

\section{BUIN}

\section{Mission Beginnings, 1901-1919}

From their base among the Alu people of the Shortland Islands, Catholic missionaries of the Marist congregation (a mixture of French and German personnnel) became the first permanent European residents of Bougainville when they settled at Kieta in 1901. Theirs was a precarious situation. In July 1902 some young men from Koromira were clearing ground at the mission site, Tubiana, when they were attacked and two of them were killed. The assailants were local bush people, dissatisfied with the pay that they had received after working for three years on the mission property at Poporang in the Shortlands. Another explanation recorded later, but not incompatible with this one, is that a man had died in Bava village and that the mission labourers were deemed to have poisoned him. In any case, in March 1903 a German naval vessel, the Cormoran, arrived at Kieta to investigate the affair. The master, Captain Grapow, proposed a punitive expedition, but was persuaded otherwise by the missionaries. It was a portentous intervention. The Marists thereby hammered the first rivet into what would become an enduring and pervasively influential bond between the Catholic Church and Bougainvilleans. Certainly, the significance of this peace-making action, which was arranged by Father Pierre Meyer, was not lost on the people of Numa Numa, 40 miles north of Kieta, whose reputation for ferocity gave them much reason to fear a man-of-war. Visiting there a month later, Meyer recruited 11 'boys' (as workers) and, in June, he obtained land, on condition that he intercede for Numa Numa also should occasion rise [Laracy 1976: 75-6; 2002].

Four years later, building on the close trading and kinship links between the Alu and the Telei-speakers across the Bougainville Strait, the Marists established a station at Patupatuai on the Buin coast under the protection of a mumira, or chief, named Kopana, who had formerly worked in Queensland. The coast was thinly populated. But the interior, where the people were concentrated, was too unsettled for the missionaries to live there permanently at first. So, for a decade they restricted themselves to patrolling, visiting the inland villages on foot and recruiting children for the school on the coast; biding their time before advancing further. As early as December 1905 Fancois Allotte visited Kikimogu, six hours 
distant. There he made friendly contact with the mumira Tsiperao, and even recruited three boys, but was not seduced into surrendering caution [Allotte 1918]. In 1912 the Marists bought land at Turiboiru, an hour's walk inland, at a site conveniently situated near the big village of Moro with its satellites of Mamaromino and Kukumanu, in west Buin or Rerebere. In May 1914 another inland property was acquired at Muguai in east Buin or Borobere. Still, these were only tentative moves. On 11 October 1914 Father J. B. Poncelet said Mass for the first time at Muguai, and for the next few years he visited there every fortnight to say a Sunday Mass and to stay for three or four days at a time. These efforts slowly brought results. In 1915 parents presented babies for baptism for the first time. On 17 September 1916 women came to Mass for the first time. There were 150 of them, together with 200 men, and the mumira Posena, who was also the government-appointed headman or kukerai, pledged their lasting attachment to the Catholic mission. It was also at Muguai, two years later, that girls were freely given to the mission for schooling. Hitherto, the missionaries had had to buy them from their families [Allotte 1924].

Following the breakthrough at Muguai, the mission turned its attention to Moro. In 1916 it built a chapel and a house there, and a missionary, Father Joseph Grisward, was appointed to make fortnightly visits from Patupatuai. From both places Catholic influence radiated further among the Telei. By 1917 chapels had been built at Maisura, Atempiro, Tautureke, and Aku; and baptism numbers were rising sharply. Ranging from two to 59 a year between 1905 and 1915, they were 150 in 1917, 170 in 1918 and 182 in 1919 [Allotte 1924].

Meanwhile, an invader of another kind - the enforcer of colonial rule was also becoming interested in Buin. Following Francis West's observation, this was for a simple and widely applicable reason. '[Since] the possibility of European enterprise ... always depended upon the suppression of raiding, murder and violence ... The establishment of law and order [was] the most fundamental action of colonial rule' [West 1966: 18].

\section{The Moro - Bagui Feud, Phase One, 1911-1915}

In 1899, following an attack the year before on the cutter Sea Ghost, SMS ${ }^{1}$ Möve brought a police party from Rabaul to raid the villages of Tinputz and Datoel in north-east Bougainville; and in 1904, another one marched into Buka to quell fighting there between bush and coast people in order to ensure unhindered progress in labour recruiting [Sack and Clark eds and trans, 1979: 251, 171-2; Sack 2001: 71; Thomson 1904: 202-3; Flaus 1899a, 1899b]. In 1905 Governor Hahl sent another patrol to the south coast of Bougainville, to avenge the killing of an Australian labour recruiter named 'Peanuts' McConville by Tomu the chief 
of Kaukauai village [Allotte 1918; Bennett 2000: 71; Sack and Clark eds and trans, 1979: 256]. With the setting up of a government post at Kieta in September 1905 - again 'to establish public peace and to persuade the people to engage in trade and to enter into employment' - the strike rate increased markedly [Hahl 1980: 110; Firth 1982: 86]. In 1906 there were seven punitive expeditions against the Nasioi; in 1907 there was one into Buin, at the behest of the Marists, to suppress fighting at Moro; in 1908, after several interventions in the Crown Prince Range, the district officer led a patrol of 20 soldiers across the island; and in 1909 there was an expedition into the hills behind Numa Numa [Sack and Clark eds and trans. 1979: 275, 291, 294, 307 ; Hahl 1980: 123-4].

But it was the labour-rich southern plain that was regarded as the most significantly disturbed area. Austrian anthropologist Richard Thurnwald, who spent some time there in 1908-09, reported on an inland cycle of feuding and killings. The local people, he noted, sang of sacrifices to the spirits, of the mysteries of nature, of feasts and feuds [Thurnwald, R., 1936b: 14-15]. In 1912 the German administration announced its intention to pacify that area and to make it safe for labour recruiters, so as to ensure the prosperity and progress of the numerous plantations then beginning to be established along the north-east coast of the island. (The first one was started in 1908). Most of these were Australian enterprises. They were attracted to Bougainville by the looser labour regulations that prevailed there, in contrast to those of the British Solomons, and by the continuing possibility of more easily obtaining freehold land. The British regime had curbed the permanent alienation of land in fee simple by private sale in 1912 [Bennett 1987: 135-48; Hookey 1969: 236-7; Woodford 1913]. Such was the influx of 'English planters' that in January 1914 there was even a call for a British consul to be appointed to Bougainville [Thomas 1914; Woodford 1914].

The events that prompted the presumed need for pacification of the southern plain, though, arose independently of these developments and were of an intimately local nature. They involved a feud between the neighbouring villages of Moro and Bagui. The latter, which is to be distinguished from the village of the same name in Oria, near Muguai, is adjacent to what has become Buin Town, across the Silibai River from Buin High School [Regan 2002a].

Once set in motion, the pendulum of reciprocal reprisal swung busily. Father Joseph Grisward has left a detailed account of its movements [Grisward 1923]. Unfortunately, the information available does not allow one to set these events fully in context. Some matters that might contribute to a fuller understanding of them remain obscure. What were the ramified kin and lineage connections between the people involved? What were their traditional 'political' linkages? Is 'adultery' a code for associated conflicts and points of dispute? What was the incidence of such 
feuding throughout the Buin area? Such questions cannot be answered satisfactorily. Still, a distinctive and visually elevating factual autonomy does attach to the Moro-Bagui conflict. Whatever else might have happened or have been happening in the district, the series of known episodes central to the present discussion was clear to observers. And it was identified as a discrete phenomenon, as attested by an extensive documentary record. Thanks particularly, but not exclusively, to Grisward it is also endowed with a 'biographic element', the lack of which, as KlausFriederich Koch persuasively maintains, tends to weaken generalised accounts of Melanesian violence [Koch 1983: 201]. The feud was also demonstrably critical in attracting official efforts at repression. Finally (and possibly conclusively?), Grisward's account has been endorsed by the latter-day Bougainville leader John Momis, whose tumbuna (forebears) feature prominently in it. Anthony Regan has recorded comments of Momis on the matter.

Kunkei was the father of Babala, who gave the orders for the police to be killed. Kunkei was gaoled for the first killings. He was killed by his brother-inlaw on his way back from gaol. Babala was about 35 when he was executed. He was a person held in high regard, almost awe, by the people of not just Buin, but also of Siwai. He is still remembered in both areas. Indeed, Noah Musungku of Siwai, who ran a pyramid fast money scheme in Bougainville and Moresby beginning five years ago, claims to be a modern spokesperson of the kingdom of Babala. Momis is regarded by many in Buin to have inherited some of the spirit of Babala. Some old men who knew Babala told Momis in the '70s that they could see Babala in Momis' car, travelling with him. This was particularly at the time of the 1975 secession. The basic point is that people were proud of Babala's resistance to the impositions of outsiders ... and saw Momis as continuing that resistance [Regan 2002a].

Whatever the putative shortcomings of a narrow focus, Grisward at least furnishes a uniquely precise sequence of events. With a couple of minor refinements drawn from his confrère Allotte, it runs as follows:

a) Presumably in 1910, Kaleba of Bagui committed adultery with one of the wives of Kunkei, the chief of Moro.

b) In December 1910, Kunkei retaliated by having Kaleba killed by a man named Metala. In this Metala was assisted by an associate named Tziopai, who also killed Kaleba's mother [Allotte 1918].

c) The same day the Bagui attacked a Moro couple: Nagua killed Petsiku and Okuau killed Kuati, his wife.

d) The Moro responded by killing Tubuai at Bagui. 
e) The Bagui replied by killing four victims: Murakai (by Katsiai), Lare (by a number of Bagui), Kakatam (by Bogomai), and Kokouba (in battle between the two villages).

'In 1912 and 1913' writes Grisward, 'the war was at its height', and had already claimed eight lives. By this time the Kieta administration, equipped with a newly acquired steam launch, the Buka, was ready to intervene. On 24 June 1913 Police Master Fritsch and 30 soldiers arrived at Patupatuai, and that night took the road for Moro and Bagui. Apparently warned of his coming, most of the villagers had fled, but Fritsch did manage to capture two of Kunkei's wives. A short while later, Kunkei himself was apprehended, the chief having incautiously followed the patrol to the coast. He was aboard the Buka on 26 June when it left for Kieta. A month later, on 16 July, a number of Moro people came to Patupatuai bringing spears, arrows and pigs as gifts for the missionaries and asking them to procure the release of Kunkei.

a) Some time later Kunkei escaped from Kieta and reached Buin, where he sought refuge in Kopana's village.

b) There he was killed by Kopana, Mota and Kisu, all of whom were government officials.

c) Kunkei's head was cut off, and was claimed by Kisu who displayed it in the new men's house that he had built in his village on the coast west of Kangu. The body was hidden in a big banyan tree at Puntungu, and left to rot.

d) Kisu said that the new skull came to him from Motuna (Siwai). Some Moro people, though, hearing rumours of the matter, went to Kisu's house and identified the skull as being that of Kunkei. They recognised it not only by its shape but on account of two missing teeth, recently knocked out by blows from the police.

At this point in his narrative Grisward comments 'Kisu, Motu and Kopana must die' (doivent mourir), and possibly, he feared, not just they. For in December 1914, within a week of his landing at Kieta, the Australian district officer, Captain H. B. Ogilvy, was summoned southwards by the Marists. The reason, he noted, was that 'the natives in the back country of Buin were very restless and were killing each other, a thing they had not done for a considerable time'. Apparently, says Ogilvy, the missionaries even feared for their own lives, and for those of the three nuns, stationed at Patupatuai since 23 January 1908. Accordingly, he went to Buin with a troop of 12 police. He gave presents to 'friendly chiefs' and urged them to build roads from village to village, and warned that if anyone were killed on such a road the government would punish the offenders severely. Ogilvy then departed, leaving six police boys at Buin to supervise activities there. He returned in February 1915, to find that there had been a murder on the road. In the ensuing 
action, he reported, 'one kanaka was killed' [Ogilvy 1917; Ignace n.d. (1924?)]. Meanwhile, regardless of government disapproval, the feud endured unabated, as Grisward records.

a) On 28 June 1915 Kisu was assassinated at Paruogu (Kikimogu). He was killed in an ambush near the men's club house belonging to one Lugoge by a man named Kaika who had been hired by Babala, the son of Kunkei and by Tsibin, the chief of Kikimogu and brother-in-law of Babala. Imprudently, Kisu had travelled inland with a European labour recruiter. His attackers seized the rifle and ammunition with which he had been armed, while the recruiter retreated rapidly, 'regained his schooner and weighed anchor'.

b) Two days later Grisward visited the Reberere village of Mamamorino. There the chief, Kabala, told him that he had asked the Moro people for the body of Kisu so that he might burn it, but was told that they had already cut it up into pieces for distribution to allied villages. The bush, wrote Grisward, 'seems to have become pagan and savage again'.

c) He would scarcely have been dismayed, therefore, when on 9 September 1915 the district officer from Kieta again came to Buin, supported by two white soldiers and 20 native police, to investigate the death of Kisu. The next day the party marched to Moro and Kikimogu, but returned empty handed, except for Kisu's skull, which was buried at the mission. All the people, together with their pigs, had fled their homes. They thereby not only escaped punishment but, observed Grisward, were encouraged to persist in their desire for vengeance, even if it meant 'taking their time' about it, as proved to be the case.

\section{Other Episodes, 1915-1918}

Meanwhile the administration had other and more pressing things to attend to than indigenous feuding. In October 1915 Ogilvy, who in June had been transferred from Kieta to Rabaul as the military officer in command of Native Affairs was despatched with a strong force to north Bougainville. His task was to kill or capture Bowu of Kowmoomoo village who had long been harassing Soraken, a plantation owned by the Choiseul Plantation Company, a Burns Philp subsidiary. In this he succeeded where a similarly-intentioned German expedition had failed three years before. Bowu was not only shot, but Ogilvy also cut his head off to display it as warning to other would be dissidents [Rowley 1958: 198-9]. The same point was made, rather less dramatically the next day (20 October) at Keekee village. There one man was shot and two others (Lapapiri and Sidipuasi) were captured. They were sentenced to periods of five and two years deportation respectively. As for Buin, from late 1915 to 1918 the documentary record is concerned 
with other matters than Moro and Bagui, and derives mainly from government sources. Of particular concern was the recruiting of labourers by planters from the British Solomons. These Buin people, induced by the difference in pay (ten shillings per month in the Solomons as compared to five in New Guinea) and the convenience of casual employment, would paddle out to one of the three Aluowned islands of Haihaisina, Eruansa, and Saulatu, which lay just inside the Australian boundary, and be taken from there to plantations in the Shortlands. A. R. McGregor, the new and notably heavy-handed district officer at Kieta, reported on the matter in April 1916, and lodged a complaint with his British counterpart at Faisi. As a result two planters, Scott and Atkinson, were each fined 50 pounds for breach of the quarantine regulations and were ordered to return their mis-acquired workers. The practice of illegal recruiting, though - like other unauthorised border crossings — was far from being suppressed. McGregor also visited Buin in June 1916. On this occasion, for reasons not ascertained, he shot a boy and destroyed property at Mongai village, and destroyed gardens at Kikimogu because the people were slow to provide him with carriers. Some months later, following 'rumours of unsatisfactory conduct', his services with the administration were formally terminated.

McGregor was replaced by Lieutenant A. J. Hunter, who made his first visit to Buin in February 1917. The main disorder reported on this tour was the rape of a woman at Ugano village by one of the police boys. That was one of several incidents which on the 16th of that month prompted William Barnett, the acting resident commissioner of the British Solomons, to write to Brigadier S. A. Pethebridge, the Australian Administrator, reporting allegations of 'rough treatment at the hands of the Bougainville soldiers and native police who are said to have run riot among the villages, outraging women and destroying property to such an extent that they are only too ready to get away. They say that the present regime is worse for the natives than under the former German rule'. ${ }^{2}$ This state of affairs was leading people from Bougainville to seek refuge in the Shortlands. Pethebridges's response to Barnett's letter, was to despatch Commander W. J. Burrows in HMAS Una to investigate the charges. Burrows spent three days, 14-16 April 1917, in Buin, in the course of which he ventured 15 miles inland to Barilo village. He also entertained eight kukerai aboard the Una.

In his report Burrows conceded that 'there appears to be some small grounds for the general charge of harsh treatment by the native police in the Buin district since the occupation'. Thus, he concurred with the dismissal of McGregor, but saw ill-discipline among the police as the more serious problem. In addition to the rape at Ugano, there had been a murder. At the request of Kopana, two police boys whom Hunter had left in Buin in February to supervise road works had 
killed Veniko (Binako), the kukerai of Atempiro village, in consequence of Veniko's having made 'bad talk' against Kopana for attempting to tyrannise other kukerai. Returning to Buin for a second time in July, Hunter upheld Burrow's analysis. He took Kopana into custody and sent him to Rabaul for judgement [National Archives of Australia (NAA) 1915-21; Western Pacific High Commission (WPHC) 1916-17; Bennett 2000: 71-8].

During 1918, under Hunter's successor, Captain Somerset, and his associates, Tye and Carpenter, the Administration's presence in Buin was asserted somewhat more systematically. In April a start was made on census taking and on consolidating scattered hamlets into orderly 'line villages' which, among other things, it was hoped, would simplify tax collecting. The latter prospect, noted Father Poncelet, in an observation also recorded by Sister Ignace, aroused 'great agitation everywhere. The natives insist that they have no money, nor the means of procuring it. Their moaning can be heard everywhere, and they are asking the mission to be their advocate in the matter'. On 21 and 22 April people from many villages gathered at Patupatuai for that purpose, with some of them bringing 'children for the school'. It was of little avail. Gavman (the 'government') would not be deterred, and any resistance would be met by force. On 16 June Tye went to Paruogu to investigate the death of Kisu three years before. He only succeeded in killing the chief, Kanku. That night, though, he then joined forces with Somerset, who had arrived with 40 police aboard the chartered mission vessel Raphael, to begin the task of tax gathering. They began at Mamamarino, among a hostile population. They burned houses at Artsini, Ibirei and Barilo to enforce submission and at Kaitu, where a mission boy named Kalai received an axe wound, three people were shot [Poncelet, 1918-24; Ignace n.d. (1924?)].

\section{The Moro-Bagui Feud, Phase Two, 1919}

With the extension of the government agenda, initiated in 1918, the strand of violence contained in that enterprise converged in a particular way as the indigenous contest between Moro and Bagui had not been resolved and Moro, together with its Rerebere allies, strove to maintain a more defiant attachment to traditional ways than their rivals. This disposition and the lingering desire for revenge surfaced dramatically at Moro in 1919 when, on instructions from Police Master Rawlings, Mota, one of the killers of Kunkei, and two police boys went there to supervise the building of a new village. Again, Grisward [1923] supplies most of the details.

a) On 4 May 1919 Mota, two policemen and Antonio Kagaba, a mission catechist, who had been baptised on 15 August 1914 (number 150 in the register) were massacred at Moro. Kagaba [Turiboiru], according to eyewitnesses (especially a man named Lugan) had been killed accidentally, while 
trying to shield Mota from being attacked with an axe. The policemen, on the other hand, according to Poncelet, on the authority of Babala, were killed 'to avenge Maumara, killed last year by the police at Paruogu, and from opposition to the civilisation of the whites' [Poncelet 1918-24].

b) The next day Rawlings and a force of police, with Grisward and Poncelet in attendance, went to Moro. They followed a detour because the direct route had been blocked with large trees. The Moro had three rifles, one taken from Kisu and two from the dead policemen, and about 80 rounds of ammunition and as Rawling's party approached Babala's club house they opened fire on it. The police responded, the Moro fled, and the party entered the village. There they found the bodies of Mota and the policemen lying on a large piece of wood, ready to be displayed to other villages. The body of Kagaba, though, had been honourably cremated by his family. Of the victims, Mota's body was taken to his family at Baitoga and cremated there, while those of the policemen were buried at Patupatuai. Sister Ignace noted that none of the baptised were involved in the killing [Ignace n.d. (1924?)].

c) On 13 May Captain Cardew, the district officer, arrived at Patupatuai and on 16th went with four European assistants and 42 policemen to Moro. They destroyed the village and its plantations and killed the pigs, and left a strong force behind to continue the hunt for the killers.

Besides reporting on these events, Grisward also offers a closely informed explanation. In the days after the murders he learned that the plot had been hatched by a group of chiefs, all of them stubbornly pagan - Babala, Tsibin, Obumom, Tsiune and Perokana — and that it had been kept hidden from the Christians. He also reveals that Perokana had a personal antipathy for Mota, whom he saw as an upstart. Perokana had high traditional rank, and was affronted by the pretensions of Mota, a lesser chief but who nevertheless 'had the hat of the No. 1 kukerai of the government'. 'In these sad circumstances', he further notes, 'the mission exercised her charity with all the devotion of which she was capable. In the reprisals she protected the baptised, of whom none had been in the plot, and the multitude of the innocents. Since no people from any of the guilty villages dared come near the government officials by themselves, the baptised, without delay and at the direction of the missionary, escorted a crowd of them there. This was the beginning of the submissions' [Grisward 1923].

\section{The Moro-Bagui Feud, Final Phase, 1920}

With the destruction of Moro the wanted men were soon captured and were sent to Rabaul for trial. There Kaika, the killer of Kisu (1915); Obumon, the killer of Mota (1919); and Babala, the principal organiser of the 1919 massacre were all 
condemned to death. Various others involved in the affray were sentenced to hard labour. The executions were all carried out in Buin. Again, Grisward [1923] provides a chronicle which is not only detailed but which is valuably supplemented by the journal of his confrere J. B. Poncelet.

a) On the afternoon of 1 January 1920, shortly after being baptised (number 798), Obumom was executed by firing squad at Moro, on the same spot as the killings of 4 May 1919. He was buried nearby. After the burial Grisward preached in the Telei language on the circumstances that had led to this sad occasion. He was heard by a congregation of several hundred men who, unarmed and squatting on the ground, called out 'we will kill no more'.

b) Uncertainty, though, was still widespread among the villages. On 29 January Grisward accompanied Lieutenant Erwin to Kikimogu, whose inhabitants were still in hiding and dispersed, to attempt pacification by more gentle methods. The first person to present himself was Chief Tsibin. He was accompanied by his father, the renowned mumira Tsiperao, whose enormous clubhouse had earlier been destroyed by police. The following morning 55 men, together with 37 women and many children, made their submission by giving their names to Irwin, and by promising to build a new village for themselves and their still absent neighbours. Local tradition records that Tsiperao made a further concession to the new order: his 'thoughts stayed in his mind and he did not finish the plan [to extend his club house]'. The Canberra-based linguist Don Laycock collected the story behind that comment.

Tsiperau planned an enormous clubhouse for the men to build. Now some men were going to battle, carrying spears, bows, axes and clubs. Tsiperao was out walking when he saw them; he made them go back from the road, and took from them the spears and bows and put them aside, saying 'Now there is no fighting. Go home and prepare timber for my clubhouse'. They listened to his words, and piled up all the weapons. Then they went into the bush with knives and axes. They cut trees and brought them to build the clubhouse, planting the posts in the cleared area. Then they built the clubhouse called Kuuturui, which means 'in all the villages [there is peace]'. When they had finished Tsiperao said to all the people 'Now listen to my words: there is to be no fighting anywhere'. Now from the time they built the clubhouse it was not long before the whites came and burnt it. So Tsiperao's thoughts stayed in his heart, and he did not finish his plan. The whites just burned the clubhouses, and they were finished from then on. He did not complete his ideas [Laycock 1968]. 
Later, on 30 January, the people of Kanaoro and Moro also agreed to build new villages.

c) Still, the law had its own course to run. On 11 February Babala was executed by shooting, at Moro. He, too, was baptised (number 811), with the name of Paul. By his own wish he was not blindfolded. He was buried near Obumon.

d) The last of the trio was Kaika, who was baptised (number 843) and hanged on 3 May, and was buried near the others.

e) Kopana, although also a killer of Kunkei, had — fortunately for him been arrested in 1917 and was dealt with more leniently than would later have been the case. But an early release from prison was scarcely a reprieve. He died, possibly by poisoning, at Kakaola in Buin 1920 [Grisward 1923; Poncelet 1918-24].

\section{Aftermath of the Feud: The Mission Established, 1920-1922.}

With the time of traditional fighting at an end, the southern plain became an unambiguously safe territory for missionaries to work in. Moreover, it brought with it a clear demonstration to the villagers that, with their old order shattered, an alliance with the mission could be useful. Apart from any other benefits that it might be thought likely to confer on them, it could also cushion the impact of government control and provide a point of entry into a new and more appropriate way of life. Following the executions Grisward and Poncelet noted that the people were everywhere calling for missionaries and catechists. They responded enthusiastically. During 1920 and 1921 chapel/schools were constructed at Mamamorino, Kugumaru, Luaguo, Tula, Kanaoro, Kikimogu, Laguai, Nakorei, Barilo, Laitaro, Nakaro, Aku, Nabuku, Morulam, Maika, Mituai, Kaukauai, Kahakiru, and Mokakura; and the whole district from Lavelai to the Mivo river was quickly occupied by catechists. Some were even located in the Motuna (Siwai) district; at Kolegutu, Siwai village, and Kaparu [Grisward 1923; Poncelet 1924].

Complementing these developments, the mission shifted its operational base from the coast to the inland. Permanent mission stations were opened at Muguai and at Monoitu (in Siwai) in 1921 and at Turiboiru (near later Buin Town) in 1922. That same year Patupatuai was closed, its purpose fulfilled.

\section{SIWAI}

By 1921, then, the Marists had conquered Buin. Still, there remained urgent work for them to do in the Motuna/Siwai district westwards of there, between the Mivo and Puriata rivers, if they were to be the dominant religious influence in southern Bougainville. A few children from Siwai had attended the Patupatuai school as 
early as 1908 and there were occasional missionary visits subsequently. The first baptism recorded there was on 7 April 1912 and there had been 52 of them by 6 October 1917. Then there is a gap in the record until the local baptismal register comes into service on 15 June 1922.

The timing of the Marist advance into Siwai in 1921 was influenced by the arrival of Protestant competition for the souls of Bougainvilleans, in the form of Methodists from the neighbouring British Solomons. Established in New Georgia since 1902, the Methodists expanded northwards to Mono in 1911. From there they were in a position to use traditional linkages to help them cross the strait into Siwai. A deep-seated strategic concern about this possibility had been expressed by the local Marist superior as early as 1905 when he wrote, 'It is necessary that our missionaries occupy the chief parts of Bougainville and prevent the infiltration of Protestants' [Laracy 1976: 60]. His successor, Maurice Boch, was more explicit. In September 1914 Boch wrote, 'Another inconvenience of the abolition of the German frontier will be the invasion of Protestant sects. I have warned Father Allotte to assure himself of all the villages of the coast, especially of the Morohe side. I will get the people of Gaomai [in the Shortlands] to act similarly on that part of Bougainville, because there are frequent relations between them' [Boch 1914].

Quite apart from the element of rivalry inherent in denominational difference, Marist sensibilities in the matter were heightened by the belief that they had been given a monopoly on Bougainville. The earliest clear expression of this dates from 1912, when Father Allotte wrote 'The Government has undertaken not to allow the establishment of Protestantism on the island of Bougainville, if we are able in a reasonable time to extend our activity over the major part of the native population' [Allotte 1912]. Later, in 1918, he made a similar remark: 'I have heard it said that at the time the Catholic mission was being established on Bougainville it was promised in Berlin that Protestants would not be allowed to establish themselves there' [1918]. As reports of what was, apparently, at best, an informal comment these statements are quite credible. A search of official files in Rabaul early in 1918 and in Catholic archives in Samoa (from where the Bougainville mission was founded), though, failed to produce any documentary evidence of it. Undeterred, the bellicose Father Boch endorsed the claim in 1935 - I even caught echoes of it in conversations with missionaries in 1966 - but he also conceded that it could not be proved. 'The German government even gave Father Flaus, representing this prefecture, la promesse purement verbale (an informal verbal comment) that by virtue of being pioneers we could retain a monopoly of evangelisation on Bougainville' [Boch 1935].

However insubstantial the promise was, it did underpin a firmly held conviction within the mission — and one sympathetically noted by a judicial commission 
in 1929 - that having borne the burden and heat of the day the Marists had at least established a moral precedence [Phillips 1929: 4, 96]. And they would attempt strenuously to enforce it. The assault by heterodoxy began in 1917 when indigenous Methodist teachers after landing at Irinai on the Siwai coast moved into the Buin villages of Lamuai and Tantareke. Quickly the Marists placed a chapel and a school at Tantareke and gathered all the children, leaving none for the Methodists. Forestier and Poncelet then went to Kieta to complain of the Methodist intrusion to the district officer who, not wishing to have affairs in Buin complicated by sectarian rivalry, ordered that the Methodists be expelled. Accordingly, instructed by Police Master Tye and the Kukerai Posena, they paddled off from Buin to Alu, en route to the Shortlands, on 28 March 1918. In contrast, a teacher named Devita who settled at Tonu in Siwai in 1917 seems to have been left alone. If so, he was not left without support for long, for by 1921 other Methodist teachers from the south were also moving into Siwai [Poncelet 1918-24; Phillips 1929: 7].

As they did so new tension, and a fertile source of trouble, emerged. That is, sectarian rivalry. This intensified after a European Methodist missionary, Alan Voyce, following his colleague Allan Cropp, who had been itinerating in Bougainville since 1922, settled permanently at Tonu in 1926 [Luxton 1955: 124-31]. Moreover, the Seventh-Day Adventists also became players in what would become a complicated game throughout the southern districts after they settled at Lavelai on the east coast of Buin in 1924 [Dixon 1985: 211]. That affairs in Siwai never became as conspicuously violent as they had been in Buin a decade before was possibly due, at least in part, to the deterrent effect of the pacification campaign there. Moreover, that effect was surely reinforced by a more proximate display of government force. This was the hanging on 18 May 1923 at Hire village of two murderers, Joseph Haranu of Kolegutu and Peter Lising of Lakenba. Incidentally, for killing a man named Toma, theirs were the only two officially recorded executions in the New Guinea Territory from the beginning of civilian rule in 1921 to 1924, inclusive [Nelson 1978: 144]. Both men were baptised by Grisward before being executed. Their bodies were later buried at Monoitu. The Turiboiru baptismal register, though, also lists Loubai (number 1402) who was executed on 23 July 1924 for killing Toma, who had committed adultery with Koki, the wife of Mure of Piarino. The only subsequent recorded executions of Bougainvilleans were those of a labourer who killed a white man named John Scott, the manager of Inus plantation in 1925, and of millenarian cultists by Japanese soldiers on Buka in December 1942 [Chaize 1925; O’Reilly and Sédès 1949: 199-200].

Meanwhile, returning to the south, the problems - and the apparent possibilities of future violence — were mounting. In 1929, therefore, following complaints from the Methodist and Seventh-Day Adventist missionaries, and on 
the advice of the government anthropologist, E. W. P. Chinnery, the administrator of the New Guinea Territory appointed Justice B. M. Phillips to investigate events in southern Bougainville. Between 18 March and 12 April the commission sat at Kieta, Kangu (Buin) and Hidei (Siwai). It heard 26 specific complaints, some of them dating back to 1924. Most were from Siwai. Some of them were based on hearsay, and others on misunderstandings (as when on one occasion Voyce was deemed to be threatening a man called Moki with 'calaboose' (prison) when he spoke of 'kiap', a government field officer); but there were other complaints for which there was more solid evidence, and which had serious implications. The most contentious of these concerned the erection of mission buildings on disputed land. The problems arose not just because villages might be divided in their religious sympathies. That complication entwined with the fact that in what was by custom a matrilineal land-owning society men were tending to assume rights of disposal over their wives' land, and were using it to endow the mission that they personally favoured. The most serious clash to arise from this occurred early in 1929 and involved two villages.

Chilion Kiau, a local man trained as a Methodist teacher in the Solomons was building a chapel and a house at his village of Oso (or Osokori), where most of the people were Methodist. However, Toachi, the kukerai, who was not a 'true owner' at Oso, disliked the Methodist mission because it 'disapproves of working, taro-getting and fishing on Sundays'. So, he complained to Grisward that the Methodists were building against his wishes. Subsequently Opuina of the neighbouring Catholic village of Hukuha, visited Osa and spoke to Kariha,who sympathised with Toachi, to discuss the matter and was told 'suppose you like breakem, you breakem'. He then intimated something of what he was planning to Grisward, who told him 'Just as you like. It is your ground; you are the owners; do what you like on your own ground'. Thus it was that in the early morning a group of men led by Opuina and armed with axes, tomahawks and clubs (but, significantly, not spears) raided Oso and destroyed the offending buildings. Retaliation was immediate. Before Opuina's party could return home a group of men from Oso, reinforced by some from Tonu, learned of the raid, and agreed on 'a church for a church', saying 'the Catholics have built a Catholic church on land belonging to us at Hukuhu [sic] village; they have "roused [rausim]" a Methodist church; "all right"; we will "rouse" their Catholic church at Hukuhu'. So they set about wrecking the saksak [woven bush material] structure, and were engaged in doing so when the opposition returned. A brawl then ensued in which two men, one from each side, received severe axe wounds. Then the fighting ceased. The commissioner's comment was that 'it is exceedingly fortunate that this brawl did not have very much more serious results than it did'. His principal recommenda- 
tion, which was duly adopted, was that occupation of village sites for mission purposes ought, like mission station properties, be subject to licence regulations and that occupation and building consents should be approved from the district office [Phillips 1929: 6-19, 106-10].

By 1930, then, the 'pacification' of southern Bougainville, at least in its first, and — with sad irony - least bloody phase was complete. Inter-mission rivalries would persist in Siwai, and to the west and north in Banoni and Nagovisi, but the only violence that attended them was rhetorical. If only new players had not stepped onto the stage to add new acts to the Jacobean tragedy of Bougainville history!

\section{REFLECTIONS}

The foregoing narrative, a sequentially ordered chronology of events, is innocent - at least explicitly so - of 'theory'. It has no skeleton of argument, and eschews analysis in favour of reportage. Which is not to say that it should be seen as devoid of meaning. Rather, the explanation of the events is contained in the relating of them. This is a story that illustrates the complexity of those events, and the interactions within and between the three main agencies - the villagers, the missionaries, the administrators - that shaped the beginning of southern Bougainville's loss of traditional, customary autonomy. By the 1930s, having become Christian, the people were singing of the wonders and wealth of the white man's world, and expecting Christianity to help them procure some of it for themselves — which to a degree it did [Laracy 1976: 140-3, 148-50, 157; 1999: 282-8]. Not the least of the benefits that may be salvaged from the destruction that has attended the process of contact with outside forces has been the recording by the missionaries, in permanent and detailed form, of certain events that have helped determine what it means to be Bougainvillean. Consequently, that can be done without relying on concessions to intellectually demanding forms of understanding that confuse belief with knowledge and assumption with substance; rather, it may be done with the same disciplined regard for precise names and dates that should help inoculate any historical reconstruction against the subjectivity of the historian and to dignify the tale being told. Even so, it was a close run thing in the case of the documents on which this paper has largely been based. The French Marist priest and historian Patrick O'Reilly collected them on Bougainville in 1935 and took them back to Paris. There, unlike most of the documents - mission and government alike - that might have been found on Bougainville and in the territorial administrative centre of Rabaul early in 1942, they survived destruction during World War II, and only came to light again in 
1967 [Laracy 2005]. But for O’Reilly's action, a significant piece of Bougainville history would have been consigned to virtual unknowability, and the Moro-Bagui feud reduced to 'phantom history', a spectre that haunts many explorations of the Pacific past [Sack 2001].

\section{Endnote}

1. SMS is the German abbreviation for His Majesty's Ship

2. Notes in the possession of Hugh Laracy, Auckland, from NAA (National Archives of Australia), CRS, A457, 710, 1915-21 and WPHC (Western Pacific High Commission) records, 1916-17, Auckland University. 


\title{
'IMPERIUM IN IMPERIO'?: THE CATHOLIC CHURCH IN BOUGAINVILLE
}

\author{
by Hugh Laracy
}

n 1966 I made the first of what would eventually be three extended field-trips
to Bougainville and Buka in order to study Catholic Church there. This was an undertaking in which I enjoyed the cooperation of church personnel, as informants, translators, hosts and transport providers. In particular, their assistance enabled me to observe at first hand the notably large scale of Catholic operations in the principal islands of what in 1898 the Vatican had designated the prefecture apostolic of the North Solomons (Salomons Septentrionales), and had entrusted to the French-founded Marist congregation [Laracy 1976]. ${ }^{1}$ There was a network of 30 mission stations serving 53,000 Catholics, who constituted 80 per cent of the total population of 73,000. Each station - or parish centre - typically consisted of church, school, presbytery and convent. There were 38 expatriate and five indigenous priests; 26 expatriate and 31 indigenous brothers; 54 expatriate and 40 indigenous nuns; plus 20 expatriate lay missionaries, who worked mainly as teachers and nurses [Appendix 1]. The church had a fleet of six ships, the largest of which, the St Joseph, made the 200 mile trip to Rabaul every three weeks, to sell copra and to collect supplies [Sol Mons, June 1965]. The church was also heavily involved in organising a number of externally funded economic development schemes [Appendix 2]. This task was eased by the fact that its expatriate staff were mostly drawn from prosperous countries with large, vigorous and generous Catholic populations, namely the United States, Germany and Australia.

Soon after that first trip, in Paris, early in 1967, I located a large corpus of letters, journals and memoirs which made it possible to document in considerable detail the beginnings of what would eventually become a pervasive and predominant, 
Catholic presence on Bougainville. This dusty, brownpaper-wrapped cornucopia, which also contained materials on indigenous history, such as the feuding between the Buin villages of Morou and Bagui from 1912 to 1920, had been compiled by a French Marist priest named Patrick O'Reilly, who had visited Bougainville on a research trip in 1934-35. The administrative 'pacification' of Buin in response to that feuding had earlier been initiated by the Germans, and was subsequently accomplished with notable severity by the Australians. [Laracy, 'The Pacification of Southern Bougainville' this volume]. For his part, O'Reilly, later a renowned scholar, intended writing a history of the mission. To that end he had sequestered whatever records he deemed useful. The book was never written. O'Reilly did, though, with the aid of a missionary informant named Paul Montauban eventually write a good history of the impact of World War II on Bougainville. Thanks to his predatory modus operandi, he also ensured the survival of papers that would otherwise have been destroyed in the recent decade of 'conflict' there [O'Reilly and Sédès 1949; Laracy 2005]. ${ }^{2}$

These records show Marist missionaries establishing themselves at Kieta in 1901, four years ahead of the German administration, and then going on to found five more stations between Burunotui on the west coast of Buka and Patupatuai on the Buin coast before their proselytising monopoly was broken in 1922. That break occurred with the arrival in Siwai of Methodist missionaries from Australia. The advent of Protestant competition, however, only stimulated the Marists to make more intense efforts to consolidate their advantage of a two decade headstart in the race for Bougainvillean souls. Missionaries were dispersed more widely, more stations were founded, greater use was made of Tok Pisin, English-speaking staff were recruited and English was taught in some mission schools. By 1939, when the Marists occupied 18 posts and had a following of about 25,000, the Catholic versus Protestant contest that had been a regular occurrence on mission fields in various parts of the Pacific since the mid-1800s had, at least in this instance, been decisively won by the Catholics. More critical struggles, though, lay ahead [Laracy 1976; Oliver 1991].

Meanwhile, in 1930, Thomas Wade, an American who had arrived in the mission only in 1923 had been made bishop of the North Solomons. It was an inspired appointment. Wade was an energetic and enterprising leader. Moreover, as the first native speaker of English to become bishop in any of the Catholic missions of the Pacific (most of the bishops were either French or German until at least the 1950s) he had a distinct advantage in publicising his work and in being able to tap readily into new sources of support for it. Not only did Wade draw heavily on America but he also worked to make Catholic Australia peculiarly aware of the Bougainville mission. Indeed, he succeeded to the point where, 
at least for the next two decades, the Marist operation on Bougainville had the strongest Australian constituency of any Catholic mission in Papua New Guinea (although its prominence in Australia scarcely compared with that of the Methodist mission to New Britain and New Ireland). 3

In the first step towards that eventuality, Wade was consecrated bishop in Sydney, but with Archbishop Mannix of Melbourne also in attendance, in May 1930. He used the occasion to advertise the needs of his mission, and made a notably effective appeal for medical missionaries to join him in his work. Wade also built on the sympathy and interest he attracted at that time by producing a film about the mission, Saints and Savages [1931], and by encouraging publication of a charming collection of letters written by his young New Zealand-born confrère, Emmet McHardy, Blazing the Trail in the Solomons [1935]. McHardy had done the actual filming and his illustrated book was widely read — and famously persuasive. Later visits by Wade to Australia in 1934 and 1936 were also well publicised. In 1936 there were even plans to bring a cruise liner of Australian pilgrims to Bougainville in 1937 for a Eucharistic Congress to celebrate the centenary of Marist missions in the Pacific [Advocate, 20 December 1934, 10 September 1936; Durning 1985; Laracy 1998a, 1998b, 1999].

The first medical volunteer to answer Wade's call, in 1931, was Amy Richardson, a nursing sister at St Vincent's Hospital, Darlinghurst. In 1933 she recruited three more nurses, and they were joined by Dr J. Luxford Meagher. He was a member of a prominent Melbourne family and, as a series of articles on Bougainville in the Catholic Leader indicates, also had a talent for journalism. From these beginnings the Marist Medical Mission League was set up in Sydney in February 1935 with the well-known surgeon and, later, author H. M. Moran as its first president. The League continued to supply money and medics to Bougainville until being disbanded in 1976 [Advocate 1 March, 20 December 1934, 21 May 1936, 18 May, 2 December 1937, 19 August 1940; Kettle 1989: 43-6, 289-92; L'Estrange n.d.]. There were other important Australian links, too. Marist Brothers, professionally trained and experienced teachers, were introduced in 1941 to open a school at Chabai. And after World War II there was a steady flow of lay volunteers to help first with the tasks of reconstruction and then of development [Boyle 1989: 46-55; Doyle 1972: 599]. Furthermore, in 1946 one of the best-known Catholic priests in Australia, Monsignor James Hannan, resigned from the post of national missions promoter in order to pursue his ministry on Bougainville [Laracy 1996].

By 1950, then, thanks to a good start and a strong and sustained follow-up, the Catholic mission was clearly the most widespread, popularly supported and coherently organised institution in Bougainville. Conversely, Bougainville could 
be seen as a Catholic fiefdom - as it was, resentfully, by various Australian colonial Administration officials in the post-war decades. For its part the mission had never been particularly beholden to the colonial Administration. It had no reason to yield to civil authority's perennial call for Erastianism, that is, to subordinate its authority to that of the state. It had grown by its own exertions. Its staff had not retreated ahead of the Japanese invasion in 1942, and twelve of them had died in the subsequent conflict [Laracy 1976: 117]. In any case, the primary purpose of the missionaries being there was to plant the Catholic Church firmly among the people of Bougainville. If, therefore, they had succeeded to the point where Catholic identity seemed almost to be coincident with Bougainville identity that was grounds for confidence rather than for misgivings. Hence the place in Catholic mythology of the guerrilla fighter Mesiamo of Biroi village in Nagovisi, and known as the 'Black Brigadier'. As the story was told in the Australian Catholic Missions.

Misiamo [sic] did not fight for Australia — he fought for the 'Lotu' [the Church Faith]. He was not very fervent before the war - there always seemed to be complications on the way of his full acceptance of the Faith. Then came the Japanese patrols thrusting up from the coast, with the decision of Imperial Nippon that the Catholic Faith was finished in the Solomons. The churches were burned, the schools dispersed. Then the Nagavisi — and Misiamo understood. Either they fought, or the Faith died. The Nagavisi fought.

In the village council houses they declared formal war on the ... despoilers, and Misiamo carried that declaration into effect ... Long before war's end the Nagavisi country was a closed land to the Japanese.

But Misiamo was not only a soldier — he was a leader, and a Christian leader, above all [Catholic Missions 1946: 10]. ${ }^{4}$

As history, that assessment of Mesiamo's disposition is quite unsound. Hannan was using it to illustrate the inadequacy of the post-war Australian Administration on Bougainville, a matter which he also caused to have raised in the Australian parliament in 1947 [Advocate, 9 April 1947; PD (Parliamentary Debates), 16 April 1947: 1299-1300]. In contrast, a speaker from Nagovisi offered a less tendentious view of Mesiamo at the Bougainville conference held in Canberra in 2000:

I don't believe he was a Catholic, because he married more than five wives. I just wanted to make that correction. If the Church believed that Misiamo [sic] was fighting for the Church, I think Misiamo was too clever for them. 
Maybe so, but the mythical version in which piety reinforced patriotism still served a unifying function for priests and people.

Given the compact insularity of Bougainville, the ethnic/chromatic distinctiveness of its people and a pervasive sense of being distant from the concerns of central government, the close coincidence of religious and regional identity there ensured that the Catholic Church would readily sympathise with what might be deemed to be the immediate interests of Bougainville in the temporal as well as in the religious order.

While that sympathy would in the 1960 s come to have conspicuous political implications, the Marists had already long manifested it in a specifically ecclesiastical way. That is, in conformity with the doctrinal and institutional metaculture of Catholicism, by seeking to enrol Bougainvilleans in the elite, European-normed — but internationally comparable - course of study leading to the priesthood [Laracy 1999, 2000]. 5 Before the opening of the University of Papua New Guinea in 1966, even seminarians who did not complete the course were likely to be far better educated than any other of their compatriots.

The beginnings of the process, though, were modest. Most of the pre-war English-speaking missionaries were employed at various times in teaching catechists, or local teachers. Four of their proteges were in 1937 selected to begin seminary studies at Vunapope. They were Anton Kieri, Paul Lapun, Aloysius Noga Tamuka and Peter Tatamus. Of these Lapun later became a noted politician, while Tamuka and Tatamus, after a disjointed course of studies, which they completed at Torokina, were eventually ordained in 1953. Their successors followed a more orderly route: from Chanel College (founded in 1955) at Ulapia, near Rabaul, to Holy Spirit seminary, which was opened at Madang in 1963 and was transferred to Bomana near Port Moresby in 1968. Among the first graduates of this course were Peter Kurongku (later archbishop of Port Moresby), Gregory Singkai (later bishop of Bougainville) and Alexis Holyweek Sarei (later premier of Bougainville, and holder of a Roman degree in theology). All three were ordained in 1966 [Aerts 1994; Sarei 1974].

Numerous others followed them, some to ordination, some dropping out en route and some leaving the priesthood after ordination, but all had been introduced to the intellectual discipline of abstract thinking and the rigour of Scholastic philosophy and to the ways of the clerical gentleman. Accordingly, in 1970 Wally Fingleton, an Australian who had joined the mission in 1948, could write that 'Bougainvilleans, including Leo Hannett, Daniel Tsibin ... Leo Morgan, Joseph Auna, Joseph Tonnaku, Aloysius Noga and others of the "Bougainville Club" in Moresby, along with our three Members, Donatus Mola, Paul Lapun and Joseph Lue, form a group which is more literate and articulate than any other like group in New Guinea' [Fingleton 1970: 13-14]. 
The minds of the 1960s seminarians had, however, been shaped by more than just the traditional curriculum. They were stimulated also by the liberal, inclusive, adaptive, up-dating, diversity-endorsing, particularity-respecting and decolonising principles embedded in the teachings of the Second Vatican Council (1962-65). They were thus equipped — and disposed — to be formidable critics of established structures and assumptions in both church and state. This was reflected in much of the writing in Dialogue, a broadsheet published at the Madang seminary. Yet while nationalistic demands for indigenous self-determination earned certain writers such as John Momis and Leo Hannett a reputation in some circles as 'radicals', that opinion was far from universal. Nor was it necessarily pejorative. Not only were the kind of sentiments they expressed finding increasing currency in the world at large beyond Papua New Guinea but, more pertinently, they were accepted by Leo Lemay, who had succeeded Wade as bishop of Bougainville in 1960. When Momis was expelled from Holy Spirit seminary Lemay arranged for him to continue his studies with the Columban Fathers in Australia (Momis, this volume). Hannett also spent time in Australia, at the Marist seminary near Sydney, before enrolling at the University of Papua New Guinea.

While working steadily to develop the structure of the church, Lemay (1960-74) also carried further the task of grafting it more securely onto the rootstock on which it would ultimately have to depend; that is, the people of Bougainville. To this end he and his staff saw it as part of their task to help satisfy the rising material aspirations of their followers, not least through education [Acta 1958; L'Estrange 1957, 1958]. Thus, in 1961 the Marist Brothers school at Kieta (opened 1949) began teaching secondary classes. And in 1964 the quality of the instruction it provided was shown when it achieved a 100 per cent success rate in the Territory-wide Intermediate Examination, as it also did in 1965 when two pupils, Peter Sisiou and John Dove, came first and third-equal overall, respectively [Boyle 1989: 183-4]. Already, since 1955, the mission had been working to produce candidates for registration as teachers in accordance with the government policy of promoting literacy, but mostly at its own expense. For instance, in the year 1955-56 the mission received a grant-in-aid of $£ 3,459$ but itself spent an additional $£ 18,656$ on education. Although government funding subsequently increased substantially, education remained a major expense for the mission, as in 1965, when it ran 120 primary schools catering for 11,000 pupils, plus three secondary schools and two teacher training colleges. At that time, the government educated only a thousand students in Bougainville. In 1970 Fingleton wrote that 'the Catholic mission of Bougainville educates some 12,000 children out of a total district population of about 73,000' [L'Estrange 1956; Fingleton 1970: 13; Sol Mons, June 1965, December 1965]. 
The comparison, whether stated or implied was, of course, invidious to the government. On the other hand, it also pointed to the rapport the mission sought to foster with its indigenous constituency. That same disposition was also shown in other ways as, for instance, after a large scale rejection of the mission on Buka in 1961. There, a mood of economic frustration and disappointment fuelled resentments which merged with a cargo-cult tradition that had been spasmodically manifest since the early 1930s. And so was born the Hahalis Welfare Society, to which 3,000 Catholics had defected by 1964 .

Central to the Welfare's sense of grievance was the notion that the missionaries cared little about their well-being and had not provided them with the knowledge needed to become rich which, as agents of a benign God, it was thought they ought to have done. Recognising the need to give the lie to this, and to similar dangerous murmurings elsewhere, the mission's response was to direct much of its energy and resources into development schemes. By the mid-1960s, therefore, Catholic Bougainville was abuzz with projects for timber milling, house building, resettlement, road making, land clearing and for the planting of coconuts and cocoa. Whatever the theological tensions that might be thought to exist between possessions and piety, the Marists were clearly adept at making use of 'the mammon of iniquity' to further their cause [Laracy 1976: 135-43; Ryan 1970: 275-337].

More than that, though, as would be seen in the royalties dispute over mining at Panguna, the Marists were also prepared to stand up to the civil authorities in support of indigenous interests on what appeared to them to be matters of morality and justice. Thus, in April 1965, Fingleton exposed in the press in Sydney a scheme by which the government proposed to take by 'right of eminent domain', and in the face of local opposition, 200 acres of land at Tonolei Harbour to service a private timber milling operation. The landowners were given $£ 30,000$, while the timber was valued at between $£ 6,000,000$ and $£ 10,000,000$. Similarly, the year before, Fingleton had challenged the Administration for proposing to quarry road mettle at Malabita Hill without the agreement of the landowners, and for offering a royalty substantially below the standard rate [Sol Mons, June 1965; Fingleton 1970: 17-19].

When, from the mid-1960s, landowners of Panguna in central Bougainville were disgruntled by the depredations the proposed mine was expected to bring to their lands and waterways, and chagrinned at being denied royalty payments (in addition to modest occupation fees and compensation), it was scarcely surprising that their missionaries were sympathetic. Following a meeting of landowners at Tunuru Mission in August 1966 to air their grievances, Lemay wrote to the Administrator, Donald Cleland, denying that the missionaries had instigated the protest but affirming the mission's position. 'Where', he wrote, 
the Administration is not being fair to the people ... [by refusing] to have due regard for Native law and custom ... I stick with the people whom I have come to serve ... [This position] is not anti-Administration but pro-People.

It was also a practical position as well as a moral one. 'Our local people', wrote Lemay,

do not want to be dispossessed of their few acres of ground; it is more precious to them than gold and silver.

He went on to deliver a sadly prescient warning that the royalty issue could detonate a secession movement, and war [Lemay 1966b]. And so it came to pass. Nor was he alone in his prophecy. As another Marist, Robert Wiley, recalled in 1991,

... when the BCL (Bougainville Copper Ltd) big men were visiting Tunaru I said to them you'll push this through as there is no way the old people will fight with you. Then I pointed to the school children and said that's where the problem will come - through education. There'll be hatred. Today many of those 60s students are fighting for the BRA (Bougainville Revolutionary Army).

One such was Philip Taukang who, reported Wiley, complimented the church by saying

you were the only ones who told us the truth ... no one could believe that the mountain was going to be removed [Link No. 23 1991].

Lemay would have been gratified by that statement. For in September 1966, following a meeting with his clergy, he published an open letter in a special issue of Catholic News endorsing the view of landowners in Buin and Nasioi that the laws regarding mining and timber milling were unjust insofar as they 'go against Native customs'. 'Our sympathy', he declared 'is entirely with our people'. He did, though, urge them to work through their politicians to change the laws and not 'fight the Government':

Insist that you want Native customs observed as regards land, timber and mineral ownership. Tell your leaders that you want a fair law, one that admits your rights to your land, timber and minerals, and that gives you a fair share of the profits called royalties [Lemay 1966a]. 
Given the destruction and disruption, and the recriminations and conflicts of loyalty that followed the development of the Panguna mine, it is not inconceivable that, in the second century of its Catholic history, Bougainville will have greater need of the consolations - and speculations - of religion, be it Catholic or Protestant, than it ever had in the first hundred years. For the problem of balancing the part against the whole, of reconciling unity with separation, or of relinquishing one demand and conceding its opposite, which has so bedevilled Bougainville since 1988, is not likely to go away. At base it is a philosophical and moral issue no less than a political one [Laracy 1991: 53-9].

\section{Endnotes}

1. The prefecture conformed to the boundaries of the original Anglo-German division of the Solomons, and so also included Ysabel, Choiseul and the Shortlands. The ecclesiastical boundary was not changed after the political one was adjusted in 1899. The prefecture was raised to a vicariate in 1930 but the islands south-east of Bougainville remained within its boundaries until 1959. The vicariate apostolic of North Solomons became the Diocese of Bougainville in 1967 [Laracy 1976].

2. I am indebted to my wife Eugenie for her help with the enormous task of transcribing the O'Reilly material in Paris in 1967.

3. In discussion at the conference in August 2000 from which this book originates, 'Bougainville: Change and Identities, Division and Integration' hosted by The Australian National University's 'State, Society and Governance in Melanesia' (SSGM) program in the Research School of Pacific and Asian Studies [see taped proceedings], Hank Nelson made some useful comments on these matters. 'The Methodist mission in New Britain-New Ireland had a much more coherent, better organised constituency in Australia. That mission is an Australian mission. Its direction, funds and personnel (whether lay or ordained) came out of Australia. Often the heads of the Methodist church in Australia had served a term in the islands. And because they tend to be the more committed and most enthusiastic of Methodists, they were disproportionate in the leadership of Australian Methodism. Indeed now, I think, the chairperson of the Synod is an ex-missionary from New Guinea. That also meant that in all of your Methodist circuits, whether in Albury or Wagga, or wherever you are, you would have an ex-missionary out of New Guinea as one of the members, and they're always performing through those circuits.

'And in terms of influence, you've just got to look at who goes down on the Montevideo Maru. Well, one of them is a Beazley, the uncle of Kim and the brother of Beazley Sr, who asked all those questions about Papua New Guinea through the '50s and so on. Or Earle Page, the head of the Country Party. His brother is the secretary in Rabaul, and a lay preacher in the Methodist church. One could go on about such connections ...

'In contrast, Bougainville Methodism is New Zealand-based and coming north, and that's taking it out of the consciousness of Australian Methodism. So that in 1940 your Methodist missionaries there, Luxton, Alley, Voyce; and the Methodist lay women, teachers and nurses, such as Common, are all New Zealanders'. [Tape 6, side A; For Common and other women, see Beniston 1994.]

4. For a less tendentious assessment of Mesiamo, see Patrol Reports, Bougainville District, Buin No. 1, 1954-55 (Special), 10 July 1955, National Archives and Records Service of Papua New Guinea.

5. For pertinent illustrations of the Catholic 'metaculture', see Laracy [1999, 2000]. 


\section{APPENDIX 1}

\section{Diocese of Bougainville Statistics}

\section{Personnel:}

Priests -

Bothers -

Sisters -

Seminarians -

Marists

Native

Diocesan

$S \mathrm{M}$

F M S

B S J

S M S M

C S J

C S N

Madang

Ulapia

Chabai

Catechists -

Lay Missionaries -

Native Teachers -

Certified Male -

Certified Female -

Permit Male -

Permit Female -

II Population:

Total -

Catholics -

Protestants -

Catechumens -

Hahalis -

Pagans -

III Stations:

Main stations

Churches

Chapels

IV Medical:

Hospitals

Beds

Maternities

Births

Dispensaries

Hansenide

Patients

Staff:

$\begin{array}{lr}\text { Doctors } & 2 \\ \text { R Ns } & 15 \\ \text { M Assts } & 6 \\ \text { I M W A } & 14 \\ \text { Lab Tech } & 1 \\ \text { I M W O } & 1\end{array}$

16

1,431

25

1

48

2

15

6

14

1
1 July 1966-30 June 1967

VSchools:

Primary - 112

Boys $\quad 6,134$

Girls $\quad 5,729$

11,863

Secondary -3

Boys $\quad 176$

Girls $\quad 126$

302

Teacher training 2

Rigu 13

Asitavi 28

41

$\begin{array}{lr}\text { Total in above schools: } & 12,206 \\ \text { Catechists Trainees } & 38\end{array}$

Tearouki Nurse Trainees $\quad 15$

Chabai Seminary 23

Chabai Novitiate Trainees $\quad 10$

12,292

VI Spiritual Works:

Baptisms $\quad$ Children 2,609

$72,490 \quad$ Adults 25

54,289 Confirmations 1,485

11,961 Communions -

$851 \quad$ Devotional $\quad 895,350$

3,4449 Paschal 24,831

$\begin{array}{cc}\text { Marriages - } & \\ \text { Regular } & 297\end{array}$

30 Mixed 8

49 Disp Cult 8

425 Anointing of Sick 172

Deaths -

Children 198

Source: Leo L Lemay S. M. (Society of Mary, 'Marists') 3 August 1967 


\section{APPENDIX 2}

\section{Economic Development Projects Organised by the Catholic Mission in the Vicariate Apostolic of the North Solomons as at October 1966}

\begin{tabular}{|c|c|c|c|c|c|c|}
\hline \multirow[b]{3}{*}{ District } & \multirow[b]{3}{*}{ Project } & \multirow[b]{3}{*}{ Members } & \multicolumn{3}{|c|}{ CAPITAL (\$ Australian) } & \multirow[b]{3}{*}{ Equipment } \\
\hline & & & \multirow{2}{*}{$\begin{array}{c}\text { Members' } \\
\text { Contributions } \\
\$\end{array}$} & \multicolumn{2}{|c|}{ Grants } & \\
\hline & & & & $\begin{array}{c}\text { Amount } \\
\$\end{array}$ & Source & \\
\hline Lemanmanu & $\begin{array}{l}\text { Milling } \\
\text { Housing }\end{array}$ & $110^{*}$ & 2,000 & 2,000 & Oxfam & 2 sawmills \\
\hline Hanahan & $\begin{array}{l}\text { Milling } \\
\text { Housing }\end{array}$ & $200^{*}$ & 4,000 & 1,000 & Oxfam & 2 sawmills \\
\hline Gagan & $\begin{array}{l}\text { Milling } \\
\text { Housing } \\
\text { Copra }\end{array}$ & $20^{*}$ & 2,000 & 6,000 & $\begin{array}{l}\text { German } \\
\text { Government }\end{array}$ & $\begin{array}{l}1 \text { copra } \\
\text { dryer }\end{array}$ \\
\hline Gogohe & $\begin{array}{l}\text { Milling } \\
\text { Housing } \\
\text { Copra }\end{array}$ & $150^{*}$ & 3,000 & $\begin{array}{l}2,824 \\
9,412 \\
2,000\end{array}$ & $\begin{array}{l}\text { German } \\
\text { Government } \\
\text { Misereor }\end{array}$ & $\begin{array}{l}1 \text { tractor } \\
1 \text { workshop } \\
1 \text { sawmill }\end{array}$ \\
\hline Hantoa & $\begin{array}{l}\text { Milling } \\
\text { Housing }\end{array}$ & $150^{*}$ & 2,000 & Nil & & 1 sawmill \\
\hline Sipai & $\begin{array}{l}\text { Resettlement } \\
\text { Planting }\end{array}$ & 1850 & Nil & 5,000 & $\begin{array}{l}\text { Freedom } \\
\text { from Hunger } \\
\text { Campaign }\end{array}$ & 1 sawmill \\
\hline Kuraio & $\begin{array}{l}\text { Resettlement } \\
\text { Planting }\end{array}$ & 1500 & Nil & 5,000 & $\begin{array}{l}\text { Freedom } \\
\text { from Hunger } \\
\text { Campaign }\end{array}$ & $\begin{array}{l}1 \text { sawmill } \\
1 \text { tractor }\end{array}$ \\
\hline Torokina & Planting & 1100 & Nil & 7,000 & Oxfam & \\
\hline Sovele & $\begin{array}{l}\text { Road making } \\
\text { Land clearing }\end{array}$ & $\begin{array}{ll}g & 3500 \\
g & \end{array}$ & Nil & 11,059 & $\begin{array}{l}\text { German } \\
\text { Government }\end{array}$ & 1 bulldozer \\
\hline Moratona & $\begin{array}{l}\text { Milling } \\
\text { Housing } \\
\text { Road making } \\
\text { Land clearing }\end{array}$ & $\begin{array}{ll} & 220 \\
g & \\
g & \end{array}$ & Nil & 10,000 & $\begin{array}{l}\text { N C W C } \\
\text { Misereor }\end{array}$ & $\begin{array}{l}5 \text { sawmills } \\
1 \text { bulldozer }\end{array}$ \\
\hline Turiboiru & Milling & $100^{*}$ & 2,000 & Nil & & 1 sawmill \\
\hline Tabago & Milling & $100^{*}$ & 2,000 & Nil & & $\begin{array}{l}1 \text { sawmill } \\
\text { (2 rice } \\
\text { hullers } \\
\text { since } 1951\end{array}$ \\
\hline
\end{tabular}

* Denotes membership based on shareholding, usually one per family. The unstarred figures refer to actual or potential beneficiaries of projects. 


\title{
1914: CHANGING THE GUARD AT KIETA
}

\author{
by Hugh Laracy
}

\begin{abstract}
$\mathrm{A}^{\mathrm{s}}$ $s$ was also the case for the rest of what in mid-1914 was still German New Guinea, the political future of the Bougainville district was profoundly affected by World War I. The change from German to Australian control was a major step on the way that, in retrospect, at least, led directly to its eventual incorporation into the nation of Papua New Guinea. Portentous as their coming was - yet consistent with the neglectfulness that has tended to characterise central government's management of the remote south-eastern district - the Australians were late in getting to Bougainville.

On 19 August 1914 the troopship HMAS Berrima, a former P \& O liner, left Sydney carrying a 1,023 strong infantry battalion plus support units [Mackenzie 1927: 23]. It reached Rabaul, the administrative capital of German New Guinea, on 11 September. Two days later, after putting up a display of armed resistance, the German authorities there capitulated. Thereupon, Major Francis Heritage proclaimed the Australian military occupation of 'the whole Island of New Britain and its dependencies'. Over the next few weeks other German posts were taken over. On 17 October, for instance, the British flag was hoisted at Kavieng in New Ireland, and a small garrison was planted there [Senate 1922: 9-101].

Meanwhile, the German officials on Bougainville, informed by radio of what was happening in other parts of the colony, waited for the tide of occupation to reach them. An early intimation of that eventuality was given when two ships that had put out from Bougainville bound for Rabaul shortly before the start of the occupation were seized by the Australians; the Sumatra on 11 September and the Madang on 13 September. The latter, ironically, carried two British subjects who were being deported from Bougainville [Senate 1922: 132]. Late in November, in a gesture of resigned defiance, District Officer August Doellinger scuttled his two-year old 60-tonne steam launch Buka [Holmes to Minister of Defence,
\end{abstract}


15 December 1914]. But the German flag still flew at Kieta. Indeed, it was not lowered until 90 days after the occupying Naval and Military Expeditionary Force to German New Guinea (to give the force its full name) had reached Rabaul.

The countdown to that formal sign of defeat began on 7 December when the Meklong, a 438-tonne former Norddeutscher Lloyd vessel, sailed from Rabaul. It was captained by Lieutenant John Strasburg, a master who in pre-war years had become well acquainted with New Guinea waters and who had piloted the Berrima on its way to war. It carried two companies of infantry totalling 230 troops under the command of Lieutenant Colonel W. W. Russell Watson.

Two days later, at 11 a.m., the Meklong called at the village of Rorovana (a little north of Kieta) to enquire if there were any German troops on the island, a suspicion that had contributed to delaying the Australian advance [Mackenzie 1927: 117-8]. On being told that there were none, the Meklong then proceeded to Kieta, where it arrived at 1 p.m. The transfer of power was swift and undramatic. A party of soldiers led by Lieutenant William Holmes went ashore and changed the flags and brought the German officials and their families, together with two other Germans, out to the Meklong. The official deportees were:

Dr August Doellinger (district officer), plus wife and child;

Dr Kroning (medical officer), plus wife and child;

Herr Ewest (assistant district officer), plus wife;

Herr Fritsch (police master);

Herr Girnus (assistant medical officer).

After unloading cargo and stores and landing a 54-strong garrison, the Meklong was again ready for sea. At 6 p.m. that same day, 9 December, it sailed from Kieta. Before leaving Bougainville, it stopped at Tinputz and then on the north coast at Soroken. In doing so it became, said Strasburg, the largest ship to have hitherto passed through Buka Passage. The Meklong regained Rabaul at 3 p.m. on 2 December, and unloaded its prisoners. In his report Watson was especially generous in his praise of the captain. 'The services', he wrote, 'of Lieut Strasburg, the master of the Meklong [who was also familiar with Tok Pisin] were invaluable, and his navigation of the difficult waters of these islands relieved me of all anxiety as to the safety of the ship' [Holmes to Minister of Defence, 15 December $1914^{3}$; Strasburg to Prime Minister, 4 August 19154; Senate 1922: 12-13; Laracy 2002].

Meanwhile, the first Kieta garrison did not serve long. Lt. J. M. Maughan and his troops were replaced by Captain H. B. Ogilvy and a smaller party on 23 December [Holmes to Minister of Defence 19145]. Ogilvy, a severe official who soon attracted criticism from the Catholic mission by pressing for land rent 
payments, but who impressed his superiors, left Bougainville on promotion late in 1915 [Forestier to Woodford, 9 August 1915'. He was replaced as district officer by Captain George Simcocks. Under Simcocks and his three immediate successors, McGregor, Hunter and Somerset, the main aim of the Administration remained that of managing 'pacification'. Then, with the end of the war, Australian policy was broadened in the direction of 'development'. To this end Captain R. Charlton of the Survey Department was commissioned to report on the resources and commercial prospects of Bougainville [Mackenzie1927: 283]. His report was favourable, especially for the north-east. ' ...there are upwards of 20 large plantations along the coast [Appendix 1]. Excellent harbours abound everywhere, and the producer has no difficulty in getting his copra away'. For tapping the resources of the 'southern and south-western districts', Charlton advocated a 'vigorous policy of road-building' [Administrator to Secretary of Defence, 22 April 19197].

A particular effort to realise these possibilities was made by Captain H. C. Cardew, who had become district officer late in 1918. Writing in January 1920, Maurice Boch, the newly appointed superior of the Catholic mission, and himself recently demobbed from the French army, was unstinting — indeed, extravagant — in his praise of Cardew.

We started our work in these Islands 21 years ago and I am here myself from (sic) 14 years. I have seen the administration of the Germans in time of peace - of Australia in time of war. I have been the witness of many, too many, methods and trials - the ones helping, the others stopping the progress of the Colony. But I must confess how I have been agreeably surprised when after two years absence, I came back from the Western Front, I found that more has been done during that short period, than from the beginning of colonization.

Splendid roads are uniting with the sea the different villages disseminated far away in the bush; bringing, by the facility of communications, the pacification of the wildest countries of Bougainville, AND stopping the secular fights which took place in these spots.

With a handful of police boys, the District Officer has the situation well in hand.

The murders, too many times, have been punished by bloodshed, [with] the innocents paying for the guilty ones. Now, according to the justice, the guilty men are traced, taken and punished.

All [sic] the villages in that vast District of Bougainville and Buka have been entirely [sic] rebuilt according to the rules, not only of the hygiene but of aesthetics. They are quite clean, look very nice and the natives are proud of them. 
I am glad to say that Captain H.C. Cardew, presently in charge, is responsible for all these changes, and I feel it is my duty to let you know what he has done, because he did all this nice work not for show or for any personal interest, but for the benefit of all [Boch to Administrator, 26 January 19218].

While the 'improvements' of which Boch is so admiring may not have been as great as he says, or unequivocally in the best interests of the villagers, his comments are valuable in that they help illuminate a significant episode in the history of Bougainville's engagement with external forces and in the lives of its people, especially in the south. A less visible but more far-reaching outcome of World War I was the allocation of German New Guinea — including Bougainville — as a League of Nations C-class Mandate to Australia late in 1920. 


\section{APPENDIX 1}

\section{Commercial Land Holdings Registered in 1912-1914}

[The actual place names have been left in German as they were then recorded, so that Ernus/Enus is known today as Inus; but geographic features that are part of a name — cape or bay — have been translated.]

\section{KIETA District Office}

1. Mrs Calder,

2. Mrs Calder,

3. Peter Hansen,

4. $\mathrm{H} \& \mathrm{Co},{ }^{9}$

5. Adam Forsayth, 10

6. Forsayth/Lukas,

7. Forsayth/Lucas,

8. Vella Lavella Plantation and Trading Company /

R.H. Cogswell,

9. C. Piggott,

10. Buka Plantations and Trading Company Numa Numa,

11. Buka Company,

12. Captain Hamilton,

13. Choiseul Plantations Ltd / Hans Fischer, Rabaul,
42 Ha @ 5 M, Toboroi, 1912

50 Ha@5 M, Eko-Igison, 1913

1000 Ha@ 5 M, Kekere (Bangassa Popoto), 1913

270 Ha@ 5 M, Arawa, 1913

$1000 \mathrm{Ha} @ 5 \mathrm{M}$, in Buin, 1912

1000, $2000 \mathrm{Ha} @ 5$ M, East Coast Bougainville, between Oropera and Kasipauwaa Rivers, 1913 1000 Ha@5M, Tangra and Baniu Harbour, 1914 1000 Ha@ 5 M, Moruna-Enus, 1912

300 Ha @ 5 M, Numa Numa Bay, 1912, 1914

P. [Piggott] receives another $200 \mathrm{Ha}$

500 Ha@ 5 M, Asapiripiri, 1913

$500 \mathrm{Ha} @ 5 \mathrm{M}$, Tetabutub, 1913

500 Ha @ 5 M, Teari, East Coast, Bougainville,

Place Ernus, 1913

2000 Ha @ 5 M, Cape Le Gras, 1913

[Notes from Grundbuch (register of landed property), by courtesy of Dr Peter Sack]

\section{Endnotes}

1. 'Report on the Claims of Captain J. Strasburg for a War Gratuity', Journals of the Senate, Parliament of Australia, No. S. 1.

2. 'Report on the Claims of Captain J. Strasburg for a War Gratuity'.

3. ref: 33, 33/39 AWM (Australian War Memorial Archives).

4. ref: A518, G822/1/3 NAA (National Archives of Australia).

5. ref: 33, 33/39 AWM.

6. ref: A1/15, 1915/25424 NAA.

7. ref: $33,56 / 2$ AWM.

8. ref: $457,701 / 1$ NAA.

9. Hernsheim and Co.

10. Sydney representative of Walter Lucas. 


\section{BETWEEN THE WAITMAN'S WARS: $1914-42$}

by Peter Elder

The progress of the indigenous races of New Guinea is in the hands of three great forces - the Administration (which is responsible for government and health), missions, and commercial enterprise ...

Native life, however, is a very delicate and complex structure, built up by various ideas and practices ... As many of these conflict with the standards of government, they must be modified ... [It is] ... inevitable that ... the native, with integral parts of his life and activity lying broken before him, constantly finds himself in a sea of doubt and bewilderment, unable to realize the justice of our actions or their benefit to himself.

(E. W. P. Chinnery, Government Anthropologist of the Mandated Territory of New Guinea in 1924-1939 [Australia 1926: 82-3]).

\section{INTRODUCTION}

Bougainvilleans have inherited the effects of two major foreign wars. The first started in Europe in 1914. Germany's participation had important consequences for the Pacific after the allied victory of 1918 when Germany lost its colonies. The terms of the 1919 treaty of peace put German New Guinea (including Bougainville) into Australian hands [Lyng 1925: 213]. At the peace conference Australiass Prime Minister William Morris Hughes had demanded New Guinea to counter Japanese aggrandisement in the Pacific. An ally of the victorious powers, Japan had been awarded control of other former German island colonies in the Pacific. These were the Marianas, the Carolines and the Marshalls, all to be strate- 
gically important during the Pacific war after 1941 [Oliver 1962: 142]. The second of the European wars erupted in 1939, following the invasion of Poland by Germany, and ended in 1945 having spread to the Middle East, South-East Asia and the Pacific.

Japan and the United States had fallen out during the 1930s over the Sino-Japanese conflict. An American embargo on oil for Japan's armies in China fomented a crisis that led to war between the United States and Japan, precipitated by a pre-emptive attack on Pearl Harbor by Japanese aircraft in late 1941. The belligerents contested control of the Pacific and South-East Asia, transforming the conflict into a global war that terminated with the defeat of Germany and Japan. The fighting over Bougainville during the first war of the waitman ('White' or European person or persons) was trivial (see Laracy, 'Changing of the Guard', this volume) compared with the effects of military operations mounted in $1943-45$ by the United States and Australia against the Japanese forces on the island.

The Australian administration of Bougainville, suspended during the Japanese occupation of 1942-45, lasted from December 1914 until September 1975 when Papua New Guinea gained independence. At first, a military expeditionary force controlled civil affairs until replaced in December 1920 by a colonial Administration based in Rabaul. Its C-class Mandate from the Trusteeship Council of the League of Nations obliged Australia to take care of the Territory of New Guinea (TNG) until it was ready for self-determination. This goal had not been even nearly attained when the Japanese landings disrupted Australia's civil authority on Bougainville.

This chapter is a thematic sketch, extracted from archival and secondary sources in Australia illustrative of the colonial Administration, missionary undertakings, and the plantation economy imposed on the Bougainville people between 1914 and 1942. The Western presence was first implanted in Bougainville before 1914, then under German administration. Chinnery's model of the main features of Australian colonialism in New Guinea - the Administration, Missions and Plantations - shapes the chapter. It does not aspire to be the elucidatory history of Bougainville prescribed in the 1970s [Griffin 1973a : 444]; it is a survey of events in Bougainville during the three decades before World War II when the exotic, particularly black culture, fascinated Europe. This phenomenon emerged late, in the wake of the abolition of slave trading in European colonies; it was a reaction by Western intellectuals to colonialism and provided the spur for anthropologists, ethnographers and collectors of material culture to work in the Melanesian world and other places of black culture. These specialists have a place here because of their contribution to understanding the background of some historical sequences and it is for them to uncover the myths, fables and magic 
knowledge of Bougainvilleans markedly absent from this account of Bougainville between the wars.

Until constitutional authority for many aspects of the Bougainville Peace Agreement was enacted by the Papua New Guinea Parliament on 26 March 2002 [Post Courier, 27 March 2002], a 'regional' history of Bougainville was an acceptable concept. However, prospective autonomy for Bougainville, within the political boundaries of Papua New Guinea [Post Courier, 6 January 2003,] suggests the possibility of a different approach directed at an 'independent' Bougainville and written from a local perspective.

An impartial treatment of both the colonised and the colonisers is vital for an informed historical account. It has been suggested that 'In a period of energising nationhood, it would be tragic if we lost sight of the need to record the experiences of white people in Papua New Guinea, although the focus of attention has changed' [Griffin to F. P. Archer, 24 May 1974, Pacific Manuscripts Bureau (PMB) 1184/4]. However most of the written sources relating to Bougainville before Papua New Guinea's Independence were produced in the colonial context and reflect European attitudes in the administrative history of the rest of colonial Papua and New Guinea. This is documented extensively in the official records of contacts with the local people detailed in the patrol reports, the Administration's annual reports, mission records etc. [McPherson 2001: 10].

Apart from the copious mission correspondence, few records survive of Bougainville between the two wars, and they are white man's records only. In them locals are largely ignored. This is the lacuna in the sources that confronted James Griffin in 1974 in researching the career of Paul Mason, a leading coast watcher on Bougainville during World War II. Griffin notes that the true history of the Australian evacuation from Bougainville (notably, the hasty abandonment of the Kieta District Office on 23 January 1942) and how the local people reacted and felt about the departure of the Australians has gone unrecorded [Griffin to W. J. Read, 14 May 1974, PMB 1184/4].2

By the 1920s, Buka, much of the surrounding islands, and large parts of Bougainville Island, except in the south, had been transformed into plantations. Many had been pioneered by German settlers and were located wherever the terrain was suitable. The nomenclature adopted by Europeans for most of the plantations derived from the terms locals used for those places. Such names (for example, Jame, Raua) had cultural significance [Archer to 'Moocha', 10 March 1928, PMB 1184/4] ${ }^{3}$ for the local people [Blackwood 1935: 17-18]. For a Waitman, however, the name of the plantation was known by the European planter's name followed by what was understood to be its location; e.g. Archer at Jame, Campbell at Raua. 
A scholar from the Pacific has to acknowledge the beneficial collocation of colonialism and traditional societies culminating in the independent state of Papua New Guinea [Lātūkefu 1989: xi]. This work celebrates the synergy from the entwining of two substantially different cultures; however, it does not deal with the problem that interpretations of acculturation and of conflict resolution are often based only on the colonists' accounts of dealings with the locals. Re-examination of analysis of the data by an educated Bougainvillean who has a universal intellectual outlook, but has cultural origins in Bougainville could provide a fresh view of the impact of colonial institutions on the island's traditional society [Griffin 1973a: 442-3, 435].

\title{
THE ADMINISTRATION
}

\author{
'uncontrolled' area - exploratory patrols \\ 'under government' — pacification, arrests \\ 'under administrative control' — census, luluai
}

[Brown $2001: 22]$

In 1921 Bougainville had a population of 46,832. The Australian Administration governed from Kieta, an outpost of 119 men and 29 women. The district officer at Kieta was the delegate of the New Guinea government at Rabaul and carried out in Bougainville the policies prescribed for the Territory. He controlled a 'native' police force of 40 constables and five junior officers [Australia 1921: 134, 138, 119].

As in Papua, the New Guinea mandate had to establish its authority by pacification, fostering commerce and promoting native welfare. Lamentably, there was no Hubert Murray to guide New Guinea towards a self-governing civil society, a task that had to be undertaken at first because of the military occupation of the plantation colony.

In 1921, there was a smooth transition of authority when the military administration ended and the civil power took over. When the troops returned to Australia, some military personnel continued their municipal work as officers of the New Guinea Public Service in field positions as well as at the Rabaul headquarters. The Expropriation Board then emerged as the predominant force in the Administration because of its engagement in the maintenance and disposal of the former German plantations and business undertakings [Rowley 1958: 33].

The allocation and registration of land for Europeans was a major task for officers of the Administration who had to negotiate with owners, approve valuations, and prepare documents for the registrar of titles in Rabaul [Stuart 1977: 
83]. In 1926, the district officer at Kieta, Major T. L. McAdam, dealt with payments to traditional owners for land granted to Australian companies by the German Administration before 1914 [District Officer, Kieta to Choiseul Plantations Limited (CPL) Soraken, 18 September 1926, NBAC, NM 115/156]. Documentation for new titles required under the Territory's land laws had to be issued for plantation owners such as Choiseul Plantations Limited (CPL, a subsidiary of Burns, Philp \& Co Ltd, - Burns Philp (BP) in common parlance). These replaced those previously issued by the Australian military Administration in accordance with German law [Secretary Choiseul Plantations Ltd (CPL) to Burns Philp, Rabaul, 18 March 1927, Noel Butlin Archives Centre (NBAC), NM 115/156]. ${ }^{4}$

Police posts manned by 'native police' [Chinnery to Admin, Rabaul, 6 March 1936, NLA, MS 766/6/1] ${ }^{5}$ were under the supervision of Australian patrol officers [TNG Annual Report 1924: 57]. A police post had been established at Kangu on the Buin coast in South Bougainville in 1919 [Connell 1978: 49] but regular patrols did not take place in the region until after 1933 although some patrols were made in 1924-25. There were 21 patrols in the Kieta District during 1932-33 of which 16 dealt with tax collection, census recording, plantation inspections and routine police matters. Most of the remaining patrols were expeditions to penetrate and consolidate 'new country' so that most of Bougainville could be regarded as 'under complete control'. Patrols also snuffed out cargo cult disturbances on Buka [Unpublished report on Native Affairs and District Administration, National Library of Australia (NLA), MS 766/6/1, 1932-33].

The government anthropologist for New Guinea, E. W. P. Chinnery visited Bougainville sometime between October 1928 and June 1929, taking a census and recording ethnographic data [Chinnery 1930]. In the aftermath of the sectarian strife in Siwai (see Laracy, 'The Pacification of Southern Bougainville, 1900-1930' this volume), Chinnery attempted some conciliation, which was rebuffed by the combative leader of the Marist mission on Bougainville, Father Maurice Boch [Laracy 1976: 62-3]. Almost 50 years later, Jill Nash [Nash 1974: 8], a respected academic anthropologist and experienced field worker in south Bougainville, concluded that Chinnery had ended feuds and ambushes in the south of Bougainville. A response to the scarcity of trained patrol officers involved liaison between the Administration and the traditional authority system through government-appointed kúkurais (government-appointed village headman; Tok Pisin for rooster) [Thurnwald, R., 1936b: 351].

The line village consolidation program that started in the 1920s [Callan 1976: 3] was a salient feature of Australian Administration on Bougainville. People were displaced from traditional hamlets that consisted of a group of two to 
nine houses, usually clustered near water and concealed from passing strangers. To maintain their local privacy and access to water the occupants of these hamlets often changed location. The line villages were examples of applied social planning by white administrators. Chinnery, impressed by a report of a native hut seen in 1925 at Ieta on Buka Passage, had some reservations and thought a compromise was possible between retaining the customary type of dwelling and introducing European standards of hygiene [Chinnery to Government Secretary, Rabaul, 25 November 1925, NLA MS 766/5/2 $]^{6}$. Regimentation in the line villages was thought to condition the able-bodied men to the barracks discipline on the plantations where they could be recruited as labourers. However, the administrative convenience of rationalising the locals' housing arrangements cut across traditional cultural ways.

The economy of Bougainville, in common with the rest of New Guinea, was dependent upon the export of copra and the importation of trade goods and supplies for the plantations [Rowley 1958: 7]. The German Administration's policy was that the colony should be developed as a business proposition and that the local people be treated humanely. This latter aspiration was ignored if it endangered commerce. The British approach to colonisation shared the same commercial objective but regarded the welfare of the indigenous people to be an inalienable trust [Lyng 1925: 10]. Seaforth Mackenzie [Mackenzie 1927: 224] declared 'the true doctrine for the colonisation of a tropical possession is that the governing race is not there for the good of its own nationals but for the good of the people of the country'. Tom Harrisson, disillusioned by fine words like Mackenzie's, after a lengthy sojourn in the New Hebrides in 1934, decided that it is 'very hard to believe any more of the stuff we British talk about developing and protecting native races' [Harrisson 1937: 204-5]. He was referring to the effects of plantation life upon the locals and its 'blackbirding' antecedents in Melanesia that he thought had been condoned by the British government, despite having abolished the slave trade in the 1830s.

When the Australian occupation force took over the administration of German New Guinea in 1914 it adopted a 'business as usual' approach that secured the cooperation of the German business community and planters [Rowley 1958: 7-10]. This felicitous situation ended when civil authority replaced the military Administration on 9 May 1921, foreshadowing the strict enforcement of the provisions of the Treaty of Versailles that affected New Guinea. The Australian government expropriated the plantations, stores, buildings, ships and other property of the German settlers whose only recourse was to claim compensation from the German government [Lyng 1925: 213]. 
In 1927, the Australian Commonwealth government issued three catalogues of former German-owned plantations, trading posts and business sites, in TNG, including Bougainville, available for sale by tender on terms reasonable to Australian ex-servicemen. This was the work of the Expropriation Board, set up after a royal commission on New Guinea on which W. H. Lucas had served as a commissioner. Lucas had been a senior manager for Burns Philp; predictably, he was appointed chairman of the board. The board had paramount authority in land matters and the chairman was considered more powerful than the Administrator of the Territory [Griffin, et al. 1979: 49-50], since he had direct access to the Australian federal minister in Melbourne through Burns Philp connections. Confidential messages were exchanged between officers of the board and the chairman of Burns Philp concerning tenders to be discussed in cabinet [Mackenzie to Major Potts, 13 April 1926, NBAC, NM 115/145]. A board officer lamented he was 'not able to catch my friend Major Marr, Minister for Home and Territories and Secretary to Cabinet ... probing matters in PM's department ...' [Potts to Burns, 26 April 1926, NBAC, NM 115/145]. This was political cronyism favouring the interests of Burns Philp.

Fred Archer, an ex-serviceman from World War I, acquired Jame plantation on Buka Passage. He was scathing about the occupation of former German New Guinea by Australia, and of the Australians as '... a rough and ready crowd with rough and ready methods' inclined to 'making do'. He regarded this careless approach as a dereliction of the modernisation the Germans had attempted [Archer to 'Moocha'].

The rundown state of the plantations was evident after the deportation to Germany of the former managers. By 1917 internment in Australia and deportation to their homeland had already depleted the numbers of German settlers and planters [Rowley 1958: 57]. The complete exclusion of Germans from New Guinea in 1920 accelerated the dereliction of Bougainville agriculture [Rowley 1958: 317].

Criticism of the Australian Administration also came from Chinnery [Chinnery to Government Secretary, Rabaul, 5 April 1928, NLA, MS 766/5/3] who recounted that:

... the experienced German officials and planters with their firm and definite methods, were followed by military officials and planters, most of whom had no previous experience in native life or in handling natives. Whipping was abolished and the native was told much more about the brotherhood of man than was good for him, and he learned more of the vagaries of the 'New fellar Master' than he was capable of understanding ... nothing so injures the pres- 
tige of the Government in out-lying districts as delay in adjusting disorders of this kind (tribal fighting in New Britain).

Effective pacification had to be exerted if the plantation economy was to thrive; the Australian military faced this problem within a year of its initial landing at Kieta. The Australians inherited from the Germans the problem of cannibalism and headhunting and the 'skirmishing frontier' (Rowley's term), but there were no restraints of the kind Hubert Murray put on pacification in Papua [Rowley 1958: 199]. The German colonial Administration had been stigmatised for instilling fear in the locals because of its repressive and brutal means of pacification [Mackenzie 1927: 223] but the Australians did not shrink from using similar methods. The official Australian war history asserts that internecine fighting and head hunting were eliminated under the Australian regime and that 'the cannibal has become a gardener, and the head-hunter a tax-payer' [Mackenzie 1927: 226]. This was a transformation accomplished with conspicuous brutality.

Since 1912, cannibals from the mountains of the northern part of inland Bougainville had made frequent raids on the coastal villages and islands. On the north-west coast at Soraken plantation, women were abducted and labourers who strayed into the bush were slaughtered for cannibal feasts. Mackenzie asserts that the local tribes were controlled by 'an influential cannibal chief' called Bowu from Kaumumu and that the overseer at Soraken had been threatened by Lapapiri, the kukurai at Kiki village, while attempting to apprehend absconding labourers [Mackenzie 1927: 307-8].

In October 1915, more than 60 native police were deployed around Soraken by the officer-in-charge of native affairs at Rabaul. The Australian military commander at Rabaul wanted to avoid a punitive expedition and directed the party to deal only with Bowu and his followers [Rowley 1958: 198]. However, the expedition leader decided to attack Bowu's village at Kaumumu. Bowu was killed and his severed head displayed to the local people. A similar incident took place at the nearby village of Kiki where the paramount chief Lapapiri was shot dead [Mackenzie 1927: 309-10].

The raid resembled a military operation because both the innocent and the guilty may have died [Rowley 1958: 198]. The Irish-born expedition leader and his brother had conducted similar punitive raids in New Britain earlier when villages were burned down and suspects were shot and their heads put on public display [Rowley 1958: 196], 'with the idea of impressing the local natives' [Mackenzie 1987: xxviii]. ${ }^{7}$ This action can be seen as part of the customary retribution exercised by various colonial powers, including the British, in the Pacific. 
Apart from the moral enormity of what the Australians had done it is doubtful if the display of severed heads had the intended effect since these acts had taken place outside the customary ceremonial context. Nevertheless, the Administration and the manager of Soraken plantation commended the leader of the expedition [Rowley 1958: 198-9].

The Telei speakers of southern Bougainville living on the great Buin plain [Oliver 1949: 3] regarded head hunting as socially acceptable but were not cannibals. A German ethnographer who had observed the Telei for six months in 1911 wrote:

random murder, that is not politically sanctioned, is unknown; these are ancient customs and must be accepted as part of the culture. Enemies cannot be killed without the consent of the village headman. He is the ultimate authority in all instances [Frizzi 1914: 21].

The raid at Kaumumu in northern Bougainville was part of a campaign to eradicate the cannibalism prevalent in that locality [Südsee Handbuch, in English, 1917-1920: 98]. The practice was considered by Mackenzie to be the result of a low protein diet and a way of celebrating victory over one's enemies [Mackenzie 1927: 219-20], but this is a questionable conclusion. Almost 60 years later Eugene Ogan carried out fieldwork among the Nasioi of south-east central Bougainville observing mortuary feasts which he regarded as non-lethal reflections of past traditional head hunting rites that had social significance not confined to celebrating victories. Failure to observe customary gift exchange obligations, and other lapses, could be settled at these feasts by taunts and punishment symbolised in ceremonial acts of reconciliation [Ogan 1972: 35-7]. ${ }^{8}$

An example of past practices modified into less lethal forms was observed by Beatrice Blackwood on the east coast of Buka in 1929. It concerned a stone the locals called Tchinaleke which represented a woman who persuaded people to eat human flesh by feeding her daughter and son-in-law portions of her own flesh saying it was pig [Blackwood 1935: 530]. Here a shameful practice — 'shameful' in terms of Western ethics — was subsumed in myth.

The effectiveness and social consequences of the punitive expeditions and other measures undertaken by both the German and Australian administrations were demonstrated by a notable German ethnographer, Richard Thurnwald, who visited Buin in 1908-09 [Lowie 1954: 3] and 1933-34 [Elkin 1954: 127]. He found Buin in 1908 to be a densely populated landscape not yet engulfed by European influences, although a small Marist mission had been established there 
before the German outpost [Thurnwald 1936b: 347]. He described the endemic violence marked by the customary head hunting and collection of skulls in the district. Thurnwald felt at ease among the head hunters because of the respect he was accorded as a white man [Thurnwald 1936b: 356]. This impression was in part dispelled in 1933 when Thurnwald returned to Buin and discovered the local men were now more inclined to cheat and rob him. A less negative impression, foreshadowing Ogan's findings, was formed when Douglas Oliver found that among the Siwai in 1938 feast giving had become a surrogate for fighting and in the village club houses the jaw bones of pigs had replaced the human skulls formerly found there [Oliver 1949: 34].

The Australian control of Bougainville had changed many things during the 25 years between Thurnwald's visits to Buin. The expansion of the missions had promoted a spread of literacy among the young men working on the plantations. An increase of trading in copra from the 'native groves' had been stimulated by the introduction of a cash economy, confined largely to petty trading in coconuts, copra and pigs. Shell money was supplemented by silver coinage, largely introduced by the labourers who had returned to their villages after their contracts had expired. People found themselves confronting and absorbing new ways but the most profound changes came with the erosion of chiefly authority around Buin.

The core of the local culture was weakened when a patrol captured and hanged three obstructive chiefs in reprisal for the killing of two locals who were policemen. Replacement of these chiefs by kúkurai who were not from chiefly families, and the destruction of the ceremonial hall of the paramount chief of Buin, crushed all visible opposition to the government. This exercise of power helped the Administration to eliminate head hunting and expedite the mustering of workers for the plantations because the safe entry of labour recruiters into an area previously closed to them was now assured [Thurnwald, R., 1936b: 353].

Mesiamo, born in south Bougainville in about 1905, cooperated with the Administration. A 'big man' from the Nagovisi village of Biro, he was interviewed by Jill Nash in the early 1970s [Nash 2001: 112-24]. ${ }^{9}$ During the Australian campaign to re-capture Bougainville from the Japanese in 1944-45, Mesiamo encountered an Australian commando unit that used his negotiating skills to conciliate the Nagovisi and the Siwai in allowing soldiers to operate from a Siwai village [Long 1963: 145]. Lucy Mair [Mair 1948: 202-03] credits Mesiamo for his leadership in the post-war reconstruction of Nagovisi. Nash sees Mesiamo as a south Bougainville man of consequence but one who failed to realise his potential as an indigenous leader because he succumbed later to the Administration's paternalism. In Buin and the rest of Bougainville the traditional order of society was replaced by passive compliance with the white man's wishes as exemplified by Mesiamo [Nash 2001: 114]. 
The civil Administration pursued pacification less ferociously than its military predecessor to make the plantation economy secure. Punitive expeditions were conducted on a moderate scale, and the patrols were directed to undertake routine tasks. Native welfare, apart from the line village consolidation, was tackled by organising tultul, that is, men who assisted the government-appointed village headmen, the luluai, or kukurai, and their assistants, in a range of duties, especially as medical orderlies and sometimes as interpreters; in 1924 there were almost 70 tultul serving a population of 3,500 in the Kieta District [TNG Annual Report 1924-25: 50-2]. The Territory Annual Report notes that men recruited to work on the plantations suffered because 'imported Chinese rice' replaced their diet of taro and yams [TNG Annual Report 1924-25: 41]. The report also refers to native groves where the local cultivators were encouraged to enter the copra trade with their small annual plantings [TNG Annual Report 1924-25: 36].

Head tax was applied to areas that were considered under complete 'government control' and, in 1924, the Kieta District yielded $£ 3,257$, or slightly less than $£ 1$ per head of the recorded population. Since the tax was 10 shillings per head this suggests that more than the recorded population numbers paid tax. At the Permanent Mandates Commission in Geneva the British authority on colonialism, Lord Lugard, asked Chinnery if the head tax was too high. Chinnery said that when the copra price was high there was no difficulty in collecting tax. $\mathrm{He}$ prevaricated, since the global economic depression of 1929 had ruined the copra trade [TNG, Annual Report 1934-35: 8]. Mackenzie asserts that the expansion of areas put under 'control' was simply to enlarge the catchment area for head tax [Mackenzie 1927: 226-7].

The Australians had adopted many aspects of the previous German Administration. There was little difference between the two colonisers except for the expropriation policy and the line village consolidation program. The Germans had done the pioneering work in the colony and the Australians made this the foundation for colonial management.

\section{MISSIONS}

on Bougainville Island, Methodist and Catholic converts were burning down each other's chapels as late as 1930 - to the considerable embarassment of their spiritual mentors [Oliver 1962: 113].

Hugh Laracy and Elizabeth Momis have dealt in detail with the influence of missionaries on Bougainville elsewhere in this book; accordingly, there is only a brief account of the missions here. 
The modernising society introduced by Europeans into the Melanesian world concentrated on the rejection of traditional beliefs, creating cultural tensions that Western christology did not reconcile completely. The official view was that 'the new social and religious ideas introduced struck killing blows at the very root of native culture ... in almost every district where missions have become established, the old customs are rapidly disappearing' [TNG Annual Report 1932-33: 158].

The Catholic Marists had come to Kieta in 1901, followed by the Methodists of the Missionary Society of New Zealand in 1921 and the Seventh-Day Adventists in 1924 [TNG Annual Report 1929-30: 105]. The monopoly of Catholic Marists in Bougainville was threatened by the Protestant sects that arrived after the establishment of the Australian civil Administration in New Guinea. Tensions between the missionaries came to a head in the late 1920s. Partition of territory for evangelism caused sectarian disturbances in the Kieta district in 1929 between Catholic Marists and Protestant Methodists [TNG Annual Report 1929-30: 105] There were also quasi-religious cargo cult outbreaks in Buka and Bougainville in the late 1920s and the early 1930s [TNG Annual Report 1935-36: 21].

These events were a reaction to the acculturation locals had suffered from the advent of colonisers and missionaries. Under the German Administration in the early 1900s, the Franco-German Marists had been encouraged to establish and expand their mission in Bougainville [Laracy, this volume]. The Marists operated plantations on a commercial scale to defray their costs and introduce their adherents to industrial labour. The arrival over the next decade of new religious adversaries - the Methodists and Seventh-Day Adventists - was a serious affront to the Catholic Marist Fathers. Father Albert Binois SM, prefect apostolic [McHardy 1935: 96-7], writing to his pupils in Rome from Koromira, described the interlopers as 'the friends of the devil' [12 May 1929, PMB 4]. ${ }^{10}$ Protestant zealots threatened the monopoly of conversions hitherto enjoyed by the cosmopolitan Marists (now augmented by Americans and New Zealanders) leading to outbreaks of violence between the followers of the competing denominations, egged on by their mentors [TNG Annual Report 1929]. ${ }^{11}$

James Griffin has made two points of significance relating to the missions [1995: 10]. First, the Marists and Methodists came to Bougainville from the Solomons, a fact that enhanced a 'sense of Solomons identity' among the local followers of these missions but isolated them from affiliation with New Guinea. Second, from 1914 the Australian Administration and the Marists did not always share a common objective for the locals. In 1930 Father Boch, head of the Marists at Koromira, complained to the district officer at Kieta, Major McAdam, that the 
Administration condoned polygamy under the pretence of preserving 'native' culture. (Boch considered it a form of slavery that contravened the terms of the League of Nations Mandate.) Boch also contended that in the Territory of New Guinea there was no separation between Christianity and paganism [Father Boch to Major McAdam, 7 February 1930, PMB 4]. This is how the mission could register its dissent from official policy.

Dissent was not confined to the Marists. A Bougainville sceptic, Mesiamo, grew to adulthood before the full impact of the missions was imposed upon the Nagovisi and stood out in contrast to island leaders nurtured by the churches [Nash 2001: 123]. If more life stories of individualists like Mesiamo could be collected then a significant and affective picture of Bougainville society in the first half of the 20th century may emerge for serious historical attention.

\section{PLANTATIONS}

... scientific technology applied to agriculture in the Far East and in the last years of German rule in New Guinea was subsequently neglected prior to the 1950s in favour of mortgage deferments, close control of the Melanesian market for copra and discouragement of indigenous entrepreneurs in competition with estates. [Newbury 1989: 41]

The lack of specific records of the land holdings of small local copra producers frustrate a complete enumeration of the plantations operating between 1914 and 1941 These were concealed in aggregate figures that appeared in the Territory's annual reports that did not identify individual 'native groves'. The distribution of European plantations on Bougainville before 1942 was mainly on the east coast and Buka [Connell 1978: 52]. The south of the island had been used by the Germans as a labour source rather than as a copra producing area [Connell 1978: 49] and the only European plantation in the region was Toboruai established in 1930 in the hinterland of Kahili [Connell 1978: 54-5]. Connell suggests the traditional gardens in the Siwai met the locals' needs and the remoteness of the region made the transportation of food surpluses impossible [Connell 1978: 60].

German enterprise in the region had been considerable: 'the German companies which began to be a power in the Pacific about 1875 ... during the next twenty years, opened numerous stations ... from China to Samoa ...' [Cilento 1928: 1]. Expansion of the Hamburg trading firm of Godeffroy und Sohn and others into the Pacific [Hempenstall 1978: 16] had directed the attention of the German government towards New Guinea where it expected a private company could be made responsible for the colonial Administration as well as commerce. 


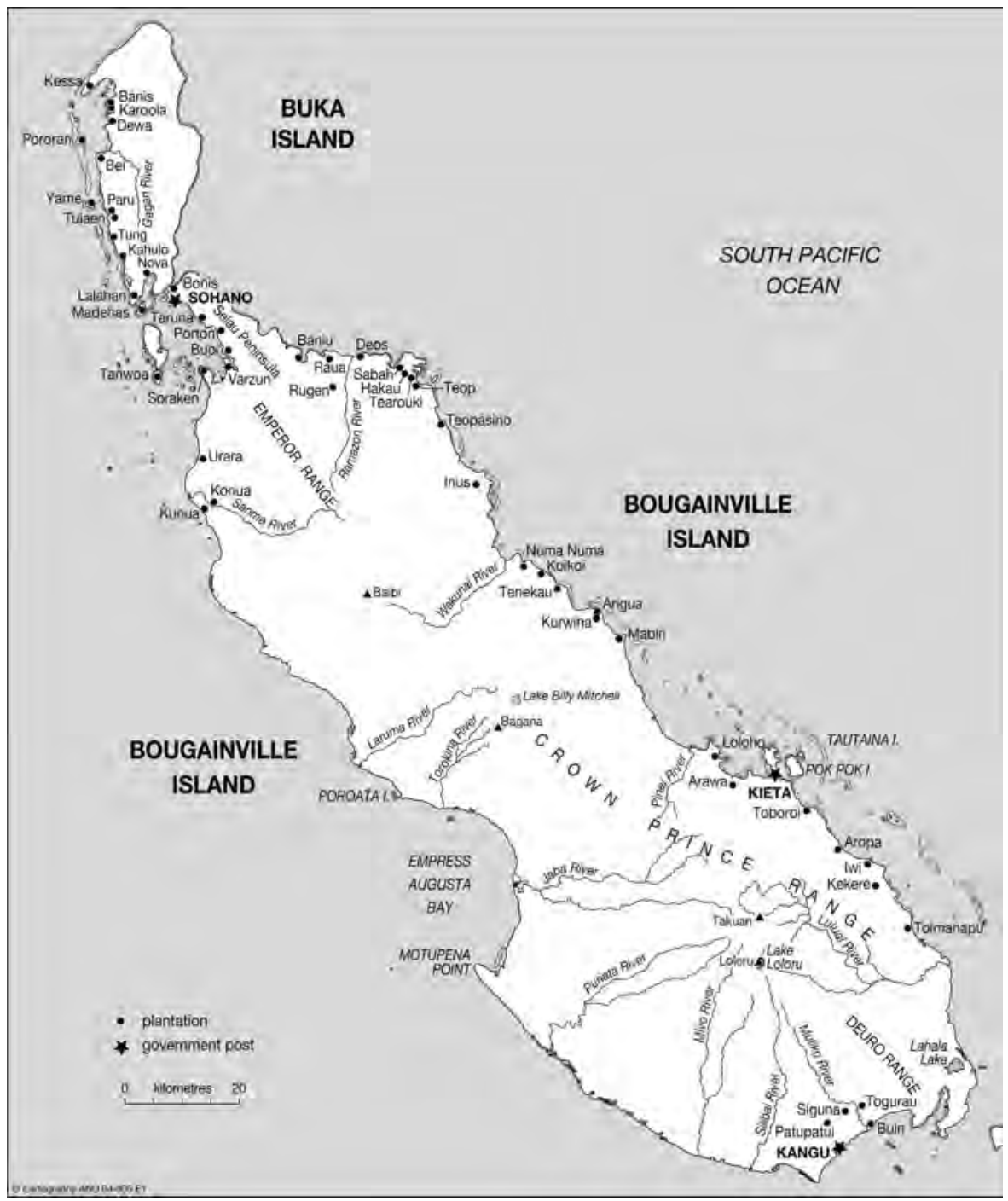

Map 1. Plantations in 1948-1968

The German New Guinea Company was formed but had failed by the end of the 19th century, and a German colonial Administration had to take over its non-commercial activities [Newbury 1989: 42-3; see also Sack, this volume]. However, the company did become a commercial success when its investment was redirected into what Newbury calls 'that mixture of plantation and Melanesian copra-marketing' that eventually snowballed into a valuable asset that later fell into Australian hands. 
By 1918, many of the villages in Bougainville had been subjected to the labour recruiting instituted in 1887 under German control [Deutsche HandelsUnd-Plantagen Gesellschaft (DHPG) or German Trading and Plantation Company 1887-1914, PMB 1210/1]. Before colonial contact, these communities had experienced 'decades of autonomous adaptation to sedentary agriculture' [Newbury 1989: 37]; they were seen by the German managers of the New Guinea Company in 1887 as garden cultivators unaware of their potential to produce beyond immediate needs. Accustomed to working the soil, their skills could be adapted for the plantation industry. The New Guinea Company noted this opportunity because the DHPG, a chartered company, backed by the German government, had used Solomon Islanders satisfactorily in Samoa as plantation workers [Sack and Clark eds and trans. 1979: 20]. So, too, Bougainvilleans were judged suitable subjects for the industrial discipline imposed by German colonisers in the ethnographic tradition of the 1860s, a doctrine that sought a humane alternative to slavery [Pels and Salemink 2000: 20]. This was accompanied by the assumption that native peoples could not withstand the onslaught of modernity because of their subservient character; nevertheless, this same trait made them tractable for a plantation work force.

German ordinances regulated the conditions of labour with little regard for the welfare of the workers who had been recruited from traditional communities [Hempenstall 1978: 165]. When the Australian military Administration took over from the Germans at Kieta in December 1914 [Rowley 1958: 119] little would have changed for the local plantation workers who continued to labour under a regime similar to the German. While Australians generally replaced the German managers, in some cases German managers were able to stay on. German labour laws remained in force, in accordance with the terms of the capitulation for the continuation of 'the laws and customs of the colony' by the new colonial masters [Rowley 1958: 3-4]. There was one salutary change. Europeans could no longer administer informal corporal punishment as sanctioned under the old regime [Oliver 1973: 89]. Despite the illegality of the practice, flogging continued after 1922 because, as Rowley wrote, it was 'deeply ingrained into the system'. As late as 1939 a labour commission heard appeals from planters for its reintroduction into New Guinea law [Rowley 1958: 105].

Eugene Ogan [1972: 59] has indicated that in the Aropa valley before 1914 the local Nasioi and Torau coastal people provided a source of available labour which, nevertheless, the German managers had to supplement with migrants from New Ireland, New Britain and the British Solomon Islands. These newcomers brought with them the plantation experience to be suitable overseers ('boss boys'). Having 'redskins' working alongside Bougainvillean labourers was regarded by 
European planters as essential in keeping the labour lines working [Archer to JK Murray, 26 March 1951, PMB 1184/2]. Discipline was maintained by corporal punishment for infringements of the labour rules. Robert Stuart, an Anglo-Indian plantation overseer at Inus (later owner of two plantations), in his reminiscences of his life on Bougainville from 1925 to 1968, avers he used a stock whip to urge his 'boys' to work harder at Inus [Stuart 1977: 50].

Some of Ogan's ethnographic informants had worked on plantations between the wars and they had been paid small amounts of cash mainly for the purchase of trade store goods [Ogan 1972: 59-60]. Bougainvilleans were introduced to the cash economy under the Australian Administration through the presence of outsiders from among the 'boss boys'. Integral to this process was the accumulation of tambu [traditional shell currency] by village 'big men', that had taken place first among the Tolai in New Britain after 1884 when copra was purchased from the cultivators of the 'native groves' by the German colonists and a similar process took place on Bougainville [Newbury 1989: 43].

Entrance by local individuals to the copra industry was restricted to being a "boss boy' or a small producer operating a 'native grove'. There was no access to the necessary capital to allow for expansion. Two examples may be advanced for Bougainvilleans who rose from labouring: at Bei plantation where Tukan, from Malasang on Buka, planted a large area of coconut palms and processed the copra, but remained an employee; and Jame plantation, where Archer's indispensable deputy, Siarua from Rorovana, frequently took his master's place [Henshaw 1989: 71].

The plantation industry was reserved for the returned Australian soldiers. W. M. Hughes, the Australian prime minister, had promised in 1919 that all German properties should be available for Australian ex-soldiers [McBeale \& Co, London to A. K. MacKintosh, Burns Philp, Sydney, 3 October 1922, NBAC, N115/145]. While Burns Philp financed ex-soldiers, the locals were excluded because of their lack of equity [Buckley and Klugman 1983: 180]. Archer, unlike many ex-diggers who had purchased plantations from the Expropriation Board ['White Exploiters in Black New Guinea' Gordon Thomas, 25 May 1948, PMB 600] ${ }^{12}$ survived the collapse of copra prices in 1929 [Stuart 1977: 83] ${ }^{13}$. Of the plantations sold to eligible purchasers by the custodian of expropriated properties, some were on island groups such as Jame, Nissan, the Carterets, Mathias Island, Manuna, Kulu and the distant Tasman group, 240 miles to the east of Bougainville. Many others were located on Buka and the north-west and east coasts of Bougainville. These included Kessa, Dewau, Raua, Tinputz and Buen, Tiop, Mabiri, Arawa, Aropa, Iwi and Kekere [Australia 1926: 169-201, 217]. Other plantations were largely Australian-owned, and some had been operated by the Marists before 1914. ${ }^{14}$ 
A comparison of this listing - which includes the majority of plantations that were in European hands during 1914-1941 — with the plantations that later claimed compensation for war damage, after World War II [Richards, Inspector to J. C. Archer, custodian, Port Moresby, 6 December 1947, NAA, A1713/S235], shows that all the plantations auctioned by the Expropriation Board in 1927 still existed in 1947. Although Arawa, Raua and Tiop (Teop) are absent from the claimant plantations it does not mean that they were no longer operating; they and others remained commercial entities. That the plantations owned by Burns Philp and other principals are not listed as claimant properties is a matter for further research.

The anomaly of Japanese operating plantations on Bougainville arose because the Status and Jurisdiction Ordinance 1916 conferred on all non-indigenous persons who were not of European extraction the same status as Japanese under German jurisdiction. They were subject to the same jurisdiction as the white residents of the Territory. The effect of this ordinance was that 'Chinese, Malay and other non-indigenous coloured races' were exempt from the directions of the director of Native Affairs. This was a device to allow Japanese to enter and work in the Territory as an integral part of the Territory's industrial life. This relaxation of the 'White Australia' policy was applied to individuals as workers, but from July 1921 the Navigation Act prohibited Japanese trading with Papua and New Guinea [Australia 1921: 15].

The Chinese, brought to Bougainville as indentured labourers by German companies, were described by Rudolph Jahnke, a German-Australian who came to New Guinea in 1906, as 'poor and humble folk - real Canton coolie types' [Archer to Cahill, 31 August 1969, PMB 1184/2]. The 1916 ordinance released the Chinese from indentured labour, which accounts for the presence of prosperous Chinese storekeepers, such as Wong You at Kieta [Stuart 1977: 98], and Chinese in occupations more lucrative than that of plantation workers. Jahnke [Archer to Cahill, 31 August 1969, PMB 1184/2] saw their New Guinea-born offspring as 'Australian-educated, plantation owners and Mercedes owners'.

Japanese, too, enjoyed freedom to operate independently as entrepreneurs in pearling, harvesting trochus and green snail shell, and growing native food [Stuart 1977: 86-7]. Tashiro was a Japanese pearling schooner skipper who retained links to the navy in his homeland that later secured him an appointment in the force that occupied Bougainville after 1942 [Stuart 1977: 93].

Australian commercial interests had turned to Bougainville just before the outbreak of war with Germany in 1914. Promoting the interests of Burns Philp, Lucas $^{15}$ noted that land policy in New Guinea allowed the purchase by Europeans 
of land from the indigenous owners, a concession not permitted in the adjacent British Solomon Islands Protectorate. He argued that freehold land on Bougainville was cheap at five marks per hectare. Lucas declared that labour on the island was plentiful and attracted lower wages compared with the situation in the Solomon Islands. There was the added benefit that 'there are plenty of natives on these islands anxious for plantation work under British masters, but who will not work for the Germans' [Buckley and Klugman 1983: 254-5].

The preference of Bougainvilleans for 'British' — that is, Australian masters is questionable. Lucas nurtured anti-German feelings, stemming from 1905 when the German government attempted to crush Burns Philp as trade competitors in the Marshall Islands [Secretary CPL to Secretary Dept of Home and Territories, 14 November 1927, NBAC, NM 115/156]. Lucas was not an impartial observer of German plantation methods and it is unlikely that he had canvassed the sentiments of the workers towards their German managers. A general impression held by Australians was that German methods were harsher than their own. A former patrol officer described the 'small band of European planters' on the big island of Bougainville as,

colourful, independent characters who stood sturdily on their own feet and who, while not meticulous in observing all the Government laws, did not run squealing to the District Office when the natives sometimes got the best of them ... [McCarthy 1963: 176]

Fred Archer took over Jame Plantation on Buka Passage when the expropriated German plantations were sold to Australian returned soldiers in 1926-27 [Archer to Gavin Long, 11 April 1958, PMB 1184/1]. He wrote to his family in Australia, 'I shall have to buy copra from the kanakas and try to induce them to buy trade goods in return.' [Archer to 'Dear Family', 15 September 1927, PMB 1184/1]. Archer had worked previously for the Territory Administration as an overseer on plantations in various parts of New Guinea formerly owned by German settlers that were held by the Expropriation Board pending their disposal. This experience in plantation work gave him advantage over others who knew nothing about labour relations in tropical agriculture.

An extract from a letter Archer wrote before coming to Jame could apply to Bougainville. Writing in 1924 from N'Drava plantation on Wuvulu Island, where he had some 'boys' from Buka, Archer observed:

All the Kanakas ... will want to sell something ... any excuse to get tobacco ... they will try to bluff you into something \& if you call their bluff or put one 
over on them they laugh heartily \& give vent to a long drawn out 'Ee-oh' and say 'Goddamn! You savee long me feller' \& thus they wheedle ... [Archer to 'Dear Moocha', 11 January 1924, PMB 1184/1]

Archer's letter indicates that he had satisfactory trade dealings with the kúkurai in the villages to whom he advanced tobacco against their promises to supply him with food in the future.

Archer wrote to Paul Mason in 1956 [Archer to Mason, 2 May 1956, PMB $1184 / 5]$ recalling that the European pioneers of Bougainville were Germans and French Marists together with a few 'English folk'. ${ }^{16}$ Archer pointed out that the low prices of the 1930s hit the planters who had bought the ex-German properties. Burns Philp ('blood pirates') and W. R. Carpenter ('would rob Christ') squeezed the planters they had financed so hard that the government had to issue rice, canned fish, tobacco, printed cloth and cash to pay the local labourers. The big copra traders like Burns Philp, W. R. Carpenter and Colyer Watson colluded to keep the copra prices down until the government was forced to declare a moratorium on planters' debts because the prices in 1939, 1940 and 1941 were so low.

In 1942, the Australian administration fled Bougainville, faced with the threat of Japanese landings there. In mid-1942 silver coinage was used to pay off the 'time-finished' indentured plantation labourers. The cash had been advanced by the Australian army in Port Moresby to coast watchers like Claude Campbell of Raua plantation who had chosen to stay on Bougainville during the Japanese occupation since there were no kiaps or district officers to pay the men. Campbell had suggested making this payment in order 'to preserve what prestige we may have with the natives' [Campbell to Read, n.d. PMB 1184/2];17 it was also a stratagem to counter Japanese taunts of 'Why work for the "English" [Australians] who have no money to pay you' [Campbell to Archer, 30 June 1942, PMB 1184/2].

Fred Urban, German-born naturalised British subject who was the manager at Hakau plantation, asked for funds to pay his workers and to 'prevent lawlessness and looting' [Urban to Read, 10 May 1942, PMB 1184/5]. He complained that 27 indentured labourers had deserted because they did not get their monthly pay and that mission interests from 'small Buka' had been a contributory factor in the desertion of 19 'boys' from that location. Urban's work force was 35 Nagovisi and Siwai workers of whom 25 had finished their indentures. He reported that the Burns Philp plantation at Tinputz had been looted, but locals and labourers from Tinputz had voluntarily returned some things. In this confused situation Urban said he needed $£ 160$ to 'keep the place going' [Urban to Read, 10 May 1942, PMB 1184/5]. Like Campbell he wanted to carry on with the plantation work 
despite the Japanese occupation. Urban was accused later of trading with the enemy in supplying vegetables to the Japanese, probably the most pragmatic thing he could do to keep some semblance of normality for the plantation and its workers. Cash economies had operated on Bougainville to varying degrees between 1914 (or earlier) and 1942, stimulated by the introduction by the Australian Administration of a head tax designed to bring locals into the cash economy [Ogan 1972: 79].

An undated article on the World War II coast watchers stated that in 1941 the Bougainville population was 150 Europeans and Americans engaged in missionary, Administration and plantation work, while the fifty thousand locals were the backbone of the plantation industry. On Buka - 50 kilometres long and 16 kilometres wide - there were 10,000 locals and 'several dozen' Europeans [press cutting, n.d., PMB 1184/5]. In 1951, the Administrator at Port Moresby gave Archer the following district population figures for 1941: Buka Passage 17,090; Kieta 14,778; Buin 18,338 [J. K. Murray to Archer, 12 January 1951, PMB 1184/2].

The plantations, together with the missions, were a significant manifestation of European acculturation in Bougainville. Sir Paulias Matane from East New Britain, the first ambassador to the United States, first secretary of Foreign Affairs and from 2004 the governor-general of Papua New Guinea, has depicted in his historical novel, The Ripples of the South Pacific Ocean [2003], aspects of the impact of the plantation economy upon local people [Post Courier, 18 February 2003]. Matane's main character is forced to work on a plantation but rises above his humble position, learning from the colonial masters whose respect he earns as well as that of his own people. He is drawn to study Western theology to resolve his dilemma about the gulf between the white man's professed Christian ideals and the intemperate lives of the colonisers. Archer noticed young Bougainvilleans in the 1920s willing to equip themselves for the white man's world by studying multiplication tables at night [Henshaw 1989: 95]. ${ }^{18}$ Matane's work of fiction and Archer's recollections provide a glimpse of the feelings and aspirations of the Bougainville people most affected by the white man's presence.

To summarise in Ogan's words, [2001: 198] that although colonial Bougainville has been presented as 'the separate projects of administrator, planter and missionary' these domains were interactive; they 'sometimes conflicted, sometimes reinforced each other in their effects on the colonised. 


\section{ANTHROPOLOGISTS AND OTHERS}

In Melanesia those who excel at socio-political exchange - who are outstanding competitors - commonly achieve admiration and respect: they are Melanesia’s big men.

[Sillitoe 1998: 99]

Sillitoe's generalisation is a prelude of ethnographic observation and anthropological interpretation not otherwise possible to abstract from historiography. Anthropology provides a picture of human activities based on direct observation. At first 'the man on the spot' was not burdened by theory or the strict neutrality of scientific method [Clifford 1988: 27]. Observers of 'primitive societies' were missionaries, traders and administrators, attracted by the exotic, who excelled at bricolage, i.e. undisciplined collecting. But natural scientists like A. C. Haddon and Baldwin Spencer made ethnography systematic and professional.

Richard Thurnwald, an Austrian anthropologist, was the first scholar on Bougainville (1908-09) to attempt a responsible, systematic study of one of its social groups. His observations of a particular society at two stages, 25 years apart, may have introduced to the discipline the concept of social change [H. Griffin, this volume]. Ernst Frizzi's ethnographic and anthropometric data of the Nasioi was collected in 1911 on the slopes of the hinterland beyond Kieta [Ogan 1972: 13].

Beatrice Blackwood, an English ethnologist, came to north-west Bougainville in 1930 as a participant observer of the daily lives of the local people and formed a close rapport with the village women [Blackwood 1935: xxii]. Her book Both Sides of Buka Passage, published in 1935, was judged by Douglas Oliver [Oliver 1949: 22] to be the best complete ethnographic description he had seen of any part of Bougainville. Blackwood described in limpid prose the social group she studied with particular emphases on material culture, bush horticulture, mythology etc. Her work was contemporaneous with that of Margaret Mead who avoided interpreters by using an ethnographic technique described as 'a synthetic cultural description based on participant observation' [Clifford 1988: 30]. Participant observation was the foundation of Blackwood's research; doubtless influenced by Evans-Pritchard at Oxford who had declared that 'facts can only be selected and arranged in the light of theory' [Clifford 1988: 32]. Mead came from the American tradition of cultural anthropology, unlike Blackwood's training, but they shared the practice of participant observation and had been guided to their respective study sites in New Guinea by Chinnery.

E. W. P. Chinnery, an Australian colonial administrator, collected sociological and demographic data for the New Guinea Administration in the 1920s and 
1930s. A self-taught anthropologist, Chinnery learned to be an ethnographic observer in Papua as a patrol officer. He joined the Papuan service in Port Moresby in 1909 and advanced to field duties the following year, going on a succession of long and dangerous patrols until 1917 when he enlisted in the Australian Imperial Force [Chinnery's resumé, n.d., NAA, A1/121/9821]. Chinnery had steeped himself in anthropological literature, shifting his unstructured perception of the unfathomable Melanesian 'savage' to that of a rationalised ethnographic object. Chinnery had corresponded with A. C. Haddon at Cambridge, and collaborated in producing a paper on millenarian movements in Papua, published in 1917. Chinnery returned to Port Moresby from England in 1920. Hubert Murray declined to appoint him as the government anthropologist for Papua, notwithstanding Chinnery's diploma from Cambridge where he had studied under Haddon. After three years as labour supervisor with New Guinea Copper Mines at Bootless Inlet [Chinnery to Deane, NAA, A452/59/6066 Pt 1, 28 November 1921], Chinnery was appointed the government anthropologist in New Guinea in May 1924. Haddon had persuaded the Australian government to appoint an anthropologist in Rabaul to meet its obligations under the League of Nations Mandate. These were 'to safeguard the rights and interests, and generally to promote the moral progress of the native population of New Guinea [Wisdom to Secretary, Department of Home and Territories, NAA, A452/59/6066 Pt 1, 12 January 1924].

Chinnery considered that native welfare and the development of European enterprises were interdependent [1932: 89] and he pursued this policy, insisting that patrol officers should be properly trained before going to the field. Government patrols were thus an indispensable adjunct to labour recruiting for European-directed enterprises. The scale of labour recruitment is demonstrated by the annual requirement of 34,000 labourers for the plantations in New Guinea. Bougainville would have contributed substantially to this number.

Chinnery was keen on the inculcation of basic training in ethnographic techniques for patrol officers and for a systematic study of social organisation by the Administration at the policy level [Chinnery 1932: 89]. This was the direction of the instruction given by A. R. Brown, the foundation professor of anthropology at the University of Sydney, where the cadet patrol officers attended short courses.

Chinnery visited Bougainville sometime between October 1928 to June 1929, conducting ethnological surveys in the Mortlocks and south Bougainville among the Nasioi, Arawa, Telei, Siwai, Banoni, Baitsi and Nagovisi people [Chinnery to Government Secretary, Rabaul, 17 September 1929, NLA, MS 766/5/6]. As mentioned above, he investigated the sectarian unrest in the Kieta census district, where Seventh-Day Adventist teachers from the Solomons clashed 
with Catholic interests. In the Siwai and Buin districts he found more Solomon Islands teachers attempting to extend the Methodist mission illegally at the instigation of the Reverend Mr Voyce. These were incidents characterised by Chinnery as 'aggressive mission competition' [Chinnery to Government Secretary, Rabaul, 4 February 1929, NLA, MS 766/5/3].

In 1932, Chinnery became director of Native Affairs and District Administration in control of administrative patrols [Report of Native Affairs and District Administration, 1932-33 n.d, NLA, MS 766/6/1]. Noting Jill Nash's contention that Chinnery's patrols succeeded in bringing relative quiet to Bougainville, it can be concluded that pacification under Chinnery was more benign than before 1924 .

Patrick O'Reilly, a Catholic priest, spent a year during the mid-1930s (probably 1936: see PMB 4) with the Marists at the Koromira mission collecting 'large quantities of ethnographica for the Musée de l'Homme in Paris [Oliver 1949: 22]. Hugh Laracy has noted the great value of O'Reilly's papers and their remarkable preservation in Paris during World War II. [Laracy, 'The Pacification of Southern Bougainville, 1900-1930', this volume]. They are of particular interest to the Société des Océanistes, in whose scholarly ambience Bougainvilleans have a place.

Douglas Oliver, the American academic anthropologist, was, like Chinnery, an avid collector of ethnographic data; Oliver also collected material culture objects. Oliver's 1938 expedition to south-eastern Bougainville was sponsored by the Peabody Museum of American Archaeology and Ethnology at Harvard University [Oliver 1949: 24]. Like Thurnwald on his second trip to the Terei (Telei) people of Buin in 1933-34, Oliver's wife was with him as a fieldworker. Oliver's party landed on the south-east coast in mid-February 1938 and went by foot to the north-eastern part of Siwai, remaining there until August. The party resumed work in the region in October, continuing until February 1939 when they left for recuperation in Sydney. Linguistic material had been collected from 'uncivilised' Keriaka, Rotokas and Eivo 'natives' from the inland. There was a brief stay at Soraken and at Konua. On returning to Kieta in July 1939, Oliver completed an anthropometric survey along the central portion of the east coast, before leaving for the United States in November 1939. In retrospect, Oliver was acutely aware that he had seen southern Bougainville before the devastation of war and military occupation changed in all respects [Oliver 1949: 24].

Essentially an expedition to collect material related to social anthropology such as linguistic, ethnographic and anthropometric data, there was also a significant gathering of material culture objects. The Burns Philp trade store in Kieta charged Oliver $£ 6.11 .7$ for the freight of 'Curios etc.' from Kieta to Sydney [NBAC, NM115/324, ledger sheet, 18 November 1939]. This consignment 
included objects from the still uncontrolled Rotokas region and weapons from Konua. Oliver points out that all examples of transportable material culture were collected for the Peabody Museum [Oliver 1949: 25]. He also acknowledged the help he got from his compatriot Catholic, Bishop Thomas Wade, and the 'energetic' collector of ethnographica for the Auckland and Dunedin museums in New Zealand, the Reverend Mr Alf Voyce.

Oliver allies himself with Thurnwald and Blackwood in their shared understanding of the importance of pigs in Melanesia with particular reference in his case to Siwai activities and institutions [Oliver 1949: 29]. He also draws attention to the complex man-land relationship in a pre-literate subsistence culture like the Siwai [Oliver 1991: 57, 99-100].

Examining the four accounts of anthropologists working on sites in Bougainville between the wars - Thurnwald, Blackwood, Chinnery and Oliver - one is struck by the inevitable Eurocentric bias of each scholar. They are all extracting intellectual property in the form of sociological and ethnographic data, and tangible objects. Similarly, Voyce sold artifacts to the museums to help the Methodist mission on Bougainville [personal communication, Pamela Swadling, 2003]. Thurnwald appears to have looked for theoretical conclusions from his fieldwork as Oliver also is certain to have done. Blackwood is the ethnographer par excellence; her results were returned to Oxford but her book could be made accessible later to educated Bougainvilleans who read English. As a practical, applied anthropologist, working in the interests of the colonial power, Chinnery has perhaps left a more lasting impression than other anthropologists (Malinowski notwithstanding). His legacy lies in his management of the system of patrolling (carried out by the kiaps) that contributed to the framework of governance in the former New Guinea colony left to its political successors. This is not to deny the contribution of the others whose work is an academic legacy to successors who have added their research to the history of Bougainville.

\section{CONCLUSION}

The task of getting behind the mask of the white man's official records to discover the Bougainvilleans' inner perceptions has little expectation of success. Here the approach has been to use, inter alia, what Europeans have written, mainly informally, about the people of Buka and Bougainville.

Australia acquired Bougainville as part of a Mandate of the League of Nations to maintain former German New Guinea until she was ready for political independence and, in a display of political realism, as a defensive shield against Japan in the Pacific. A brief period of military occupation followed which 
continued the punitive campaigns started by the German colonisers; this was followed by a civil Administration that aimed to control the locals through regular patrolling. The Christian mission to civilise a 'savage' society also contributed in clearing the way for the installation of the plantation economy that destroyed precontact Bougainville's traditional ways.

The island was marked out by the property boundaries of the plantations, the work of German pioneers who had planted the economic agricultural crops that replaced much of the indigenous garden culture. The cash economy that followed the establishment of the plantations, the attendant trade stores and the head tax all profoundly changed the traditional modes of exchange, resulting in an alienated society locked in to the vagaries of world trade cycles.

Jack Read wrote to Fred Archer in 1944, in the context of the effects upon Bougainvilleans of military occupation by Japanese, Americans and Australians: 'I hope they have not been contaminated beyond redemption by the wave of civilisation that was forced on us' [Read to Archer, 17 January 1944, PMB 1184/5]. Any significant attempt on the part of locals to act on their own initiative, particularly in the copra trade, was stultified by the paternalism of the Administration, the proselytising of the missions and lack of access to capital.

Recent moves to self-government in Bougainville have changed the status of its history from one that is purely provincial to an autonomous view of itself standing alone outside Papua New Guinea. In short, a history of Bougainville should be unique and not a mere appendix to the history of Papua New Guinea. A parallel case may be seen in Australian history which was taught at the University of Melbourne in the 1950s under the rubric 'British History B'. What has been presented here are some snapshots of the events for re-interpretation in the spirit of an autonomous state. It remains for a competent Bougainvillean historian to put together a story from all possible sources so that 'the grievous inquest of history' (Winston Churchill's words) may have a body of evidence from which to extract informed conclusions.

\section{Endnotes}

1. Reports that the final recommendations of the Bougainville Constitutional Committee is in the hands of the National Government of Papua New Guinea.

2. Mason had been manager at Inus plantation before World War II; his residence there was burned down during the crisis in 1990.

3. 'Dear Moocha' (his mother?). Fred Archer, the owner of Jame plantation writes, 'The plantation here according to natives is "YAM-ING".'

4. It is noteworthy that Burns, Philp \& Co Ltd (BP) had to comply with 'native' rights, at the insistence of the commissioner for Native Affairs, regarding purchase price [Greenwood, Burns 
Philp (BP) Rabaul manager to BP Sydney, 27 October 1927, NM 115/520]; fishing rights [Brown to BP Rabaul, 9 May 1928]; land reservations [Sec. Choisuel Plantations Limited (CPL) Sydney to BP Rabaul, 18 March 1927]. Some matters came to court in Rabaul but BP was keen to get its titles finalised [Turnbull BP Rabaul to Shiress BP Sydney, 1 September 1926, NM 115/131]. The problem for BP was that several plantations in the Soraken area had been leased from the German authorities and these had to be converted. Moreover, the titles issued by the Australian military authorities were executed according to the pre-existing German land laws requiring entry in a 'Ground Book' and these had to be converted, too. The German authorities wanted BP to register as a German company in acordance with a policy of excluding Australian firms from German Pacific colonies. Although BP started clearing and planting before August 1914, having got permission to take up 5,000 hectares, there was no registration in the 'Ground Book' or survey made of the properties. Australian military surveyors surveyed BP's blocks (Soraken 1,000 ha, Arigua 2,000 ha, Banui 1,000 ha) and a German style title was issued on 2 April 1920 although BP objected to this. Finally, an ordinance was passed in June 1924 requiring land holders to transfer to title under the new legislation. BP complied with this requirement. See Memo on dispute with New Guinea administration, 5 November 1927, Noel Butlin Archives Centre (NBAC), NM 115/156.

5. Chinnery indicates that 'native' constables were in charge of police posts located outside village sites and were accompanied by their wives to 'avoid interference with native women'. The constable was demonstrator, instructor and labourer. While the village chief retained full control, the constable had to use 'all his powers of sympathy and help the natives in their various trials and troubles'.

6. Chinnery wrote: 'The native houses alongside [the 'improved' type], though less clean appeared to me to be more suitable to live in ...'

7. The editor of this edition of Mackenzie's book, Hank Nelson, points out at p. xxx that Bowu and Lapapiri are the only locals that are named.

8. The dietary aspect of consuming human flesh is not discussed by Ogan (who was discussing head-hunting, and not cannibalism) but there is a consensus that a protein deficiency argument is not tenable. This view is supported by Blackwood [1935].

9. An historical overview of colonial Bougainville, during the 1930s, is provided by the author at pp. $122-24$.

10. Father Binois writes, in French, of 'the superstitions of the natives and the attacks of our adversaries, friends of the devil, the Adventists and the Methodists'.

11. Reverend A. H. Voyce of the Methodists had threatened the kukurai of Monokei with arrest if he did not allow a mission site to be established in the village. At Borinu, Father Seiler said he would 'rouse' the Protestants from the island.

12. Thomas writes that when the Expropriation Board was formed to take over German properties 'experienced Germans were replaced by Australian returned soldiers with little or no experience of tropical conditions, "coconut lancers"'.

13. Copra was $£ 30$ per tonne in 1926 and dropped to $£ 13$ per tonne in 1929 with a final descent to $£ 3.10$ per tonne.

14. References here are for Arigua [Thomas to Sandford, 3 August 1956, Pacific Manuscript Bureau (PMB) 600]; CPL [Leo Watkins to Archer, 30 September 1961, PMB 1184/2]; Numa Numa [Thomas to A. F. Gow, 24 May 1957, PMB 600]; Inus [Stuart 1977: 35]; Bonis [Archer notes, n.d., PMB 1184]; Toimanonapau [Archer notes, n.d., PMB 1184]; Burunutui and Burumtui [Archer notes, n.d., PMB 1184]; Bei [Archer to Dudley James, solicitor, Rabaul, 9 March 1953, PMB 1184/2]. 
15. Lucas was the company's island inspector, 1911-20.

16. Archer lists the following: Jim Campbell (who was present at the raid on Kaumumu village) and assistants who developed CPL; A. S. Booth (former Methodist missionary) at Numa Numa; Hickey at Toimanapu with Tom Ebery; Gordon Thomas trading for HSAG (Hamburg South Sea Company) at Poroporan in 1911-12; the Bougainville Syndicate that set up Karoola made up of Swedes, English and Germans: Robert Stuart working up Tenakau; Richards at Rua in 1920, Stewart at Arawa 1922; Albert Evensen for Burns Philp in 1923

17. Coast watcher Read was called the 'local Gestapo Chief' by Archer [Archer to Campbell, 25 June 1942, PMB 1184/2].

18. Henshaw writes 'Fred Archer remembers young Bougainvilleans in the mid-1920s staying up in darkened villages after sunset, learning maths tables by the light of a coconut oil lamp ...' 


\title{
BOUGAINVILLE IN WORLD WAR II
}

\author{
by Hank Nelson
}

\section{TWO STORIES}

1. - Just after dawn on 1 November 1943 twelve transports carrying over 14,000 American marines steamed north-west towards Empress Augusta Bay on the west coast of Bougainville. Those looking towards the land saw the curve of the beach and the jungle rising ridge to mountain all the way to smoking Mount Bagana. It was, their official historian wrote, 'wilder and more majestic scenery' than they had encountered anywhere else in the South Pacific. Just before the transports halted and the marines transferred to landing craft, one of the captains asked his navigating officer for the ship's position. The navigator replied, 'About three miles inland, sir!' [Morison 1975: 299].

The officer had read his charts correctly, but those charts placed the Capes marking the limits of Empress Augusta Bay, Capes Torokina and Mutupina, about eight or nine miles south-west of their actual location. The best charts then available were still the result of imperfect work done by the Germans when Britain and Germany were defining their island empires. Fortunately, aerial and submarine reconnaissance had warned that the coast was not where the older maps said it was. A map prepared by the Allied Geographic Section just before the landing has the disarming note that the south-west coast was 'approximate and is reported to lie to the eastward' [Allied Geographic Section ... 1943]. ${ }^{1}$ Over a year later, on 21 November 1944, the Allied Geographic Section stated in its special report [No. 65, Bougainville: 3] that the best maps then available were from the Australian Army's 1:250,000 series, but that they were 'Inaccurate as regards villages and tracks in the SE sector. Positions of villages in the interior are only approximate' and there was 'scanty marking of hill features'.

In 1940 Rabaul was still the dominant town in Australian New Guinea, but the delays and disputes about the shifting centre of administration, the growth of the Morobe goldfields, the depressed price of copra, and the pioneering patrols 
through the highlands were shifting attention west to Lae and beyond. Bougainville was being left on the edge of Australian consciousness, and the fact that the best of their maps did not show exactly where the land ended and the sea began, or the location of inland villages, was indicative of Australia's marginal interest in the island.

2. - Seventy kilometres north-east of Buka, six islands rise within the reef that circles a lagoon. On 24 August 1767 Philip Carteret of the Swallow was the first European to report the existence of the islands, and that night he had his first sight of another 'large, flat, green island', part of a second group that he called the Sir Charles Hardy Islands [Sharp 1960: 111]. The first group of atolls became known as the Carteret Islands, and the Sir Charles Hardy were often called the Green Islands, with Nissan the main island in the group. But as is often the case in the Pacific, several names continued to be used. The Carterets were also called the Tulun Islands, for tulun is the name for horizon in the language of the Hanahan people of eastern Buka, and it was the Hanahan who colonised the islands on their horizon. The Carterets have also been called the Nine Islands, but as they have been reduced by earthquake and erosion to six, this name has lost favour. At some time the name Green Islands was applied not to Nissan but to the Carterets. In 1907 Richard Parkinson said it was the Carterets that 'we designate today as "Green Islands" [1999: 352]. The people of the Carterets when they spoke to foreigners therefore began to say that they were from 'Green Island', but they pronounced it 'Kilinailau'. Soon foreigners had accepted 'Kilinailau' as the local name, and so Kilinailau Island began to appear on their maps. In their first Annual Report on their newly acquired Mandated Territory the Australians used Nissan and Kilinailau to identify the atolls north and north-east of Buka, and they remained the dominant but not the only names [Territory of New Guinea (TNG), 1921-22, 24]. ${ }^{2}$ By 1940 within the Kieta District the Nissan Islands were said to have a population of 178 people and the Kilinailau Islands 446 [Australia, Report to the Council of the League of Nations 1939-40: 135]. ${ }^{2}$ But when the Americans and New Zealanders landed on Nissan in February 1944, they often used the old name for the group, the Green Islands [Morison 1975; Ross 1955]. ${ }^{4}$

While Nissan or the Green Islands were occupied by the Japanese, the scene of a brief battle, recaptured by the Allies and developed as an air base, the Carterets or Kilinailau were almost by-passed by the war. There were no Europeans to leave, and no Japanese troops landed. An aeroplane came over and dropped two bombs, killing one man and injuring another, but that was all the violence of war that came to Kilinailau. So eleven people of Kilinailau set off in a canoe to ask their kin in Buka what was going on. At Malasang village on south-east Buka the Japanese demanded to know who they were and what they were doing. They replied that 
they were from 'Kilinailau', for they were talking to foreigners, and there was not much point in explaining that they were from tulun, the horizon. But while Europeans saw no connection between 'Kilinailau' and 'Green Island', of course the Japanese, with their indifference to ' $r$ ' and 'l', did. They immediately thought the people were from the Green Islands, and these were now occupied by the Allies. Hard pressed, cut off from Japan and aware that the local people were turning against them, the Japanese decided that the innocent people from the atolls on the horizon were spies. They took them to Sohano and beheaded ten of them [Mueller 1972: 78, fn i]..$^{5}$

In a world war the people of the Carterets had suffered in one random, gratuitous bombing raid, and also in a case of mistaken identity that had its origins in Europeans' uncertain navigation, uncertain hearing, confusing and numerous names on maps, and Japanese pronunciation. None of this was within the knowledge, control or influence of the people of the Carterets. Much of what happened to other Melanesians in the war was equally inexplicable, but within what they knew about the material and the spiritual world they had to try and give it meaning [McCarthy 1944].

\section{PRE WAR}

By 1914 the Germans had enumerated 16,000 people in Bougainville, and estimated this was less than half the total population. By 1931 the Australians thought that they administered 36,000, by 193541,000 , and by the eve of the war this had reached 50,000. In the interior of the main island there were still communities that had never been visited by a government patrol, but the numbers in these groups were too small to change the overall statistics. Population growth was uneven. On Buka the population was almost stable through the 1920s and 1930 s, but on parts of the mainland there were areas of vigorous growth. ${ }^{6}$ Compared to other districts, on Bougainville there were few indentured labourers from other areas - just 131 in 1940. Even on Manus there were over 400 'foreign' labourers, and on New Britain and in Morobe over 5,000. Among the New Guineans from other districts on Bougainville, only the 80 from the Sepik formed a significant group. But Bougainvilleans were prepared to leave home: nearly 1,000 of them were working elsewhere in the Territory, over 700 of them on New Britain [TNG, Annual Report 1939-40: 36]. Before 1940 the 'Bukas' were well known through the Territory, but Bougainvilleans at home saw fewer outsiders than the peoples of any other district.

The 200 or so foreigners in Bougainville on the eve of war included about 80 Chinese, two Japanese and one Korean at Buka Passage, three of four Japanese 
further south, and four or five families of Fijian and other distant islanders (Allied Geographic Section 1943: 53; Iwamoto 1999: 125). In the racial classification of the time mixed race people, such as Bobby Pitt, were usually placed with Asiatics - those who by status and salary were somewhere between Europeans and Bougainvilleans [Read 1941-43: 125].7 At Kieta (south of the government rest house) and at Buka Passage (on the Buka coast opposite Bonis plantation) there were concentrations of Chinese stores and houses inevitably called 'Chinatown'. The 130 Europeans were mainly British, but they were a diverse lot. The most common occupation was missionary, mainly because the Marist Mission Society had a foreign staff of 64 [TNG, Annual Report 1939-40: 128]. ${ }^{8}$ The 25 Sisters accounted for half the foreign women on Bougainville, and the 21 French, 15 Americans, 13 Germans, three Luxembourgers, and one Belgian employed by the Marists diluted the British dominance. ${ }^{9}$ The Australian troops thought that Father Richard O'Sullivan at Patupatuai was the only Australian priest in the mission [McNab 1998: 94]. ${ }^{10}$ The Marists were widely dispersed: Bishop Thomas Wade, three other priests and three Sisters were in Kieta, two priests, two Brothers and three Sisters at Tinputz, but other stations had less than four staff, and 11 priests worked alone.

The Reverend Harry Voyce, his wife and Sister Ada Lee (a teacher) of the Methodist Missionary Society of New Zealand were at Kihili near Buin, the Reverend Don Alley and his wife at Teop, and Clarence Luxton, his wife, and a trained nurse, Sister Elizabeth Common, at Skotolan on Buka [see summaries of Methodists in Carter 1973; Luxton 1955; Williams 1972; Laracy 1976; Garrett 1997]. Both the Marists and the Methodists had gone north from the Solomons, and both had exploited old alliances between the islanders — such as those between the Shortlands and Buin, or Mono and the Siwai. Both churches moved some people for education or church work between the British and the Australian Solomons, and the Methodists also employed other Pacific Islanders, such as the Fijians, Usaia Sotutu and Eroni Kotosoma. The Malaita on its last trip north in January 1942 left 16 Bougainvilleans at Kieta; they had just completed three years training at the Methodist college at Roviana in the Solomon Islands. Within Bougainville the churches continued to use old alliances, so that the Methodists went north from Buin to establish churches behind Kieta at Moru and Lamausi, and that area became part of the Methodist Buin circuit while the Kieta coast was Catholic [Williams 1972: 258]. The Methodist pattern was of a European missionary supervising teachers, and by 1940 they claimed to have 146 stations in Bougainville, each under the control of an islander, some of whom came from the British Solomons and a few from elsewhere in the Methodist Pacific [TNG, Annual Report 1939-40: 128]. The Seventh-Day Adventists had one European 
missionary, Cyril Pascoe, at Rumba, and teachers at Buin, inland of Kieta and further north on the coast [Pacific Islands Yearbook 1942: 31]. And like the other missionaries the Seventh-Day Adventists had gone north and brought Solomon Islands teachers with them. Compared to the government officers, the missionaries were more numerous, had more diverse national backgrounds, were more likely to be female, stayed longer, and were more likely to learn a local language.

The Marists resented the Protestants arriving on Bougainville 20 years after them, and entering areas where they already had converts. When the Methodists introduced more teachers from New Georgia into the Siwai the Marists equipped their catechists with bicycles so that they could respond quickly to propagation of error. Competition turned to conflict: churches were destroyed and government officers had to calm enthusiasm [Laracy 1976: 63-4; and 'The Pacification of Southern Bougainville', this volume]. On Teop Island, where the one large village was divided in allegiance, the Methodist teacher from the British Solomons, David Voeta, was found guilty of disturbing the peace, 'suffered several terms in gaol, but continued in his work as teacher with unflagging zeal' [Luxton 1955: 162]. Each mission was enlisting converts to fight other missions, and Bougainvilleans were enlisting missions in their contests with other Bougainvilleans.

The government divided the Kieta District (its name for what is now Bougainville) into three sub-districts: Kieta, Buka Passage and Buin. The district officer and a patrol officer were at Kieta, and one or two kiaps (government field officers) at Sohano and another in the south at Kangu. The Department of Public Health was almost as strong as the Department of District Services and Native Affairs with a doctor and a European medical assistant at Kieta and at least one more European medical assistant in a sub-district. A European warrant officer of the New Guinea Police Force stationed in Kieta commanded 60 police. The police often maintained a post, such as at Wakunai, giving the government a fourth station. A clerk, an agricultural officer and schooner master completed the 11 or 12 public servants in the district.

In the 1930s the Australian government officers on Bougainville had most trouble, not with people from uncontrolled areas, but with those who were among the longest contacted. In 1913 the Germans had dealt with a cult at Lontis on the north-west of Buka by exiling the leaders to Morobe. In 1932 another movement swept the area. The leaders, Pako, Terasin and Muling (who had also been involved in 1913), variously prophesied cataclysm followed by wealth in food, axes, firearms and even motor cars. The arrival of ships was greeted with excited expectation, some people even claiming cargo. The Australians sent the convicted leaders to Madang where Pako died. By 1935 Sanop of Gogohei village, claiming to be inspired by the spirit of Pako, was again preaching that there would be an 
earthquake, the resurrection of the dead, and the distribution of cargo. To prepare for the distribution of the firearms that were on their way, his followers began drilling with carved wooden rifles. Several thousand people on Bougainville were influenced by Pako, and his teachings spread across Buka Passage to northern Bougainville. Catholic catechists and government appointed officials joined the movement. Even in the carefully worded reports that the Australians sent to Geneva, they made clear that the cult members wanted equality in power and wealth, were quick to believe that they had been deceived by Europeans, and while they hoped for restitution by ritual and the supernatural, they were also ready to fight for their rights. At the end of 1935 the government officers took strong action, arresting Pako and many of the other cult leaders. They claimed that when Pako was shown to be powerless, many of his former followers ridiculed him. The Australians said they were confident the movement had 'collapsed' [TNG, Annual Report 1935-36: 21-3; Laracy 1976: 86-8]. Both the 1939 and 1940 annual district reports began with the assertion that 'Routine administration ... was carried on as in previous years'. Although there were still large areas of central and west Bougainville only 'under partial government influence', on the eve of war Kieta seemed to be the quiet district, a long way from the frontier of contact in the highlands, and from the mines, airfields and new capital being built in Morobe.

Starting with Kessa and Carola in north-west Buka, 60 plantations cut orderly lines of palms into the west coast to Buka Passage, along the west of Bonis Peninsula to Soraken then down the east coast from Baniu through Tinputz, Tiop, Inus, Numa Numa, Tenakau, Arigua, Kurwina, Arawa, Aropa, Iwi and Kekere to Toimanapu. ${ }^{11}$ Over half of the coast, in the south and west, was without plantations. Adjoining plantations — as on Queen Carola Harbour, or as with Tinputz and Tiop, and Arigua and Kurwina - were rare: most plantations were isolated rectangles cut into the coast, each with its own anchorage. The plantations were almost solely concerned with the one crop, coconuts, and just a few hundred hectares were given to cocoa, coffee and rubber. ${ }^{12}$ There was not even much interplanting to use the shade from the palms, but over 2,500 head of cattle and 1,000 goats helped keep the plantations clean of weeds. Two women, both recently widowed, ran plantations, Mrs Eve Falkner at Tearouki and Mrs C. Huson at Haramon on Buka. 13

The plantations had expanded under the Mandate but they faced hard times by 1940 . The price of copra which had been averaging $£ 13.10 .00$ a tonne in 1929-30 fell to $£ 4.11 .00$ in 1933-34, recovered briefly, and then fell again when war broke out in Europe [TNG, Annual Report 1939-40: 100]. Where in 1929-30 copra had made up nearly 90 per cent of Territory exports, in 1939-40 it was just 14 per cent. As Bougainville produced 15 per cent of the Territory's copra, 
the island had lost its significance in the Territory economy. Declining plantation income had also meant that more plantations were in the hands of companies particularly Burns, Philp \& Co Ltd and their associated company, Choiseul Plantations Ltd. ${ }^{14}$ The war in Europe meant a shortage of shipping in the islands, and it was the private owners' copra that was likely to be left in the shed, not the company's. By 1940 on Bougainville the plantation overseers outnumbered the owners. The tough times also meant that the number of Bougainvilleans working on the plantations declined as planters left weeds to flourish and even uncollected nuts to rot. ${ }^{15}$ Robert Stuart, who bought the small Tenakau plantation in 1929, had an income of $£ 1,000$ his first year but that soon fell to $£ 250$. Without additional income he could not pay off the outstanding debt and meet the costs of his 40 labourers. He survived by recruiting, shelling (gathering trochus shell on the reefs) and managing neighbouring plantations, but he no longer bought whisky by the case [Stuart 1977: 83, 94].

On Bougainville over 1,300 men were signing indenture contracts each year — and in 1940 just four women. Most were new contracts and, unlike in other districts, most were for less than three years. To work on a plantation was a common experience among Bougainville men, but it was clear that they were not inclined to do it for long. Those two years that many of them spent on a plantation were their closest contact with a world outside the village, and what they thought of that experience did much to shape their attitudes to the rest of the world. Other Bougainvilleans living near plantations sometimes worked casually for the planters, contracting for particular tasks — clearing an agreed area of bush for new plantings or cleaning a neglected corner of a plantation. But the casual workers could bring with them their own women, children, food and language; they entered the cash economy but not the culture of the plantation. At the standard rate of five shillings a month, a labourer who worked the full three years had nine pounds at the end of his contract. Bob Stuart paid a bonus of a pound so that the 'time-finish' men (who had completed their indentured labour contract) had two 'fuses' to spend in Wong You's Kieta trade store - two rolls of one hundred shillings that looked like sticks of dynamite [Stuart 1977: 98]. They were hard-earned fuses. On many labour lines the threat and the fact of violence were common, and it was not all one way; John 'Wee Bobbie' Scott, the manager at Inus, was hacked to death in 1925, and Stuart records three or four occasions when he was attacked. The great restraint on planters was that they recruited on Bougainville, and word travelled quickly about labour lines where the food was poor, hours long and kicks and cuffs frequent. The other critical factor was that the bosboi (foreman) was often more significant than the planter and on Bougainville the bosboi was usually from Bougainville. Kerosene, who virtually ran Tenakau alone for eight years was from Buka. The local 
bosboi was constantly encountering people from the communities of the men he commanded, and that too curbed excess. The conditions set down for carriers reveal the demands that could be made on Bougainvillean muscle; a carrier could be asked to carry 50 pounds for 10 hours for payment of six pence plus food [Allied Geographic Section 1943: 48].

From the granting of a reward claim at Kupei in 1930, a few men had been mining at Kupei, Korpe, Moroni and Pumkuna. Often just three or four white miners worked on the field at the crest and on the southern slopes of the Crown Prince Range, and by 1940 only one of Kupei's two leases was being worked effectively. A small stamper and mill treated over a 1,000 tonnes of ore in the year, but the previous year's report of copper and other minerals in the area had excited no interest [TNG, Annual Report 1939-40: 122; Fisher 1973: 362-7]. In December 1941 there were five white miners at Kupei [Read 1941-43: Appendix B].

There are several measures of the social and economic condition of Bougainville in 1940. There were four cars there, 14 trucks, and one motor bike. And at Arigua plantation there was a light railway, diesel engine and flat-top trucks [Stuart 1977: 133]. At Soraken plantation there was a light railway running for a mile from the drier to the beach: it had four trucks but no engine. Unlike the peoples around Rabaul and Port Moresby, no Bougainvilleans owned trucks but they had accumulated the cash to buy bicycles. Although no one wanted to estimate how many wilwils (bicycles) were on the island, on the Buin plain and on Buka they were said to be 'plentiful' [Allied Geographic Section 1943: 48]. Unlike Rabaul, Lae, Wau and even the highlands, the aeroplane had had almost no impact on Bougainville before 1940. One measure of the cash in the hands of Bougainvilleans is the number who were paying the ten shillings head tax. In 1938-39 $£ 3,245$ were collected and in 1939-40 $£ 2,265$, the amount varying more with the number of people visited than with declining funds [TNG, Annual Report 1938-39:32; 1939-40:33]. Relative to population, the Bougainvilleans were paying less than New Irelanders, about the same as people on New Britain, and more than those in Morobe, Madang and the Sepik. In terms of schools provided by the missions the Bougainvilleans probably had more per capita than any other district except New Ireland [TNG, Annual Report 1939-40: 128].16

On the eve of war Bougainville was at the limit of the Australian administration's consciousness, but that did not mean that Bougainvilleans were missing what little was available to New Guineans, they faced slight competition from outsiders whether from other districts or other countries, they themselves were participating in events elsewhere in the Territory, they had more chance of going to a mission school, the population was increasing, they were earning as much or more cash — some having enough to invest in a wilwil. 
One change in technology had its impact on Bougainville in the 1930s, and later it determined the significance of Bougainville in the war, and influenced the course of battles. During the Great War the Australian Military Administration had established a wireless station at Kieta. The mast stood on the ridge above the bungalows belonging to the wireless and the police masters as well as the jail, the tennis court, the beach and Kieta Harbour. In 1922 Amalgamated Wireless (Australasia) Ltd (AWA) — in which the Australian government held a controlling interest took over the Territory stations. In 1928 and 1929 the Reverend John Flynn, Alfred Traeger and AWA combined to develop the Flying Doctor Service and the pedal wireless that serviced it. ${ }^{17}$ By 1933 the first pedal wireless had connected Buka Passage and Kieta, and Pacific Islands Monthly (PIM) began writing enthusiastically about the transmitting and receiving sets operating on 'power supplied by a native, who sits on a thing like a bicycle frame, and pedals lustily' [PIM September 1934: 10]. Already AWA was experimenting with a set that would transmit and receive voice as well as Morse code, and the word 'sked' — the time when the outstations knew that someone was ready to hear and relay their messages - entered Territory English. By 1939 AWA was introducing the 3B transmitter and receiver, its parts enclosed in metal boxes, and powered by batteries that could be recharged with a petrol engine. The radio could now be used by planters who had little ability to correct faults, and it could be carried on patrols - although it needed at least a dozen men to shift its awkward bulk [Feldt 1967: 16; Sinclair 1984]. Within the Kieta District, stations were operated by Percy Good at Kessa plantation in the north of Buka, the government officer at Buka Passage, Paul Mason at Inus plantation, Drummond Thomson at Numa Numa plantation, AWA at Kieta, Tom Ebery at Toimonapu, and the government officer at Kangu. This meant that a line of communication was open for messages, important and trivial, right down the east coast [Read 1941-43: 2; Mason Report 1941-43; Feuer 1992]. ${ }^{18}$

There was one other factor critical to radio communications in the Mandate. In 1933 J. H. L. Waterhouse was appointed principal of Nordup government school in Rabaul. Students responded to his skill as a teacher and to his confidence in their abilities. In the late 1930s he began to teach some of them to be wireless operators. They learnt about Morse code, frequencies, battery charging and the characteristics of the 3B set. Wireless, Waterhouse said, was the coming thing. The Administration posted Nordup students to outstations. Among them were Nelson Tokidoro and Amos Tamti. At Talasea, Keith McCarthy relied on Tokidoro to send the only messages that Australia was receiving after the Japanese landed at Rabaul. At Buka Passage Tamti was the kiap's righthand man, and when conditions made it impossible to communicate by voice, Tamti sent and received Morse [Read 1941-43: 2; Toborua 1967: 39-42; Nelson-Tokidoro interview 1992a]. 


\section{TALK OF WAR}

Apart from the setting up of the coastwatching service and issuing plans, there were no preparations for war in the Mandate before the outbreak of war in Europe in September 1939. Australians were inhibited by the conditions of the Mandate and by their inability to make basic decisions about whether New Guinean police could be called upon for service in the event of war. But as the Australians made few preparations in Darwin, Broome or Thursday Island either, those factors peculiar to New Guinea probably had slight influence. The actions taken to protect Bougainville were much the same as those taken on Manus, New Ireland, and more than was done for Lae, Madang and Wewak. A grass airstrip was built south of Kieta near Aropa, but it was boggy, the connecting road to Kieta was poor, and it was never used by the Australians. The only other airfield was on southern Buka, parallel to the Passage and it had been levelled by Bougainvilleans with picks, shovels and wheelbarrows. Planned to become a forward operational base, by the end of 1941 Buka was just an emergency field [Gillison 1962: 128]. But during 1941 the waters off Soraken plantation, always protected from wind and swell, were exploited as a base and refuelling point by the Catalina crews making long reconnaissance flights over the south-west Pacific. The Catalinas usually arrived in the afternoon, and often two aircraft waited there to take-off at dawn. Overnight some of the crew stayed on board to monitor the radio, but most went ashore where Rolf Cambridge, the Soraken manager, invited them to sleep on the verandah and add bananas, pawpaws and pineapples to their air force rations [Riddell 1992: 3].

Australia's most obvious commitment to the defence of Bougainville was just one section of No. 1 Independent Company. Shipped north in July 1941, the Company was stationed in Kavieng and then, in August, sections were sent to Manus and Buka [McNab 1998: 85]. In October Lieutenant John Mackie and 25 men of 3 Section replaced the nine men who were on Buka previously. At first deployed to defend the airstrip, the men camped behind Chinatown where they could buy themselves a beer and a feed at Chin Yung's, Laurie Chan's or Wong You's. Their 'idyllic life drifted along' with only one aeroplane, an obsolete Wirraway from Rabaul, landing on the strip [McNab 1998: 86]. But Mackie soon realised that if they were to fight as they were trained, even survive, they would have to have bases on the main island and know the country. In the New Guinea islands it was only on Bougainville that Australia deployed a force that was trained in guerrilla warfare and had the country in which they could operate effectively. ${ }^{19}$

Soon after the outbreak of the war in Europe the Administrators in Papua and New Guinea wondered whether they should advise white women to leave 
[Sweeting 1970]. Australian policy changed from not dissuading those who wanted to leave to one of encouraging all those not in essential occupations to go, and warning those who stayed that in the event of hostilities the government might not have the transport to help them. ${ }^{20}$ Those women who went to Australia found it difficult to obtain permits to re-enter the Territory, but the urgency felt by some government officers was blunted because they were told to 'avoid anything in the nature of a panic'. ${ }^{21}$ By mid-1941 the Territory Administrations had listed the total numbers of women and children to be evacuated: Papua 669 and New Guinea 1,714. In the Kieta District alone there were 66, including 30 working for the Marists and two for the Methodists. ${ }^{22}$ Four days after the bombing of Pearl Harbour, Cabinet ordered the evacuation of European women and children from Darwin, New Guinea and Papua. The prepared plan for the combined use of aircraft and ships was issued immediately. On north Bougainville police runners took written notes telling women that they were to pack two suit cases, and provide their own blankets and food for a schooner voyage to Rabaul. The Methodist mission schooner, the Bilua, picked up the women and children and brought them to Buka Passage where they met the Asakaze. As the women picked up further south had taken the only bunks in the captain's cabin, all other women and children camped on the deck. The Asakaze ploughed through a storm for two days before reaching Rabaul and there the sick and sorry passengers boarded the Macdhui for the voyage to Sydney. Fourteen women, one elderly man and six children were evacuated from Bougainville. Four nurses working for the Marists agreed to leave, the 24 Sisters exercised their right to stay, and Mrs Huson, Mrs Falkner and Mrs C. Campbell refused to leave. ${ }^{23}$ Huson and Falkner had both been in the Solomons for 20 years, and their lives and livelihoods were on their plantations. Mrs Campbell at Raua plantation said that she had a sick husband and would not leave him. Even when the government offered to evacuate both, Mrs Campbell still would not go. In New Guinea there was no attempt to evacuate Chinese or other foreign women until a few weeks later, and then some of the Chinese from Wau and Bulolo reached Australia, but it was too late for those Chinese in the islands already occupied by the Japanese. ${ }^{24}$

Some planters chose to leave of their own accord and, as a result, by the end of 1941 Bob Stuart was managing three plantations as well as running Tenakau [Stuart 1977: 132-3]. ${ }^{25}$ The Japanese government quietly informed Japanese residents in the islands to leave, and Tashiro Tsunesuke and Osaki both left [Iwamoto 1999: 124; Stuart 1977: 136]. The Japanese who remained were interned immediately after 8 December. Ishibashi and Ikeda and their families and Kikuchi, a Korean fisherman, were imprisoned on Sohano, until they could be shipped to Australia. There appeared to be no resentment between the parties. The Japanese 
were allowed to buy beer (perhaps because they shared it with their guards) and, when they went on board the Malaita, Bob Stuart called on Ikeda to have a last few words [Stuart 1977: 136; McNab 1998: 87]. Ikeda and Ishibashi's boats were seized, but their agents were credited with hiring fees [Read 1941-43: 4].

The Australians in New Guinea were not prepared for war, but they certainly expected it. Pacific Islands Monthly frequently warned that Japan would 'launch an attack upon us in the Pacific, without warning and without mercy' [PIM March 1942]. On Bougainville, Bob Stuart said:

We planters discussed the possibility of War many times, and had all agreed that the Japanese would take these islands and possibly Australia too. All that remained to be seen now was how and when ... [Stuart 1977: 131].

Senior Australian military officers shared the fears expressed in the press and on plantation verandahs: five months before the Japanese landing they informed the commanding officer in Rabaul that he could expect an attack of the 'heaviest scale' — and that it would be one that would overwhelm his force [Nelson 1992b: 212]. The chiefs of staff, with nearly a division at risk in Singapore, three divisions in north Africa and the Middle East and attacks threatening on the Australian mainland, decided they had 'tasks of a higher priority'. The Australian servicemen and civilians in the New Guinea islands were known to be in danger, but they were going to have to look after themselves.

In November 1941 Assistant District Officer Jack Read was posted to Buka Passage. Read had entered the government service as a cadet in 1929, and had been a kiap on the mainland and New Britain, but this was the first time he had been to the Solomons. Later he would say that his lack of knowledge of the country and people were handicaps for him. The Australian troops, who had got to know and like his predecessor, Ken Bridge, regretted Read's appointment [McNab 1998: 86]. With Read were Eric Guthrie, from the Department of Agriculture, and Frank Green, medical assistant - kiap (government field officer), didiman (agricultural field officer) and likkik dokta (medical assistant) the tripela masta of the field service. ${ }^{26}$ At Kieta, J. I. Merrylees, who had served as an officer in the British forces in the Great War, had long familiarity with the district officer's residence on the point above the harbour. ${ }^{27}$ With the shortage of staff following the enlistment of men for the war in Europe, George Stevenson, the patrol officer at Kangu had been shifted, and Buin was without a kiap.

The wireless reports of the bombing of Rabaul on 4 January 1942 increased apprehension on Bougainville, but it was not until 10 January that six Japanese float planes were seen flying down the east coast. ${ }^{28}$ There were, one of the soldiers 
at Buka said, more Japanese in the air than Australians on the ground [ $\mathrm{McNab}$ 1998: 88]. On 21 January a float plane flew low and slow across Buka airstrip and the troops began their war, firing with all their weapons - revolvers, 303 rifles, sub-machine guns, and one Vickers medium machine gun. They thought it a triumph when they forced the plane to climb away. By then they knew that Rabaul had been bombed heavily and that a Japanese invasion fleet had been sighted off New Ireland. The Catalinas had left Soraken, taking much of their gear with them. Read and Mackie decided it was time for them to escape the confines of Buka for inland bases on Bougainville where they already had ration dumps. On 23 January, the day that Rabaul and Kavieng were captured by the Japanese, the Australians abandoned Buka Passage. As the Australians left, Japanese aircraft bombed Soraken, Sohano and along the Passage and riddled a few buildings with machine gun fire. The Australians decided - quite reasonably — that the Japanese were about to land. Labourers fled and the troops trudging to their new camps had to carry their own gear. Jack Read, in the government schooner, made his first trip down the north-east coast of Bougainville.

At Kieta, Merrylees had hidden stores at Kupei, but on 22 January he told Read that he was going to commandeer a vessel and sail for Woodlark Island. The 10 or so Europeans had all voted to go and they planned to leave at 4.00 p.m. the next day [Mann, AWM 54; Read 1941-43: 8]. ${ }^{29}$ The sense of unease among the Europeans increased the following day when they were unable to raise Buka and Rabaul on the radio, and Bougainvilleans brought reports of explosions at Buka Passage. At midday H. Dougherty, the operator at the AWA station at Kieta, saw a lone Japanese plane drop behind Pok Pok Island and thought it had landed. The Australians decided to sail immediately on Wong You's Herald, the one small launch available. Carrying a full load of fuel and fearful of venturing out of the harbour in the overloaded Herald, the Europeans told the New Guinean crew to take the launch down to Toberoi plantation. Telling the police to 'go bush' and leaving the burnt AWA radio behind them, the Europeans crammed on to Doyle's truck and went by land to meet the Herald. Read said that as they were short of space they discarded luggage, and a couple of men who missed embarkation rode down the coast on bicycles [Read 1941-43: 12-15]. At Toberoi they heard reports of two Japanese soldiers landing and raising the Japanese flag, and of a Japanese ship-of-war standing off Kieta. They decided that the Herald would take half of the assembled 14 Europeans to Buin, and then come back and collect the rest, but on the first run they met Luxton sailing north on the Bilua, commandeered his boat, gathered the rest of their passengers, seized Tom Ebery's radio, and told the reluctant Luxton, the only one with a master's certificate, to take them to Woodlark. Off Woodlark they decided they would go to Samarai and then, after 
a difficult and dangerous voyage, they arrived in Port Moresby on 4 February. Luxton wanted to turn around and go straight back to Bougainville, but the navy now claimed the Bilua. Four of the men from Kieta immediately joined the Australian Army. With the sailing of the Bilua, the Seventh-Day Adventist pastor, Pascoe, had gone, and Alley was the one remaining European Methodist missionary. The only government officers were those in the north, and another three planters had escaped. Some planters - from Tom Ebery at Toimonapu to Percy Good at Kessa - were still on their plantations or had taken to inland havens. Stuart was over a day's walk inland from Tenakau where he had a 'marvellous view of the coast' and where he was determined to stay [Stuart 1977: 136; Luxton 1955: 171-4; Read 1941-43: 13-15]. ${ }^{30}$ But most of the planters were still uncertain whether it was better to stay or make a dash to the south or west by small boat.

Read and others made fun of the panic among the white community fleeing Kieta: 'varied and vivid', he wrote, were the tales of the 'jockeying for a place on the little vessel' [Read 1941-43: 14]. But the Australians in Kieta had to make an immediate decision, and they believed that Kavieng, Rabaul and Buka had fallen and the Japanese were at the entrance to the Kieta harbour. The slight evidence that they had confirmed that the Japanese were at Kieta, and that was what Merrylees announced when he reached Port Moresby. Had the Japanese landed at Kieta on 23 January then the men would have been congratulated on their fortunate escape and their courageous voyage. But the Japanese did not occupy Kieta then - the escape with seconds to spare became the escape with six months to spare.

After the government officers left Kieta, 'Hundreds of natives from nearby villages flocked into the town to join in an orgy of looting and destruction. They smashed every store and laid waste its contents' [Read 1941-43: 15]. Sergeant Yauwiga, from the Sepik, and the few police left in Kieta were powerless, and anarchy continued until Doctor B. Kröning of Toberoi plantation and Brother Henry, a New Zealander, combined to assert a new authority under a white flag. Kröning had served with the German administration, and according to Read 'made no secret of the fact that he was a staunch believer in Nazism' [Read 1941-43: 17]. Read and some of the Independent Company came down to Kieta, and for the second time a reluctant Kröning lost power to the Australians. The Australians recovered some of the loot, calaboosed (jailed) many Bougainvilleans and then used them as carriers and labourers. The fittest of the deserted lepers on Pok Pok island were sent home and the rest given into the care of the Catholic mission. The patients at the Native Hospital, abandoned by white and then black staff, had saved themselves or been rescued by relatives - except one who had 
crawled a short distance and died. At the end of February planters and miners came in to Kieta, drank the last grog on Bougainville, and about eight of them sailed for the Solomons. A few days later the soldiers arrested Kröning and put him and his wife on a schooner with another two planters on their way to Tulagi and Australia.

In March a Japanese fleet appeared off north Buka, Japanese soldiers came ashore and placed Percy Good (Kessa Plantation) on parole. Fred Archer, further down the coast, radioed Read who passed the message on to Tulagi and to Australia. Wireless stations in Australia, the United States and Great Britain told the world that a Japanese force was off Buka. The Japanese, assuming that Good must have provided the information, returned to Kessa Plantation, murdered him in his home, buried him in a shallow grave and left. The killing of Good told all peoples on Bougainville of the new, dangerous forces that had arrived.

\section{WAR}

The war on Bougainville can be divided into stages, each sharply different: from January until August 1942, few Japanese arrived and they rarely came into direct contact with the remaining Australians; from August 1942 to July 1943 the coastwatchers provided critical reports on Japanese aircraft and shipping while major battles were fought in the Solomons; in mid-1943 the Japanese briefly dominated all Bougainville; from November 1943 to October 1944 the Americans held their base at Torokina and fought off Japanese counter-attacks; and from October 1944 to the end of the war the Australians took over from the Americans and began the recapture of Bougainville.

The Japanese did not occupy Buka Passage until 30 March 1942, five weeks after they landed at Rabaul, and after they had established their first base in the British Solomons. Until mid-1942 there were rarely more than 50 Japanese on Bougainville. In July a small detachment controlled Kieta for a few weeks, but it was not until December that the Japanese came back. For much of Bougainville, Japanese occupation was only effective from 1943 when the build-up of the Japanese Army, Navy, civilians and auxiliaries reached its maximum of 65,000. (The largest number of foreigners on Bougainville was probably early in 1944 when the Americans had over 60,000 inside the Torokina perimeter [see Miller 1959: 352] — a total of about 130,000 foreigners to 50,000 Bougainvilleans.) 31 No battles were fought on Bougainville until the end of 1943: for Bougainville the war began with threats and rumours, Europeans leaving, minor movements of aircraft, ships and troops, and only isolated violence. It was a long, gentle and yet, unsettling introduction. 
At Buka Passage most Bougainvilleans welcomed, or accepted, the arrival of the Japanese. Many outsiders have assumed that they saw in the Japanese the fulfilment of the prophecies of Pako and Sanop and that stories must soon have been circulating that the Japanese 'king' was coming to issue cargo to the people [McNab 1998: 106]. But Read thought that most Bougainvilleans had been entirely pragmatic: the Australians were gone, some had left in panic, and the Japanese were obviously the new power in the islands. Because it was uncertain how long the Japanese would be dominant, prudent people simply had to make their accommodation with them. Any hope that the Japanese might be more tolerant and generous was soon destroyed. Labourers conscripted by the Japanese were less likely to be paid, and slight resistance could provoke fury. The elderly chief at Lemankoa in the north of Buka refused to come in to collect his Japanese armband. Buka people brought him in and a Japanese soldier cut his throat in public. The Japanese flogged other Buka leaders thought to be uncooperative [Read 1941-43: 38]. But some people still disappeared when the Japanese were in the area, and — in the light of later events — no one should be surprised that Japanese surveyors found that their marker pegs were pulled out. Saposa Islanders from north-west Bougainville even sent a surveyor's flag to Read's camp just to show him what they were doing [Read 1941-43: 64].

The police, because they were trained, had rifles, prestige and the backing of either the Allies or Japanese. They had power and choices. Mackie found that Corporal Sali from Talasea (New Britain), 'an excellent type of man', attached himself to the Australian soldiers. Later Mackie learnt that Sali had had a disagreement with Read, and 'it seemed that Mackie was collecting all Read's disgruntled police boys' [McNab 1998: 118]. The police could also choose to work for the Japanese. Seven left their posts within days of the first Japanese raid, and although some of them were approached by their fellow policemen, they had had enough of the Australians. Four of the seven were from Bougainville, and may have felt that their first loyalty was to their home communities. ${ }^{32}$ In March 1942 Read sent Corporal Auna, another Talasea recruit, to carry a radio part to Mackie on Buka. But Auna had taken part in looting that he was supposed to prevent, and he knew that he was likely to be punished. He took the package to Mackie and then went to the Japanese and led them to the Australians. Only the intervention of Usaia Sotutu and his followers enabled the four Australians to escape [Read 1941-43: 30; McNab 1998: 100]. 33

When the government officers and the troops were enforcing their war-time morality, the police had more power than they did on violent pre-war frontiers. In August 1942 at Tetakia in north Bougainville some people found and kept the contents of a parachute dropped to supply the Australians. The police decided 
who was responsible and while Mackie carried out the formal enquiry and decided on the punishments - a house burnt, people fined and given up to 20 strokes with a cane - it was the police who carried them out [McNab 1998: 126-8]. ${ }^{34}$ The Australians warned villagers that they would be executed if they helped the Japanese, and when some people guided the Japanese to troops near Inus plantation, the Australians lined the village, told them the guilty would be killed and then instructed the police to shoot one of the men who led the Japanese [McNab 1998: 140-1]. Calling in a bombing raid on defiant villagers made punishment more impersonal, but it was still the police who lit the marker fires and then ran for their lives as soon as they heard the aircraft coming [McNab 1998: 138]. In April 1942 Sergeant Waramabi from the Sepik and Constable Sanei went to a store dump near Katsinkoveri on the Bonis Peninsula, and found some bags of rice had been stolen. Attempting to recover them, the police were attacked, Waramabi was killed, and the wounded Sanei escaped. Compared with peace time, this was an extraordinary act of defiance, and from then the police were determined to even the score [Read 1941-43: 36].

In 1943 when the Japanese were in pursuit of the coastwatchers, the police carried out feats of endurance and daring, walking vast distances and negotiating with villagers who might well betray them. Finding two men on a track, the police suspected that the Japanese had posted them there to keep watch. Forced to walk in front, one made a break for the jungle, the police fired at him, and probably missed, but the other was shot immediately [Thorpe 1996: 37]. Some of the clashes with the Japanese and their Bougainvillean allies were brief but violent. At the attack on Read's post at Aita in the central north in mid-1943 a 'battleroyal' was waged - 'the air was filled with automatic rifle fire, the bursting of grenades; and finally, the raking rattle of heavier machine guns'. The Bougainvilleans with the Japanese knew many of the men with Read and they called out to them by name [Read 1941-43: 103]. On Bougainville there was intimacy between enemies.

Nineteen police came off Bougainville by submarine in July 1943. All except one was from another district, and that one was from Nissan. Among those police who stayed were three from Bougainville, but others were from New Britain, the Sepik, Madang, Morobe and New Ireland, some of whom were married to Bougainvilleans. For the police, the struggle to survive on Bougainville or the voyage out, the reception in Guadalcanal, and the transfer to other units (some in Australia), was a continuation of extraordinary experiences.

For the people of Bougainville the first 18 months of war were a prelude only, but there was no doubt the old values had been turned upside down. Frank Burns, the manager at Teopasino plantation, surrendered to the Japanese at Buka 
Passage and he was seen working on the grass-cutting line before he was shipped to Rabaul. Some property belonging to Chinese settlers, planters and the government was looted, and the people who did the looting, having reason to fear the return of the Australians, were pushed towards the Japanese. The people guiding the Japanese to Stuart's hideout were those who had looted Mabiri and stolen pigs on Tenakau, and Stuart accepted that they wanted him out of the way. But across Bougainville the looting was sporadic; and it was often done after places had been abandoned and when goods were likely to be destroyed by bombs or neglect, and when Japanese foraging parties were known to be shooting plantation cattle and stripping and destroying the contents of buildings. Frank Roche, one of the Kupei miners, stayed because he said he had valuable equipment to look after, but people from the coast north of Kieta led the Japanese inland where they captured Roche, led him like a dog on a rope till he was exhausted, and then one of the Japanese beheaded him [Read 1941-43: 83]. Tom Ebery and the Chinese trader Mack Lee were killed in similarly humiliating circumstances. Two Chinese women were said to have been raped to death by Bougainvilleans [Read 1941-43: 83]. George Stevenson, the pre-war patrol officer from Kangu, returned to work with the coastwatchers in 1943 and was ambushed and killed attempting to set up an observation post in the south. In another combined Bougainville and Japanese attack on a camp one Australian was killed and three taken prisoner [McNab 1998: 208]. The Japanese increased their pressure on Bougainvilleans by executing some men who admitted they had carried for the Australians. The Australians responded with violence and subtlety. In June 1943 two Bougainvilleans returned by submarine with relief troops. On New Britain when the Japanese landed, the two Bougainvilleans had been conscripted by the Japanese, taken by ship to Buna, and forced to carry in the Kokoda campaign. Rescued by the Australians, they had been sent to Australia and were now expected to tell their fellow islanders of the Allied victories in Papua and of the power of the Allied armies yet to be directed at the Japanese on Bougainville [McNab 1998: 150; Read 1941-43: 89].35

The Australians were strongest in their condemnation of a group of Bougainvilleans from the Kieta area known as the 'Black Dogs'. Eric Feldt said that they 'raided inland villages, pillaging, raping, and murdering. They combined with the Japanese to wipe out the last of the remaining Europeans and Chinese' [Feldt 1967: 196]. The Australians thought they had been influenced by Tashiro who had returned with the Japanese forces. After Kerosene, Stuart's bosboi, was captured and taken to Kieta, he certainly learnt about Tashiro's authority. Tashiro demanded to know where the Australians were, and when Kerosene could not tell him, Tashiro had him tied to a post of Wong You's store and beaten every day with an axe handle [Stuart 1977: 157]. The Kieta Black Dogs travelled widely, and 
a resurgence of tribal warfare added to the general turbulence. Stuart, attempting to avoid Japanese patrols, went into rough country near Mount Bagana and there a mission teacher told him that already people had been killed in local raid and counter-raid [Stuart 1977: 150].

The Australians thought that their strongest allies on Bougainville included New Guineans from other districts, the Seventh-Day Adventists and the Methodists. The link between the Fijian Methodists and the Australians was particularly strong. In fact the Australians conceded that many of them would not have survived, let alone operated successfully for nearly 18 months, without the Fijians. Read, who did not praise easily, recommended Usaia Sotutu for an award because of his 'courage, initiative and loyalty' [Read 1941-43: 114]. When Stevenson was shot it was Sotutu who had dashed to his side and given covering fire until his rifle jammed. Even then he had only left when he was certain that Stevenson was dead. Sotutu operated right across Bougainville, from Buka and north Bougainville with Mackie and Read to Buin with Mason [Griffin 1978: 126-68]. ${ }^{36}$ Some mixed race people, particularly Anton Jossten and Bobby Pitt, took risks for the Australians. But it was not simply a result of minority groups tending to join the Australians — in fact the minority groups were often in a position where they had to commit themselves more fully to one side or the other, not necessarily the Australians. And some peoples from nominally Catholic areas assisted the Australians. Read said that the American, Father Lebel of the Marist Mission, became his 'best and most helpful friend on Bougainville' [Read 1941-43: 31]. Lebel's meetings with the Australians were known to Bougainvilleans — and aided by them - as were other contacts between members of the Marist Mission and the Australians. But in most areas there was not a simple choice of villagers siding with one side to the exclusion of the other. In Buin some people were in the invidious position of working for the Japanese on the new airstrip during the day and carrying for the Australians at night [McNab 1998: 148]. Private Alexander 'Sandy' McNab said of Korp ${ }^{37}$ the Tultul of Namkerio village in the north-east:

He was always up to some mischief and he was one of those guilty of looting our first parachute drop. He was also one of the leaders in the attack on our cook boy Kene, when he got into trouble over village women. However when he got the opportunity to betray us to the Japanese he remained loyal. Being the foxy old bugger that he was he may have concluded that we were getting on top of the Japanese in the war and decided to back the stronger side [McNab 1998: 137; Read 1941-43: 71]! 
That statement may be interpreted to mean that Korp (Read says Kop) was acting bravely and opportunistically on behalf of his people.

From the American landings on Guadalcanal in August 1942 and the beginning of high-casualty land, sea and air battles, Bougainville had been important in the war. Japanese bombers flying from Rabaul and supported by fighters staging through or operating from fields on Bougainville (because of their shorter range) were seen or heard by Read, Mason, the troops and their islander allies. Read on north Bougainville could give over two hours warning to the forces on Guadalcanal. That was time for ships to put to sea, disperse and be at high speed; troops on crowded beach heads to take cover; and for fighter aircraft to refuel, rearm and climb so that their first attack was from above the Japanese. That was the significance of those brief reports: '17 fighters now going yours'; and 'Can hear many planes going yours via East coast. Think heavy jobs' [Read 1941-43: 57-62; Feldt 1967; Lord 1977; McNab 1998].38 But from early 1943 the Americans had secured Guadalcanal and were preparing to advance into New Georgia in June. The Australians, hunted by greater numbers of Japanese, more Bougainvilleans turning against them and their main purpose served, had to get out. On 31 December 1942 an American submarine picked up Huson, Falkner, the two Campbells and 26 other people including 14 Marist Sisters and three mixed-race girls. Others left on 29 March 1943 on the submarine that landed some soldiers and took out others: three Marist sisters, 24 Chinese women and children, and one mixed-race woman and her two children. The last of the Australian servicemen, and more Chinese, Fijians, police and 27 other New Guineans were evacuated on two submarines in July 1943. ${ }^{39}$ The Japanese then had uncontested control of the land of Bougainville — but the sea and the sky were being claimed by the Allies.

To November 1943, the Bougainvilleans had seen aircraft after aircraft take off from Buka and up to 60 aeroplanes flying overhead; in the south they had seen over 60 Japanese ships gathered for the battles in the Solomons; and they had watched the gradual increase in the numbers of Japanese soldiers and the building of gun pits, new airfields and the landing of hundreds of vehicles. But it was the arrival of the Americans at Torokina that changed the material signs of war and brought major battles to the Island. Father Miltrup at Piano in the south did not meet any Japanese in October 1942, and had few encounters with them until 1943. But once the heavy Allied aerial bombing began as a prelude to the American landing the Japanese applied severe restrictions, and malnutrition, malaria, accusations of spying and constant bombing were, Miltrup said, beyond the 'limit for frayed shattered nerves' ${ }^{40}$

In the early American planning for the war it was assumed that the recapture of Rabaul was essential and that that operation would be the major battle in the 
south-west Pacific and the major demand on resources. ${ }^{41}$ In early 1943 the proposed bases in the Trobriands, Woodlark, the Huon Peninsula, Bougainville and New Britain were all seen as stepping stones on the way to Rabaul, but in mid-1943 the Joint Chiefs were gradually convinced that Rabaul need not be recaptured. In spite of General Douglas McArthur's arguments, by August it was decided that Rabaul would be encircled, battered into impotence, and left in Japanese hands. In June 1943 the Americans began developing air bases on Kiriwina and Woodlark, in September the Australians captured Salamaua and Lae and were planning to land at Finschhafen; and in August the Americans, having taken New Georgia and Vella Lavella, were ready to advance to Bougainville. By then they knew that what they wanted was not a battle, not recovered territory, but simply one more base in the circle being put around Rabaul. Torokina was chosen because it was lightly defended, the Japanese would take a long time to gather the force needed for a counter attack, and it would provide an air and sea base within striking distance of Rabaul. The later landings in west New Britain (December), Nissan (February 1944), Manus (February 1944) and Emirau (March 1944) completed the encirclement of Rabaul.

Torokina demonstrated to Bougainvilleans the material wealth of the Allies, particularly of the Americans, and the destructive power of the machines of war. Within a fortnight of the opening assault on 1 November the Americans had landed 34,000 men and 23,000 tonnes of goods at Torokina [Shaw and Kane 1963: 246]. That was just half the number of men who were later to be inside the Torokina perimeter. The American-held base was a semi-circle with about six miles of beach frontage and extending a maximum inland of five miles towards Hellzapoppin Ridge. Emphasis was placed on airfield construction, and by the end of December 1943 three strips were operational, including one long bomber field. With the airfields were taxiways, standing areas, hangars, over 20 other buildings, and thousands of tonnes of fuel. The tank farm included one giant tank, 20 smaller tanks, and five miles of overland pipeline from tanker moorings [Gailey 1991: 130-1]. On 19 December over 70 aircraft left Torokina for Rabaul. There had, Admiral Halsey said, been 'neither bull nor dozing at Torokina' [Shaw and Kane 1963: 283]. Just the clearing of the space on which the quartermaster was to place his stores required six bulldozers and 20 dump trucks. The hospital was housed in 70 Quonset huts. Torokina's own saw mills provided much of the timber; the bakeries cooked fresh bread daily. Soon the multi-laned roads were crowded with a variety of military vehicles. Three tennis courts, a baseball diamond and Loewe's Bougainville (the outdoor picture theatre) made 'Empress Augusta Bay ... about as pleasant a beachhead as one could hope for' [Miller 1959: 269]. ${ }^{42}$ Bob Hope, Jack Benny, Randolph Scott, Carole Landis and other stars 
entertained the troops, putting on up to five shows on the one day [Jackson 1989: 80-3]. And it is at Torokina that there are the most persistent stories of Japanese climbing trees or sneaking through the perimeter to watch films, baseball games and concerts.

By 8 March 15,000 Japanese had slogged and scrambled their way to launch a counter-attack on the Torokina perimeter. Against more numerous troops in prepared positions and supported by tanks, artillery and aircraft, the Japanese had no chance. Admiral Halsey said the Japanese attacks were 'savage, suicidal, and somewhat stupid' [Shaw and Kane 1963: 286]. In 17 days of fighting they lost 5,000 dead to the Americans' 263. Whole swathes of rainforest — as on South Knob Hill - were blasted clean by American artillery. Soon the Australians were bringing Bougainvilleans to look at the might of the Allied base at Torokina. As a manifestation of the power of men and machines to construct and destruct, Torokina as base and battleground was an awesome sight — even to the Americans who were expert at the making of both.

By a strange twist, black Americans struggling for equality in the armed services suffered a sharp reversal on Bougainville. In the segregated American army black soldiers served in separate units, usually with senior white officers, and most were in labour, transport and service units. But on Bougainville black units were used in combat - a black artillery unit served successfully, and following the defeat of the Japanese counter-attack black infantrymen went into action. After an early engagement in which it performed well, one company believed it was under heavy attack and began firing wildly. Some men threw their weapons away, and most casualties were a result of Americans shooting Americans. In spite of the fact that white units had behaved equally erratically in the jungle, that only one company of the 93rd Division was involved and that the Fijians had already demonstrated their skill as soldiers on Bougainville, all black American troops were condemned, and were not again used in combat in the Pacific. Bougainville had gained a place in the history of American race relations [Gailey 1991: Ch 10].

After the landings at Torokina the Allied soldiers were more diverse. Apart from the many black and white Americans, the Fijian 1st Battalion landed at Torokina within three weeks of the first landing, and by January it had met up with Usaia Sotutu at Ibu in central Bougainville [Ravuvu 1974: 45]. Two squadrons of the New Zealand air force operated off the Torokina strips; New Zealand ground troops were in the invasion force that took Nissan and later the Royal New Zealand Air Force (RNZAF) operated off Nissan [Ross 1955]. The Australians returned with the Americans in the Australian New Guinea Administration Unit (ANGAU) and the Allied Intelligence Bureau (AIB), the organisation then controlling the coastwatchers and the ' $M$ ' Special Unit. Much 
of the work beyond the perimeter fell to Australians, Fijians and Papua New Guineans. Many of the men in the AIB had been in Bougainville before: Ken Bridge had been a patrol officer at Buka Passage, Sandford, Stuart and Mason had been planters, Wigley had been with the 1st Independent Company, and Yauwiga was with the returning police. After the Australians took over at Torokina in October 1944, the Papuan Infantry Battalion and A Company of 1 New Guinea Infantry Battalion operated on Bougainville.

The brief radioed reports of Bridge, Stuart, Sanford and others have survived and are retained in the Australian War Memorial. 43 The following are summaries of Paul Mason's reports sent from inland of Kieta from November 1944.

17 Dec 1944: Mason said he was feeding many women and children. They were too weak to walk to Torokina, and he asked for a food drop. It was dropped a few days later.

19 Dec 23: 'Nips' from Moroni went to Orai to collect food, and returned carrying seven with arrow wounds.

27 Dec: Japanese at Sipura were on a ridge, surrounded by villagers. Bougainvillean scouts working for Mason were ready to light signal fires to guide an air strike.

28 Dec: The scouts lit the fires but the Japanese realised what was happening, lit other fires, and confused the attacking aircraft.

10 Jan 1945: Scouts returned from Reboine with a man said to have been responsible for killing Tom Ebery. He was sent to Torokina.

3 Feb: Scouts returned from the Koromira area where they induced the people to kill their pro-Japanese leader and desert the enemy.

23 Feb: The Bakapan people killed seven Japanese. The Japanese burnt their village.

1 March: Villagers in the central Luluai Valley counted 42 Japanese dead after they opened up on them with a captured Light Machine Gun and grenades.

9 March: A patrol back from Koromira-Toimonapu area said that the Japanese there had not killed pigs or poultry and the people were still friendly to the Japanese. Villagers killed 22 Japanese from Wida and Kovidau and through to Isini.

31 March: A village leader of Moroni was said to have betrayed four men of Kusira who had helped an ANGAU patrol. The Japanese executed three of the men.

6 April: Scouts reported a continuous battle in the Bovo River area between Japanese and villagers.

12 April: Two village men guarding women were shot by Japanese. The Japanese ate one. 
6 May: Allied planes bombed Auda near Koromira killing 13 and wounding 45 people who were working for Mason. Auda was then an 'unrestricted' area and the pilots did not know that Mason's people had moved there.

8 May: The Japanese at Oria called ten villagers in to pay them. Instead they opened fire on them and just three wounded escaped.

Equally revealing of the confused, sporadic violence on Bougainville in the last year of the war are the interrogation reports by Australian New Guinea Administration Unit (ANGAU) officers of Bougainvilleans who had been living in Japanese controlled areas. Rolf Cambridge, then in ANGAU, questioned Na'aru of Tonui in Siwai who said that Taetae took food to three Japanese who were living alone. When Taetae did not return, the people searched for him and saw the Japanese cooking parts of him and cutting flesh and storing it in a haversack. They told the Japanese leader at Sinanai, and he came back with them, and found the three men with the uncooked flesh. He told the people to assemble at Sinanai where the three Japanese were shot in front of them. At Labaru the Japanese stole food twice and on the third day the people waited for them and killed two. Told by other villagers what had happened, the Japanese then surrounded Labaru took all the men away and shot two of them [ANGAU, Reports from Bougainville, November-December 1944]. ${ }^{44}$

Released Indians and Ambonese provide another insight into the confused and turbulent war. ${ }^{45}$ Gopal Pershad Jah said he had left Madras with the Indian Army, was captured by the Japanese in Singapore, and then shipped to Bougainville in 1943. In his group, 25 had been killed by Allied bombing, 39 had died of illness and nine were executed by the Japanese. In one interesting exchange in north Bougainville Major Jack Costello, who had served on Bougainville in the pre-war, arranged for a Bougainvillean to carry a note to an Indian prisoner of war. A Fijian working on the docks at Torokina wrote the message in Urdu and the Indian had enough Tok Pisin to explain that if he escaped others would be executed in punishment, and the Indians could not escape as a group as some were too ill to travel. The Indians reluctantly said that they had to stay with the Japanese [ANGAU, Reports from Bougainville, November-December 1944]. ${ }^{46}$

Those few Japanese who wished to abandon both the war and their commitment to the ideal of the Japanese soldier had to make a difficult mental and physical crossing [Australian Army 1945]. ${ }^{47}$ Two sides and marauding Bougainvilleans were likely to kill them before they could reach Allied soldiers who would accept their surrender. Kawaguchi Yoshiharu had served in China, but was called up again and sent to New Guinea, and in June he was posted to the front in north Bougainville. Previously two of his friends had tried to surrender. They had gone forward waving the documents saying that they would be well 
treated if they came forward and gave themselves up to the Australians. But the Australians had opened fire, killed one, and the other, who was wounded, crawled back and a Japanese officer found him with the pamphlet and shot him for attempting to desert. Kawaguchi therefore decided that the only way was to steal a canoe and paddle along the coast to Soraken where he could surrender to Australian troops well behind the frontline and not carrying loaded weapons. And after a two-day trip he surrendered and lived.

To the surprise of Australians other Japanese found safe ways to end their war. One Japanese stopped an Australian driving a jeep, jumped into the front seat, whistled, two of his mates jumped in the back, and the driver then drove them into camp [Schacht 1990: 193]. Peter Medcalf who fought with the 15th Battalion on Bougainville stated the attitude of the frontline soldier: 'Taking prisoners was not only impractical, it was downright unpopular'. The troops had scant concern for the conventions of war, because they 'were in the extermination business' [Medcalf 1986: 62, 85].

In November 1944 A Company of 1 New Guinea Infantry Battalion (NGIB) left Camp Diddy near Nadzab and sailed for Bougainville. Under Australian officers and senior non-commissioned officers, the company went into action in south-west Bougainville on 16 December, killing four Japanese and taking one prisoner. In a savage encounter at the Hupai River on 26 December 18 Japanese were killed and Corporal Barofa was awarded the military medal after dragging a dying Australian sergeant clear of Japanese fire then taking command of half the patrol [New Guinea Infantry Battalion; ${ }^{48}$ Byrnes 1989: 235]. Separated from the rest of the company one platoon carried out long patrols from a base on the Numa Numa Trail. Replaced by the Papuan Infantry Battalion (PIB), A Company joined the rest of 1NGIB on New Britain.

The companies of the PIB were spread across the Australian fronts from Bonis to Buin. Fighting in the last months of the war, the Papuans encountered some Japanese already suffering from severe deprivation. On 9 August 1945 near Rusei in the Siwai the Papuans saw signs of a Japanese dragging himself along. When they caught up with him they killed him. Further along the track they found two Japanese, killed one and the other fled in 'record time'. They set an ambush and one Japanese carrying potatoes was shot, and soon after seven Japanese entered the trap and five died [Papuan Infantry Battalion, War Diary: 9 August 1945]. But where the Japanese were in strength, still healthy and holding strong positions, a different war was being fought. Recognising the skill of the NGIB and PIB in the jungle, Australian units asked them to carry out reconnaissance patrols before attacks and to locate forward observation posts for the artillery. At times individual and small groups of Papuan and New Guinean soldiers were instructed to carry out 
dangerous tasks that the Australians themselves were reluctant to do. The Papuans and their officers were irate when Australian troops failed to act after a patrol report and the PIB had to 'recce the same ground time after time' [Papuan Infantry Battalion, War Diary: 4 June 1945]. The Australians countered with the complaint that Papuans and New Guineans sometimes deliberately guided them away from Japanese positions [Pinney 1992: 128]. 49

In the last year of the war Australians in New Guinea were fighting in the Sepik, on New Britain and on Bougainville, and their greatest commitment was to the campaign on Bougainville. The necessity for those final battles on Australian territory has long been doubted. In April 1945 Harold Holt told the House of Representatives that the campaigns against the Japanese in New Guinea were costly in terms of money and lives, and the Japanese were no threat to Australia. He said that the 'terrible price' was unjustified and Australia should 'be content to contain the enemy where he is' [Robertson and McCarthy 1985: 402]. The troops themselves knew that they were not fighting to win the war — those battles were being fought by the Americans further north - but were fighting a 'politicians' war' [Budden 1973: 147].50 In fact it was more a 'generals' war', Sir Thomas Blamey, commander-in-chief of the Australian Army, even ridiculing the idea that the Japanese in Bougainville were impotent [Horner 1998: 521]. But faced with criticism, the government chose to defend Blamey and so it shares responsibility. At the time, the argument in defence of the policy was that Australia needed to continue to fight in New Guinea to strengthen its position in the post-war peace talks, and to liberate the New Guinean peoples on whose behalf Australians had accepted international obligations. The Australians also pointed out that in the Philippines, the Americans were clearing their own colony of all the Japanese. The policy on Bougainville was, both generals and politicians agreed, to destroy the enemy where that could be done with relatively light casualties, and to progressively free New Guineans from Japanese rule and release Australians from armed service [Robertson and McCarthy 1985: 411; Long 1963: Ch 3].

Nearly all the Australian troops sent to Bougainville were militia units, most of them from Queensland [Long 1963: 99]. ${ }^{51}$ The distinction between militia and the Australian Imperial Force (AIF) was declining, but the militia still felt that the 'glamour' and publicity went to the AIF, and some men were still conscious that they had been 'chocos' (the chocolate soldiers) and 'koalas' (not to be shot or exported) and that some of them had been branded failures in the fighting in Papua in 1942. So, in spite of having doubts about why they were there and having tough battles (such as at Slater's Knoll) dismissed as 'mopping up', the militia units often fought tenaciously. Their casualties were testimony: the 25th battalion suffered 215 casualties (dead and wounded), the 58/59th suffered 209 
[Long 1963: 237]. The 58/59th casualties were made up of 49 killed and 160 wounded and another 80 evacuated because of illness and accident. That was one third of the original battalion strength of just over 750 [Mathews 1961: 212]. In north Bougainville on what was then called Part Ridge, Frank Partridge won Australia's last Victoria Cross of the war and the first given to a militiaman [Wigmore 1963: 267-9].52

Where fighting early in the war in Papua and New Guinea had been dependent on carrier lines and lightly armed, probing patrols, on Bougainville the forward troops could often call upon observer and strike aircraft, artillery and tanks. Particularly in the south, bulldozers cut rough roads, and troops operated from a road head serviced by jeeps and tractor trains - tractors pulling eight or so jeep trailers. The physical impact of battle on people and environment was greater than in most of Papua and New Guinea. By August 1945 the Japanese had been pushed into the Bonis Peninsula, the east coast and around Buin [Nelson 1982: 178]. ${ }^{53}$ Many Bougainvilleans had been liberated, but it was the liberation that had caused so much of the stress. The Australian policy of napalming Japanese gardens, and bombing and strafing buildings and concentrations of people beyond their own front, increased accidental deaths, forced more Bougainvilleans into the bush, and made it more likely that the Japanese would seize village garden produce, pigs and fowls. Bougainvilleans, still intensely aware of allies and enemies among their own people, were caught between the predatory Japanese and the violence of the Australian policy to destroy all Japanese.

\section{THE COST}

From August 1945 it was possible to begin to calculate the cost of the war on Bougainville. The American Marines had lost 436 dead [Shaw and Kane 1963: 587]. With other losses in the American Army and those of aircrew the total American dead was probably close to 1,000. The 42 Fijians who died in the Solomons included those who were killed accidentally, those who had died of illness and one, Corporal Sikanaivalu, who died winning a Victoria Cross [Ravuvu 1974: 57]. Most of the New Zealanders who died in the Pacific were in the air force, and while they rarely died in Bougainville many had taken-off from fields at Torokina and Nissan: Royal New Zealand Air Force (RNZAF) 338 and 10 New Zealand 3rd Division. In the Pacific Islands Regiment, 54 Papua New Guineans had died on Bougainville. The Australian Army suffered 516 deaths after taking over from the Americans at Torokina. To these may be added the few army deaths in Bougainville before October 1944 and deaths in the Royal Australian Air Force and Royal Australian Navy. The total Japanese forces on Bougainville had 
numbered 65,000 in 1943 . They had been reduced by death and disease by 23,000 or 24,000 during the year of American operations. In the months when the Australians had been expanding out of Torokina 8,500 Japanese had been killed and 9,800 had died of deprivation and illness. As 23,571 Japanese surrendered, over 40,000 Japanese and their volunteer and conscripted auxiliaries had died on Bougainville. By contrast less than 2,000 Allied servicemen had died. 54

For the Japanese and the Bougainvilleans the dying did not end with the war. The Australians did not have the transport or the stores and medicines to bring immediate relief, and they probably thought that their first concern was for the 14,000 Australians to be released from Japanese prisoner of war camps. While moving to, and being held at, temporary assembly points the Japanese were dependent on their own inadequate resources and they continued to die. Some Bougainvilleans suffered through 1946 as they waited for their gardens to come into production and for ANGAU and the new civil administration to respond to their needs.

Particular groups of noncombatants had suffered harshly. In the Marist Mission four priests, six brothers and two nuns had died. The impact of the war on Bougainvilleans can be gauged from the immediate post-war patrol reports and from the district census. A. J. Humphries patrolling south of the Luluai River in 1947 collected one Japanese, Lance-Corporal Matsingaga, and reported that the village population had dropped 42 per cent during the war. His figures did not, he said, include any children who had been born and died during the war. R. R. Cole who went north from the old government station at Kangu into the Mamaromino area in 1946 said that the pre-war population of 1,636 had been reduced to 1,083, and that there were many orphans aged between three and 14 in the villages. In Pariro where the people had not been supporting Japanese but just had Japanese foraging parties moving through, Humphries still found that the population had dropped by one-third. On the north-east coast few village books had survived but at Minsiveren the luluai (government appointed chief) produced his book for C. W. Slattery who found that the 201 people of the pre-war were now reduced to 148 [Patrol Reports, Bougainville]. The district officer in his 1947/48 annual report thought that overall there had been a 20 to 25 per cent loss in population and that the greatest losses had been in the Kieta and Buin areas, and he noted that rehabilitation had been rapid. By then, he said, the field staff had paid just over $£ 100,000$ in war damage compensation to Bougainvilleans, and the despondency of the immediate post-war had almost gone [Department of District Services and Native Affairs, Annual Reports]. 55

The first comprehensive post-war census of 1950 confirmed the particular studies made by patrol officers. The total population of the Bougainville District 
was 41,190 and in 1940 it had been 49,067 . That is a 16 per cent decline in population. But even that figure understates the impact of the war. The people of Bougainville suffered little deprivation until 1943 so the population was growing until then. It was probably over 52,000. By 1950 the recovery had already begun - the point of maximum decline may have been in 1946 when the population could have been under 40,000. If those figures are taken as the pre- and post-war totals then the fall was 25 per cent. And that one quarter decline took place after 1943.

Measured by the numbers of foreigners (three for every Bougainvillean) and the diversity of those foreigners; the amount of material landed on Bougainville; the demonstrations of the destructive capacity of mankind (they killed nearly 45,000 of each other); and the impact on the Bougainvilleans who joined, avoided and observed the war and lost a quarter of their number, then the war on Bougainville was as profound, disturbing and destructive as anywhere in the Pacific. The impact of the war on relations between Bougainvilleans was so profound that ceremonies of compensation and reconciliation for sides taken and things done continued until the late 1980s; and then the alliances and cleavages expressed within a world war were confirmed or swept aside in a civil war.

\section{Endnotes}

1. Map 13, dated 23 June 1943.

2. The 'Geographical Description' and the 'Notes on the Natives' were reprinted, no date, as a separate publication.

3. See other maps in Pacific Islands Year Book [1935], and Official Handbook of the Territory of New Guinea [1943].

4. These publications have no index entries for Nissan, just Green.

5. Post-war, Mueller was a Catholic missionary on the Carterets.

6. The population on Buka was 7,600 in 1921, then dipped before recovering to 7,608 in 1940 [Annual Reports]. Scragg [1957] includes a comparison with Buka.

7. Read also includes Polynesians with 'Asiatics'.

8. The missionaries are also listed in Pacific Islands Year Book [1942: 26].

9. The New Guinea Administration told the Australian government that there were 27 white women to be evacuated from Bougainville, and, in addition, there were 30 women employed by the Marists and two by the Methodists [McNicol to Secretary, Prime Minister's Department 12 June 1941].

10. There were Australian brothers and Australian women in the Marist mission.

11. Annual Report [1939-40: 84], gives 61 plantations.

12. Fred Urban, the Austrian-born naturalised Australian, grew coffee at Hakau on the north-east coast.

13. Their husbands are listed in the Pacific Islands Year Book [1935-36]. 
14. Burns, Philp \& Co Ltd (BP) managed the properties of Choiseul Plantations Ltd (CPL) and held a minority of shares in the company. Senior individuals in BPs [idiomatic use for BP's company] held a majority of shares in Choiseul [Buckley and Klugman 1983: 223-4]. Read [1941-43: 10] says Choiseul owned eight plantations on Bougainville.

15. The total number of indentured labourers in the Kieta District fell from 2,919 in 1938 to 2,647 in 1940 [TNG, Annual Reports].

16. Bougainville had 610 village schools, a quarter of the Territory's total.

17. See entries on Flynn and Traeger [Bucknall 1981; Behr 1990] in the Australian Dictionary of Biography, [Vols 8 and 12].

18. Feuer's book is largely composed of extracts from Read's and Masons' reports.

19. On Manus and New Ireland there was not the area, and on New Britain the troops were neither trained nor prepared for a guerilla war.

20. War Cabinet decision of 13 March 1941 [Evacuation of Women and Children, BF 16/2/1, Pt 1, A518, National Archives of Australia (NAA)].

21. War Cabinet decision of 13 March 1941 [Evacuation of Women and Children, BF 16/2/1, Pt 1, A518, NAA].

22. McNicol to Prime Minister's Dept, 12 June 1941, BJ 16/2/1/ Pt. 1, A516 [NAA].

23. One of those who was left was Nari Campbell, aged 15. She used some of the war-time experiences of her family in her novel (see References).

24. BJ 16/2/1, Pts 1 and 2, A518; Read [1941-43]; Luxton [1955: 166-9] quotes a report by Mrs Luxton. There are some differences in the numbers of those evacuated. The Asakaze was later involved in atrocity when the Japanese killed internees on its deck.

25. Stuart managed Arigua, Kurwina and Mabiri.

26. Green escaped by boat soon after with Harold Beck, Rolf Cambridge, Doug Trotter (plantation manager), Bob Parer and H. Taylor (miners). Guthrie was evacuated by submarine in December 1942, but he had dropped out of coastwatching operations several months earlier.

27. He had been acting district officer at Kieta, posted to Kavieng, and then returned as district officer.

28. There is some uncertainty of the date so I have taken the date given by Brookes who flew to Buka on that day, [RAAF Operations from Rabaul, 81/4/194, AWM 54, Australian War Memorial].

29. See particularly Max Mann, medical assistant, 'Account of Civilians Leaving Kieta', 183/5/2, AWM 54; and Read 1941-43: 8. By 16 January 1942 the white community in Kieta was suggesting it was better to leave 'prior' to the Japanese arrival. ['Evacuation of Women and Children from British Solomon Islands including Bougainville', Radio from Kieta, 16 Jan 1942, CM 16/2/1 Pt 1, A518, NAA].

30. Eric Feldt's account of Bougainville early in the war is largely based on Read.

31. 'All together 62,000 men, including naval units, were attached or assigned to XIV Corps'.

32. Read [1941-43: Appendix D], lists what happened to 42 police.

33. Read says that Auna was carrying just a note.

34. McNab [1998: 126-8] reprints Mackie's report.

35. McNab says there were three Bougainvilleans on the submarine.

36. Griffin provides much information on Mason and Bougainville in the war.

37. Read says Kop [Read 1941-43: 71]

38. Read's Report reprints many radio reports. Feldt, first published in 1946, remains the basic account on coastwatching. Lord's book is also well-known. The coastwatchers have been 
praised, and that praise has been deserved, but the men of the 1st Independent Company have recently pointed out that their work has sometimes been overlooked and denigrated. They have shown that at times Read was certainly sending radio reports, but it was the soldiers who were doing the patrolling, gathering much of the information, and most at risk.

39. Read Report, lists those leaving on submarines [1941-43: 77, 88-9, 110-11].

40. Father Miltrup was German, but he was going to be killed and, with the help of a sympathetic Japanese, escaped to the Australians.

41. There are numerous summaries of American planning in several of the official histories: for example, Miller [1959]; Shaw and Kane [1963].

42. One of the Americans at Torokina was Francis Hennessy, the brother of Father James Hennessy of Boston. Father Hennessy had been arrested by the Japanese on Buka, was sent to Rabaul and died in the sinking of the Montevideo Maru [Decker 1942: 108].

43. Allied Intelligence Bureau Radio Reports [423/9/35, AWM].

44. Interrogation of Natives, Lieutenant. R. Cambridge, Siwai 27 November 1944, 80/6/14, AWM 54].

45. Information obtained from Indian Army soldiers, captured by Japanese in Malaya [423/9/34, AWM].

46. Interrogation of Natives, Patrol to North East Bougainville by Costello [80/6/14, AWM].

47. GHQ-AFPAC Draft preliminary prisoners of war interrogations, [1945, 779/3/84, AWM].

48. [AWM, 54, 8/4/5].

49. For Pinney see also [1952; 1990]. The other significant author who turned his wartime experience on Bougainville into literature is T. A. G. Hungerford [1952; 1950; 1985]. Hungerford writes of gratitude to the scouts [1985, p. 43]. In 'The Nun's patrol' [1950] he gives an account of the rescue of Marist missionaries in April 1945. Pinney and Hungerford served in the same unit, 2/8 Commando Squadron.

50. The term is also used elsewhere.

51. Long [1963] says eight of the 12 battalions on Bougainville in December 1944 were from Queensland, p. 99.

52. Then 22 years old, Partridge was too young to be accepted by the Australian Imperial Force.

53. There were 18,628 Japanese at Buin, 3,053 at Buka, 1,635 at Numa Numa and 177 at Kieta.

54. These are broad figures. The Japanese air force deaths on and around Bougainville and deaths of Japanese sailors in Bougainville waters are not included here.

55. Many of the Bougainvilleans now had Commonwealth Bank accounts (1,918 were started in the year) and the District Commissioner thought that although money had been spent on European foods, much had been spent appropriately. Bougainvilleans had then received less than one-third of the compensation that was to be paid to them. 


\title{
SOURCES ON \\ PRE-MINING BOUGAINVILLE*
}

\author{
by Helga M. Griffin
}

$\mathrm{D}$

ocumentary and other records on pre-mining Bougainville (that is, Bougainville before the mid-1960s) are, of course, essential for the writing of a comprehensive history of the province. That so far only one scholar - Douglas Oliver, the doyen of Pacific anthropologists, — has attempted anything like such a general history [1973, revised and updated 1991] suggests that there may be problems with the sources. And that is so. But there have been other reasons for the neglect of this subject. Before the advent of mining little public interest was shown in Bougainville because it was seen as a backwater. Furthermore, written records that did exist were the work of foreigners with, necessarily, flawed or biased perceptions. This was a handicap before Bougainvilleans learnt to record their oral traditions in a lasting form and until, more recently, they began to produce their own histories. This chapter explores the difficulties with the existing material, and the major gaps that exist in the documentary record.

\section{LOCATING THE AVAILABLE MATERIAL - ACCESS THROUGH BIBLIOGRAPHIES}

As with other remote parts of the Pacific, in Bougainville the preservation and use of documentary material, including government and private records and scholarly publications, has expanded since colonial contact. Naturally, publications about Bougainville multiplied rapidly from the 1960s when spectacular development and turmoil accompanied the establishment of the giant copper-gold mine in the mountains beyond Kieta township. The outbreak of the civil war in 1988 stimulated even wider public interest and publications. Much of that material, however, is not readily accessible. Even materials concerning the establishment and operation of the mine are often only located in government or company records, or in 
obscure professional and literary journals or in newspapers no longer in publication. As a result, bibliographical guides to Bougainville have taken on particular importance. The first that I am aware of can be dated to the establishment of the University of Papua New Guinea (UPNG) in 1966, but no all-inclusive bibliography of publications and manuscripts on Bougainville has been published to date.

In 1968, Colin Freeman, librarian of the UPNG New Guinea Collection, compiled a typescript 'Bougainville Island Bibliography' that was based on the references in Douglas Oliver's pioneering Studies in the Anthropology of Bougainville, Solomon Islands [1949]. Freeman's additional sources were derived almost exclusively from the UPNG library. A three volume Ethnographic Bibliography of New Guinea was also published that year [1968] by the Department of Anthropology and Sociology of The Australian National University (ANU). It has three pages of references under Bougainville in its second volume under the District Index. Later, in 1980, A North Solomons Bibliography was prepared by the Diploma of Science 2 students of the Administrative College of Papua New Guinea at Waigani. This was distributed as a roneoed document of 39 pages the following year. Arranged in a standard format, it follows the list of authors alphabetically through sections of published and unpublished materials. Alan Butler, chief librarian at the UPNG Library, compiled and published $A$ New Guinea Bibliography, a five-volume work [1984-90]. He released Volumes 3 and 4 with Gary Cumings and Volume 5 with his wife, Inge Butler. Based on farranging research, it is thematically presented but has no key to material on Bougainville or its districts. However, those readers who are familiar with the cultural and language groups of Bougainville listed in volumes 1 and 3 can immediately reach a section which lists publications about them. Before this, Elizabeth Tatsiua, of the North Solomons Provincial Government library, compiled a long list of published sources [1984] about the Bougainville Province. The library's copies were destroyed when the Provincial Government centre was burnt during the Bougainville conflict. Fortunately some scholars had already been given copies of it. Various scholars have prepared their own bibliographies of Bougainvillerelated material, which they sometimes circulate. Material on Bougainville can also be extracted from such general guides to sources as Sally Edridge's Solomon Islands Bibliography to 1980 [1985] which lists documentary material covering the broad region (including the 'North Solomons') under topics (e.g. Voyages, Regional Studies, Zoology, Cargo Cults) and 'Time Slots' (e.g 1893-1941). Terence Wesley-Smith's bibliographical essay on Bougainville [1992], on the other hand, while it specifically discusses 'the emerging literature on the so-called Bougainville crisis that began in 1988 and remains unresolved early in 1992', 
it also includes a broad sweep of sources under such select headings as 'General', 'Mining, Change and Development' and 'Secessionist Politics'. His citations include material predating the disturbances caused by the Bougainville Copper Ltd (BCL) mine.

\section{ISSUES CONCERNING THE FIRST GENERAL HISTORY OF BOUGAINVILLE}

As already stated, the first general history, Bougainville: A Personal History, was published in 1973 by Douglas Oliver — then at Harvard University. With a commitment to Bougainville as a scholar since the late 1930s, and prompted by the ferment generated in the late 1960s by the operations of the mine at Panguna, Oliver undertook to write a general history of the province for ordinary readers to serve a public need. In view of the problems posed by the gaps in sources, the speed with which Oliver's history was written was surprising. Oliver was an adviser to BCL and the publication of the book was subsidised by the company. Possibly because considerable pressure was placed on him to deliver as soon as possible after the mine began production, Oliver may have sought to avoid some of the pitfalls of an under-researched study by giving his book the subtitle of a 'personal history'. In other words, no one could dispute what was personal to him, and other persons' notions of gaps in source material were not necessarily gaps to him. Disappointingly, the personal element was missing from the book. It scarcely mentioned Oliver's rich encounter with Bougainvillean individuals at the time of his fieldwork among the Siwai in the late 1930s and the concerns expressed by individuals and communities over their perplexing cultural transitions.

His approach in writing this book can be called 'cut and paste', or modular history - a mode of recording information which is perhaps better suited to social sciences like anthropology rather than to history. It subordinates individual experiences to communal generalities (culture) and integral narrative to separate topics or themes, which can then be moved about in relation to each other without confusion once a model, type or typology has been established. Associated with the modular approach of classical anthropology is the tendency to 'freeze' the society being studied into an 'ethnographic present' (see, for example, Ogan's 'Introduction to Bougainville Cultures', this volume). The noted academic anthropologist, A. P. Elkin, had made the same point in his essay on 'Research development in the South West Pacific' [1954]. He pointed out 'one defect' in the structural-functional approaches in anthropology in that 'The excellent picture they [the anthropologists] gave was synchronic, being limited to one "moment" in time. They describe how societies or cultures function, but they do not provide an 
explanation of how they came to exist, nor how they would react to changing circumstances'. [Elkin 1954: 131] But modular (or slice) history can of course be used to trace developments if modules of the same subject matter are set up at intervals of time and, as well, when sets of statistics are used to provide indications of change.

In his 1991 revised and updated book, Black Islanders. A Personal Perspective, 1937-1991, Oliver avoids claiming that this is a 'history'. It is a more comprehensive account of Bougainville cultures and especially of the post-mining phase. The memory of the first edition nevertheless lingers. Describing 'history' clearly is its intention. The book begins, not with a brief introduction to the year 1937, but with 28,000 years ago; the earlier chapters are still much the same, except for the addition of long quotations. These quotations have saved the author the task of analysing and expanding the previously less-researched parts of his book. Contributing causes of the conflict are still not examined in depth. Thus the element of 'cut and paste' and of 'freezing' society - that is, of timeless ethnography - still remain in parts of this later publication in which all the maps and some photos are undated and unreferenced and the location where a picture was taken is not necessarily stated.

The value of Oliver's two editions should not, however, be underestimated. The issue I raise here suggests that in a place like Bougainville, where traditional culture and change to it remain of great importance and where historians therefore depend so much on the specialised observations of anthropologists, the two professions ought to have been working much more hand in hand for better understanding of what has occurred. It was of course salutary that many readers without previous knowledge of Bougainville or its people had Oliver's manuals that explained to them in cogent and clear terms, some of the island's vicissitudes. But longer-term Bougainville watchers could be disappointed in Oliver's failure to explore the more complex features of Bougainville in the pre-mining sections of the two editions of his 'history' books.

\section{LACUNAE IN SOURCE MATERIAL AND RESEARCH}

Among the lacunae in source material and research about early Bougainville, I would suggest that the following are among the most significant:

- Lack of systematic anthropological profiles for Bougainville societies before colonial control;

- Lack of an 'ethnographic map' for all Bougainville societies;

- Large intervals in time when ethnographies were recorded;

- The possible influence of the hidden values of the record makers; 
- The paucity of records concerning the period of German colonial control (1886 to 1914$)$;

- Difficulties with access to foreign archives;

- Incomplete records of much of the period of Australian colonial control (1914 to 1975$)$;

- Inadequate coverage of topics in which research has been undertaken. Each of these — and some related — matters requires some elaboration.

\section{Lack of Systematic Anthropological Profiles}

There is a lack of systematic anthropological profiles for a majority of Bougainvillean societies before they fell under colonial/imperial administration. We do not know just how much they differed and in what respects they were similar; how they perceived themselves and how others saw them. There are small and partial exceptions, mainly in the studies by a few German and Austrian anthropologists and other observers, notably Richard Thurnwald (whose work is discussed later in this chapter and also examined by Keil in the chapter on 'Buin Social Structure', this volume). The less comprehensive ethnographic studies recorded in German are by the agronomist, planter and trader, Richard Parkinson, surveying mainly Nissan, Buka and parts of coastal Bougainville [1899, 1907], Ribbe on Bougainville Straits [1903], Krause on Nissan [1906] and Frizzi on the Nasioi and Telei [1914]. There are, however, problems associated with all of this material.

With the exception of Thurnwald and Parkinson, we know scarcely anything about those men, how extensively they travelled in Bougainville, whose interests they served, or how well they were trained as scientific observers. All of them collected artifacts for museums in Germany for which their ethnographic notes provided a context for the objects from what were, to them, exotic cultures. Without an accompanying analytical study that was comprehensive such insights hindered visitors to museums from seeing the manufacturers of the objects as normal human beings with basic human needs like themselves. Thurnwald is the only one who presented his anthropological study with depth and breadth and who raised questions of 'scientific' scrutiny for his readers to consider. The publications by these ethnographers in the German language could not be read even by educated Bougainvilleans for whom English was the only European language.

Almost without exception foreign scholars who began to publish about Bougainville in the later 1960s had never studied the work of the German ethnographers in sufficient depth; their critical appraisals of German observers remained a blank. This was most disappointing in the case of Douglas Oliver whose muchacclaimed study of the Siwai neighbours of the Telei speakers bristled with questions. Jared Keil ('Buin Social Structure', this volume) has tried to address some of the puzzles which Thurnwald's work has bequeathed to us. 


\section{Lack of an 'Ethnographic Map' for all Bougainvillean Societies}

Ten systematic anthropological studies about various Bougainvillean communities are known to me: Thurnwald on Buin [1912]; Blackwood on north Bougainville and south Buka [1935]; Oliver on the 'Siuai' (Siwai) [1955 and earlier major reports]; Rimoldi's PhD on the Hahalis co-operative movement on Buka [1971, published with Eleanor Rimoldi as co-author in 1992]; Ogan on the Nasioi [1972]; Nash on Nagovisi [1972 PhD, published 1974], Sarei's Doctorate of Divinity thesis on Solos [published 1974]; Keil's unpublished doctoral thesis on Buin [1975] and Mitchell on Nagovisi [PhD 1971, published 1976]. I have not seen Michael Hammet's PhD on the Eivo-Simiko [1977] nor Stephen Nachman's work on Nissan [c. 1980? personal communication by Leo Hannett, from Nissan]. As well, Douglas Oliver [1991: 91] has noted others who did their fieldwork in the 1970s: John Rutherford among the Aita; Robert Shoffner at Teop. In addition, the work of the geographer, John Connell, concerning the 'modern' Siwai has produced a number of publications [1977, 1978a, 1991].

Despite the availability of this admittedly incomplete material, as yet there has been no attempt made to analyse the existing ethnographic record for the whole of Bougainville in any depth. ${ }^{2}$ Bougainvillean communities have always stressed the differences that exist between themselves, with, for example, people from the mountains seeing themselves as different from those on the coast (first observed by the resident planter, Parkinson [1907]; and discussed in more detail by Ogan - 'An Introduction to Bougainville Cultures', this volume; and Regan, this volume). Debates about 'all Bougainville' black skins versus mainland New Guinea 'redskins' generated by secessionist rhetoric has tended to obscure this fact.

The diffident respect with which anthropologists tend to regard each other may be part of the reason why no one to date has attempted to provide an ethnographic map of Bougainville based even on the existing sources. A person with deep understanding of the people of one society, developed over many months of living among them, and then by keeping in touch when possible, is likely to feel unqualified to make comparative judgments about the observations and analysis of another scholar-observer who has studied a society in another part of Bougainville. While it is disappointing that sufficient comparative analysis between communities has not been made, it must also be admitted that there would be significant difficulties involved in making such a study.

\section{Large Intervals in Time when Ethnographies were Recorded}

Many of the existing sources mentioned above relate to very different time periods, and the likelihood that there have been significant changes in any society over extended periods must tend to make any observer diffident in making comparisons. 
How can we compare and contrast Oliver's Siuai (Siwai) of the 1930s [1949, 1955] with Thurnwald's Buin of 1908-09 [1912]. Their frozen 'ethnographic present', or slice of history, is 20 years apart. When Thurnwald returned to Buin in 1933-34, he commented on the immense changes that had taken place since he was there 1908-09. Presumably, therefore, Oliver's portrait of the Siwai is hardly a proper generic prototype of a pre-contact society. Thurnwald's return, a generation after his first visit to review changes in 'traditional' Buin, can be seen as a contribution to anthropology by providing one method by which to graph social change. Elkin [1954: 131] pays tribute to Thurnwald as the only scholar to have returned to the sites of his fieldwork to investigate change and development.

On the other hand, discerning continuity and change can probably only be achieved by regular review of the observations made. On the basis of his work in Buin in the early 1970s Keil ['Buin Social Structure', this volume] observed that a decline in the 'unu feasts' [celebration of boys' initiation] which Thurnwald was witnessing in 1933-34 did not appear to have been as drastic as Thurnwald perceived them to be. But, the question remains, is it not possible that they have enjoyed a cultural revival in Buin after Papua New Guinea's political Independence in 1975? Keil modestly states that since he was not there at the time when Richard and Hilde Thurnwalds were in Buin in the 1930s — nor in the same places — his observations about their work cannot be conclusive.

\section{The Possible Influence of Hidden Values of the Record Makers}

A further problem associated with making comparisons between communities concerns the extent to which Bougainvilleans of the society in question would regard themselves as recognisable in the works of foreign scholars. There are problems associated with any strangers in any part of the world recording the affairs of a community not their own. Hidden values and agendas play an important role in any human endeavour. In the late 1990s Eugene Ogan spoke cogently at The Australian National University of his own field work among the Nasioi in the 1960 s and 1970s, on his participant observations, on the democratic tenor of that society as well as the strong influence of its women. I was suddenly struck by a possible correlation that seemed to exist between the political experiences 'at home' of five of the major anthropologists who worked in Bougainville before 1975 and the societies that each of them describe.

In 1908 Richard Thurnwald compiled a feudal, 'patrilineal' and hierarchical model of social structure in Buin. 'Aristocratic' chiefs and their wives had a privileged status which was supported by strict taboos. His study has always reminded me that he was born and educated in Austria, and was therefore a creature of 19th century central Europe. He had read European history as part of his cultural formation 
and had practised law in Bosnia as a civil servant of the Austro-Hungarian imperial authorities. How far did this background influence the feudal model of the hierarchical and patriarchal society he described for Buin? A similar question can be asked about Beatrice Blackwood who brought her experience as an ethnologistlaboratory assistant at Oxford University to bear on her fieldwork on either side of Buka Passage in north Bougainville around 1930. In north Bougainville and south Buka she found a quasi-aristocratic social order in which inherited positions were protected by defined roles and strict taboos. Is it the model of a class system in which, as in England, some political privileges have been inherited?

Oliver, during his fieldwork among the Siwai of south-west Bougainville in 1938-39, wrote up a model of 'big man' political leadership in a context of consensual politics. Belonging strictly to his Siwai study, it became a generic type ascribed to the 'big man' behaviour in other parts of Papua New Guinea: the man who creates wealth and influence in his own lifetime and who buys obligations from others by the gifts he bestows. His oldest son does not inherit his position but he may well have a head start after his father's demise. A simplified image of a republican, presidential style of governance in the United States certainly has some resonance with such a Melanesian 'big man', for whom public shame is an ancillary weapon.

When he speaks of his work on the Nasioi of the later 1960s, Ogan portrays a distinctive Bougainville society which nevertheless shares features with other Melanesian communities. Ogan's monograph stressed economics rather than social structure or political leadership. His model is still democratic, but Oliver's Siwai 'big man' has been replaced in Nasioi society by a greater emphasis on its consensual nature, and on women with rights to matrilineal access to land. Women become strong and perhaps, in relation to the proto-emancipation of women, there is a resonance with circumstances in the United States. The Nagovisi women of Jill Nash's observations are stronger still in their capacity to exercise authority.

In other words, how much do people project hidden values from their own acculturation and contemporary events onto what they observe elsewhere? How does one account for unrecorded presumed social change over time (as, for example, Bill Sagir does in this volume)? How do we know that Bougainvilleans (for example Alexis Sarei [1974]) are not presenting a pre-colonial picture of their homeland as much more devoid of those vile actions which members of all human societies now and again inflict on each other, sometimes for long periods of time?

These speculations do not preclude the considerable probability that the record makers were all quite accurate in their observations. There is a considerable probability as well that the connections I have made are over-simplified. In the 
interest of accuracy there is no harm in exploring the connections between a source (an ethnography) and its producer. The problem of being an accurate recorder of 'reality' also perplexed the Tongan antrhopoplogist, Epeli Hau'ofa, when he was researching his PhD on the Mekeo of Papua in the early 1970s. He asked: 'Does an anthropologist record always what is actual experience or what people think the anthropologist wants to hear' [personal communication 1971]? Machiavelli's famous pragmatic political study of Renaissance Italy, The Prince [1513] revolutionised political thought in Europe about the dichotomy between real politics and the prevailing models of princely governance promulgated by Christian humanists in Western Europe. The dichotomy between preferred ideology and pragmatism evident in what has been published about Bougainville is not unique. What of Max Rimoldi's description of the Hahalis community in the mid to late 1960s, with its sexual freedom and contempt for the Catholic Church? Does this not enshrine a libertarian view of society? By contrast Alexis Sarei's Doctor of Divinity thesis on marriage among the Solos [1974] is surely influenced by his Christian acculturation and by the Catholic Church's antipathy to the Hahalis cult. Is it at all possible to lay aside the cloak of one's habitual mental approach? And how does one tell 'the dancer from the dance'? Perhaps the eternal vigilance of the sceptic has its place in doing justice to both the observer and the observed. How to get right the mixture of skepticism and trust for any progress to be made in mapping a foreign culture? If ideological clashes stimulate thought, is that not more desirable than the pretence that a work is bias-free?

Is there some lesson to be learnt from this? In its simplest form surely there is a need for ethnographic studies to be conducted in a number of societies on Bougainville by Bougainvilleans themselves and by other Papua New Guineans, as well as by foreign scholars. There might be particular advantages in trained Bougainvillean anthropologists studying both all the above named foreign texts on Bougainville societies and their own and other societies. Among other things, this might help in the process of mapping what is 'traditional' and what is innovative. The work on Buka by the Papua New Guinea anthropologists, Bill Sagir from Manus and Roselyne Kenneth from Buka (both in this volume), and by the Teop linguist, Ruth Saovana-Spriggs in other publications [see Saovana-Spriggs 2003: 195-213] perhaps marks the beginning of this essential participation by scholar-analysts from the Papua New Guinea region. As it is, existing sources have opened only tantalising glimpses of what might once have been considered truly 'traditional'.

\section{The Paucity of Records from the German Colonial Period}

The German phase of colonial Administration (1886-1914), which perhaps contributed to the self-image of Bougainvilleans as being markedly different from 
Papua New Guinea mainlanders, ought to be carefully scrutinised. The absence of an ongoing set of German colonial administration and many other records for the period 1886-1914 places great obstacles in the way of understanding this, the earliest part of Bougainvillle's intensive engagement with the outside world. We have no ongoing German records for the 'modernisation' and development of Kieta, the other towns, or the sub-districts. The administrative records that were kept have disappeared. Some sources do give glimpses of change, and the resistance to change, during the implementation of defined policies and objectives.

The fact that the few available records were written in German has meant that even they are not readily available to Bougainvilleans or English speaking outside observers until the Sack/Clark translations. ${ }^{3}$ The bibliography of records for German New Guinea, which Sack compiled and edited [1980], provides a starting point for any researcher interested in this period. Most notable, as Sack has pointed out [2000], is the loss of a key set of records documenting German administration from the Kieta-based headquarters of the province. In his own writings, however [this volume], Sack has shown that up to a point this loss can be by-passed. A scholar with a background in German imperial policy of the 19th and 20th centuries and a lawyer's specialisation in legislation on land and taxation policies, and able to read the handwriting of German officials in correspondence and reports, Sack is ideally qualified to fill in some of the large blanks of information about the German administrative landscape.

\section{Access to Foreign Archives}

Much of the limited material on Bougainville before World War II is held in archives outside Papua New Guinea, and in many cases are recorded in languages other than Tok Pisin or English. The research of records of French and some German missionaries, conducted by Hugh Laracy, has been the most far-ranging and difficult investigation in international archives for the disclosure of Bougainville's early history. The paucity of German readers among scholars interested in the German phase of governance has, with the notable exception of Sack and Stewart Firth, inhibited a similar undertaking. Firth wrote the first general study of German rule in New Guinea [1982] although Bougainville has only a minor place in it. Peter and Bridget Sack's collection of documents in English translation, The Land Law in German New Guinea [1975] have their interpretative value in assessing land alienation in Bougainville under German rule. As Sack has pointed out [2000] the loss of station records from the Kieta-base inhibits the tracing of development in the German North Solomons and of quantitative analysis and comparisons with other parts of German New Guinea and Papua. 


\section{Incomplete and Inaccessible Records of Australian Colonial Administration}

Many of the records of the Australian Administration of New Guinea were lost during World War II, and in addition many of the post-war government records were closed by a 30 year rule of the Australian Archives Act. For example, until 1 January 2005, access was denied to documents written from 1 January to 31 December 1974 (except by rare, and usually exceptional, privilege). As a result, records concerning the period from 1969 to 1974 - a period of critical importance to understanding Bougainville's history - have only recently become available. At the time of writing (early 2005), colonial records concerning $1975-$ the year of Bougainville's first unilateral declaration of independence [see J. Momis, this volume] are still not available. The government documents relating to the decision to employ a police riot squad against defiant Rorovana villagers when, on 1 August 1969, survey pegs were put in place for the resumption of their land for a mine port, were closed until 1 January 2000. The coverage of these critical events by newspapers was largely upstaged by the excitement that men had reached the moon a week earlier.

\section{Gaps in the Subjects for Research Undertaken todate}

There are other major (thematic) gaps in the analytical research undertaken about Bougainvilleans and other Pacific Islanders. Systematic studies serving as the broader contextual backing for any history of the province might have investigated the labour trade in Bougainville; the transition from barter to cash economies from the colonial phase onwards; the operation and impacts of colonial administration at the local level in different periods; the political implications of colonial law and order processes; the nature and significance of so-called 'cargo cults' wherever they occurred; Bougainvillean participation in World War II, and its effects on different localities; a demographic profile of Bougainville societies since the beginning of contact; a careful scrutiny of the wide-spread Bougainvillean grievance of neglect by government; and how Bougainvilleans have responded to foreign scholarship. The list could go on.

While this volume attempts to fill in some of the lacunae, one must not forget to mention important monographs that have already dealt with aspects of Bougainville history. Notable among them is Hugh Laracy's pioneering work on the Marists and the Catholic Church in Solomon Islands, including Bougainville [1976]. Equally, the period of Australian Administration has featured in books, articles and newspapers. Most notable among specialist monographs dealing with that period is Donald Denoon's Getting Under the Skin [2000], which deals with the failure of the Australian Administration's mining policies. Based on thorough research in archives, this book stands out as one of the few monographs in literature on Bougainville which otherwise abounds in articles and commentaries. 


\section{INACCESSIBILITY AND NEGLECT OF THE WORK OF AN IMPORTANT PIONEER OBSERVER}

Something that has puzzled me for many years is that the early writings on Bougainville of the Austrian scholar, Richard Thurnwald (1869-1954), based on his first stay there (1908-9), had been virtually ignored by scholars before the crisis. It seemed odd that a foreign language should be a barrier to anthropologists who in any case have an obligation to cross barriers of language in support of their fieldwork. It was not until the early 1990s that Douglas Oliver published a serious examination of why the neighbouring Motuna and Telei speakers arrived at such different ways of conducting their communal lives. But no one to date has subjected Thurnwald's ethnography of Buin [1912] to detailed public scrutiny. Thurnwald's 'first-contact' experiences (1908-09) in Bougainville, even if they are a mixture of anecdotal reporting and the serious observations of a scholar, have been totally overlooked in the English-language publications of scholars who arrived at least 20 years later and more. That is odd, as Thurnwald was the earliest trained scholar to study any Bougainvillean society in a systematic way. He spent at least seven months in Buin during his 10 months on Bougainville, in a period before German colonial 'pacification' had occurred there [see Laracy, 'The Pacification of Southern Bougainville', this volume]. As mentioned already, he returned to Buin 25 years later, and was able to consider the changes that occurred in Buin society as a result of 'pacification'.

After Thurnwald's death the noted Australian academic anthropologist, A. P. Elkin, noted the 'esteem and respect' with which Thurnwald was regarded in anthropological research development [Elkin 1954: 130]; Robert Lowie's obituary in German speaks of him as 'the leading German ethnologist'; while Eugene Ogan has referred to him as 'among the most famous' academic anthropologists to that time (early 1970s) [1975: 329]. Thurnwald's German biographer, Marion MelkKoch, who had privileged access to manuscripts that had been held in private hands, considers Thurnwald's scholarly perspectives to be 'decades before his time' [1989: 133, 276].

Already in 1926 Thurnwald's serious contribution to research in New Guinea was publicly acknowledged when Bronislaw Malinowski wrote in the 'Introduction' to his Crime and Custom in Savage Society, that so far Richard Thurnwald was the only 'writer who fully appreciated the importance of reciprocity in primitive social organization ... Throughout his monograph [1921, on the Banaro on German New Guinea], which is perhaps the best account of the social organisation of a savage tribe, he shows how the symmetry of social structure pervades native life' [1926: 24]. The concept of equivalent reciprocity by the 
1970s was widely associated with communities in Melanesia. It concerns the way individuals and communities, as in Bougainville, regulate their relationships around an inherently egalitarian ideal of 'equivalence'. In their dealings with outsiders, this principle of justice applies to trade, the application of 'pay-back' in sorcery and sometimes even in how battles are conducted. In similar vein, Regan [this volume] writes of the 'balance' sought by Bougainvilleans in the communal democracy and justice they traditionally sought, and still do. The idea appears first in Thurnwald's discussion of the hierarchical and patriarchal role of chiefs in Buin. A chief, he stated on the basis of his fieldwork in 1908, was nevertheless only 'primus inter pares', the first among equals [1912, 3: 48]. A closer study of Thurnwald's 1908-09 fieldwork is necessary to assess how much of this idea is already present in the fruits of that research. Lowie, in his obituary in German of Thurnwald, confirms that 'the principle of equivalent reciprocity was worked out by Thurnwald' in his study of the Banaro, that is, before 1921. [1954: 4]. And yet, despite Thurnwald's reputation for serious and innovative research, Jared Keil is the only anthropologist working on Bougainville who has closely analysed some of the articles published by both Richard and Hilde Thurnwald in the 1930s ['Buin Social Structure', this volume]. He was unable to place the works of 1912 and before under such scrutiny because of the barrier of language.

Of course until Melk-Koch's biography of Thurnwald appeared in German in 1989 (it has not been translated into English), little was known in any detail of his precise professional credentials. The solid professional background he brought to Buin was until then unknown and remains so while his works are available only in German. As Melk-Koch documents, Thurnwald had received his training in law and in economics at the University of Vienna and applied his legal training as a servant of government in the Austro-Hungarian imperial outpost of BosniaHercegovnia. There his fascination with cultural pluralism determined a change in career. Having also studied sociology at Graz University, he took up the study of anthropological ethnology at Berlin University while in paid employment as a museum curator at the Berlin Museum of Ethnology (nowadays named the Berlin Ethnographic Museum). He acquired basic linguistic competence in Latin, Greek, French, English, Italian, Hungarian, Serbian, Russian, Dutch, Arabic and Persian [Melk-Koch 1989: 17, 18] and Hebrew [Melk-Koch 1989: 35]. Hence he brought remarkable inter-disciplinary professional experiences to bear on his pioneering fieldwork in Bougainville. One might ask has any scholar who has studied communities in Bougainville brought such a range of professional credentials to bear on his work? A true scholar, not just tied to his own territories of fieldwork, he remained engaged in scholarly discourse well after he left New Guinea. and was to continue to register his wide spectrum of scholarly interests in 
an impressive list of publications. In 1926 he became a member of the Londonbased Royal Anthropological Institute [Lowie 1954: 2]. Melk-Koch's biography lists his published works in a block of 25 pages [1989: 326-51]. Until his death, Thurnwald edited from his base at Berlin the scholarly journal Sociologus, which he had founded. This also documents his interest in the new field of ethnopsychology and in 'primitive' notions of law and rights, a subject with a much older history among colonial administrators and their legal advisers. Economics and cultural heritage were among his other many research topics.

Thurnwald was sent to German New Guinea in late 1906 by the Berlin Museum of Ethnology which financed him (inadequately) to collect artifacts and research their manufacture, use and significance. After completing a year's work on the Gazelle Peninsula, in early 1908 he arrived in Kieta where he set up his base. By April he was in Buin in a camp on the coast. With his linguisitic flair, a reasonable competence in Tok Pisin can be assumed, although this lingua franca was then not used widely in south Bougainville. Thurnwald published three accounts of his travels in Bougainville [1908, on Nissan; 1909 on Buin and Kieta; 1910a on travel by sea southwards from Buin]. His research in Buin was written up from voluminous field notes after his return to Berlin in 1909. By 1912 he had published two large volumes that focused predominantly on his work in Buin, Forschungen auf den Salomo-Inseln and dem Bismark-Archipel [Research on the Solomon Islands and the Bismarck Archipelago]. They were intended as part of a planned six-volume set comparing human societies. Three volumes were intended to examine life among the Telei speakers (Buin). Volume 1 is mostly devoted to his collection of texts for 139 Buin songs, 42 of them with musical notation. ${ }^{4}$ Volume 3 has the sub-title of Volk, Staat und Wirtschaft [People, State and Economy]. It includes a record of legends and actual happenings that can be cross-referenced to the songs translated in volume 1, as well as a set of genealogical tables by which kinship connections between people in Buin and the Shortland Islands can apparently be traced. As Melk-Koch points out [1989: 154], Thurnwald compiled Volume 3 too hastily and gave the genealogical tables undue space at the expense of more informative material which remained incomplete because he was pressured to leave Germany again for mainland New Guinea in 1913. He never completed volume 2, intended for his Telei (Buin) grammar and associated dictionary listing approximately 8,000 words. Interrupted by World War I when he was mapping the upper reaches of the Sepik River in German New Guinea, he was unable to return to Buin as he had intended, to verify his work on the Telei language. He refused to publish that valuable pioneering work until he could do it with greater authority. ${ }^{5}$

During the year of his stay in Bougainville, Thurnwald also made numerous anthropometric measurements, had models of buildings reconstructed for overseas 
museums, took numerous photographs, collected some of the skulls that were so plentiful in Buin, sent an abundance of artifacts, accompanied by cultural notes, to the Berlin Museum of Ethnology and recorded Buin songs on waxed rolls. [For Thurnwald in Bougainville see Melk-Koch 1989, especially pp. 91-159; and for H. Griffin's brief review of Koch see 1990, 57-8].

For a representative early history of Bougainville one of the requirements would seem to have been to take notice of whatever can be gleaned from this rich contribution, ancillary to the information provided by missionaries who worked most closely to the Telei speakers in early colonial times. Even Thurnwald's travel reports provide insights for historians about such broader issues as the remarkable communal diversity in Bougainville and the desire of Buin people for an end to ongoing cycles of fighting. In 1908 he was asked to be the mediator in an attempt to establish peace between two large feuding communities. Those involved complained that they wanted to end the cycle of violence. The son of a local chief succeeded in getting Thurnwald's consent to act as impartial and symbolic mediator and to venture with him and a group of assistants from both Buin and distant New Guinea into dangerous territory to negotiate a peace between the antagonists. Thurnwald wrote of how, at that time, scarcely a week went by without yet another homicide being reported from the hinterland. Thurnwald describes in detail that journey and a peace settlement in which he played the leading role in April 1908 [1909: 523-5]. The description of how simply and peacefully he managed to stop the feud borders on the bizarre. One has to remember that Thurnwald's Viennese humour occasionally makes an appearance in his less formal reporting. The background to the ongoing feud, which began with a love affair, is briefly recorded by him in that report as well in more detail as a separate story based on field notes (No. 10, 'The fight over Manta'), in his monograph of Buin [1912, 3: 72-4].

Only Thurnwald's occasional publications on Bougainville in English, when and after he was based at Yale University in the early 1930s and had toured American universities as a guest lecturer, appear to have been read by scholars studying Bougainville communities. His best-known essay, 'The price of the White Man's peace' [1936b], stands as a critical assessment of the effect of colonial and mission interventions. From his earliest writings about Bougainville his opposition to colonialism and its agents is manifest. This and other essays from the 1930s were written during and after he and his wife, Hilde, a sociologist, were funded jointly by the Rockefeller Foundation and the Australian Research Council to review his work in Buin (1933-34) after their visit to Australia. While these essays may be based on some of the generalisations arrived at in the early publications, they are mere summaries of the much more detailed and more 
complex earlier work. It is important not to take as conclusive these updates by the Thurnwalds in the 1930s without scrutiny of the earlier publications. An example will suffice to make the point.

Mistranslation of work written in German can also cause problems. A translation (translator unnamed) of Hilde Thurnwald's 'Ehe und Mutterschaft in Buin' [1938: 215-16] states that Richard 'found' only four clans (by which he appears to have meant clans and sub-clans) in Buin in 1908. Correctly translated, this passage reads that Thurnwald 'only got to know' (familiarised himself with only) four clans; that is, he studied only four. Matching this up with a passage in the 'Introduction' to his Songs and Legends of Buin [1912, 1: 13] one finds, more believably, that he noted that there were so many clans in Buin that a responsible scholar could not possibly study them all 'properly and conclusively' in the short time he was there. He goes on to criticise the method prevalent among ethnographers to do 'random sampling' of clans while noting a large range of them. $\mathrm{He}$ therefore delineated a small area within the larger region and studied the four. This, he says, is a more 'scientific' approach.

Examples about misunderstanding and neglect do not entail giving Thurnwald undue credit. But they do illustrate the dilemmas posed to scholars dealing with early German sources. So much change undoubtedly occurred in Buin societies in the almost 100 years since Thurnwald's first visit there that there is now some difficulty in determining what was accurate and what was not. Careful comparison of others sources can help. To that end I translated four of Thurnwald's Buin poems (songs) from German to English and placed the lines beside the original Telei text for Jared Keil to take on a fieldtrip to Buin in early 2004. They are magnificent evocations of love and a feeling for nature. But no one in the villages where they were put to the test knew them or understood the language. We knew at least at the outset that these villages were not part of the geographical area of Thurnwald's research and that the people may well have spoken a different dialect to the language that was collected. The lack of recognition by present-day villagers may also be explanations by such reasons as: possible shifts in memory; loss of aspects of traditional culture; shifts to a variant language that has replaced an earlier version; the absence of the music associated with the words so that a prompt is missing; and perhaps other reasons as well. Perhaps Thurnwald's method of writing down the verses in Telei was under-developed when compared with the linguistic fluency of Don Laycock who examined the Telei languages at greater length in the late 1960s and early 1970s [Onishi, ed. 2003].

But then against this negative experiment I can cite several more hopeful examples to moderate incredulity about the past. The picture that Thurnwald 
painted of (1908-09) Buin society (Telei speakers) included a description of paths set aside for the private use of the wives of chiefs. It was considered indecent for a chief's wife or daughter to be seen by 'bondsmen' (for analysis of the stratification in Buin society, see Keil, this volume). Although Thurnwald only mentioned this in passing, I assumed it was important information, as it obviously was because Hilde Thurnwald repeated in 1934, that to disobey the taboo could entail instant death [Thurnwald, H., 1934: 151]. She added in a footnote that in 1908 her husband met hardly any women on his travels in Buin, neither did the missionaries. In 1971, after I had observed village men and women at Tabago Mission sit segregated either side of the church aisle, I questioned the ex-seminarian Aloysius Noga (born circa 1925) of Piano Village about the above statements made by the Thurnwalds. He said that he knew nothing about such customs. However, Paul Mason, who arrived as a young teenager in the Shortlands around 1914, and became a noted trader, planter and World War II coastwatcher, told James Griffin [Griffin 1978] that in the 1920s he saw women in Buin with covered faces and he knew about the private paths they used. This would suggest that by that time government and missions had not yet changed all customs.

When in 1933-34 Hilde Thurnwald went to Buin, she engaged in studies of women's social roles and collaborated with her husband. More independent in presentation is her book of 16 biographical portraits of Buin women, Menschen der Südsee [1937], whose daily lives might throw light on anthropological conjectures. A number of her portraits could not be published because they were too revealing of secret information. Hilde kept her word about confidentiality. Otherwise she has recorded, with an ear to how people told her their stories, invaluable random insights into the physical circumstances and people's activities, criticisms, aspirations and values of life in Buin villages at that time. Ogan once cited the case [1975: 331] of an outstanding medical student from Buin angrily tearing a page out of one of Hilde Thurnwald's articles [1934: 151] because she described a Buin practice current in 1908-09 which the student wanted to be false. The offending custom allowed a 'chief' the right to sleep with his son's prospective wife on the eve of their marriage. A devout Christian, the student could not believe that his ancestors behaved like this. And yet every society in the world has had people who have performed actions which today are not considered acceptable behaviour.

In refutation of the existence of that custom, Elizabeth Ibua Momis of Buin has described a modern practice known to her, that requires a bride-to-be to go to the home of her future parents-in-law before her marriage. She does not go to sleep with the bridegroom's father, but to be instructed by his mother about her new home, her duties as a wife and on local gardening arrangements. ${ }^{6}$ And that is 
no doubt true today and may or may not have been true in 1908. If not true, one has to ask: how did the error come about? If true, then one has to ask when and how and why the custom changed? On the other hand, a similar custom was recorded on Buka by Blackwood (and see Sagir, this volume, concerning recent abolition of the practice in Buka). Hilde Thurnwald reminds us that this is reminiscent of customs encountered among the Banaro (described by her husband in 1916) and Russian peasants. But is what Hilde Thurnwald described so remarkable? By comparison one needs to refer to what we know of the droit de seigneur (right of the lord) which prevailed in Europe in the past. It is the theme of Mozart's 18th century opera, The Marriage of Figaro, in which a Spanish count's customary feudal privilege to sleep with the bride-to-be of a servant on the night before her wedding is thwarted and subsequently abolished altogether.

The study of anthropology and history provides us with perspective across societies and it can demonstrate that, while societies may be excitingly different, people throughout the world have much more in common than is sometimes apparent. We are not sure that Hilde Thurnwald - or her husband who first raised this matter obliquely in 1908 [1912, 3: 13] — were correct in describing the custom. Nevertheless, one has to remember that Hilde talked to many women in the 1930s in confidence and therefore had some scope for checking information about the history of womens' lives in stratified Buin society.

I hope to have demonstrated what a rich untapped source the publications of both Richard and Hilde Thurnwald remain. The above is a set of related samples I have examined only briefly. There may still be other, comparably precious, source material in languages other than English to be tapped for a fuller record of early Bougainville history. The neglect by later scholars to examine seriously all of Thurnwald's portrait of Buin may have been conditioned by the known pitfalls of working through inexpert translations. Of course it is also possible that the discipline of anthropology had moved on by the 1930s and found the broad interdisciplinary sweep embraced by Richard Thurnwald irrelevant, irritating or unfashionable. Nowadays inter-disciplinary studies have resumed scholarly approval.

\section{PRESERVATION OF MATERIAL CULTURE}

A fuller picture of Bougainvillle's history can be obtained not just from the written record but also by access to material culture. There are, of course, also reasons other than an interest in history that support the need for the preservation of Bougainville's material culture. Bougainvilleans have a right to know what material culture was collected and removed by Europeans in the early colonial period, which of it still exists, where that is held and whether it can be made more acces- 
sible to them in some form. They have a right to know of their past accomplishments and to take pride in their cultural heritage.

During 1973, while searching through the Victorian State Library's publications about German New Guinea, I discovered a book by Karl and Lily Rechinger [1908: 174] a husband and wife team of botanists from the Vienna Museum. They had been on a plant collecting journey through German New Guinea and in 1905 were given a passage to Bougainville on the Seestern by Governor Albert Hahl. The book is an enthusiastic poetic and scientific tract, mainly about botany but also about their travels. The judge-governor stopped along the route to arbitrate in disputes and mete out justice under the attentive eye of the Rechingers who were with him when he set up the Kieta station. They quote market prices for artifacts [Rechinger and Rechinger 1908: 174] and comment on a pile of artifacts on the deck. When yet another person came to trade for a bunch of spears, they heard Hahl exclaim in mock despair: 'Tomorrow', pointing to the spears, 'Mi cookim coffee?' (sic) In other words for Europeans by then they had no more value than tinder.

Yet in the 1970s, having been alerted to what appeared to be a dearth of material culture on Bougainville, compared with other parts of Papua New Guinea, James Griffin and I had been wondering whether Bougainvilleans had traditionally produced less material culture than craftsmen in other Melanesian communities. In 1975 we noted that the Papua New Guinea National Museum had nothing from Bougainville in its displays. We examined available German publications and modern books on Pacific art. We were not surprised to discover how extensively visitors to Bougainville traded for artifacts. Even Friedrich Burger, the popular writer who was not particularly interested in pronouncing on the issue, was surprised at the large-scale collecting of material culture taking place on Bougainville [1923: 174]. While Burger is not important in any history of Bougainville and only enters this discussion almost by accident, he brought to my attention an important fact which led to an investigation on a broader scale. Something of an adventurer he visited Bougainville and wrote up a brief sketch of his visit. He made the passing remark that among German planters and officials, collectors of spears and other wooden items were known as Feuerholz ([Mr] Tinderwood).

James Griffin and I wrote a small pamphlet about the large-scale disappearance and export of artifacts from Bougainville [Griffin and Griffin 1975]. This study condensed joint wide reading of late 19th century and early 20th century publications about Bougainville's material culture and revealed the mania for collecting artifacts that swept the region in the early 20th century and probably from then on. Our study concerned itself only with the German colonial period, 
although it is well-known that foreigners continued to collect utilitarian works of fine craftsmanship. Artifacts of symbolic significance, associated with traditional customs and rituals, became obsolete after Christian proselytism took root. After national Independence in 1975 Papua New Guinea's museum authorities began to forbid the export of genuine 'antiques' and encouraged the revival of knowledge of traditional crafts. Late in 1975 we demonstrated that museums in Europe and elsewhere were well-stocked with samples of Bougainville's 'traditional' material culture while at the time the National Museum of Papua New Guinea in Port Moresby had nothing from Bougainville. Little material corresponding to that stored in European museums is manufactured in Bougainville today.

The point is that some of Bougainville's material culture should have been returned home. We provided a number of clues as to where artifacts from Bougainville might still be found overseas. It is possible, of course, that material was destroyed in Europe during bombing raids in World War II. On the other hand, had large quantities of cultural material been returned from overseas to the Kieta-based North Solomons Cultural Centre (established in 1974-5), a similar fate would have ensued because it was burnt down during the 'crisis', (1988-1997). It is evident, therefore, that precious materials of heritage value ought always to be stored in more than one place and that exact replicas should also be made. Copies of original documents stored in more than one place are also vital for the preservation of research resources.

\section{MERE FRAGMENTS CAN BE USEFUL}

Mere fragments of history can be illuminating, and I provide an example of one that could be significant for people who like to celebrate first occasions and feats of human endurance. In early 1968, just before I came to live in Papua New Guinea, I had read Gavin Souter's evocative New Guinea: the Last Unknown [1963] and his account of the attempt by Otto von Ehlers, an intrepid and foolhardy German explorer, to cross mainland New Guinea from coast to coast in 1895 [pp. 79-80]. Only some years later did I realise its significance for Bougainville. We had read the recorded attempts by foreign explorers to cross the mainland from coast to coast but Papua New Guineans did not feature as leaders of explorations. Exploration in the European sense was not a feature of Papua New Guinea cultures at a time when neighbouring ethnic communities resisted intrusion by those who did not belong. This was particularly true when neighbours were at war or attributed an unexplained death to hidden sorcery from beyond a community. Souter [1963] describes how men from Buka (Bougainville) and New Ireland were the first men known to survive a crossing of the territories of New Guinea and Papua. They 
survived the hazards and the acute deprivations of the expedition which was initially led by von Ehlers and Piering, a German police sergeant. After both Germans and some New Irelanders were killed, ${ }^{7}$ Ranga/Rangai and Opia/Upia from 'Buka' took over the leadership of the expedition. It is a gruesome and intricate story derived from two books [Tappenbeck 1901: 109-12; Hahl (1937), translated by Sack and Clark 1980: 32-5]. In their translation of Hahl [1980] Sack and Clark borrowed a photo from Wendland [1939] to accompany Hahl's account of the Ranga-Opia story. It was taken in 1896 of the 23 Melanesians who survived the expedition out of a total of 42 participants. Wendland had identified the two men from 'Buka' as clearly the leaders. The story of the intrepid Bougainvillean explorers has several implications, two of which I raise below.

Firstly, in the past we honoured white men who were explorers and officials (though usually assisted in crucial ways by indigenous carriers and police) for crossing large tracts of what is now called Papua New Guinea through territory in which groups of people were allegedly hostile to each other and to foreign interlopers. Until I lived in Papua New Guinea I failed to see the significance of the Ranga/Opia story. Not only had these Bougainvilleans become the heroic leaders of such an expedition but they were the first known men ever to have succeeded in a coast to coast crossing of Papua New Guinea. Yet their feat was not memorialised. I also learnt at that time that the German colonial masters liked to choose men from 'Buka' (i.e. Buka and Bougainville) to work for them because they were strong, healthy and trustworthy. They could be used as allies in a situation fraught with danger. Unbeknown to them, they could be used as tools in a colonial 'divide and conquer' situation.

James Griffin drew another conclusion from this story in the (unpublished) paper $^{8}$ he delivered to the 1977 Australian New Zealand Association of Science (ANZAAS) conference in Melbourne. He relied on Souter's account and on my translation of Ernst Tappenbeck's view [1901] of the Ehlers-Piering and Ranga-Opia. story. Tappenbeck, the quartermaster who provisioned the prison in which the two 'Buka' criminals were being held until their trial, speculated that if the disaffected New Irelanders on that expedition had not leaked the story of the murder of von Ehlers to the German authorities, the Bukas may never have gone to trial nor, therefore, have broken out of gaol, nor become murdering fugitives in self-defence. Tappenbeck could not conceal his admiration for Ranga and Opia. Griffin regards Tappenbeck's account as a paradigm of the kind of difficulties facing any alliance between groups of Papua New Guineans who seek political unity. The tendency to fragmentation remains even in the face of opposition to colonial overlords. Traditional fault-lines, based on the geography of clan loyalties, operate against the modern state. Indigenous political unity is therefore a triumph of adaptation, an adventure in modernisation, not a pre-determined eventuality. 


\section{CAN WE EVER KNOW WHAT REALLY HAPPENED?}

The foregoing discussion considers just some of the difficulties involved in use of existing records to reconstruct Bougainville's history before mining development began in the 1960s. This discussion gives rise to broader questions.

One of the few authorities on German New Guinea, Peter Sack, has pointed out the pitfalls of much narrative history that uncritically draws upon sparse documentary sources, thereby creating a 'phantom' past. He has written a monumental work on what he calls the 'phantom history' of German New Guinea [2001], which challenges received opinions on the study of that subject, including Bougainville's place in that history. In the absence of access to the ongoing records produced by the district officers at Kieta (because it no longer exists) how can we make the quantitative analysis that is essential to any believable picture of demographic, economic and sociological developments, any believable account of ills associated with the colonial plantation economy, law and order situation and of retributions targeted at criminal offenders? How can we compare Bougainville with any other part of German New Guinea or English and Australian Papua? (I speak in general terms about points Sack raised at the conference). ${ }^{9}$ Reliable history, he said, should not rely on the entertainment value of a good story. Full records and scrupulous application of them are essential.

The marginal methodological differences are also influenced by whether one is French or English or German or Japanese or Indonesian by acculturation. German academics are tolerant in ways that differ from the English who traditionally have placed greater value on the literary finished product and its logical conciseness rather than on illuminating digressions and a forest of reliable and visible footnotes. An English scholar is more likely to keep a large part of the whole evidence (the research apparatus) in his filing cabinet for immediate validation if questioned. It is not surprising that post-modernism was born in Europe from architecture, with a mandate for exposing structural supports and service pipes as equally valid (egalitarian) ingredients of beauty. There are always marginal differences in methodology even within a discipline. Whether we like it or not, and whether he is right or not, Sack's wake-up call is a salutary prompt to anyone examining existing sources on Bougainville.

Nevertheless, we must not lose hope. We can be inspired by working with the sources of anthropology and history. Inspiration is derived from knowledge that these disciplines never stand still. The bibliography of writings on Bougainville history to 1975 , which I began to compile 25 years ago, will obviously have to be revised in the light of more recent research and publications. 
I wonder what research may be prompted by the essays in this book? Much pleasure is anticipated when more Bougainvilleans place their own records on a map of knowledge that we all can share.

\section{Endnotes}

* I am indebted to Anthony Regan and James Griffin for comments on the first draft of this paper and for Regan's advice on restructuring my arguments which have benefited this paper.

1. For example, Robin Hide, a senior research scholar with long association with The Australian National University, has prepared a specific bibliography of Bougainville for his own scholarship. His updated [2005] copy is in my possession with thanks.

2. There are some partial exceptions, including Oliver [1949, 1991 and 1993a, 1993b) and Ogan [1992 and this volume], but they compare just a few societies.

3. For example, editors and translators Peter G. Sack and Dymphna Clark, German New Guinea. Annual Reports, 1886-87 to 1912-13, and Draft for A. R. 1913-14, and Albert Habl. Governor of New Guinea, all published by ANU Press. [Draft has 1979 on title page, but 1980 on the cover].

4. In 2004, I translated four of the touching Buin poems (from German into English, with accompanying Buin text) that Thurnwald had collected in 1908 so that the people of Buin could be exposed to them when Jared Keil visited in 2004. Keil subsequently told me that in the particular village in which they were read, no one who heard them understood the archaic language Thurnwald had recorded.

5. Although critical of Thurnwald's Buin grammar, Don Laycock of the The Australian National University was to establish that about 5,000 (that is, 60 per cent) of the original words were correctly given [Melk-Koch 1989: 152]. Laycock's Buin Dictionary was edited and published posthumously in 2003 by the Japanese scholar Masayuki Onishi under Laycock's name [Laycock 2003]. Thurnwald's pioneering work in Buin linguistics does not merit even a passing mention in this publication.

6. E. I. Momis during discussion in State Society and Governance in Melanesia, taped proceedings of Bougainville Conference 2000.

7. In 2000 Dr Sack reminded me that Ranga's murder of von Ehlers and Piering, the German commissioner for police, was not purely for his own survival. It was fuelled by a pay-back motive. Tappenbeck [1901:109-10] whose sympathies are clearly with the Melanesians in this matter, bravely suggests that Piering had sexually molested Ranga's wife some time before the expedition was mounted.

8. Paper held by its author in Canberra [Griffin family archives].

9. First draft paper for article by P. Sack. Copy with the author, Canberra. 



$$
\begin{gathered}
\text { ECONOMIC } \\
\text { AND SOCIAL } \\
\text { CHANGE POST- } \\
\text { WORLD WAR II }
\end{gathered}
$$




\title{
POST-WAR RECONSTRUCTION IN BOUGAINVILLE: PLANTATIONS, SMALLHOLDERS AND INDIGENOUS CAPITAL
}

\author{
by Scott MacWilliam
}

W hen the revolt broke out on Bougainville in late 1988, an immediate if less often noted target of attacks than on Bougainville Copper Ltd (BCL) was property owned by the Bougainville Development Corporation (BDC) and other indigenous firms. Raising the language of class struggle, 'those in revolt failed to confine their campaign to the Conzinc Riotinto Australia Ltd majority-owned mine at Panguna' and 'deliberately destroyed plant, equipment and property owned by "fellow" Bougainvilleans' [Thompson and MacWilliam 1992: 103]. If such attacks confused observers who were certain that the conflict was yet another instance of a 'local' opposition to the destruction and exploitation brought by an international firm, this was hardly surprising. The 'insider' versus 'outsider' construction of events on Bougainville was and still remains the predominant lens through which the island's political economy is understood in academic and other descriptions [O’Callaghan 2002].

Not least this is because despite more than 40 years of often detailed examination of developments among the Bougainville Province's people, there is no adequate understanding of the origins and advance of the class which raised so much local popular hostility, particularly at the end of the 1980s. The inadequacy exists despite the fact that over the previous decade and a half, from self-government and then through the first post-Independence years, Bougainvillean businessmen and women had encircled and then made inroads into the operations of one of the world's largest mining companies. Bougainvillean-owned firms had taken over very large copra and cocoa plantations, engaged in commerce, trans- 
portation on road, air and sea, moved into the exporting of agricultural produce, and expanded activities in manufacturing to Port Moresby [Thompson and MacWilliam 1992: 55-119].

The structure of the BDC, as a provincial development corporation, was effective in gaining popular support and funds for the activities of the corporation. By the mid-1980s, however, this commercial form no longer suited the aspirations of the business people who controlled the firm. The dominance of the provincial government on the share register of BDC meant constant pressure for dividends to be distributed to 'the people' of the Province to provide welfare, rather than have them held by the firm to reduce interest payments on borrowings, and thereby increasing profitability. This opposition between welfare and profits had also been played out in the operations of the Road Mine Tailings Leases Trust Fund, formed as the business arm of the Panguna Landowners' Association, with continuing pressure to increase returns from the pool of royalties paid by the mine to local landowners. In 1985, BDC was effectively privatised 'against the prolonged efforts of provincial officials, led by the newly elected Melanesian Alliance-led Provincial Government, to block the sale' of a large parcel of shares to individuals [Thompson and MacWilliam 1992: 108].

This chapter does not attempt to answer the fascinating question: why was the advance of indigenous capital, as well as the popular dissatisfaction with its activities in the Bougainville, so underestimated in the years leading up to the 1988 revolt? Hopefully, before too long, attention will be directed at this critical matter. Rather the focus here is upon an earlier period in the construction of the Bougainvillean bourgeoisie, the first decade and a half after World War II. While a more substantial history of indigenous accumulation will undoubtedly require an examination of the inter-war years, if not before, still the 10-15 years after the global military conflict ended are of considerable importance for any reckoning.

\section{POST-WAR DEVELOPMENT}

In order to understand post-war reconstruction on Bougainville, as well as other parts of Papua New Guinea and other countries affected by the global military conflict, it is necessary to connect the political economy of rebuilding parts of the country to a major change in the colonial government's policies: its new emphasis on bringing 'development'. The severity of the war damage played an important part in what could occur over the next decade on Bougainville. Rebuilding and replanting required much of the labour that was available. However to comprehensively grasp what occurred, it is also necessary to move beyond Bougainville and the South Pacific and adopt a wider focus. This means examining the 
meaning given to reconstruction elsewhere in the post-war period, especially for societies where the great bulk of the population lived on smallholdings in rural areas. To do this necessitates some comparative history.

In his Age of Extremes, Eric Hobsbawm makes the point that in the latter half of the 20th century the most significant political-sociological event has been the death of the peasantry, the movement of large sections of the population out of the countryside. Hobsbawm details the movement in many countries, including Britain, Belgium, United States of America, Spain, Portugal, Japan and Finland [1995: 289-90].

Hobsbawm has overstated the case, of course, because even at the beginning of the 21 st century, about 50 per cent of the world's population still lives in rural areas and are peasants. But it is also important to recognise that in the countries where people stayed on the land, governments continually formulated means to prevent urbanisation. That is, the continued occupation of smallholdings did not occur accidentally or out of inertia. It was quite deliberate. It was a central part of government policy. That policy was usually conducted through the modern idea of development, an idea formed from the early 19th century onward [Cowen and Shenton 1996].

Development was given a renewed impetus in the post-war period. Two of the Australian ministers responsible for Papua New Guinea, Eddie Ward and Paul Hasluck, from the Labor and Liberal sides of Australian party politics respectively, liked to stress that their colonial rule was quite distinct from that of the British. As good Australians, they did not want to be thought of as just imitation 'Brits'. But in fact they were greatly influenced by the way the idea of development had become an international one, with application in British as well as Australian colonial territories [MacWilliam 1996; Wright 1999].

Central to this idea of development, which became so important for Australian colonial policy, was the belief that development could not be allowed to occur spontaneously, but instead only through the activities of private enterprise. The modern idea of development, as practised in late colonial Papua New Guinea, required government action to anticipate and deal with the negative consequences which flowed from the spontaneous process, often paraphrased as Adam Smith's 'invisible hand' of capitalist development [Smith 1978]. In particular, and here the experience of the previous decade and a half of depression and war was particularly critical in influencing state officials, the negatives included unemployment and disorder. Where colonial administrations, including the Australian Administration in Papua New Guinea, governed primarily rural populations, a central task of policy and practice became stopping people moving into the towns. Instead, rural smallholdings were to become sites for the expanded production 
of agricultural produce and consumers of marketed, including imported, products. The expanded production included immediately consumed food, as well as locally and internationally marketed crops. It is important to recognise, therefore, when considering Bougainville in the 10 years after the war, that reconstruction did not mean a return to pre-war terms of production: it meant the fostering of 'development', in the international sense just outlined. (The standard radical anti-colonial criticism that 'not enough was done to develop' particular places presumes the same idea of development intent but shows the other side of the coin.)

For present purposes, there are three key elements of development in postwar Bougainville that need to be considered. The first is how smallholders were, according to the international idea of development, given central importance. The second was the place given to plantations. The third is slightly more controversial: it is the advance of indigenous capital. In a short phrase, the third component is of 'Bougainvilleans becoming bourgeois'.

\section{SMALLHOLDER EXPANSION}

What of the smallholders, the bulk of the Bougainvillean population, in post-war development? They had been greatly affected by the war. It was not only soldiers and others directly involved in fighting who were affected but non-combatants also who were killed, wounded and had their gardens, roads and bridges destroyed. After the military conflict ended, changing the basis of the smallholder attachment to land was to be effected by providing schools, roads and bridges, putting limits on labour recruiting, as well as introducing crops and animals on an expanded scale. While the direction was more easily and effectively applied in some areas of Bougainville than others, nevertheless the central premise - of the need to retain household attachment to land in order to develop productive force - guided colonial policy toward the entire island's population throughout the late colonial period.

Within three years of the military conflict ending, a patrol to Koromira SubDivision, on the eastern coast of the island, south of Kieta, and proximate to Administration offices as well as plantations, noted that:

Copra is being smoked by all groups and being sold to local planters. The groves in this area are very extensive, and enquiries were made whether the groups could band together and ship their copra direct to buyers, thereby increasing profits. The natives also enquired whether this could be arranged for them by the Government, also whether trade goods and supplies could be 
bought and shipped direct in return. The writer feels that this could be an opening for a cooperative movement, which, under supervision, could develop on a large scale [Patrol Reports, Bougainville District, Kieta No.10, 1948-49 of Koromira Sub-Division]. ${ }^{1}$

In the same area, three years later, the limits to further smallholder expansion were already obvious:

All the villages were making copra either at the village sites or down on the coast. Other natives have a share farming arrangement with the plantations in the area, but very few are actually employed on plantations. There are still many groves of coconuts untouched [planted before the war but not yet rehabilitated: SM], both on the coast and in the vicinity of the village sites. It appears that there are not enough people to clear them, dry copra and work in their gardens at the same time [Patrol Reports, Kieta No.4, 1950-51 of Koromira Sub-Division].

Elsewhere, where the 'years of Japanese occupation took heavy toll on the palms and consequently reduced the coconut to a very minor item in the diet of the natives', seed nuts were distributed by Administration personnel soon after their return to Bougainville 'in the villages where the losses had been most severe'. Within a few years 'most of the villages (were) well supplied with healthy young palms' [Patrol Report No. 4, 1950-51 of Paubake Paramountcy, Buin SubDivision, Buin Sub-District].

Increasing the supply of pigs on Bougainville in the late 1940s also was central to the colonial state's developmental role, as the following extract from a Patrol Report of 1950-51 on Kono Paramountcy in Buin indicates:

The number of pigs are increasing throughout the area and the villages of Sulukun and Kamoro have concentrated on breeding and now have their herds large enough to permit selling to outsiders. The sale of pigs by the Administration and the introduction of the Tamworth boar in 1949 has raised the standard and a good quality pig is now scattered amongst the villages [Patrol Reports, Buin No.1, 1950-51 of Kono Paramountcy, Buin SubDivision].

Where - as in Paubake Paramountcy — there was a scarcity of pigs but villagers had 'considerable funds, obtained through the payment of war damage and (being) keen to purchase pigs, especially those obtained from departmental 
sources', pressure was exerted for the Department of Agriculture, Stock and Fisheries to provide increased output from Livestock Breeding Stations [Patrol Reports, Buin No.4, 1950-51 of Paubake Paramountcy, Buin Sub-Division].

As with coconuts and pigs, so with other crops including rice. In the 1948-49 report of an earlier patrol to Paubake:

Kaukau (sweet potatoes) and bananas are more than plentiful in the area and large gardens are now being planted on a commercial basis for sale to the Administration. Between 20,000-30,000 lbs of kaukau and bananas are produced for sale by this small group [of approximately 530 adults] [Patrol Reports, Buin No.9, 1948-49].

There were several important constraints on the availability of labour for smallholder expansion in many areas, including those close to plantations as well as others at a distance from purchasing outlets. The distribution of war damage compensation payments reduced the need to produce crops for sale. Shortages of labour for plantations raised wages but with shortages of consumer goods, money became a display item rather than the basis for purchasing consumer goods and stimulating the search for wage employment, circulating commodities. The war and the effects of bombing on gardens also destroyed labour discipline, especially among young males who took to gambling with a vengeance. In the 1955-56 report of a patrol to Makis Paramountcy in Buin it was noted that:

The most popular game is a card game 'Lucky' which had apparently been introduced by labourers returning from employment both outside and inside the District. These games usually took place in the men's meeting houses, or 'Haus Karamut', often in isolated places in the bush, and in the best traditions of Australian gambling meetings had scouts or 'cockatoos' stationed at points of vantage to give warning of any approaching strangers, who might take legal action against the participants. These games were for high stakes and it was not unusual for one player to lose as much as $£ 100$ at a sitting.

In conversations with patrol officers, paramount chiefs stressed that:

(G)ambling was one of the main reasons for there being such a large number of absentees from the villages. They say that the young men are able to go to bigger centres, such as Rabaul and Sohano, and under the guise of taking employment as casual workers are able to indulge their passion for gambling and quite often live for long periods on their winnings without working ... 
'Lucky' games are common at most places of employment, and as a result of the employees' participation, very few returning workers have any money to show for their period of labour [Patrol Reports, Buin No.3, 1955-56].

While Administration officials attempted to reduce gambling with threats of prosecution, greater efforts were made to push households into expanding agricultural production especially where they occupied large areas of fertile soil. As one effect of the pushing, the demand for expanded agricultural extension services was constant, both from households and from other colonial officials. Where, as in Makis Paramountcy, 'the general apathy of the people' was the 'most alarming observation' of a mid-1950s patrol, constant attempts were made to increase households' agricultural production. The appointment of agricultural extension officers was urged 'to take on extension duties and encourage the natives in the production of cash crops such as cocoa, coconuts, rice under supervision so that it is husbanded correctly'. Extension officers were also to be given 'power to purchase what goods are produced in whatever quantities they are produced'. The marketing role was to be undertaken even if their initial efforts resulted in a loss to Administration funds, 'but as the market expanded then it would be an economic business' [Patrol Reports, Buin No.3, 1954-55 of Patrol to Makis Paramountcy].

Apart from the general objective of expanding the production and consumption of commodities, why would the Administration be urged to enter the potentially loss-making area of trade? There are several reasons which can be dealt with here, but a more complete answer to the question will become obvious later. With the availability of war damages compensation funds, many people had entered trade. During the mid-1950s in Buin Sub-District, there were about 90 trade stores in operation, 'the bulk of them owned and operated by natives'. Due to 'inexperience in business procedures, wasteful buying methods, and their kinship obligations' these stores have run at a loss and slowly eaten away the original capital of the proprietors', causing scepticism about the activity [Patrol Reports, Buin No 3, 1955-56 of Patrol to Makis Paramountcy].

Further, without a wholesale buying agency, and required to purchase store supplies at retail prices from stores owned by a European and a Chinese trader, indigenous traders were forced to operate on small margins. ${ }^{2}$ So, the Administration was to enter trade not only to stimulate commerce in areas where private European and Chinese traders did not or could not operate. Administration trading activities were also to raise the return to households thereby lifting welfare. As well, as an effect of increasing returns, since straddling (see below) between production and trade was an important feature of this phase of indigenous accumulation (of capital), higher profits were to be secured for indigenous traders as well. The 
Administration was pressed to operate as a bulk purchaser, wholesale supplier as well as risk taker. However, as will be shown below, there was considerable ambiguity within the Administration regarding encouragement for indigenes who acted privately as traders. This ambiguity was directly linked with the wider objective of checking the rise of indigenous accumulators, as individuals 'becoming bourgeois', by pushing indigenes into cooperatives active in production and trade.

\section{COMPANY AND OWNER-OCCUPIED OPERATIONS}

Prior to the war, Bougainville had been one of the most important districts for the location of largeholdings, primarily producing copra for international markets. By 1942, Burns Philp through subsidiary firms and the associated Choiseul Plantations Ltd (CPL) had become the largest company managing plantations on the island as well as, with W. R. Carpenter \& Co Ltd, one of the principal trading firms in copra and supplies purchased for largeholding operations. As the military struggle on the island ended, Burns Philp officials moved speedily to re-establish the firm's presence on CPL and Burns Philp plantations. Re-establishment was aided by the fact that the firm had kept copies of plantation records, including land titles, at its Sydney head office, rather than in Rabaul, where all similar records were destroyed. However re-establishment and reconstruction took place under very different conditions than those that had enabled the firm to become so dominant before 1942.3

Burns Philp's plantation interests on Bougainville began in 1912 through CPL which was formed the previous year to acquire freehold lands and establish plantations in the British Solomon Islands. Owing to the abolition of freehold land there, the firm failed to acquire suitable land and shifted its attention to nearby Bougainville, then a German territory. Permission was given by the German authorities for the firm to take up 5,000 hectares on Soraken, Arigua, Kunua, Baniu and Teopasino plantations. Although clearing and planting had begun before the outbreak of World War I, the Australian shareholders of CPL were reluctant to register the firm as a German company, as the authorities wanted. Titles for the plantations were not registered until April 1920, after Australia acquired the League of Nations Mandate Territory of New Guinea. Between the wars, CPL acquired another plantation on Bougainville, Buoi, which was much smaller than nearby Soraken, and run in combination with the much larger operation. Kunua was not re-opened after World War II, due mainly to the unsheltered coast on the western side of Bougainvillle, making sea transport to and from the plantation difficult. 
Burns Philp, although primarily a trading company, had a minority shareholding in CPL from the outset. The firm also acted as a plantation manager, combining the running of CPL plantations with three others - Tinputz, Kurwina (excised from Arigua in the mid-1930s) and Toimonapu, which the firm acquired from debtors. These plantations were held through subsidiary plantation companies that also owned many more largeholdings on New Ireland and New Britain. Indebtedness of plantation owner-occupiers and other plantation companies which began in the 1920s and accelerated in the 1930s, forced Burns Philp to expand its plantation operations to maintain the tonnages of copra it could sell internationally.

By the end of the 1930s Burns Philp was trying to run all plantations, including those on Bougainville, in a much more systematic way as a form of industrial capital. The war stopped the changes then underway in the operation of the firm's plantations, leaving instead the job of rebuilding operations once the military conflict ended. There was immense damage to most plantations in New Guinea, including those owned by Burns Philp. The first task after the war was to rebuild plant, including housing, which in turn meant securing a cash-flow from operations. The quickest way to recommence plantation operations was to collect and process the nuts that had already fallen. Burns Philp managers' reports speak of stacks of nuts 15 and 20 feet high under trees, accessible once elementary cleaning up had been done.

In part the urgency of reconstruction was brought about because of the existence, during a period of global food shortages, of a British constructed scheme to purchase copra and other agricultural produce from the colonies. Consequently copra prices for Papua New Guinea as well as for Fiji were favourable. So companies, including Burns Philp, wanted to get the crops out as quickly as possible. They had to repair or reconstruct their plantations to take advantage of favourable international market conditions for agricultural produce. But they also had to operate within reformed, changed terms for largeholding operations.

It is particularly important to recognise what these changes meant for the large plantation companies. Soon after Hasluck came to office in 1951, the Australian colonial Administration made a point of informing Burns Philp that there was to be no new plantation development, on Bougainville or anywhere else, based upon an increased area of land operated as largeholdings. Burns Philp were told that they were not to negotiate for new holdings, but were instead simply to work the holdings they held already. Paradoxically, this instruction suited those in control at the head office of the firm. They were two rather old men, James Burns and Joseph Mitchell, who were inclined to engage more in trade than in production, and in the accumulation of a large portfolio of rarely traded shares. 
Without any further expansion of the area under plantations, through their plantation operations, Burns Philp and other largeholding producers, including W. R. Carpenter., were allocated a quite specific role in post-war colonial development. Their principal role, as far as the colonial authorities were concerned, was to provide revenue for the scheme of smallholder agriculture. They were not to undermine this scheme either through drawing too much village labour away to work on plantation revitalisation and expansion. Consequently, there were quite specific limits set on the amount of labour a company like Burns Philp could employ. Patrol officers, labour officials and other Administration personnel would examine Burns Philp records to see where the plantation workers came from. And, if too many labourers were judged to have come from one village - thereby depleting its own supply of labour beyond a particular acceptable number - Burns Philp would be instructed that it had to send workers back to that particular place.

So, in the first 10 years after the war, Burns Philp was reconstructing its plantations within the restraints of the colonial scheme of agrarian development, but also in favourable international conditions for agricultural produce. The result was that they had a substantial amount of money to spend on upgrading the properties, replanting where trees had been destroyed, and upgrading plantation rail-lines, roads and bridges. In the first few years after reconstruction began, the firm sent little in the way of profits back to the Australian parent company. Instead, Burns Philp ploughed the money back into re-building plantations, a practice which continued until the mid-1950s.

Of importance for the subsequent future of agriculture, rebuilding included starting to employ, for the first time on an extensive basis, a firm strategy of interplanting coconuts and cocoa. Pre-war, Burns Philp had been at the forefront in implementing this strategy. It was a particularly important practice because the two crops were on different international commodity cycles. ${ }^{4}$ And so, it usually meant that plantations stayed profitable even if prices were down for one crop. Not until the late 1970s and early 1980s were Burns Philp plantations on Bougainville unprofitable because both crops suffered price declines simultaneously. Inter-planting also meant that the firm could increase its planted acreage on existing largeholdings by using labour more intensively, and not necessarily requiring greater numbers of workers at a time when demand for labour was increasing anyway due to other changes in Bougainville and Papua New Guinea agriculture.

The intensification of labour processes was made even more important by the emergence of another major competitor for already scarce supplies of labour for plantations. If the colonial Administration's drive to expand household production formed the principal barrier, the advance of the indigenous class of 
capital with extensive plantings of coconuts and later cocoa put the class directly in the path of the international plantation firms and expatriate owner-occupiers.

\section{BOUGAINVILLEANS BECOMING BOURGEOIS}

The tendency to treat households in occupation of smallholdings as 'subsistence farmers' has downplayed the extent to which the terms of occupation changed after the war [see above, and also Thompson and MacWilliam 1992: 120-55]. With the possible exception of indigenous coffee largeholdings in the Highlands [Finney 1973], the place of agricultural production in the formation of indigenous capital in Papua New Guinea has been largely ignored, only really noticed once the takeover of former European-owned plantations began in the 1970s.

Yet once the war ended, enlargement of the area planted by indigenes as largeholdings, of much greater area and more substantial tree numbers than formed individual household operations, began. Administration encouragement for revitalising damaged plantings, for replanting of earlier crops and for the introduction of new crops, including cocoa, spurred expanded household production but also accelerated the process of indigenous accumulation. By 1954-55, in North Nasioi Sub-Division, of Kieta Sub-District, as cocoa planting began to take over smallholding activities, one indigenous farmer was reported as having a plantation consisting of 'some thousands of trees' [Patrol Report No. 13]. The land disputes between indigenes, which in the 1950s and 1960s became a constant feature of rural life on Bougainville, were evident in the tussles between smallholders as well as the opposition between the household and largeholding, capitalist, forms of indigenous production.

In areas of the island where climate, soil and other conditions suited agricultural expansion, outputs of internationally marketed crops, especially copra and cocoa, as well as locally marketed rice and vegetables, formed the base of the class's activities. A central feature of this phase of the class's expansion — which was matched by similar developments in other parts of the colony, and in other countries [Finney 1973; Swainson 1980: 173-211; Cowen and MacWilliam 1996: 138-209] — was the phenomenon of straddling between higher wage and salaried positions, trading and farming. Employment with the Administration, missions, and plantations as drivers, interpreters, chiefs, and field supervisors, or self-employment in areas of skilled labour provided the means of accumulation through employing labour on enlarged plantings of tree and other crops. That is, as is the case in the formation of an indigenous class of capital elsewhere, including in Australia itself [Smith 2004], indigenous enterprise was diverse and rarely confined to one field of endeavour 
Yet a central part of the colonial development project involved restraining the formation of the Bougainville bourgeoisie. While there is little research on the formation of this class, and the records that are available have been very poorly utilised, nevertheless the main parameters of advance as well as the Administration's drive to constrain the class's activities are apparent [see also Thompson and MacWilliam 1992: 85-119]. It is important to emphasise that the movement from acquisition of wealth, including by and through having numerous wives, pigs and other forms of consumption goods, became especially pronounced as well as uneven.

For the moment, two instances of the process underway will suffice. The first is drawn from a Buin Patrol Report of 1952-53, and refers to an individual who was employed by the colonial Administration as a driver and mechanic, and straddled (see above) from higher wage employment into commerce and agriculture. According to the Patrol Report, the person in question:

... owns three trucks, has three trade stores, two bakeries and large rice gardens producing approximately two tons of excellent rice annually which he sells through his stores. His rice is machine hulled by his own huller for which he charges other natives 25 per cent of the production value of their crop for hull. Nevertheless, he identifies himself more closely with the Administration than with the native people. He lives in European fashion and keeps himself apart from the natives [Patrol Reports, Buin No.4, 1952-53 of Patrol to Kono Paramountcy; Connell 1978: 199-200].

The patrol officer who submitted the report described this businessman as having 'tremendous commercial influence'. The substantial advance of this businessman occurred, as will be recalled from earlier cited reports, despite the slow pace of post-war agricultural expansion in Buin, southern Bougainville, by comparison with other parts of the island. Nor were export crops as prominent among revitalised and new plantings in the area.

Consider then an individual operating in Koromira of Kieta Sub-District, where the agricultural expansion was especially substantial.

None of the [nearby] plantations (out of four) can get more than one or two employees from the Koromira people, who are working their own coconut groves. The Koromiras appear to be seeking means to increase their cash acquisitions. It is possible that their undirected efforts in this direction could lead to a breakdown of their old self-subsistence economy without the replacement of any sound new economy. The area should shortly be ripe for the formation of 
a cooperative based upon the present activities of the native Nikora at Bangana near the Koromira Mission. He makes his own copra and purchases both nuts and copra from villages in the vicinity. He employs 27 natives in this work, mostly Nagovisis, and pays them from 25/- to 30/- per month with rations or $£ 6$ per month, including pay in lieu of rations. His premises were inspected and indicate a real effort to house and care for his employees as required by law. He was instructed to pay off four under-age employees and an endeavour was made to acquaint him with his responsibilities under the Native Labour Ordinance [Patrol Reports, Kieta No. 3, 1952-53 of Patrol to Koromira SubDivision]. ${ }^{5}$

Apart from providing an indication of the scale and diversity of the operations conducted by this indigenous businessman, the above passage draws attention to official concerns for the possible effects of enlarged acquisition as well as accumulation. Households producing an export crop became vulnerable to price fluctuations, a principal characteristic of an 'unsound' new economy, which would in turn result in 'breakdown' and disorder, the very condition which development aimed to forestall [Cowen and Shenton 1996]. By confining the activities of the individual entrepreneur, who hired wage labour, including under-age workers, within the cocoon of cooperative endeavour, direction could be given to development. This direction, it was hoped and intended, would ensure that 'self-subsistence' was replaced with a 'sound new economy' based in household production and consumption protected from the most extreme fluctuations of international markets.

That this summary is not a misrepresentation of the direction favoured by the Administration - that is, towards smallholders and indigenous capital alike - is suggested in the statement drawn from the earlier patrol of Koromira cited above, as well as others in reports from various parts of Bougainville. The colonial Administration was far more concerned with the difficulties posed by the advance of this class, and the claims made by its representatives for an enlarged share of state power, than with the plantation operations of Burns Philp and other international largeholding firms. The latter could be dealt with quite easily, especially given their limited ability to engage in local representative politics, but also because plantation operations played a minor part within the over-all activities of these firms.

\section{CONCLUSION}

Apart from any interest that might exist in the immediate post-war period itself, what are the implications for later developments on Bougainville and in Papua 
New Guinea for the new post-war directions outlined here? The first is the effect upon labour supplies and availability which lead to important political tussles. The major expansion of smallholder agriculture, which gathered pace even more once cocoa became firmly established as a smallholder crop from the late 1950s, limited the numbers of workers available for employment on largeholdings, in non-agricultural wage positions in general and particularly for working at the Panguna mine. This in turn stimulated immigration from other parts of Papua New Guinea, and provided a continuous seedbed for ethnic tension, which employers were not hesitant to incite at appropriate moments [Thompson and MacWilliam 1992: 85-119]. As well, areas on the island where little smallholder expansion occurred became labour reservoirs, further fueling competition over jobs. Thus the competition over wage employment was expressed in ethnic, insider-outsider, terms as well as in the construction of 'Bougainvillean' as an identity to mask class antagonism.

Secondly, removing the barriers to the advance of indigenous capital became a central concern of late colonial nationalist politics. In Bougainville this took a particularly aggressive form. The range of policies developed and followed by the colonial Administration to try to stop the formation of, as well as block and check the emerging indigenous commercial business class, subsequently produced demands 'to make up for lost time' in the years immediately preceding and after Independence. In the 1970s and early 1980s, representatives of the Bougainville bourgeoisie played secessionist politics to the limits in order to construct their own space within the national state. (That secessionism was subsequently used on behalf of increasing welfare more generally against capital, by the destruction and closure of the Panguna mine as well as by attacks on businesses owned by Bougainvilleans, is only one of the ironies of the late 1980s revolt on the island.) The unevenness of the advance of local capital also played a part in the construction of 'Bougainvillean' identity to obscure competition within the class.

Finally, for now, there is the importance of development in the post-war period for the continuing opposition between smallholder production and the forms of capitalist enterprise which employ wage labour. When the copper and gold mine at Panguna was the most prominent form of enterprise on the island and in the Bougainville Province, opposition could be embodied in the insider-outsider form noted at the commencement of this chapter. But with no mine, nor any comparable form of capitalist enterprise present, how will the opposition be played out now if the main forms of capital present are local? As the members of the Bougainville bourgeoisie seek to re-build their operations, what forms of mediation can be or will be constructed to permit development along the lines that were established during an earlier moment of reconstruction? 


\section{Endnotes}

1. Copies of the Patrol Reports cited here were held in the North Solomons Provincial Government offices and used by the author during research trips to Arawa in 1984 and 1985. I have not had the opportunity to use the more substantial holdings of Patrol Reports which have been micro-fiche copied and are now held at the Papua New Guinea National Archives and the National Library of Australia.

2. The claim that indigenes were 'exploited' by European traders was widely made and regularly examined in post-war New Guinea. See for example, 'Alleged Exploitation of New Guinea Natives by European Traders', National Archives of Australia, Series A518/1, Item DG 840/1/4, 1954-1957. The claims were made with reference to urban-based stores as well as those which operated on plantations.

3. The information on Burns Philp presented here is drawn from Company Archives held in the Noel Butlin Archives Centre (NBAC), The Australian National University.

4. It is unlikely, however, that Burns Philp was the first plantation operator to utilise interplanting. An informant has suggested that the first substantial inter-plantings were made on Karkar Island in the early 1920s but I have not had an opportunity to confirm this.

5. In 1947, with 1,291 acres planted and 2,815 undeveloped, and much of the labour employed on cleaning and rebuilding buildings, roads, railway line and other infrastructure, Burns Philpmanaged Arigua plantation employed 85 workers also drawn from areas of Bougainville that had become labour reservoirs, supplying workers for the largest plantations as well as for the operations of indigenous employers. 


\title{
POST-1960S COCOA AND COPRA PRODUCTION IN BOUGAINVILLE
}

\author{
by Joachim Lummani
}

\begin{abstract}
Cocoa and copra production have been an integral part of agricultural development in Bougainville, copra since the early 20th century and cocoa mainly since the 1960 s. ${ }^{1}$ The decade of civil war from late 1988 saw a significant decline in the production of these crops. Since the late 1990s, however, agricultural activities have once again been given priority. Resumption of mining, the major factor in the Bougainville economy in the 1970s and 1980s, is not currently being considered seriously because of the problematic social and environmental costs associated with it. While emphasis on perennial tree crop plantations, such as cocoa and coconuts, may be necessary for Bougainville's economic recovery, it can also be expected to cause or contribute to a range of social and other problems associated with land use.
\end{abstract}

\section{GENERAL PARAMETERS OF COCOA AND COCONUT INDUSTRY ON BOUGAINVILLE}

\section{Cocoa and Coconut Area and Distribution}

The Bougainville Province covers a total area of about 8,788 square kilometres [Griffin with Kawona 1989: 225], approximately two per cent of Papua New Guinea's total land area. An estimated 332,000 hectares are considered suitable for agricultural production [Bleeker and Freyne 1981: 8; see also NSPG 1982: Pt 1, Ch. 3, p. 6]. The 1980 census survey estimated the number of smallholder cocoa growers at 15,792 and that of coconut growers at 9,186, cultivating an estimated total area of 18,035 and 34,285 hectares respectively [NSPG 1982: Pt 1, Ch 5, pp. 1, 7; Ch. 3, p. 7; and see Table 4]. The total area under large scale plantation cultivation was then between 20,000 to 30,000 hectares, though a 1982 study for the North Solomons Provincial Government (NSPG) put the figure at 20,682 hectares (see Table 1 below). Most cocoa areas are inter-cropped with coconuts. 
Cocoa and coconuts are grown across the province. Generally, cocoa has been the dominant crop in the south, around Buin, Boku and towards the Jaba River; while copra has been more important than cocoa as a source of cash income on Buka Island, along the north-east coast, and as far south as coastal Kieta. Buka Island has been a mixed cocoa and copra zone, its south given over to cocoa, while copra is grown on the smaller islands.

Before 1988, the year that the period of conflict began, Teop, Keriaka, Suir and Buka Island were the largest producers of cocoa in the north, as well as having the highest per capita income from it. Large producers in the centre were the Nasioi, Rotokas, Aita and Koromira area and in the south, it was the Buin, Nagovisi and Siwai area. Teop and Rotokas were the largest producers in terms of both large scale plantation and smallholder production. Most copra was produced in Hahon, Teop, Selau, Kunua, Keriaka and Buka Island. According to 1980 data, these areas accounted for about 50-60 per cent of provincial production, and 64 per cent of all production by village farmers.

\section{Potential Arable Land for Agricultural Production on Bougainville}

Bougainville's capacity for agricultural production is constrained by both technical and human factors. Climate, soil, vegetation, topography and rainfall variations are among the factors that determine the capability of land for agricultural production within each district, and which in turn influence land use and cropping patterns. The distribution of arable land and land actually utilised in the early 1980s is summarised in Table 1.

Table 1: Distribution of Arable Land and Land Under Cash Crops (hectares) Early 1980s

\begin{tabular}{lrrr}
\hline $\begin{array}{l}\text { Admin } \\
\text { District }\end{array}$ & $\begin{array}{r}\text { Total } \\
\text { Arable(1) }\end{array}$ & $\begin{array}{r}\text { Smallholder } \\
\text { Cash Crops (2) }\end{array}$ & Plantations (3) \\
\hline Buka & 68,000 & 19,528 & 3,289 \\
Tinputz & 30,500 & 7,563 & 7,030 \\
Wakunai & 45,500 & 3,916 & 3,405 \\
Kieta & 32,500 & 9,485 & 4,960 \\
Buin & 49,000 & 4,360 & 168 \\
Boku & 56,000 & 3,360 & - \\
Torokina & 14,000 & 495 & - \\
Kunua & 36,500 & 3,313 & 1,830 \\
Total & 332,000 & 52,020 & 20,682 \\
\hline
\end{tabular}

Source: NSPG, 1982 
The areas under smallholder and plantation cash-crop cultivation in 1980 were 52,020 and 20,682 hectares respectively. They represented about 15.7 per cent and 6.2 per cent respectively of the total potential arable land. The total area under cash-crop production was 72,702 hectares, approximately 22 per cent of total potential arable land. There was some evidence of an increase in the smallholder area under cash-crop cultivation, as implied by the increasing production trend until 1988/89 (see Figure 3 in the Appendix).

In 1964 , five per cent $\left(420 \mathrm{~km}^{2}\right)$ of the area of Bougainville was devoted to village food gardens and cash crops, with a further 1.5 per cent $\left(126 \mathrm{~km}^{2}\right)$ used for non-indigenous plantations [McAlpine 1967 p. 160]. A detailed national study conducted by the Commonwealth Scientific and Research Organisation (CSIRO) in the 1980s found that 55 per cent of the provincial land mass was devoted to agricultural land use, where that was defined by the presence of anthropogenic vegetation (altered by humans), current food gardens and cash crops [McAlpine and Quigley no date. Table 1]. These authors reported that 80 per cent $\left(7428 \mathrm{~km}^{2}\right)$ of the total area of $9329 \mathrm{~km}^{2}$ was forested. A recent study by Bourke and Betitis [2003] recorded the average population density as 19 persons $/ \mathrm{km}^{2}$ in 2000, with the range from 15 persons $/ \mathrm{km}^{2}$ on Bougainville Island to 1224 persons $/ \mathrm{km}^{2}$ in the Carteret Islands the highest recorded population density in PNG and at a level where food was chronically scarce. Bourke and Betitis [2003: 7] estimated that 160,000 tonnes of staple food was grown in the province in 2000, of which two thirds (65 per cent) by weight was sweet potato. Other important staple foods were cassava (12\%), banana (8\%), coconut $(6 \%)$, Chinese taro $(5 \%)$, taro $(2 \%)$ and yam $(2 \%)$.

\section{Land Systems on Bougainville}

CSIRO classified landscapes in Bougainville and Buka into 40 land systems (areas with similar patterns of topography, soil and vegetation) [NSPG 1982: Pt 1, Ch. 2, p. 5]. According to the CSIRO's classification, approximately 36 per cent of land in Bougainville and Buka was considered suitable for both food crop and cash-crop production, subject to local limitations in terms of differences in soil fertility, drainage, preparation costs and possibility of erosion.

\section{DEMOGRAPHIC SITUATION ON BOUGAINVILLE}

Rapid population increase on Bougainville, if not eased by some means, will constrain the extension of agricultural production and lead to increased competition over available arable land. Bougainville's average annual population growth rate is about 3-3.5 per cent per annum, above the national average of 2.3 per cent. With an increasing population, it seems likely that the communal land tenure 
system, which guarantees the use of land by all members of a community, will become difficult to maintain in the long run. There is, of course, no uniformity in the intensity of land use and of its scarcity throughout the province. One cannot say with certainty that shortages of access to productive land had not already begun to occur in various places before the conflict.

Table 2: Population Estimates for Bougainville Districts, 1995

\begin{tabular}{lr}
\hline District & Population Estimate \\
\hline Buka & 28,000 \\
Atolls & 9,000 \\
North West & 16,000 \\
North East & 14,000 \\
Central & 30,000 \\
Siwai & 13,000 \\
Telei & 23,000 \\
Bana & 17,000 \\
Total & 150,000 \\
\hline
\end{tabular}

Source: Pourhosseini 1995: 13

The population of the province was about 39,000 in 1939; 59,250 in 1967 and 129,000 in 1980 [Hirsch with Beck 1991: 165; NSPG 1982: Pt 1, Ch. 3]. The actual provincial population in 1995 was estimated as about 150,000 (see Table 2 above) but, with immigration, this would have been around 160,000 or slightly higher in 1988. The 2000 National Population Census indicates a population of 175,160 [Papua New Guinea National Statistical Office 2002]. ${ }^{2}$

It has not been possible to access data on internal demographic structures and their impact on access to land within each district of Bougainville from the pre-conflict years. However, Mitchell's study [1976], based on fieldwork conducted from 1969-70 and 1971-73 in the Nagovis area of Bougainville, provides some insight in this respect. Applying 1970 data on population, age and sex structure for the areas of Nagovis he was studying, Mitchell projected a rapid growth in the rural population in excess of six per cent per annum. He mentions cases of shortages of land for gardening, resulting in villagers being forced to make gardens further away from home or to depend more on imported food items [Mitchell 1976: 127]. Land pressures vary considerably both between and within each district. Nevertheless, it is clear that rapid population growth can have considerable impact on availability of land. 
The 'Provincial Nutrition and Garden Survey and Associated Land Use Study' undertaken as part of a broad ranging development study, organised by NSPG in the early 1980s, indicated some of the problems likely to arise in areas where the growth of population started to push against the supply of arable land [NSPG 1982: Pt. 1, Ch. 3, p. 12]. Some of these were already evident before the conflict:

- the contraction of the per capita garden area, resulting in gardens being unable to provide sufficient food;

- the shortening of fallow periods (two to five years on average), thus adversely affecting soil fertility and yields (as had already begun in Siwai at the time of the aforementioned study);

- competition for land between food crops and cash crops;

- the clearing and cultivation of marginal and unsuitable land, likely to result in poor yields, loss of crops, soil erosion, and so on;

- a lack of access to land for some people who would then need to turn to other means of support.

The 1980 rural population estimate was 97,000, mainly involved in subsistence agriculture and cash-cropping. The North Solomons Provincial Government study predicted that this figure could double by 2000, if a 3-3.5 per cent annual growth rate applied. Since then, the rural population has possibly increased considerably, especially if in some areas the rural population grows at a higher rate than the overall increase of provincial population (as may be suggested by Mitchell, above).

A 'Village Survey', also conducted in 1981 as part of the NSPG 'Development Study', estimated the average family size as five members per household and number of food gardens per family unit as two. [NSPG 1982, Pt. 1, Ch. 3, p. 12]. A fallow period generally varies from five to 15 years, with an average of about six years. In some areas, villages have very short fallow periods. Examples cited in the study were Taokas, Tearoki-Aita, Nasioi, Suir and Bakadaa community government areas and were said to reflect local population pressures associated, inter alia, with intensifying land use.

\section{Population and Land Availability, 2000}

In the absence of recent studies on population and land availability on Bougainville, a general indication of the significant variation in land/population pressures between districts is provided by analysis in the 1982 NSPG study. Data on the likely relationship between the supply of, and demand for, land resulting from projected population increases between 1982 and 2000 is presented in Table 3. 
Table 3: Projected Population and Land Availability by District, 2000.

\begin{tabular}{lrrrrrr}
\hline & 1982 & & Land & Land & Total & Balance of \\
Admin & Rural & Population & Required & Required & Land & Arable Land \\
Village & forecast & for Food & for Cash & Available & Available \\
District & Population & for 2000 & crops 2000 & Crops 2000 & 2000 & 2000 \\
$(1)$ & $(2)$ & $(3)$ & $(4)$ & $(5)$ & $(6)$ & $(7)$ \\
\hline Buka & 19,046 & 35,640 & 17,820 & 36,709 & 64,711 & 10,182 \\
Tinputz & 6,677 & 12,500 & 6,250 & 14,125 & 23,470 & 3,095 \\
Wakunai & 6,121 & 11,470 & 5,735 & 7,341 & 42,095 & 29,019 \\
Kieta & 19,680 & 36,840 & 18,420 & 17,683 & 27,540 & $(8,563)$ \\
Buin & 15,041 & 28,160 & 14,080 & 8,166 & 48,832 & 26,585 \\
Boku & 18,306 & 34,260 & 17,130 & 6,852 & 56,000 & 32,018 \\
Torokina & 1,710 & 3,200 & 1,600 & 928 & 14,000 & 11,472 \\
Kunua & 5,948 & 11,140 & 5,570 & 6,238 & 34,670 & 22,862 \\
Total & 92,529 & 173,210 & 86,605 & 98,042 & 311,318 & 143,796 \\
\hline
\end{tabular}

Source: NSPG 1982

The final column in Table 3 shows a balance of arable land still expected to be available in each district in 2000 after accounting for how much land was expected to be required for food and cash crops. This shows that in 1982 it was anticipated that by 2000 there would be a large deficit in Kieta and a small margin in Tinputz, while Boku, Buin, Wakunai and Kunua districts were expected to have a comfortable excess of land over requirements. Buka and Torokina districts were expected to have a balance of moderate dimensions.

The anticipated deficit situation in the Kieta area was expected to be a product of a number of factors in addition to the most obvious ones - the limited total arable land available and the large and growing population including limitations imposed by agro-climatic conditions, soil fertility, and so on. Further, some areas of the Kieta district were occupied by the mine and the Arawa, Loloho and Kieta towns, while other parts were occupied by migrants from other parts of Papua New Guinea. As a result, Kieta may have been experiencing particularly intense pressures on land in 1982, and some of those pressures may well have reduced in intensity by 2000 . If so, then the deficit situation anticipated in 1982 may well have become quite different by 2000. In the absence of recent land and population studies, it is not possible to know this with certainty. What this data does demonstrate, however, is the potential for serious land shortages in some areas of Bougainville, especially in situations where increasing proportions of land are devoted to cash crops. 


\section{COCOA AND COPRA PRODUCTION}

From the 1960s to the 1980s, most rural Bougainvilleans became dependent upon cocoa and coconuts as the dominant source of cash income. For example, the average cash income from the two crops in 1980 was K728 per rural household, equivalent to K154 per capita, of which cocoa contributed K131 and copra K23. The provincial average income from cocoa growing households was K807 per household. These data were about eight years old when the conflict started in 1988. By now somewhat out of date, the figures do indicate the significance of cash crop income in the pre-conflict period. In the post-conflict situation, alternative sources of cash income are much reduced (with the Panguna mine not operating) the reliance on cash crop income can be expected to have increased.

Kunua, Wakunai and Tinputz, had the highest share of income from cultivators. Tinputz district was mainly a centre of production from smallholdings and plantations. Although cocoa was dominant in south Bougainville, there were virtually no plantations there. Those in Buin (see Table 6 in the Appendix) went out of production prior to the conflict. Kihill and Patupatuai plantations used to be owned by the Uniting and Catholic churches. Toburuai plantation, inter-cropped with cocoa and coconuts (not shown in Table 6 in the Appendix), was overgrown by weeds some years before 1988, enhancing opportunities for illegal harvests by local villagers.

The increasing population will probably continue to depend on these crops for a long time to come, particularly if no other significant agricultural crops are adopted. Historically, the plantation sector has been associated with large-scale production for exports. But smallholders have gradually increased their contributions to the cocoa and coconut industries in Papua New Guinea. Smallholders currently contribute about two-thirds and four-fifths of cocoa and copra production in Papua New Guinea, respectively.

\section{Cocoa}

Before the conflict Bougainville accounted for about one-third of national cocoa production and smallholders accounted for well over 60 per cent of total production in the province (Table 7 in the Appendix). In the years just before the conflict, there was a steady growth in smallholder production while production by the plantation sector declined (Figure 1).

Cocoa production in Bougainville reached its highest level in 1988/89, with 18,441 tonnes, which was also the highest in the country. Output declined as the conflict intensified. Smallholder production declined by about 28 per cent and 69 per cent in 1989/90 and 1990/91 respectively, while the plantation sector fell by 58 per cent and 99 per cent in those years (Table 7 in the Appendix). 
Figure 1: Bougainville cocoa production 1978/79-1998/99

plantations versus smallholders

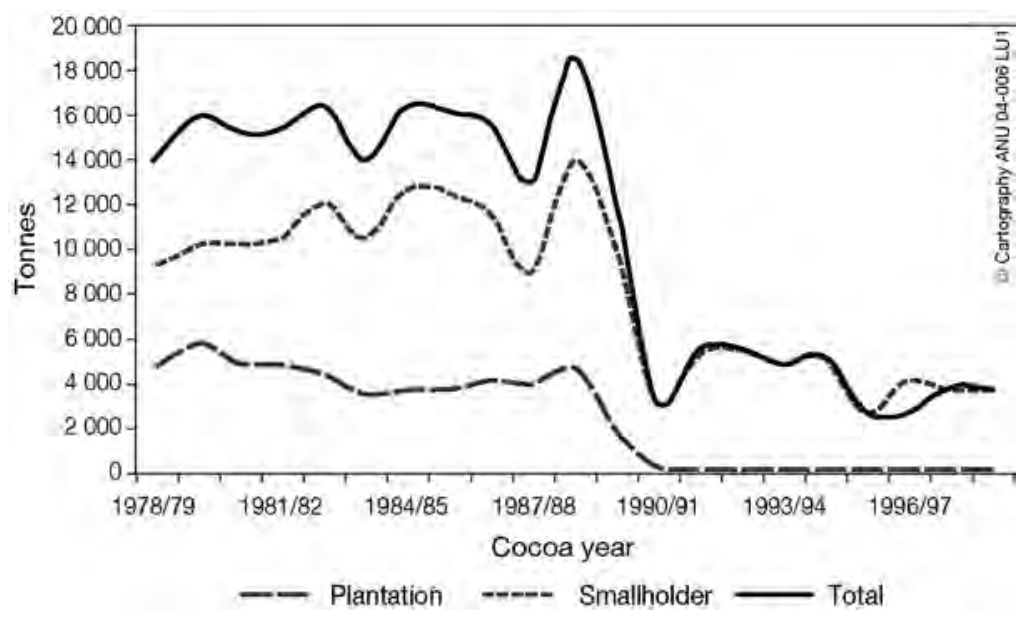

Source: (Cocoa Board of Papua New Guinea 1999)

There was intensive cocoa planting in most parts of Bougainville from the 1960s to the 1980s [Figure 3 in the Appendix; Mitchell 1976: 81; Hirsch with Beck 1991: 165]. There were, however, often factors involved in the increase of production during the period, one being an improved road transport system.

It has not been possible to obtain data indicating the extent to which increased production might have been a result of yield increases in established areas as a result of Bougainvillean smallholders adopting better yielding varieties and applying fertilisers. However, comparison of the data from 1980 with 1999 in the Report of the Cocoa and Coconut Baseline Survey, Bougainville Province (the 1999 Baseline Survey) indicates increased production was probably a result of additional land being planted with cocoa. The number of hectares planted by each grower increased significantly between 1980 and 1990 - 166.7 per cent overall - from 1.14 hectares per grower in 1980 to about 3.04 hectares per grower in 1999 [Cocoa and Copra Extension Agency of Papua New Guinea 1999: 10-13].

It may be that increasing family size has created pressure for increased planting. A survey undertaken in 2000 on smallholder cocoa and coconut growers in East New Britain, a province which, to some extent, shares socio-economic characteristics with Bougainville, found that 67 per cent of those who got into farming in the previous decade were prompted to do so mainly by population increase and changing lifestyles, while smallholder farmers also planted more 
cocoa and coconut trees [Omuru et al. 2000]. The 1999 Baseline Survey indicated that about 60 per cent of smallholder farmers had plans to expand their cocoa blocks. In 2000 smallholder producers were busy planting seedlings distributed by the Cocoa and Coconut Extension Agency, based at Kubu (Hutjena) on Buka Island. About three million seedlings had been distributed in that year, with more to come [Louis Kurika, Coconut and Cocoa Research Institute officer, Buka, personal communication, 2000]. The increasing production was mainly restricted to smallholders because almost all plantations were non-operational.

If increased planting of smallholder cocoa continues it is bound to contribute to existing land pressures associated with growing population pressures, especially in already densely populated rural areas. Farmers in sparsely populated areas are likely to make new clearings for agricultural purposes, while those from densely populated areas of the province, such as south Bougainville, are likely to make more intense use of available land. ${ }^{3}$ In areas where some land is still available, people are more likely to meet their cash demands by increasing the number of hectares planted (causing additional land clearance) rather than attempting to raise the yield per hectare, for example through the use of fertilisers (something that smallholder farmers have seldom resorted to in Papua New Guinea - for example, a 2000 study found that out of a sample of 100 farmers surveyed, only eight per cent used some form of fertiliser while only 10 per cent used herbicide/ weedicide) [Omuru et al. 2000].

In 2000 the Bougainville Administration was proposing that plantations in the province should be sold to local people, preferably the original landowners. This is an idea which is not without difficulties. Similar situations in other areas of Papua New Guinea led to competing groups claiming to be the original landowners. There is also no guarantee that sale of plantation land to original landowners will result in the land being used for further agricultural development. If the proposal is implemented, original landowners are unlikely to accept people from other parts of Bougainville or Papua New Guinea as a whole, at least in part because not so long ago many experienced social problems associated with the influx of plantation migrants from elsewhere.

\section{Copra}

Data from the Copra Marketing Board (CMB) does not enable the disaggregation of production by districts. Copra production by sector shows a relatively larger proportion coming from the smallholder sector (see Figure 2).

The fall in copra prices in 1988/89 (see Figure 5 in the Appendix) was a factor in the decline in production otherwise due to the conflict. Copra production rapidly increased as farmers sought to meet basic requirements. 
Figure 2: Bougainville copra production 1985-1998 smallholders versus plantations

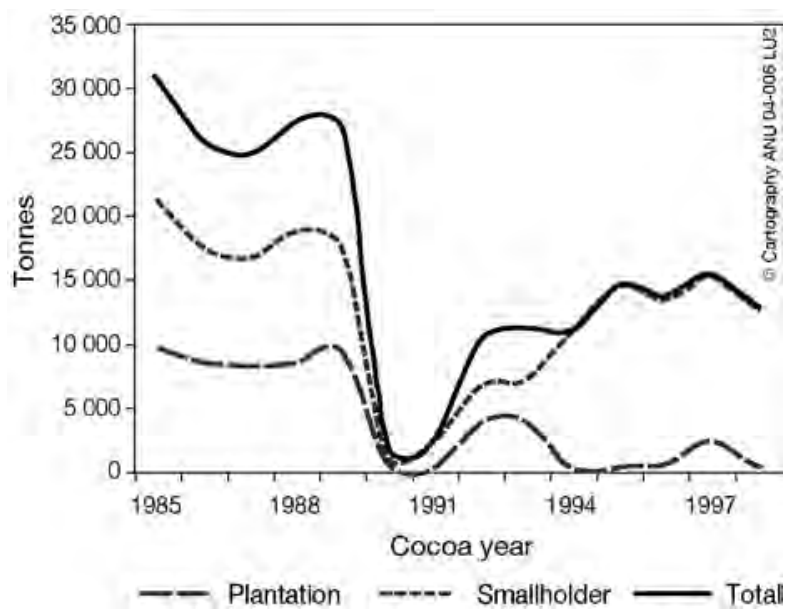

Source: Copra Marketing Board of Papua New Guinea 1999

Unlike cocoa trees, coconut palms do not require regular maintenance to keep them producing. While a total of about 19.9 million cocoa trees were destroyed during the conflict as well as by the 1996 and 1997 drought in Papua New Guinea, only 866,822 coconut palms were destroyed. The coconut industry is at present an immediate provider of cash for smallholder farmers while many also undertake new plantings. As a result, smallholder copra production continues to rise (see Figure 2).

\section{Changes in Land Area under Smallholder Production}

The area per grower for both smallholder cocoa and coconut growers in Bougainville has increased from 1980, as demonstrated by the data presented in Tables 4 and 5. The total area under smallholder cultivation for cocoa has increased while that of coconuts has slightly decreased (see also Table 7).

Table 4: Number of Cocoa and Coconut Growers, Distribution of Arable Land, and Area Per Household, 1980

\begin{tabular}{lrrc}
\hline Cash Crop & Household & Area (ha) & Area Per Household (ha) \\
\hline Cocoa & 15,792 & 18,035 & 1.14 \\
Coconut & 9,186 & 34,285 & 3.73 \\
Total & 24,978 & 52,320 & \\
\hline
\end{tabular}

Source: NSPG 1982 
The 1999 Baseline Survey compiled by the Papua New Guinea Cocoa and Coconut Extension Agency revealed the following estimates:

Table 5: Number of Cocoa and Coconut Growers, Distribution of Arable Land and Area Per Household, 1999

\begin{tabular}{lrrc}
\hline Cash Crop & Households & Area (ha) & Area Per Household \\
\hline Cocoa & 15,715 & 47,774 & 3.04 \\
Coconut & 8,151 & 32,382 & 3.97 \\
Total & 23,866 & 80,156 & \\
\hline
\end{tabular}

Source: Cocoa and Coconut Extension Agency of Papua New Guinea 1999

The total area under smallholder cocoa cultivation has increased by about 164.9 per cent since 1980, while the number of smallholder cocoa growers saw a slight fall of 0.49 per cent. The 1982/83 'North Solomons Provincial Crop Survey' cited in the 1999 Baseline Survey estimated 1.43 hectares per grower. This is much lower than the rate of 3.04 hectares per household for cocoa estimated for 1999. The increase in area per farmer for cocoa, and the relatively fewer number of farmers in 1999 compared to 1980, implies not just increased areas of land being used per farmer but also increased competition for available fertile land for agricultural production.

For coconut growing, the 5.6 per cent reduction in the area under smallholder cultivation combined with the 11.27 per cent reduction in the number of growers resulted in the marginal increase of 6.4 per cent in area per grower. By contrast, the area per grower for cocoa increased by 166.7 per cent between 1980 and 1988 .

As the 1982 NSPG study pointed out: 'unless small farmers are trained in good husbandry and adopt new technology in the form of improved varieties of planting materials, they will continue to clear large areas of land'. Mitchell made several suggestions directed at reducing the pressure on farmers to allocate more land to cocoa trees: (i) that rural farmers should be shown how to make their existing stands more productive by supplying them with chemical fertilisers and insecticides; (ii) that a program of intensive rural-based agricultural assistance be designed, which focuses on maintenance, rejuvenation, improved harvesting and processing techniques; and (iii) that realistic efforts be made to reduce the rapid rate of population growth. In the light of Bougainville's complex land tenure systems and types of communal ownership, such suggestions seem worthwhile. Perhaps an examination of land tenure customs and associated issues that are likely to create social problems should also be given priority.

Population growth may slow down, sooner or later. Nevertheless, in the meantime, it can be expected that there will be continuing pressure for increased 
tree crop plantings to meet increasing cash requirements while at the same time maintaining traditional food gardens. Such trends will only intensify competition over land and associated social problems. In south Bougainville, which has the second largest population, people openly speak about reclaiming land that has been sold to people from other parts of Papua New Guinea (personal observation).

Generally, two options are available for satisfying the rising demand for consumer goods as the rural population becomes increasingly involved in modern economic activities: (i) get paid employment or (ii) turn to cash-cropping activities. In the absence of economic activities that create wage employment most people are likely to turn to cash-cropping activities. The continuance of large-scale land clearances can be expected to usher in further long-term problems.

Many and varying circumstances contributed to the emergence of the conflict in Bougainville. Population pressure on land use was one of these. In Bougainville transactions involving customary land were less common than, for example, in East New Britain ${ }^{4}$. That land was being alienated in Bougainville from customary terms of tenure, as well as being immobilised from habitual, cyclical methods of production, possibly contributed to a build-up of potentially disruptive social energy. Another contributing factor may have been that the conflict also coincided with a period of falling world cocoa and copra prices in mid-1988 (Figures 4 and 5 in the Appendix to this chapter).

\section{SOME IMPLICATIONS OF PERENNIAL TREE-CROP PLANTINGS}

Perennial tree-crop plantings, particularly cocoa, in the form of permanent establishments, affected many traditional aspects of lives of Bougainvilleans. As with mining activities, nothing in the experience of the majority had prepared them to assess the trade-off between the economic gains to be derived by planting cocoa trees and the disruption to their social interactions that allocating land to such purposes could cause. Aspects of traditional culture, such as power relations, landuse patterns, access to land, attitudes and behavior, were significantly affected by cocoa planting on communally owned land.

In this part of the chapter I have made use of arguments about patterns of land use in Nagovis developed in an illuminating article by Mitchell [1982] and also in his monograph Land and Agriculture in Nagovisi [1976: 118-149]. Unlike the flexibility that prevailed concerning use of land before extensive planting of cocoa began in the early 1960s, from that time individuals began to identify themselves with tracts of land on which they planted their cocoa stands. Previous patterns involving the temporary use of customary land for subsistence gardens were changed into 
a pattern of permanent land use, with land tracts becoming controlled by individuals or small groups. The inequalities in landholdings among clan lineages which happened to exist at the time land was allocated to cocoa have been 'frozen' and exacerbated, with members of lineages that happened to be land-poor in the 1960s finding their situation growing worse as the population grows. This is because land on which cocoa is planted becomes frozen from movement through the normal cycle of land tracts (under which land tended to move gradually between lineages, over several generations - for example, through transfer of land as part of mortuary arrangements). In the pre-cocoa era, inequalities were irrelevant mainly because of the relative abundance of land for the main purpose for which it was then required - namely subsistence agriculture. The freezing of the normal cycle of movement of land tracts among lineages caused imbalance in land resources.

Money became the key in the new forms of cooperative activities, which included cocoa business groups and trade stores. A range of consequences flowed from increasing cocoa planting. For example, the associated restrictions on peoples' choices regarding planting food crops and undertaking other activities probably contributed to a build-up of social frustrations. Before the introduction of cocoa, individual members of households could cultivate small plots as they thought fit and with different aims.

Tracts occupied by cocoa became avenues for access to social and economic power. They provided individuals, who had been living by the more restrictive norms that were typical of traditional communities, with a new opportunity to acquire an ascendancy over others by virtue of their wealth. Minorities in clans or village communities - those with ample land available for cocoa — gained access to a 'good life' denied to the majority. While most members of a clan or village community had the means to own some material possessions, they usually were what Odera Oruka [1981] describes as 'socially insignificant personal properties'. They were not of a kind to provide social and economic power over others. Such a situation no doubt contributed to envy, distrust and ensuing social disharmony in communities used to an essentially egalitarian situation.

As a new form of wealth, money facilitated the acquisition of material possessions, which, in turn, were instrumental in changing the character of traditional communities. Money became a significant cause in the fragmentation of the social fabric from which antagonistic sub-groups emerged. New social classes began to command power, prestige and access to cargo. As Galtung [1974: 27] has pointed out, the introduction of cocoa can be seen as having stimulated and, in turn, underpinned hierarchical interaction patterns. It induced people into relationships across class, where previously most of them had taken for granted a considerable degree of social and economic equality. 
The point of this chapter is to show how cash-crop activity has contributed to change in Bougainvillean society. The key change has been from a relatively egalitarian-based society towards one that is more class-based. There is some inevitability in the process, in so far as Bougainville is part of a dynamic global community. At the same time, increasing economic inequality amongst the previously egalitarian Bougainvillean people arising from various sources, including unequal access to land for cash crops, was undoubtedly a factor in the origins of the conflict. Francis Ona, the leader of the Bougainville Revolutionary Army and his early supporters were in fact seeking to restore egalitarian fairness by trying to suppress developmental change. The question arises, however, as to whether they in fact contributed to an ever-widening situation of inequality, in that after the conflict Bougainvilleans are even more dependant on cash crop income than before the conflict, when there were more diverse sources of income.

If agriculture is to be the main basis for Bougainville's economic development into the future, its people must acknowledge and deal with the trend away from communal ownership towards individual tenure as agriculture develops. Land is the first limiting factor in most tropical areas. Bougainvillean communities, like others in Melanesia, still lack general awareness of the consequences of land shortage and of the fact that land can be a negotiable possession. It ought, nevertheless, to be recognised that their traditional system of tenure and use of land may continue to operate satisfactorily, as long as land is plentiful and as long as annual and other seasonal crops are the main part of the agricultural system. Difficulties will certainly arise when demand for land increases, especially demand for land for cash crops. 


\section{APPENDIX}

Table 6: Plantations in the Bougainville Province, 2000

\begin{tabular}{|c|c|c|c|c|c|c|c|c|c|c|}
\hline Plantation & Kessa & Karoola & Dew: & Bunot & Bei & & Skotolan & n Laiahan & Poe & Nova \\
\hline Area (ha) & 7 & 497 & 228 & 70.9 & 122. & & 82 & 137 & 56.07 & 179.3 \\
\hline Location & Buka & Buka & Buka & Buka & Buk & & Buka & Buka & Buka & Buka \\
\hline Plantation & Madehas & Watagu & Bolo & Hahail & Halap & puna & Korte & Ablaman & Haramon & Tulaen \\
\hline Area (ha) & 323 & 260 & 450 & 450 & 78 & & 62.5 & 27.8 & 71.7 & 51.1 \\
\hline Location & Buka & Buka & Buka & Buka & Buka & & Buka & Buka & Buka & Buka \\
\hline Plantation & Pokonien & Tongolan & n Nugi & guria Banic & Raua & & Tinputz & z Rugen & Deos & Sabah \\
\hline Area (ha) & 211.9 & 23.8 & 257 & 800 & 4785 & & 495.6 & 386.8 & 188 & 365 \\
\hline Location & Nissan N & Tissan & Fead & Teop & Teop & & Teop & Teop & Teop & Teop \\
\hline Plantation & Hakau & Tearouki & Teopa & asino & Tan & nwoa 1 & Porton & Watagu & Ururu & Soroken \\
\hline Area (ha) & 258 & 202 & 928 & 860 & 110 & & 100.5 & 97.9 & 119.3 & 940.7 \\
\hline Location & Teop & Teop & Teop & Teo & Put & & Puto & Puto & Puto & Puto \\
\hline Plantation & Soroken & Jervau & Baniu & Kuraio & NumaN & Tuma & Koikoi & i Tenakau & 1 Arigua & Kurwina \\
\hline Area (ha) & 120.6 & 36.27 & 6.3 & 57 & 1488 & & 119 & 600 & 827 & 840 \\
\hline Location & Puto & Puto & uto & Torokina & Numa & & Numa & Numa & Numa & Numa \\
\hline Plantation & Bove & Kubwan & Bioi & Toboroi & Kekere & Korc & omira & Iwi & oimanapu $\mathrm{l}$ & Mariwi \\
\hline Area (ha) & 219 & 2.5 & 00 & 69.2 & 70 & 268 & & 367 & 5.6 & \\
\hline Location & Kieta & Kieta & Kieta $A$ & Aropa & Aropa & Arop & & Aropa A & ropa & Buin \\
\hline Plantation & Kangoi & Patupatu & & Kihill & & & & & & \\
\hline Area (ha) & 61.7 & 249 & & 144 & & & & & & \\
\hline Location & Buin & Buin & & Buin & & & & & & \\
\hline \multicolumn{2}{|c|}{ Total Area (ha) } & 20,364 & & & & & & & & \\
\hline
\end{tabular}


Table 7: Bougainville Cocoa Production by Sector: 1962/63-1998/99

\begin{tabular}{|c|c|c|c|c|c|c|c|}
\hline Cocoa & & $\%$ & Small- & $\%$ & & $\%$ change & Smallholder \\
\hline year & Plantations & change & holders & change & Total & Total & $\%$ of Total \\
\hline $1962 / 63$ & n.a. & - & 94 & - & - & - & - \\
\hline $1963 / 64$ & n.a. & - & 177 & 88 & - & - & - \\
\hline $1964 / 65$ & n.a. & - & 307 & 73 & - & - & - \\
\hline $1965 / 66$ & n.a. & - & 358 & 17 & - & - & - \\
\hline $1966 / 67$ & n.a. & - & 313 & -13 & - & - & - \\
\hline $1967 / 68$ & n.a. & - & 618 & 97 & - & - & - \\
\hline $1968 / 69$ & n.a. & - & 1071 & 73 & - & - & - \\
\hline $1969 / 70$ & n.a. & - & 1490 & 39 & - & - & - \\
\hline $1970 / 71$ & n.a. & - & 2273 & 53 & - & - & - \\
\hline $1971 / 72$ & n.a. & - & 2295 & 1 & - & - & - \\
\hline $1972 / 73$ & n.a. & - & 1130 & -51 & - & - & - \\
\hline $1973 / 74$ & n.a. & - & 4063 & 260 & - & - & - \\
\hline $1974 / 75$ & n.a. & - & 5115 & 26 & - & - & - \\
\hline $1975 / 76$ & n.a. & - & 5510 & 8 & - & - & - \\
\hline $1976 / 77$ & n.a. & - & 5546 & 1 & - & - & - \\
\hline $1977 / 78$ & n.a. & - & 6297 & 14 & & - & - \\
\hline $1978 / 79$ & 4657 & - & 9281 & 47 & 13938 & - & 67 \\
\hline $1979 / 80$ & 5690 & 22 & 10151 & 9 & 15841 & 14 & 64 \\
\hline $1980 / 81$ & 4926 & -13 & 10221 & 1 & 15147 & -4 & 67 \\
\hline $1981 / 82$ & 4812 & -2 & 10405 & 2 & 15217 & 0 & 68 \\
\hline $1982 / 83$ & 4372 & -9 & 11943 & 15 & 16315 & 7 & 73 \\
\hline $1983 / 84$ & 3463 & -21 & 10441 & -13 & 13904 & -15 & 75 \\
\hline $1984 / 85$ & 3667 & 6 & 12618 & 21 & 16285 & 17 & 77 \\
\hline $1985 / 86$ & 3686 & 1 & 12395 & -2 & 16081 & -1 & 77 \\
\hline $1986 / 87$ & 4108 & 11 & 11448 & -8 & 15556 & -3 & 74 \\
\hline $1987 / 88$ & 4008 & -2 & 8895 & -22 & 12903 & -17 & 69 \\
\hline $1988 / 89$ & 4600 & 15 & 13841 & 56 & 18441 & 43 & 75 \\
\hline $1989 / 90$ & 1923 & -58 & 10019 & -28 & 11942 & -35 & 84 \\
\hline $1990 / 91$ & 15 & -99 & 3131 & -69 & 3146 & -74 & 100 \\
\hline $1991 / 92$ & 21 & 40 & 5348 & 71 & 5369 & 70 & 100 \\
\hline $1992 / 93$ & 16 & -24 & 5426 & 1 & 5442 & 1 & 100 \\
\hline $1993 / 94$ & 27 & 69 & 4752 & -12 & 4779 & -12 & 99 \\
\hline $1994 / 95$ & 23 & -15 & 5086 & 7 & 5109 & 7 & 100 \\
\hline $1995 / 96$ & 32 & 39 & 2587 & -49 & 2619 & -49 & 99 \\
\hline $1996 / 97$ & 42 & 31 & 4066 & 57 & 4108 & 57 & 99 \\
\hline $1997 / 98$ & 7 & -83 & 3692 & -9 & 3699 & -10 & 100 \\
\hline $1998 / 99$ & 8 & 14 & 3641 & -1 & 3649 & -1 & 100 \\
\hline
\end{tabular}


Compiled from the following sources:

(1) 1962/63-1965/66 from NSPG Development Study 1982, Vol. 2, Pt 2, Ch. 23: 11

(2) 1966/67-1977/78, NSPG Development Study 1982, Vol. 2, Pt 1, Ch. 5: 1

(3) 1978/79-1998/99 from the Cocoa Board of Papua New Guinea 1999

Note: The abbreviation n.a. stands for not available

Figure 3: Smallholder cocoa production on Bougainville: 1962/63-1998/99

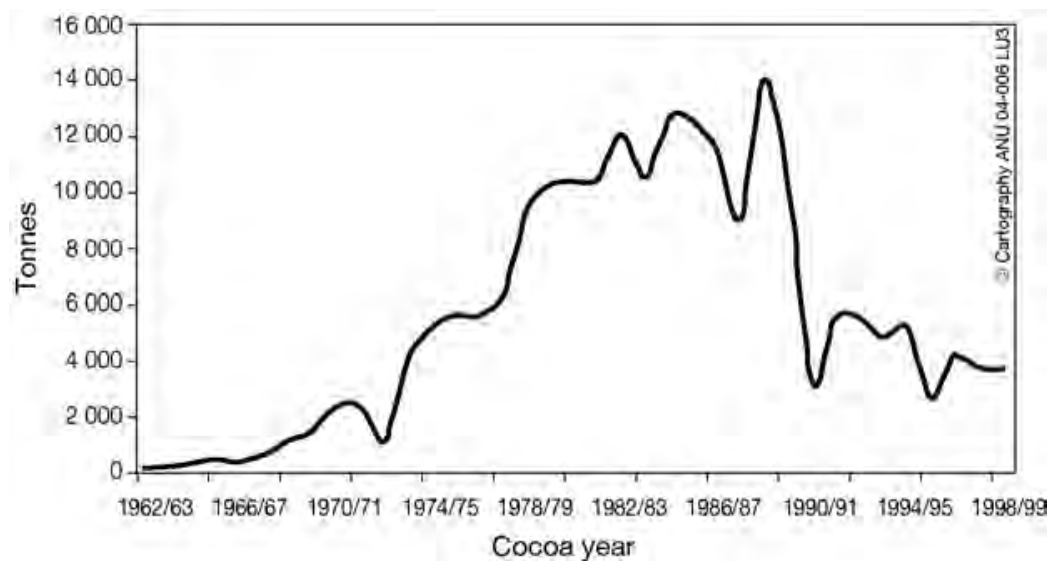

Source (s): Cocoa Board of Papua New Guinea 1999 and North Solomons Provincial Government Development Study 1982

Figure 4: Domestic and world cocoa price trends: 1974-1999

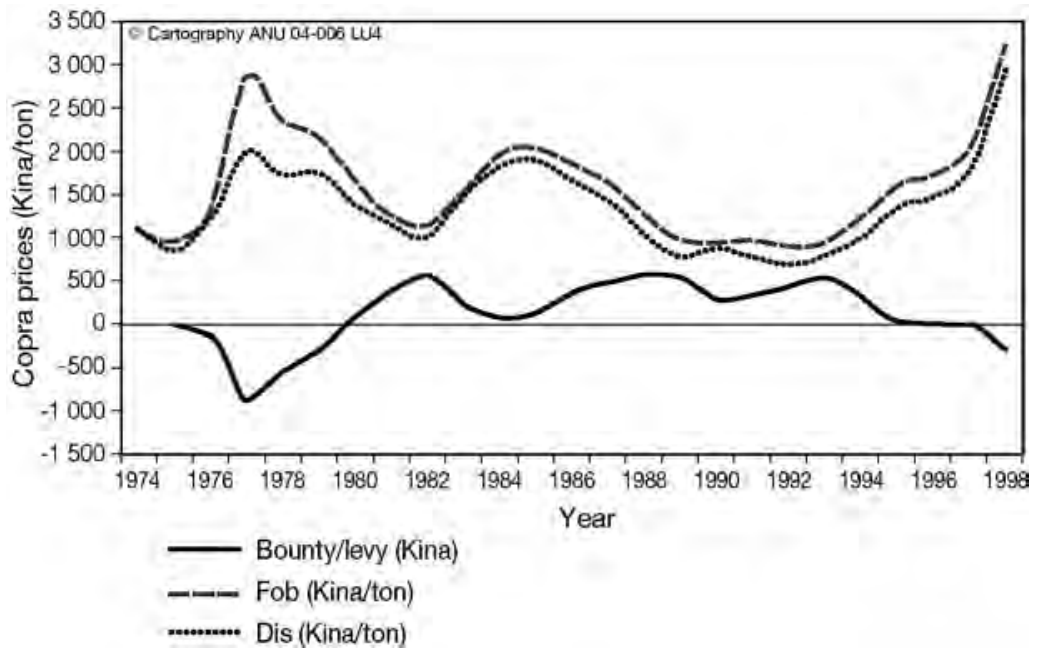

Source: Cocoa Board of Papua New Guinea 1999 
Figure 5: Copra prices in Papua New Guinea 1970-2000

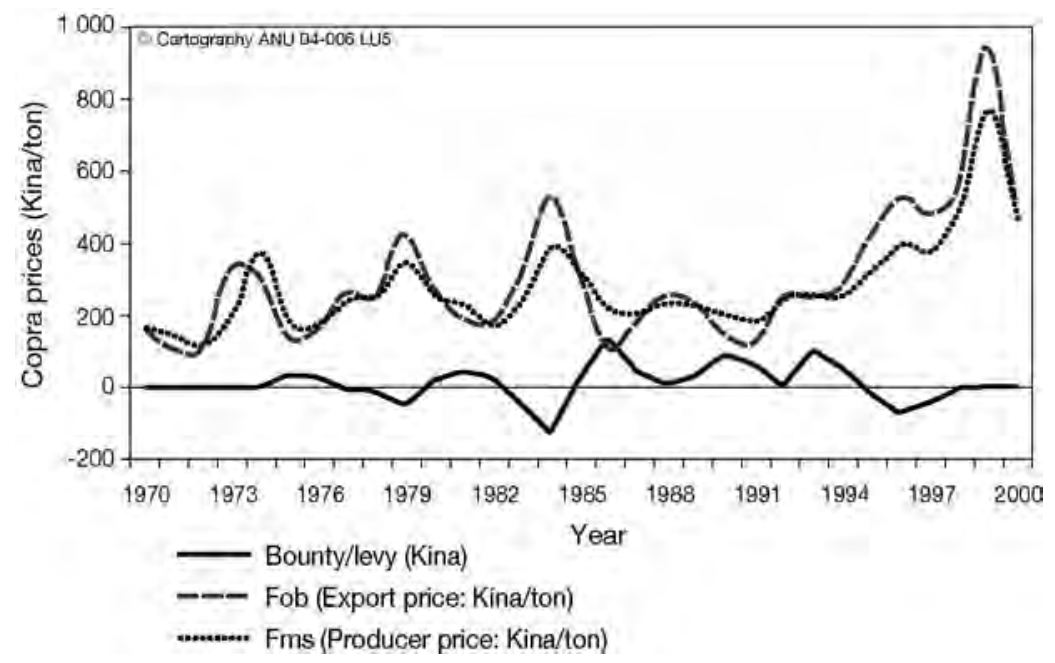

Source: Omuru in press

\section{Endnotes}

1. This paper draws extensively on Economic Consultants Ltd [1982] North Solomons Provincial Government Development Study. Final Report: Background Papers Part 1 and 2 (in text cited as NSPG which commissioned the study; cross-referenced in general bibliography). Other available studies on Bougainville have been utilised and, where possible, their accuracy has been confirmed. It has not been possible to map the more distant past with relevant statistics and other reliable information while, as a result of the conflict, statistical accuracy became impossible from late 1988.

2. Editors' note: However, it is estimated that about 5,300 people living in the 'no-go zone' in the mountains of central Bougainville (in the vicinity of Panguna) were not counted in the 2000 census exercise, in which case the total population in 2000 was a little over 180,000.

3. In Buin (south Bougainville), some villages within the vicinity of the author's home were facing land shortages prior to the conflict, mainly as a result of rapid population increases. Some families were making intense use of the same piece of land for planting food with shortened fallow periods.

4. Land, as a mobile factor of production, can serve as a neutralising agent of potentially disruptive social energy. Bougainville is said to have had the lowest out-migration rate in Papua New Guinea prior to the conflict. Those who remained outside the island were said to be mainly contract workers or students. It was quite usual for provincial education officials to encourage high school students to go back to their villages if they could not get an offer of study or work after graduation, using the expression, 'there is no place like home'. Before the conflict, it was also uncommon to find Bougainvillean squatter settlers in towns and cities away from home, nor in their own provincial centres. Such circumstances, although good, in various ways, could serve to ensure a situation where social energy could build up gradually with a potential to erupt in the absence of means for releasing such energy. In the long run, it would not be wise to continue encouraging graduating students to go home to till the land in view of a rapidly 
increasing population. The occupational capacity of the provincial economy, in the long run, will also not be able to absorb the educated ones who remain in the province. According to the author's observations land in Bougainville does not change hands as frequently as, for example, in East New Britain, where there is greater opportunity for the general public to own a piece of land. There are a number of expatriates, and many non-Tolais, who have bought blocks of land, some from individual landowners, while others acquired them through government tenders. Even cocoa and coconut plantations now frequently change hands. One has to recognise the challenges that are posed to people who still live on communally-owned land but whose traditional communities have undergone changes. In times gone by, there were far fewer problems, when the population was small, as was the size of most families, there were no perennial tree-cash crop-plantings, nor other crops planted for cash, and the demand for modern material goods that cash could purchase, was non-existent. 


\title{
THE PANGUNA MINE
}

\author{
by Don Vernon
}

he mineralisation which led to the development of the Panguna mine was
discovered in 1961 and confirmed by Conzinc Riotinto Australia Ltd (CRA) in 1964. After extensive exploration and the preparation of a detailed feasibility study, an agreement was negotiated with the Australian Government and subsequently ratified by the Papua New Guinea House of Assembly in 1967 (renegotiated in 1974 by the pre-independence Papua New Guinea Government under its first prime minister, then Chief Minister Michael Somare) and a decision to proceed with developing the mine was made in 1969. The plant was commissioned in 1972 and closed as a result of rebel activity in 1989.

This chapter describes briefly the mine's operation and then highlights four of the major issues facing the company during its 25 years on Bougainville. After that I will touch on some of the positive aspects of the mining operation in order to give some balance to my account.

My own contact with Bougainville goes back to 1966 when I was project manager of the CRA evaluation team working out of Melbourne. My family and I moved to Panguna in 1970 when I took up the role of assistant general manager. In 1975 I became managing director of Bougainville Copper Ltd (BCL). When I moved back to Melbourne in 1977, I remained on the BCL Board, becoming chairman from 1979 to 1986 . My years on Bougainville were among the most interesting and fulfilling in my professional career.

\section{THE MINE}

The Panguna operation consisted of a low grade copper-gold orebody which was mined by conventional open cut methods using electric shovels and 100-150 tonne trucks. Approximately 100,000 tonnes of waste rock per day was stored on the down-stream side of the mine, and over 100,000 tonnes of ore went to the concentrator each day. There a conventional crushing, grinding and flotation 


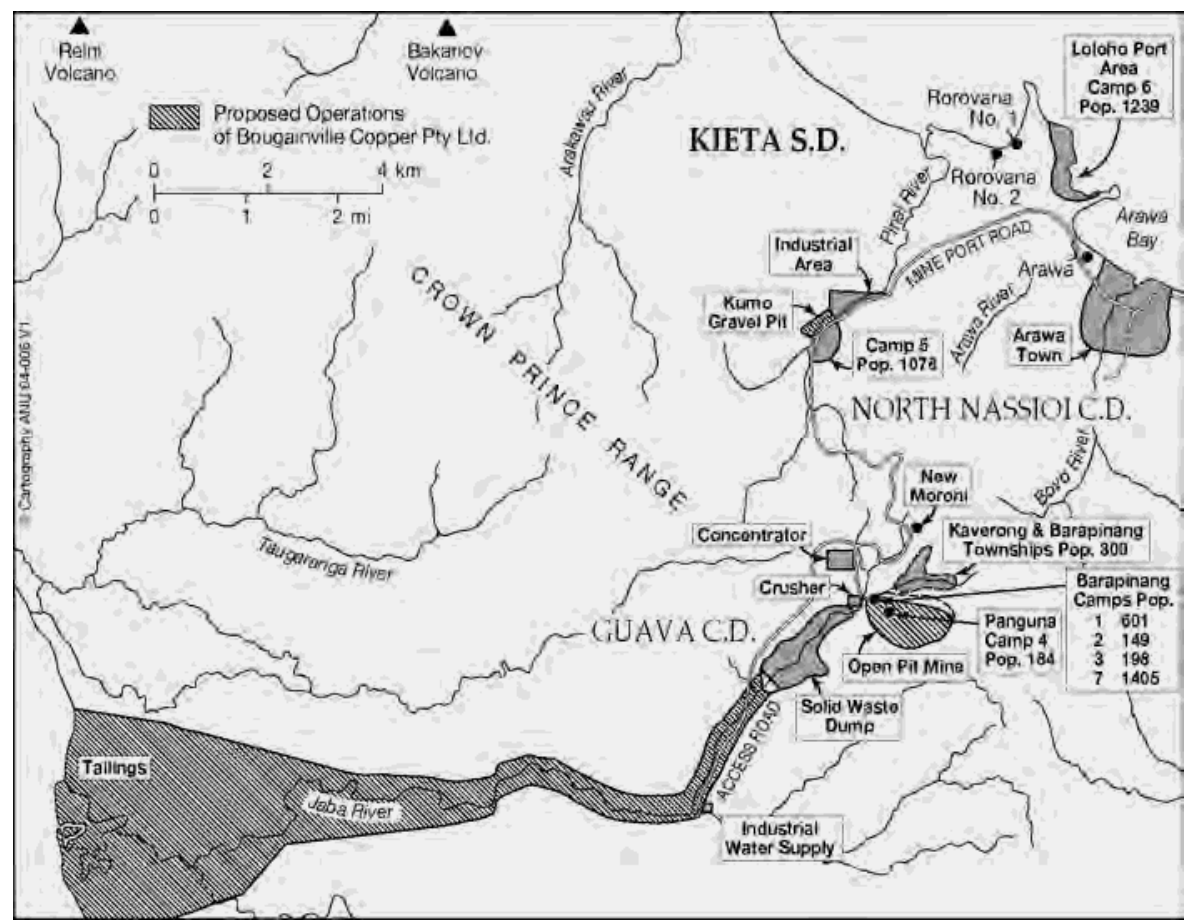

Map 1. The Panguna mine, c. 1972

process produced a concentrate slurry containing 30 per cent copper and one ounce per tonne of gold [see also Davies, this volume]. The tailings material was discharged from the concentrator into the Jaba River which carried the material to the west coast. The concentrate slurry was pumped to the port on the east coast where it was filtered, dried and loaded onto 25,000 tonne ships for export to overseas copper-gold smelters.

Initially the major customers were Japan, Germany and Spain but subsequently the customer list was expanded to include China and South Korea. Technically, the operation was regarded as one of the most efficient in the world. Credit for this achievement must go initially to the original designers but subsequently to the local managers and staff, over 80 per cent of whom were Papua New Guineans. It must be said that this was made possible by the excellent training facilities developed by the company for the training of tradesmen in particular, but also plant operators for all earthmoving equipment, concentrator operators and powerhouse operators. Separate facilities were also provided for training small business personnel who were interested in undertaking contract work for the company. In fact, so successful were the training programs on Bougainville that they were subsequently introduced to all other CRA activities in Australia. 


\section{MAJOR ISSUES}

Four major issues stand out when considering the history of the mine: land ownership; communication problems; fragmentation within Papua New Guinea and the environmental consequences of the mining operation.

\section{Land Ownership}

To the casual observer flying over Bougainville's rugged Crown Prince Range in the mid-1960s, the idea that a developer needed to worry about land issues would have seemed ludicrous. Where the mining lease was to be gazetted, there were thickly forested mountain slopes, often covered in clouds, with only the occasional small hamlet and garden clearing. The area was obviously thinly populated by subsistence farmers and hunter gatherers and closer inspection confirmed that there was very little cash cropping. Yet we were to learn that every square metre of the apparent wilderness belonged to someone under customary land law.

I remember that, not long after I first visited Bougainville in 1966, I spoke with Gene Ogan, ${ }^{1}$ who knew more about Nasioi land tenure than any other Westerner. He was of the opinion that land ownership arrangements among the Nasioi were more complex than any other he had experienced. If we were looking for a difficult place in which to develop a mine the Nasioi census division of what was then the Bougainville District of the Territory of Papua and New Guinea was just such a place. History, of course, proved Eugene Ogan to have been correct.

For the uninitiated it was not immediately obvious that the Nasioi derived rights to land through matrilineal inheritance, especially as these rights appeared to be exercised by men. Nor did European concepts of land tenure provide a satisfactory template for the complexities of customary land law in the mountains of Bougainville. Yet the company had, through its early research, gained a fair impression of the paramount role land played in the lives of all the people of Papua New Guinea. It also recognised that the project that was taking shape would have a considerable impact on the people of central Bougainville. In order to incorporate sociological factors into its planning, BCL sponsored a multifaceted research program under the auspices of the University of Hawai' $i$ and the Development Studies Centre of The Australian National University. The study was coordinated by Douglas Oliver.

Of course, the company's need for land extended beyond the 3,671 hectares of the special mining lease which covered the ore body, the mine's workshops, crusher, concentrator and Panguna township. To the west was the tailings lease that encroached upon the Nagovis and Banoni census divisions. To the east the port mine access road extended 26 kilometres down the mountains and across the 
coastal plain to Loloho (Dodoko), site of a custom built port and a power house which generated electricity for the mine and for the new town at Arawa. The latter was an open town built on the site of an expatriate owned copra plantation. As such it was not a BCL lease although many BCL employees lived there.

In total, just over 13,000 hectares were included in the company's leases, or about 1.5 per cent of Bougainville's total area. Eventually, the Administration determined that 806 blocks of land defined by local custom were affected, 510 of which lay within the special mining lease. The 'owners' of these blocks (perhaps 'custodian' would be a better word), were the people to whom royalties, occupation fees, compensation and other payments were made. A fortunate minority received these payments for blocks around the fringes of the mine that were left untouched by development. Others, however, saw their land literally disappear as the pit grew or else watched it gradually disappear under waste rock or tailings.

Within the special mining lease it was necessary to relocate the people of a number of hamlets early in the life of the mine. About 300 people were affected, predominantly from Moroni, Dapera and Piruari. Initially it was intended to follow the Administration's example at Arawa and to purchase a coastal plantation on which to resettle the displaced people. Broad, fertile acres with cash-cropping potential and road access seemed, to Australian eyes, to be preferable to the hard scrabble existence of the mountain villagers.

That view was not shared by people within the special mining lease. Their ties to their land went very deep indeed, as we soon realised. This was where their ancestors had lived, where their parents were buried and where every rock and pool had widely understood significance. We might see it as a difficult environment, but to them it was home. If we move to a coastal plantation, they said, the local people will see us as intruders speaking a different language. The fact that you will give us legal title to our new blocks would mean nothing to those whose ancestors once owned the plantation. They are simply waiting for the white man to leave before resuming what is rightfully theirs. We mountain people, they said, could never take up coastal land without incurring the enmity of the local clans.

So a compromise was worked out whereby the inhabitants were resettled locally. Some moved to neighbouring villages, but others were resettled in permanent material houses on the waste dump itself, close enough to the mine and concentrator to constantly hear the noise and see the reflected light of the 24 hour-a-day, 365 day-a-year operation. Admittedly, the new accommodation was seen as superior to the old and was accompanied by cash payments. And it should also be noted that some of the villagers found well-paid work with the company. Yet it was an unsatisfactory arrangement and I have never thought otherwise. 
The problem with land went beyond the nature of its inheritance and the numerous kinds of rights to land enjoyed by various kinfolk. For what is probably the first time in the island's history a land shortage developed on Bougainville and, in part, the company was to blame. Later in this chapter I will describe the efforts made by BCL to improve the standard of living of Bougainvilleans. For the moment, it is enough to record that success in this area assisted in increasing the birth rate to around 3.5 per cent, ${ }^{2}$ well above the national average and very high by world standards. In 1971, when the mine was being constructed, life expectancy was around 47 years. A decade later it had risen to 60 years. In the same period infant mortality dropped by 60 per cent.

Not only was mine development instrumental in increasing the number of mouths to feed, but it also led to a change in land-use patterns through an increase in cash cropping. Prior to the mine the Bougainville road network was rudimentary, most plantation crops of cocoa and copra being transported in small coastal vessels. The construction of a first-class sealed road from Kieta to Panguna, and an extension of a dirt road west of Panguna to the confluence of the Kawerong and the Jaba rivers made it relatively easy for local government to build a connection to the road linking Boku and Buin. This new, expanding network was a catalyst for cash-crop plantings and land for gardens became less plentiful. As a result, customary land law was subjected to new demands and, over time, this may have contributed to disputes and a growth in intergenerational misunderstanding.

Migration into Bougainville from other parts of Papua New Guinea also caused some pressure on land in the vicinity of Arawa and Kieta where squatter settlements developed. The growth of these enclaves was to become a point of social concern among Bougainvilleans.

To the expatriates working for BCL, the nature of local land tenure was seen as difficult to grasp and to reconcile with Australian concepts of valuation and compensation. However, I am certain that it was equally difficult for the average Bougainvillean to understand the Australian concept that saw minerals as belonging to the Crown, for the benefit of the nation as a whole. Those landowners who sought advice from the American priests, who were members of the Marist Order, would have received little enlightenment. Some of these priests appeared to believe that the American practice of private mineral rights was the natural order of things. Or it may simply have been that their concern for the moral wellbeing of their parishioners made them fear a development that might reduce the influence of the Church. Whatever the reason, there is no doubt that some individual clergy had little sympathy for Crown ownership of minerals and said so. 


\section{Communication Problems}

The most fundamental communication problem that confronted the CRA geologists who found the orebody and their successors who built and operated the mine was, quite simply, language. In the 1960s there were still areas of Papua New Guinea where even Neo-Melanesian (Pidgin or Tok Pisin) and Police Motu were not spoken. By the standards of, for example the Highlands, communication with Bougainvilleans was - on the surface - relatively easy as Pidgin was widely understood. Yet Pidgin is a blunt linguistic instrument, unless spoken well. Many Europeans spoke it imperfectly and were not aware of its potential.

Bougainville itself had over 20 distinct languages and well over double that number of associated dialects [see Tryon, this volume, for detail]. The company's operations affected, from east to west, Torau, Nasioi, Nagovisi and Banoni speakers. Had there been a dominant local language, it might have been possible to encourage its use; in the absence of such a language, it was Pidgin which became the common means of communication with the majority of employees and with most villagers. BCL staff were encouraged to learn Pidgin, as were their families, through formal company-sponsored language programs.

In the first few years the handful of CRA people relied on Administration officers to interpret but, by the time construction started in earnest in 1969, the company had a village relations department that employed Bougainvillean field officers overseen by expatriate managers. As the years went by the senior ranks of the department were filled by Bougainvilleans.

The village relations department was focused primarily on the concerns of people within the port, road, mine and tailings leases, but BCL also maintained liaison offices at Buin and Buka at the southern and northern ends of the island respectively. These, however, were viewed with suspicion by the Bougainville Interim Provincial Government established in 1974 and, in the mid-1970s, these two offices were closed. In retrospect this diplomatic concession may have been a mistake as it allowed some quite outrageous rumours to spread unchecked throughout the island.

One of the problems experienced in the first few years was to explain to a technologically unsophisticated audience the nature of a modern resource development when there was no precedent for such an operation in Papua New Guinea. Indeed, few expatriates had a clear idea of the eventual shape and form of the mine and its ancillary operations. Final decisions on lease boundaries were not made until 1970 and a final decision as to the method of tailings disposal was not taken until 1972. That decision was reviewed regularly and, as I mention later, the decision to change the method of tailings disposal was made in 1986.

In 1966 a group of Bougainvilleans was taken on a tour of major Australian mining sites in the hope that they would be able to tell people what an open pit 
looked like. It is doubtful whether this well-meaning initiative did much good in preparing people for the impact of mining. Yet at least one of these men, a school teacher from Dapera married to a Guava woman, did a sterling job for the company for many years, eventually becoming a manager in the mine's village relations department.

The local people who acted as village relations officers had a difficult job. They certainly understood the local customs but they were themselves subject to local loyalties and politics and thus under suspicion that they favoured some groups more than others. Alternatively, they might be seen as company stooges. To some extent the presence of a Papua New Guinea Administration office in Panguna (initially staffed by expatriate field officers of the Department of District Services) helped to diffuse the occasional disagreement.

The presence of government officers on site served as an avenue of appeal for people who felt aggrieved by the actions of BCL's village relations officers. However, this office was localised in 1978 with the role being taken over by a Bougainvillean from the Siwai census division. Subsequently, in the mid-1980s, the North Solomons Provincial Government (NSPG) - as the provincial government for Bougainville was named from 1976 - closed the office. The reason for doing so is not known, but it may have been that the growing effectiveness of the Panguna Landowners' Association made the intermediary 'ombudsman' role appear superfluous.

One of the chief difficulties facing BCL was that the village people appeared not to have clearly identifiable leaders able to speak authoritatively on their behalf. The 'chiefs', who seem to have emerged in the 1990s as a result of the civil strife, were not evident in the 1970s and 1980s. And, in fairness, it was equally frustrating for village people when they discovered that corporations had hierarchies and that the company people they dealt with on a day-to-day basis had to refer many matters to their managers. The occasional reluctance to make decisions on the part of local field officers may have stemmed from embarrassment at having to go to an expatriate manager or superintendent with what might be interpreted as bad news.

One other factor demonstrates the difficulty of bridging the communications gulf in the mountain villages of central Bougainville. 'Cargo cult' thinking was, and probably still is, alive and well in the area. When you see life through such a paradigm it is very hard to carry on a dialogue with people steeped in an entirely different tradition.

There was also an inherent scepticism about BCL's motives and a reluctance to accept that a business which had forced itself onto an unwilling society was able to act in a disinterested and socially responsible way. The Bougainville Copper 
Foundation, to which I will return later, is an example. Its aim was to improve the lot of all Bougainvilleans, but its projects were often suspected of being a front for BCL to extract wealth from the island in new and devious ways. Whether this scepticism was purely a reaction to the imposition of the mine, or whether it grew out of the insular nature of traditional Bougainville society, I am not qualified to judge. But I do know that such a mindset existed and that it affected communication between the company and its neighbours.

As I have already intimated the Catholics were a major presence on the island (see Laracy, 'Imperium in Imperio' this volume), overshadowing the presence of other Christian churches. In particular they played a major role in education and it was not until 1964 that an Administration high school was opened on Bougainville.

We made a point of keeping in touch with Bishop Leo Lemay SM, as well as the clergy at Tunuru, near Loloho, Morotona on the west coast and at Deomori near Panguna itself. We were also in contact with Father Fingleton from the Buin area. A sometimes trenchant critic of BCL, Father Fingleton nevertheless won my considerable respect for his experience so that I eventually accepted a number of his recommendations.

We also made a point of maintaining a dialogue with a number of academic authorities on Bougainville and Papua New Guinea. I have already mentioned Eugene Ogan and Douglas Oliver; they were just two of a stream of anthropologists whose insights we prized. Others who proved valuable in helping us to understand the fuller implications of our activities in both Bougainville and Papua New Guinea included the historian Jim Griffin and the astute political analyst, Ted Wolfers. ${ }^{3}$ And there were others, too numerous to name here, whose advice we were happy to have.

In addition, of course, we endeavoured to maintain communications with the NSPG and the province's elected representatives in the Papua New Guinea House of Assembly. In retrospect one cannot help but be struck by the wealth of talent contained in Papua New Guinea's first provincial administration. Under the premiership of first Alexis Sarei and then Leo Hannett, it had men like James Togel, the provincial secretary, the late Theodore Miriung, the province's first legal officer and Mel Togolo the provincial planner who also later became a BCL director. They were all extremely capable and clearly determined to get the best return for their people from the mining operation.

The one issue that made communications between the company and the NSPG sometimes difficult was that the Bougainville Copper Agreement had been signed before provincial governments had been conceived. This was to become an increasing source of frustration to both parties. The National Government in Port 
Moresby obviously saw no urgent need to amend the 1974 Agreement in ways that would strengthen the NSPG at the expense of its own income from the mine.

In reflecting on communication problems I well remember a comment made to me by Mekere Morauta many years ago when he was a banker rather than a politician. At the time Mekere was the first Papua New Guinean to become a director of BCL and he said to me that he had reached the stage where he felt a stranger in his own village. He found it difficult to communicate with his own parents because he did not understand them and they did not understand him. So perhaps we should not be surprised that BCL had difficulties.

\section{Fragmentation of Papua New Guinea}

The third major issue that complicated life for BCL management was the fragmentation of Papua New Guinea's society. This occurred at both the national and at the provincial level. Rarely did one feel that those who spoke on behalf of the authorities had the wholehearted support of the populace.

In retrospect, this is barely surprising. Future generations may well wonder at the expectations of the United Nations and Australia in relation to the heterogenous society that attained self government in 1973 and full independence in 1975. The new nation did not lack talent, intelligence or natural resources. What it did lack was a sense of shared history that extended back more than a few generations. Here were people of Melanesian, Micronesian and Polynesian stock speaking a multitude of tongues: people who, for thousands of years, had been kept apart by rugged mountain ranges and wide tracts of ocean; people whose cultures were as various as their languages or their physical appearance.

Yet we Westerners were swept up in the post-war enthusiasm for shedding our colonial past. Our confidence in the essential rightness of our economic and political systems encouraged the belief that these systems would 'take' in virgin soil. Those who saw that the laws and morés that had served the Pacific peoples for millennia might hinder the grafting on of such institutions as representative democracy were politely ignored. Surely the material benefits that would flow from nationhood would more than compensate for any social or cultural adjustments? Why should Papua New Guinea be dependent when, at the time, African nations had apparently made the transition successfully?

Papua New Guinea was even denied (thank goodness) the experience of a war of liberation from an oppressive colonial regime. It thus missed out on developing the social cohesion and the shared myths that such a struggle can create although, in turn, primal loyalties to family, clan and tribe may have been weakened accordingly.

None of these considerations crossed people's minds when the Bougainville Copper Agreement (1967) was being negotiated — nor when it was revised radi- 
cally in 1974. Quite simply the wealth and other benefits projected from the operation of the mine were seen by its sponsors as providing the economic support that would permit the new entity to function as a modern nation. And, in a sense, that is what happened. But, what was not foreseen was the way in which the deeply ingrained sense of separateness that characterised so many groups in Papua New Guinea would be accentuated by the project. For this there were many reasons and I will list only a few.

The first is that the people of Bougainville had long believed that theirs was the forgotten district, largely ignored by the Administration of the Territory of Papua and New Guinea. Christian missions had partially filled the vacuum caused by official neglect. The truth of this does not concern us now for it was generally accepted by Bougainvilleans before the 1970s that the Bougainville District was something of a tropical backwater with most Administration attention being directed to the relatively densely populated Highlands region. So, when the riches that flowed from the mine catapulted Bougainville to the position of the wealthiest province (exceeded in per capita Gross Domestic Product only by the National Capital District) there was a sense that the bounty was long overdue - and, among Bougainvilleans, no enthusiasm for sharing that bounty.

Secondly, the Bougainvillean people had experienced a variety of nominal and official overlords in less than a century. The strength and quality of their impact, or lack of it, has been well documented. One suspects that after Bougainvilleans had been exposed and subjected to so many administrative and cultural changes, the subsequent shift to Papua New Guinea sovereignty was seen by many as inflicting yet another alien authority upon people who were beginning to develop a sense of unity for the first time in their history.

Bougainvilleans had long known that their distinctive skin colour distinguished them from other people in Papua New Guinea and linked them to some of the people in the neighbouring Solomon Islands. For most of their history this had meant very little; it certainly had not lead to a strong sense of Bougainvillean identity. An individual had, by all accounts, little faith in any one outside his immediate family and linguistic group. It took the influx of Papua New Guinea citizens from other parts of the country ('redskins'), in particular those from the Highlands, to promote a stronger sense of Bougainvillean identity. That sense of difference was fuelled by resentment at the thought of the royalties, taxes and other benefits being enjoyed by non-Bougainvilleans while Bougainvilleans underwent the social and environmental impacts that came from playing host to one of the world's largest copper mines.

Provincial government was a pragmatic attempt by the Papua New Guinea Government to mollify the secessionist inclinations of its most far-flung district. 
As an institution, it served for a while to satisfy the need of Bougainvilleans for a greater say in their own destiny. But it soon became apparent that the National Government did not see a need to grant the NSPG more than a token role in major economic decisions. Given the calibre and the ambitions of the Bougainvillean provincial leadership this limited view was bound to lead to a clash sooner or later. The rapid development that occurred in Bougainville after 1972 created an expectation of further social and economic growth — spurred by the province's soaring population. Each year the case for directing a greater proportion of the benefits from mining to the NSPG and to the local landowners appeared more obvious.

BCL was repeatedly forced to point out to the NSPG and to local landowners that its legitimacy rested on the 1967 and 1974 mining agreements: agreements that predated provincial government. In 1974 it had been agreed that the National Government and BCL would meet every seven years to thrash out the differences that experience suggested would inevitably develop in such an important and comprehensive relationship. In both 1981 and 1988 BCL wrote to the authorities in Port Moresby, reminding them that the seven year review was imminent. Those letters contained a list of issues that the company wished to raise at the meetings; but on both occasions BCL recommended the presence of Bougainvillean representatives at the review. Prior to sending these letters, BCL had ascertained the willingness of Bougainvilleans to attend.

The Papua New Guinea authorities agreed that the NSPG should send representatives; whereupon the Provincial Government approached the Papua New Guinea Government and requested discussions between the NSPG and the National Government so that they could arrive at a common negotiating position vis a vis BCL. Such discussions were held in 1981without success. But in 1988 this was not acceptable to the Papua New Guinea Government. The NSPG refused to nominate representatives to attend the review - and BCL refused to attend without representation of those people most directly affected by the mine.

One can only wonder what pressures caused the people in Port Moresby to give the 1988 meeting a low priority. Perhaps they thought that the needs of the other provinces made the anticipated demands of the nation's wealthiest province appear churlish. Perhaps, as so often happens, political goals eclipsed the national good. Whatever the reason, we are left wondering whether the closure of the mine and the subsequent prolonged disaster inflicted on the people of Bougainville and of Papua New Guinea as a whole — might have been averted had the 1981 and 1988 reviews been conducted as originally intended.

The inability of the politicians and public servants in Port Moresby to understand the viewpoint of their opposite numbers in Arawa is surprising. Yet this inability is mirrored within the Bougainville Province itself, where the 
landowners most affected by the mining operations appear to have felt that their own provincial representatives had failed to assist them. The fact is, of course, that many Bougainvillean people outside the lease areas were beneficiaries of the burgeoning economy and infrastructure inspired by mining. Even those who strongly advocated secession from Papua New Guinea did so in the belief that mining would continue and would fund their political and constitutional aspirations. Where the frustrations of the local people were echoed was in political pamphleteering. Here the controversial nature of the content served to obscure the genuine grievances. For the most part it is probably true to say that in 1988 the population of other parts of Bougainville looked with some envy at the evidence of material prosperity in central Bougainville and had only qualified sympathy for the losses experienced by the Nasioi and Nagovis people.

\section{Environmental Impacts}

The environmental impact of the Panguna mine was obvious and considerable. Over the 17 year life of the operation some 10 million tonnes of copper-gold concentrate were extracted from about 1.25 billion tonnes of material in the concentrator. What remained fell into two categories; the solid waste rock and the finer residue, known as tailings, that remained after the copper-gold content had been extracted. Tailings which were in slurry form, were discharged into the Kawerong River, a tributary of the Jaba River. The silt laden Jaba meanders westward across the flat coastal plains to the sea where it has formed a delta of about 900-1,000 hectares.

The heavy waste rock was trucked into some of the short, steep valleys that run into the Kawerong within the special mining lease. Over the years these filled up creating some 300 hectares of flat land, but totally obliterating the underlying terrain. The tailings, given their large solids content, were a special challenge. In many mines they are contained behind dam walls, but in the seismically unstable Crown Prince Range with a very high rainfall and not many miles away from an active volcano, this was not an option. In the late 1960s the technology for shifting very large tonnages of slurry over such long distances by pipeline had yet to be developed. The best expert evidence was that river deposition would carry 80 per cent of the tailings out to sea. The rest would fall to the bed of the Kawerong/Jaba causing it to rise and spread laterally.

We now realise that the hydrological experts underestimated the extent of this deposition and the consequent spread of tailings. Only some 60 per cent was carried out to sea. After ten years tailings disposal was revisited. By this time pipeline technology had advanced, and, in 1986, the decision was made to build a 33 kilometre tailings pipeline from the concentrator to the Jaba delta. Construction of this US\$76 million project was more than 70 per cent complete when the mine closed. 
There is no simple solution to any tailings problem; while pipeline disposal into deep water is usually judged preferable to the lateral spread of material that results from riverine disposal, there is always going to be destruction of life on the sea floor. Also, a pipeline is an extremely expensive solution. Yet the environmental burden born by the villages in Nagovis justified the cost.

From the start of operations BCL carried out environmental research into the effect of its activities. Some of that work focussed on how best to treat the 9,000 hectares of tailings. The closure of the mine has meant that nature has been left to do the job unaided and that the years of trialling which species and soil additives best promoted regrowth have been futile. Perhaps not futile, for some of that knowledge may well prove useful in other situations.

The environmental impacts of BCL's operations were real and considerable. However, the perception of environmental change went beyond the reality. Over time the mine became a convenient explanation for any aspect of day-to-day existence that people believed had deteriorated over time. If the weather seemed wetter or drier than before, then BCL was to blame. If the crops were not as prolific, or the game not as abundant, as they had been — then the mining operation was probably the cause. Various illnesses were obviously caused by chemical pollution - or so it seemed to many people in central Bougainville. When no scientific basis for the claims could be found it was automatically assumed that BCL was not telling the truth.

In 1988 the Papua New Guinea ministers for Minerals and Energy, and for Provincial Affairs, visited Panguna and heard these complaints. As a result, the Government commissioned a New Zealand consultancy, Applied Geology Associates (AGA) to report on the environmental and social impacts of the mine, past, present and future. The AGA report acknowledged the substantial environmental impact of the mine, but failed to find any significant levels of chemical pollution that would substantiate the broad range of concerns expressed by the villagers. As soon as this finding was announced Francis Ona (then secretary to the New Panguna Landowner's Association and later the leader of the secessionist Bougainville Revolutionary Army) condemned the AGA study as a 'whitewash'. By dashing the hopes of those who felt entitled to another form of compensation, the AGA study intensified the level of public frustration and support for those prepared to resort to violence.

The environmental issue is critical to understanding the outcome for the Panguna mine. However, the important lesson is to appreciate the social consequences of imposing major changes on the environment and the way environmental decisions were shaped by extraneous political, economic, and even technological, factors. 


\section{POSITIVE ASPECTS}

The four issues I have just mentioned were all serious enough to have brought the mining operation to a close long before 1989, were it not for the fact that the mine had considerable benefits for Papua New Guinea and for Bougainville Province. The contribution that BCL made to the new nation through taxes, royalties and other imposts is well known. So too is the contribution that flowed from the Papua New Guinea Government's shareholding in the company — and to this should be added the dividends that went to individual Papua New Guinea shareholders. What I want to do now is to briefly examine some of the positive aspects of the mine for the people of Bougainville.

The mineral royalties paid by BCL that the National Government eventually redirected to the NSPG, plus the direct taxes that the NSPG levied on the company, accounted for over a third of the Province's budget by 1988. That the NSPG was able to raise another third from other provincial taxes was only possible because of the multiplier effect of the mine. Without BCL the provincial tax base would have been smaller and Bougainville would have relied heavily on National Government grants and subsidies. Instead of being the national leader in terms of income, health, education and political evolution, Bougainville would, in all probability, have remained a relative backwater.

Modern mining is a capital-intensive industry and critics often claim it does little to combat joblessness. Yet at the end of 1988 BCL had over 3,500 employees, 83 per cent of whom were Papua New Guinea citizens. Of this national workforce Bougainvilleans made up about a third — although others were employed by the numerous contactors engaged by the company. However, ultimately the greatest long-term benefit to both the people of Papua New Guinea and those of the Bougainville Province was not the wages paid to employees or contractors but rather the training that BCL gave its people.

It was fully understood from the start that the company would localise its operations as quickly as possible. A truly remarkable training effort from the very start of building the mine meant that, when operations started, Papua New Guinea citizens who may never have driven a car were confidently driving 105 tonne tip trucks, bulldozers and giant shovels. Not only did they operate these complex machines safely and competently, but they did so with an efficiency that exceeded that of many Australian mines. The mine training college which BCL built at Panguna was the best technical training facility in Papua New Guinea. More than 12,000 employees undertook its courses and many emerged as fully qualified tradesmen with skills that would serve them for life. In addition, the company sponsored the tertiary education of promising young Papua New 
Guineans in both Papua New Guinea and Australian institutions, including postgraduate studies. From their ranks would come the professionalism that would take the company into the 21 st century - or so it was thought.

BCL also set out to encourage local business both through training and, wherever possible, through tailoring its needs to the capacities of local producers. The Panguna Development Foundation, later called the Bougainville Copper Foundation (BCF), opened for business in 1971, before production began. Its objectives were:

- to make grants and donations in Papua New Guinea for charitable, public, scientific, educational and artistic purposes;

- to assist and promote participation by Papua New Guineans in commerce, services and industry;

- to provide medical, educational and welfare services for people in Papua New Guinea, and

- to provide and assist in the provision of training in professional, commercial, agricultural and industrial skills to people in Papua New Guinea.

The foundation was financially underpinned by BCL, but decisions were made by an executive committee, the majority of whose members were Papua New Guineans. BCL provided management services to the Foundation on the understanding that none of the BCF's income or property was transferred to BCL.

An early BCF initiative was Arawa Enterprises, a retail-wholesale trading company, created in the hope that through local share ownership it would be possible to direct some of the financial returns from trading to the community. BCF also took over the agricultural extension work started by BCL through a subsidiary called the North Solomons Agricultural Foundation. Thus, indirectly, a mining company found itself seeking to create provincial self-sufficiency in pork, bacon, eggs and vegetables. Yet another BCF offshoot was the North Solomons Medical Foundation set up to create an alternative to the public hospital. The Medical Foundation's clinic and small hospital were initially funded by the BCF, but it was intended that costs would be covered by fees. Despite this, the Medical Foundation proved to be a most popular facility.

The fundamental aim of the BCF was to support community activities and projects. As a charitable body it was legally bound to distribute 80 per cent of its net income to worthy causes. And this it did, largely in the areas of education and health, with some money going to social and cultural projects. I believe that the BCF did a lot of good although, for reasons I have already touched upon, its activities were viewed with suspicion by those who did not want to concede unselfish motives to BCL. 
It is not easy for someone like myself to write objectively about an island, a people and an operation that were the focus of my personal and professional life for so many years. In the broadest way possible the Panguna mine seems to encapsulate the classic conundrum that lies at the heart of many great minerals operations; the benefits are great and widely spread. The disadvantages, however, are localised and acutely felt by a small number. I believe that BCL was ahead of its time in seeking to do the honourable thing by the people of Bougainville. Not many companies, even today, can match the effort BCL devoted to understanding and ameliorating the social and environmental impact of its activities. The closure of the mine was a major economic and social setback for Papua New Guinea and a dreadful human disaster for Bougainville, and I do not intend to gloss over this stark fact. Yet, insofar as later mining projects in Papua New Guinea were allowed to involve the local landowners in consultations over their planning and operation — in a way that was denied to BCL and the Bougainvilleans — it may be that the experience has served as a very expensive lesson.

\section{Endnotes}

1. Ogan is an American anthropologist who was at that time undertaking the research for his $\mathrm{PhD}$ thesis among the Nasioi-speaking people in the Aropa Valley, some kilometres away from Panguna.

2. The company was probably only partly responsible for rising population because there is some evidence that the population increase was becoming obvious in the late 1950s, before CRA became involved in Bougainville.

3. Neither Griffin nor Wolfers was in the employ of, or contracted by, CRA or BCL. 


\title{
TORAU RESPONSE TO CHANGE
}

\author{
by Melchior Togolo
}

W

hen I started thinking about this paper, I thought I should write in the third person with the idea of being a detached and objective observer or a dispassionate social scientist. As I wrote about the Torau, my own people, I became more and more emotional. As I thought and wrote I could feel my whole body trembling and my emotions bursting at the seams. I was confused: should I be objective and dispassionate or let my thoughts blow and flow. I decided to abandon detachment and objectivity, throw them away, and write the stories as they were told to me and as I felt them.

Firstly, I will talk about the responses of my people to mining and its impact, their fears and aspirations, and their attempts at adaptation. Contrary to Colin Filer who attempted to connect the origins of the rebellion to a process of local social disintegration 'brought about by large-scale mining projects' [1990: 88], I am going to argue that mining did not lead to social disintegration of the Torau, one of the five ethnic groups of people affected by the Panguna mine. While mining has the potential to generate a 'volatile mixture of grievances and frustrations' [Filer 1990: 76], I would add that this is not unique to mining and certainly does not lead inevitably to social disintegration but rather adds to the already existing processes of social change. I do not agree that societies self-destruct. I believe that they go through a process of social and environmental adaptation. The argument is more to do with understanding the accumulative and incremental changes that lead to social disruption or social order and which assume a variety of affiliations within and between communities. These do not necessarily cause complete disintegration.

Secondly, I will extend this to my people's responses to the Bougainville 'crisis' of 1988 to 1997 - a phenomenon with similar social influence - and how they attempted to cope with the perceived external threats of that period. I will be arguing that the crisis brought my people together and made them a lot stronger as a community. But all this needs to be viewed against a larger historical canvas. 
My people live in three main villages: Rorovana 1 and 2, Vito and Tarara. We are a close knit grouping who share one culture, one language and common values of ethics and folklore. Rorovana is the largest of the three settlements. About 500 people lived there in the 1960s as I was growing up. Now the population is estimated to have grown close to 2,000. There were multi-layered connections with the neighbouring Nasioi and Eivo peoples and strong influences from the Catholic Church and the Australian Administration. From the early years of German rule, numbers of our young men had travelled to many parts of Papua New Guinea, working on plantations, as domestic servants in Rabaul, for the Church, on Chinese coastal boats and for the colonial Administration. My people have been part of the cash economy since the Germans encouraged villagers to plant coconuts. As I was growing up my dad was busy clearing land, planting coconuts and making copra; my uncle was a theatre orderly at the Administration's hospital in Kieta, one brother was working in Rabaul, another for the Mission and others for Chinese-owned companies. Scarcely any women left the village except for visits to other villages or occasional shopping in Kieta.

Soon after I started school at the village, the good Fathers (the Catholic missionaries of the Marist Order that ran the school) decided that my class must be sent to a school far from home so that we could not run away back to the village as some students from the previous group had done. My education from that point took place in schools in north Bougainville, Kokopo Minor Seminary in East New Britain, Bomana Marist College, beyond Port Moresby, followed by study at universities in Port Moresby, the United Kingdom and the United States.

I was away from the village when CRAE (Conzinc Riotinto Australia Exploration) began exploring, and the colonial Administration decided to acquire a part of the Torau land for mine-related purposes (notably port facilities and a recreation area). The stories I heard were told to me on my regular visits home during school holidays. Our people did not want a mine. They feared losing their land. They feared the effects of mining on the land and the sea, on their children and their society. They argued, resisted, pulled out surveyor's pegs, battled against the police riot squads and company bulldozers. My uncle made up songs, still sung today, about the mine and the destruction of the land, asking, 'Why can't you wait until our children grow up so we will have our educated people to protect our rights?' In the early 1970s I was in Moresby, writing letters to the newspapers, taking on Sir Frank Espie, then managing director of Bougainville Copper Ltd (BCL), about social and environmental issues at conferences and in print. Bougainville leaders and students in Moresby did all we could to protest, to support our people.

In spite of all the objections, the project went ahead. Resistance to the resumption of the land at Uruava made international headlines [Denoon 2000: 
125]. But 10 years later there were many improvements in the village because of the mine. Numbers of our people were working for the company and I was an alternate director of the BCL Board, sitting beside Sir Frank who, by this time, was the chairman of the Board. ${ }^{1}$ I considered myself grown up since my university days and I think the progressive Sir Frank would have been the first one to agree with me. On the other hand, because of my association with BCL, certain people may want to identify me as one of those Bougainvilleans who had apparently grown fat from eating at the table of the mining company [Filer 1992: 123], or label me as belonging to a 'Bougainvillean bourgeoisie', having betrayed my own people by my so-called economic activities [Filer 1992: 123]. Rejecting these detrimental labels, I would like to suggest that the Torau as a people exhibited features and characteristics which, combined with a unique history, have helped them to cope with various massive changes, due not only to mining.

My observation is that there were two polarised responses to the mine and its impact. First, there was a sort of acceptance of the mine and integration of everything associated with it. Compensation agreements provided many benefits. Our people were trained and employed at the mine. They demanded services from both the company and the government. Many enjoyed a very comfortable standard of living. At the same time there was ambivalence, sadness, anger and fear about the intrusion of foreigners, damage to the environment, as well as changes and divisions in the village. My own development had so may parallels with that of my people. As provincial planner with the North Solomons Provincial Government from 1977, and later as provincial secretary from 1982, I was determined to work closely with mine personnel to ensure maximum communication between the company and our provincial government which were - whatever the shortcomings in the Mining Agreement and on the ground - enmeshed in a variety of ways.

Mining, as an economic activity, does not take place in a social vacuum; its various influences are wide-ranging and deeply felt. The two Rorovana villages lost their land at Dodoko (mispronounced as Loloho by a Chinese plantation manager) which became the mine's port and recreation area. Land acquired at Uruava was used to build accommodation for single men and recreational facilities for senior management. Access to fishing grounds and recreational land was also taken up by mining related developments. My estimate is that slightly more than a third of Uruava land was thus used for mining purposes. Not everyone lost land, but a majority of clans were represented among those who did. With much productive land gone, many people were prevented from engaging in smallholder coconut plantations and lost the potential to develop agricultural land for cash crops and subsistence. We Rorovanas also lost our source of water. The Pinei or Arakau River, which used to supply water for bathing and drinking, was degraded. 
Fish, mud crabs and mussels disappeared from the river. With the loss of its rapid flow, the river turned into an unhealthy semi-swamp at the back of Rorovana 2.

Thousands of foreigners - Papua New Guineans and others - came onto Torau land. This deluge of people threatened to inundate the Torau's physical and cultural landscape. Nothing was comparable except perhaps the Japanese stampede into the village in 1943. This was still vivid in memory. The influx of people during the construction period was overwhelming for a quiet and sleepy fishing village. At the peak of the construction period, there were over 10,000 people in the Arawa-Dodoko-Birempa-Paguna region. Construction workers on weekend trips would walk through the village, going into houses, talking to the young girls, offending and confronting with every step and gesture. After strong complaints from the people, the company soon put a stop to this.

On the other side of the coin, the Torau were compensated for some of their losses. A water supply was laid on to the village. Rents and compensation, much greater than originally proposed by the Administration, were paid for every plant and tree and the loss of fish. Toraus were also trained and employed by the mining company and sub-contractors. Some were skilled and sought-after workers, staying with their employers for years. The standard of living for many families increased and, as a consequence, their relative level of wealth improved. Proudly independent, the Torau let everyone at the Loloho port site know who the real landowners of the area were. If it was necessary to use physical force to get that understanding across to the strangers, it was used. The Torau were a strongly coherent group and fiercely proud of their identity.

But were the essential elements of the society destroyed as a result of all these economic and social changes? Did mining lead to 'social disintegration' for the Torau, as Filer [1990] has argued occurred with the Nasioi-speaking groups in the mountains? To answer such allegations, it is necessary to begin by describing some features of Torau society and then assess some of the impacts of the social and economic changes associated with the mine.

Torau ancestry is directly linked to groups from the Shortland and Choiseul islands in the western Solomons. It is thus similar to that of the Uruava or Poraka people who would have arrived about 80 to 100 years earlier and settled on the present Arawa village site. ${ }^{2}$ As a group, the Torau probably came in the last wave of migration that took place from the Solomon Islands 150-200 years ago and settled on the present day Rorovana village, on the east coast of Bougainville [Oliver 1991]. Torau stories describe the migration along the coast of Bougainville in search of land on which to settle so a chief could have his own community. They also describe the ceremonies that took place where the village of Rorovana now stands, at the time when Toraus acquired the land peacefully from related 
Nasioi clans who identified with them through cultural totems. While the relationship between Torau and Nasioi has undergone many changes, clan links between them still provide very strong bonds. Trading partnerships, knowledge of each other's language and some intermarriage were part of the traditional relationships. The relationship was particularly active during World War II when Nasioi helped Toraus fleeing from the Japanese by providing them with food and the use of land. There are also close ties between Eivo and Torau clans that have been renewed in each generation. Many of these traditional relationships have been regenerated as young people meet in mission and government schools or work in urban situations outside Kieta.

The impact of missionaries was significant even before the early 1930s when the mission was set up at Tunuru, near Rorovana. Our people were eager for education and a number of young men became catechists ${ }^{3}$ and teachers before the war. Emmet McHardy, the New Zealand Marist priest who taught at Tunuru Catholic Mission in 1935, in a letter to his parents on 11 August, described the Rorovanas as 'as a peculiar and warlike people, being in no way related to the Nasioi who own the rest of the Kieta district' [McHardy 1935: 32]. But he also felt more or less at home when he stayed there because people were prepared to be baptised. If there was acceptance of the missionary message, the attitude to kiaps (government patrol officers) was more critical. The men, often clan leaders, who were forced to carry the young kiaps across the river to the village, would entertain their community with stories of how they stumbled and fell, causing the kiap to tumble into the river, yelling and cursing at the clumsiness of the carriers. Ever careful to do the right thing for the kiap, our people built pit latrines as ordered, but continued to use the beach as they had always done while accepting the kiap's praise for having clean latrines. Patrol reports of the late 1940s and 1950s included the kiap's assessment of the Torau as highly intelligent and eager to learn new ways.

My grandfather, Naruke, told me of his experience working with the German missionaries at Ulamona sawmill in West New Britain in the early 1930s. While he believed deeply in sorcery and the old ways, he encouraged me to be educated because he knew that one day I could be involved in the development of a 'new people'. At the height of cash-crop development in the 1960s I used to listen to his warning of the dangers of using all the land for coconut plantations. He would say that with the lack of spacing of children, growth in the village population would put pressure on the land, already threatened by the planting of too many coconut trees. I did not understand his great wisdom then, but what he said is proving to be true. I benefited very much from his great wisdom, his knowledge of tradition, experience of other cultures and languages and was awed by his great kindness and selfless commitment to us, his grandchildren. When he died in August 1969 I was devastated. Away in school, I was unable to go back and bury 
him. I took some consolation in writing the following poem about him just after the 10th anniversary of his passing.

The Fisherman

He is awake with the first crow

Cutting through water in great urgency His path illuminated with natural light He would be calling the first light

He meets the great ocean dawn Speaking his mind to the gods Calling each ancestor by name He is awake before the fish

Seagulls flying over his head Singing the tune he knows Whistling to great black porpoises

Swimming steadily and whistling back

It is the tune of the fishes

Sinking down to the depth for hearing Guiding the canoe to the school

The porpoises keep the regular beat

Pulling his oar in keeping With the sacred rhythm the only call Him his friends and enemies know well While bound to this timeless struggle

The wide sea becoming a sliding mirror Reflecting sharp eyes sunk into his head A natural protection from the severe glare Seeing the rays planted into the deep

Daring not to look at the burning sky His bald head is a shining oil of sweat His dusty hair twisted balls of curls A ring of dried grass suffering desert heat 
His face weathered from elements

Salt flakes making traces of history

Colour of contour a dying moss

The marks of seasoned fishermen

His arms are compact of power

Directing total movement

Urging the canoe to keep pace

With the swim of the porpoises

The canoe is a dug out log An outrigger and float to balance

The work of a hand of a master

Dancing the water with one pull

The sea an eternal home

The canoe a floating house

It has been from his ancestors

$\mathrm{He}$ is part of this eternity

His hands bear readings of activities

Occasionally splashing his face cool

And mopping with his palm to dry

As if to dispel the heat of the sun

While tasting salt the spirit of power

He seems the only connection with the past

When men would record their names

By endurance and amount of catch

It's said he is the greatest

And his fame widely heard

Though it is not proper to say

For the voice of silence would tell

He shall land home

With the falling of the sun

The provisions of the day made

With eagerness to start again.

[unpublished, 4 December 1979] 
But I was able to consider, even at such a young age, the great changes he would have gone through. These included his experience of other Bougainvillean cultures and Western colonisation.

In the 1950s there were certain influential leaders in the village such as old Chief Gausu, Tultul (colonially appointed village head man) Wau, Uncle Binawata and my father, endearingly nicknamed lapun (old one), who openly challenged the strongly held beliefs in sorcery, who worked for communal unity and who pushed for hygiene and education. They had travelled to other places in Papua New Guinea mixing with people from different areas and exposing the community to modern ways of living. I remember when I was a young boy, the leaders would decide who would welcome a visiting kiap or a white health officer with a cup of tea in a village house. This was recognised as a part of the modern way of living with the colonial agents of change and demonstrated that they knew how to treat a white man, a person from a different culture.

While the Torau understood the title of chief to be hereditary, from father to son, it does not necessarily go to the firstborn son. Values of leadership, understanding of oral history and social and economic achievements are vital in attaining the title of a chief. Hereditary and ascription contribute equally to the making of a chief. Importantly, the Torau social structure was organised through the clan system. In more recent times, due to exposure to education and external factors, the concept of a chief has been changing. While the chief was revered and recognised as an ultimate leader, it was the clan leaders that played the most important leadership role in their clans as against a single 'big man' ruling the whole community. I see this as a process of dilution of the powers of a ruler and devolution of decision making to clan leaders.

In terms of property succession, I sense that the traditionally accepted norm of a matrilineal group like the Torau is also being challenged. Currently, while men speak on behalf of mothers and sisters, the women still clearly retain rights over land. Ownership of rights to land and property continue to be determined through matrilineal descent. Property succession is generally from mother to daughter.

When land was required for a port facility for the mine, Torau land was acquired, under great duress and with threats of compulsory acquisition. Negotiations, which were carried out by clan leaders under the guidance of a fiery young Torau called Raphael Bele, were tough. ${ }^{4}$ The Torau vigorously resisted and refused to give up their land.

Why was the resistance so strong? Part of the answer is self evident - my people were losing their land. When I was a student, a group of us tried to explain what land means to us [Dove, et al. 1974]. In writing that paper I was joined by 
two Nasioi-speaking student friends. The views we expressed were not figments of our imaginations, but a genuine attempt to articulate the feelings of our peoples. We feared what would happen to us without land, surrounded as we were by foreigners. For me, pride in my Torau culture and community also had to be taken into account. We have a seemingly innate determination not to be pushed around by anyone. It would not be true, however, to say that there were no internal conflicts over the issues involved. The community was deeply divided, as may have been expected. Divisions occurred within families and between clans over land and property succession. There were hard feelings about what seemed to be the usurpation of matrilineal rights by men. At such times the community would invoke the unwritten code of property succession. There were always people who strove for compromise as the better part of valour. Clan leaders took responsibility to come up with a united stand that eventually led to a compromise. Tough resistance ensured that the total land area that was initially proposed to be excised by the company was reduced radically. The compensation finally agreed upon by the company, with support from the Administration, was considerably more than had been originally offered.

It was agreed that some of the Uruava land and the whole of Dodoko land would be leased to the company rather than acquired through an outright purchase. In this way the Torau felt comfortable that they would still retain their rights to the land. And leasing was seen as avoiding any final severance of the land, upholding the perception that it still belonged to us. Uruava land was already fully cultivated. Individual family holdings were surveyed with the help of didiman (government agricultural officer) David Brown (Brown later became one of the trustees of the Uruava Trust Fund which managed the lease payments).

In the majority of cases, the titles to various village blocks were in the names of female clanswomen who were considered the rightful holders. The women were very strong in voicing the view that land rights had to be determined according to custom. Where there was no direct female line, or where the land was specifically identified with a male member of the clan, some titles were held under the names of men. But in general, rentals were paid to the senior women whose names appeared as titleholders and who were directed by custom to distribute directly to female lines.

There was one area where the ownership belonged clearly to a particular clan, but no one individual had economic properties on it and therefore direct claim on it. It was decided by the clan leaders that the rental from this land would be paid to all Torau people including those in Vito and Tarara. Even my young family was entitled to K3 per annum! Because the amounts were miniscule, it was agreed that the money be put into the village school fund. It is possible that those 
who claim to own that piece of land may one day challenge this decision. But in the context of the late 1960s and the threats of compulsory acquisition, the decision to give this money to all Toraus was very significant. First of all, it was a symbolic gesture of unity. Secondly, it was a gesture of fairness and equity. It demonstrated the view that since the impact of the mine had affected everyone, it was appropriate that everyone share some of the benefits. Although largely symbolic, there was recognition in the arrangement that sacrifices and benefits were to be shared. So, rather than disintegrate the community, the impact of the mine made the community stronger and more coherent. ${ }^{5}$ The Torau worked at keeping the community strong. Because it was a small and homogeneous group, and because any external social and political pressure could impact on group solidarity, it was critical that social harmony and adherence to the traditions of co-existence were maintained.

Now let me summarise the Torau response to mining. The initial fierce resistance to mining might have been expected of a small community, having already integrated the impact of mission and government to a large extent on its own terms. Our people had chosen to be exposed to the outside world and, as a group, were relatively open to education. However, with our limited land threatened, and a rapidly increasing population already putting pressure on available resources, the prospect of the mine, even if none of us really understood what it would eventually become, was not all that welcome. The fierce resistance paid off when the compensation deals were improved, and no one ever forgot the physical struggle or the partial victory. Certainly the Torau as a whole came to enjoy many benefits as a result of mining activity. The water supply, employment, permanent houses, generators and transport were some of them. So was the endless supply of mattresses and furniture through a hole in the wall of the Bougainville Copper warehouse.

But even if the Torau were enjoying these benefits, tensions existed. Among them were anger about the amounts and unfair distribution of compensation, frustration over localisation and contracts awarded to non-landowner groups. The depletion of marine life was an issue of considerable concern while the presence of too many foreigners on Torau land created problems. Internally it was becoming obvious that men were usurping the role of women over rights to land. Nevertheless despite social tensions, the quintessential elements of the society held together as far as I could observe. For example, the senior women continued to play an important role in the community. They were consulted over major decisions and if an issue was critical in the cementing of social bonds, they spoke out in public and took a stand. In fact, social ethics required them to do so. It would have been an abdication of responsibility to do otherwise. 
At the same time huge changes were taking place in the social structure of the village, and they were not exclusively determined by the mine. As I have indicated already, forces for change were not new to us. The Christian churches, the colonial Administrations, education, modern agriculture, new forms of communication and urban developments were only a few among a host of such factors. In the 1960s, a variety of forces — quite apart from those introduced by the mine contributed to the changing socio-political landscape, and not only in Rorovana but in other parts of Bougainville as well. New religions appeared. There was intermarriage with people from other areas. Differences in wealth and opportunities for education and employment marked some of the visible changes. Education and commerce were powerful influences more generally, as was the exposure of Bougainville to a global world and to broader Papua New Guinea issues. Meanwhile there were the changes at a micro level. Differences between families emerged because of primary and derivative rights to land and property. Community based local government was introduced and the ebb and flow of inter- and intravillage politics continued to leave their marks.

Not only was it the case that the process of change did not lead to social disintegration, but one needs to add that change is normal in an emerging and effervescent society. While mining's impact was certainly significant, it was only one of the great currents of change sweeping Bougainville at the time. Specifying mining exclusively as the force behind 'social disintegration' overlooks the impact of other agents of change.

This is not to say that mining did not cause disruption to our community. Together with other forces, it certainly created disorder and discontent. But disintegration — breaking apart, crumbling, falling to pieces? No. The initial response to mining and the longer term living with the mine both demonstrated a community capable of absorbing huge changes and of adapting to the consequences. The Torau have certainly been eclectic in their attitudes and adaptation to changes. This is reflected in the stories of our origin and migration. Through trade and intermarriage the Torau gave, as well as borrowed from, other cultures and new forms of technology and social relationships. To explain the impact of mining, and indeed of any major development, as causing social disintegration is too simplistic. Even using the Panguna case to predict what will happen in Ok Tedi, Porgera, Lihir or Kutubu has its limits, because that analysis is based solely on one ethnic unit, the Nasioi speakers of Panguna. What about the other four language groups whose land was needed for the mine, of which the Torau are just one? ${ }^{6}$ I would also hazard a guess that the silent majority of the Nasioi-speaking people, while generally sympathetic to the concept of the so called 'economic justice' were less inclined to be involved. After all the impetus for social disruption was engineered 
and articulated by a small group who 'formed the nucleus of the new PLA (Panguna Landowners' Association)' [Filer 1992: 132]. One of the causes of dissatisfaction with the old PLA was a major decision to stop the gravy train. In the mid-1980s, with the advice of the Investment Advisory Committee (a group of private sector professionals), the Road Mining Tailing Lease Trust Fund adopted rigorous governance procedures, which made loans, borrowings and donations difficult to obtain. Before the new PLA was created, certain people who later became executives of the new PLA were refused loans because of past loan delinquency. Their so-called business activities and political grandstanding were subjected to closer scrutiny and evaluation by the Trust. This part of the story has rarely been told. I would suggest that the new PLA might not have been created solely because of discontent with mining as such, but because rules on access to the Road Mining Tailings Lease Trust Fund were being more rigorously applied. Criteria for donations were established and business propositions were dealt with on a commercial basis.

A final point. Our people, like most communities, are pragmatic. We fight a potential threat or a known enemy and we conquer, somehow. It may be a very visible victory, or a subtle one, but we are conscious of the need to survive. External threats usually serve to bind us rather than separate us, and internal divisions are managed with an eye on the survival of the community. If this was shown in our response to mining, it was even more evident in the reaction to the Bougainville crisis.

How did the Torau respond to the Bougainville crisis? From the early 1980s onward, a number of Toraus worked in the mine, with contractors or in the towns, and were deeply entrenched in the modern economy. Some were starting to run their own businesses such as fishing, transport or small stores in the village. Most of them were relatively satisfied with their occupations. Many village men were fishermen and supplied the town population and other village groups with fish and made good money in the process. In the 1980s, potential income from fishing was estimated at K3,500 per annum, compared to the average income of K760 per household per annum [NSPG 1982]. In the 1980s village cash crops were being revived and production began to slowly pick up. For the Torau this was a stable period with the local economy maturing to provide better outlets for village produce. Of course, as we know now, it was not to last.

The initial Torau reaction when the conflict began in late 1988 was one of bewilderment. Most of us thought the disruption was just temporary and that it would go away. The crisis was seen as a local issue among the Panguna landowners that had nothing to do with us. We saw it as a problem arising purely from the way the benefits were distributed among them. We, and many others too, thought 
that although the Panguna landowners were experiencing the negative aspects of mining, they were being well compensated and their leaders needed to sit down with Bougainville Copper to address the problems. But it was also clear that the real problem lay with the clans and the cultural mechanisms of the distribution of compensation money. It seemed that the Panguna families were deeply polarised over compensation issues [Okole 1990; Quodling 1991] and needed an external mediator to help facilitate dialogue. Some people suggested that a Catholic priest be asked to intervene and help the families talk to one another. Normally, with the Torau, when there is a family feud, a leader from another clan is asked to mediate by sitting quietly with influential family members and discussing issues to avoid social disintegration. This was not happening with the Panguna families. As far as I can ascertain, the Torau did not connect the Panguna landowners crisis with secession or independence for Bougainville.

The Torau did not support the sabotage of company properties that began in November 1988, although they sympathised with the concerns of the Panguna families. The clan leaders strongly advised against Toraus joining the so-called rebellion. They felt this was nothing to do with the Torau. Some of the young people heard that mineral royalties would be paid to those who signed up to support the rebellion but, as a group, they decided against it. As I attended some of the village meetings where there was discussion of what we should do, I could feel a real sense of fear among the people that something big, serious and overpowering was going to happen and the people did not want to be part of it.

The Torau community closed ranks to protect itself. The rebel forces killed and wounded several innocent Torau in Uruava and one near Rorovana 2 in 1990. With this experience, as well as the departure of the Papua New Guinea Defence Force (PNGDF), the Torau protective shutters came down. Things were going to be difficult and more dangerous. By mid-1991, there was a sense of loss and despair and because they did not support the rebellion, the Torau feared that they would be singled out as a group. They were also accused of cooperating with the government of Papua New Guinea and the military. At this stage, the Torau were desperately trying to avoid being caught in the crossfire between the military and rebel forces. Rorovana villages had a big population of women and children and the leaders were obviously concerned for their safety.

At the end of 1992, what had been most feared actually happened. Rorovana village was invaded by groups supporting the rebels. Some people managed to escape and paddled many hours to safety at Wakunai. Those who remained were forced to leave their homes and move to Arawa town. Later they were taken to the jungles of Kongara. Although the people of Marai and the surrounding areas were kind and looked after them, the Torau feared for their lives as the area was 
constantly surveyed by Papua New Guinea military scouts. They feared that fighting could break out and women and children would be killed.

While in that area, the Torau became something of a problem for the rebels. The hostages quickly began to learn the Nasioi language and some became fluent. Also better able now to understand what was going on among the local population, they became friendly with the local community and established clan links. Torau knowledge of the Nasioi language became an intelligence risk for the rebels who were concerned that intelligence would get back to the Papua New Guinea military, so they began to make arrangements to send the Torau back to their villages. There was a slow movement back to Rorovana villages in the later part of 1994. This coincided with a more general opening up of freedom of movement in central Bougainville about the time of the peace conference held in Arawa in October 1994. But prior to this period the Torau had seen Papua New Guinea military reconnaissance in the area where they were staying in the Kongara (in the mountains south of Panguna). In fact members of the Torau Resistance Forces armed groups that opposed the rebel Bougainville Revolutionary Army (BRA) drawn mainly from amongst those who had escaped to Wakunai in 1992 had led the Papua New Guinea military in surveillance into that area. They had met some of the Torau living in Kongara and had promised to come and rescue them. It would seem that some Nasioi, although I think not the local BRA, may have seen the secret meetings or strongly suspected the contacts that our people in Kongara were having with the Resistance Forces. This added pressure led to their release. Even as they were leaving they were being hustled. The Torau perception was that BRA regarded them as a security risk.

With the horrific experience of the killings of innocent villagers and the continued threats meted out to them, the Torau decided to protect themselves. They joined forces with the Resistance. This was a turning point in their lives. They looked upon young and able men to lead them out of their misery. I was told that the young people who took part in the Resistance continued to consult with the traditional leaders who were seen as the symbols of unity.

During the almost three years of absence from their ancestral place, the Torau experienced a great deal of psychological stress which affected their physical and emotional health. Strange to say, most of the old women and men who were severely affected by this phenomenon did not die until they came home in 1994. The people often described this as old women and men 'hanging on to die at the place of birth of the ancestors'.

Even now the people talk about the stress of having been forcibly removed from their villages and coerced to live on other people's land. Besides being homesick, living on other people's land was shameful and humiliating. Toraus felt that 
their culture and identity was threatened by being removed from their villages the anchor of custom and the beacon of their identity. Their sense of place was a link to their past and held the history of their first settlement. They considered that this psychological stress was harming the wellbeing of their group most.

In June 1999 I visited my village for two weeks, taking my two youngest daughters with me. While Naomi, who was about nine years old when we left Bougainville, could remember most things about the village, Anita who was five at the time could hardly remember anything. I took them because they wanted to see all their relatives and their place of birth. They wanted to renew their connection with the village and Anita wanted to work on her family tree. At Rorovana I found that the people were in self-protection mode. I could feel a very strong community bond that had not been as emphatic in the 1980s. My people related to me their fears and sufferings. They talked of the loss of modern amenities and health facilities, the absence of banks and post offices, the decline in retailing outlets. They also talked of their aspirations to have their children educated and all those things that normal parents want for their children. And they laughed at some of the funny things that had happened to them.

What I noticed most, however, was the return to tradition and a deep spirituality. I felt that this was probably occurring as part of the people's efforts to shield themselves, directing their attention to other things and perhaps appealing to superior powers, be they the Christian God or Ancestral Spirits. Traditional marriages were coming back as a way of reinforcing old and safe ways, affirming long-term relationships and trust in the community that one knows best. After all, experience had shown that outsiders could not really be trusted. Customary leadership was being reaffirmed and supported because it had been proven to work during the crisis. I was sad that I had not participated in this phase of their journey through life. It was an experience that will be treasured and passed on to generations.

In conclusion, I believe that in spite of the immense changes that happened in the lives of our people during the last three or four generations, since the early 20th century, our communities have continued to be relatively coherent and have tended to consolidate themselves whenever there has been a perceived external threat to their survival. The processes that have either changed our lives or to which we have been able to adapt ourselves started long before the mine came to Panguna. I will emphasise yet again how many foreign influences we have had to deal with in the brief 150 to 200 years since we migrated to our present village sites. Like others on the eastern coast of Bougainville, we came in intimate contact with Christian missionaries in the early 1900s and with German colonial officials soon after. Australian military administrators replaced the Germans in 1914 during 
World War I before the Australian civilian Administration took over. Then there were also Chinese traders, merchants and planters and the overwhelming assault on our land by the Japanese soldiers and Allied forces during World War II. All of these settlers, visitors and intruders had their own peculiarities. Our contacts with things Western have been stronger than many observers may have assumed.

As I have tried to show, mining did not bring about disintegration for the Rorovana community. As one of the five language or ethnic groups affected by the mine, we Torau adapted to the changing environment and tried to make the best out of the situation. I would suggest that a community, which once 'negotiated' its way through a new environment during its first settlement in Bougainville, and subsequently coped with the impact of the missionaries and successive colonial regimes, does not so easily disintegrate under the impact of a mining project. On the contrary, it can be argued that those communities that have endured disruptions brought about by external or internal, social and economic pressures, are inherently strong, quite coherent, very resilient and not prone to disintegration. The long processes of adaptation have given the Torau social tools to manage such immense changes.

So too, I think, the Bougainville crisis has made our people re-examine their loyalties to one another. It has confirmed in us the belief that community solidarity is a greater ideal than individualism. It has taught us that communal needs and aspirations are best addressed by the community acting as a group. When I was home in June 1999 I noted the willingness of people to draw on traditions. This had once again become a basis for social relations, something clearly more evident than it had been in the 1980s. Traditional modes of production were again being cultivated in the absence of modern forms of commerce and social service delivery. What does all this mean? I believe that the organism of society, and the local community as a subset, are dynamic. They adapt and balance themselves over and again. Society itself is not a passive reality. It is an ever living, dynamic process forming itself into human civilisation. 


\section{Endnotes}

1. I was later appointed a director of BCL from 1990 until I resigned in 1993 when I began working for another mining company.

2. The Uruava language and culture have now disappeared as a result of intermarriage with a larger Nasioi group of people. My grandfather, Naruke, after whom my first daughter was named, was the last Uruava language speaker I can remember as a young boy. As well as speaking Torau and Uruava languages, he was fluent in the Numanuma and Nasioi languages and understood Eivo and Nagovisi.

3. On 15 December 1929, Emmet McHardy wrote to his parents about Rorovana, saying 'I stayed a couple of days there, and was more or less at home for many of the people were baptised, and there is a little chapel there in charge of a native catechist'.

4. Bele was later elected to become a Bougainvillean representative in the colonial legislature (the House of Assembly, from 1972 to 1975, and the Papua New Guinea Parliament until 1992. Apart from the majority of Torau supporting him, most of Raphael Bele's support came from South Nasioi and the Rotokas people of Wakunai. As a Torau, he came from a minority group but got most of his support from outside the Torau enclave. That says something about the popularity of this man.

5. It could also be argued that the mine, furthermore, did not disintegrate the people of the Lower Tailings area, the Nagovisi. In fact, in 1988 they agreed to pull out of the Road Mine Tailings Trust Fund because they felt that the Panguna people were unduly interfering in the running of the Trust. When the new Panguna Landowners Association took over they feared they were now going to lose all control and demanded to break away and form their own association.

6. The others were the Nasioi of Panguna, the Arawa people, the descendents of intermarriage between Poraka and Nasioi speakers, the Nagovisi of the lower tailings area and the Banoni people whose coastal village was near the outlet of the Jaba River on the West Coast of Bougainville. 


\title{
MOVEMENTS TOWARDS \\ SECESSION 1964-76
}

\author{
by James Griffin
}

\begin{abstract}
A though there were isolated calls for secession in Bougainville before 1964, it $\mathrm{A}_{\text {is an apt date to begin a discussion of relations between the colony of Papua }}$ New Guinea and Bougainville District (later Province). Following the Federal elections in Australia in December 1963, a new regime was established in the Australian Department of Territories under Charles Barnes (minister) and George Warwick Smith (secretary); the first exploratory steps were taken in what has been called 'the greatest single event in the economic history of Papua New Guinea' [Downs 1980: 340]; and the first nation-wide elections for a national legislature - the House of Assembly — on a common roll were held [Bettison et al. eds 1965]. The Barnes-Warwick Smith regime was to embrace enthusiastically the World Bank report on Papua New Guinea [IRBD 1965] advocating a selective and intensive development policy to replace the so-called 'uniform development' of the preceding minister, (Sir) Paul Hasluck (1951-63) [Hasluck 1976]. Neither Barnes nor Warwick Smith had any experience of Papua New Guinea and ardently believed that what was good for Australians would in the long run benefit Melanesians. Independence, they thought, need not come to Papua New Guinea until the 1980s or 1990s [Griffin et al. 1979: 138-42], and economic should precede political development [Parker 1971]. Therefore, when the Conzinc Riotinto of Australia Exploration ${ }^{1}$ (CRAE) prospector, Ken Phillips, visited Kieta in January 1964 and established a year later that a substantial mineral deposit existed in central Bougainville, the Australian Administration was obliged to promote its development vigorously but unimaginatively according to Australian mining principles. Meanwhile, the elections to the House of Assembly, with only one member exclusively representing Bougainville, alerted its leaders to the relative powerlessness of the district, to the reality that independence would occur in the foreseeable future, and to the fact that a destiny of integration within Papua
\end{abstract}


New Guinea had been decided for them. Obviously, if Bougainville leaders wished to dispute that destiny, moves would have to be made before the independence movement gained full momentum.

Fortunately, Ken Phillips set down a memoir of his experiences from 1964 to 1966 [Bedford and Mamak 1977: 151-60]. It is interesting both for what it says and for what it does not say. Briefly, what appears is that Phillips was not made aware of any of the following points:

- the disgruntlement of people in the Panguna-Kupei area with their own lack of returns from (small scale) gold mining that had been carried out from 1930 ;

- the depth of resentment at the lack of development in and alleged 'neglect' of the province by the Australian Administration, for a dramatic example of which see the literature on the Hahalis Welfare Society [Rimoldi 1971; Rimoldi and Rimoldi 1992];

- the poor state of race relations, worse than in most areas in the country;

- the prevalence of cargoism [Ogan 1974]; and

- the emerging sense of ethnonational identity which was both ascriptive and historically conditioned [Griffin 1973a, 1973c, 1973d; but see Denoon 2000]. What is noteworthy is that Phillips himself appears to have got on quite well with the local people and that he and the kiap in charge at Kieta, Assistant District Officer Max Denehy, were convinced that Australian rules should not be the name of the game in the land of the Nasioi and that the villagers in the explored area would have to be compensated substantially if mining was to go forward without violence. Denehy, however, was removed in 1966, after a number of obstructive incidents, not provoked by him, led to police intervention and his transfer elsewhere as a scapegoat [Bedford and Mamak 1977: 159].

Under Warwick Smith, Canberra assumed detailed day-to-day control by telephone and telex [Downs 1980: 346] where experienced, delegated authority should have been exercised. Even psychologists were sent in to analyse the putative mental ills of people who would not understand why they did not own the subsurface of their land [Downs 1980: 349]. Eventually in 1967 a martinet, Tom Ellis, was made supremo in the Department of District Administration in Port Moresby while a soul-mate, Des Ashton, was made district commissioner in Kieta. The task of persuading villagers to freely accept the presence of CRAE had been rendered virtually impossible by Barnes's visit to Kieta in early 1966. He stopped for a mere half hour in Port Moresby for briefing, flew to Kieta, took no notice of Denehy, drove straight to a meeting with the people and told them that Panguna was to be developed for the benefit of Papua New Guinea as a whole and that their benefits would be confined to multiplier effects. The Kieta councillors asked 
for the royalties to go to the landowners and 40 per cent of the profit to development in the province [House of Assembly Debates (HAD) 1 August 1966]. At Panguna the next day, Oni, a leader at Moroni village (later to be disgraced for dealing with CRAE in land which he affected to 'own'), 'asked plaintively if there was not a silver shilling somewhere' for his people. To this Barnes said no nothing - although even then he knew the mining ordinance was being changed to allow at least small occupation fees [Bedford and Mamak 1977: 158-9; Downs 1980: 342]. Yet two things can be said in extenuation. On the goldfields of Papua New Guinea, no clan had claimed before that prospectors could not help themselves to minerals if they had the requisite authority, and some of those prospectors were itinerant Papua New Guineans without any local rights [Downs 1980: 342]. Secondly, the aim of mining policy was to prevent rises in the price of land throughout Papua New Guinea and to ensure that no precedents were set which would elsewhere restrict use of land for development. Conzinc Riotinto Australia (CRA) was not allowed to deal directly in land with the Nasioi.

It was hardly to be expected that Catholic clergy, still smarting from their rejection on Buka Island in the early 1960s by the Hahalis Welfare Society [Laracy 1976; Rimoldi 1971], would not intervene as champions of their flock — some 75 per cent of the people of the province. One Australian priest was particularly articulate about this and contemporary grievances relating to forestry and road metal [Fingleton 1970], while American priests were not just incredulous about the British principle of eminent domain but condemned the moral pollution as well as the environmental destruction that industrialisation would bring [Downs 1980: 347-52]. It was, however, an Irish priest who asked Phillips 'if it was true that ... CRA was going to mine the whole of the Crown Prince Range with a hole running from Mt Bagana (central Bougainville) to Tonolei Harbour' (east of Buin on the south coast). The people, he said, were frightened the island would tip over and sink. Father Duffy, however, seems to have believed only the first part of that furphy [Bedford and Mamak, 1977: 156].

By 1967 CRA had forfeited credibility even though the advent of (Sir) Frank Espie as managing director rumoured a fluid link with SP brewery ${ }^{2}$ and (Sir) Paul Lapun in the House of Assembly had won for minesite landholders five per cent of the royalties on copper in later 1966. An Australian official's opposition to this concession had been heartfelt and prophetic:

Either the government owns the minerals in the ground or it does not - there can be no compromise. (Interjection — it owns 95 per cent of them!) It might own 95 per cent this week, but in a few months it will own less and less again. Once the principle of all the people owning the land is compromised, there 
will be trouble ... We have done everything possible to protect his [the owner's] rights, but the minerals in this country belong to all the people. They do not belong, nor should they belong to the owner of the land - to a person who has the good fortune to be sitting on top of a mineral. [HAD 14 June 1966: 154].

Paul Lapun's position was supported by Melanesian fundamentalists from other areas such as (Sir) Peter Lus:

I do not know about this new law you are trying to teach us ... How can it be that the ground underneath the surface belongs to the government? [HAD 14 June 1966: 1486].

In November 1966 Lapun's Mining New Guinea Bill No. 2, 1966, had 'provoked forty-five other members to enter a debate which occupied the better part of two days' [Downs 1980: 345; HAD 1, 11: 21-24, November 1966). Even Sir Donald Cleland, the Administrator, had indicated that he thought the royalty to be reasonable and would 'take the heat out of opposition to the mine' [Downs 1980: 345]. So, officially, did Lapun:

I say to you that they [the landholders] will be content with 5 per cent. They will be happy ... I am a Buka man ... the people ... they will be happy ... and also pleased about the major part of the royalties going to the Government to help it develop this country. This is a fact. [quoted in Downs, 1980: 345].

Lapun's bill was carried 31/21 from among 64 members of the House of Assembly. Lapun was not prophetic. Although they believed in Lapun [Ogan 1973], the Panguna people still wanted CRA to leave. Consistently they asked for the copper to be left in the ground for their children or grandchildren to exploit. They would know how because they would be educated. Copper would not rot [Griffin, 1970].

In 1967 the House of Assembly ratified an agreement with a newly incorporated Bougainville Copper Pty Ltd (BCPL), which was given an initial lease of 42 years with provision for two extensions of 21 years each [Boniwell, 1972: 98]. From 1965, when the CRAE report admitted to 'a large body of low-grade copper ore which could support mining operation', to 1967, when it was estimated that there were substantially more than 90 million tonnes of ore with 0.63 per cent copper and 0.58 pennyweight per tonne of gold, expectations were to grow by 1969 to 'at least 760,000 [later 900,00] tonnes of ore with a grade of 0.47 per cent 
copper and .4 dwt gold per ton' ['White Paper', Papua New Guinea House of Assembly, Parliamentary Papers, June 1969]. With preliminary expenditure of A $\$ 40$ million and ultimately some $A \$ 400$ million investment (much of it from foreign borrowings), BCPL needed guarantees of its authority and rights. It was assured by the Australian Administration that Papua New Guinea's independence would not come for at least 15 years. It is not clear what CRA's attitude would have been if it could have anticipated Gough Whitlam's ${ }^{3}$ more precipitate thrust for independence by 1975. Bougainville Copper Ltd, or BCL (as BCPL became in 1973), was to be exempted from company tax until 1981-82 and other concessions were to be made until the capital investment was recovered. Subsequently 50 per cent of its taxable income, eventually rising to a 66 per cent ceiling, was to be paid in tax [Griffin 1970: 9-10]. Yet, at the time, the agreement appeared favourable to Papua New Guinea. The government was to get a 20 per cent equity, there was scope for national shareholdings (9,000 residents took out one million shares) and the Panguna Development Foundation was to be set up [Togolo, and Vernon, both this volume] with two million shares held in trust for later distribution to Papua New Guinea residents. Provision was made for training programs, entrepreneurial promotion, scholarships and so on. Nevertheless, there had not been one Papua New Guinean signatory to the agreement, leaving its legitimacy open to postcolonial challenge. When, in BCL's first full year of operation (1973-74), profits came to a stupendous and abnormal A $\$ 158$ million, the Agreement came to look like a 'rip-off'. However, company officials maintained they did not anticipate the upswing in copper and other metal prices. The deregulation of gold in the world market in 1972 from a fixed US\$35 an ounce to an immediate average US\$89 an ounce (and then later to over US\$800) proved a bonanza. CRA has been adamant that in 1967 it would not have signed an agreement with terms such as the revised one of 1974 .

The most dramatic incidents before 1973 occurred in 1969 when the Administration resumed the expatriate-owned Arawa plantation and Arawa village land for the mining town, as well as land belonging to Rorovana village for the Loloho port site. Having granted BCPL a special lease of about 10,000 acres near Panguna, having moved resident villagers to sites nearby and having satisfied itself that some $\mathrm{A} \$ 20,000$ in occupation fees and a prospective $A \$ 80,000$ per annum in royalties for 1,000 people whose land was required was just, the Administration assumed a show of force would overcome further opposition, just as it had the obstructive behaviour of minesite owners and their neighbours. After all, this was not only the received wisdom of two generations of kiaps (government field officers) but of humane anthropologists employed by the company to advise it on village relations [Griffin et al 1979: 151, 175]. In early August 1969 passive 
resistance to the riot squad by the Rorovana resulted in sensational media publicity for their cause. It was raised in the Australian Parliament by Labor members while Paul Lapun and ex-seminarian, student and secession activist Leo Hannett (b.1942), assisted by a few academics, unionists and religious leaders, toured eastern Australia. The tactics:

were extraordinarily effective. CRA was faced with costly delays; repression was going to mean ineradicable hostility. Paul Lapun talked about appealing to the United Nations. There were fears of guerilla warfare. The world press looked askance. And there was a Federal election coming up in Australia [Griffin 1970: 11].

The Australian Prime Minister, John Gorton, now overrode Barnes and Warwick Smith and allowed CRA/BCPL to negotiate directly with villagers. The result was substantially improved compensation for the Rorovana people for the resumption of their land as a port. This was later applied also to the Arawas on part of whose land the town was being built.

When Michael Somare's National Coalition gained power in Papua New Guinea in April 1972 and Lapun became Minister for Mines and Energy, Donatus Mola (Member of the House of Assembly, North Bougainville) Minister for Business Development, and Father John Momis Deputy Speaker, the stage was set for a new mining policy and a radical renegotiation of the agreement. Although Frank Espie found this unthinkable [personal communication 1973], the bonanza profit of 1973-74 settled it. The renegotiation was accomplished in 1974 [Downs 1980: 540-5] and was accepted by Bougainville leaders. Because of the inclusion of a seven-year review clause in the revised agreement and the procedures set up by Bougainville Copper for compensation, it seemed to most observers that the mine would eventually be acceptable to Bougainvilleans and that mechanisms now were in place for resolving future problems.

The major question then became what degree of autonomy should be granted to Bougainville and, by extension, to the other provinces of Papua New Guinea. In Port Moresby it seemed inconceivable that Bougainville should be given unique status, and that this curtailed the scope of negotiations. Sentiment for secession had been expressed in the 1950s [Griffin 1972: 264] and was, one might say, 'officially' articulated on 8 September 1968, when 25 Bougainvilleans, led by Lapun and Hannett in Port Moresby, initiated the Mungkas Society [Griffin 1973b] and requested a referendum on their province's future [Hannett 1969]. The problem over land in 1969 precipitated a political society, Napidakoe Navitu [Griffin 1982], with Lapun as patron. It openly advocated secession 
although Lapun at the time was deputy leader of the nationalist Pangu Pati. For various reasons Napidakoe Navitu did not succeed in branching out much beyond central Bougainville, and the attempt by its expatriate secretary, Barry Middlemiss [Griffin 1972: 272-4] to stage an informal referendum in 1969 proved a fiasco. A period of relative calm followed, with Lapun being finally converted to integration with Papua New Guinea. The appointment of Momis as deputy chairman of the Constitutional Planning Committee suggested that a formula could be found to satisfy Bougainvilleans, although the University of Papua New Guinea studentsponsored Bougainville Political Awareness seminar in Kieta in mid-December 1973 made it clear that secession was very much alive even among those who appeared well-adjusted to national institutions [Griffin 1973b]. As it turned out, the killing of two Bougainville civil servants in a payback at Goroka at Christmas rallied the whole province behind an ethnonational banner. By the end of 1973, under pressure from Hannett's Bougainville Special Political Committee [Mamak and Bedford 1974] and the Bougainville Combined Councils Conference [Griffin 1977], Somare was obliged to grant Interim District (later Provincial) Government to Bougainville. However, he had great difficulty in persuading Cabinet to agree to such a level of decentralisation. A condition was that it would be offered to all provinces [Somare 1975: 119]. One of the demands was for all mining royalties, except those going to landowners, to be paid to the provincial government without any reduction in normal subventions from Port Moresby.

Unfortunately, the National Government's failure and/or inability to deliver on a decentralising constitution, a provincial election, the royalties or any other conspicuous gesture of faith in decentralisation continually aggravated suspicion in Kieta [Ballard 1981: 110-115]. A tradition that only confrontation with Port Moresby would achieve results had already been created. As Daniel Tsibin from Buin had said in 1966, '.. is it not a pity [for the government in Port Moresby] to be forced to build roads as a result of [the Hahalis] rebellion' [Tsibin 1966: 33]. Towards the end of 1974, the Bougainville Interim Provincial Government (BIPG) refused 'further negotiations and thereafter threatened to divert the Jaba River, which serves the copper mine, and to secede if its demands were not met' [Ballard 1981: 114]. This crisis was damped down when an agreement was signed at Arawa on 18 September:

transferring royalties unconditionally to Bougainville from July 1975, adding $\$ 401,000$ to the Bougainville works plan and providing for additional funds for BIPG staff and further discussions on tertiary educational institutions for Bougainville [Ballard 1981: 114]. 
However, the provincial works program for 1975-76 was still to be negotiated, and for this, and other issues, the Bougainville Interim Provincial Government (BIPG) had planned enthusiastically and effectively, at an estimated cost of A $\$ 5.3$ millon. The Department of Finance calculated that the province could spend only $\$ 1.37$ million [Ballard 1981: 117] — or, at least that is what it decided to offer. On 29 April a Port Moresby team came to Arawa and shocked the BIPG officials not only by the stringency of its offer but also by its dismissive attitude to the BIPG's careful planning and its seeming lack of commitment to operational decentralisation. No offer was made on the basis that the BIPG requests could be seen as a rolling program nor was this proposed by BIPG officials. An impasse had been reached. On 30 May, an almost unanimous vote of the BIPG assembly, with the support of allegedly 'some 200 elected traditional leaders', resolved that Bougainville should secede and declared its decision to be 'non-negotiable' [Griffin et al 1979: 214-15]. The BIPG asked for A \$150 million to set up its own government, in return for which there would be a slow phasing out of Papua New Guinea's 20 per cent equity in Bougainville Copper. Hannett, then provincial planner in the forefront of these decisions, declared the secession movement to be non-violent. Ironically, he had, in an interview publicised in the Australian Financial Review of 30 April, denounced secession as 'dishonest' and as a word put into the mouths of Bougainvilleans by outsiders when they were seeking only an appropriate degree of decentralisation. In July, (Sir) Alexis Sarei, chairman of the BIPG, estimated that secession was supported by 86 per cent of the people in the province [Griffin et al 1979: 216]. In August, Momis and the Hahalis leader, John Teosin, flew to the United Nations [Momis, this volume] expecting that some consideration would be given to their request for self-determination, only to find that the United Nation's concept allowed only for decolonisation within the imperially-determined boundaries, not for choice of nationhood by groups within such boundaries [Griffin et al. 1979: 214-61]. The Australian ambassador has recorded how Momis and Teosin were bewildered by the lack of concern of Afro-Asian representatives [personal commmunication Ambassador R. Harry to J. Griffin 1979].

On 1 September 1975, the now new Bougainville flag was raised at Arawa. Somare refused to use violence against secessionist leaders and concentrated his police on the maintenance of law and order. Although in early 1976 there were a few acts of riot, the issue was resolved by talks that began in February [Momis, this volume] and, to the credit of both sides, by August agreed on provincial government for Bougainville. Again, as with the 1974 renegotiation, there seemed enough flexibility in the system to deal with future problems, and those who signed the agreement for provincial government must be said to have had legiti- 
macy with their own people. As the central government guaranteed adequate resourcing, there were grounds for confidence that a 'building-block' Papua New Guinean nationalism was now in progress [Griffin and Togolo 1997]. Only a rare dissenter, unimpressed by the 'nation-building' political science literature of the 1960s [see Connor 1972, 1973] felt that ethnonational sentiments did not necessarily have a price [Griffin 1976] and would need to be carefully monitored and, if possible, deftly manipulated. This foresight demanded that the National Government have some conspicuous presence in the province. Future hindsight would not then complain that, in spite of, or because of, the complacency engendered by the two basic documents of 1974 and 1976, the National Government in Port Moresby had proved to be as remote from Arawa in the 14th year of independence as it had been from Kieta under the Pax Australiana.

\section{Endnotes}

1. The subsidiary company which did the actual exploration as distinct from mining.

2. 'SP' (South Pacific), is the name of the Papua New Guinea brewery. It was a current joke to hear 'Espie', the name, as 'SP' the brewery, and some locals thought there was a connection.

3. Gough Whitlam was Australian Federal Labor Party Leader (1967-77) and Prime Minister (1972-75). 


\title{
SHAPING LEADERSHIP \\ THROUGH BOUGAINVILLE \\ INDIGENOUS VALUES AND \\ CATHOLIC SEMINARY TRAINING \\ - A PERSONAL JOURNEY
}

\author{
John Lawrence Momis
}

\section{AN UNUSUAL FAMILY BACKGROUND}

For a Bougainville leader I had an unusual birth and upbringing. I was born in 1942, far away from my true home in Buin, in the small coastal town of Salamaua, the preWorld War II district headquarters of Morobe District. My father (Joesph Kakata) was from Morou Village in Buin, and my mother (Helen Shoon Wah) was of mixed Chinese and New Ireland descent. At the time my father was probably the first Bougainvillean man to marry a woman of mixed Chinese and 'native' parentage.

I was later told that our family was ostracised by many of my mother's relatives (from the Chinese side of the family) because it was unheard of for a 'native' to marry a mixed race woman. I understand that my family had a hard and lonely life during the war, far from home, without the support of close relatives and friends. We were constantly on the run. Later in life I remember my father saying that you had to be a real man to be married with children in such unfriendly and insecure circumstances.

When we heard that the Japanese were going to attack Salamaua, my father took the family on foot from the coast and up to Wau, in the mountains, a journey of about three days. We spent most of the rest of the war in and around Wau, hiding from the Japanese, or from other enemies, some of whom were trying to get hold of my mother. 
One evening some people came with a white man to our house. They came with some liquor to drink with my father, intending to get him intoxicated so that they could take my mother. My father was too smart for them. He indicated to the unwelcome strangers that before unlocking the door he was getting my mother to prepare the glasses for a drinking party. In fact, at the same time he quietly got my mother to take my brother and me out the window where she tiptoed quickly in the stillness of the night to our hideout. It had been built by my father on the side of the mountain, and was where we would go during Japanese air raids. With the visitors still waiting at the door, apparently believing that he was really going to let them in, my father also jumped through the window and followed us to our hideout. When they finally realised that we had gone, they sprayed our house with bullets and called my father all kinds of names.

At the end of the war, late in 1945 or early in 1946, our family returned to Bougainville by an army boat, our first port of call being Torokina, on the west coast. It was the Australian New Guinea Administrative Unit (ANGAU) headquarters, where Bougainvillean leaders were being called to be briefed about the reconstruction effort that was to be undertaken by all sectors of the community.

It was in Torokina that my parents separated. I remained with my father, who took me back to Morou, in Buin. My mother took my brother Jim with her back to New Ireland where her brothers and sisters were. I did not see my mother and brother again for almost 30 years, until after I was elected to the House of Assembly (the colonial legislature) in 1972. In the meantime, I had also finished my primary, secondary and tertiary education and been ordained a Catholic priest.

\section{My Father}

My father was a mumira - a hereditary chief in Buin. Indeed, he was a paramount chief, descended from an important chiefly clan. His cousin, Papala, was what I would describe as a freedom fighter, one who gave his life so that his people would be set free. This occurred in the period of German colonial authority, after he had ordered his soldiers to kill the paramount luluai, policemen and catechist in the famous Morou massacre. My people's oral traditions are clear that he ordered them killed because he saw them as agents of the foreign powers seeking to impose their authority with its corruptive influences. Papala's own father, Kungkei, had been jailed by the Germans because he declared war on another clan. After serving a jail term in Kieta, he was killed by Kitu, his brother-in-law, a chief in another clan. The Morou people retaliated and killed Kitu who had been on a recruitment mission to gather village people to work for the Germans as plantation workers or policemen. 
On the day he was executed by a firing squad ordered by the Germans, Papala was baptised. Just before he died a Catholic priest asked him if he had anything to say to which he replied, 'Take my life and let my people go'. It was said that the priest later spoke highly of Papala's courage. The people of Buin who know the story of Papala say that the role that I have played in Bougainville's fight for self-determination is the continuation of what Papala started many years ago.

My father went to Turiboiru Catholic Mission School where he learned to read and write in both the Telei language of Buin and in Tok Pisin. He then trained as a catechist at Burunotui, on Buka Island, where he was taught by Father Thomas Wade who later became the first bishop of Bougainville. After graduating he worked for two years as a catechist at Muguai Mission Station, near Buin, and in the surrounding villages. Then, as a young man, he left for Rabaul where he worked as a mangki masta (personal servant) for an Australian police officer. Being a self-confident and capable young man, he was able to pick up much about the ways of the white masta, including a basic knowledge of law, and of the rights of the 'natives', knowledge that put him in good stead when negotiating difficult situations later in his life.

On his return to Buin in the 1940 s, my father resumed his hereditary role as a mumira. When the time came for me, too, to be given chiefly power by my father, a very big feast was held to which relatives and other chiefs were invited. My father and I were dressed appropriately in traditional chiefly regalia and were carried, accompanied by chanting and singing, standing on two live pigs tied to long poles, to a decorated platform perched on a high single post. We scaled the long ladder to the high platform from which my father addressed the big crowd below, basically installing me and promulgating my authority, as a paramount chief. Great celebrations and feasting followed the ritual, costing my father and me about K30,000 for the pigs, chicken, fish and vegetables distributed on that day.

My father died in 1976 after a long illness. It was during the time when I was terribly busy dealing with the political negotiations with the Papua New Guinea government following Bougainville's attempted secession of September 1975. I nevertheless made sure I visited my father on a regular basis, spending time at his bedside. The night before he died, he called me and my sisters and my stepmother together and told us that after suffering much, and nearing the end of his life in this world, he felt at peace with his God, with us, and with himself. His only regret was that he would not see his other son, Jim, before he died. He looked at me and said to me, 'Son have courage and continue to serve our people and look after your mother and your sisters'. These were his parting words to me before he slept that night, and he died at 5.00 the next morning. Although he had been a strict disciplinarian, I felt that I had lost my best friend and mentor. A huge crowd attended his funeral. One of the mourners was Rabbie Namaliu, later to be prime minister of 
Papua New Guinea, but at that time the chief of staff of Chief Somare, the then prime minister, who said to me after the funeral, 'Your father must have been a man of courage and determination for even in death you could see that in his face'.

\section{Growing up in Buin}

On returning to Morou my father made sure that I met our relatives in the village and got to know them. He built a permanent-material house, using mainly war-time timber and galvanised iron. It was the only house of its kind in the village at that time, the rest being built from 'bush material', with thatched sago palm roofing.

In those days there were no 'red skins' (people from other parts of Papua New Guinea, whose skin colour is in general lighter than that of the average Bougainvillean) in the village, and I was conscious of my skin colour, which was a little lighter than that of the other children. Whenever my father was away from the village, he would leave me in the care of my wonderful aunt. She taught me the basic village chores, like going with her to the gardens to get food, feeding the pigs, fishing in the river, collecting edible greens and fetching drinking water from specially designated streams, and not from the other creeks and rivers chosen specifically for washing and swimming. My uncle would take me and the other boys hunting for wild pigs and possums and taught us to make traps (for wild pigs and river fish). Our daily food consisted of kaukau (sweet potato), taro, cooking bananas, and greens, and sometimes some protein (such as fish or pork). In those days store goods such as rice, meat, sugar, tea, coffee and milk were not available.

As none of the other village children spoke Tok Pisin I soon learnt to speak Telei, and began to be acculturated into the Buin society and custom. My father made sure that I was aware of the importance of the different rituals regarding initiation, marriage, death and celebrations of life.

In 1948 my father got a job as a dokta boi (medical assistant) at the Kangu Hospital. Kangu was a small centre on the south coast of Bougainville, within sight of the nearest of the Shortland Islands (part of Solomon Islands, and where I have many relatives). Kangu was then the sub-district headquarters of Buin, South Bougainville. Living as a 'native' child at Kangu, I was part of a small group that had the 'privilege' of observing how the colonial Administration officials carried out their official responsibilities. We noticed that they were neat and tidy and punctual, and that they socialised mostly among themselves, and not with the 'natives'. Yet we also saw them as role models, their behaviour encouraging us to go to school, and to work and to study hard, so that we could one day be like them. Every fortnight a Catholic priest came to say Mass, and to give religious instructions to the pupils at the school. We noticed that the priests behaved differently from the other white people, seeming to be more sensitive, and closer, to the 'native' people. 


\section{Early Education}

In 1951 I began my primary education at Kangu Government Agency School, and stayed there through to grade six. It was the first government school established in Bougainville and took in students from the whole district. As young boys and teenagers we were impressed by the first batch of teachers, mainly from East New Britain, New Ireland and Bougainville. It was the first time for us to see educated Papua New Guineans speaking and teaching in English. The exception was the principal, Tom Taylor, an Australian with exceptional leadership qualities. The teachers inspired and encouraged us to work and study hard, because, as they would tell us, our people needed us. They emphasised not only academic education, but also encouraged us to value practical skills such as carpentry, cane furniture making, Buin basket weaving and agriculture.

In the interests of broadening our education the teachers organised visits by important people - kiaps (Administration field officers), medical doctors, missionaries, paramount luluai (Administration-appointed local 'chiefs') and others - who would talk to us about their experiences. Paul Mason who owned and managed Inus Plantation was always a popular visitor because he would talk to us about his coastwatching exploits during the war against the Japanese. $\mathrm{He}$ would also bring his movie camera and take pictures of us during our class activities, sports and work, and show them to us later. We also had the privilege of a visit from the Administrator of Papua and New Guinea, Sir Donald Cleland.

In preparation for important visits - such as that from the administrator we would construct specially decorated archways along the road leading to the school, and would paint the stones lining the flowerbeds with our special white paint made from crushed coral mixed with water. The school grounds and buildings would be thoroughly cleaned. The night before, our school uniform lap laps (a piece of cloth, wrapped round the waist like a sarong) would be 'ironed' - we slept on them! We would practise songs specially chosen for the big day. The whole welcoming ceremony, including the march-past, would be rehearsed over and over until we got everything right.

The annual Buin Show, a popular event for the whole of Buin, was always held on the school grounds. It included a variety of organised activities such as sports, choir competitions, agricultural and cultural displays, and other educational presentations. The parents and relatives of the school students would come to the show and leave more than satisfied, proud of what their children were learning. Our school team also participated in the local soccer competition involving various teams from round Buin, and we won many grand finals.

Our school also had its own trade store, which competed successfully with the local Chinese shops, making enough money to a buy utility truck for the 
school as well as funding other school needs. Under the management of the principal's wife, Mrs Gwen Taylor, the senior students worked in the store, learning simple bookkeeping and management skills.

Overall, the teachers devised the school program in such a way that values of self-reliance, commitment, pride and discipline were instilled into us. From their humble beginnings at Kangu many students went on to higher institutions of learning to become teachers, health workers and public servants.

It was at Kangu School that I passed a test resulting in my being selected, in September 1956, to go to Keravat (East New Britain) to join other students from the New Guinea Islands to sit for an Australian Scholarship examination. It was a daunting task being far from home, feeling a bit of a stranger, and sitting for the test with students who had already completed higher grades. But when the results came out, I was overjoyed to find out that I was one of five students from the New Guinea Islands to join students from the rest of the country selected to study in Australia.

From 1957 I attended St Brendan's College, Yeppoon, Central Queensland, a big boarding school run by the Christian Brothers, renowned for both academic and sporting achievements. Many students from Papua New Guinea still go to St Brendan's. I received a good all-around education there, and made many friends among the Australian boys. The Christian Brothers instilled discipline and built our self-confidence, consistent with the school's motto, Ne dubita dabitur (Do not doubt that it will be given).

Upon completion of my secondary education in Australia in 1962, I was offered the Walter Strong Scholarship to study law at the University of Sydney in Australia. But I turned it down in favour of studying for the Catholic priesthood at the Holy Spirit Seminary in Madang. It was not an easy decision for me to turn down the chance to make a career in the world, but I wanted to work for the Church as a priest and as a servant of the people.

\section{SEMINARY TRAINING AND CATHOLIC SOCIAL JUSTICE TEACHING}

My introduction to social justice was at the hands of my father, who would tell me to help others, especially the poor and the weak and strangers. It was, however, my six years of seminary education that equipped me with the vision to try to change the world in which we live. My knowledge of social justice issues was deepened and expanded by what we learnt there, which included philosophy, theology, canon law, ethics and morals, sociology and Catholic social teachings.

At Holy Spirit Seminary my contemporaries were future leaders like Alexis Sarei who became the first premier of the North Solomons Provincial Government, 
Leo Hannett who became its second premier, Ignatius Kilage who became the first chief ombudsman of Papua New Guinea and later governor-general of Papua New Guinea, Peter Kurongku, a Bougainvillean who became archbishop of Port Moresby, Gregory Singkai, another Bougainvillean, who became the bishop of Bougainville, and Theodore Miriung who was murdered by the Papua New Guinea Defence Force in 1996, when he was premier of Bougainville during the Bougainville crisis.

At the time I was at the seminary, Papua New Guinea was beginning to face the many questions concerning its approaching Independence. Like other future leaders we at the seminary found ourselves grappling with the challenges of growing nationalism and patriotism. Emerging leaders like Michael Somare, John Guise, Paul Lapun and their contemporaries were beginning to agitate for political independence for the Territory of Papua and New Guinea. Back in my own District of Bougainville the Catholic Church was responding to pressure from the people for more rapid development by setting up cooperatives and other socioeconomic projects, for and with the people. Although Bougainville had many expatriate-owned cocoa and coconut plantations, the colonial Administration had never actively promoted people's participation in major socio-economic activities. Almost all schools and health facilities were still run by the churches. In the process of working with the people, the missionaries also raised their awareness about their human rights and obligations with respect to the use of land and other resources, and the need to care for the environment.

Attending the seminary at a time when our people were searching for a new national identity in the face of the many challenging issues of colonialism and liberation, inevitably we chose to identify with our Papua New Guinea people as they grappled with these issues. We opted to take a plunge into the abyss of human affairs and, guided by Christian principles, tried to find feasible solutions to human problems. We could not be indifferent in the face of the challenges. We believed that we could ultimately influence and forge a new socio-economic-political order based on universal principles of justice and peace.

In 1964, when the United Nations mission came to assess how Australia was administering its Trust Territory of New Guinea, we spoke with them. We said that Australia was failing dismally to adequately prepare the Territory's Public Service for Independence. We also emphasised the inalienable right of people to self-determination, saying that Papua New Guineans should be given political independence sooner rather than later.

We had a student newspaper at the seminary, appropriately called Dialogue. It carried the views of the students on wide-ranging issues, such as the indigenisation of the Church, political independence, the preparations for mining at 
Panguna, land rights, education and a range of socio-economic issues. Some of the issues discussed were controversial and attracted both support and opposition from various people both in the Church and civil society.

We had good lecturers at Holy Spirit Seminary who were not only highly qualified in their various disciplines but also determined to enable the future priests to learn about important issues affecting the lives of the people. One was a black American priest who took us for philosophy, at the same time sharing with us his experiences as a black man living in a predominantly white society. We also learned about the great black American freedom fighter, Martin Luther King.

From our study of Catholic social teaching we became more and more convinced that the kingdom of God that Christ came to establish has its beginnings in the existential historical world and culminates in its eschatological dimension in heaven. In other words, Christ's mission encompasses humanity's temporal as well as eternal needs, and in a holistic way. While we appreciated the importance of drawing the distinction between church and state, and the fact that they are independent of each other, we nevertheless maintained that they should work together in an interdependent way. After all, human life is holistic, and both state and church are morally bound to cooperate to serve the best interests of humanity. So there should not be any dichotomy between the spiritual and material, and between the sacred and the profane. Human beings have an inalienable right to actively participate in the process of liberation and development, which includes self-determination.

During the colonial era, we lived in a highly stratified society, with indigenous people clearly at the bottom of the heap. Development policies and strategies were elitist, and consistently and systematically marginalised our people. We seminarians did not agree with what we saw. We felt that as Christian leaders we were called to make a difference, to change the structures that disempowered the people, and so to transform the world. We adopted a new vision, mission and strategy that would promote equitable distribution of power and benefits in society. We advocated 'conscientisation' - the raising of consciousness - of the people so that they could become active agents of change and development and not mere passive recipients of goods and services.

When Christ was inaugurating His mission to build God's kingdom in the world He went back to His hometown of Nazareth. There He stood in the temple in the midst of the people and announced, 'The spirit of the Lord is upon me. He has anointed me to bring the good news to the poor, to proclaim liberty to captives and new sight to the blind; to free the oppressed and the Lord's year of favour' [Luke 4: 18-19]. Discerning the signs of the times, we responded to the challenge of building the kingdom of God in our midst both by preaching the 
Good News of Jesus Christ and by promoting justice and freedom in the world. Catholic social teaching enlightened and encouraged us to be proactively involved in trying to mould a new society out of a fluid and tractable situation.

When the Son of God, the Second Person of the Blessed Trinity, opted to be one of us by being born of a woman, He sanctioned and sanctified human participation in the building of God's Kingdom in the world. In other words, humanity is formally authorised by God to be responsible for the establishment of His Kingdom in our midst. Furthermore, thanks to the pascal mystery of Christ, who died and rose again to new life, humanity has been liberated and empowered to transform the world by promoting just and equitable structures. Now we know that even God the Almighty opted for the new economy of salvation, as promulgated by Jesus Christ, the human being. By it we also, as human beings, are responsible for our own liberation, development and ultimately for our own salvation. Human participation is an inherent element in any process of development — and of government.

\section{Mining and Politics in Bougainville}

In 1968, after problems arose for me at the seminary, I spent a year teaching at St Joseph's Marist Brothers' High School at Kieta in Central Bougainville. While in that area, I heard the people's concerns about the proposed development of the Panguna mine. In a Melanesian society land is inalienable and is part and parcel of people's lives. Further, there is no separation between the surface and what is under the land - both belong to the landowners. Basically the landowners of the areas that the company wanted for mining and mining-related purposes wanted to be treated fairly, and to be given the opportunity to participate as stakeholders in the development of their resources and not be treated as mere spectators. Their concerns included: getting a fair financial deal from the mining company; the mine's possible detrimental impact on the society and the environment; the disparity in the pay scales between mining company employees and public servants and other non-mining workers; the enclave development on the part of the company, and the marginalisation of the landowners; and the development of squatter camps and other detrimental social impacts of mining and its related activities.

During that same year, a Bougainville Combined Councils' Conference was held in Kieta to discuss a proposal for a referendum on Independence. I was asked by our leaders to attend the conference and speak on the issue. Much to the disapproval of most of the colonial Administration officers in the area, I spoke about our inalienable right to self-determination and the fact that neither the kiaps nor anybody else had the right to deprive the people of this right. 
About the same time another United Nations Decolonisation Committee mission visited Kieta, and I was asked to represent the people in conveying their concern that a moratorium should be imposed on further mining exploration in Bougainville.

At the high school I tried to raise the awareness and the social consciousness of the students regarding the burning issues of the time. I encouraged them to set up a student's representative council so that they would learn to run their own affairs, and accept responsibility for their own decisions.

In 1969, after a year teaching at Rigu, Bishop Leo Lemay sent me to St Columban's Seminary in Sydney to do my final year of seminary studies. Even in Sydney I tried to keep abreast of what was happening back home, especially when the police riot squad moved in to forcibly remove the women of Rorovana to enable the mining company to take their land at Loloho. I was angry to see that the colonial government seemed to be collaborating with a multi-national corporation (Conzinc Riotinto Australia) to ignore the landowner's legitimate concerns. I resolved that one day we would succeed in getting a better deal for the landowners and the people of Bougainville.

Bernard Narakobi was a student in Sydney at the time that I was there. We took the opportunity to address the students at the University of Sydney about the way the Australian colonial Administration was using heavy-handed tactics in Bougainville to take people's land against their will. Even at St Columban's Seminary we had a forum where I spoke about the Panguna mine, explaining why the original Bougainville Copper Agreement was contrary to the Melanesian land tenure system and therefore not acceptable to the people.

At the end of 1969 I returned to Bougainville and was ordained a priest in January 1970. I was then appointed Catholic Education Secretary and held that position until I stood for election to the House of Assembly (the colonial legislature) in 1972. It was representatives of the combined leaders of Bougainville who requested my bishop to give me permission to contest the 1972 elections as their candidate. This was a surprising development, as until then I had never dreamt of becoming a politician.

\section{WORKING FOR CHANGE - USING THE POLITICAL SYSTEM}

I went to the House of Assembly with a mission to change the mining policy and to seek the introduction of a decentralised system of government for Papua New Guinea based on the principle of subsidiarity, which could give Bougainvilleans real self-determination. 
In my maiden speech in the House of Assembly I called for the formulation of a new mining policy and for the re-negotiation of the Bougainville Copper Agreement (BCA) in accordance with it. The new Somare government did develop such a new policy and later successfully renegotiated the original BCA in line with that new policy. The new BCA called for a review every seven years, which should have occurred in 1981 and 1988, but it was a requirement which the National Government basically ignored, with tragic consequences. In particular, had the government under Prime Minister Sir Julius Chan renegotiated the BCA in 1981, the bloody Bougainville crisis may have been pre-empted. The Bougainville leadership, including myself, consistently and constantly reminded the company and the government of the dangers of marginalising the landowners by ignoring their concerns.

Towards the end of 1972 Chief Minister Michael Somare appointed me as deputy chairman of the Constitutional Planning Committee (CPC) - the committee of the House of Assembly charged with responsibility for developing the detailed proposals for Papua New Guinea's independence Constitution. Because of the demands of his other duties, Chief Somare seldom participated in the CPC's activities, and I was de facto chairman. After lengthy consultations with the people the CPC made its Final Report in mid-1974, containing detailed recommendations for Papua New Guinea's Independence constitution.

I suspect that in appointing me as his deputy chairman, Chief Somare expected me merely to deputise for him, and that the CPC would be just a rubber stamp for the government's proposals. But as I saw it, I led a committee comprising elected representatives from both sides of the House and it should not be just a rubber stamp for the government. We felt that we also owed it to our constituencies to reflect our people's views. In the end the CPC developed into a committee of the legislature rather than a government committee, much to the dislike and dissatisfaction of the government.

My impression was that the main concern of the Somare government was to achieve the mere transfer of power from Canberra to Port Moresby. While we all wanted a change from Canberra to Port Moresby, the CPC was interested in more than just quantitative change - it sought qualitative change as well. What powers were going to be transferred, and into whose hands, and subject to what conditions? We wanted to grasp the opportunity presented by approaching Independence to embark on a strategy that would liberate us from structural and attitudinal impediments, and empower us to become the active agents of change and development.

The CPC conducted intensive consultation with the people in the districts (later to be called provinces). The people were given ample opportunity to submit 
their views to the CPC both verbally and in writing. We wanted a truly homegrown constitution and the CPC report contained recommendations that both reflected the people's views and were intended to suit Papua New Guinea's peculiar needs and aspirations. We did not want to merely adopt constitutional arrangements from elsewhere that would not be responsive to the felt needs and aspirations of an emerging Papua New Guinea society.

In light of the views and proposals received from the people, the CPC analysed the issues involved in developing an effective national government in a diverse country such as Papua New Guinea. We saw three sets of issues as of particular importance. One concerned the need for leadership of high quality. The second involved the need for a decentralised system of government based on the principle of subsidiarity. The third was using the Independence constitution to provide a vision for the new nation.

The CPC attached great importance to the roles of leaders. We believed that unless our new nation had visionary leaders who possessed qualities of leadership such as integrity and a commitment to human rights and freedom, we would not overcome the many problems ahead of us. It was such considerations that led us to recommend the creation of the office of ombudsman that would deal not only with the normal functions of handling public complaints about government maladministration, but would also administer an enforceable code of conduct for leaders (now called the leadership code). Reflecting the views received from the people, in the CPC's view, a leader was required not only to behave in an upright manner but also to be seen to be behaving in such a manner. To us, the leadership code was not to be interpreted as a restriction on the behaviour of the leaders but rather as something to assist them to excel in their roles.

Because Papua New Guinea was a young democracy we were conscious of the need to protect the people from unprincipled and unscrupulous leaders, but at the same time we wanted to encourage people to actively participate in and support democratically elected governments; hence we recommended that the constitution should reflect the importance of human rights and obligations.

The CPC also wanted the Independence constitution to contribute to creating a national vision of an egalitarian, intelligent, and democratic society. Reflecting the views received from the people, the kind of society we envisaged is enshrined in the 'National Goals and Directive Principles' of the Constitution. In order to avoid the exploitation of our people, as had occurred in so many other third world nations, we recommended that the 'National Goals and Directive Principles' must be adhered to in our development policies and programs, even though they would not be legally enforceable through the courts (that is, justiciable). Unfortunately, because they are not justiciable, successive governments 
have never really tried to adhere to them. Perhaps we should have been more selective and made at least some of the 'National Goals and Directive Principles' justiciable.

The CPC attached great importance to developing a constitutionally guaranteed decentralised system of government that would provide a certain measure of autonomy to governments for the provinces, so as to enable the people to effectively and meaningfully participate in the processes of government and development. A highly centralised and bureaucratised system of government, as had existed under the colonial regime, would only marginalise and alienate the people. They would become victims of dependency and therefore vulnerable to manipulation and exploitation. Application of the principle of subsidiarity would enable the people to participate fully in the process of government, creating a partnership between provincial governments and the national government, enabling them to work together to forge 'unity in diversity' within the parameters set by the constitutional sovereignty of one nation. This would be a system of government capable of accommodating the diversity inherent in Papua New Guinea society.

While the CPC's proposals on provincial government reflected the views of the people generally, they were also of particular significance to me as a Bougainvillean leader. It seemed to me that they offered the opportunity for developing a workable framework within which my people's desire for self-determination could be fostered in a way that would not threaten the unity of Papua New Guinea.

After the CPC had submitted its Final Report to the House of Assembly, and as the deadline for Independence drew nearer, the Somare government surprised a lot of people when it presented its own White Paper on constitutional development to the House of Assembly, thereby showing its disapproval of the CPC's report. This came as a slap in the face to those of us who had worked so hard to develop a truly home-grown and democratic constitution, one that would be not just a legal document but also a moral document challenging the people with a vision enshrined in the 'National Goals and Directive Principles' to build a society based on love and justice.

\section{Bougainville's Attempted Secession of 1975}

Tensions between the former CPC members and the government continued to grow as the CPC's proposals were debated in the House of Assembly late in 1974 and early in 1975. If anything the tensions intensified when debates on the final drafts of the Constitution began in April 1975 - this time in the National Constituent Assembly (the members of the House of Assembly were re-constituted as the National Constituent Assembly for the sole purpose of debating, amending and adopting the Constitution). Throughout this same period, tensions 
were also developing between the Bougainville leadership and the Somare government over Bougainville's efforts to develop its provincial government, largely in line with the CPC's detailed proposals on the provincial government system.

It was at the end of July 1975 that Chief Minister Somare moved in the National Constituent Assembly for deletion from the Draft Constitution of the whole chapter on the provincial government system. The Constituent Assembly's agreement to this motion was the straw that broke the camel's back, and I resigned from the House of Assembly. I went back to Bougainville and conferred with the leaders on the options to advance our cause. At their request, I went with a key member of what had emerged as the joint Bougainville leadership, John Teosin (leader of the Hahalis Welfare Society of Buka) to the United Nations headquarters in New York to present our case for Bougainville Independence to the United Nations Committee on Decolonisation. The response we received, however, was disappointing.

In the meantime, on 1 September 1975, the leaders of Bougainville had unilaterally declared Bougainville's Independence from Papua New Guinea, in advance of Papua New Guinea’s own political Independence.

On my return from New York I was appointed leader of the Bougainville team to plan our strategy for self-determination. The Bougainville 'leadership', comprising Alexis Sarei, Leo Hannett, Aloysius Noga, Hamao Tato, myself and others, now held a long series of strategy meetings. Many people were now determined to achieve immediate political independence for Bougainville, and some called for armed insurrection against the National Government. As leader of the Strategy Committee, I argued that as educated Christian people it would be against our principles to resort to armed conflict. Others said it was a waste of time and effort talking to a national government that had already deleted the chapter on the provincial government system from the newly adopted Constitution. Of course, the injustice of the distribution of the proceeds of the rich copper mine at Panguna also made many of the leaders frustrated and angry.

It soon became clear that there were immense practical difficulties in the way of achieving early independence, especially in the face of the lack of support from the international community. There were already the beginnings of divisions in Bougainville, and some instances of political violence. At the same time, the new Papua New Guinea National Government was, in general, exercising restraint. Michael Somare was under considerable pressure from some quarters to take a tougher stand against Bougainville by sending in the army to crush the rebellion. But friends of Bougainville like the late Gabriel Gris, the late Sir Ignatious Kilage, Bernard Narakobi and others prevailed on the Prime Minister to refrain from doing so. It was not clear, however, in which direction things would go. 
One day as I sat in my office early in 1976 I had the brainwave to pick up the phone and ring Prime Minister Michael Somare and ask him to declare a truce so that the two sides could talk and see if we could not find a way out of the impasse. He asked me if I thought my people would listen to me if I proposed a meeting with the National Government. I told him that I would try.

I then went on Radio Bougainville and made an impassioned plea to the people of Bougainville to lay down their arms and instead negotiate with the National Government. After the radio broadcast, in the evening at about 7.30, I got in a car and drove to Buin accompanied by the late John Bika (later a minister in the North Solomons Provincial Government, and in 1989 murdered by suspected Bougainville Revolutionary Army members for supporting a negotiated settlement to the then escalating conflict, which would have involved not only high autonomy for Bougainville but also distribution to landowners and the Bougainville government of a significantly increased share of mining revenue). Along the way we had meetings with the people explaining why I thought it was best that we negotiate with the National Government. We arrived in Buin at the late Aloysius Noga's house at about 4.00 a.m. After convincing him to negotiate rather than try to fight the National Government we then called a big meeting in Buin town the same day to seek the endorsement of the people. It took a lot of convincing, but eventually they agreed that we should negotiate, and mandated a team of leaders to do so on their behalf.

I must give credit to Chief Somare. When I rang him asking for a truce to give us time to negotiate he quickly grabbed the opportunity to talk and thus engaged Bougainville in a dynamic pursuit of a peaceful solution. The agreement to negotiate avoided what could have been a bloody confrontation between the people and the Papua New Guinea security forces.

\section{The Bougainville Agreement, 1976, and the Provincial Government System}

The negotiations continued for some months, and were far from easy. We eventually negotiated a good deal, and in August 1976 the Bougainville Agreement was signed. It provided for amendments to the Papua New Guinea Constitution, under which Bougainville was able to establish its own provincial government with limited autonomy but with provisions for further devolution of powers and functions to Bougainville. It also provided for transfer to the Bougainville government of the mining royalties payable by Bougainville Copper Ltd (BCL) to the National Government.

In the 1977 national general elections, I contested and won the regional seat and was then appointed the first Minister for Decentralisation. During my term as 
minister we successfully set up 19 provincial governments. Many government ministers, members of the Parliament and the senior bureaucrats had agreed to the policy of decentralisation with considerable reluctance. Unfortunately there was a great deal of mismanagement in many provinces. As more provincial governments got into trouble the more reluctant the National Government became to further devolve powers and functions to provincial governments. We should probably have stipulated stringent conditions to be met before a province qualified to be granted provincial government status, and should also have had arrangements for subsequent devolution of powers and functions to individual provincial governments according to assessment of their financial and administrative capacity and level of political responsibility. Had this been the basis for the provincial government system, Bougainville would not have suffered the detrimental consequences of the failures and the mismanagement of the other provinces.

The Bougainville Agreement should have given Bougainville what it wanted. Unfortunately, the National Government later did not really honour its undertaking of further devolution of powers and functions to Bougainville. The real issue at stake when people demand 'independence' is not so much separation but rather having effective control over their own affairs and enjoying meaningful participation in the process of government and development. However, successive national governments failed to treat Bougainville as a special case with its unique needs and this then led to future problems.

Despite constant warning that Bougainville was different from the other provinces, successive Papua New Guinea leaders failed to recognise the root cause of rebellion and secession. The warnings had dwelt on the following issues:

- the resentments over the impact of, and the unfairness of the distribution of the huge proceeds from, the Panguna mine;

- the strong sense of a Bougainville identity;

- the calls for a referendum on independence;

- the preparedness of Bougainvilleans to fight and shed blood for self-determination,

Papua New Guinea's leaders were so overwhelmed, and overly impressed, by the apparent financial and technological success of the huge Panguna mine, that they failed to recognise the validity of the concerns of the landowners and the leadership of Bougainville. Bougainvilleans were not satisfied with being mere passive recipients of goods and services but preferred to be the active agents of change and development. They advocated that their representatives participate meaningfully in the decisions that affected their wellbeing and their future.

The people of Bougainville lost confidence in the National Government both because it did not seem to be listening to them, and because of the perception 
that it was listening to and siding with the mining company. Despite the huge profits the outsiders were making from the mine, the landowners and the people of Bougainville had no sealed roads and bridges built by the National Government. In fact many of the landowners and the people whose land was near the mine were amongst the most neglected people in Bougainville. Even the North Solomons Provincial Government perhaps sinned by omission by not taking a stronger stand against the marginalising influence of BCL which was being operated as an enclave, leaving the local community disillusioned, marginalised, powerless and angry.

\section{CONCLUSION}

Had the leaders of government and industry in Papua New Guinea read the signs of the times correctly, and appreciated the importance of the principle of subsidiarity in a diverse cultural situation, the bloody Bougainville conflict could have been pre-empted by granting an adequate measure of autonomy to Bougainville and by giving more attention to the concerns of mine-lease landowners. Structures that deliver services to the people without their meaningful involvement only promote dependency, and vulnerability to manipulation and exploitation by the powerful.

No matter how intransigent the people may sometimes seem in their demands, it is important to try to understand the root causes of their grievances and their subsequent demands. Leaders need to appreciate the process of ongoing systematic marginalisation and disempowerment of people by patterns of economic development over which they have no control, and by government policies and structures. We need systems that empower the people through structural distribution of governmental power and responsibility. Even though Papua New Guinea is supposed to be an elected representative democracy, too much power is still vested in the National Government and particularly in a bureaucracy insensitive to and aloof from people at grassroots level who are in fact the owners of the resources being dealt with by government decisions. The Melanesian method of consultative and consensual forms of decision making should be used by the stakeholders in reaching agreements on important major issues. Accommodating the substance of the various interests of the stakeholders, in ways that are synergistic, offers the best practical guarantee of sustainability, endurance and mutual acceptability. 


\section{THE BOUGAINVILLE CATHOLIC CHURCH AND 'INDIGENISATION'}

by Elizabeth Ibua Momis

$\mathrm{T}$

his chapter examines localisation practice in the Catholic Church in Bougainville. In doing so, it touches on some related questions: how has the Church fulfilled its apostolic mission to plant the Word of God in the various communities who have welcomed Christ? Did the Marist missionaries, the first proselytisers to come to Bougainville as early as 1901, interpret and apply the gospel values according to the contemporary needs of the people when preaching the Word of God? How influential have these missionaries been when one considers what, in recent times, Bougainvilleans have lived through, how they have struggled, killed, wept and mourned, and yet have been able to rise above these situations, have been able to forgive and to get on with life? I do not think that anyone can easily forgive and forget after such events. It has therefore been remarkable to witness numerous, and ongoing, instances of both personal and communal acts of forgiveness and reconciliation ceremonies. There must be reasons why Bougainvilleans can do this with such goodness of heart, skill and dignity!

We need to acknowledge that each of the three main churches in Bougainville (Catholic, United and Seventh-Day Adventist) has played a vital role in contributing to the kind of people Bougainvilleans are today, and what they, too, were before the Bougainville Copper company started production in 1972. It is the Catholic Church which has had the longest presence in Bougainville, whose people are still about 75-80 per cent Catholic. It took a particularly holistic approach in its missionary work, thus influencing both religious and secular aspects of people's lives.

The early Marist missionaries were mostly from France and Germany. They arrived initially from the Shortland Islands, then part of the British Solomon Islands Protectorate. Later, in 1940, Bishop Thomas Wade requested the Sisters of 
St Joseph from Orange in California to come to Bougainville and, two years later the Marist Brothers. In conjunction with their pastoral and socio-economic activities that the sisters and brothers offered both high standards of education and good quality health services. The Marist approach to education laid a good foundation and may well have influenced highly educated Bougainvilleans to look critically at life and at the issues facing them.

In the strict meaning of 'indigenisation', the Catholic Church still has a long way to go before it becomes fully 'Bougainvilleanised'. This is not something to be gauged only by numbers of indigenous clergy and members of religious orders and of Bougainvillean lay persons participating in the Church ministries. It pertains as much to the whole life of the Church, the degree of inculturation of its liturgies, the acceptance by the people of its sacraments and of how well the local clergy have been empowered in relation to Church administration and decision making. Indigenisation means that expatriates are only supporters and consultants whenever they are invited.

Despite the overall slow pace with which the Catholic Church initially localised itself, its saturating influence in Bougainville cannot be doubted. Despite all the killings and material losses during the conflict (1988 to 1997) and their material and environmental losses in the years preceding it, Bougainvilleans have proved the strength of their internal stamina to pursue their true identity. For the majority Catholics, it was the instilling of so deep a faith and spirituality by the Marist missionaries as well as the people's acceptance of the holisitic approach of the Marist evangelists, that nourished their spirit of endurance. It is also amazing to observe how many who have attended church schools are gifted with philosophical and analytical minds. In my view, that factor too has been a significant influence on the way in which Bougainvilleans have handled the impact of the conflict.

Although the situation in many ways continues to be difficult, Bougainvilleans have, in my view, exhibited a deep desire for an authentic Bougainville type of leadership and a government of, for and by the people. The people have demonstrated a persistent ambition to foster an identity of their own. That has been manifested in both a dialogue and a constant struggle, already evident in the 1960s. One cannot help but see how the influence of Christianity, which has informed the religious convictions of the Bougainville people, has been a profound influence throughout, helping to shape people's views on their own identity. When they have been knee-deep in divisions and conflicts, Christian beliefs have still encouraged people to seek forgiveness from each other for their transgressions and to establish genuine reconciliation. I have no doubt that these beliefs prevented further massacres from taking place, during and after the 
conflict, even after loved ones had died. It is remarkable that, under such duress, both the individual and whole communities can forgive those responsible for their pain. You may argue that the capacity to forgive is natural to people. Such a view understates the difficulty of doing so. An appropriate and deep spiritual formation certainly provides support for the heroism required to not only forgive someone 'from the heart' but also to then aspire to work together in unity with known perpetrators of misery and crime. Of course there is still a long way to go before reconciliation in relation to many outstanding cases arising from the conflict can be attended to.

Examining the influence of the Church from the 1950s to the 1980s, its impact and the results are only too obvious. One only has to think of Bougainvillean leaders, present and past, like Aloysius Tamuka (Noga), Leo Hannett, Melchior Togolo, Alexis Sarei, John Momis, Theodore Miriung, Gregory Singkai and Peter Kurongku, as well as women leaders, and many more who are the products of schools run by the missionaries of Bougainville.

\section{ASPECTS OF THE CHURCH'S ROLE IN DEVELOPMENT IN BOUGAINVILLE}

After the Marists, the Methodist missionaries came a few years later, from Australia, Fiji, Samoa and the Solomon Islands. Venturing into remote areas by foot and by boat, they set up schools, health centres and clubs to teach local women and men basic literacy. Women missionaries used women's organisations such as 'women's clubs' to teach local women about basic health and hygiene and train them for modern home management in sewing, cooking and other domestic skills.

The missionaries had the vision to promote the human dignity of the Bougainvillean people, not just by preaching the Word of God, but also in various practical ways and especially through secular education. In doing so they played an important part in raising awareness about social issues.

\section{Social Services: Practical Training, Education and Health}

As part of its commitment to education and training, the Marist mission set up a number of formation and training centres from as early as 1925. A Catechist Training School at Burunotui on the west coat of Buka - and later at Tarlena and Asitavi - was introduced as the work of catechists became more vital. There young men in particular learnt not only matters pertaining to faith, but also how to read and write and to deal with numbers. In 1946 agricultural schools were built at Patupatuai and Tarlena and a boys' vocational school at Torokina. When 
World War II left devastation everywhere, Tearouki Plantation was re-opened in 1948 to help with the Vicariate's finances.

In 1948 the Marist Teaching Brothers established a school at Chabai in north-west Bougainville. The following year they started the first high school for boys at Rigu near Kieta town on the central east coast of Bougainville, naming it after St Joseph. Many present Bougainvillean leaders are products of this school. A teacher training program was later run there too, modeled on the one introduced earlier at Asitavi Girl's High School (below). In 1953, Brother Angas built an engineering workshop at Tsiroge to train young men to repair the engines of ships, generators and all manner of motor vehicles. Brother Pius came from Germany in 1955 and took over the running of this workshop. Later on many of those who were trained at Tsiroge were to find employment with Bougainville Copper. Carpentry and building skills were also taught by the Brothers of $\mathrm{St}$ Joseph who built many of the mission houses and churches throughout the Diocese of Bougainville. Many of them still stand today [Diocese of Bougainville 2001: 19-22].

Brother Patrick, another Marist, established the Christian Farmers' School at Mabiri, 30 kilometres from Rigu. This agricultural training institution not only catered for its young students but was open to anyone, no matter how old, who wanted to improve his knowledge and skill in farming. Such an endeavour led the Marists to help launch the Bougainville Christian Farmers' Association. Another farm school modeled on Mabiri was also set up by the Marists at Burunotui, north-west Buka, where members of the order had first landed on Buka.

In 1956, a time when in most parts of Bougainville public roles for women were frowned upon, Sister Catherine Matzunitsi, now known as Sister Emma, opened St Mary's High School at Asitavi, then a remote place on the east central coastal mainland, only accessible by boat or foot. It was run by both Marist Sisters and lay missionaries. As at that time it was the only single sex girls' high school on Bougainville, it was not only Catholics who were educated there. It provided both high school programs and courses in teacher training (the latter being phased out in 1968 when the staff were transferred to Kabaleo Teachers' College in East New Britain). About the same time the teacher training staff at Rigu was also sent to the corresponding male institution at Vunakanau in East New Britain. Since the Bougainville 'conflict' St Mary's has become a co-educational institution but there are plans to phase this out by 2007. The Church still runs many schools in Bougainville and elsewhere in Papua New Guinea you will find Bougainvillean women serving as school principals, especially of its many community schools. Old students from St Mary's High School at Asitavi figure prominently among them. 
Even now, after the conflict, the Catholic Church continues to play a major role in education in Bougainville. Of the approximately 140-150 community schools in Bougainville, 123 are conducted as Catholic agency schools. Of the eight high schools, three are Catholic, three run by the government and one by the Uniting Church, while the eighth — Bana High School — was recently established by the Banoni and Nagovisi people themselves. There are four Catholic vocational schools, and the Mabiri Kristen Farmer's School continues to operate.

When church schools were asked to come under the unified national system of education in the early 1970s, the Uniting and Catholic Church school authorities agreed, while Seventh-Day Adventist schools remained outside the system. This meant that the teachers in Catholic 'agency' schools would be paid by the National Education Department and that their core curriculum and administrative matters would be governed through the national education system. However, the church schools, especially the Catholic ones, have maintained their identity and holistic approach at all levels and in both formal and non-formal situations.

Church-run schools are virtually self-reliant. Apart from its obvious benefits, self-reliance had been a necessary goal because church schools receive government grants only to subsidise costs whereas government schools receive full grants. The Catholic Church still has authority over its Catholic agency schools and health centres through its own education and health boards. Before the Bougainville conflict, the boards worked well with the relevant government authorities and similar relationships are being established in the early 2000s. Through the National Catholic Education Secretariat of the National Catholic Bishops' Conference, the Catholic Church has continued the responsibility of forming and moulding the future educated population, providing both national and provincial seminars for teaching staff geared towards the needs of the times. Teachers are still being provided with the opportunities to improve their ability to impart and witness their apostolic mission.

While in other provinces, community schools still had expatriate principals in the 1970s, by that time practically all Catholic schools' head teacher positions in Bougainville had been localised. By the 1980s localisation in all schools in Bougainville had extended to the teachers in all community schools. In the vocational and high schools localisation occurred later in the 1980s. From 1983 until 1989 I was principal of St Mary's Provincial High School, Asitavi. Of the 13 teaching staff, only two were expatriates, the rest being Bougainvilleans. Likewise, in 1988, a Bougainvillean Marist Teaching Brother, Brother Julian Hakumin, was appointed principal at St Joseph's High School, Rigu. At both of these Catholic high schools the support from a couple of expatriate staff who remained to teach or work at ancillary level was of great value. Contributing to the acceptance of 
localisation by the expatriate clergy was the essential Marist missionary approach which inspired members of the order to move to a mission country, establish a Catholic community and local church and eventually leave for the next new challenge. Many of our Catholic schools remained open throughout the crisis due to their intrepid teaching staff who were imbued with this same spirit. During those turbulent times the community supported them with food and accommodation as their regular salaries ceased to be paid.

From the very beginning many of the missionaries ventured into remote areas to establish health centres in every mission station alongside schools. Two health centres, namely Tearouki and Morotana, were staffed with highly qualified doctors and nurses. Tearouki Health Centre trained many of the Catholic nurses who were to be of such value to their communities during the Bougainville crisis, serving our people with dedication and commitment, often despite acute shortages of medicine.

\section{Seminary and Training of Religious Men and Women from Bougainville}

Of course, the Church was initially dependant on expatriate personnel. Even as late as the 1940s, expatriate staff dominated. In 1945 the American, Bishop Wade, together with 16 expatriate Marist Fathers as well as 13 Sisters and two Brothers returned to Bougainville from abroad and began the great task of post-war reconstruction of missionary activity. In 1947 more Sisters and Brothers followed as well as 10 Marist Fathers to assist the Vicariate.

Despite this dependence, from an early stage the Church worked to replace the expatriate personnel. At that time localisation of clergy and religious could only be effected, so it seemed, in a strong context of existing clerical structures. As a result, the focus was on the seminary training and formation of Bougainvilleans as priests, thereby empowering young men to lead our people in their spiritual lives. A minor seminary was established at Chabai in 1932 for the initial preparation of young men for training for the local diocesan priesthood. [Diocese of Bougainville 2001: 13-14]. The next level of seminary training for the Catholic priesthood was available in Rabaul, where Paul Lapun, Peter Tatamas, John Teosin and Aloysius Tamuka (Noga) studied before the outbreak of World War II. After the War, in 1945, the Marists established the first major seminary for Papua New Guinea at Torokina on the west coast of Bougainville, no doubt because the United States army had left such a huge infrastructure there. Its first candidates were one Papuan, two from East New Britain and two Bougainvilleans. However, perhaps because of its geographic remoteness, Torokina failed to attract nationwide candidates and the seminary there was soon closed. Subsequently candidates from Bougainville were obliged to study at the more conveniently sited seminaries 
at Rabaul and Madang. The first two diocesan local priests were ordained in 1953: Aloysius Tamuka (Noga) from Tabago parish in Buin and Peter Tatamas of Lemanmanu in Buka. Despite the remote location of seminaries from their own homeland after the closure of the Torokina facility, Bougainvilleans continued to respond to the call of the priesthood.

The focus of indigenisation was not solely on the priesthood. Two local orders of nuns and brothers were established, the Little Sisters of Nazareth and the Brothers of St Joseph. In their efforts to raise the dignity of women, in 1936 the expatriate Marist Missionary Sisters established the Little Sisters of Nazareth, a local Bougainvillean foundation [Constitution of the Sisters of Nazareth 2001:1]. Numbering 38 members in 2004, they are involved in education, health and pastoral ministries. As its founders wanted this local order of religious women to flourish, they did not receive Bougainvillean candidates into their own order until the local congregation was fully localised in 1972. That year the first Bougainvillean mother general was elected by the members of the order. The European nuns kept themselves largely separate from the local sisters. The Brothers of St Joseph were also founded locally by the Marist priests to assist them in their work on mission stations, but especially in their work of constructing and maintaining buildings all over Bougainville. There have been eight Brothers of St Joseph to date. The local Marist Bougainvillean priests number four, while there are seven Marist Teaching Brothers.

Progress towards full indigenisation of the clergy still has some distance to go. In 2004, the bishop is an expatriate, as are two priests and three nuns. However, there are 17 Bougainvillean diocesan priests, 13 Marist Fathers, 38 local Bougainvillean Sisters, 10 Brothers of St Joseph and six Marist Teaching Brothers. Some of them are engaged not only in a pastoral capacity but in all sectors of our local communities, as well as in teaching and administration in seminaries in Papua New Guinea and beyond. Some hold administrative positions in various parts of the Province, in their own secular or religious communities and at diocesan centres such as the Mabiri Ministry School.

\section{Changes under Bougainvillean Leadership}

Leo Lemay, the charismatic American Marist bishop of Bougainville from 1959 to 1974, was a great preacher on the justice related issues that caused such controversy in Bougainville in the 1960s and early 1970s. He prepared the Bougainvillean priest, Gregory Singkai, to succeed him. Soon after being consecrated and taking office in 1974, the late Bishop Singkai implemented major changes in the Church structure and government by emphasising the goal of 'self-reliance', especially through the parish councils. This change in direction met with resistance, especially as financial support for the work of the Church had until then been coming freely 
from overseas charity and funding agencies, such as Misserio and Propagation of the Faith. Now the Catholic faithful were told to help the Church to become selfreliant by supporting their own parish priests and religious through their contributions to the parish councils. As was to be expected, this worked well in only some of the parishes throughout Bougainville. A lot of clergy and religious had to depend on their own resources. Religious orders and the local congregations of Brothers and Sisters fared somewhat better, especially because some of them were getting regular salaries through the departments of Education and Health as a result of partial integration of church schools and health facilities into the government systems. During the Bougainville conflict (1988 to 1997), Bishop Singkai supported autonomy for Bougainville and suffered for the cause, even being taken hostage at one stage and being confined at Koromira. He was persuaded to leave Bougainville via Honiara. However, he eventually returned to the province where he died in 1996.

Another Bougainvillean, Peter Kurongku, was also consecrated bishop of Honiara, Solomon Islands, where he served as auxiliary to the Marist bishop, Adrian Smith, before being appointed archbishop of Port Moresby in 1987. He also introduced many changes, some which shocked many Catholics, both lay and clergy in the archdiocese of Port Moresby. (For example, he invited Filipino priests to come to the archdiocese of Port Moresby from where they spread to other parts of Papua New Guinea.) He, too, was not afraid to speak out on justice issues. When, during the crisis, the national army blindly landed on Bougainville and began to 'shoot and kill' and to commit other atrocities, Archbishop Kurongku spoke up against such actions. He condemned both the Papua New Guinea army and the self-styled Bougainvillean Revolutionary Army (BRA). He also provided homeless Bougainvilleans with accommodation during the critical period of the conflict, something that annoyed some clergy. The archbishop continued to voice his views until he died in 1999.

As the number of expatriate missionaries decreased from the 1970s, and the numbers of indigenous priests, sisters and brothers was much too low to meet the needs of the growing Catholic population, the Church leaders had to look seriously at ways of involving the laity in the pastoral ministry. A major move in this direction occurred in 1974 when, in order to meet pastoral needs of the diocese, a catechetical centre - the Marist Ministry School — was established at Mabiri. Many lay people were trained there as catechists to work in the parishes, as discussed below. The School was initially run by Father (now Bishop) Henk Kronenberg. He was assisted by diocesan priest, Father Benedict His, who had been well prepared by study in the Philippines at the Asia Pacific Socio-Pastoral Institute in Manila. In 2004 it is directed by another Bougainvillean diocesan 
priest, Father Bernhard Unabali, who recently studied in Rome. The training of lay people to carry on the work of the Church in Bougainville continues to be regarded as work of vital importance. When the civil war left many parishes without clergy or religious it was young people who had originally been selected by parish councils to train at the Ministry School who as graduates stood out in filling the gaps. Some of them now assist the priests as Communion ministers. During the crisis lay women were also trained to distribute the Eucharist, a special role previously the preserve only of nuns.

One of Bishop Singkai's greatest achievements was the diocesan synod in 1985, held round the theme 'Yumi Yet I Sios ('We Are The Church'). In this gathering of the faithful in Bougainville, clergy, members of religious orders and lay persons selected from the different parishes as well as heads, managers and administrators of Catholic institutions came together for a whole week. Chairpersons of each of the parish councils were also invited. Everyone worked together very well in both small groups and in large plenary sessions. The structure of the local Catholic Church was evaluated and a new one developed. That new structure was just being implemented when the Bougainville conflict erupted in late 1988. Bougainvillean men and women were very much empowered during these synod sessions, especially young leaders. They saw themselves as being valued by the church asking them to attend.

Even before the synod was called, Bougainville may well have been the only diocese in Papua New Guinea which called an annual diocesan senate at which all Catholics serving on the parish councils came together to discuss issues of common interest. Active participation was encouraged and a good flow of communication took place. Despite the presence of clergy and members of religious orders, lay Bougainvilleans were not inhibited and spoke out frankly.

\section{Social Justice Issues}

The Marist missionaries have been particularly supportive of any of the people's initiatives during times of controversy and crisis. From the late 1960s, missionaries in the main churches made people aware of their rights and of what constituted a healthy physical and spiritual environment. They agreed with the views of many of our people that outsiders, such as multi-national companies, should not be able to just walk in and exploit the resources of the land considered sacred by its Bougainvillean traditional owners. As with every Melanesian clan, land is handed down from generation to generation in sacred trust. Land provides security. It enshrines a heritage. It is the source for food, for construction materials and traditional medicine. It is inalienable, unable to be readily bought and sold as in Australia or European countries. 
It may be helpful to provide a few examples to demonstrate how education by the Church has contributed to making people aware of justice related issues in cross-cultural situations and how at times members of the clergy provided practical advice on how to deal with conflicting values in a way that Western agents of change could not ignore.

On 17 May 1990, during the crisis, the rebel leader Francis Ona proclaimed the Bougainville Province as the 'Republic of Me'ekamui' and declared the struggle to deliver land to its rightful owners to be a 'holy war'. It is no surprise that in 1989 Bishop Singkai — the first indigenous bishop to implement the ideology of self-reliance for the Church in Bougainville — made a personal visit to Francis Ona and the militant landowners. Ona spoke to him in the following words:

Our land is being polluted, our water is being polluted, the air we breathe is being polluted with dangerous chemicals that are slowly killing and destroying our land for future generations. Better that we die fighting than to be slowly poisoned [Diocese of Bougainville 1989: 3].

During the colonial era, as far back as 1967, the owners of the land which Bougainville Copper Ltd (BCL) was trying to acquire for mining purposes strongly disapproved of the purchase and refused to accept the 'occupation fee' being proposed by the colonial Administration. Their anger had been fuelled because the colonial mining legislation did not state that permission from landowners for prospecting was necessary nor that compensation was due for damages to property during prospecting and mining. As long ago as that, Bougainvilleans could not be fooled by an unjust piece of legislation

Ordained as priest in 1970, John Momis in 1974 delivered a paper in Canberra in which he made strong points about the mining Agreement between Cozinc Riotinto Australia (CRA) and the colonial government. He warned that:

sooner or later there will be a strong popular movement demanding changes in the operation of the mine, and the longer the company waits, the less it will be left with. If no action is taken to re-negotiate the mining Agreement to give a fairer share to landowners in the mining benefits and the royalty payment, there will unquestionably be more bitterness, more mutual distrust, perhaps even violence. [Momis 1989: 19]

In 1966 Bishop Lemay had encouraged Paul Lapun (then an elected Bougainvillean representative in the colonial legislature - the House of Assembly) to demand that 
compensation be paid to the owners whose land had been alienated and destroyed by mining. Lemay and members of the clergy discussed this issue with Lapun, publicised the issue and supported him in various ways to put the matter to the House of Assembly. Seeking 40 per cent royalties for landowners from mining profits, Lapun lobbied members of the Assembly. Ultimately, the proposed law provided for a mere five per cent royalty payment. Nevertheless, against the Australian Administration's strenuous opposition, Lapun was successful in having the bill accepted, and five per cent of the Government's share of 1.25 per cent royalty on the value of Bougainville Copper Ltd's production was required to be paid to the Panguna landowners themselves [Oliver 1991: 182].

In 1969, it was the women of Rorovana Village who grouped together to stop the destruction of their cash crops and the confiscation of their precious land [Togolo, this volume]. They thrust themselves between the feet of riot squad police and, in a potent symbolic gesture, pulled out the survey peg. Subsequently they stood in front of the mining company's bulldozers to inhibit the knocking down of their coconut tress and the clearing of their forest.

\section{Socio-economic Innovations}

Although some plantations and other practical projects were founded directly to finance the missions, other Marist endeavours were instrumental in getting the people established in socio-economic activities. The main ones were the growing of coconuts and cocoa, the setting up cooperative movements and of saw-mills. They included the initiatives of the following persons during the 1960s and 1970s:

- Father Bill Mentzer's work at Kurai on the west coast of Bougainville, involving a large scheme of resettling mountain people on the thinly populated coast and getting them to grow coconut trees and cocoa shrubs [Laracy 1976: 142].

- Father Brosnan (a young Australian) on the north-west coast at Sipai Mission Station also managed a resettlement scheme involving coconut and cocoa groves for both Catholics and Methodists [Laracy 1976: 142].

Each of the above schemes also involved a saw mill to produce timber for copper driers, as well as cocoa fermenteries, storage sheds, connecting roads and trucks for transport [Diocese of Bougainville 2001: 13-14].

Other projects included those at the following locations:

- Torokina, on the south-west coast, where Father Jim Moore encouraged cash cropping.

- Sovele, south-west inland, where Father Denis Mahony assisted people in getting credit scheme activities going under a cooperative movements structure. 
- Tabago beyond Buin town in south Bougainville, where Father Wally Fingleton fired up the local people to insist that the government of the day pay them a just price for the gravel that was being removed from the Malabita Hill quarry. He also encouraged people to plant rice and cocoa.

- Gogohe, on Buka island, where Father Assump Suinday set up a cooperative movement for cocoa and copra producers.

- Also on Buka, at Lemanmanu, where Father Demers stimulated a housing and marketing initiative,

- At Gagan, also on Buka, where Father Luchen assisted in the setting up of a saw mill.

- In the Koromira area of the south-east of the Bougainville mainland, where Father Herman Woeste took a special direction by establishing the 'Rainbow Centre'. Directed at young people involved in crime, the centre ran programs that provided reform and rehabilitation. It assisted some in gaining employment, even in management positions.

These are just a few examples of how the missionaries from the early 1960s on influenced people and helped them to review their attitudes to their simple lifestyle and to meet modern challenges by involving them in new economic activities. These activities were a significant part of the reasons why, by the time the crisis erupted, almost every Bougainville family was at least a small coconut or cocoa plantation owner.

\section{CONCLUSION}

The goal of integral human development guided the churches in their mission endeavours. The work of the churches in assisting and training women and of empowering them generally has been of the utmost importance to the empowerment of women in Papua New Guinea. It was the churches that devoted themselves to ministries such as education and health. In Bougainville, their intensive efforts in this regard were having significant impact on local leadership long before the colonial Administration had the resources to provide wide-scale services. In addition there were other projects intended to meet the more institutional concerns of the churches (such as the training of catechists). Still other programs linked people's ordinary lives with their spiritual orientation. Most schools, health centres, clubs and associations in Bougainville were established by missionary groups, both religious and lay.

The Catholic Church in the 1960s took a firm stand in support of people's concerns about development, especially mining. It was the Church's education system that contributed to the emergence of educated leaders who made the 
people aware of their rights and of their freedom to speak out on matters relating to justice, peace, unity, community-building and harmony. The Bougainville conflict and the ensuing peace process, has presented the Catholic Church, as well as our brothers and sisters in the Uniting and Seventh-Day Adventist churches, with the challenge to continue to preach and give witness to the gospel values. That means that they set a new direction during these critical times by continuing to promote the dignity of the people who have been reduced in so many ways. Every Bougainvillean must contribute to the 'building up of the kingdom of God' in Bougainville today by proclaiming and living the gospel values so that our lives will be permeated by justice, by peace and by a better sense of community. 



$$
\begin{aligned}
& \text { PERSPECTIVES } \\
& \text { ON PARTICULAR } \\
& \text { BOUGAINVILLE } \\
& \text { SOCIETIES }
\end{aligned}
$$




\title{
BUIN SOCIAL STRUCTURE
}

\author{
by Jared Keil
}

he Buin of southern Bougainville Island (Papua New Guinea) are most
closely related, linguistically and culturally, to their western neighbours, the Siwai. Yet the Buin and Siwai differ dramatically in certain respects. The Siwai, made famous in the writings of Douglas Oliver, are characterised by 'big man' politics and matrilineal descent (although Oliver discusses regional variations within Siwai; see below). What about the Buin? The Thurnwalds have described Buin society as characterised by hereditary strata and a paternal emphasis (more below).

\section{THE THURNWALDS REVISITED}

Richard Thurnwald spent seven months among the Buin during 1908-09 [Thurnwald, R., 1934b: 119 fn 3; Melk-Koch 1992: 257, 258]. Richard and Hilde Thurnwald carried out research among the Buin during 1933-34 for a period of ten months [Thurnwald, R., 1934b: 119 fn 1; Melk-Koch 1992: 258].

\section{Rigid Stratification?}

Richard Thurnwald described Buin society as stratified and feudalisch (feudal) ${ }^{1}$. There were múmira ${ }^{2}$ (chiefs) and there were kitere (bondsmen): the múmira families 'constitute an aristocracy' [1934b: 125, see also 133]. He noted that 'The relations between múmira and kitere are not exactly the same in each region of Buin. Nevertheless general principles can be ascertained for the whole area' [Thurnwald, R., 1934b: 125].

The Thurnwalds were told that in the 'old days' the power of the mumira was considerable: 'Discipline in the old times was kept rigidly and sometimes cruelly' [Thurnwald, R., 1934b: 126]. Múmira, Thurnwald noted, claimed ownership of all land, pigs, and shell valuables, as well as of 'their "bondsmen" (kitere)' [Thurnwald, R., 1934b: 125]. A múmira could kill his kitere for various 
infringements of proper behaviours: 'The bondsmen were treated as serfs, whom their chief could kill without fear of vendetta' [Thurnwald, R., 1936b: 350]. A chief could also 'sell a bondsman to his friend,' and the bondsman may be 'killed without warning' by the allied chief in order to place his skull in his new hall [Thurnwald, R., 1936b: 349]. In addition, there were 'slave[s]' used as human sacrifices at the erection of a múmira's large 'assembly hall' [Thurnwald, R., 1934a: 2811].

In the 'old days', Thurnwald noted, 'The main obligation of the kitere ... was to support his múmira's enterprises in warfare, and particularly in head hunting to offer the skulls to the personal war-god (orómrui) of his chief' [1934b: 126]. By 1933-34, feuding, warfare and head-hunting 'have become obsolete' [Thurnwald, R., 1934b: 126]. The other main obligation of the kitere, then as well as in the old days, was the raising of pigs [Thurnwald, R., 1934b: 126].

A múmira's male kitere were obliged to help the múmira to clear gardens, repair fences, and build houses, 'particularly in the erection of the chief's hall (abácio)'3 [Thurnwald, R., 1934b: 126]. Female kitere helped the mumiana (múmira's wife) in garden work and house work; in addition, the Thurnwalds reported, female kitere sometimes served as nanáboko, sexual partners for the mumira and their allies and guests [Thurnwald, R., 1934b: 126; Thurnwald, H., 1934: 155]. Richard Thurnwald noted that all of these services 'are remunerated, either by meals of pig or by ábuta [coarse shell valuables]' [1934b: 126].

He stated that 'the interests of the men centre around three foci': women, pigs and shell valuables. Various objects and services, pigs, and wives were recompensed with shell valuables: 'In Buin the process of exchange is complicated by the intervention of the "shell money"' [Thurnwald, R., 1934b: 124]. Feasts (large and small) were held for many occasions: 'In the life of the Buin people there is no incident which cannot serve as an occasion for feasting upon pigs and pudding' [Thurnwald, R., 1934b: 123, 124].

As with human skulls, a powerful múmira's orómrui was pleased to see pigs' jaw bones in the múmira's clubhouse, indicating that this múmira held lavish feasts, where many pigs were slaughtered. In addition to life crises rituals, one of the most important and lavish ceremonial feasts was the unu [Thurnwald, R., 1934b: 123, 131]: 'The core of the social organisation is the ... ceremony by which the youths are dedicated to the highest chief, thus constituting lines of feudal vassalage' [Thurnwald, R., 1934a: 2811].

In addition, in the old days 'The kitere must show respect for his múmira, and in particular he must avoid looking upon the chief's wives and daughters', and, for this reason, kitere avoided walking along the tracks used by mumiana on their way to the gardens [Thurnwald, R., 1934b: 126]. 


\section{Or More Flexible?}

Yet, in the midst of discussing all of this 'rigid' stratification, Thurnwald noted that: 'The chief is housed, dressed and fed exactly like his bondsman ... [and] [S]tratification, therefore, can only be discovered by close observation of the behaviour and customs, and by obtaining confidential information' [Thurnwald, R., 1934b: 125]! In fact, 'It is true that complete reciprocity prevails between these [i.e., chiefs'] families as well as among their "bondsmen" (kitere)' and 'The idea of friendly help is even extended to the relations between ruler and ruled' [Thurnwald, R., 1934b: 125, 123].

There were also obligations of the múmira and rights of the kitere. A múmira 'would never antagonise his kitere, since he relied on their help as his henchmen as well as raisers of pigs and cultivators of soil' and 'a chief would not wantonly deprive himself of the source of his revenue and prestige' [Thurnwald, R., 1934b: $126,127]$. A múmira's 'discipline and authority had therefore always to be tempered with diplomacy' and 'The average chief did not forget to reward his kitere adequately, in particular by means of frequent feasts, to insure the good will of his people and increase his popularity and prestige' [Thurnwald, R., 1934b: 127]. Furthermore, the rights of mumira were 'checked by the right which the kitere claimed to leave his múmira and seek the tutelage of another chief', although in the old times this was often dangerous and risky [Thurnwald, R., 1934b: 126]. In addition, 'the bondsman was protected by his múmira, who would also avenge him in case of any assault or black magic' [Thurnwald, R., 1934b: 126].

Moreover, although the múmira claimed to own all land, the land 'is divided up for usufruct among its adult male members' and a kitere family receives land 'from his [i.e., the kitere's] ancestors' [Thurnwald, R., 1934b: 125]. And, despite the fact that the mumira claimed to own all pigs and shell valuables, individual kitere owned and raised pigs, although they were expected to dispose of them only with the knowledge and approval of their múmira. When a kitere gave a pig to someone else, even to his, or another, múmira, he would be compensated for it, although in a case involving another múmira his múmira was able to claim part of that compensation. In addition, Thurnwald noted that múmira were obligated to provide pigs and shell valuables to their kitere when the latter required them (as, for example, for life crisis rituals); again, there would be compensation due to the múmira. [1934b: 126].

In addition, múmira and kitere were not monolithic entities: there was 'a rank-system among the chiefs', with 'smaller' chiefs, 'big' chiefs and a 'few supreme chiefs of a large division of the thickly populated country' [Thurnwald, R., 1934b: 125; 1934a: 2810]: "The head of a múmira family is the "múmira tútoberu," the others are simply called múmira' [Thurnwald, R., 1934b: 127]. And there were also clearly differences, over time and space, dependent on individual 
temperaments and personalities: Thurnwald frequently mentions old 'brutal and shrewd' Cíbelau-Máugoci, 'one of the unusually terroristic rulers', who, presumably, did not temper his discipline and authority with diplomacy, as did most Buin leaders [Thurnwald, R., 1934b: 127, 133; see also 138]. Cíbelau-Máugoci ${ }^{4}$ was 'able to extend [his] power over a number of' supreme chiefs [Thurnwald, R., 1934b: 134].

Both Hilde and Richard Thurnwald noted that there were intermediate classes' such as minei and burrepi. Minei (also denoting the main pillar of the clubhouse) were the main supporters of a múmira; but 'minei were men of mixed descent', the result of intermarriage between múmira and kitere [Thurnwald, R., 1934b: 132]. Minei were generally wealthier (in pigs and shell valuables) than kitere and had greater prestige [Thurnwald, R., 1934b: 133]. Búrepi 'do not constitute a class like the minei who are kinsmen of the múmira aristocracy. A man of means among the kitere is just called a búrepi, a rich man' [Thurnwald, R., 1934b: 133].

\section{Conquest and Invasion?}

The Thurnwalds argued that the mumiralkitere distinction was based on an invasion or conquest of the original aboriginal inhabitants of the Buin area by people who belonged 'to a stock that swept over Buin from the Alu and Mono Islands' [Thurnwald, R., 1934b: 133; Thurnwald, H., 1938: 214-15].

Thus you find a thin layer of aristocracy, which has come from the Alu and Mono Islands, and which belongs to a particular race. These are the tall, blackskinned, Solomon Islanders who have their strongholds on the small islands, and used to exercise their power by means of head-hunting raids and rape of women and children among the native population of the larger islands [Thurnwald, R., 1934a: 2810].

Hence, the conquerors (the múmira) and the conquered (the kitere) were originally distinct — physically, linguistically, and culturally.

'The Buin language is non-Melanesian' [Thurnwald, R., 1934b: $119 \mathrm{fn}$ 2] or Papuan. '[T] he speech of the Papuan population has been preserved as a mother language' [Thurnwald, R., 1934a: 2810]: 'the Papuan language of the [aboriginal] women replaced the Melanesian of the invaders' [1936b: 350]. Why the language of the invaded and not the invaders was preserved was not mentioned. But Thurnwald also argued that 'often two expressions are available: one derived from the invaders, and one from the "mothers" [Thurnwald, R., 1936b: 350]:

As I began to learn the language, I repeatedly encountered words identical in meaning, the one from the Papuan language, its counterpart from the 
Melanesian language spoken on the Alu Islands. Soon I could state from observation that the Alu words had been used mostly by the chiefs' class [Thurnwald, R., 1951: 138].

Exactly when this supposed invasion or conquest occurred seems unclear. Richard and Hilde Thurnwald offered contradictory accounts on this matter: Sometimes they argued that this invasion or conquest occurred 'centuries' before their ethnographic present [Thurnwald, R., 1936b: 349; Thurnwald, H., 1934: 168]. Elsewhere, Thurnwald wrote, '[Y] ou may easily distinguish various physical types since the invasion of this part by the Alumono race seems fairly recent' [1934a: 2811].

\section{Breakdown?}

Thurnwald theorised that the mumiralkitere distinction was already breaking down even before the appearance of Europeans among the Buin'5: '[I]n Buin stratification may still be traced, even though apparently declining', as there has been 'blending' between conquerors and conquered [Thurnwald, R., 1934a: 2810, 28116; see also 1936b: 349-50].

The Thurnwalds believed that there was evidence of this weakening of the earlier strict status system brought in by the invaders in the fact that succession and inheritance were not purely from father to eldest son: it was 'possible for a daughter's son to succeed if he live in the place and if he were designated by his grandfather to be his successor' and 'If there be no other heir, it is permissible for a half brother (the son of a kitere wife) or a minei ... to succeed if he be considered suitable' [Thurnwald, R., 1934b: 127, 128; Thurnwald, H., 1934: 143, 144].

This indicates how, with the passage of time, men who were not pure blooded members of the aristocracy, attained to positions of authority. To-day many claim to be 'múmira' who indeed are of very mixed ancestry ... At the present time the aristocracy is in a few places still more or less preserved, but in many others it is undoubtedly completely disintegrated. Although the process of disintegration had begun long before the advent of the whites, it was undoubtedly accelerated by them [Thurnwald, R., 1934b: 128].

Thus the hereditary aristocracy's power and authority was 'countered by the influence of wealth ... long ago' [Thurnwald, R., 1934b: 132].

Yet Thurnwald generalised that a 'wife enjoys the protection of her husband. This was particularly important in the old times. The splendour of his fame as a fighter was demonstrated concretely in the form of valuables and ornaments, of wealth in pigs and shell money' [Thurnwald, R., 1934b: 122; emphasis added]. 
Similarly, Thurnwald noted that the position of a burepi (a rich kitere), 'particularly in the old times, was the result of a shrewd participation in his múmira's troubles, both as regards wars and feasts' [Thurnwald, R., 1934b: 133; emphasis added]. Thurnwald specifically acknowledged that, although it had 'been strengthened by modern contact', 'this profit making and the rationalistic side of bargaining ... existed even in the pre-European epoch' [Thurnwald, R., 1934b: 138].

\section{Cultural Malaise?}

Thurnwald also noted other changes that had taken place between his first and second visits. In the span of only about 25 years, the Buin had gone from 'almost complete integrity to a growing disintegration of the old order' (Thurnwald, R., 1936b: 347): they 'have lost their independence' [Thurnwald, R., 1936a: 327].

The appointment by the Australian colonial Administration of government 'chiefs' (kúkurai), 'who were not selected from the múmira families contributed, of course, to a further deterioration of the chief's position and a shattering of authority of the múmira' [Thurnwald, R., 1934b: 128]. The kúkurais 'influence has grown beyond that held in the past by a great ... supreme chief' [Thurnwald, R., 1936b: 352].

Since the government put an end to fighting and feuding 'and the Mission condemned the use of panpipes', certain types of songs are 'rapidly falling into oblivion' [Thurnwald, R., 1936c: 5]. 'Big feasts like the Unu ... and the blowing of Pan pipes, have degenerated' [Thurnwald, R., 1936a: 327].

Thurnwald thought that a single event 'broke' the Buin and led to their 'acceptance' of, or 'resignation' to, government: 'a messenger and two police boys were sent by the patrol officer' to address a problem. Following provocation and quarrel, the three were killed and 'general dissatisfaction' and 'a general rising seemed imminent' [Thurnwald, R., 1936b: 352]:

An expedition was sent out by the Government, and three chiefs of Mórou were captured and hanged; others were shot or imprisoned, including a well-known sorcerer. The múmira family of Mórou was extinguished, and the halls of their allies, particularly of the most important of all chiefs, the so-called 'king' of Buin, of Cíbelau of Kikimóugu, were burned. [Thurnwald, R., 1936b: 353]

For Thurnwald, 'this one incident sufficed to break resistance, and ... all the people submitted, from then on, to the orders of the Government ... The backbone not only of the chiefs, but also of native culture and tradition had been broken'. This took 'the spice ... out of native life' [Thurnwald, R., 1936b: 353]. This incident took place in 1920 [Thurnwald, R., 1936c: 14] $]^{7}$. 


\section{Different Times and Different Places?}

Hilde and Richard Thurnwald both used the phrase 'old times' to mean both the earlier time of Thurnwald's original research in 1908-09 [Thurnwald, R., 1934b: 120; 1936c: 6] and, sometimes, to the knowledge and oral history of their informants and genealogies from either or both of the periods of fieldwork. For example, Hilde Thurnwald wrote about 'the old epoch' and 'the really ancient days of perhaps fifty years or more ago' [1934: 143].

But it seems difficult to accept that what the Thurnwalds were describing is merely the difference between what Thurnwald found in 1908-09 ('rigid stratification') and what they both observed in 1933-34 ('breakdown'). As the above quotations demonstrate, every time they discussed differences between these two time periods, they added that: even before 1908-09, there were instances of 'breakdown'. Sometimes, as quoted above, the 'breakdown' was seen as 'particularly' true of the 'old times'. In addition, all evidence seems to reject a conquest of the Buin area by invaders from the islands of the Bougainville Straits ${ }^{8}$.

In contrast with, and in opposition to, the Thurnwalds' invasion/conquest theory, Oliver has long argued that the linguistically- and culturally-related societies of southern Bougainville can be seen as logical variants of each other in a cline that flows from north-west to south-east along the Greater Buin Plain, from Nagovisi to Siwai to Buin [Oliver 1943; 1968; 1993a; 1993b]. In these 'controlled comparisons', Oliver has argued that the more remote and mountainous north-western area (Nagovisi and western Siwai) was characterised by less contact with the islanders of the Bougainville Straits, more difficult gardening, less pigs, shell valuables and feasting, and an emphasis on matrilineal descent (with local groups and local leaders associated with those descent groups). In contrast, as one moved towards the south east, Oliver has argued that there was greater contact with the islanders of the Bougainville Straits, gardening was easier (less mountainous) and there were more pigs, shell valuables and feasting. In western Siwai (adjacent to the Nagovisi) there was matrilocality and the mumi (local leader) was the elder/leader of the descent group; in north-eastern Siwai (adjacent to the Buin) matrilineal descent groups existed alongside a classic case of 'big man' politics, whereby people resided and identified with individual mumi ('big men') as the latter created followers through renown in warfare and feasting and there was 'incipient patriliny' and 'patrilineal succession [to the status of mumi] is ... incipient' [Oliver 1943: 60; 1968: 166; 1993a: 30]. In Buin, where the most contact with the islanders of the Bougainville Straits occurred, and the most garden produce, pigs, and shell valuables were evident, matrilineal descent was weakest and a paternal bias became dominant, along with stratification. 


\section{MOGOROI VILLAGE AND SURROUNDINGS 1971-73}

I lived in Mogoroi village for two years, carrying out anthropological fieldwork in 1971-73, and I lived in the same region for another six months in 1982-83. I found that the social structure described by the Thurnwalds and the changes which the Thurnwalds recorded as having taken place over time were strikingly similar to what I was told about the 'old times'. Of course, as every fieldworker has probably experienced, this was described with a mixture of pride in, and rejection of, the past. (For more 'local history' from the Mogoroi region, see Keil [1975], especially pp. 23-51).

But I was told that the stratification between mumira and kitere was not ever as black and white as the Thurnwalds portrayed it. The Buin of Mogoroi told me that, even in the past, mumira and kitere could and did marry; any offspring would attempt to raise their status; and inheritance and succession was never strictly from father to eldest son. Given the reality of marriage prestations, many kitere and their families and kin probably could not afford to and did not marry many mumira. And, much of this relates to the funereal feasts and ceremonies necessary for the proper guidance of a deceased's spirit to the Buin afterworld. Normative statements regarding status, leadership, group composition, succession, and inheritance are just that: ideals. Rules and norms sometimes contradict one another and following one rule may lead to the 'breaking' of another rule.

The Buin, I discovered, could and did deal with anomalies and contradictions. They told me of three basic rules concerning inheritance and succession: (1) the deceased's eldest son should inherit his father's status, rights and obligations; (2) the deceased's eldest son should be the person 'responsible for' carrying out the myriad of ceremonies and feasts for insuring that the deceased journeys to the afterworld; and (3) the person responsible for carrying out the deceased's funeral feasts should inherit the deceased's status, rights and obligations. Thurnwald recognised that 'It is the heir's duty to arrange the cremation and the feasts connected with it' [1934b: 128]. The length and extent of such ceremonies and feasts varied with the status and wealth of the deceased: 'If a man who is not a chief dies, it depends upon his wealth and that of his kinsmen and friends how sumptuous the feasts will be. Essentially, there is no difference between the social strata' [Thurnwald, R., 1934b: 129].

I was told that, today as in the past, the responsibility for carrying out the deceased's funeral feasts is frequently contested and disputed. But, I found (in 1971-73) that for the Buin, rule (3) (above) is the most important and the most crucial. Ideally, this should be the eldest son of the deceased. But, if the ideal heir is helped by others (by kin, by neighbours, by his mumira or allies), these latter 
(and their offspring) can, if they so choose, make claims on the deceased's rights and status, even years after the fact.

I was repeatedly told that, in the past, land was not something to fight about; there was sufficient land. But, today, with high population growth rates and the increasing use of land for cash crops, rights to land are being claimed wherever and however they can be.

Thurnwald mentioned that 'communities are kept together' and 'the members of a settlement [are] united' by múmira [1934b: 124, 140]. I found it useful to label local communities mumira-groups. Each mumira-group is associated with particular plots of land and particular members of the mumira class, one of whom is its leader. I also found it useful to label this leader a mumira-leader ${ }^{9}$. This helps to differentiate individuals within the mumira stratum. Thus, there are mumira-leaders and there are other, 'lesser' mumira who are not 'leaders'. Similarly, some mumira-groups and leaders were relatively powerful and others were relatively weak. Whether in the past or today, in relation to raiding and warfare or to feasting, I was told that these distinctions were crucial.

Membership in a local mumira-group is, ideally, ascriptive, a person being a member, upon birth, of the mumira-group of his or her father. Since postmarital residence is virilocal, upon marriage (if they come from different mumira-groups) a woman changes her mumira-group membership from that of her father to that of her husband.

I was told how, over time and given particular circumstances: (1) an individual of mixed parentage can be raised or lowered in status; (2) an individual can claim a different status from that into which s/he had been born; (3) the individual composition of a local mumira-group can change over time (in addition to the births and deaths of its members); and (4) an entire mumira-group can die out or be absorbed within another mumira-group (for more details on this, see Keil [1975], especially pp. 65-92 and 134-61).

Thurnwald noted that, following the 'breaking of the spirit' of Buin native life with government control and the end of head-hunting and fighting: 'It is true that the "merry-go-round" of exchanging pigs for shell money and shell money for pigs still continues' [1936b: 353]. And it continued through the 1970s as well, as did ceremonial feasting. In the Mogoroi area, throughout my period of fieldwork, there were many feasts held, including life crisis rituals (marking the growth stages of individuals, marriage and, most elaborately, funereal ceremonies). And the unu, far from having 'faded away', was still being described as the most important and most elaborate ceremony taking place among the Buin: I attended many unus during my fieldwork.

The men's clubhouses, the abaito, are also still extremely important. Every community (every mumira-group) has one, filled with a set (usually six in the 
Mogoroi area) of slit-gongs (tuiruma). The building of a new abaito or the creation of a new slit-gong are important occasions surrounded by much celebration and feasting.

Individuals and mumira-leaders refer to the members (especially the men) of their own (or another) mumira-group as $\eta$ korogo (my men) or bogorogo (his men). ${ }^{10}$

Pigs (and, to a much lesser extent, shell valuables) are still crucial to these rituals and ceremonies and are still an important part of Buin life. And, although it was theoretically possible to buy pigs from strangers, most Buin in 1971-73 (and 1982-83) obtained pigs through kin and, especially, through mumira, and, most especially, through their mumira-leader or other mumira-leaders to whom they (and their group) were allied. In 1971-73, government-appointed officials had disappeared, and local government councillors and elected government representatives did not deal with these issues in the local community.

\section{Paternal Emphasis and/or Matriliny?}

Often, Bougainville is described as composed of societies that are 'matrilineal'. The Buin are sometimes noted as an 'exception'.

The Thurnwalds portrayed Buin culture and society as patrilineal and patriarchal: 'among the people of Buin the families are organised on a patriarchal and patrilineal basis' [Thurnwald, H., 1934: 168]. Thurnwald specifically stated that the Buin acknowledge 'descent in the patrilineal line' [1934b: 134; see also 1951: 138]. But it is difficult to know exactly what the Thurnwalds mean by 'patrilineal'. Are there 'patrilineal descent groups', such as patriclans or patrilineages? ${ }^{11}$ In common anthropological terminology, the Buin in the Mogoroi region do not have patrilineal descent groups of any kind. (The mumira-group is clearly not a descent group of any kind.) ${ }^{12}$

There clearly is a paternal emphasis among the Buin and there is virilocal post-marital residence. There is an ideal of father-to-son inheritance and succession. But there is no patrilineal descent or patrilineal descent groups. ${ }^{13}$ In fact, the Thurnwalds note that there is matrilineal descent and there are matrilineal descent groups among the Buin Hilde Thurnwald argued that 'Matrilineal totemism and the cultural system of which it forms a part may be regarded as belonging to an ancient stratum of population, to the "indigenous inhabitants" before the infiltration of "aliens"; today matrilineal totemism was not very important in Buin and 'has little to do with the regulation of marriage' [1934: 146, 168].

As far as could be ascertained by questioning old people, intermarriage between people of the same totem does not seem to have been prohibited even in the old times, although the totems were then regarded as more important 
than they are to-day, and were even associated with certain physical characteristics (e.g., lines on the palms of the hands) ... Indeed, the institution of matrilineal totems does not in any way affect the selection of a consort [Thurnwald, H., 1934: 146].

Yet in a later publication, Hilde Thurnwald notes that matrilineal totemism 'only has any meaning in practice as far as the marriage taboos are concerned', 'and even thirty years ago the marriage taboo between members of the same totem was taken pretty seriously' [1938: 240, 215-16]. ${ }^{14}$

I also found that there were named matriclans among the Buin. But many people knew very little about matriclans, even their own matriclan membership; only older women seemed particularly knowledgeable about these matters. In the Mogoroi region, people were members of the following matriclans: Kaakata (a bird, White Cockatoo); Kenumau (a species of tree); Mokogo (a bird, Marbled Frogmouth); Tourikana (a bird, Yellow-Throated White-Eye); Maramo (an eel); Kokorake (a bird, Woodford's Rail); and Kukurei (a bird, Domestic Fowl). ${ }^{15}$

Everyone is a member of his or her mother's matriclan and nothing (not even adoption) can alter this identification. ${ }^{16}$ These matriclans, I was told, were each named after a primary natural object with which they were associated, and which the members should avoid. Members of each matriclan were said to share a particular pattern of lines on the palm of the (right) hand. And matriclans were said to be exogamous. ${ }^{17}$ I could discover no Buin term for 'matriclan'. ${ }^{18}$

But, unlike their counterparts in Siwai, Buin matriclans are not local or cooperating groups at any level: there are no named or acknowledged segments of a matriclan. ${ }^{19}$ And I could discover no stories pertaining to the origins of the matriclans (compare this with Oliver's rich data from the Siwai). ${ }^{20}$

\section{CONCLUSION}

Of course, the Thurnwalds might be correct; I was not there at that time and place. ${ }^{21}$ But, without the invasion/conquest theory and its concomitant 'degeneration' over time since that invasion/conquest, the Buin present themselves to me as a living culture, although profoundly changed over the years, decades and centuries. In re-reading the Thurnwalds, it is possible to see both realities: there must have been particularly strong and aggressive mumira-leaders in the past and there also must have been relatively satisfied and benign mumira-leaders, not to mention other mumira and kitere.

In fact, there appears to be evidence that, especially at the approximate time and place of Thurnwald's first visit to Buin, the Buin had been most affected and 
influenced by the changes taking place around them, through trade and contact. The close of the 19th century was the time of 'Kings' Gorai and Ferguson in the Shortland Islands, and the influences of such changes, along with the beginnings of missionisation and government control, were obviously profound. ${ }^{22}$ The people of Mogori told me that the centre of the greatest and mightiest of Buin mumira was around the village of Mammarominno, just inland from the coastal areas where Thurnwald first resided among the Buin [see map at the end of Thurnwald, R., 1912].

Thurnwald asked where such changes (that is, what he saw as the 'breakdown' of Buin culture) will lead: will the 'next generation' 'awake to self-consciousness and a desire to build up their own culture' [1936b: 356]? After a decade of suffering through war and embargo, I can only hope that the next generation of Buin succeed.

\section{Endnotes}

1. Unfortunately, I cannot read German and so am largely limited to the writings of Richard and Hilde Thurnwald published in English (a real drawback in this project). Helga Griffin has kindly provided some translation from the original German.

2. In this paper, I use the nomenclature and orthography utilised by Hilde and Richard Thurnwald when discussing and quoting them. Otherwise I use the orthography developed by me in the field. The Thurnwalds, for example, use accents in the words kitere and mumira; I do not. My work in the field was greatly helped by the advice and materials given to me by Don Laycock in 1971 in Canberra, consisting of much of the materials prepared for his dictionary and grammar of the Buin language. This was finally published posthumously [Laycock 2003, edited by Onishi]. Laycock recognised six dialects of Buin: in addition to the central dialect spoken around the village of Paariro (where he had carried out his fieldwork in 1966-67), there were eastern, western, northern, southern and north-eastern (Uisai) dialects [Onishi 2003: viii]. But I am not aware of any detailed map showing which dialects are spoken where.

3. The Thurnwalds refer to the abácio as an 'assembly hall', 'great hall' or 'chief's hall'. In the Mogoroi area, it is abaito. I refer to this as a 'clubhouse', in line with Oliver's usage for the cognate term in Siwai.

4. This individual is referred to again, below. In addition, I believe that this individual is the same man discussed by Laracy, 'The Pacification of Southern Bougainville' this volume (there as Siberau).

5. Thurnwald argued that the conquerors (male) intermarried with the aboriginal women; so, in fact, there were never any 'full-blooded múmira' following the supposed conquest!

6. Thurnwald 1934a was based on the proceedings of a conference held in Canada in June 1933. So, presumably, this work was based solely on Thurnwald's 1908-09 visit to Buin.

7. One of the individuals mentioned in this incident, Cíbelau, is, I believe, once again, the same individual mentioned above and in endnote 4, as well as in Laracy, this volume. Also see the entry for Tiperau in Laycock 2003: 216.

8. Of course, as discussed below, there is no doubt that the peoples of Buin had been interacting with the peoples of the islands of the Bougainville Straits, probably for centuries. This involved 
raiding, trading and intermarriage. People from Alu and Mono Islands did come to Buin and people from Buin did travel and settle in the islands of the Bougainville Straits [Oliver 1993a: 5; 1993b: 2, 11]. But this is quite different from an invasion and/or conquest. I cannot get into all the evidence against the invasion/conquest theory here, but Oliver [1993b: 28] more recently concluded: 'There is no evidence for such a colonisation from archaeology [Terrell and Irwin 1972], from history [Laracy 1976], or from anthropometry [Oliver 1955]'. In terms of linguistics, Laycock [1969: 2] has noted that the Buin language shows 'some slight influence from neighbouring Melanesian languages, principally those of the Shortland Islands (Mono and Alu)'. According to Laycock, Thurnwald discusses a poetic village name 'as "alte Aussprache" [old pronunciation], hereby missing completely the whole system operative in transforming ordinary language names into poetic ones, as described in this paper' [Laycock 1969: $1 \mathrm{fn}$ 2].

9. Prior to the colonial Administration's requirements that 'line villages' be built, most Buin lived in scattered houses or hamlets composed of several houses. A mumira-group was thus a dispersed residential unit and its members identified with the group's land and mumira-leader.

10. Grisward [1910: 92] noted that these terms denote a relation of friendship. Buin and Siwai terms are cognates: 'A mumis followers were referred to, generally, as his "children" (kitoria) or his "friends/companions" (pokonopo)' [Oliver 1993a: 14].

11. Hilde Thurnwald noted that 'Children follow the mother's totem, but ... this classification only has any meaning in practice as far as the marriage taboos are concerned. For the rest, the children belong to the father's clan and follow the rank of the father' [Thurnwald, H., 1938: 240].

12. I regret that I earlier used the terms 'agnates' and 'agnatic descent' and I regret even more the fact that I discussed kin-related groupings within a mumira-group which I termed 'agnatic core groups' [Keil 1975: 69-70 and Keil 1980: 502]. But I argued that the 'mumira group is thus not a descent group' 'in any useful or conventional sense' [Keil 1980: 502; 1975: 69].

13. Oliver [1993b: 17] mentions Buin 'patrifiliation'.

14. Thurnwald had, in fact, noted that matrilineal totemism regulated marriage. Perry, in analysing the genealogical tables collected by Thurnwald in Buin, noted: 'he tells us that marriage is regulated by some mechanism connected with the totemic clans into which the population of Buin is organised, and yet he makes no effort to record the totems of the persons whose names are given in the tables. We are thus unable to obtain any clear conception of, or exact information upon, the marriage regulations of this district in so far as they are regulated by the totemic organisation' [Perry 1914: 806].

15. Thurnwald, in describing drawings of the different patterns of lines on the palm of the hand, lists four clans [in German, Totemsippen]: manugau (fish eagle); tou (a small bird); uau (a dove); and ugu (the hornbill) [Thurnwald, R., 1912: 536]. Chinnery, a government anthropologist, made a visit and surveyed various societies in southern Bougainville in 1929-30 [Chinnery 1924 (sic): 69]. Among the Buin, Chinnery found 28 'social groups' ('clans' in his Appendix) among the individuals residing in 29 villages [Chinnery 1924 (sic): 111, 118]. In descending order the clans (and the number of individual members) are: Kakata (437); Pirigi (418); Turikau (391); Mokogo (294); Kukure (207); Piripirianai (85); Ugu (70); Maurugu (55); Tokenu (48); Upatsi (45); Moruka (39); Mosiga (36); Ne-Agara (32); Kuru (29); Kua (27); Meako (26); Boboki (11); Kelai (11); Sikino (11); Turugum (11); Kutsia (8); Aukaba (3); Nanaku (3); Samuai (2); Rukatu (2); Kenamau (2); Owu (2); and Okino (1) [Chinnery 1924 (sic): 111-12; 118-21]. Wheeler was in Alu and Mono Islands in 1908-09; he never visited Buin, but met R. Thurnwald in Alu [Wheeler 1926: vii, ix, xv]. Wheeler compares and contrasts matriclans and totems found in Mono and Alu Islands with those found among the Buim (sic: Buin). Wheeler lists the following as Buin totems or totem-clans also found in Mono-Alu (all are followed by the word miva (or 
mipa, meaning sacred, taboo, forbidden): kagu, moruko, kakata, kuru, sikino, mosiga, and ugu. Wheeler lists the following as Buin totems or totem-clans not also found in Mono-Alu: boboki, baramo, pirigi, turikau, kerai, uririga, maurugu, and huru [Wheeler 1914: 42-3].

16. 'A Buin, from birth, traces relationships to others through his or her mother for the purpose of defining kin ties (that is, for identifying the proper kin term to use for his or her relatives)' [Keil 1975: 93].

17. The Buin told me that, increasingly, people of the same matriclan marry. Chinnery [1924 (sic): $112]$ noted that 'The social groups are said to be exogamous, but throughout the district I found many instances of marriage between people of the same group. In most of these cases the wife and husband belonged to different villages. Marriage between two people of the same social group living some distance apart is apparently not considered a very serious breach, but marriage between two people of the same group and the same village is said to be bad.'

18. Thurnwald states that the Buin term tubu means clan [Thurnwald, R., 1912: 536]. But this term does not seem to appear again in any other work. (It is known to me only as a female name, which I transcribe as Tuubu. Laycock [2003: 236] transcribes it as Tuиpu.) Wheeler states that the Buin term mure means totem-clan and the Buin word perekuva means clan (1914: 41). Mure does not appear in this context anywhere else that I am aware of; I know perekuba as the generic term for bird, as does Laycock [2003: 150] (perekupa). Finally, Laycock [2003: 6] lists aaka(na) as a noun meaning 'Clan, matriliny'. I have never heard this term and have not found it elsewhere. The Buin do have terms meaning 'my clanmate [imo]', 'his clanmate', etc. (all in singular, dual and plural forms); the Siwai term for 'my clanmate' is imo [Oliver 1993a: 24].

19. Oliver has pointed out that 'In 1938-1939, during my brief forays into north-west Buin (whose inhabitants were adjacent to and in frequent contact, including marriage, with those of north-east Siwai), I found their institutions to be closely similar to those of the neighboring Siwai - including the presence of the same and no other matrilineal clans and the division of those into subclans and matrilineages [Oliver 1943: 62n]' [Oliver 1993b: $36 \mathrm{fn} 37$ ]. [Oliver is here [in a 1993 article] quoting an earlier work [dated 1943] by himself.)

20. Among the Siwai, each matriclan has an associated 'growing-up' ritual, maru, involving washing and other actions intended to promote the 'health and well-being' of clan members, often at life-crises [Oliver 1993a: 15, 23]. Among the Buin, maru exists, but the Buin (and I) are very unclear about its meaning and significance. Although the Thurnwalds (especially Hilde Thurnwald) frequently mention ritual washing at first pregnancy, birth and marriage, the term maru does not seem to be mentioned by either of them. The Buin told me that, although maru does involve women (especially older women) as both practitioners and celebrants, it is not attached to, or in any way involved with, matriclans. Individual Buin seemed even more unsure of their maru affiliation than their matriclan membership. In the Mogoroi area, I was told that the following maru existed: Ekukui, Kubouumo, and Oriribo. (These names, unlike matriclan names, did not have any other denotata, as far as I was able to determine). Laycock [2003: 349] lists Eekukui and Kupouumo (as well as Kara, Tiurato and Turikaumiipo) as 'name[s] of a totem'. Laycock [2003: 320] also states that maru means totem.

21. Thurnwald's first visit to Buin was mainly along the coast and beach [1936a: 329; 1951: 137]. According to Melk-Koch [1992: 258], Thurnwald was based at Kabuai. On the map at the end of Thurnwald [1912], Kabuai is located east of 'Patpatuai'. Richard and Hilde Thurnwald's visit in the 1930s, seemed to focus around the communities of Kugumaru and Aku in the southcentral Buin area.

22. Recall Thurnwald referring to 'the so-called "king" of Buin': Cíbelau [Thurnwald, R., 1936b: 353, quoted above]. 


\title{
WE ARE BORN CHIEFS: \\ CHIEFLY IDENTITY \\ AND POWER IN \\ HAKU, BUKA ISLAND*
}

\author{
by Bill Sagir
}

'W are born chiefs', Haku chiefs (tsunono) in Lontis village in the north of Buka Island would tell me time and again during the course of my fieldwork for my $\mathrm{PhD}$ thesis. Their claim is supported by a popular Haku belief that tsunono do not have to achieve their positions but are simply born into them. It occurred to me, however, that over time tsunono may possibly have constructed an identity of themselves as superior beings whose chiefly positions, titles, power and responsibilities belong to them as a customary birthright. Most other Melanesian leaders have to work hard to achieve their authority during their own lifetime.

It is usual for communal identities to be constructed through people's common experiences and in opposition to other forces, other identities. For example, Bougainvilleans regard their 'black' skin with pride. They contrast themselves favourably against 'redskin' Papua New Guineans. Who then were the people in opposition to whom tsunono constructed their identity as 'born' chiefs? I will show in this chapter that since the beginning of the colonial era the 'others' against whom tsunono engaged in a process of constructing their chiefly identity were leaders in new, rival political structures introduced by successive colonial rulers and, later, by the Independent state of Papua New Guinea. Throughout, power struggles ensued between 'traditional' and 'modern' leaders.

However, I also argue that these contests for leadership were already endemic in traditional Haku societies. In pre-colonial times, just as today, there were contests, rivalries and disputes about the interpretation and application of the principles that supposedly determine claims to titular genealogical seniority or 
rank [Petersen 1999: 369], namely of genealogical seniority and the priority of residential settlement. Members of senior lines who claim descent from the firstborn children of the first settlers in a particular locality (founders of a sub-clan) have claim to the highest positions in the political structure. But the principles of 'firstborn' and 'first-settled' have been both open to interpretation and subject to contestation. The 'ambiguities of rank' [Goldman 1970: 24] in Haku society, as in other Austronesian-speaking societies, make it inevitable that there are always several contenders to any one ranked position in a sub-clan. These rivalries and contests over positions of power and authority help to ensure that Haku society regenerates itself.

New political structures, emerging since the imposition of colonial rule, have been integrated into this volatile system. Although tsunono try to make it appear that it is a struggle between the ancien régime (tsunono) and new political structures with modern leaders, some tsunono have become part of new political structures in order to safeguard and consolidate the status they once enjoyed in the traditional political system. Conflict between new and old priorities helps further to stimulate the contestations and the disputes. Such is the dynamic of Haku socio-political life.

\section{HAKU - THE PEOPLE AND THEIR SOCIAL STRUCTURES}

The Haku people live on the northernmost tip of Buka Island from Elutupan on the north-east to Lontis on the north-west. The other Haku villages are Tandeki, Hanpan, Lumanmanu (more often spelt Lemanmanu) ${ }^{1}$ and Lumankoa (Lemankoa). ${ }^{2}$

Until the imposition of colonial rule, the Haku, like all people in Buka, belonged to one of two moieties, the Nakaripa or the Naboen. This dual structure was then bisected again into four maximal social groups, or named totemic clans [see Petersen 1999: 391]. By rank Nakas and Natasi were placed under Nakaripa and Naboen in a quadripartite structure [Mosko 1985], as shown in the diagram below. In a sense Nakaripa and Naboen traditionally encompassed the other two groups. There is a saying that in the past Nakaripa and Naboen 'covered' (karamapin in Tok Pisin) and represented Nakas and Natasi as well.

\begin{tabular}{|c|c|}
\hline NAKARIPA & NABOEN \\
\hline NAKAS & NATASI \\
\hline
\end{tabular}


While today it is more correct to speak of the activities of the four clans, there are still echoes of social organisation which reflect the original duality and this has its consequences for leadership. For example, even today Nakas and Natasi do not have 'paramount chieftainships' (munihil) but come under the munihil of Nakaripa and Naboen respectively.

Each of the clans has its own totemic symbol: Nakaripa has the fowl (koa or kekeliou), Naboen the eagle (manu), Nakas the dog (muki) and Natasi has the sea hawk (kotoiana) and are compositely referred to as pinaposa. Members of these pinaposa are scattered throughout Buka and north Bougainville and hardly know each other. Yet I was told that people could tell to which group a person belongs by reading the palm of that person's hand.

Below these maximal groups are localised named sections of the clans which had broken away long ago. The fissioning of sub-clans occurred:

- when the population of sub-clans grew too large, creating pressures on land; or

- when struggles and disputes over leadership positions in the sub-clans became disruptive, in which case break away groups founded their own settlements but nevertheless remained as sub-sections of the main sub-clans.

Foreigners may perhaps find it confusing that these localised sub-clans are also referred to by the Haku term pinaposa. They are named after the land on which they settled so that people and place became conceptually merged [Petersen 1999: 376]. Their members are known to each other better than at the maximal group level, but they are not all descended from one common female or male ancestor.

Founders of these sub-sections could attain higher positions in their new settlement groups than would have been possible if they had not broken away. This is an approximation of what Bellwood has called the principle of 'founder rank enhancement' [Bellwood 1996: 30-31]. When the founders of a new subsection wanted to build their own tsuhana (club house) they had to return to the main sub-clan to which they had previously belonged in order to obtain parts of the tsuhana from its members (for example, most of one of the rafters). For instance, among the Nakaripa people in Haku, there are three main sub-clans, namely Gogonuna, Tegese and Mangoana. The first two are based in Lontis, while Mangoana is based in Lumankoa. It was from these main sub-clans that numerous sub-sections derived their origins. Some sub-sections were further sub-divided, as for example, when Sakin, which had earlier fissioned off from Gogonuna, subdivided into Moni and Hankalana. From Moni was founded Solohu (see Figure 1 below). 
Figure 1: Relationship between sub-clans/settlements in Nakaripa clan

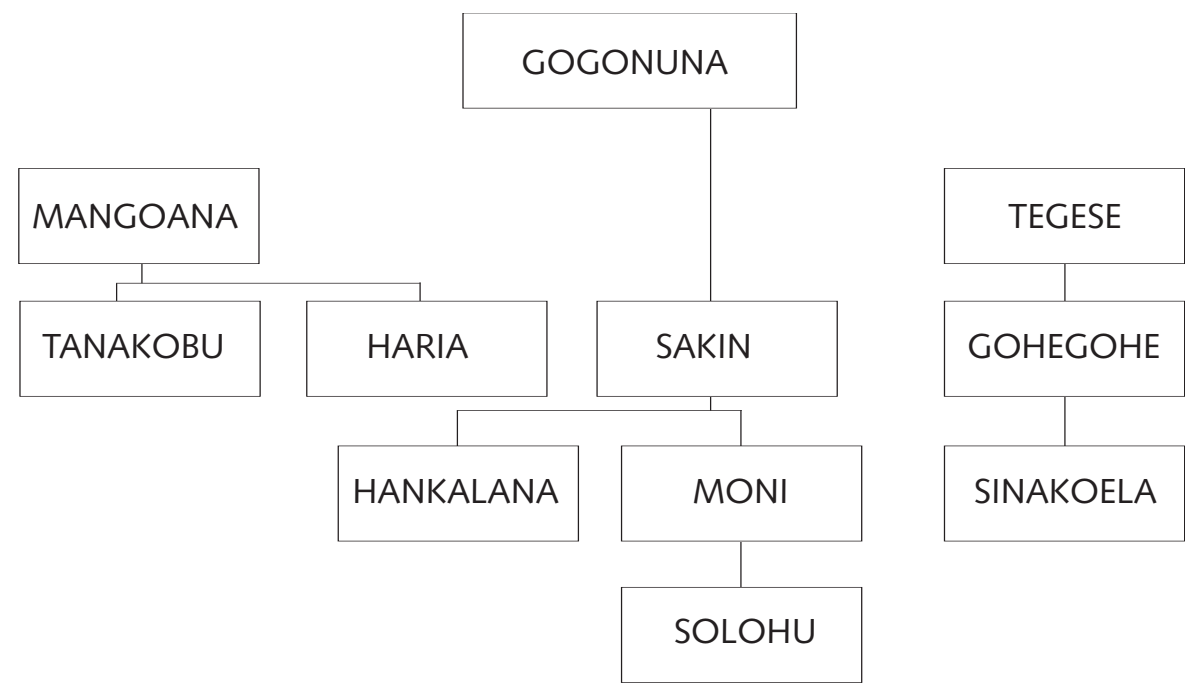

There are smaller units within the sub-clans, known as ngorere. I gloss this as matrilineage. Members of a ngorere trace their ancestry to a common female ancestor, often four to five generations earlier. Ngorere members are tied to each other by blood (ngorere = umbilical cord) and there is a much greater level of cooperation among members at the level of the matrilineage.

In Haku ngorere are ranked on the basis of seniority of settlement. The most senior ngorere is the one that is ideally genealogically closest to the original founders of the sub-clan, that is, first settlers. The leader (tsunono) of the ngorere who is 'genealogically' closest to the original founders is the $p a t{ }^{3}$, the highestranking tsunono within the sub-clan. However, this genealogical closeness cannot be determined with a high degree of certainty and is often the source of interngorere rivalry within any given sub-clan. The tsunono of the second highest-ranking ngorere becomes the tsunono, followed by the peits and then the butbutul. The heads of other ngorere are ordinary tsunono but they can also in time take on one of these positions. In everyday language, all these political officials are called tsunono.

The above description shows that even leadership in the sub-clans follows a 'quadripartite structure' with the patu or gohus at the top, followed by tsunono, peits and butbutul. The significance of this 'quadripartite structure' is manifested in the club-house (tsuhana), which is built with four posts on either side. Each post represents one of the sub-clan's chiefs. 
At the moiety level, the highest-ranking chief was the munibil, the chief of the whole territory. The whole of Haku is still symbolically divided into Nakaripa and Naboen territories. Nakaripa territory includes the villages of Lumankoa and Lontis, and Naboen territory includes the villages of Lumanmanu, Hanpan, Tandeki and Elutupan. The munibil of Nakaripa, now held by a ngorere in the sub-clan of Mangoana, is the chief of the whole Nakaripa territory while his Naboen counterpart, a ngorere in the sub-clan of Tanamalo, looks after the whole Naboen territory. Nakas and Natasi are scattered in the two territories and do not have either their own territories, in the sense that Nakaripa and Naboen have, or their own munibil.

\section{HAKU — HISTORY, LANGUAGE, POPULATION}

According to archaeological evidence, the ancestors of the current population of Buka - all Austronesian speakers - arrived about 3,200 years ago [Oliver 1991:3; Spriggs, this volume], probably replacing non-Austronesian-speaking settlers whose ancestors had arrived there almost 29,000 years ago [Wickler 1995; Spriggs, this volume]. Haku oral traditions maintain that the original place of dispersal of the people of Buka is Bei on the west coast of the island. Haku people say that their ancestors had lived harmoniously around Bei for a long time. However, as their population grew, so did quarrels, leading to dispersal to central Buka (Solos), Haku, Halia and the offshore islands.

One version of the migration story, documented by Rimoldi and Rimoldi [1992] and by Sabin [1988], is that Naboen clan moved first, followed closely by the Nakaripa. In Haku, the two groups have settled side by side in their current territories (see above). In other versions of the migration story, each group claims its ancestors to have been the first to settle in Haku. The order of migration and settlement is an important criterion for claiming seniority in Haku leadership (below).

In the pre-conflict period, Haku was an electoral constituency of the mid1970s North Solomons Provincial Assembly and is a census division for national census purposes. The total population of Haku, according to the 2000 census, was 8,175 , or 22.3 per cent of the total population of Buka $(36,676)$ at that time. The table below shows the breakdown of Haku population by village as well as by gender for each village.

Subsistence farming of vegetables and fruit, pig-raising and fishing are the mainstay of the majority of Haku and a tsunono may intervene in activities associated with these tasks. His more important interventions are usually associated with the production of taro (Colocasia esculenta; in Haku: potutu), the most important crop in terms of the ceremonial and cultural value attached to it. The 
tsunono supervises the timetable and the conditons for planting it and, while alone in the gardens at a particular time, performs the magic that secures a better crop. The harvest also takes place under the tsunono's direction as do the taro feasts that are celebrated in his tsuhana (club house).

Table 1: Population of Haku by Village and Gender [NSO 2002].

\begin{tabular}{lrrr}
\hline Village & \multicolumn{3}{c}{ Total Resident Population } \\
& Male & Female & Total \\
\hline Elutupan & 471 & 469 & 940 \\
Hanpan & 212 & 205 & 417 \\
Tandeki* & 328 & 318 & 646 \\
Lemanmanu & 986 & 976 & 1,962 \\
Lemankoa & 1,159 & 1,060 & 2,219 \\
Lontis** & 1,020 & 971 & 1,991 \\
TOTAL & 4,176 & 3,999 & 8,175 \\
\hline
\end{tabular}

*Tandeki is not listed in the 2000 census. There is a Tanamalo listed after Hanpan. In fact, Tandeki is the next village after Elutupan and Hanpan, and Tanamalo is part of Lemanmanu, being the settlement of the paramount chief of Naboen. I therefore take the population figures of Tanamalo to be that of Tandeki.

** My census of Lontis village in March 1999 showed a population of 2,102, comprising 1,078 males and 1,024 females. According to the 2000 census, Lontis was down by 111 people. It could be possible that Lontis people living in a settlement in Lemankoa were not counted as part of Lontis. The whole of this settlement (Taluhu) may have been counted as part of Lemankoa when in fact one part of Taluhu is comprised of Lontis people who participate in the social and political life in Lontis rather than Lemankoa. For example, they send their children to school in Lontis rather than Lemankoa even though the schools in Lemankoa are closer.

\section{HAKU CHIEFTAINSHIP}

\section{Tsunono}

In the Haku language the authority and/or power of tsunono (the chief/s) is commonly known as nitsunono. It is the Buka equivalent of the Polynesian mana (divine potency). Only tsunono and tubikau have nitsunono. ${ }^{4}$ The tsunono's head is the locus of his nitsunono, but it 'flows' through his whole body so that whatever 
he touches is made potent. It is said that whatever is touched by the head of the tsunono is specifically made potent, invigorated or even made 'sacred' (a goagono). An informant directed my attention to an occasion where a sacrifice (uhats) was offered to the spirits of the dead ancestors for a sick woman. Baskets of food, intended to appease the ancestral spirits, were held over a senior tsunono's head while he pleaded with the spirits to make the woman well. The food was made sacred and fit for the spirits by being held over the tsunono's head.

The tsunono's mouth is also said to be 'sacred' and the words he says carry his nitsunono. It is said that in the days before the white people came, if a tsunono was unhappy with somebody and said something against him or her, that person died straight away. It was considered that the death was not caused by sorcery but by the words of the tsunono. In the past, when a tsunono declared an area of land or sea to be free from hunting, gardening, or fishing, this taboo (hahots) was observed because the tsunono's words are power, and the situation is much the same today.

The origin or source of the tsunono's power is said to be God (Murkohiongo) himself. It is said that God made the first tsunono and gave him nitsunono. This power was passed on from one to the next tsunono to the present day. This is the source of their legitimacy.

Tsunono say that the things they do today that are classed as kastom are the same as those that tsunono did in the past. The content of these things may have changed due to modern influences but the form is more or less the same. My informants tell me that many of the customs that are observed nowadays (for example, the celebration of mortuary feasts) have remained very much the same today as they were in the past. Although money and store goods have become important new features in these feasts, the essential ritual has not changed.

While nitsunono is said to be of divine origin and rests in the tsunono's body the tsunono must nevertheless show overt manifestations, or 'empirical evidence' [see R. Firth 1967: 174-94] of his power. Such evidence includes the hosting of large and successful kinalala (large feasts) for which the host tsunono kills many pigs to be distributed in baskets with other food to tsunono from all Haku villages. A successful kinalala means that the host tsunono will be praised and known in the whole of Haku and beyond. A tsunono also manifests his power by killing pigs regularly. These pigs are eaten with other tsunono at his tsuhana (club house) where the jaws of the pigs are hoisted to the rafters for decoration and to impress visitors from other sub-clans, or from other villages, so they can marvel at their host's power. It is said that pigs killed by a tsunono and shared in a tsunono's club-house enhance his power. As will be mentioned later, once warfare ceased during colonial rule, competitive feast-giving increased as an indication of prestige. 
Another overt manifestation of the tsunono's power is his possession of many strings of beroana (shell money) and paiou (strings of porpoise or flying fox teeth). These paiou and beroana are kept by the tsunono's sister who is a tuhikau (woman of high rank). The more paiou and beroana a tsunono has, the greater also is his power.

Tsunono in Haku are proud of their power, and continue practising their leadership in their various sub-clans and matrilineages without much recognition from national and provincial authorities. This lack of wider conspicuous recognition today may have contributed to the claim in a 1988 North Solomons Provincial Government report that traditional leaders in Bougainville were 'nonexistent' [NSPG 1988b]. At least in Haku, traditional authority was at that time still strong at the village, sub-clan and ngorere levels.

\section{The Ambiguities of Rank in Haku}

The system of rank in Haku is determined not just by the principle of first-settled but also by the principle of firstborn [see Petersen 1999: 374]. Being genealogically close to the ancestors who first settled in a particular locale, and who are thus presumed to have founded the sub-clan, gives a lineage high social status. The head of the lineage closest to the founding ancestor claims the position of patu of the sub-clan. At the same time, to be descended from a line of firstborn daughters of the original settlers (founding ancestors) accords a lineage and its head 'superior ontological and social status to others who are more peripheral or derivative' [Reuter 1993: 492]. In addition, being a firstborn male or female gives one genealogical seniority vis-á-vis later-born siblings. Genealogical seniority entails that the firstborn child (male or female) is the most senior while the last born is the most junior. Firstborn females in high status lineages are accorded very high status and honour and their firstborn sons become chiefs.

Haku people today cannot ascertain with any degree of certainty who their founding ancestors were and who is genealogically closest to these founding ancestors. Over the years, since their ancestors first settled on the Haku coast, various lineages in the sub-clans have held the different sub-clan leadership positions. My informants acknowledged that in the past, ngorere were quite small numerically. This meant that if a patu died without a successor being ready to take his place, the position was taken over by another lineage whose leader became patu. I recorded a case where one ngorere which should hold the position of patu in a Nakaripa sub-clan, but which had left that sub-clan and joined a Nakas sub-clan in which it now holds the positions of peits ${ }^{5}$. This move had been made because the Nakaripa sub-clan needed protection from this Nakas sub-clan. I was told, that if this ngorere ever returns to the original sub-clan, the Nakaripa would take 
back the position of patu from the Nakas sub-clan. There were also cases where migrants from other places who had settled with sub-clans in Lontis became ngorere within them, and were asked to take over other political offices within that sub-clan. These migrant ngorere were required to 'stand up front' while the original ngorere usually 'hid behind them'. This occurred where a ngorere was dying out and wanted to 'hide behind' another in order to strengthen itself numerically.

The other ambiguity of rank in Haku is that while the firstborn son of the firstborn female is genealogically a senior figure, he would also usually be much younger than his mother's brothers, who are one generation above him. The latter are both more experienced and knowledgeable than the nephew. So who is senior? The mother's brothers because of their knowledge and experience, or the nephew because of his genealogical seniority? I recorded a case in Lontis where a tuhikau did not have a son to inherit her mother's eldest brother's position of patu of one of the sub-clans. I inquired what would happen in such a case and was told that the position of patu could either be passed on to the brother's firstborn niece's eldest son (who was only nine years old at the time of my fieldwork) or it could be passed on to one of his other sister's sons. But if it went to one of the sons of the later-born sisters, there would not be as much nitsunono attached to the patu as if it went to the eldest sister's eldest son or, failing that, the eldest niece's eldest son. But even while this lineage works out how to pass on the position, other lineages are claiming the position of patu in that sub-clan and there is no guarantee that the incumbent patu's nephews or the eldest nieces eldest son will take that position.

The examples provided show that positions of high rank in Haku are open to contestation. Being the firstborn in a senior lineage does not guarantee that a man will become chief of a sub-clan. Often a lineage with the highest population at particular points in time takes the position with the support of other lineages even if contrary to the principle of geneological seniority and priority of settlement.

\section{IMPACT OF FOREIGN INFLUENCE AND RULE ON CHIEFLY POWER}

\section{The Pre-Colonial Period - 1860s to 1884}

Well before colonial rule was imposed on the people of Buka, they had contact with foreign explorers, whalers and labour recruiters. Of these, the latter had the most penetrating influence. Recorded systematic interaction with the people of Buka began in the 1860s, when Europeans started recruiting islanders to work on plantations in Samoa, Fiji and Queensland. Labourers were obtained through 
both formal and informal recruitment channels. For example, between 1881 and 1883, eleven thousand islanders were recruited to work in the north Queensland sugarcane fields, including men from the 'formidable Buka and Bougainville islands' [Docker 1970: 180].

When, after some years of working in foreign plantations, the labourers returned to their villages, Docker [1970: 137] suggests that 'Many men, especially those who had been absent for a long period, felt themselves superior in knowledge and experience to the untravelled people at home and offered challenges to their assumptions and authority. Religious as well as secular authority was called into question ...' Those arriving home with some knowledge of Christianity 'may have intended to spread Christianity among their fellows' [Corris 1973: 121] or may have intended to eliminate pagan practices because they now seemed offensive [Corris 1973: 121].

\section{The Colonial Period to World War II}

German sovereign rule was imposed on Buka and Bougainville in 1885 [see J. Griffin 'Boundaries', and Sack, both this volume], and the Pax Germania enabled easy recruitment of labour for German plantations in the Bismarck Archipelago and Samoa. Pacification as a prerequisite for labour recruitment in Buka is most poignantly expressed in the German Annual Report for 1904-05:

On the island of Buka the old feud between the hill people and the coastal inhabitants broke out again. The appearance of a detachment of troops in the mountains sufficed to bring about the end of hostilities. The intervention in Buka was made necessary in particular by the need to ensure that recruitment of labour could proceed without interruption [Sack and Clark 1979: 251].

Labourers from the islands were regarded as being 'handy, persevering and biddable' as Germany's New Guinea Company administration had observed in its first Annual Report for 1886-87 [Sack and Clark eds. 1979: 20] a quality attributed to their prior exposure to plantation labour in Queensland and Samoa. Buka labourers gained a reputation for being reliable and trustworthy.

When, from 1921, Australia was entrusted with the supervision of the Mandated Territory of New Guinea, Buka and Bougainville continued to be valued as reservoirs of labour for the colonial administration and European plantations. While Australia introduced some changes to labour recruitment practice, on the ground methods remained much the same as in German times.

One consequence of labour migration in both German and Australian colonial times was the influx of new forms of magic and sorcery into Buka. While working in 
the Bismarck Archipelago, Buka labourers had bought forms of magic and sorcery which, on their return home, they used to challenge the power and authority of their local tsunono. Previously tsunono had made use of persons who possessed knowledge of magic and sorcery to maintain social order. The influx of magic and sorcery from different places devalued the role of chiefs in the control and sanctioning of these mysterious powers. In the 1920s and 1930s, Buka labourers were taken to work on plantations in north Bougainville where they purchased the north Bougainvillean forms of the ruko (initiation) cult, together with its associated magic and sorcery. Upon their return, the men who possessed the ruko-associated magic and sorcery controlled the ruko cult. According to Rimoldi and Rimoldi [1992: 40], the 'owners' of the ruko magic and sorcery were recognised as tsunono and rivaled the munibilthe chief of the whole Nakaripa or Naboen territory. They became muniruko (monaruko in Halia) — the stem or the source of the ruko cult. ${ }^{6}$

Pacification had other effects of which the Germans, and later the Australians, were probably never aware. In Buka, for example, as a result of Pax Germania, groups like Nakas and Natasi, which had previously served as warriors for Nakaripa and Naboen chiefs, began to assert themselves as clans on par with Nakaripa and Naboen. Many of my informants in Lontis told me that Nakas and Natasi became pinaposa only after the arrival of Europeans. In my view, this was as a result of Pax Germania.

Some Buka chiefs used German military forces to serve their own purposes and consolidate their own positions vis-á-vis other chiefs and sub-clans. For example, Chief Magara and Chief Nebot from Buka sought help from the Germans against their enemy, a warrior named Cohe. The Germans destroyed Cohe's village and, to show their appreciation, Magara and Nebot presented a dozen men to the government for training as police [Firth 1982: 86] ${ }^{7}$. The end result of this could well have been that Magara and Nebot increased their power because they had the more powerful Germans on their side.

Another effect of German pacification was the increased tempo in other modes of competition, particularly competitive tsuhana building and competitive feast-giving (kinalala) by rival tsunono, activities documented by Rimoldi and Rimoldi [1992]. This too may have been a result of Pax Germania and later, Pax Australiana. While such competition was an aspect of pre-contact socio-political life, it rose to new heights after the colonial Administrations had succeeded in pacifying enemy 'tribes' in Buka, perhaps to replace warfare and provide an alternative means of proving the nitsunono of chiefs. As Petersen [1999] notes, prestige is achieved through various means; it is not ascribed.

In the early 1900s, the Germans introduced a policy of collecting head tax; it was continued by the Australians. This was not only a means of raising revenue for 
the colony but a system of extending and establishing colonial state control over the 'native' population. The policy forced people to find money to pay head tax by either selling 'marketable goods' [Sack and Clark 1979: 291] or selling their labour for miniscule wages to European plantation owners. The German Annual Report for 1907-08, for example, stated that head tax payments for people in the hinterland of Kieta would be increased 'only after the establishment of large-scale plantations, offering the natives work opportunities and provided their labour [was] paid for in cash' [Sack and Clark 1979: 291]. Later on, people began growing cash crops like coconuts and cocoa in order to pay head tax, something that intensified under the Australians, especially after World War II.

Colonial head tax policy had a number of consequences. It made access to cash essential and began the process of commercialisation of the local economy, stimulating desire for European goods and the money needed to obtain them. The desire for money encouraged cash cropping, which in turn resulted in tsunono and tuhikau dividing up ngorere land to give each family a block of land to plant such long-term crops. The chiefs could not have foreseen that one consequence of this practice would be to reduce their power.

The Germans had also introduced a system of appointing village chiefs (luluai) in 1896. The luluai were assisted by tultul. The luluai had limited police powers and judicial authority in the villages, dealing with minor legal disputes involving property up to the value of 25 marks. As insignia of office, a luluai wore a cap and carried a staff, supplied by the government. They did not earn a salary but received occasional small gifts from the Administration [Sack and Clark 1979: 171, 195]. No mention is made in the Annual Reports of the actual appointments of luluai in Buka. According to Firth [1982: 86] however, Buka men who had served in the German police since the 1880s had returned to their villages and, by 1905 , were serving as unofficial luluai 'enforcing loyalty to the Germans'. Appointments were presumably made after the Germans established their first Bougainville administrative post in Kieta, in 1905. The Australians continued this system of 'native' administration until the introduction of local government councils in the 1960s.

The German Annual Reports for 1905-06 and 1907-08 show that, from the very beginning, Administration-appointed village officials were not readily accepted and were not shown respect. Village people in Bougainville, as elsewhere in the mandated Territory, had their own leaders who commanded attention. These leaders had control over resources, which gave them renown, power and esteem. The Administration-appointed headmen (luluai) often did not have control over such resources, and thus were not easily accepted.

In north Bougainville and Buka, so Blackwood wrote in 1935 during the period of Australia's trusteeship, the Administration often made inquiries about 
who the natives wanted as their luluai (or kukurai, as Blackwood identified them according to local practice). ${ }^{8}$ Where possible, someone who was already a tsunono (tsunaun) would be chosen, in which case the tsunono was 'materially strengthened by the fact that his authority is already recognised in the village' [Blackwood 1935: 48]. When a tsunono declined to become an Administration functionary as well, or was judged by the Administration official to be too old or too stupid, another man would be chosen at the discretion of the official. In such cases, Blackwood commented, 'the natives are obliged to acknowledge him, [but] he continues to rank, in their estimation, as a commoner, and his position is not an easy one, unless he is friends with the hereditary head of the group' [Blackwood 1935: 49]. She admitted, though, that the colonial practice of appointing village headmen had distorted the powers of the traditional leaders (tsunono). 'Exactly what the powers of the tsunaun were in the olden days', she wrote, 'it is now very difficult, and perhaps impossible, to ascertain' [Blackwood 1935: 48].

Douglas Oliver, writing in 1955 about his late 1930s observations of the 'Siuai' (Siwai) of south Bougainville in 1955, made similar observations to Blackwood's about Buka a few years earlier. He observed that the appointed village officials were the proper persons to arbitrate in disputes [1955: 406]. However, in many Siwai villages, people preferred their traditional leaders to be the arbitrators, 'leaving the bypassed [appointed] headman only those cases involving violations of such Administration regulations as failure to do road-work and failure to maintain a "line" house in good repair'. The traditional leader may have lacked the physical force of the headman appointed and supported by the Administration, but the former's 'decisions and assessments [were nevertheless] usually executed' [Oliver 1955: 407].

With the passing of time and with the declining authority of traditional leaders, some Buka chiefs sought to bolster their positions of power by combining their traditional leadership with a position of authority bestowed on them by the government or some other modern agency. In the Haku village of Lumanmanu, for example, the chief of one lineage was appointed luluai in the 1950s. He persuaded other chiefs in his sub-clan to agree that since he was already a government representative in the village, he should also become munibil of all Naboen in Haku.

The competition between 'traditional' chiefs and government appointed officials for power and authority in the villages has continued to this day, each claiming legitimacy from a different source, one 'traditional' and the other 'modern'. The incorporation of new political systems into an existing situation of competition and rivalry has deepened the ambiguity of rank in the 'traditional' system. This was indicated to me during an interview with a Naboen informant. 
Although I already knew the answer, in order to find out what he knew on the subject, I asked him to identify the munibil of Nakaripa. He identified Donatus Mola as the munibil. This was not true, according to my Nakaripa informants. Mola was tsunono of his sub-clan, but not of all Nakaripa. It seemed to me that my Naboen informant identified Mola just because he had been a Member of the House of Assembly and had held a number of ministerial portfolios until he lost the 1977 elections.

\section{WORLD WAR II TO PAPUA NEW GUINEA'S INDEPENDENCE, 1975}

After World War II, the Australian colonial Administration looked for new ways to govern the colony. In 1949, elected government councils were established in the Gazelle Peninsula, Milne Bay, Port Moresby and Manus [Waddell 1975: 13] and, in the late 1950s and early 1960s, they were introduced in Bougainville. The Buka Local Government Council (BLGC) was established in 1961 [Rimoldi and Rimoldi 1992: 87]. The largest such council in Bougainville, it covered all of Buka and the off-shore islands of Petats, Matsungan, Pororan and Hitou, and included three different language groups. In the council's early years, most councillors were traditional chiefs who also happened to be wealthy [Anis 1977]. As the years passed, traditional leaders began to fail to live up to the expectations of their people, and younger men started to replace them. As Connell [1977] notes for all councils in Bougainville, traditional leaders had 'certain ability derived from the consensus elements in traditional society' [Connell 1977: 137] but lacked other skills that would enable them to engage with others, including Europeans, beyond the village [see Morauta 1974]. Younger men, of whom some were also genealogically placed to become tsunono, were seen to be 'more confident debaters and administrators' [Connell 1977: 137] and were elected to replace the 'old guard'.

Opposition to the BLGC began as soon as it was established. The main source of opposition was the Hahalis Welfare Society (Welfare). The Welfare launched a two-pronged attack; one on the BLGC, the other on the tsunono. Welfare opposition to the council is well documented by the Rimoldis [Rimoldi 1971; Rimoldi and Rimoldi 1992]. Leaders of Welfare knew about the work and the failures of councils in other parts of the country, particularly the Gazelle Peninsula. They accused the colonial government of exploiting the people by collecting taxes from them without giving something back. The aim of the Welfare was to help people to work in order to bring about development in the villages. But the people of Buka were divided into two opposing groups, one supporting the Council, the other the Welfare. According to Laracy [1976: 139], 
this division was along traditional 'moiety' lines, with the Naboen supporting the Welfare and the Nakaripa the Council. This view is not supported by data I collected in Haku. In 1965, most Haku chiefs, both Naboen and Nakaripa, and their people joined the Welfare. They left their villages to live in Hahalis and only a handful of chiefs remained in the village and were regarded as Council supporters.

The BLGC did not, however, bring any form of tangible development to its 'supporters'. It was the Catholic Church, through its resident parish priest in Lumanmanu, Father Paul Lemers, who tried to assist the people to bring about some qualitative changes. He organised Haku chiefs and others who had not joined the Welfare, or who had left it, to form the Haku Development Society. Money was collected and Father Lemers bought sawmilling equipment with which timber was cut and people began building permanent houses for themselves.

The Welfare also challenged traditional (established) leadership in Buka, seeking to limit the powers of tsunono. My informants in Lontis told me that Teosin (Welfare leader) and his henchmen stopped the practice where a tsunono cohabited with women betrothed to men in their lineage and clans before they went to live with their husbands. They also attempted to abolish other practices. As Laracy [1976: 136] noted:

At a more complex level, it [the Welfare Society] was an expression of change within the traditional authority structure and represented the reaction of the young men against the power of older leaders, a motive which led the Welfare to abolish bride price, ending the tsunono's exclusive privilege of access to a number of women and their traditional right to control the marriage and sexual life of their subordinates.

Interest in, and support for the BLGC had in any case begun to decline in the late 1960s and early 1970s. In the early 1970s, in most parts of Bougainville, village governments, covering much smaller areas than local government councils, began to replace councils. Connell [1977] observed that these village governments were strong and most active in areas that supported Bougainvillean secession - and Buka was not in favour of secession. My informants in Lontis, however, told me that a village government existed in Haku before the introduction of community governments in 1978. They said that under the village government, tsunono had increased authority over their people. People listened to them because they represented kastom and held traditional power while at the same time representing the government in their villages. As tsunono, they could make hamal (curse) on people 
who disobeyed them. As councillors, they could take disobedient people to court. As a result, people feared and obeyed their leaders, and this was seen as enabling things to work better in the villages.

Finally, it must not be overlooked that Christianity also made incisive incursions into traditional life during the colonial period. The Catholic missionaries of the Society of Mary (Marists) were the first missionaries to arrive in Bougainville and Buka via the Shortlands. The Marists tried to integrate aspects of local customs into Catholicism and give them Christian meanings. After the Marists opened up a station at Burunotui on the west coast of Buka in 1910, they took in young men who were in line to become tsunono, and trained them as catechists. These catechists, together with their wives (tuhikau), brought the Bible to Haku.

Catholics in Haku take pride that Catholicism was first brought to them by their chiefs, and not by foreign priests. Although the catechists were not priests, a link had nevertheless been entrenched symbolically between the new religion and the tsunonos' traditional role as priests and mediators. For Haku chiefs, then as now, the introduction of Christianity was merely an extension of the religious spiritual economy which included traditional religious beliefs as well as Christianity. This point was brought home to me after I participated in a ritual sacrifice on behalf of a sick woman who was believed to be held captive by spirits. It involved the offering of food and pork to those spirits in a masalai (spirit place). Knowing that the tsunono who had officiated in this ritual was at one time a Marist Brother, I asked him what the parish priest at Lumanmanu would say if he heard about what we just did. He just stared at me and said:

And what would he say? There is only one God. We call him Murkohiongo. Christians call him God. Everything comes from him. Jesus is not only God. $\mathrm{He}$ is also a tsunono, the chief of all the tsunono. That is why I invoked his name first. I asked him to accept our sacrifice and make [the sick woman] well. Then I called on the juntun [autochthonous spirits of particular masalai places] and the spirits of our dead relatives.

\section{HAKU CHIEFLY POWER IN THE POST-INDEPENDENCE ERA}

\section{The Provincial Government Debates and the Rhetoric of Traditional Leadership}

The emergence of Bougainville ethno-nationalism in the later 1960s and 1970s, and the development of the provincial government there, brought with it a debate 
about the role of traditional leaders. The debates and the negotiations leading to the granting and establishment of provincial government in Bougainville have been ably dealt with by Mamak and Bedford [1974], Conyers [1976], Ballard [1981], and most recently by Griffin and Togolo [1997]. I will focus here on the rhetoric about traditional leadership in these debates before discussing roles of traditional leaders following the establishment of provincial government. Almost without exception, the leaders of the groups that emerged during the early 1970s' debates on secession and provincial government envisaged a new Bougainville in which traditional leaders would have had important roles. Even the district (later provincial) government would be built on the wisdom of traditional leaders.

The Kieta-based Napidakoe Navitu Association (Navitu), which drew its membership from central Bougainville, included traditional leaders and advocated 'a return to traditional life and customs' [Mamak and Bedford, 1974: 59]. It sought to 'restore, maintain, foster and encourage among the people of Bougainville an understanding and appreciation of their traditional culture' [Griffin 1982: 124]. Navitu members treated traditional leaders with great respect. Its leaders were selected by consensus in opposition to the Kieta Local Government Council whose members were elected according to a Westernimposed system of democratic elections [Griffin 1982: 124]. Navitu, therefore, provided a potent role model for other parts of Bouganville.

The rhetoric of the Bougainville Special Political Committee (BSPC), established in 1973 to plan for a district government for Bougainville based on traditional leadership, is best summed up in statements made by its leader, Leo Hannett. Comparing the functioning of local government councils with the way traditional leaders operated, Hannett told a meeting in May 1973 that:

The council system has been with us for more than twelve years yet the old people continue to ask: 'When will change come to our village?' One fault of the system is that it is based on an alien conception of political rule and organisation. It does not take into account the traditional system of leadership or the ways in which our elders used to exercise their authority in the past. The method of recruiting people to run the councils, for instance, has always been a source of embarrassment to our established traditional leaders. I have discussed this problem with some of them. They say, 'Why do we have to stand for election when we are big men in our own right?' Yes, if these men wish to work within the council system, why should they first have to shame themselves in front of the people like that? I think the time has come for us to find some way of allowing our traditional leaders to play an effective role in 
the new political organisation we hope to establish here. In order for this new organisation to survive it must be based on those traditional values and customs that are good and conducive to development. Here our traditional leaders could work together very effectively and in harmony with the young men [quoted in Mamak and Bedford 1974: 58].

At the same meeting, Hannett atacked the Western-imposed legal system that he said was undermining the authority of traditional leaders.

How often do we hear the case of a village elder attempting to bring some lawbreaker to justice, only to find that the offence committed is not recognised under the present regulations? How much more embarrassment must our elders be made to suffer? We must restore the traditional system of justice (customary law) so that our recognised elders can once again dispense justice and help perserve [sic] the integrity of village social structure [quoted in Mamak and Bedford 1974: 58].

Hannett was instrumental in the drafting of a submission to the parliamentary committee preparing Papua New Guinea's Independence constitution - the Constitutional Planning Committee (CPC) — when it visited Bougainville in July 1973, calling for Bougainville to be granted district (provincial) government, as an alternative to secession. Traditional leaders would be incorporated into the governmental structure to run the affairs of their own villages. Village government would make up the lowest level of provincial authority in the new Bougainville, but it was certainly not to be seen as the least important [Mamak and Bedford 1974: 77]. People in different areas of Bougainville would decide on how traditional leaders could help in making the villages good places to live, doing away with problems brought about by externally imposed local government councils. Leadership in village governments would be exercised in the manner that it was done traditionally' [Mamak and Bedford 1974: 77]. Traditional leaders would settle disputes relating to traditional matters such as land ownership, marriages and other minor problems. They would be either elected (modern system) or appointed by consensus (traditional way) to the village government [Mamak and Bedford 1974: 77]. The incorporation of traditional leaders in the proposed district government structures would enable them to be recognised as they were in the past. They were, however, to work closely with young, educated people in their villages. 


\section{Community Governments in Haku}

Village governments were established in the mid-1970s, but were replaced by larger and more formal local government bodies when the North Solomons Provincial Government (NSPG) passed a provincial law in 1978 to introduce a new community government system. Smaller than the previous local government councils but larger than the village governments, community government membership was to be either elected or appointed. The six Haku villages formed one community government area. According to my informants in Lontis, community government members in Haku were elected rather than appointed. Although some tsunono were elected to the Haku Community Government (HCG), in its initial stages most of its members were non-tsunono.

Eventually, it was younger leaders who were elected, apparently being seen by the people as being more capable than traditional leaders. In Lontis for example, the people voted a tsunono as their councillor in 1980, and he was then elected as the chairman of the HCG. In this capacity he worked together with chiefs of different villages and clans to carry out small projects in the villages. Before the introduction of village courts in 1983, tsunono in each village in Haku worked together to resolve disputes. Although the tsunono from Lontis regained his village-based seat in the following election, he lost the chairmanship of the HCG to a younger, university-educated man. Many of the village-based projects that he had initiated were forgotten. The new chairman was more interested in provincial politics and wanted to use the community government as a steppingstone for election to the NSPG.

\section{Village Courts in Haku}

Village courts were introduced in Bougainville in 1983, intended to function primarily as informal mediation forums in which traditional leaders would play important roles. In Haku they provided a new arena for contestation and claims to legitimacy in what was a struggle for power between tsunono and young educated men. A 1988 NSPG report, which I discuss further below, stated that village courts were stopping traditional leaders from settling disputes in their villages [NSPG 1988a: 10].

The Haku experience of village courts was in fact quite different. According to my informants, the HCG often recommended tsunono for appointment as village court magistrates. In Lontis, for example, all village court magistrates were tsunono, who tried as much as possible to use kastom in dispute resolution. I was told that villagers were generally satisfied with their performance. Some tsunono feared, though, that as young educated men were taking over the community government, they would recommend young men who were not tsunono to be 
appointed as village court magistrates. We do not know whether this would have happened because the Bougainville crisis brought an end to the young men's control of the community government.

\section{Proposals for Establishing Councils of Chiefs}

Towards the end of the 1980s, there was growing concern in Bougainville about law and order problems, and the weakening of traditional custom (kastom) and traditional authority was identified by many people as a major contributing factor. The NSPG proposed strengthening traditional authority by establishing councils of chiefs, and research into this proposal was commissioned and a report provided in 1988 [Sabin 1988; NSPG 1988b]. The purpose of the councils of chiefs would have been to:

- revive good Bougainvillean customs and teach them to younger generations;

- maintain social order in the villages;

- replace village courts as the forum for conflict resolution using custom as opposed to law; and

- replace community governments (eventually).

The report to the NSPG put much of the blame for the decline in traditional authority on village courts and community governments. Community governments were criticised for not allowing traditional leaders to participate in the running of community/village affairs. One of the original aims of community governments was to enable village people and their leaders to participate in government and bring about development in their communities. Instead younger, educated people used the community government to pursue their own political aspirations.

Village courts were blamed for taking away the dispute resolution tasks of traditional leaders and rendering them almost useless. Village court magistrates and other officials were not traditional leaders. The NSPG appointed these village court officials, usually younger educated people, after consultations with community governments. They usurped the dispute resolution roles of the traditional authorities [Regan 1995: 7], resulting in the power struggle already mentioned [Regan 1995: 1], thereby contributing to a breakdown of social order. Village courts were seen to lack credibility because, firstly, they did not involve traditional authorities. (According to the report to the NSPG, village courts did not even recognise traditional authorities.) Secondly, they modelled themselves on introduced courts and had become too formal. ${ }^{9}$ Village courts were meant to operate informally and make use of traditional dispute settlement methods and remedies, just as traditional authorities used to do in the past [Regan 1995: 8]. Instead, under young leaders they had become more like the higher courts. 
Although my informants in Lontis blamed the NSPG more than any other provincial institution for the erosion of the authority of traditional leaders, the report to the NSPG allocated only one paragraph to the role of the Provincial Government itself. Yet, the statement is quite powerful, suggesting that the NSPG had failed to live up to the rhetoric of traditional leadership preached by provincial leaders in the pre-provincial government debates. The report states that:

Ever since Provincial Government was granted to this province, our traditional leaders were never officially recognised by the Government. They [the traditional leaders] seem to remember that they may have been involved in a little way during the early stages of Village Government. This is as far as they got, and then ... the Provincial Government deliberately discarded them [NSPG 1988b: 10. Emphasis added].

The report defended the NSPG, claiming that the alleged discarding of the traditional leaders was not intentional. The NSPG had always wanted to involve traditional leaders. It was, however, 'the nature of the system that was given to the people' [NSPG 1988b: 10] that failed to get the traditional leaders involved in provincial politics. There had been little serious consideration of the report when the Bougainville conflict started in 1988.

\section{RECONSTRUCTING HAKU CHIEFTAINSHIP DURING THE BOUGAINVILLE CONFLICT, 1990-93}

The Bougainville conflict saw a cessation of formal government, at least from the time of the withdrawal of National Government forces in March 1990, and brought chaos in most villages in Haku as well as Bougainville generally. One response was the re-invention or reconstruction of traditional authority [see Filer 1992]. In Haku, as in many other areas, a Council of Chiefs (COC) was formed. The impetus for this reconstruction of chieftainship in Haku can in part be traced back to debates on strengthening traditional authority in the 1987-88 provincial government era. But more importantly, after the March 1990 cease-fire, the idea of forming COCs was also encouraged by the Bougainville Revolutionary Army (BRA) who had taken over Buka after the withdrawal of Papua New Guinea forces from March 1990. Some tsunono also claim that they developed the idea of forming the COCs together with their educated men, most of whom had left their jobs in Kieta and Arawa because of the conflict. Whatever the source of this idea, tsunono and educated men worked together to reconstruct traditional authority in Haku. 


\section{Negotiating Membership of the COC}

The formation of this COC, however, was not without difficulties. Problems emerged when members of various matrilineages - in particular sub-clans argued with each other over who was entitled to occupy what positions in the leadership structure within the sub-clan. The arguments centred particularly on who were the members of senior lines descending from the first settlers-cumfounders of the sub-clans. Tsunono from other sub-clans had to mediate in these disputes. In most cases they had to re-work genealogies to determine who was entitled to what positions in the sub-clan.

There was one major dispute at the clan level involving the position of munibil of the Naboen. There was a reworking of genealogies and retracing of history in this particular case. The incumbent, Munibil Ruits Henina, was told that his female ancestor had migrated from Petats and settled in Haku, and he was not entitled to be munibil of Naboen because his uncle, Tato, from whom he inherited the position, was not genealogically placed to be munihil. Tato had gained the position of munibil only because the Australian colonial authorities had appointed him a luluai and village leaders at the time thought it would be wise to give him the position of munibil as well. The ngorere of Havini, who claimed to be rightly entitled to the position of munibil, argued with Henina and told him to go back to Petats. Henina got into a mona (boat) and was sailing away, but other tsunono stopped him by offering him paiou and beroana (that is, strings of shell money and flying fox teeth). Tsunono from other pinaposa were called on to mediate and the dispute was resolved on the understanding that the position would be transferred to Havini's ngorere after Henina's death.

\section{Chiefly Power and Chiefly Identity: The Haku COC , 1990-93}

When all these disputes were resolved, each sub-clan selected one of their tsunono (often the most senior tsunono - that is, the patu) to represent them in the COC. The number of tsunono representing each village depended on the number of localised sub-clans in that village. Lontis, for example, has 14 sub-clans and therefore had 14 representatives on the Haku COC. Members of the COC then appointed 10 senior tsunono to form a kind of executive committee, known as the Assembly of Chiefs (AOC). Here again membership was negotiated. In Lontis, there was a dispute between Nakaripa and Nakas clans over membership in the AOC. Nakas wanted to take all three seats reserved for Lontis, arguing that they were more populous than Nakaripa. In the end, Nakaripa got one seat and Nakas two.

One of my informants, who was a member of this inner group, told me that they were the decision makers. The other tsunono executed these decisions. Indeed, tsunono who were members of the COC, but not the AOC, told me that 
they really did not have a function. According to them, the senior tsunono formed the AOC mainly to show others that they were of higher rank.

It is clear that the COC became an arena for contestation between tsunono. One tsunono informant told me that the main reason for forming the COCs was to enable the people to see who the real chiefs were. It provided the ground for contest whenever chiefs reworked genealogies in order to lay claims to senior positions in their sub-clans, and thus membership of the COC. The ambiguities of rank in Haku society made such contests possible.

Between May and September 1990, BRA groups from mainland Bougainville began going through Haku villages and other parts of Buka, harassing people suspected of siding with the National Government and its military forces. The tsunono then decided to allow their young men to join the BRA. The purpose of this BRA wing in Haku was more to protect the people from harassment than to propagate and adhere to the ideologies of Francis Ona and his followers. ${ }^{10}$

In September 1990, Haku chiefs were among Buka leaders who invited the National Government authorities and the Papua New Guinea Defence Force (PNGDF) back to Buka. The PNGDF landed first at Kessa near Lontis on 19 September 1990 and later made forced landings at Buka Passage. The BRA wing in Haku sided with the chiefs and the PNGDF and were among those who formed the Buka Liberation Front (BLF) which supported the PNGDF in driving the BRA out of Buka during late 1990 and 1991, bringing Buka back under Papua New Guinea control. The situation on Buka remained unsettled until around 1993, and as a result the enhanced power and authority of tsunono that had developed from March 1990 continued to some degree.

\section{POLITICAL RIVALRIES IN THE POST-CONFLICT PERIOD}

\section{Post-Conflict Socio-political Reconstruction}

In the absence of any form of government authority from March 1990, tsunono filled the vacuum. With the return of National Government in late 1990, rival political structures began to be put in place that challenged the power and authority of the tsunono. Field notes (in translation) of an interview with one of my main informants illustrate the point:

'... after the withdrawal of the PNGDF, there was no government in the villages and tsunono felt that they had power ... they really had power to control the place [villages] during the crisis in 1990.' 
'It seems that at that time tsunono really had power because they controlled the place and maintained law and order in the absence of government.'

'Tsunono were strong leaders ... they showed strong leadership during that time [1990] until 1993.’

And yet it was tsunono who were among those who asked for the return of the PNGDF, and the main reason I was given for this was the need for both security and the return of government services, such as health and education. One informant said: 'We had no guns [to protect our people] and the BRA from the other side [meaning the main island of Bougainville] would come and attack us.' The one serious health problem that people had then was tropical ulcers, which they could not treat with bush medicines. Small ailments (for example, coughs) were treated with bush medicines. Another concern which tsunono shared with the people was the shortage of clothes. 'We have become used to wearing clothes, and it would have been really shameful for us to go around naked', one man told me.

But it was also the return of the PNGDF and the establishment of government services that also caused the decline of tsunono's authority. Tsunono have tried to rationalise what happened by saying that they took on the responsibilities of government in the 1990-93 period only because there was no government. After its return, they gave responsibility to the government while retaining their traditional roles. One tsunono put this in a fanciful way saying that they gave back to Caesar what belonged to Caesar but hung on to what was theirs. ${ }^{11}$

In early 1991, the Buka Interim Authority (BIA) was established, following the passing of the Bougainville Interim Authorities Act 1991 by the National Government (exercising the powers of the NSPG, which has been suspended from August 1990). The purpose of this law was 'to establish interim authorities in Bougainville to assist in the restoration of services in Bougainville ...' [GPNG 1991]. The BIA was one of several such bodies established in areas of Bougainville where National Government authority was re-established (at least in part). It was a legally constituted government, unlike the COCs, and covered the whole island of Buka and the off-shore islands (an area previously under six community governments). Tsunono had some participation in the BIA, but this body was large and seemed remote from tsunono and ordinary village people. For them the COCs were still 'the governments'. But the authority of chiefs through the COC was declining due to the presence of higher government structures in the form of the PNGDF, the provincial administrator (representing the National Government), the administrative arm of the suspended NSPG, and the BIA. By 1993, government and business services had been largely re-established in Buka and in the 
process tsunono gradually moved back-stage. By 1996, with the passing of the Bougainville Council of Elders Act by the re-established provincial government renamed the Bougainville Transitional Government (BTG) - tsunono had in the main returned to their traditional roles in their ngorere and sub-clan.

\section{The Politics of Legitimacy: Tsunono Versus the Council of Elders}

The power and authority the tsunono enjoyed in the 'new way of exercising traditional authority' through the COC AOC ended with the establishment of the Leitana Council of Elders (LCOE) under the Bougainville Council of Elders Act of 1996. This was 'an Act relating to Local-level Government based on the custom of the people of Bougainville and the traditional authority of the chiefs and clan leaders of the people of Bougainville.' [BTG 1996]. Two of the underlying goals and principles of the Act are to ensure:

- that the structures of local-level government are based upon and take full account of the customary structures and institutions of clan, sub-clan, village, family and marriage and the customs of the communities of Bougainville;

- that the authority and power of persons inherent in those customary structures and institutions are asserted more fully so that the character and personality of each person can be better formed or reformed in ways that reflect the highest values and standards of the community. [BTG 1996]

In practice though, the Leitana Council of Elders (LCOE) contravenes these two underlying goals of the Council of Elders Act, at least in the Haku experience. The LCOE has practically brought Buka and other parts of Bougainville back to what Somare [1991: 106] has aptly called the 'tyranny of the ballot box'. It is a return to the pre-crisis electoral politics criticised in the 1988 report to the NSPG on the establishment of Councils of Chiefs in Bougainville. The LCOE now has elections that are mostly contested and won by young, educated men who contest with tsunono for power and authority in the village. In Lontis a general view advanced by both tsunono and ordinary people is that the LCOE has destroyed the work and the rule of tsunono in the villages. According to tsunono in Lontis, the young educated members of the LCOE are more concerned about money - "poket moni as the tsunono put it - than with serving the people. My survey indicates that most village people in Lontis believe that the LCOE has not done anything for the people of Haku ${ }^{12}$ (wok ino kirap — nothing has been achieved). During the time of my fieldwork, LCOE members seemed to be more concerned with provincial and national politics than with what was going on in the villages.

A number of tsunono in Lontis indicated to me that they did not want to contest the LCOE elections because to do so would demean their positions as 
'born chiefs'. When an election for the Bougainville People's Congress ${ }^{13}$ took place in May 1999, the LCOE decided that in Buka only tsunono would participate in electing representatives for the Buka constituencies. However, not all the men who nominated were tsunono, and on the appointed day, not all tsunono turned out to vote. A tsunono in Lontis, who did participate in the election, told me that most tsunono did not turn out because they did not want to be used as the LCOE's 'rubber stamp' (Ol i laik mekim ol tsunono kamap raba stemp tasol - they want the chief to be just a rubber stamp). Another tsunono, who did not participate, told me that there was no point in taking part because the LCOE and the Bougainville Peoples' Congress are not 'true government'. He said these governments were just yalsa (floating in the air or on water with no roots in the ground). According to this chief, a true government for Bougainville would be one that involved tsunono in higher levels of government and administration. In his view, tsunono should have been allowed to choose to appoint someone from their own ranks to the Bougainville People's Congress. He did not like the idea of the LCOE gathering up tsunono to vote for non-tsunono.

\section{CONCLUSION: WHAT FUTURE FOR HAKU CHIEFS?}

Haku chieftainship has survived over 100 years of colonial and post-colonial impacts. It may not be the same as it was at the time of contact by foreign intruders, but it has survived while at the same time being transformed in various ways. Haku people do not seem to want to do away with chieftanship. Despite their disappointments with certain tsunono, Haku people generally feel that they are unique in being among the few societies in Bougainville and Papua New Guinea who have hereditary chiefs. It gives them their cultural identity. It would be hard to do away with tsunonoship in Haku.

It will also be in the interests of tsunono themselves to ensure that the institution persists. Tsunono believe that they are born leaders, unlike present-day politicians who are elected and have to assure the people that they represent of their leadership qualities within the official political system. Tsunono believe in their inherent authority and that this comes from God (Murkohiongo). This belief is important in that:

- it gives legitimacy to tsunono's power and authority; and

— it gives tsunono a sense of being different from elected leaders.

In Haku society today, tsunono are performing their customary roles in their own pinaposa (sub-clan) and ngorere (matrilineage). Popular perceptions are that tsunono in Lontis are performing their duties very well at this level (pinaposa and 
ngorere) but that the cooperation among tsunono at the village level is minimal. Ordinary men and women want their tsunono to organise themselves again as they did in the period 1990-93 and work together at the village level as well as the wider, linguistically defined Haku area. Tsunono on the other hand argue that it is the task of the LCOE to look after the people at the village level and beyond. They want to deal with the concerns of their own matrilineages and sub-clans. But if the formation of the Haku COC during the crisis is anything to go by, one can be assured that if an urgent future need arises, tsunono should still be able to prove their responsible leadership in the wider Haku sphere.

\section{Endnotes}

*This paper is based on information I gathered during fieldwork in Lontis, Buka, where I spent one and a half years. I have no intention of disparaging any person or organisation. All shortcomings in this paper remain my own.

The research for the fieldwork was made possible through support from AusAID (Australian Assistance and International Development) branch of the Department of Foreign Affairs and the Research School of Pacific and Asian Studies at the Australian National University.

Included among those persons who assisted in various ways mention must be made of Thomas Betitis, Philip Bulut, Mathias and Carol Horn, Rosa and Peter Kaia, Mathias and Albert Terea, Edward Kaia, Roselyne Kenneth, John Komarin, Thomas Maru, Mark Mosko, Paschal and Elmah Nangoe, Louis Patei, Alan Rumsey, Regina Sagir, Ignatius Sopolo, Amos Tami, and Jude Thamo. The list of those who assisted is, however, too long to include everyone here.

1. Lumanmanu means house of the eagle; from luma (house) and manu (eagle). The name was changed to Lemanmanu during colonial times.

2. Lumankoa means house of the fowl, from luma (house) and koa (fowl). As with Lumanmanu, the name was changed to Lemankoa during the colonial era.

3. Patu and gohus are often used interchangeably to refer to the same political office. Gohus would be specifically applied to heads of branches or off-shoots of the main sub-clans.

4. The tubikau is the female counter-part of the tsunono. The relationship between a tsunono and his sister, who is tubikau, is a perfect example of gender complimentarity, expressed in terms of brother-sister sibling solidarity. Rimoldi and Rimoldi [1992: 175] suggest that the tsunono's power and status derive from his sister who is tubikau (teitahol in Halia): '... the woman of chiefly rank inherits her status from her mother, and by virtue of her status her elder brother becomes tsunono' [1992: 175].

5. Although this ngorere was genealogically the most senior in the Nakaripa sub-clan, it did not have the same rank and status when it joined the Nakas sub-clan. The simple reason for this is that this ngorere is not an original Nakas ngorere.

6. The ruko as a social institution was used in traditional Buka society for two main purposes. Firstly, it was used to initiate young men into their respective societies. Secondly, it was used to maintain order and equality in society. In this second case, if chiefs saw that one individual had too much of something (for example, fish), they would conspire among themselves and agree that something should be done. One of them would then go the concerned person's house. Another would go into nearby bushes and make the ruko (spirit) sounds with a bull-roarer. 
The chief who had gone to that house would then tell the inhabitants that he would go and find out what the spirits wanted and would go into the bushes. Upon his return, he would tell the inhabitants of the house that the spirits wanted some of the fish they had. The inhabitants would then give the fish to this chief to take to the spirits. The fish would be shared among the chiefs involved.

7. Firth does not state when this interaction between the Germans and the two Buka chiefs took place. His sources are German reports and correspondence dated 1904, 1905, 1907, 1908, which means that this could have taken place in the late 1890 s or early 1900 s.

8. In Tok Pisin a rooster. Originally a term of mockery directed at those who strutted as new leaders and 'crowed' for the foreign Administration, it became homogenised through widespread use, losing its original meaning as a rebuke.

9. This was not a problem peculiar to Bougainville. Throughout Papua New Guinea, complaints were, and still are, being made about village courts being too formal, like higher-level courts, notwithstanding the fact that they were intended to function primarily as informal forums and are so described in the Village Court Act of 1973, which brought them into existence. In my village in Madang, for example, people decided to establish an alternative dispute resolution forum, made up of village elders and youth and women's representatives which dealt with problems in a more informal manner than did the village court. The main focus of this alternative forum is mediation, rather than adjudication. Other writers have noted that not long after their establishment in 1975, village courts were being accused of being 'too Western' [Gawi et al. 1976: 264]. Specific examples of the operation of village courts are provided by Westermark [1978], for Agarabi, Eastern Highlands and by Scaglion [1979], for Abelam, East Sepik.

10. This is not to say that there were no strong supporters of the BRA cause in Buka. The Haku area was in fact divided into those who strongly supported BRA and those who did not strongly support it but had to join up as a means of protecting their people.

11. It echoes a saying in the Bible which would have been familiar to tsunono catechists. It is a statement by Jesus about the separate responsibility a citizen has to the secular ruler or authority (for example, Caesar at the time of Jesus) on the one hand, and to the spiritual god, or religion, on the other hand.

12. The counter-argument from the Lontis member of the LCOE is that the LCOE has not been given sufficient funds by the National Government to carry out its work more efficiently.

13. Editors' note: The Bougainvillle People's Congress was elected under 'informal' arrangements intended to meet the requirements of the Lincoln Agreement for the establishment of a Bougainville Reconciliation Government. For discussion of its origins, roles and operations see Regan [2001: 12-13]. 


\title{
LAND FOR AGRICULTURE - SILENT WOMEN: MENS' VOICES
}

\author{
by Roselyne Kenneth
}

E ntitlement to land constitutes an important base for a person's status in Haku society on Buka Island. Associated with it are political consequences for the individual as well as for the society. This chapter focuses on the part played by both men and women in negotiations and decisions governing access to agricultural land in their communities, especially the part played by 'maternal uncles' 1 and womens' voices in such processes. It also examines to what extent sociopolitical changes have affected the standing of women and their authority in contemporary society.

On occasions when matters about customary land are discussed, the scene is dominated by men. A first impression is therefore that although the society is matrilineal, it is the men who dominate socio-political life. However, from the perspective of traditional Haku society, absence from public life was not the same as lacking power. The traditional position of women, although rarely exposed in public, included the power to exercise authority, especially in matters concerning land and other inherited rights. Thus, if women remain silent during public meetings, it does not mean that they lack the power to exercise authority in certain matters.

\section{CONTEMPORARY SOCIAL STRUCTURE IN HAKU}

\section{Location}

The name Haku derives from the dialect spoken by approximately $12,000^{2}$ people divided between five main villages. ${ }^{3}$ The Haku dialect is one of the four dialects that make up the Halia language which is spoken by the inhabitants of the northeast and south coasts of Buka and the villages of Selau on the northernmost part of 
Bougainville Island. The description, Haku, is a recent name and previously the dialect was called Ha Lonteis, (literally, for Lontis).

In matrilineal societies, membership to social groupings is reckoned through the female or mother's line and recruitment is by birth. There are three main social groupings that Haku people identify — clans, sub-clans and matrilineages. Clan members can usually trace their connections about six generations back. However, clans and sub-clans are not corporate groups since their members live over a wide area and are not tied by much internal organisation. Clan members do get together for certain purposes. When a dispute erupts between clans over land, meetings take place to provide solidarity and for discussion on how to protect the interests of one's own group. Also, when a person dies, those related to the deceased at clan level come together to mourn, to bury the dead and to participate in the mortuary feasts. They also cooperate in bridal payments. Clan members do not necessarily share feelings of solidarity — indeed, there are often feelings of rivalry between lineages.

Solidarity and cooperation are confined to the matrilineage which is the most important social and economic unit. It is through membership in a lineage that the individual finds a sense of belonging, by knowing which portion of land he or she owns and is entitled to, who is his or her leader, and with which people he or she is expected to interact and to coorporate.

Haku society is in some senses aristocratic. The lineages making up a clan are ranked. The most senior lineages in a clan not only have a higher status but have liberties in the use of land and other resources. However, the system is not static. Subordinate lineages are expected through sorcery and violence to attempt to take over the rights of more senior lineages. Because of fear of elimination through sorcery, efforts are made to protect the heads of the more senior lineages, and their successors - even if they are children.

\section{Impact of Colonialism and Development}

Significant socio-economic changes began to occur in Haku during the colonial days. They influenced the Haku people to depend increasingly on cash income, imported food items, clothing made of cloth and various new forms of transport. Hand in hand went a change in people's attitudes towards the values and norms enshrined in their traditional culture. Nowadays, the Haku depend heavily on foreign imports for luxuries such as radios, guitars and tape recorders, as well as the Western staples of tea, sugar, tobacco, flour, rice, tinned meat and fish to supplement home grown foodstuffs. They have learnt to depend on modern fishing equipment and gardening tools and on Western-style clothing. Money is also required for school fees and to meet the cost of medical treatment and 
associated medicines. It is needed for all manner of household requirements, deemed essential nowadays to a greater or lesser degree. Most of the 'modern' staples have been integrated into the ceremonial exchange systems such as bride price and mortuary feasts. The goods and the money either come primarily in the form of remittances sent by relatives who live in the urban centres elsewhere in Papua New Guinea, or through money earned from cash crops and the sale of food items at markets. Today most extended families have some form of 'business' to make money. It may be through ownership or a share in a trade store, a PMV (public motor vehicle) or bus, by the use or the loan of an outboard motor, or by the sale of food at weekly local markets and stalls.

The Haku perceive development as activity that will bring in money or that utilises material not locally made. Trade stores are valued highly by both men and women, especially in times of feasting because goods obtained from the store are integrated into the ceremonial system.

\section{LAND}

\section{Land Tenure}

Haku land symbolises the historical and cultural distinctiveness of the clan. Each clan is identified by reference to its land, where its ancestors first settled and were buried, and where its sacred sites have been established. These sites contain rocks, pools of water and animals that serve as guardians of the land. Official ownership of land, like succession and inheritance, is traced through the mother's line. Rights to land include access for subsistence agriculture, for the cultivation of cash crops and for residential purposes.

In Haku tradition, maternal land provides material and social security for the women. Once a woman has inherited land she becomes the sole owner of it. Even if, after marriage, she went to live with her husband and his people, her birthright to her land and that of her children can never be taken away from them. Male relatives, such as brothers and uncles, have access to maternal land for subsistence and cash crop purposes, but at their death the ownership of even the cash crops that they plant on such land reverts to their maternal relatives.

The traditional land tenure system also enshrines the aristocratic arrangements of the Haku. Because the chief's lineage ${ }^{4}$ is the highest in rank of the three lineages making up a clan, it occupies the central position on the land. Traditionally the male chief and his eldest sister's houses would be in the centre of the hamlet so that they could be protected at all times. The chief's lineage's access and dealings with land should never be questioned. 
Once, according to tradition, land tenure was more flexible than it is now, and usufructory rights to land were passed beyond the clan and matrilineage to affinal and other distant relatives. The male head of the clan had the right to sell land either to other people from Buka, or to expatriates, although rarely would he do so without consulting other clan elders first. Moreover, every firstborn son of a chief was allowed the same rights on his father's land as his father. Children of male lineage members thus were allowed to live on their father's land, and had access to property owned by their father. When the father died, these rights were forfeited however and reverted to the father's sisters. The widow and her children were never asked to move out immediately, and the shift only happened when the mother and children voluntarily decided to move to their natal land. A newly married couple could choose where to live. As the husbands' family would still reside patrivirilocally, this was the more common residential pattern.

Migrants would initially be allowed a temporary settlement site. They owned no land and could not plant cash crops since this inferred permanent ownership; still they were able to make gardens. Rights to own land were only accorded to migrants who were distant relatives and if they had also contributed generously and sufficiently in ceremonial feasts and bride price transactions.

\section{Land Use}

The Haku are particularistic about land and each area is named according to what it is used for and according to its location. The settlement site is called a han. The unoccupied area close to a village or houses is referred to as the oping which, when translated into English, means uninhabited. A newly cleared forested area is called a lopo (literally, newly chopped). Sometimes people conserve an area because it contains special plants like canes for house building and food preparation, herbs for ritual and medicinal purposes, or it might be a breeding spot for an endangered bird, or a dancing ground. When a section of forest is cleared, small islands $(t o l o)$ of vegetation are left standing here and there. The original forest is called ioruhu, a place faraway, while secondary regrowth is called kobkobul (literally meaning 'no longer fertile').

\section{Land Use - Subsistence and Agriculture}

The sweet potato, introduced in relatively recent history, became a substitute for taro after World War II when taro blight almost wiped it out [see Kenneth 1994]. This resulted in major changes in diet, in gardening practice and in land use. Taro makes heavy demands on the soil, and a patch that has produced a crop cannot be used immediately as the soil needs time to recover. In order to avoid frequent famine, gardening practices were altered. Taro land is now either left fallow in 
order to become regenerated or used right away to plant sweet potatoes, tapioca, yams and other vegetables. These crops do not necessarily require newly cleared land. They can be planted continuously in the same plot of ground to produce successive harvests. Apart from the famine caused by taro blight after World War II, the subsistence economy has probably changed little since pre-colonial times. Vegetable staples and gardening techniques have also persisted. However, new crops such as maize, tomatoes, beans and pawpaws were introduced, although initially these were grown on a small scale mainly to satisfy the needs of a small expatriate community.

\section{Land Use - Cash Crops}

Cash crops of copra and cocoa constitute a major source of financial income for people in Haku. Most commercial coconut plantations were established in the 19th century and coconuts have since constituted the principal commercial activity on the islands of Bougainville and Buka [Kenneth 1994]. The plantations were controlled by Europeans and were established on land confiscated from the local population before World War II. Haku men gained experience as labourers on plantations and when they returned home they started to grow their own cash crops. This new form of enterprise was encouraged partly through the availability of traders who purchased small quantities of processed copra. Since the 1950s copra production has increased due to high prices, the upgrading of the east and north coast road in the early 1960s and the establishment of the Copra Marketing Board Buka Sub-Depot in the 1970s [Kenneth 1994]. The trend has not changed so that in the 1990s much attention was still given to cash cropping. The production of copra depends on the availability of coconuts, and only those who own many trees can produce copra regularly.

Cash cropping is considered male work, and thus it is mainly men who are engaged in the production of copra and cocoa, while women control the subsistence sector. This 'modern' separation between cash cropping and subsistence has led to inequality and competition, so that while women play an important role in agricultural activities which take up most of their time, they find it hard to generate cash income on a daily basis. The development of the plantation economy has therefore, as a rule, had a negative effect on women's productive activities.

\section{Land Use - Business Activities}

Land in Haku is also used to build trade stores, fermentaries and workshops that aim to make a profit. They are owned either individually or at family level. Some of these activities are the major causes for land disputes. 


\section{WOMEN'S ABSENCE FROM LAND DISCUSSION IN PUBLIC}

Despite the fact that women are the owners of the land, there are many factors that keep them from involvement in negotiations and public discussions over land. They can be classified under the headings of cultural, social and geographic constraints.

\section{Cultural Constraints - Protection (Status, Safety and Secrecy)}

On a superficial level, it might seem as if women do not have the power to make or influence decisions about land. However, closer scrutiny reveals that women are never alienated from the political and economic sphere. The continuity of the clan is secured only through its female members and their biological capacity to give birth to new members. Equally the political authority of the senior lineages is secured only through its female members. The line of power is constantly challenged, however, by the lower-ranked lineages of the clan who try to harm the members of the senior lineage through sorcery. Thus, women's physical absence from public roles is seen by other members of the high-ranked families as a necessary measure to protect the continuity of the line of power from outside forces and from competitors. If a woman with a high rank is publicly seen by an 'enemy' group to be discussing land issues, it could endanger not only herself but all those present on that occasion. Women's absence from public life, thus, is a measure taken to protect them from physical injuries or sorcery that might endanger not only their lives but the continuity of the clan.

Where instantaneous reaction takes place, disputing groups can pick on any of the male or female members present to harm them or to destroy property belonging to the opposite party. The aim, the Haku say of their enemy, is to get rid of the assertive and knowledgeable members as a way of crippling the opponent.

Hence women's absence from public life is not due to the ambitions of men promoting their own interests. More importantly, exclusion from the public sphere does not mean that women cannot exercise influence.

Thus the Haku live in constant fear that those who hold important knowledge pertinent to land and other clan affairs, become targets for enemy groups. Knowledge about the clan and its history has to be treated secretly and younger women, the future generation of mature women, are being educated privately by their mothers or the seniors of the clan. Women who attend meetings where land and clan issues are discussed, thus, transmit the knowledge to their children, especially daughters, in private. 


\section{Cultural Constraints - Family and Affinal Ties and Commitments}

As land disputes can be traumatic and divisive, some men and women choose not to take part, even when their families are directly involved. This is especially problematic for those who settle on their spouse's land, and then find that a dispute arises between their respective kin.

The relationship between affines forms one of the main taboo situations for the Haku, to the extent that they cannot even mention each other's name. The kinship system with its prescribed rules of behaviour restricts the individual's behaviour in meetings where in-laws are present. Respectful behaviour is very important and fear of breaking any rule is enough to make people conform.

In pre-colonial days, marriages were often arranged between clans that were potential enemies and who competed for the same land areas. Land border disputes were a main reason for hostility between groups. Women who lived on their husband's land would choose not to take part if the husband was from the disputing party. If a wife chose to participate, custom would oblige her to side with members of her own kin, and thus unsettle her relationship with her in-laws, or the people she was living with. Participation in meetings, thus, would also be discouraged by the fact that it was more important to foster good and lasting relationships throughout married life. Nowadays marriage no longer serves the same purpose of being a peace mechanism. This change is contributing to a steady increase in the number of land disputes, not least between couples who may share a land boundary through their respective kin groups.

\section{Social Constraints - Age}

A woman's age determines whether she is allowed to participate in discussions on land. Haku women receive knowledge through a long process that starts when they are children, and continues throughout their lives. Thus the individual's level of knowledge follows her physical age. By the age of 18 they have not received enough knowledge to participate in decision-making processes. Those who have reached the age of about 35 are regarded as having advanced in their knowledge, but still do not have enough to participate in decision-making regarding land. Responsibilities therefore rest on the older, mature and knowledgeable members of society seen as best suited to argue in disputes. Through their experience, old and mature women have the capacity to infer from previous events. They are not as emotional as the young women, and are thus able to reach the 'right' conclusions. The most aggressive and assertive women are those in the age group between 30 to 50 years, while younger women form a silent group of passive participants absorbing knowledge of issues concerning land. 
Men also, particularly maternal uncles, must reach a certain stage of maturity before they can participate in public meetings. Men and women of high-ranking lineages are equally exposed to the dangers that might occur during public encounters, but while women choose to stay away as a precaution the men still perform their public roles as leaders, observers and supporters.

\section{Social Constraints - Fear of Formal Settings}

As mentioned above, Haku women are often restricted in their performances through prescribed rules of behaviour. The women fear that if they perform in public, they might be forced to break some of these rules. Land disputes particularly could be life threatening. At times the police are sent for. In such instances, any participant could be arrested and taken in for questioning. A woman, if arrested, would have to confront the authorities who might be men who, according to the rules of custom, she is obliged to avoid. Women therefore fear exposing themselves to embarrassment in public dealings. From past experiences of what has happened to other members of the community, the women are well aware of the implications for their reputations if they are charged with offences by the police. Some women therefore claim that the best way to avoid trouble is to refrain from attending all land disputes.

\section{Social Constraints - Christian Beliefs}

Another reason why some women may choose to refrain from participation in land disputes is that the possible outbreak of violence on such occasions contravenes the Christian ideals of peace and love. Even though their land rights are at stake, they might refuse to take part in disputes in order to maintain peace in the village. To avoid conflicts they may even share land with people who are not members of their lineage or clans. Some women's eagerness for peace and harmony has resulted in their becoming more resilient, sympathetic and kind to others. Also the conviction of some women that land belongs to God leads them to hold firmly that it is not a resource over which people ought to argue and fight.

\section{Geographic Constraints - Lack of Access}

Some women are physically alienated from participating in matters that concern their maternal and clan lands because they live on their husband's property situated some distance from their natal villages. Distance may also prevent them receiving continuous information on what is happening with their maternal land. Often they are informed about such matters well after important developments have occurred, either when relatives visit or when they go home for a visit. Women who have migrated to urban centres experience a similar situation, and it 
is only when they come home for holidays, and after they have been informed about past and present matters, that they can participate in meetings that take place while they are in the village.

\section{Cultural Conformity and Social Change - Women's Gradual Exposure}

Buka's coastal society is not static. As well as experiencing change through the normal development processes, Buka has been exposed and open to outside contacts and influences since at least the late 18th century [Blackwood 1935]. One should not take for granted, however, that such changes necessarily have been seen by Haku as wholly negative. The Haku have adapted to contemporary society through structural changes in their political economy and social institutions. The impression I have gained, both through field studies and as a member of that society, is that the Haku have been open to change and are eager to test influences from outside as well as to incorporate aspects of these with their own customs.

\section{LAND ISSUES AND DISPUTES}

Land disputes arise because of problems with ownership, usage rights, undefined boundaries and economic development leading to unequal distribution of wealth. Since land does not increase correspondingly with people's demands and desires, they have to find alternative ways of acquiring and conserving land.

\section{Land Shortage}

Two important factors contributing to land disputes are population growth and the increasing monetary value of land. The population of Haku has been constantly increasing in the last 50 years [Kenneth 1994]. When the Bougainville 'crisis' struck and then intensified, many people sought refuge at home. For an area already experiencing population pressure, a sudden further population increase brought still more pressure on, and competition for, available land and resources. As well, by the 1980s, Haku land was increasingly being valued in monetary terms. It thus became not only a scarce, but also a valuable resource. People, therefore, were forced to find new strategies to use and distribute already limited resources. This, in turn, resulted in certain traditions being undermined, modified and abandoned.

\section{Inheritance Patterns}

One common source of argument concerns access to property on the father's land. When disputes emerge, the father's sister's children may actively try to stop their maternal uncles from giving their own children access to resources. Women are 
afraid that some of their male relatives may abuse their caretaker roles and use cash crops that the women regard as planted for the lineage to benefit only the children of those relatives. Some complain that men engage in business activities on their maternal land for the benefit only of their own children and wives, while the traditional landowners receive little. In such instances, women often exert pressure on their male relatives to move to their wives' land so that they can invest for their own children (who, of course, belong to the mother's lineage). Also the tradition of allowing each firstborn son the same rights on the father's land (prior to the father's death) has been done away with.

\section{Land Boundaries}

Land boundaries are unseen and usually are marked only by natural features such as rocks, or by planted trees, or roads leading to the bush, or inland. These boundaries are not surveyed and knowledge of them is merely passed on orally from one generation to another. This form of identification has become very unreliable because the natural features that have been used as markers may have disappeared, or changed their character over time, and may be easily contested. As a result, encroaching on other's boundaries is an increasingly common strategy to acquire land and to extend boundaries.

Uncertainties resulting from unclear boundaries cause most disputes nowadays. They become complicated where land for houses or for cash crops is concerned. Women increasingly feel it is their duty to back up their kinsmen in disputes and in attempts to ward off 'outsiders' who, by force, try to encroach beyond the borders of their own land in order to build houses and to plant cash crops. Such disputes tend to be aggressive, and women have ended up removing and chopping house posts to stop settlement, or uprooting coconut plants and splitting the nuts open to stop further planting. In a number of cases, women have participated directly in the arguments, while men participated as backups. Such a role would have been impossible in the old days where women's safety was paramount.

\section{Disintegration of Affinal Behaviour}

While some women place priority on their relationships with their in-laws and their nuclear families, others consider these relationships as subsidiary to their concerns for their matrilineages in relation to issues regarding land. Due to land shortages, traditions that once regulated relationships between people are now being defied. Consequently, women who are nevertheless expected to follow proper customary behaviour can no longer afford to keep quiet, since they feel obliged to argue even in disputes with affines, often including their husbands' relatives. 


\section{Freedom from Danger}

The most aggressive group of women is that between 35 and 50 years old most of whom are married and have children. Female children and women who belong to the chieftain's line are especially valued and are therefore seen as vulnerable to danger from other groups, especially lower-ranked families of the clan. They are thus in need of constant protection. It is only when the girl has grown up, and has given birth to a female child, that a dangerous focus is no longer on her. She is no longer the youngest, or last born in the line, and the attention, and risk of attacks from outside, is transferred to her child. Mothers are freer therefore to perform in public and to participate openly in issues regarding land.

\section{Changes in Residential Patterns}

The freedom that married people once had in their preferences to set up their residence is now limited. Once, if a family settled on the husband's maternal land, it could remain there and grow gardens with ease, but only for as long as the husband was alive. Upon his death, the widow and her children were expected to take up residence on the woman's maternal land. They still had access to food gardens and cash crops on the husband's land. Today couples are more restricted in their choices. They can either settle on their husbands' land for a while, or can settle uxorilocally (in the locality of their wife's maternal group) right away. Apparently, uxorilocality has increased. The reasons are varied. Many women now allow their brothers to settle with them on their natal land. When such a brother is ready to move to his wife's land, whatever he has invested in his maternal land, such as cash crops, tend to remain with his sisters. Increasing uxorilocality has also empowered women who are members of the same lineage to meet on a daily basis, to tackle together matters of common interest and to voice issues of mutual concern.

Women also prefer to live on their maternal land since they have more freedom to establish economic enterprises with less risk of interruptions. Cash crops involve a great deal of work and money. Investments are made many years before income from crops begins to pay them off. For this reason the majority of women find it safer to establish themselves on their own land so that they will not, at some future time, be asked to move away (as when the husband dies).

\section{Education and Exposure}

The modernisation process has opened many doors for women, enhancing their mobility. Women are achieving higher levels of education and are being much more exposed to the outside world. Consequently they begin to question what it means to lose land to government bodies and to other forms of development projects. Absence from maternal land does not alienate women from their land. 
A migrant's attachments and commitments to the customary land to which she has entitlements does not diminish. On the contrary, education has encouraged women to fight for their land. Thus women are tending to become both more assertive and more aggressive when there are threats that land may be taken away from them and they are not being properly compensated.

Both formal education and a flow of information through the mass media have not only stimulated more wide-spread awareness, but have also brought a new rhetoric concerning land and the natural environment. Lessons and experiences from the Bougainville crisis have now given many Bougainvilleans insights into what it means to protect and safeguard land. Nowadays in Haku the words 'landowner' and 'compensation' are frequently used even by men and women who have never gone to school and by those too young to understand the meaning of these terms.

\section{Loss of Trust}

For as long as the Haku followed 'tradition', the power that women enjoyed was never directly challenged and their birth rights to land were respected. Today, however, women feel that they have to fight for these and that as a result there are times when they can no longer remain silent. It is not outsiders only who cause the tensions that lead to conflict. The growing inequality in the distribution of resources from maternal land is also an important source of trouble. The primary reason for inequality is that the ever-increasing demand for cash cannot be met because the resources which the land can supply are limited. In order to give equal opportunities to all those who have rights to land, there is pressure on the male leaders to rescind past decisions on allocation of land for cash cropping and business activities. There is also growing dissatisfaction with male leaders who sometimes do not consult the clan (and women especially) before allowing business projects to be associated with their land. Such male leaders might receive money that they do not account for. Together with other influential individuals, they may exploit their lineage members and benefit personally from opportunities which, according to traditional rules, ought to be benefiting the whole group. Women especially are concerned about fairness in the distribution of benefits from economic development projects within their groups. Some are now trying actively to intervene, interrupt or disrupt such activities.

It is not only women who complain that increasingly there is a lack of proper accountability of monetary compensation for land. It is also younger men who have not as yet achieved any prestigious positions who tend to be concerned. Some development projects initiated without the consent of all the lineage members have been stopped, disrupted or even burnt down, when clan members 
have felt that their leading men and the developers have been inconsiderate and dishonest. In such conflicts the younger male members of the affected lineage or clan usually join their female counterparts to question their leaders. Similar defiance may follow the tensions created by the unequal distribution of the resources of maternal land. For instance, male leaders may secretly receive money as compensation for resources they do not personally own. Women particularly are concerned about unjust practices associated with economic development projects within their groups.

\section{CONCLUSION}

Women's absence from public life cannot be regarded as an indicator that women lack the means to be influential in their society. Haku political and economic power was in the past more or less confined to the women. Men functioned mainly as their spokesmen in public. Although it may seem that even in present day Haku society men continue to dominate, in practice, in much that is important in public life and decisions regarding land, it is in fact the women who have become more influential due to the increasing value of land.

It may be the case that in matrilineal societies there is a constant challenge to women's roles in the ambitions of men to dominate them and to put patrilineal interests first. As a result it is hard to avoid conflicts over land use and issues of compensation. Central Bougainville provides an extreme example of the problems that can occur. During the pre-Independence period when arrangements were made to obtain access to customarily owned land for a giant international mining company (see Davies, Vernon, and Togolo, all in this volume), the authorities ignored the true landowners and those who are really in control in their society because compensation tended to be paid to the male spokesmen.

To understand the relationship between the men performing their public roles and the 'silent women' in Melanesian communities such as Haku, it is important to describe and analyse the active workings of the matrilineal social structures. In Haku a maternal uncle certainly tends to play an important role. At the same time it is necessary to recognise and acknowledge that in matrilineal societies such as Haku, the authority traditionally accorded to women continues to be of critical importance. In many respects that authority is at least of equal weight to that displayed by men, and it outweighs the more visible authority of men regarding decisions governing the ownership, access to and uses made of land and its resources. 


\section{Endnotes}

1. Maternal uncle is emphasised here as the society is matrilineal and rights to land are reckoned through the mother's line.

2. A Haku chief's estimate.

3. These villages are Lontis, Lemankoa, Lemanmanu, Hanpan and Eltupan. As to the origins of, and alternative spellings for, the names of Lemankoa and Lemanmanu, see Sagir (endnotes 1 and 2), this volume.

4. Lineages comprise female relatives such as his sisters, maternal aunts and their children (and male children of female members as well). 


\title{
SNAPSHOTS FROM NASIOI, 1963-2000
}

\author{
by Eugene Ogan
}

\begin{abstract}
R eturning to Bougainville after an absence of 22 years left me with a kaleidoRscope of impressions that I am still sorting through. The month of July 2000 seemed both too long and not nearly long enough to enable me to produce a careful analysis. Here I find it more appropriate to borrow from Bill Clarke a rhetorical device from an earlier collaboration [Clarke and Ogan 1973] and to offer a set of verbal snapshots, taken at different points in time during the 38 years I have visited the Nasioi speakers of central Bougainville. Snapshots cannot be more than suggestive, but may at least hint at the extraordinary changes I have observed in Nasioi lives since 1962.
\end{abstract}

Note where the camera of my memory has been pointed:

- at Nasioi, not at other Bougainvilleans;

— focused most closely on villagers, not on an educated elite or political leaders; and

- always aimed to record the passing of generations, as the elders have departed and the children look toward an uncertain future.

\section{3}

My first set of snapshots was taken at a time when villagers were eager to express their unhappiness about the lives they led under what I later [Ogan 1996] came to call 'plantation colonialism'. Indeed, just six months before my arrival in central Bougainville in November 1962, some of them had made it clear to a visiting United Nations Commission just how dissatisfied they were with colonisers who 'treated them like dogs'. They had even suggested a change in administration, 
from the Australians who were then responsible for the United Nations Trust Territory of New Guinea, to Americans who had apparently made a positive impression during World War II. I found it hard to get their lives in focus because so many of them confused my presence with the possibility that I might bring about such a change.

Villagers had by then been exposed to six decades of European interference in their lives, often to no purpose that they could appreciate. Missionaries Catholic, Methodist, Seventh-Day Adventist — had brought them versions of Christianity, but beliefs and attitudes still reflected earlier dependence on ancestral spirits to ensure the good things in life. However, what had come to dominate their lives since the war was a political economy based on plantation agriculture.

Three large plantations had long been established on land once belonging to Nasioi: Aropa, Toboroi, and Arawa. ${ }^{1}$ Until World War II war, the town of Kieta had served as district headquarters for first German and then Australian administrations. Removal of this centre to the island of Sohano made Kieta a backwater in which the administrative presence was less significant than the plantations and missions. Nasioi had been replaced (by labourers from elsewhere in Papua New Guinea) as plantation workers after the war, but the tone of their colonial situation — in particular a prevalent racism — had been set in large part by the planter community. This presence was symbolised by the Kieta Club, located on high ground looking down on the natural harbour. Nasioi only entered the Club as servants; rules limited membership to Europeans. Below the Club was the Kieta Hotel, newly established by the owner of Toboroi Plantation. Though the hotel had a liquor license, it served no alcohol lest Nasioi or other Papua New Guineans — who had obtained the privilege of drinking alcoholic beverages in 1962 demanded service.

In villages of the Aropa Valley where I lived, people were striving to improve their material welfare by expanding cash crops of coconuts and cocoa. Administration efforts to assist (for example, by forming cooperative societies) were not always welcome, and were further handicapped by the irregularly available services of an extension officer. Marketing crops remained a problem, though planters sometimes bought trade copra or wet cocoa beans from villagers. The assistant district officer was most troubled by the frequency with which 'development' seemed to become entangled with supernatural beliefs, generally called 'cargo cult' by Europeans. Too often, what began as an apparently straightforward economic effort (for example, to establish a village trade store) foundered on villager inexperience or lack of education. In such cases, Western-style economics was often replaced by rumours about a 'better way' to obtain prosperity through assistance from ancestral spirits or the Virgin Mary. 
Indeed, educational opportunities were still limited for Nasioi in 1963. Plantation labour had certainly not provided much opportunity to learn about modern technology. No Nasioi resident in Kieta even knew how to operate a motor vehicle, much less repair one. Mission schools were less concerned with secular skills, like simple bookkeeping, than with doctrine. The secondary school run by Marist Brothers at Rigu served the entire Bougainville District and chances for admission were limited; the same was true for the girls' secondary school at Asitavi. ${ }^{2}$ There was no government school available to Nasioi.

The school age population had not yet fully recovered from wartime privation; there was a 'waisting' (narrowing or reduction) of the 15-25 year age cohort in the population pyramid. The traditional method of birth spacing by means of a postpartum tabu on sexual relations between married couples had only recently begun to weaken [Ogan, et al 1976]. At the same time, efforts to eradicate malaria were beginning to lower infant and maternal mortality from that disease.

So a snapshot of Nasioi life in 1963 would have revealed considerable frustration, particularly as villagers compared their lot unfavourably with what seemed to be the wonderful material world they saw the European community enjoy. There were few facilities available that would have granted them entry to that world, while decades of plantation colonialism, together with wartime experiences of apparent abandonment by Europeans, had left them suspicious of the good intentions of outsiders.

\section{2}

The contrast between snapshots of Nasioi life taken in 1963 and in 1972 is startling, though social change always reveals some continuity with earlier times. It is also important to keep in focus some changes that are less directly connected to the development of the Panguna copper project [Davies, and Vernon, both this volume], although certainly that development had come to dominate the image of Bougainville in the eyes of others.

Nasioi lived in a new landscape. What had been the small colonial town of Kieta, surrounded by plantations, mission stations and schools, and villages, had been completely rebuilt. A new 'industrial suburb' called Toniva appeared to the south. Arawa Plantation had been transformed into a town, combining administrative headquarters with residences for government and mine personnel. A giant industrial project had been carved out of mountainous tropical forest, creating a copper mine with its new town, Panguna. To service the mine, a deep water port had been created at Loloho (Dodoko), formerly the site of a small plantation. 
Roads connected the four localities. Social scientists now spoke of an urban complex, with a whole new population of outsiders and an equally novel set of social problems. By 1971 the urban population of southeast Bougainville had grown to more than 14,000, about 15 per cent of the district total. About 5,500 of these urban residents were Europeans, compared to a handful in 1963 [Bedford and Mamak 1976: 445-8].

All these changes had been brought about by the developing copper mine, but not all Nasioi were equally affected. Those in the Guava census division bore the most profound burden: losing land, having to relocate villages, watching their forests disappear, while being forced to listen to heavy machinery pounding away 24 hours a day. Nearer the coast, land had already been lost to plantations; additional losses most severely affected Torau speakers of Rorovana [Togolo, this volume], less so Nasioi. Villagers living in the Kongara highlands might hardly have been aware of mine construction, were it not for the helicopters flying constantly over their homes. In the Aropa Valley, younger men were drawn into employment by one of the many sub-contracting firms building towns and other infrastructure. However, the farther south one traveled from Panguna, the more Nasioi were concerned with other economic opportunities.

Expansion of the Kieta wharf had begun in 1966. Its completion in 1967 gave new marketing incentive to cash-crop production. Indeed, between 1962/63 and 1972/73, Bougainville's smallholder copra production went from 2,398 to 8,696 tonnes, smallholder cocoa production from 94 to 2,030 tonnes. (Thus of all Papua New Guinea provinces, Bougainville took third place in producing copra, after East New Britain and New Ireland, and second place for producing cocoa, after East New Britain.) As the economist David Elder [cited in Denoon 2000: 16] observed in 1970, Bougainville enjoyed 'rapid indigenous agricultural growth ... which was laying the basis of a prosperous future, with or without copper.'

Economic development narrowly defined made up just one part of the picture of Nasioi lives that one could construct in 1972. Educational opportunities had expanded almost exponentially. New government elementary schools were part of urban development. Although mission schools still predominated at the elementary level, there were new government secondary schools at Buin, Buka and Arawa open to all Bougainvilleans who could meet admission requirements. That admittedly small percentage of Nasioi and other Bougainvilleans who had been able to complete mission secondary schools was well-prepared to take advantage of the newly established University of Papua New Guinea.

Another element in opening up educational opportunity came from Bougainville Copper Limited (BCL). In the face of Papua New Guinea's 'long neglect of education in general and especially technical education' [Denoon 2000: 
149], the company was at pains to localise its work force for both economic and political reasons. BCL has made much of its record of apprenticeships, scholarships and on-the-job training [see, for example, Vernon, this volume], and even the company's severest critics ${ }^{3}$ would have to note the contrast with what had existed 10 years earlier. As Denoon states, the direct impact on Nasioi in this respect as in others was highly uneven. However, by 1972 Nasioi accounted for about 45 per cent of all apprentices and 50 per cent of the highest paid Papua New Guineans [Denoon 2000: 168-9]. Furthermore, there was a more subtle form of education going on among those Nasioi most exposed to the changes of 1972, one that might have gone unnoticed by those unfamiliar with the 'malign effects' [Denoon 2000: 160] of plantation colonialism. By working side by side with Europeans and doing the same kinds of work - even if at a relatively unskilled level - Nasioi could now see themselves as potentially able to attain goals they had once thought beyond their reach. They could 'unlearn' the lessons of their alleged inferiority taught by European racist attitudes during the previous six decades. As Bedford and Mamak [1976: 467] noted for the urban context, the 'white elite no longer controls ... to the extent it did in the sixties.'

All the social change visible in 1972 inevitably had other, often negative effects that cannot be discussed at length here, but one in particular demands mention. In 1971 many of the subcontractors who had employed some 6,500 workers from other parts of Papua New Guinea [Denoon 2000: 151] finished. However serious were the efforts of these employers to repatriate their workers, in fact an unknown but high percentage stayed on, beginning the settlement of squatters that would become an explosive problem in future years.

A different kind of population explosion attracted the attention of Nasioi who had been relatively unaffected by the mine. More and more elders began to comment on the large numbers of children they saw, and wondered where they would find land for the kind of gardening and cash cropping which had previously been basic to the livelihood of most Bougainvilleans. Even among those who had not lost the thousands of acres taken by the mine and associated developments [see Denoon 2000: 104-05], thoughtful Nasioi villagers had begun to worry about land shortages.

\section{8}

Snapshots of Nasioi lives taken in 1978 were so varied that they could be arranged to illustrate quite different stories. Kongara villagers remained relatively isolated from much of the modern economic and social sector produced by the mine. Health and educational services were so concentrated in the Kieta-Arawa-Panguna 
area that Kongara people probably had less access to these than they had enjoyed before 1964. Efforts to establish coffee as Kongara's cash crop in the 1950s and 1960s had never succeeded. Some villagers had exercised rights to lower-lying lands to produce cocoa and copra; some even worked for wages on the cash crops of other, better situated, Nasioi. Except for the relatively few who had received education and training, Kongara people had become marginal to much of the excitement of 'modernity'.

Nasioi in the Aropa Valley and Koromira were more concerned with cashcrop production and the new patterns of consumption that this production made possible. Cocoa and Copra Marketing Board facilities helped to provide cash incomes that were hardly imaginable a decade earlier. New roads made it easy to travel from villages south of Kieta to retail establishments as far away as the supermarket in Arawa. Panguna had its own commercial establishments. In contrast to the shops of Kieta's Chinatown in the 1960s, newly affluent Nasioi were welcome as customers.

Such affluence was very unevenly distributed. In 1974 Mamak and Bedford wrote about "the development of "class" distinctions between Bougainvilleans employed by the company' [1974: 13]. But it was not only Bougainville Copper employees who were becoming 'haves' as opposed to 'have nots' in a society that had never known comparably sharp distinctions in the past. Even older and uneducated villagers who had the foresight to plant cocoa and expand stands of coconuts in the 1960s were able to build houses according to European standards and to buy motor vehicles. Within a single village, such new 'big men' could employ their fellow villagers as labourers. Social discord that might ensue was very much conditioned by the degree to which the new 'haves' at least appeared to attend to more traditional social obligations of feasting and generosity.

One notable sign of discord was increasing conflict between the generations. As a result of public health efforts, especially the anti-malarial campaign in the 1960s and subsequent expansion of maternal health clinics, there was a higher proportion of young people in villages. Despite the establishment of more secondary schools, there was still not enough room for this ever-growing cohort. Nor had traditional society provided such socialising influences as initiation ceremonies for young men. The unsettling effects of this group of males between the ages of 15 and 25 upon village life were most visible in heavy drinking, particularly since outlets for alcohol sales had greatly increased in number throughout the new urban complex [Ogan 1986]. Income inequalities exacerbated intergenerational conflict because older males owned most cash crops in the villages. This was in contrast to the urban sector, where educated younger men had access to higher wage employment. 
Nasioi showed greater unity in the political arena. Compared to other Bougainville groups, their stance had been notably 'anti-Establishment' [see Anis et al. 1977 for a discussion of these attitudes in the context of the 1972 House of Assembly election]. They formed the core of Napidakoe Navitu, a political group that resisted both Bougainville Copper and administration, whether Australian or that of independent Papua New Guinea [Oliver 1991: 184-90]. In national elections, they consistently supported those they felt reflected Bougainvillean interests. (Nasioi who voted for Joseph Lue in 1968 against two European candidates were quick to disavow him in 1972 in favour of John Momis when Lue became known as a 'government man'; see Anis et al. 1976: 449). In the 1975 agitation for secession, Nasioi were the strongest supporters, though not the most visible public figures, involved in that movement [Alexis Sarei, personal commmunication 1978].

Though my 1978 snapshots revealed less discussion of secession in villages, the sense of alienation from the rest of Papua New Guinea had not disappeared. The presence of other Papua New Guineans continued to produce resentment, especially if they made forays from plantations where they were employed or, worse, became unemployed squatters. Mungkas, the Telei word for black, carried considerable political weight as Nasioi and other Bougainvilleans regularly contrasted their physical appearance with that of other Papua New Guinea citizens.

Despite social problems like this and others cited above, I could arrange my snapshots to portray Nasioi as prosperous, enjoying benefits of a modern economy undreamed of 25 years earlier. The few letters I was able to exchange with villagers during the next several years only supported that optimistic view.

\section{JULY 2000}

No such rosy picture could have been produced when I was able to focus again on Nasioi after a 22-year absence. Kieta simply had ceased to exist. Destruction caused by fires started during looting in the period of the conflict had been followed by the overgrowth of tropical vegetation. Only the wharf, re-opened in June, reminded me of what had once been a thriving, though small, commercial centre. Rebuilding the warehouses and other structures needed to restore the wharf to full operation was still in the planning stages. Rigu High School, the training ground for generations of Bougainville leaders, had been razed to the ground. Though the church at Tubiana mission still stood, the surrounding buildings were gone. Toniva, the commercial and residential area south of Kieta, was likewise desolate. Aropa Plantation had been the scene of major fighting between the Papua New Guinea Defence Force and the Bougainville Revolutionary Army and its airport 
was no longer operative save for weekly flights to support the international Peace Monitoring Group assisting in the peace process. The rest of the plantation's facilities were also gone. The Kieta-Arawa area was now served only by light aircraft, operating from Buka with stops at two other airstrips to the south.

The substantial infrastructure that had accompanied the development of Panguna's mine had suffered major damage. Loloho's port appeared from the air to have survived in somewhat better shape, and served as the main base of the Peace Monitoring Group. Loloho provided the only shipping until the security of Kieta's harbour could be guaranteed. I was unable to visit the minesite but was assured by Nasioi that it had been stripped of everything (for example, generators) that villagers could use.

Some rebuilding of Arawa had already taken place under the supervision of the Peace Monitoring Group and with aid from a number of relief agencies such as OXFAM, the Red Cross and the Australian Agency for International Development (AusAID). A health centre had replaced the old hospital (burnt down during the conflict), and plans for a new facility were in progress. The high school was operating, though most of the students I saw were female and past normal student age. Young males were more often seen loitering around the streets. An exception to young men's idleness was Sunday football, played by both sexes boasting fancy uniforms. Nevertheless, the chief image I took away from Arawa was one of burned-out buildings and communication equipment, remains of which were often completely covered over by vegetation to create a surrealistic landscape.

An important exception to this staggering loss of infrastructure was the road that runs from Buka Passage through Wakunai and Kieta to Buin. Although I did not use this for my own travel, I was assured that it was operative and, indeed, members of the Bougainville Revolutionary Army travelled in July 2000 to Wakunai for a reconciliation ceremony with former opponents from the Resistance Force. Feeder roads, however, required considerable work, vital for restoring the once-thriving copra and cocoa industries. Economic development continued to be delayed by the difficult of accessing postal or banking services.

I have noted that my focus has always been on village life. In 2000 I was able to revisit the Aropa Valley area in which I first lived in 1962 and have regularly revisited since, and also to spend almost a week in what villagers still call Number One Kongara. I believe that comparing the two sites and situations sharpened my snapshots.

If Nasioi villagers' reports really reflect in any way the general experience of Bougainville during the conflict (1988-1997), it is hard to credit the oft-quoted figure of 20,000 dead [see, for example, Downer [2001:1], directly from military 
action and indirectly from disease and privation. This figure may have significance purely as political rhetoric, or may simply reflect confusion over the normal death rates to be expected among rural populations that did not enjoy the health facilities available in the Kieta-Arawa-Loloho area during the 1970s andd 1980s. In the Aropa Valley I was told of only one villager killed by the Papua New Guinea Defence Force. In Number One Kongara the army razed two villages suspected of housing Bougainville Revolutionary Army (BRA) headquarters. A Tairima village man reported as having been killed when he attempted to return to his house was regularly named as the area's only casualty suffered in what seems to have been one of the army's few successful operations. Another Tairima man, educated to Form IV, who kept a diary from 1989 to early 1993, insisted that the combat deaths suffered by all BRA elements who came from Number One Kongara - a centre of BRA operations — totaled only 20. He was able to name them and their home villages.

Nor does there appear to have been a significant number of preventable deaths resulting from disease or lack of medical care, even for those who had to abandon their regular residences. On the contrary, both Aropa Valley and Kongara people commented - sometimes with ribald amusement — about the number of children born during these otherwise difficult times. Though I could not make anything like an accurate account during my short visit, the number of children under the age of 12 in both areas exceeded anything I remembered from earlier years. Men I had known in the 1960s as unmarried teenagers could now point to their six or eight living children.

It is certainly possible that the Nasioi experience during the conflict did not reflect that of the Siwai-Buin region, where fighting between the Bougainville Revolutionary Army, on the one hand, and the Papua New Guinea Defence Force (PNGDF) and the Bougainville Resistance Forces on the other hand was reportedly particularly fierce. Furthermore, the apparent discrepancy between the number of deaths quoted in various media and what seems to have been the case in Nasioi is in a way beside the point. If even a few children died because of the PNGDF blockade that prevented shipments of medicine, one is faced with tragedy.

In any event, my snapshots show many healthy children, even though my arrival in Kongara sent the younger group - who literally had not seen a European in their lives - screaming in terror. The old postpartum tabu on sexual relations seemed to have been completely abandoned, and the foundation of a new population explosion created. Adult Nasioi were quick to make the connection between population growth and the increasing number and severity of land disputes. 
The presence of increased numbers of children had led to a concern for education that was new to me. Community schools had boomed in the wake of what Nasioi still call 'the Crisis'. The support they receive from adults (if not always from little boys) was something I had not seen in the past. Most impressive was the new large elementary school I saw built on the site of Damung Village, one of those destroyed by the army. Construction had been carried out through community effort. Village men and women had brought the materials - often paid for by money earned in Arawa at the produce market or in casual labour across difficult terrain. (I, carrying nothing, was unable to negotiate even a portion of their route without frequent stops and subsequent collapse on reaching my final destination in 'new' Tairima.) Even the school's water tank, donated by the Red Cross, had to be hauled up the last miles by manual labour.

This kind of community, or 'grass roots', self-help was one of the most appealing features of my most recent snapshots. I have in the past noted how often villagers seemed to depend upon forces they believed more powerful in order to achieve their goals. I am not prepared to say just when, and for what reasons, these attitudes changed. However, it is not only the most educated Nasioi who now quote some version of the proverb 'Necessity is the mother of invention'. One striking example was the way that Kongara people had created 'mini-hydroelectric projects'. Adapting machinery taken from Panguna, they had created a system of water-generated electric lighting which, unlike the power available in Arawa, keeps villages illuminated 24 hours a day. Another adaptation provided rice for Kongara. In the absence of hulling machinery, villagers have used the old churns formerly used for making the traditional delicacy tama (a pudding made from starchy vegetables, seasoned with canarium almonds). A less positive innovation had been what villagers call 'home brew', though in fact the beverage is distilled to achieve higher alcohol content.

Distilling not withstanding, there is no doubt that Nasioi had profited from their exposure to modern technology during the past 25 years. One young man, assisted by Non-Government Organisation funding and a New Zealand volunteer, had established a Technical Centre in Arawa where he was training dozens of others in welding and carpentry. It seemed to me that it would be highly desirable if relief agencies would utilise such young men whenever possible, rather than employing overseas workers for the massive reconstruction task that is required.

Though secular, self-help activities of this kind appear prominently in my latest snapshots, spiritual matters were still very relevant to Nasioi life. New, evangelical forms of Christianity seemed to have replaced to a considerable degree the earlier established Catholic, Methodist/Uniting Church, and Seventh-Day Adventist faiths. Kongara people were said to now follow a religion that syncretises 
Christian with older beliefs. At least three young men who fought in Bougainville Revolutionary Army ranks told me that their combat experiences had led them to new (unspecified) spiritual awakenings. On the other hand, older Nasioi came to ask my opinion about the supernatural significance of the year 2000 and whether the 'New World Order' of which they had heard was something endorsed by the United States government. Thus, continuity is always to be seen in the midst of profound social change.

\section{CONCLUSION}

A collection of snapshots does not lend itself readily to neat summaries. In particular, I find myself unable to draw up any kind of 'profit and loss' statement as I compare 1963 to 2000. How can one measure loss of life and destruction of so much material wealth against the undeniable fact that Nasioi are no longer subject to a colonial system that denied their personal worth as human beings? For make no mistake: Nasioi in 2000 understood that they were capable of accomplishments that they could not have imagined in the days of plantation colonialism.

I do not pretend to be able to predict the future. Nasioi joined with other Bougainvilleans in 2000 to present a proposal for that future to the Papua New Guinea government. Those with whom I spoke in July 2000 were anxiously awaiting the government's response. Though the possibility of renewed violence could not be ruled out, none of my acquaintances expressed any such desire. (This is why I resent so profoundly statements made by Australians and other outsiders - some of whom have never set foot on Bougainville — who seem to want to disrupt the emergent peace process.) Rather, they talked of getting on with their lives, and restoring the prosperity they had enjoyed in the late 1970 s.

However, I feel it important to mention two factors which could darken any snapshot of brighter prospects for the people whose society I studied and with whom I have lived for periods during the 1960s and 1970s. The first is a potential population explosion. Before the Crisis, Bougainville had one of the highest natural rates of population increase in Papua New Guinea [Oliver 1991: 160-2]. Those Nasioi with whom I spoke in July 2000 were well aware that children filled the villages. Some even associated their growing numbers with increased land disputes. However, the actual dimensions of this growth and the problems almost certain to follow in an island world based on an agricultural economy have yet to be fully appreciated. Who will be able to solve these problems?

Second, traditional Nasioi society was - insofar as I have been able to determine in all of my research - remarkably egalitarian, even as compared to other Bougainville groups. Changing economic conditions have created much sharper 
divisions between 'haves' and 'have nots', whether based on mining, cash crops, or differential educational advantage. (This last point looms particularly large in view of the interrupted education of a whole cohort of young people, that resulted from the conflict.) What kinds of social and economic adjustments must be made to reconcile old and new patterns so as to increase social harmony in the aftermath of recent turmoil?

My snapshots cannot provide answers to these or other questions that confront Nasioi in the 21st century. Whatever value they have may be as a record to be consulted by all those children I met on what could be my last visit ever. It is their future for which I entertain the highest hopes. It is their images that will remain with me forever.

\section{Endnotes}

1. There were a number of smaller plantations but these did not have the impact of the larger three.

2. In 1963, the overwhelming majority of Nasioi were nominally Roman Catholic, so these were the secondary schools they would have chosen.

3. I would like to think of myself as among that number, although the competition is stiff. 


\title{
NAGOVISI THEN AND NOW, 1963-2000
}

\author{
by Jill Nash
}

I

lived in Nagovisi for a total of two and a half years during the period between 1969 and 1973. First, I was collecting data for my doctoral dissertation [Mitchell ${ }^{1}$ 1972]; on a subsequent trip, I was a post-doctoral fellow. After leaving Nagovisi in 1973, I did not return until July 2000, although I had continued to correspond with one individual. I attempted to inform myself about developments though reading and contact with colleagues, but especially during the 'Crisis', this was difficult and not very successful.

In this account, I discuss some important aspects of life in Nagovisi during my first stay followed by my impressions of life in 2000 which I gained in a trip of 10 days in July and August of that year. I paid particular attention on that visit to the subjects I had written about earlier, in order to update my knowledge of them. In this account I discuss standard ethnographic topics - such as religion, landscape and environment, family, exchange, and gender. I also reflect briefly on future possibilities.

$$
\text { 1969-1973 }
$$

On my first trips, I lived in Pomalate Village, very close to the smaller hamlet of Biroi, in Sovele parish, Boku Patrol Area, Buin Sub district. At that time, people in particular areas adhered to a single religion only, although there were skeptics and a few pagans. Pomalate was Roman Catholic — in other parts of Nagovisi, there were areas of Uniting Church affiliation as well as a small Seventh-Day Adventist enclave. The Catholic mission provided medical services and supervised the local Standard 1-6 school at Sovele. The mission personnel were largely expatriate, however, the teachers and one nurse were Bougainvillean. Certain villagers appeared to be extremely devout - most, it seemed to me, less so. As others have commented [Griffin 1990, Laracy 1976], the Catholic Church provided services 
which in other areas of Papua New Guinea might have been the responsibility of the government administration, and consequently, the salience and reputation of the Church in the lives of Nagovisi was probably greater than that of the colonial Administration.

The landscape was varied, with areas of climax rain forest, secondary growth, cleared areas for settlements, plots in various stages of the gardening cycle and areas planted with cash crops - primarily cocoa, but also some coffee [Scott 1967]. Narrow well-worn paths connected villages and hamlets to one another, and to the rivers and gardens. Other than the occasional haus kapa (house with metal roof), dwellings were made almost entirely of bush materials, although purchased nails were frequently used in place of lashing. Most people had two houses, one for cooking and socialising, the other for sleeping and storing possessions. Pomalate village comprised 10 households, thus being of average size. Some villages were larger; others — hamlets - were smaller.

Nearly every family had many children. The completed family size might be as high as 14 children. After a family's size reached about eight (that is, 6 children), some people began to be interested in curtailing further births. Older people commented on the large number of children and spoke of the sanctions that used to be applied to couples who had children too close together. Ideally, birth intervals were long: the first child should be old enough to 'walk'; that is, walk unaided to and from the garden - which apparently indicated an age of at least four years old and sometimes as much as seven years, before a second child should be born [Ogan et al. 1976: 541]. Older sanctions, such as nomma (destroying an erring couple's property), were never put into effect during my stay, despite there having been a birth interval of 1.25 years between the children of one couple. Apart from abstinence and infanticide — the latter rare in modern times but probably occasionally practiced - there were no methods of family planning in effect. Indeed, the subject of family planning was considered by the then South Bougainville representative to the House of Assembly to be comparable to genocide [Ogan et al. 1976: 547].

Kinship ties were traced matrilineally; that is, the children of a couple affiliated with the kin group of the wife. Husbands did not pass on membership in their kin groups to their own children. Residence was uxorilocal; that is, women remained in the village of their birth and husbands moved to wives' villages at marriage. Women controlled land and, with husbands, earned their sustenance through it. Gardens were administered by women. Husbands knew little of the garden plan and did work — including the difficult clearing — according to their wives' directions. Women also managed shell valuables. In practice, husbands and wives worked together on the property of the wife in order to support their children. The married couple formed an important economic unit. Husbands had 
further duties concerning their own kin groups: to advise, give moral support, but under no circumstances to benefit materially from the assets of their own groups. Brothers and sisters were thus concerned with the affairs of the kin group which fell into the areas of policy, advice, and morality and strongly excluded economic cooperation [Nash 1974].

Participation in the exchange system was an important part of life; it consumed much time and energy and produced standing in the community. Mortuary exchanges ${ }^{2}$ consisting of speeches, feasts, even land transactions which settled social debt between husband and wife and their descent groups incurred in the course of the marriage were especially elaborated, with the slaughter and consumption of pigs being mandatory at these times. Many stages of mourning might be observed through feasting and social gatherings, culminating in the allnight sira or singsing (a celebration involving dancing and singing and distribution of food, especially pork). These were times for creative expression, with the manufacture of panpipes, composing and performance of comic and insulting songs, and dancing. Contributing pigs to these feasts validated inheritance of land. There was a small revival of other celebrations, the mavo, or children's 'firsts' occasions (such as eating in the clubhouse, first menstruation), ${ }^{3}$ although certain of these, such as the baptism equivalent and the marriage equivalent, had been replaced by Catholic rites. Shell valuables were used for acquiring pigs, exchanged at marriage and used to resolve issues of liability for serious insult or injury drawing blood. There were also secular celebrations, known as pati (a Tok Pisin term for a moneymaking party or celebration) whose purpose was money-making as well as entertainment. String bands played at these occasions, food was sold, and beer consumed.

Unofficial courts operated to resolve problems large and small (people rarely sought help from the patrol officer at Boku), and discussion of a difficult conflict might take most of a day. Sometimes court was heard by a local government councillor, other times by miscellaneous important men. One of these, Mesiamo, an elderly 'big man', war hero and ex-convict, lived in Biroi and although retired from feasting, gave wise advice. Women said little unless they held a dissenting point of view, in which case, they would speak at length. The Banone-Nagovisi Local Government Council had been established in 1965, but appeared to have little influence or impact.

No one from the areas surrounding Pomalate had undertaken tertiary education, although one Nagovisi man, Clement Takera, from a village higher in the mountains, was enrolled at the university in Port Moresby. To attend high school was daunting: children, often as young as 12 or 13 years, had to leave their families to board at distant schools, not returning until the school year had finished at 
Christmas. Furthermore, school fees were sometimes seen as a great burden. In any case, Nagovisi had ambivalent feelings about the results of higher education: a distrust of the man save (educated man) was widespread, and some of these people did seem to prey on their less well-educated relatives and neighbours. The trade store organiser who collected funds but never distributed profits or reordered inventory was a prototype of such a person.

Cash cropping of cocoa had become widespread, and trees were being planted in abandoned food gardens on a regular basis. To establish a plot of cocoa was a basic requirement for the newly married [Mitchell 1976]. Most cocoa was poorly maintained, with weed removal at intervals being the primary form of care. In order to increase harvests, more trees were planted. Cocoa was dried in local fermenteries or sold as wet bean to the BANA ${ }^{4}$ Cocoa Marketing Society, a locally staffed organisation that purchased cocoa for sale overseas.

Local entrepreneurship took the form of trade store ownership. Sparsely stocked with basics - kerosene, soap and salt — or extensively outfitted with batteries, biscuits, clothing and knives, trade stores were numerous and usually cooperatively funded. Due to excessive granting of credit and irregularities in accounting, they often functioned more as a convenient place to purchase items rather than as a profitable enterprise. Cash flow problems left inadequate capital to restock without additional contributions from shareholders. Profit sharing was delayed indefinitely.

The period of my first fieldwork overlapped with the construction phase of the copper mine at Panguna. Nagovisi were generally sympathetic to the position of the landowners, yet at the same time, there was no reluctance whatsoever to take jobs building the mine infrastructure. Nearly every young man who could went to work there - often leaving a job to come home for a while, confident he would be re-hired anytime he returned to the mine. Panguna was a tumultuous place where young men had many novel experiences and interacted with people from a range of backgrounds.

Self-government for Papua New Guinea was impending; this was a topic of both interest and confusion. In anticipation of Independence, several small 'development societies' (as I called them in 1974) were formed, purportedly to accumulate money. One which was active in my area relied on cultist imagery the Pope having a 'white' bank and a 'black' bank, for example. Other people believed that, after Independence, daily life would remain much the same, with change coming only slowly. Before I left Bougainville for a period of writing in Port Moresby in December 1972, physician Luke Rovin and the teacher Peter Moini, from Nasioi and Buin respectively, were murdered near Goroka in the Highlands in the aftermath of a traffic accident. In Pomalate, people were horrified and expressed 
much negative feeling toward 'redskins', who had killed the two. Additional comments frequently heard included the idea that Bougainvilleans do not do 'payback' killing and that in comparison to mainlanders, 'we are not violent'.

\section{0}

Travel within Bougainville is hampered by poor road conditions and out-ofcommission airstrips awaiting maintenance or repair. Furthermore, white people are not permitted to travel the section of the cross-island road from Arawa to Buin traversing the Panguna region, under the edict of Francis Ona, former leader of the secessionist Bougainville Revolutionary Army, and from 1998 heading the breakaway Republic of Me'ekamui, based in Guava Village, near Panguna. From Buka I took a motorboat down the west coast, disembarking at the Marau River and boarding a vehicle. Many people travel in this way: two motorboats go from Marau to Buka on Mondays and return on Fridays. From the beach, it took two hours to reach Sovele. The road from the Marau was built by Bougainville Copper, but has not been maintained since the company ceased to operate in 1989. There are many areas of standing water and deep mud ruts. The route passed the new Bana High School near the village of Bokokolio. Village layout has changed - each house is set at some distance from others and expanses of grass and ornamental plants grow between buildings. Refinements of construction are evident: houses are built with locally milled timber and second stories on houses are common. Close to Sovele, the route joins the sealed pavement and travel is easy. I needed to walk an additional distance (taking about half an hour) to reach Pomalate Village from the district office.

My walk from the district office revealed additional changes in the landscape. There is a new path, cut parallel to the old one, vegetation having been cut down in order to discourage ambushes during the crisis. The trees which had bordered the path have been removed, many having been used for building materials; pitpit (cane grass) and other new vegetation has grown back in places. The sides of the paths and the slopes down from the ridges were planted with sweet potato during the crisis in order to situate gardens as close as possible to the care centres. ${ }^{5}$ People told me that before regrowth had started, one could see Sovele Mission from Biroi Village, a distance of 1.1 kilometres. The impression gained by walking this path is one of openness; the former path was forested and shady. There is a new hamlet on the path as well.

Pomalate Village, the site of a former care centre, is now very much larger, covering three or four times the area it did in the early 1970s. Indeed, it is contiguous with another hugely expanded settlement, Kaibokokas, previously a small hamlet 
in the bush. (Villages 30 years ago were compact 'line' villages, set apart by large tracts of secondary growth). Some of the size of Pomalate is due to the presence of old, now unoccupied housing from the care centre days, but a whole generation of females has reached maturity, married and produced children. Each has a household of her own.

I did not attempt to take a census so as to accurately obtain information about population increase (although a national census was underway during my visit). However, the children in individual families appeared to be more of similar stature; that is, closer in age to one another than I recall from my previous visit. Birth interval during the period of 1965-72 was approximately 2.7 years [Ogan, et al 1976: 543]. By contrast, the woman in whose house I stayed was 27 years old and had borne five children. I figured that this gave an average interval of 1.58 years (19 months) for her family to date.

People told me repeatedly that there was no more bush left, and the terrain has a cleared, treeless look to it. The motorboat owner who drove us from the Marau river to the district office first mentioned this to me when I commented that Viaare, a woman from Pomalate in her mid-30s who was a traveller with me via motorboat, had told me all women use bilums (net bags used by women on mainland New Guinea) now and seemed not to know what a paake or namme (workbasket) even was (in the1970s, the distinctiveness of Bougainville from the mainlanders was noted by reference to details such as this difference in a carrying device). The driver told me that because there was 'no bush' now in which to gather materials for the workbasket, women bought or made yarn or string bilums. I later learned that people who have access to bush now sell its products to those without access. There are attempts to regenerate the forest: one man is deliberately planting stands of trees. His family also saves wood ash and mixes it with garden soil to prolong fertility and reduce insect pests.

A later trip to a major garden site associated with Pomalate revealed an additional concentration of land use. Formerly, gardens of individual women were separated by areas of abandoned plots and secondary growth at various stages of development. One walked a certain distance between garden areas. Today, women's plots are adjacent to each other; indeed, the gardens look like one enormous cultivated area. Footpaths, not forest, separate individual gardens.

The cocoa stands of sisters now run together and are considerably smaller than the plots of the early 1970s. I wondered about their profitability, but was told that smaller plots will be easier to tend properly. The older 500-tree recommendation of the Department of Agriculture, Stock and Fisheries is locally viewed as too large and leads inevitably to neglect. Older stands are being cleaned and replanted with newer trees that are said to be more productive. 
Soon after my arrival at Pomalate late in the afternoon on Friday, a church service began. This turned out to be one of many held throughout my stay by a new sect known as Christian Life Centre (CLC). A sizeable number of Pomalate people and their neighbours are affiliated with this religion, having left the Catholic Church. Although I heard no expressed intolerance, the new behaviours required of church members involve different understandings and expectations. CLC members do not participate in funeral exchanges or feasts: they simply bury the dead with Christian rituals. There is no extensive mourning, traditionally the connection to land transactions and balancing of affinal debts. Tithing and other financial support ('offering') are extensive. The novelty of these new patterns of association was vividly demonstrated at the weekend Women's Camp, at which women from distant villages (as far away as Baitsi) came to participate in a threeday revival. Some of these women were total strangers to Pomalate people. I realised I had never been at a Nagovisi gathering at which local people had not been invited, nor one at which strangers had been part of the assemblage.

In 1974 I wrote about the encroachment of certain Western ideas of patriarchy; for example, the Local Government Council was composed entirely of men, and the Catholic Church reserves its highest positions to men — but then women's standing in traditional institutions seemed strong [Nash 1974]. It is difficult to evaluate the situation today. Periods of war have a way of emphasising gender difference: in my area, although women did live in the bush with their families as Bougainville Revolutionary Army affiliates, no women used guns, none was targeted as a spy, and none negotiated a cease-fire. Young men with unusual hairdos, Bob Marley T-shirts, and bandanas are seen in the village; their female contemporaries are mothers with several small children.

Men oversee the new religion - there are many male preachers, and services are usually led by men - only two women leaders appear to participate regularly. The leadership of the Catholic Church is the responsibility of males, but the Catholic presence included women - nuns - who carried out important duties in health care and education. There is no CLC counterpart. Among the matters discussed at the weekend Women's Camp that coincided with my visit was advice on how to defer to husbands.

With regard to land usage, an area of traditional concern, I was told that men have formed an advisory body to deal with the difficult issues involved in allocation of a last remaining large parcel of bush. This land had belonged to a lineage whose last member died 30 years ago. Women will not be included in decision-making, according to one informant, because they fight too much. This was asserted despite the acknowledgement that two men had nearly come to blows about the subject. Men joke about the decrease in the birth interval and take 
credit for it: close birth spacing as mentioned above, was formerly considered disgraceful and would not be discussed or referred to in a joking way.

On the other hand, one-quarter of the 40 new community police officers are women, and one of the trainers, a New Zealander stationed in Buka, told me that they outperformed the men in the class. Girls do attend school in more or less equal numbers to boys and are very much desired in the family. Several Nagovisi women work at paid employment locally as, for example, teachers, nurses or typists. There also seems to be a great consciousness of matrilineality and the importance of women, especially, perhaps as a way of contrasting Bougainville with other areas of Papua New Guinea where patriliny is practised and women seem to be denigrated. It may be that in this post-Crisis period, matriliny will emerge as a significant component of difference, as 'blackness' and 'non-violence' did in an earlier period [Nash and Ogan 1990].

My impression of life today in Pomalate Village is that many people are waiting for something to happen, perhaps for a 'real' government to be formed, so that life can start again. On more than one occasion, I heard the current interim provincial government dismissed as something powerless and inauthentic. People are busy with short-term projects, but uncertain about the future. Although life is peaceful now, all have endured a long and bad experience, which some are now beginning to interpret as a 'time-out' which took years from their lives. Many are consciously pushing aside thoughts of how to resolve the issues involved in the murders of friends and loved ones. All complained of having no money and worse, no way to make money at present. Cocoa production is not expected to fully recover until 2004 [personal communication P. C. Loviro].

In my short visit, I perceived that there are three interrelated areas of concern for the future. During the crisis, fighting utterly destroyed the copper mine and most of the infrastructure in the greater vicinity of the mine was damaged greatly or obliterated. Although it is highly likely that more metal ore exists in the mountains of Bougainville, at the present, the idea of mining on the island is unpopular with the people, the interim government, and international mining companies. Yet people in Nagovisi talk nostalgically about the years of the 1980s, prior to the Crisis; their aspirations will be influenced by the memory of this relatively prosperous and rapidly changing period. Mining has not really disappeared; instead, it has become memory and thus subject to many powerful forces of imagination, reinterpretation and repression.

The current thinking is to stress subsistence agriculture and cash cropping: the island seeks to be self-sufficient. There is great pride in the ingeniousness of those mountain villagers who have rigged up water-powered electricity generators by utilising materials scavenged from the mine. [Cavidini and King 1999]. This 
practice is surely ingenious but questionably self-sufficient. Villages at any distance from Panguna or Arawa were unable to partake of the bounty scavenged from the abandoned towns and mine.

The issues of population and land are clearly intertwined: the birthrates which were high in the late 1960s and 1970s [Ogan et al. 1976] do not seem to be lower today. People do seem very aware of closer birth spacing. I heard several times the comparison of families today with a flight of stairs (that is, one child following the previous one at short regular intervals), and the importance of having daughters to access land (through matrilineal inheritance). For an example of the latter, when catching up on news, I was told that a woman who had one baby boy when I was first in Nagovisi now had five grown-up children, 'but only one daughter', said with a pitying look. Due to the resurgence of matrilineal consciousness and perceived land shortages, it is clear that people want daughters and thus, as in the same way in places where male children are favoured, it is likely that couples may be tempted to have 'extra' babies; that is, more than they might if sex were irrelevant, to ensure sufficient female children. The large number of infant and child deaths reported to have taken place during the crisis appears to have been exaggerated, at least for Nagovisi.

I have no information on the Christian Life Centre's practices, but 'family planning' appears to be permitted although it is seen as primarily a women's issue. Catholics are forbidden from using 'artificial' (chemical or barrier) methods. However, some women in their mid-30s or early 40s have only two children. How did they do it? I was not able to find out during my short visit.

Land is now being used more intensively and extensively than during my previous stays. This is partly due to the concentration of agricultural activity near the villages due to security issues during the crisis, but also because of greater agricultural demands of an increased population. People may find it difficult to live on subsistence agriculture and cash-cropping, not only due to land shortages but because of increased aspirations. Lummani [this volume] implies that officialdom still encourages plots of 1000 trees for each married couple, while in East New Britain, another area of high population density, cocoa trees are sometimes removed in order to plant food crops. To recommend such large plots would seem to be ill advised for Nagovisi.

However, with more attention to management of different resources, there are positive directions to be pursued. People can and will adopt new efficiencies (I have mentioned one such example above) to recycle land faster or use marginal landscapes. Bush methods can be made more productive, following strategies such as those described for Paruparu village under Bougainville Revolutionary Army authority. Areas such as swamps, often written off by agricultural specialists as 
unproductive, are suitable for pig raising in the traditional manner, which produces family income. Trees can be farmed for local house-building timber and, in my opinion, should be selectively planted soon. The adoption of cash crops like pepper and vanilla, which are regarded as able to give great financial returns per hectare, require great diligence, and ought to be introduced only after thorough training. There is potential for expanded solar power usage.

It is necessary to end on a tentative note, but the situation on Bougainville is subject to change - the political rapprochment with Papua New Guinea is by no means concluded in 2000. There are many internal problems evident that will need to be dealt with sooner or later, ranging from those of a truth and reconciliation nature to the rebuilding of the island infrastructure. Real difficulties exist in implementing agricultural self-sufficiency under present conditions. Although daily life is once again placid and relatively predictable, the steps to be taken to resolve the configuration of a future Bougainville are at this point a work in progress.

\section{Endnotes}

1. My then-husband, Don Mitchell, accompanied me, pursuing his own pre- and post-doctoral research [Mitchell 1971, 1976, 1982]. I resumed my maiden name after I completed my PhD dissertation.

2. Relating to death or burial.

3. People in Nagovisi were under the impression that such ceremonies had been banned by the Catholic Church when it began its operations there, but by the 1960 s the priests seemed to have a more relaxed attitude towards such things. Even if priests did have concerns, some people went ahead with such ceremonies anyway.

4. An acronym comprising the first letters in the names for the adjoining areas of Banoni and Nagovisi.

5. 'Care centre' was the name given to camps for people displaced from villages by the Bougainville 'conflict'. 


\title{
VIGNETTES OF MOGOROI VILLAGE, BUIN, 1971-2004
}

by Jared Keil

\begin{abstract}
This is not a 'history' of the Mogoroi region and nor does it pretend to reflect 1 the priorities or emphases of the people of the region. Rather, it is a very impressionistic and idiosyncratic survey of some of the significant developments in the Mogoroi region over a period of some 33 years.
\end{abstract}

$$
1971-73
$$

I first visited Mogoroi Village, ${ }^{1}$ in the Buin area of southern Bougainville Island, in November 1971. It was then part of the Bougainville District of the Australianadministered Territory of Papua and New Guinea. I was there as a doctoral student of anthropology at Harvard University, under the supervision of Douglas Oliver. I remained in the village for two years.

People in the Mogoroi area tended to see things as 'improving' with the late 1960s introduction of cocoa as a successful cash crop. Money was coming in to most households, if only on a small, irregular basis. Most villages (and some individuals or families) had cocoa 'fermenteries' where wet beans were processed into dry beans, which were then sold to marketing cooperatives or directly to buyers. Roads were passable and several villages (or individuals or families) owned fourwheel drive trucks or tractors. ${ }^{2}$ The price of cocoa was relatively high, partly as a consequence of the Biafran war and the disruptions following that war.

The huge Panguna mine was under construction (and would export its first ore in 1972), but few men from the Mogoroi area were ever employed there. In fact, very few men from the Mogoroi area were away in employment of any kind. Some students were advancing their education elsewhere on Bougainville. 
Discussion and debates concerning the future of Bougainville and of Papua and New Guinea were vibrant and often heated. Father John Momis was a substantial presence in the Buin area. With a Buin father, he was claimed as a 'Buin'. Momis was an outspoken critic of 'development', as it is generally understood (this included criticism of the Panguna mining project). The church allowed Momis to stand for the 1972 elections while retaining his priestly role. He won the Bougainville Regional electorate with ease.

In mid-1972, Momis became the deputy (but de facto) chairman of the Constitutional Planning Committee (CPC), a committee of Papua New Guinea's colonial legislature. This committee was responsible for hearing the views of the future citizens of Papua New Guinea about the nature of the constitution and government of their future nation-state.

There was considerable discussion in the Mogoroi area about the future of Bougainville and the desire for a referendum to allow the people to vote for:

(a) inclusion of Bougainville within an independent Papua New Guinea;

(b) inclusion of Bougainville within the British Solomon Islands Protectorate;

(c) inclusion of Bougainville within an independent New Guinea Islands nation-state (along with New Britain, New Ireland and other islands); or

(d) an independent nation-state of Bougainville.

Just before Christmas of 1972, two prominent Bougainvilleans (Rovin and Moini) were murdered near Goroka in the Highlands of the New Guinea mainland after their car ran into and killed a local girl. This incident served to greatly inflame anti-Papua New Guinea (anti-Redskin) sentiment and renewed calls for independence for Bougainville. When the Territory's Chief Minister, Michale Somare, visited Bougainville shortly thereafter, he was met with demonstrations.

Already in 1971-73, I noticed large numbers of children. The people of Mogoroi seemed to see no potential problem concerning population and land.

$$
\text { 1982-83 }
$$

During my first sabbatical leave from university teaching, I returned to the Mogoroi Village area for an additional six months during 1982-83. Bougainville was now a province of the independent nation-state of Papua New Guinea, administered by the North Solomons Provincial Government. ${ }^{3}$

Conditions on Bougainville seemed to reflect those of the larger global political economy. There were idle and rusting six wheel trucks in some villages; there was little or no work for such trucks in hauling materials for road creation or road improvement. ${ }^{4}$ An image that stuck in my mind: a young man told me that he had trouble sleeping at night because he worried about how he would repay a loan he had received from a bank. 
There were even more children and young people than at the time of my earlier visit. Some young women mentioned to me that Depo-Provera and underthe-skin contraceptives were available through some in the medical establishment but many women were worried about negative effects on their health of using such means. Some people in the Mogoroi village area were beginning to be concerned over the potential problem of not having access to enough land for the present and, especially, the coming generations, for both gardening and for planting cash crops. People tried to establish rights to land through a myriad of means and claims, both 'traditional' and seemingly novel.

Drinking was an occasional problem, both as a waste of money and as a source of arguments and violence.

There was to be the official 'opening' of a new government office and police station in Buin town (the first since the old government offices and police station had been destroyed and burned during demonstrations for Bougainville independence in the late 1975 to early 1976 period). The provincial premier, Leo Hannett, selected Leo Morgan to officially open the building (Morgan was from Buka and was a senior National Government official). But the people of south Bougainville wanted Momis to officially open the building. On the appointed day, Bougainvilleans chopped down trees across roads to block any road access from Arawa to Buin town. Premier Leo Hannett flew in by helicopter and was met by an angry crowd. The official opening did not occur.

\section{4}

Most recently, I spent two weeks in the Mogoroi Village area in March 2004, after an absence of 21 years. This absence, of course, included the years of fighting and blockade (the 'Bougainville crisis'), as well as the more recent years of peace monitoring and peace keeping. And, of course, the global political economy had once again undergone significant changes, some of which were obviously once again reflected in the Bougainvillean realities.

People in the Mogoroi area spoke of the 'crisis' as, variously, a time of resistance and of misery and hardships. Many had spent much of the time in care centres or in 'the bush'. Some had spent considerable time elsewhere in Papua New Guinea or the Solomon Islands. Some people in the Buin area had been beaten, shot or killed. This seems to have occurred most often in the vicinity of the care centres and in southern Buin.

People explained to me that, following the end of the 'crisis' and the period of peace monitoring and peace keeping, people gradually returned to their home communities, houses, gardens, and cocoa. There seems to have been no explicit 
and 'official' reconciliation ceremonies in the Mogoroi area. Rather, the Christian ideology of 'God will reward and punish the do-gooders and the evil-doers after their deaths' seemed to have been accepted as an alternative to revenge and payback. As several residents of the Mogoroi area put it: we are all 'sitting easy'. That is, former and present supporters of the Bougainville Revolutionary Army (BRA) and Ona's breakaway faction, the Republic of Me'ekamui and its associated Me'ekamui Defence Force, were presently living side by side with supporters of the Bougainville autonomous government in creation.

In the Mogoroi area, there were Me'ekamui supporters. I was told that Koikei was a BRA commandant and his father, Andrew Komoro, was a vocal Me'ekamui supporter. Others more quietly supported the Me'ekamui position. Their argument seemed to be as follows: 'the two sides are presently working out exactly what "autonomy" will mean for Bougainville. If the result is okay, fine. But, if the result is not, then we will have nothing unless we keep our weapons' ${ }^{5}$ The Buin area was said to be one of the few then remaining areas on Bougainville with 'crisis' weapons. Koikei and his followers in the Mogoroi area were said to have weapons; they had refused to hand these in as part of the so-called weapons containment process. I was told that not long before my visit a container had been broken into in the Tokaino region and the weapons in it removed. ${ }^{6}$ It seemed to me that most people in the Mogoroi area were supporters of the Bougainville autonomous government in the making; however, many individuals had bizarre ideas concerning the origins of the 'crisis', the BRA, secession and autonomy.

Any government at the local level, such as the much-discussed Councils of Chiefs or Councils of Elders was non-existent or non-functioning in the Mogoroi region.

Aside from the main road circumnavigating the island, going from the east coast, to Toimanapu plantation, Buin town, Aku school and on to the Siwai area, the roads in the Buin area were in horrible condition. Although a four-wheel drive pick-up truck occasionally tried to make the trip to Mogoroi, most trucks stopped just north of the cut-off to Tabago on the main 'highway' from Buin town to Arawa and people walked the additional one and a half hours to Mogoroi each way. Trucks in the Mogoroi area were also in terrible shape; all were old. No one wanted to (or had the money to) invest in a new vehicle, given that the roads were horrible and there was also a danger of hold-ups. ${ }^{7}$

People complained that 2003 had been a particularly rainy year. When I visited, 2004 had also been excessively rainy. All this rain was having negative effects on both cocoa and gardens, and there was less money in the area than might have been expected in a year of more normal weather. 
People talked to me a lot about the 'culture of violence': the fact that the young, especially, knew nothing other than violence and the power of the gun. People said that youths stole. Men, especially young males, drank and got 'spak' (drunk). The manufacture of home brew ('jungle juice', or 'jj' distilled liquor made from fermented water, sugar and fruit) was said to be a real problem, especially among the young, including school children. Home brew was said to be the one avenue by which the young could access cash. 'Lawlessness', especially in Buin town, was said to have greatly diminished after the re-establishment of a police post in Buin, which happened not long before I arrived in Mogoroi.

Schools had been re-established and the community had built classrooms and teachers' housing. These schools were at missions and in the general community. Because of the lack of schooling during the 'crisis', students of varying ages (some well above normal school age) attended primary school. Annual school fees had risen considerably: I was told that they ranged from approximately 300 kina to 900 kina or more for high school. The community was also building a new, very large church building at Tabago, replacing the old building which was destroyed during the 'crisis'.

Some people told me that the young, especially, were abandoning the Church. I saw no evidence of this, as church attendance seemed high across all age groups. In contrast to accounts of other areas on Bougainville where other sects (largely Protestant evangelicals) had made inroads into Catholic Church adherents, there seemed to be no other churches operating in the Mogoroi area.

The hope for the future was said to lie in the production of vanilla. Apparently a successful cash crop elsewhere in Papua New Guinea, vanilla was being introduced in the region. Residents of the Mogoroi area compared the price of vanilla, by weight, very favourably with that of cocoa.

Large numbers of children were apparent, even compared to the earlier periods of 1971-73 and 1982-83. Everyone commented on the numbers of children and the lack of spacing between births today. And many people saw a connection between the large numbers of children and a growing shortage of land available for gardens and, especially, cocoa.

The Buin in the Mogoroi region seemed to view the 'crisis' as an interruption in their 'development'. Their view was that, if the crisis had not occurred, the developments of the 1970s and 1980s (more cocoa, more money, more Europeanstyle house construction, more vehicles and so on) would have continued with increasing frequency. But, due to the 'crisis', they were, in a real sense, having to 'start all over again'.

Without in any way minimising the trauma of having lived through the Bougainville 'crisis', in 2004 the people of the Mogoroi area seemed to be amazingly 
resilient and optimistic. What they wanted most were better local roads and more services in Buin town (especially postal service and banking). While it appeared that they would not be getting these in the near future (there were no resources available), as the negotiations continued as to the nature of the proposed 'autonomous' Bougainville, I tended to share their optimism for their future.

\section{Endnotes}

1. Mogoroi Village is about two kilometres north of Tabago Village and Mission. It is on a ridge which leads down to the Mailai River. Throughout the period of my fieldwork, Mogoroi Village consisted of several villages and hamlets, often referred to as Mogoroi I, Mogoroi II and Mogoroi III. And there have always been people 'belonging to' Mogoroi Village who lived in isolated hamlets.

2. This was true except when there were heavy rains, especially in the mountains; in that case it was often impossible for four-wheel drive trucks and tractors to ford the one major river that did not have a bridge.

3. Papua New Guinea adopted a provincial government system and the North Solomons Provincial Government was the first provincial government established under the new Organic Law. The use of 'North Solomons' in the name of the government was a symbolic victory, emphasising the close connection between Bougainville and the then British Solomon Islands Protectorate.

4. In the time between my first and second visits to Buin, a new road had been completed connecting Buin town with the Kieta-Arawa-Panguna urban complex via the east coast.

5. Komoro, during the 1971-73 period, was widely considered to be pro-government. He was a former village councillor and had stood for election for the colonial legislature - the House of Assembly. According to John Momis (personal communication, March 2004), the Papua New Guinea security forces treated Andrew Komoro roughly during the 'crisis', as they assumed he had knowledge concerning his son, Koikei. People told me one day that I had passed Koikei while we were both walking in opposite directions on the highway-Mogoroi road; he made no attempt, as far as I know, to communicate with me. Neither did his father, Andrew Komoro.

6. 'A number of guns in Buin District were removed recently after former combatants forcefully unlocked a container' ['More guns disposed in Bougainville', National March 24, 2004, p. 6. Also at <http://www.thenational.com.pg/0324/nation21.htm>].

7. During my two weeks' stay in the Mogoroi area I heard of one hold-up at gun point of a vehicle belonging to a person from Siwai. This incident was reported in 'Peace Threat: major robbery smashes Siwai no weapons claim', Post-Courier Online, March 30, 2004 <http://www.postcourier.com.pg/20040330/tuhome.htm>. This robbery took place on Friday March 19, 2004. 



\section{TOWARDS}

\section{UNDERSTANDING}

THE ORIGINS OF

THE CONFLICT 


\title{
IDENTITIES AMONG BOUGAINVILLEANS*
}

\author{
by Anthony J. Regan
}

I

$\mathrm{t}$ is widely accepted that a pan-Bougainville identity has emerged in the past 100 years. ${ }^{1}$ Some observers refer to it as Bougainvillean ethnicity, on the basis that it has become a political identity, associated with secessionist demands. The views of many observers on the development of this identity are summarised by Nash and Ogan who note that '... events of the 20th century — particularly plantation colonialism which was succeeded by modern industrialised neo-colonialism as represented by the copper mine - helped to create a pan-Bougainvillean sense of identity where none had existed before' [Ogan 1992, summarising Nash and Ogan 1990].

There are many reasons for the widespread interest in this new identity. One is its significance for politics in Papua New Guinea and in its neighbouring region. Another concerns the very fact that it is a new identity, incorporating people of great linguistic and cultural diversity - a microcosm of the diversity of Melanesia generally [Terrell 1978b]. However, besides this pan-Bougainville sense of identity, of course there are diversities to be recognised as well.

The central concern of this chapter is to present a generalised 'map' of the range of identities existing among Bougainvilleans in the 1980s, those that I have observed or that have been brought to my attention by Bougainvilleans. On the other hand, the range of such identities being vast, and the variations in the situation from area to area being significant, the chapter by no means presents a full and complete picture, which anyway is far from being a static one. ${ }^{2}$

Identity is a complex, 'slippery' and anyway multiple concept, given the number of overlapping categories which individuals may use to identify themselves, or which they may use to identify others - socially, culturally, and ethnically. Social identities may include gender, age, family, economic role and kin. A variety of cultural characteristics may be used to distinguish one cultural 
group from another. Ethnic markers include language, race, religion and colour. By 'ethnicity' I mean the politicisation of identity, and therefore many things may be meant including, for example, ideas and situations where political or religious use is made of any - or all — of the above. At the same time, there is much overlapping and interrelation between identities as well as constant change.

In other words, people tend to maintain numerous identities of various kinds, and to move between them readily. They also classify themselves from among their identities 'in terms of whichever of their allegiances is most under attack' [Maalouf 2001: 26] — or, we might add, which they perceive as being most under attack, or even threat.

After discussing some aspects of the Bougainville context of particular relevance to identities there, I outline what identities might have existed in precolonial Bougainville. I then outline a generalised 'map' of identities in the colonial and postcolonial situation, and finally note some of the dynamic factors involved in colonial and postcolonial Bougainville relevant to understanding identities there.

\section{ASPECTS OF THE BOUGAINVILLE CONTEXT}

Different aspects of the cultural, political and economic situation in Bougainville impact on the ways in which both active and latent identities develop and manifest themselves.

\section{Egalitarian Social Structures and Balanced Reciprocity}

In general, Bougainvillean society before colonialism, tended to be highly egalitarian. The emphasis on equality remains evident in many aspects of contemporary social structures of all language and culture groups [Regan 1998, and sources cited therein]. Where obvious inequality does occur, it tends to upset balance in or between groups. The importance to people of maintaining balance both between individuals within their groups and between groups also seems to have been a feature common to all Bougainvillean societies. Ogan [1996: 33] says of the Nasioi that the 'ideal of maintaining balance in social life appears to have been a basic principle governing interpersonal relations'. So 'balanced reciprocity' was the basis for many practices, including marriage, and, we might add, social order — and disorder — generally in the small-scale societies of precolonial Bougainville (and Melanesia more generally) where there were no centralised political organisations. It continues to be a major principle of social organisation for Bougainville today.

Disturbance of balance can occur in all sorts of ways and when, for example, an unmanageable cycle of violence is developing, usually some alternative action 
will be taken to restore balance. It may include 'customary' reconciliation ceremonies, involving exchange of shell money or pigs. In such societies with a history of strongly egalitarian social organisation, inequality in material wealth between individuals and groups resulting from the impacts of modern economic activity, that has mostly developed since the 1950s [Connell 1978; Mitchell 1982], can upset balance in ways that cannot readily be dealt with by customary methods [Filer 1990].

\section{The Importance of the Clan}

The clan, and more especially the local manifestation of the clan in land-holding lineages, is in many parts of Bougainville a fundamental social unit with, for example, political and other expression. The continuity of the clan lineage as a corporate land-holding or cooperative group is seen as of critical importance to its members. The female members are often seen as of great importance, not just as the custodians of the land and other wealth of the clan group, but also as the bearers of the children that will be the future members and leaders of the clan [see Kenneth, this volume]. Similar ideas about the importance of continuity extend to the larger groups to which people belong, 'above' the lineage.

\section{Rights of Original Owners, and Impacts of Internal Migration}

All over Bougainville the rights of original owners of land are considered important and there has long been considerable internal migration of people in the Bougainville region (inclusive of what is now the western Solomon Islands). Evidence of such movement in precolonial times emerge from oral histories of many groups, ${ }^{3}$ studies of pre-history [for example, Spriggs, this volume] and observations of some of the European visitors of the late 19th century as summarised by Oliver [1991].

One cause of such movement was volcanic activity, which probably resulted in large-scale movements [Spriggs, this volume]. Escaping conflict seems to have been a factor in some migrations, among others, the Torau, who probably migrated from the Shortland Islands to central Bougainville some time in the 19th century [Terrell and Irwin 1972; Sack 1973: 58-9; Togolo, this volume]. ${ }^{4}$ Further, what Oliver [1991: 105-6] calls the 'ubiquitous' localised warfare' caused 'many people to shift their residences to less exposed locations' ${ }^{6}$ Indeed, even for 'many years' after direct colonial rule began, inter-group fighting continued in some areas, resulting in 'some shifting of people between 'controlled' and 'uncontrolled' areas' [Oliver 1991: 94, 105-6]. In the last 20 years of the 19th and the first few years of the 20th centuries, many parts of the Bougainville coasts were populated sparsely. The German observer, Richard Parkinson, believed that this was a change 
from the recent past, probably due to migrations to escape both local warfare and to large-scale kidnapping by labour recruiters. ${ }^{7}$

Large scale 'purchase' of land for plantations was also a factor. By 1914, over three per cent of Bougainville's land, which represented 10 per cent of the total rich and relatively flat land suitable for growing coconuts, had been alienated [Oliver 1991: 31]. Some of the areas involved may have been uninhabited at the time [Spriggs, this volume; Oliver 1991: 94], but that was not the case everywhere. There was consequential loss of land to many groups, causing considerable movement of people. There was also extensive movement in some areas when the change from living in small hamlets to living in large 'line villages' was encouraged by first the German and then the Australian colonial administrations.

World War II also caused massive disruptions and movements of people [Nelson, and Ogan 'Introduction to Cultures in Bougainville', both in this volume]. In some cases, groups that moved in the 1940s have never returned to the land they left. Others returned only after two or more generations. Later relocating included that from inaccessible areas to where there was access to newly established transport infrastructure and government services, or from densely to sparsely populated areas [see, for example, Tanis, this volume].

Population movements can have long-term consequences in the disputes that they may contribute to over ownership and access to land. Pressure on, and disputes over, land have increased as population pressure and dedication of land to permanent tree crops have risen, especially since the 1970s [Mitchell 1982; Lumanni, this volume; Kenneth, this volume]. A common feature in land disputes is an emphasis on the length of the time the claimant's ancestors have been linked to the land in question. 'Originality' in terms of ownership or contact with an area is usually seen as important in such disputes [see, for example, Sagir, this volume]. The significance of the concept can be seen in terms used in some Bougainville languages, as in the case of Nasioi, where those with original claims to land are sometimes referred to as osikaiang, meaning something like 'original inhabitants'. By contrast, those who have settled on land recently — and recently can be any time within the past few generations - can often be regarded as having lesser claims than those who can assert rights through ancestors said to have been original settlers of the land.

\section{Persistence of Significance of Localised Groups, and Impacts of Variations in Patterns of Expansion of the Range of Groups to which People Belong}

Although the changes occurring since the beginning of colonial rule have included a massive expansion of the groups to which Bougainvilleans belong, the local has 
remained vitally important. The available evidence in much of Bougainville suggests that in precolonial times, people in many areas did not move much beyond a very localised territory. Friedlaender [this volume] summarises evidence collected since the 1960s about people living in areas of Bougainville other than the coast and small islands:

... the pattern of marital migration in Bougainville was very restricted in the inland regions, with almost everyone setting up marital residences only a kilometre or two from their birthplaces [Friedlaender 1975: 78]. This pattern very likely characterised earlier periods as well, especially prior to the colonial era. People were afraid to move far because of pervasive feuding, head hunting, and the fear of malevolent ancestral spirits.

Of course, not all groups were as restricted in movement as the inland people. Coastal and island communities were in some cases involved in extensive trading networks.

At the same time, changes occurring since extensive contact with Europeans began in the latter part of the 19th century have rapidly expanded the boundaries for people from all parts of Bougainville. Most now belong to a range of groups, beyond the local, that would not have existed 100 years ago. However, the expansion of people's boundaries and the groups to which they belong has occurred at very different rates for people from different areas. These variations have had significant impacts in terms of differences in the access that various localised groups have had to the state and to general economic development.

A combination of geography and outside interest in labor recruiting largely determined the order in which Bougainvillean communities developed extensive contact with the outside world. Coastal and small island communities, especially of Buka and north Bougainville, had the earliest such contact, probably from the 1860 s and 1870s, but especially from the 1880s. Proximity to the German colonial centre in what is now East New Britain was a major factor here. From the beginning of the 20th century some people of the coastal areas on the eastern side of Bougainville also began to have close contact with the colonists, as the first German administrative headquarters for Bougainville was established at Kieta and consequent plantation development began. It was a little later that the people of south and south-west Bougainville began to come under colonial control [Laracy, this volume]. Because of the barriers created by mountains, the process of engaging with the outside world was slower for the people of the higher valleys of the eastern and southern parts of Bougainville, and slower still for those of the higher mountain areas of all areas, north, central and south. After World War II 
there was, however, more intensive (though varying degrees of) contact with the outside world for all Bougainvilleans. But people in remote areas (high mountains, remote valleys and distant atolls) still had rather restricted access.

As people's boundaries expanded, they became parts of widening 'circles' of groups, each with their own identity. They have included groupings associated with churches, employment, local government and so on. In the process of engaging in and with these, additional memberships in a wider range of geographically based groups has tended to be emphasised — such as language groups, regions within Bougainville, and Bougainvilleans as a whole. New identities associated with many such groupings have also emerged.

\section{IDENTITIES IN PRECOLONIAL BOUGAINVILLE}

While we can be relatively certain that Bougainvillean identity is a product of the colonial period, we cannot be so confident about the situation with identities ethnic or other — among Bougainvilleans in the precolonial period:

Although we cannot say with any assurance what ethnic or "tribal" identities were recognized, it is unlikely that they resembled those that most affect Bougainvilleans today.' [Nash and Ogan 1990: 3]

In most parts of Bougainville, it seems likely that the basic social group was the family and small land holding and mainly clan-based lineages, of just a few households. As for the many language groups, sub-languages and dialects [Tryon, this volume], while there was almost certainly a consciousness on the part of speakers of a language as 'being different from the neighbouring speakers of different languages' [Oliver 1991: 106], there is no evidence that such consciousness was a generalised basis for group differentiation beyond that. ${ }^{8}$ Indeed, there are still areas in the border zones between larger language groups where people speak two or even three languages [Oliver 1971: 286; and see also Oliver 1991: 106ff] 9 Not only were language groups not political units, but the fairly constant inter-group conflict was as likely to be between groups speaking the same language as between people of differing languages [Oliver 1993a: 12] — at least in the case of people 'belonging' to the larger language groups. Further, as Nash and Ogan [1990: 3] point out, any distinctions that might have been made based on language would probably have been 'blurred' by 'widely shared symbols of common descent like the eagle and the hornbill' (that is, clan and sub-clan symbols).

It also seems likely that people in many areas tended to identify more strongly with a range of localised groupings within the larger language groups 
than with the language groups to which they might have in some circumstances regarded themselves as belonging. That continues to be the case among members of the Nasioi and Nagovisi language groups, as is discussed later in this chapter.

The situation with language as a basis for group differentiation was quite possibly different, however, with the smaller language groups. Examples include the Torau on the central part of the east coast of Bougainville and the Amun/Piva on the west coast. The relatively small size of the groups and their recent history of migration in the period just before the colonial era began may have contributed to a sense of identity based on distinctiveness from members of neighbouring groups speaking different languages. It has been suggested that Nasioi speakers differentiate Torau speakers on the basis of language [Nash and Ogan 1990].

There was a tremendous range of diversity in culture, language and other traits among Bougainvillean groups. ${ }^{10}$ It would not be surprising if, even in the pre-colonial era, some of these differences did provide bases for differentiation of identities that might today be classified as 'ethnic' in nature. One possible example involves differentiation of speakers of smaller language groups. Further, groups of hamlets and land-holding clan lineages sometimes combined into larger groupings under powerful local leaders, as seems to have occurred in some areas for fighting and other purposes [Oliver 1991: 105], and we can only guess at how such groups were classified by their neighbours.

Ethnic group identification on the basis of language or area may also have occurred as part of the extensive contacts between groups, as occurred as part of trading relationships between members of various language groups. An example is provided by the regional trade system involving three language groups on Buka Island, people of a distinct language group from Nissan, and groups from mainland Bougainville, with considerable specialisation in what was traded between people from particular language groups [Specht 1974]. The evidence cited below of the differentiation of groups within some of the large language groups in the postcolonial period offers the strong likelihood that similar group differentiation occurred in precolonial times.

\section{IDENTITIES IN COLONIAL AND POSTCOLONIAL BOUGAINVILLE}

As already mentioned, people's identities are constantly interacting and responding to changes in the situations in which they exist. It seems likely that identities of one kind or another existed among Bougainvilleans before the colonial period. There has probably been continuity in some of these, but at the same time they have been subject to new forces for change. They have also interacted 
with many new identities that have emerged as a result of colonial and postcolonial change. These processes began even before the first Christian mission and colonial administration posts were established in Bougainville in the early 1900s.

\section{Family, Hamlet, Village}

A starting point for any discussion of identity for most Bougainvilleans is the family group, the hamlet and the village. In the 1980s, overall, the situation continued to be much the same as that described by Oliver [1991: 95] prior to the Panguna mine being established. In general a single family of two generations occupies one house. In most areas, family groups are also usually part of a hamlet of from one or two to ten houses. In the case of some coastal and small island areas, a number of families tend to live in larger villages of 50 or more houses.

Hamlets are often (but not always) based around a single land-holding clan lineage [Oliver 1971: 280], matrilineal in all areas except Buin and some atolls. It is at this level of the land-holding lineage 'within' a clan that ideas about continuity of the clan are perhaps at their most powerful. Without continuing strength in numbers, a lineage may die out and its land go to related lineages.

Villages can also provide the focus for significant identities. Such is the case with the long established large coastal and island villages. The three main villages - Rorovana, Vito and Tarara - provide an example. (In the mid-1980s the Toraus were still a small language group of around 3,000 people). As we have seen, their language group may well have provided a significant group identity even in the precolonial period, and certainly did so in the 1980s. At the same time, however, by the 1980s significant distinctions in the identities of each of the three Torau villages had emerged. Much of the variation was a product of their different experiences in relation to access to the state and to development. Rorovana is quite close to the main centres of Kieta and Arawa, and its people have had much better opportunities for employment and access to state services as well as knowledge of how the state and the private sector operate. From the late 1960s, the Rorovana people also began to receive land rents and compensation from the mining company for land utilised for port, recreation and other mining related activities [Togolo, this volume].

To Torau speakers there are slight, but nevertheless noticeable, differences in the way the language is spoken in the three villages. The people of Rorovana are said to speak with a particularly throaty sound, those of Vito to talk faster than others, and those of Tarara to speak in a singsong manner. The Rorovana are said by the people of Vito and Tarara to have allowed Torau kastom to have been undermined by a combination of extreme land pressure and reduced reliance on traditional subsistence gardening and fishing (and cooperative activities) as a result 
of such things as receipt of land rents and compensation from Bougainville Copper Ltd (BCL) in the 1970s and 1980s, and proximity to the employment opportunities of the mine and the main urban centre, Arawa. The Rorovana people, on the other hand, tend to regard Vito and Tarara people as lacking education and sophistication. In turn, the Vito tend to differentiate themselves from the Tarara as well as the Rorovana, as remaining more true than either to Torau kastom. The Vito regard themselves as neither having forgotten gardening and fishing nor having become too much tied to the ways of the whiteman (as with Rorovana), nor having intermarried too much with the neighbouring Eivo and Wakunai people, as they suggest is the case with the Tarara people.

In general, people from Vito and Tarara tend to see the Rorovanas as too much influenced by Europeans' ways. They say that before the 1960s there was far more cooperation and communication, and much less differentiation, between the people of the three Torau villages than is now the case. Hence, even among the small Torau language group, differences in access to opportunities associated with the introduced economy are contributing to emerging differences in interests and in identity.

At this level of the hamlet, village and the clan lineage, issues about original ownership are constantly asserted in discussion, in claims, and - sometimes during conflict about land, and even in disputes about rights to power and leadership. So when land shortages occur, family groups that have migrated from another area will often be reminded that they are not original owners and occupiers, and have lesser rights over land than those that can make such a claim, even if the migration was some generations ago. Similarly, I am aware of situations where local traditional leaders have found themselves more open to challenge from members of lineages and families that have widely accepted claims to be part of the original settlers or owners than from recent migrants, and have been more ready to assert authority against such migrants.

\section{The Clan}

'Above' the localised landowning clan lineage is the clan. Among the widely dispersed speakers of large language groups, such as the Nasioi, the Siwai, the Buin, the Halia and others, a person would never know all members of his or her clan within that language group. Here the clan does not operate as a corporate unit. There is nevertheless still a sense of identity associated with the clan. People claim special characteristics for their clan members (in terms of abilities, qualities, position of lines on the palms of the hand, ${ }^{11}$ and general appearance). The local manifestation of the clan — land-holding lineages — is for many a major source of identity, and this reinforces the significance of the wider clan group. People 
know and relate to other clan members beyond their lineage but in their immediate vicinity. Further, the clan provides a basis beyond the local lineage for people to enter into relationships, not just with other speakers of the same language, but also between members of clans of differing language groups which although they have different names share the same symbol, such as the hornbill (kokomo) or the eagle (taragau). ${ }^{12}$

Among the smaller language groups, the clan can be the basis for identity for groups with known membership, as in the case of the Torau villages. Although even there the clan is not a political unit or a corporate landholding group, ${ }^{13}$ the relatively small populations of these villages means that members of the same clan are generally well known to one another. Clan members tend to claim superiority for themselves over the members of other clans - they are physically more attractive, more intelligent, have more foresight, and so on. ${ }^{14}$ They often support one another, and cooperate in various ways (including in terms of village politics). The numerical strength and continuity of the various clans is an important factor in the way the village functions, in terms of politics and distribution of land.

\section{Localised Groups within Language Groups}

'Above' the hamlet or the village is a range of identities, associated with various groupings 'within' the language group. These vary among language groups, and even areas within language groups. As far as I can ascertain, however, they exist in one form or another within most — if not all — of the larger language groups. I have developed a picture of the situation within two language groups - the Nasioi and the Nagovisi. Groups there are differentiated on the basis of separation by significant geographical features (such as major mountains or rivers), or occupation of distinct 'ecological niches' [Ogan 1992, and this volume], or both. It appears that differentiation in these cases is of long-standing. The isolation of the groups from one another and their occupation of different ecological niches have resulted in considerable variations among them. These include distinctions in language (dialect or pronunciation), material culture and cultural practices, and food, and in the identities associated with these groups. ${ }^{15}$

The areas occupied by such groups within the areas occupied by Nagovisi and Nasioi speakers are indicated very generally in Map 1. It must be emphasised, however, that identifying and naming such groups and 'mapping' the areas that they occupy is far from easy, as the outcomes of the process depend very much on where the informant originates. The various groups sometimes use different names for one another, and also can delineate group 'boundaries' differently. So, what follows should be seen as indicative of the situation in the areas in question, and not a definitive analysis. 
The Nasioi speakers of central Bougainville do not generally identify themselves as being 'Nasiois' (or Kietas, a name commonly applied to them until the early postcolonial period, and which they still tend to apply to themselves). The main exception involves situations where Nasioi speakers differentiate themselves from speakers of other Bougainville languages, in which case they may refer to themselves as 'Kietas' or 'Nasiois'. In the more common situations in which Nasio speakers are dealing with one another, they tend to identify themselves as members of one or another of at least 11 main, localised and distinctive groups.

The people of the coastal area from Tunuru, and all the way south to close to Aropa (including the villages or hamlets around Arawa and Kieta), call themselves the Pirung, or the people of the sea. This reflects their heavy reliance on coastal and sea resources. Inland from them are the lowlands valley people. They include the Apiatei, who occupy a small area west of Rorovana and south of the Pinei River. The Bava occupy the valleys west of the coastal strip occupied by the Pirung. North of the Apiatei, are the Simeku, regarded by linguists as speaking a sub-language of Nasioi that exhibits influence from the neighbouring Eivo language, to the north of the Simeku.

West of the Simeku is the isolated Paru Paru Valley, occupied by people known as the Avaipa. On the boundary of four languages, they speak a mixture of Simeku/Nasioi, Nagovisi, Eivo and Banoni. They can understand those four languages, but their complex mixture of language elements is not readily understood by the speakers of those languages. Into the lower part of the mountains of the Crown Prince Range, west of the Apiatei and the Bava, the people of the villages of Pakia, Kupei, Daratui and others are known as the Nasioi. Today they tend to be divided into the North Nasioi and the South Nasioi.

To the west of the North Nasioi, a little higher into the mountains, are the people known to some as the Damara. They border the Nagovisi, and their language shows some influence of that proximity. But to illustrate the point about difficulties of 'mapping' these groups, while some in the area in question describe themselves and their area as Damara, others use the term Ioro. Nasioi-speaking people from areas closer to the coast also describe this area and its people as Ioro. Others say that Damara is the term most used by the Kongara people to describe the people of Ioro.

It is to the south of the Damara/Ioro that the Kongara live. Most of their land is at such altitudes that many of their food sources are necessarily different in many respects from groups at lower altitudes. ${ }^{16}$ South of the Nasioi, occupying a long valley leading up to Kongara, are the Dantenai. South of them live the Koromira, occupying the coastal and valley areas around Koromira Point. While some Koromira live close to the sea, they are not as reliant on its resources as the neighbouring Pirung, who see the Koromira as migrants from the valleys and 
mountains, and so not true coastal people. Inland from the Koromira and south of the Kongara live the mountain and valley people known as the Koianu.

These distinct groups and the ways in which they identify themselves and are identified by others are not well known even to Bougainvilleans, other than speakers of the Nasioi language. Various of the identities associated with these groups are significant, however, in localised interaction not only between Nasioi speakers, but also with particular groups across neighbouring language borders (Eivo, Nagovisi, Siwai, Telei and Torau). In general, people from each of those groups tend to regard their own group members as being in one way or another superior to the members of the other groups within the language group. Members of at least some such groupings tend to believe that there are differences in the appearance between members of their own group, and those of other groups within the language group. Many Pirung, for example, see themselves as taller and generally more attractive than members of neighbouring groups. They would prefer to see their people marrying other Pirung, not just because that assists in keeping control of their land, but also because it ensures the continuity of what they see as the special qualities of their group. Middle-aged and older adult members of the various groups tell stories of how as children, when attending a large sing sing (party or festival, usually involving singing and dancing), or going to a large market, where members of another group from among the Nasioi speakers were present, they would be warned by parents and other relatives of the unsavory aspects of the typical characteristics of the members of the other groups.

There is of course nothing unusual in such tendencies in differentiation between one's own group and 'other' groups - a sense of superiority over other groups is something that probably appeals to most human societies and is used by them for a variety of purposes. ${ }^{17}$ Much the same phenomenon is seen in the ways in which members of clans (above) and of other groups discussed below differentiate themselves from other groups.

A similar situation with distinct groupings within a language group also exists amongst the Nagovisi, as described by Tanis [this volume] — the Lamane, the Telipe, the Veripe, the Booga, the Toberaki and the Tomarasi (or the Tomau) and the broad areas that they occupy are indicated in Map 1.

The significance at the local level of these sub-groupings within the language groups is reflected in such things as the fact that their names are used for local political organisations, community governments and councils of elders (forms of local-level government in Bougainville) and electoral constituencies, and that demands are made for the groups to be recognised in constituency boundaries. In terms of political organisations, the best-known case is that of Napidakoe Navitu. It developed in central Bougainville in 1969 in response to efforts by the colonial 


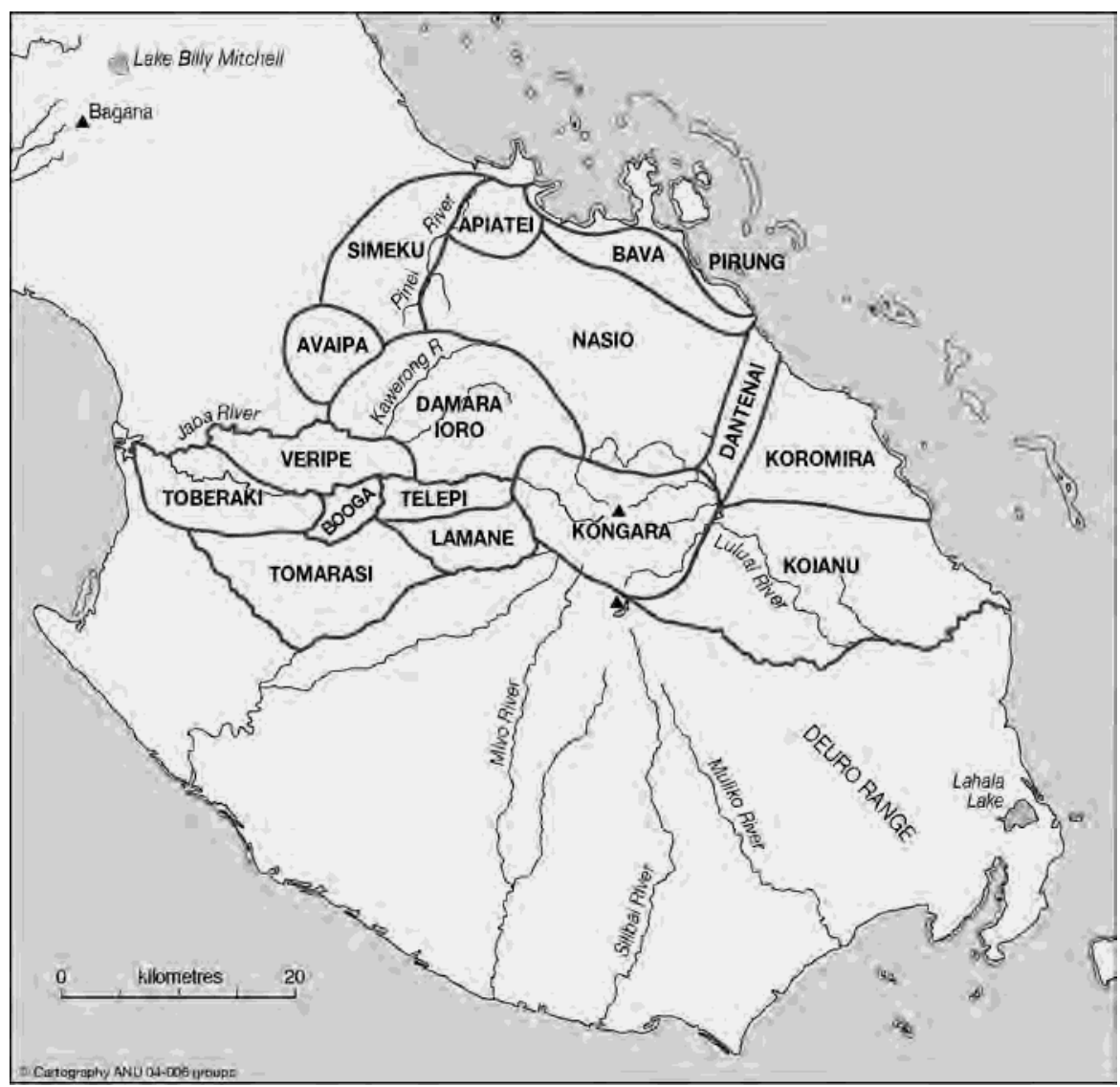

Map 1. Groupings within language groups, 2005

regime to expropriate both expatriate owned plantation and village land for mining related purposes. In that case, while the word 'Navitu' is a Nasioi language word meaning 'together' [Nash and Ogan 1990: 9], the word 'Napidakoe' was 'an anagram of the initials of the different ethnic groups in the vicinity of Kieta' [Middlemiss 1970: 100] (emphasis added) [and see also Griffin 1982: 113] — namely Nasioi (Na), Pirung (Pi), Damara (Da), Koromira/Koinau (Ko) and Eivo (E). ${ }^{18}$ Some examples are provided by Tanis [this volume] regarding the use of names of such groups in the titles given to community governments. In terms of constituencies, both the names and boundaries for those used in the North Solomons Provincial Government in elections from 1976 to 1988 and those used for the Bougainville People's Congress elected in April-May 1999 [Regan 2002a] reflect these local groupings. Use of these names reflects local pressures for recognition of already well-established group differentiation. ${ }^{19}$ 
As discussed in more detail below, there was a tendency on the part of the colonisers (missions, plantations and administration) to ascribe common characteristics to people of various language groups, and to rank them (from 'advanced' or 'progressive', to 'backward'). There was a similar tendency in relation to these groupings within the language groups. But even since the colonial era ended, the members of such groups have continued to differentiate among the groups on the basis of degree of advancement and sophistication, again, in much the same way as occurs in relation to language groups (as discussed below).

In large part, such distinctions are a product of the very different history in terms of access between say, the Pirung and Bava people, from around Arawa and Kieta, and the Kongara, Avaipa and Damara people of the high mountains. The former tend to regard themselves as more sophisticated and advanced than the remote mountain people, and vice versa. Recounting the history of a Methodist mission established in 1949 at Roreinang in the Kongara area, then a very remote area despite being just five miles from the coastal plantation of Aropa, Lātukefu notes that at the time the mission was established:

In comparison with the coastal ... Nasioi and Siwai, the people of this area were very backward indeed with regard to the attainment of the type of wealth, technology, education, health care and belief system introduced by Europeans. Consequently the Kongara people had for many years been looked down upon by the coastal people as backward and primitive kanakas [1982: 40].

Interestingly, Làtūkefu's informants about the views of the coastal people were not coastal people, but rather 'elders in Roreinang Mission Station' [Latukefu 1982: 52, note 11]! While even today (2005) the Kongara and Avaipa tend to resent what they see as the attitudes towards them of the coastal people, they also tend to accept that, in a sense, they are in fact relatively 'backward'. This translates into a strong belief in the need for change towards greater fairness and equality (and therefore balance) in 'development', and a determination to achieve this through pressure on government and on donors. ${ }^{20}$ At the same time members of 'advanced' groups tend to be concerned to protect the advantage that they have enjoyed through a longer history of access to the state and to opportunities for economic development.

\section{Language Groups}

'Above' these localised groupings are the language groups themselves. As we have seen, in the precolonial period, language was probably not a generalised basis for group differentiation, at least in the case of the larger language groups. During 
and since the colonial period, however, Bougainvilleans have increasingly tended to be identified, and to identify themselves, as members of language groups. Nash and Ogan [1990] suggest that a major reason why this development occurred was because of a 'process of "tribal" identification' on the part of the colonial regime. They suggest that such identification occurred partly because Europeans needed 'a notion of a discrete political entity with some titular leader ... to cope with the indigenous people they met in their explorations'. They further suggest that the so called 'tribes' identified by the colonists - the various Bougainville language groups - were ranked by the colonists in terms of merit, ranging from 'advanced' or 'progressive' down to 'backward' or 'primitive'. Greater interference in the lives of the lower ranked 'tribes' was seen as necessary than was the case with progressive 'tribes' [Nash and Ogan 1990].

Bougainvilleans themselves continue to make distinctions between language groups on the basis not only of the extent to which they are perceived as relatively advanced or backward, but also of appearance and other qualities. The categorisations made of language groups are very similar to those also made by Bougainvilleans in relation to groups within language groups. While it is possible that this indicates adoption by Bougainvilleans of the coloniser's approaches to categorisation of groups, it seems more likely that Bougainvilleans, like people everywhere, have long tended to rank the groups that they interact with. In doing so they tend to rank themselves highest, and members of groups with which they have problems or conflict are naturally ranked quite low. If this view is correct, then the process of development of language group identities, where none existed in precolonial times, is likely to be at least in part a locally driven process associated with the expansion of the range of groups to which people belong, rather than simply an adoption of colonial categories. This is not to say that the changes brought by the colonisers were not important, for new identities emerged in a new context, in particular one where maintaining or gaining access to the state and to economic development opportunities has been a factor of great importance. These issues require some elaboration.

There undoubtedly was the tendency mentioned by Nash and Ogan [1990] for missions, plantation and colonial administrators to rank language groups. An example comes from the letters of Emmett McHardy, a New Zealand Marist Catholic priest writing in the early 1930s who spoke of the Torau people as a 'a gay, happy people, a much higher type of native than the Nasioi' [1935: 64]. Similarly, Bougainvilleans who attended mission schools in the 1950s and 1960s often talk of how the European nuns, brothers and priests categorised people of different language groups. In one instance, nuns at Asitavi High School are remembered as saying that Kieta's were 'stubborn', Buins were 'stupid' and Bukas were 'clever'. 
The colonists' impact on the development of identities associated with language groups also went further than their rankings of groups. Much of this was probably the unintended consequence of the naming of groups, drawing boundaries, and establishing administrative and other centres. Impacts varied considerably from group to group.

The common names of some of the main language groups in Bougainville have tended to be determined by Europeans. Many speakers of what is now widely known as the 'Nasioi' language resent the use of that term, it being one that coastal Pirung people use as a slightly derogatory term for mountain people. They say that until well into the colonial period, they had no single name for their own language, instead tending to regard the variants of Nasioi spoken by their localised groups as their language. The emergence of a sense of identity associated with the Nasioi language group is a product of the colonial period, and does not bring with it any strong sense of unity. 21

The term 'Siwai' for the area occupied by the speakers of the Motuna language is now often used too to refer to the language spoken in the area. But 'Siwai' was originally a point on the south-west coast of Bougainville between Aitara and Mamagota where Europeans, among others, traded with people of the area, and as a result the name came gradually to be applied by Europeans to the whole of the nearby areas [Oliver 1955: 8; Connell 1978: 1]. Pre-World War II 'linguistic and cultural homogeneity emphasised the unity of a Siwai area, even if there was a fuzziness about the actual boundaries' [Oliver 1955: 103]. A more clearly defined Siwai identity emerged through the activities of the missions and the colonial government, and especially through introduction by colonial officials of a number of institutions such as the Siwai Local Government Council and the Siwai Society [Connell 1978: 5-6].

On the other hand, as already noted, Bougainvilleans have their own assessments of members of their own and other groups, including language groups, that generally involve perceptions of their own group as in one way or another being superior to others, and ascribe deficiencies to others. These are unlikely to have developed merely as a result of adopting the views of colonisers, but rather to be an extension of categorisations habitually long made. Just as groups such as the Pirung regard the appearance and other qualities of the members of their group as special and attractive, there is a tendency for members of language and other groups to ascribe special qualities to the appearance of members of their own group, and negative qualities to the appearance of members of neighbouring groups. $^{22}$ Many Bougainvilleans believe that they can readily distinguish the appearances of members of the various main language - and in some cases other — groups in Bougainville [Friedlaender 1975: 24]. Preferences tend to be 
expressed for marriages within language groups, again in part to ensure the continuity of the desirable qualities.

Among other things, they discuss what tend to be accepted as the variations in black skin colour among groups in Bougainville and Buka islands (members of groups in the south tending to be regarded as a little more black than those of members of groups from Buka and north Bougainville) and generally express preference for what they see as the special characteristics of the appearance of the members of their own group. For example, the Torau acknowledge that they are of a slightly lighter skin colour than members of the Telei (Buin) and Nasioi language groups, but see that as involving desirable qualities. In the Torau language these are described as tala tala (shiny) and uniari (not too black and not too light — or 'red', a skin colour seen as undesirable). There is both a desire to preserve the special skin colour and other desirable attributes of what is seen as the typical Torau appearance, such as a straight nose (isu tetele), and some concern in the Torau community that intermarriage of Toraus with members of other groups is slowly changing the appearance of the Torau for the worse.

Bougainvilleans were also far from passive in their responses to colonialism, and so played a part in the emergence of new identities or the transformation of existing ones. For example, members of various groups sought to extract advantage from the new developments under colonialism, and in the process probably contributed to the emergence and shaping of their own identities. Examples come from the processes involved in development of a distinct Buka identity, discussed below. Similarly, McHardy's assessment of the Torau as 'a higher type of native than the Nasioi' was probably as much a product of the Torau recognition of the advantages of access to employment and other opportunities of association with the Catholic mission McHardy was establishing near their village as to anything inherent in the special qualities of the Torau.

There seems little doubt that differential access to 'development', both between groups within language groups and between the people of language groups, and reactions to such differences, have helped to encourage the emergence of, and to shape, identities into the postcolonial period. For example, to the extent that the Pirung, Avaipa and the Kongara were distinct identities before and early in the colonial period, it is most unlikely that differential rates of development were a major factor. But once there were significant differences in the access that such groups had to the state and to economic 'development', it seems likely that efforts to seek and protect access, or to redress imbalances in access, would have become significant factors in shaping identities.

It seems likely that perceptions of the characteristics of language groups - and also of groups such as the Pirung and Avaipa — that developed during the colonial 
period, in part based on patterns of access to the state, were (and still are) used by members of some of those groups as part of their efforts to take advantage of economic and political opportunities. The Siwai, for example, are widely regarded in Bougainville as having a natural aptitude for business, and many a Siwai seeks to establish businesses elsewhere in Bougainville in part on the basis of that perception. People from Nagovisi, where colonial control was established somewhat later than in Buin and Siwai, still tend to be regarded in Bougainville as 'natural' labourers, reflecting patterns of the 1950s and 1960s when many Nagovisi worked as labourers on small-holder plantations in the Buin and Siwai areas [Connell 1978: 151-3]. More examples emerge in the discussion of Buka identity that follows.

Finally, into the 1980s, while language groups were undoubtedly an important source of identity, such groups have certainly not become strong corporate units. There has not even been a great deal of effort to mobilise political activity and support on the basis of language groups.

\section{Differential Access to Development - the Case of Buka Identity}

The people of the island of Buka provide an interesting case of how patterns of development beginning immediately before the colonial period probably began the shaping of a common identity where it seems likely that none existed before. The development of Buka identity was also closely connected to the development of a distinct Bougainvillean identity. But Buka identity is in fact more of a 'regional' than a language group identity, as it incorporates several language groups, and is not even restricted to Buka. The language groups involved include Halia (and the sub-language of Haku), Solos and Petats on and around Buka Island, and sometimes also language groups in the far north of Bougainville Island. However, the emergence of a Buka identity illuminates aspects of the processes that were probably involved more generally in the emergence and change of identities associated with language and other groups.

Even in precolonial times, coastal and island communities probably had far more experience of dealing with the outside world than the inland valley and mountain people [Friedlaender, this volume]. The former traded with other Bougainvillean and Solomon Island groups, and dealt with explorers, whalers, 'blackbirders' and other labor recruiters [Oliver 1991: 16-29]. As for Buka and north Bougainville, even before such intrusions from the outside world, many (though presumably not all) people were directly involved in the extensive precolonial regional trading system already mentioned [Specht 1974]. Then, from the latter part of the 19th and early 20th centuries, they seem to have been recruited as labourers earlier and on a larger scale than most of mainland Bougainville [Specht 1974]. 
Quite apart from the appalling actions of 'blackbirders' who in some cases kidnapped large groups of Bougainvilleans [Oliver 1991: 21-3], from around 1870 numerous people from Buka and nearby areas of the northern part of Bougainville were recruited more or less willingly to work as plantation labourers in Samoa, Fiji and even Queensland. Once German New Guinea was established from 1884, large numbers of people from Buka and nearby areas worked in many parts of the colony. 'Bukas'23 enjoyed a reputation for trustworthiness and energy [Griffin and Togolo 1997: 359; Oliver 1991: 21; Sack, this volume] and were regarded as natural leaders, as indicated by comments published in 1887 by a United Kingdom official in the Pacific: ${ }^{24}$

... they ['Bukas'] are the finest specimens of manhood in the South Seas. They are fine and plucky fellows ... Wherever he goes and whatever natives he mixes with a Buka man will always become the leader. [Romilly 1887: 71]

Of course, 1887 was very soon after the German colonial regime was established, and so such perceptions were presumably based on the record of 'Bukas' working elsewhere (such as Queensland, Fiji, Samoa). 'Bukas' were highly sought after as colonial police, plantation supervisors and plantation security personnel in other parts of German New Guinea. 25

In 1905, the first permanent colonial administrative headquarters for Bougainville was established, mainly to facilitate increased recruitment of labour by bringing inter-group conflict under control. The German governor, Albert Hahl, decided that Buka was not the place for the administrative headquarters because there were already so many returned colonial policemen there that 'pacification' was already achieved [Hahl 1937, trans. Sack 1980]. Instead, Kieta was chosen as proximate to the best potential new labour sources - the densely populated areas of central and south Bougainville where inter-group conflict continued unabated.

Even after the establishment of the Kieta headquarters, missions, government and plantations all employed many people from Buka as their activities expanded in various parts of Bougainville. For example, McHardy wrote in the early 1930s about establishing the Tunuru Catholic Mission, near what is now Arawa, saying that: 'The boys [working for him] here are nearly all from Buka and they are as intelligent as any in the Prefecture; one or two of them are quite handy' [1935: 63]. A 1943 terrain study of Bougainville and surrounding areas for the United States and its wartime allies noted:

The Buka people are said to be more advanced than the others and are in considerable demand as police, house servants and boatmen. The people of 
Buin are also said to be very good type (sic) and more ready to engage as laborers. [Allied Geographic Section. Allied Forces, Southwest Pacific Area 1943: 53]

Europeans were thus making use of what they saw as the superior qualities of 'Bukas', while people from Buka were presumably seeking what advantage they could gain from the way that Europeans categorised them. In the process there was no doubt plenty of scope for the stereotype of the man from Buka as of superior stock to be reinforced not just in the mind of the colonist, but also in the minds of people from both Buka and from Bougainville more generally.

While initially the majority of Bougainvilleans working elsewhere were from Buka, there were always some from Bougainville Island. From the early 20th century, the proportion of the latter climbed rapidly. By at least the early 20th century, the term 'Buka', when applied to people, came to mean any blackskinned person from Bougainville. ${ }^{26}$ Superiority of the Buka was then extended to all Bougainvilleans when they were dealing with the mainly lighter skin coloured people from other parts of New Guinea, who 'Bukas' were often supervising or against whom they often participated in punitive expeditions. By contrast, when people from Buka itself were dealing with people from other parts of Bougainville, it was the Buka who tended to claim superiority.

It seems likely that people from Buka would have sought to reinforce the perceptions of their superiority in the minds of the colonists, both because they would have believed that it was true and because they could thereby protect their privileged access to employment and financial and other reward. It is significant that McHardy, the New Zealand priest near Arawa, reported using mainly Buka 'boys' in the 1930s and that the Allied terrain study of the 1940s reported Buka people being in demand for employment. These reports suggest either that the early advantage that Buka people enjoyed in terms of access was long-lived, or that they were quite successful in reinforcing perceptions of their superiority, or both.

It could also be expected that the attitudes of people from Buka would have communicated themselves to people from other parts of Bougainville that they dealt with. Even in the 1980s and beyond, people from other parts of Bougainville tend to believe that many people from Buka have a strong sense of superiority (in terms of qualities such as intelligence and perceptiveness) over other groups of Bougainvilleans. Such perceptions seem to be related, at least in part, to what Buka people see as their role in bringing 'civilisation' to the rest of Bougainville. It is also related to the view that they are among the best-educated groups in Bougainville. It is widely accepted in Bougainville that the long advantage Buka has enjoyed in access to education has enabled a relatively high proportion of Buka people to be employed in senior positions, both in Bougainville and elsewhere in 
Papua New Guinea. There is continuing concern among many Buka leaders to protect their educational and employment opportunities. This concern is sometimes seen as an important reason for what is seen as a tendency on the part of many (though certainly not all) Buka leaders to see advantage for Buka in continuing to remain part of Papua New Guinea. It is often suggested that there was limited support among the Buka leaders for the cause of Bougainvillean secession in the late 1960s and early 1970s (and again from the late 1980s) largely because of the economic advantage that Buka people could expect from continued links with the rest of Papua New Guinea.

The sense of superiority on the part of Buka people is often noted by people from other parts of Bougainville, and sometimes resented. On the other hand, among the people of Buka, the members of each language group there tend to regard themselves as naturally superior to the other language groups on Buka.

\section{Church, Local Government, and Localised Political, Religious and Cultural Groups}

In addition to language groups there have been many other sources of new identities that have emerged in association with, or reaction to, colonial and postcolonial development. They have included identities associated with churches. For example, people identify as members of one or other of the three main churches established in Bougainville early in the 20th century (Catholic, Uniting Church, and Seventh-Day Adventist) or one of the smaller Pentecostal Protestant churches established mainly from the 1970s. People also often identify themselves as being from the local level of their church — for example, from particular Catholic parishes (a particularly strong basis for identity in many areas of Bougainville). New sources of identity associated with the state have included local-level government, cooperatives, provincial government constituencies, and so on. They have all involved the creation of new social units that have had their own resources and power structures. In part because of the resources and power involved, in many cases some, at least, of the people within the units have attached considerable significance to belonging to them, and often have interests in mobilising activity of one sort or another in association with the units, thereby contributing to development and consolidation of group identity.

Another factor contributing to the tendency for such new identities to become significant has to do with inter-relationships with long-established landholding clan lineages, local groupings of hamlets and villages, and the larger local groupings such as those among the Nasioi and the Nagovisi already discussed. For example, there were cases where localised groups with histories of conflict joined opposing religious groups — carrying on long-established conflict or rivalry 
through their religious affiliations [Oliver 1955: 316; 1971: 215; 1991: 62, 66; Elder, this volume].

Other new identities have emerged in reaction to colonial and postcolonial developments. They include those associated with what are often referred to in Bougainville as 'indigenous religious and political movements'. They include groups such as Hahalis Welfare Society [Oliver 1991: 86-9; Rimoldi and Rimoldi 1992] and Damien Dameng's Me'ekamui Pontoku Onoring [Regan 2002b; Tanis, this volume]. These and a number of similar groups ${ }^{27}$ have usually been based in parts of particular language groups - Hahalis in the Halia area of Buka and extending to most parts of Buka and some areas of north Bougainville, and Me'ekamui Pontoku Onoring based in the area of the Damara/Ioro people and influencing parts of central and south Bougainville. Originating mainly in the late colonial period (from the late 1950s onwards) such groups were seen by the Bougainville Constitutional Commission, commenting in 2004, as having 'resisted both the outside influences [on Bougainville] and the changes they were bringing, and sought not only a resurgence of [Bougainvillean] culture and kastom but also greater control by Bougainvillean communities over the process of change' [2004: 32]. A number of these movements have established their own 'governmental' structures, in opposition to local or provincial governments, collecting 'tax' revenue from their members, constructing 'government' buildings. Some had developmental goals, promoting economic activities. Mobilising people around political and developmental goals, these bodies too have involved power and resources.

\section{Regions within Bougainville}

Within Bougainville the main regions are north (usually seen as including Buka, the northern part of the mainland of Bougainville, and the atolls groups), central and south, with geographic boundaries corresponding largely to those of the three 'open' electorates that since 1972 have been the basis for election of the Bougainville representatives to the Papua New Guinea National Parliament (see Map 2). ${ }^{28}$ As can be seen from that map, the Central Bougainville Electorate is in fact situated only on the eastern side of Bougainville, and as a result, the central part of the west coast of Bougainville tends not to be included in the central region, making 'central' in some ways a misnomer. As with other 'new' identities already discussed, a significant factor in the emergence and continued importance of regional dimensions are issues concerning the distribution of access to power and resources.

Distinct regions emerged as factors in Bougainville politics from the late 1960 s or early 1970s, largely in the context of debate about the future political 
status of Bougainville. This was often portrayed as involving a 'north-south polarisation' (see, for example, Mamak and Bedford [1974: 62]), with leadership of north-Bougainville and Buka tending to oppose the proposals for Bougainville secession from what was then the Territory of Papua and New Guinea, and leadership in the southern half tending to support secession. In 1973, for example, leaders from Buka and North Bougainville made a threat that those areas could secede from the rest of Bougainville if leaders from central and south Bougainville at a Combined Councils Conference passed a resolution in favour of Bougainville seceding from Papua New Guinea [Griffin 1977: 53]. ${ }^{29}$ Such views tended to be held most strongly among leaders from Buka, reflecting views already discussed.

From at least the late 1960s, there have been the traumatic impacts of development of the Panguna mine in the mountains of central Bougainville contributing to the emergence of new political and social movements in that area, such as Napidakoe Navitu, and the strengthening of already existing movements in the area, such as Me'ekamui Pontoku Onoring. Another factor was the sense of resentment in other parts of Bougainville about what were perceived as the unfair advantages that people in Central Bougainville were deriving from mining. There was considerable concern in Buka about the shift of the colonial headquarters from Buka (Sohano Island in Buka Passage) to Kieta occasioned by the development of the mine. There were also 'jealousies over the inflow of money in the form of compensation to communities near the mine' [Bedford and Mamak 1977: 89] something in part resulting from a BCL public relations campaign to convince the public that the company had acted fairly towards landowners suffering the impacts of the mine [Bedford and Mamak 1977: 87]. ${ }^{30}$ Helping to consolidate the three distinct regional identities was the 1972 change from two to three 'open' electorates in the Papua New Guinea national legislature - the addition of a Central Bougainville electorate to the North Bougainville and South Bougainville electorates. $^{31}$ The boundaries of those electorates - see Map 2 - have not changed in the more than 30 years since.

When, in the mid to late 1970s, a single political structure for Bougainville was established for the first time, in the form of what was eventually called the North Solomons Provincial Government (NSPG), it became, among many other things, a forum for dealing with claims for power and resources. A variety of competing claims for access to and balance (and achieving redress of imbalance) in the distribution of the resources of Bougainville could, to some degree, be managed within that forum. This development provided opportunities to many groups, including the least developed groups 'within' language groups. But the three regions also became significant players. The importance of the region was 


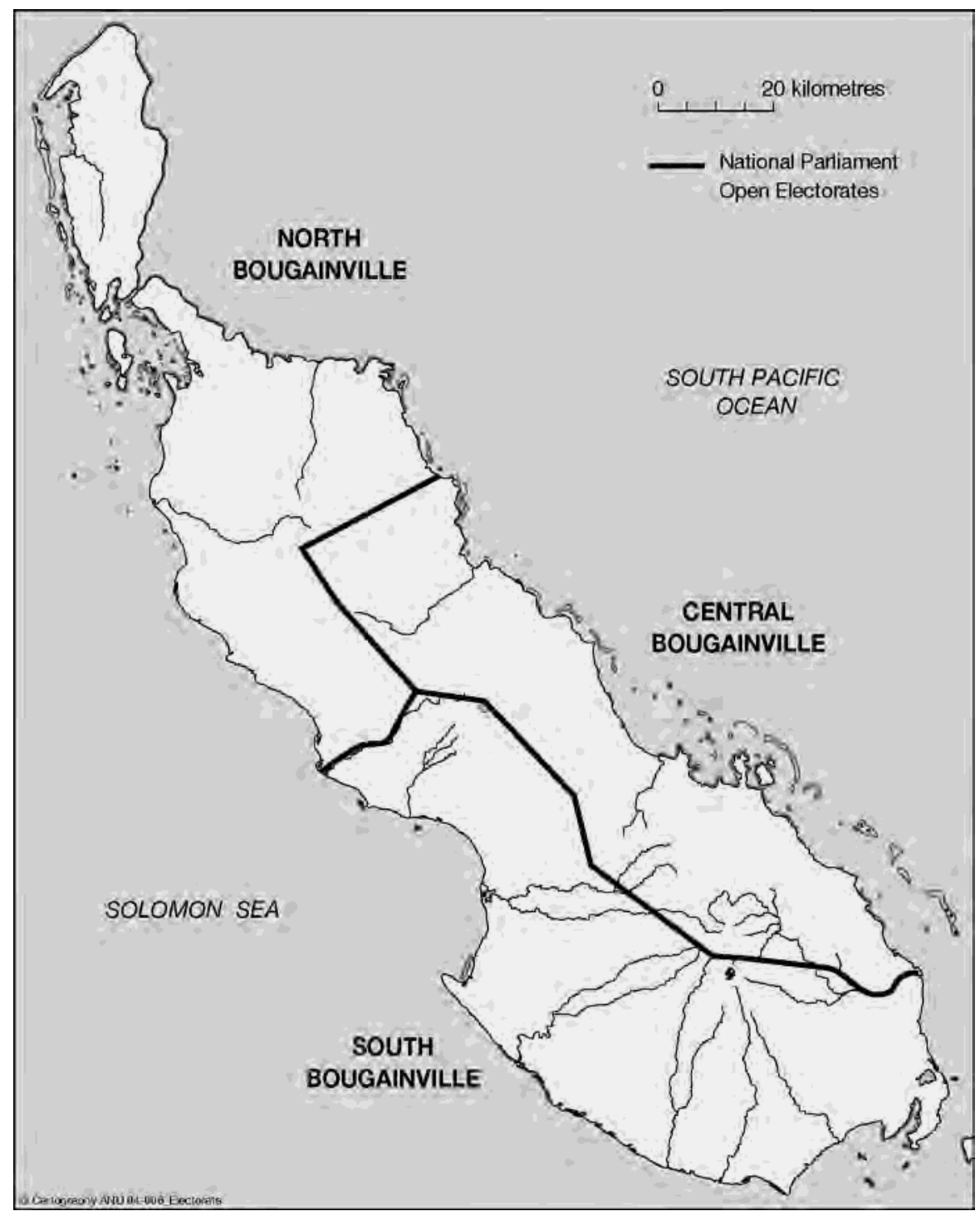

Map 2. Electoral boundaries, 1972

recognised in the provisions of the NSPG Constitution, drafted in 1976. It sought balanced regional representation in the Provincial Executive Council (PEC), through committees comprising members of the legislature elected from constituencies in each region that nominated regional representatives to the PEC. ${ }^{32}$ Further, a convention developed that the premier (elected on a 'presidential' vote by the 
whole of Bougainville), the deputy premier (appointed by the premier) and the speaker of the legislature (elected by the legislature) should all be from different regions. ${ }^{33}$ The annual provincial budget-making process was also to a large degree about ensuring that the not inconsiderable revenues of the NSPG were distributed fairly, between regions as well as between other groupings.

There is a tendency for debate about the regions to reflect not just concerns about balance, but also the special rights of 'original' inhabitants. This concern is reflected in views about the rights of people from the region to have preference in establishing businesses and take employment opportunities as, for example, when there are 'development' projects proposed for or occurring in a particular region. Similarly, there is often concern expressed regarding the internal migration that has occurred within Bougainville, for example, the Arawa/Kieta/Toniva area in the 1970s and 1980s, and to Buka in the late 1990s and early 2000s (as a result of Buka having again become the main administrative and commercial centre following the conflict in the 1988 to 1997 period).

\section{CONCLUSIONS}

While to people outside Bougainville, it may appear that Bougainvilleans are unified around a relatively distinct and distinctive identity, numerous other identities are part of the picture as well. A Bougainvillean can comfortably move between them, being at once a Bougainvillean, a person from a region, or a language group, or a group within a language group (such as the Pirung or the Bava among speakers of Nasioi, or the Lamane or the Booga among the Nagovisi), a member of a clan, a member of a local land-holding lineage, a church member and so on. Not surprisingly, new identities have emerged, while many older identities have far from disappeared.

What makes some identities more important than others? Have social or cultural identities become ethnic identities? Has there been any movement from ethnic identities to ethnicity (accepting, of course, that there are limitations in the usefulness of those terms)? Partly the answers to such questions may depend on which identity is most under attack or threat [Maalouf 2001: 26]. Certainly, where persistent and violent threats occur, it could be expected that political and other ethnicity may develop.

While we may never know with certainty the history of widespread localised violent conflict in all areas of Bougainville before and — in many areas — for a considerable period after direct colonial rule began, it would be difficult to imagine that there were not some continuing impacts from memories of such conflict. After colonial 'pacification' violent inter-group conflict did not cease alto- 
gether. It occurred, for example, between adherents of 'opposing' churches in South Bougainville in the late 1920s, as discussed in this volume by Laracy. There was vicious inter-group fighting in central Bougainville during World War II [Feldt 1967; Nelson, this volume]. The final reconciliation ceremonies to resolve the impacts of such conflict between Torau and Nasioi-speaking groups occurred 40 years later, in the 1970 s, ${ }^{34}$ while in the case of similar conflict involving Damara/Ioro and Avaipa people, reconciliation occurred in the 1980s. 35

Examination of the roles, and the extent of politicisation, of identities within Bougainville in the terrible internal conflict that occurred in Bougainville as part of the 1988-1997 conflict (especially after the withdrawal of the Papua New Guinea security forces in March 1990) is beyond the scope of this chapter. It would require consideration of the particular circumstances of Bougainville in the 1980s. This was a time of complex and rapid political, economic and cultural change in Bougainville, where economic inequality was growing, due to both the rapid spread of cash-crop activity, especially small-holder cocoa plantations developed mainly since the 1960s, and activities associated with the Panguna mine. It was a situation where land shortages were beginning to be felt in some areas of higher population, or where patterns of clan access to land were causing unequal access [Mitchell 1982; Tanis, this volume]. In a situation of complex and multilayered identities, a long history of egalitarian social structures, and 'differential access to resources' [Levine 1999: 178] due to new economic developments, it may have been a small step for some identities to become important in bitter struggles over resources. At the same time, very minor local differences in accent, material culture, diet (due to the ecological niche occupied by a group) can readily become markers in cases where tensions and conflict are occurring between groups.

In March 1990, the Papua New Guinea National Government effectively withdrew from Bougainville. Its forces and basic government administration and services only returned slowly from late in the same year, first to Buka, and then over several years to some parts of Bougainville island, and were never re-established in large parts of Bougainville island before the peace process began in 1997 [Regan 1998]. At the same time, armed groups were often operating on a localised basis, with limited control from Bougainville Revolutionary Army command structures, often pursuing localised concerns. New organisations, interests and loyalties now overlaid the patterns of unequal access to resources that had developed, over an extended period.

The 'mapping' of identities among Bougainvilleans offered in this paper can perhaps assist in the examination of these and perhaps similar issues. 


\section{Endnotes}

In writing this chapter I have been assisted by discussions with, and information provided by, people far too numerous to list here. I must record, however, my gratitude to particular people whose ideas and information helped me better identify the range of identities among Bougainvilleans, namely Damien Dameng, Joseph Kabui, Roselyne Kenneth, Theodore Miriung, Isaiah Moroko, Simon Pentanu, John Siau, James Tanis, Mel Togolo and Marcelline Tunim. I have also benefited from comments on an early draft of this chapter from Raymond Apthorpe, Helga Griffin, James Griffin, Joseph Kabui, David Hegarty, Ron May, John Siau and James Tanis.

1. See, for example, Griffin [1982; 1990] (and other writings by Griffin referred to in those pieces); Mamak and Bedford [1974]; Nash and Ogan [1990]; Filer [1990 and 1992]; May [1990]; Ghai and Regan [2000].

2. While drawing on examples from many areas, my particular focus is on the Nasioi, Torau and Nagovisi language areas of central and south Bougainville.

3. See, for example, the migration stories in Siwai and Nagovisi 'clan "histories"' discussed by Oliver [1993a and 1993b: 24].

4. The migration stories of the Torau are well documented [see Terrell and Irwin 1972 and the sources that they cite]. It seems not to have been documented, however, that the Amun/Piva of the central and northern areas of the west coast of Bougainville apparently have a similar history of migration from the Shortland Islands area, perhaps at a similar time to the migration of the Torau. It is not clear why this history has not attracted similar interest to that given to the Torau, one possible explanation being the comparative remoteness of the Amun/Piva speakers in relatively inaccessible parts of Bougainville.

5. There is ample evidence in support of this view in the recorded observations of virtually all early European observers of Bougainville in the late 19th and early 20th centuries, and those of almost all anthropologists who have worked in Bougainville (see, for example, the work of Nash [1974: 56-7]).

6. Sack [1973: 56-7] cites the observations of former Papua New Guinea Chief Land Titles Commissioner, Kimmorley, concerning the customary arrangements among the Siwai for the leasing of land 'by refugees from fighting in the old days who fled to places distant from their home'.

7. Oliver [1991: 94] cites Parkinson [1907] in support of this view, and Thurnwald [1909: 512-20] expresses a similar opinion concerning the Buin plains, in particular. (I am grateful to Helga Griffin for drawing my attention to Thurnwald's observations, and for translating them from the original German.)

8. In relation to the Motuna speakers of Siwai, see Oliver [1993a], and in relation to the Nasioi and the Nagovisi see Nash and Ogan [1990: 4].

9. See also the discussion of the people of the area known as the Avaipa, below.

10. See, for example, Ogan, Tryon, and Friedlaender, each in this volume, and Oliver [1971, 1991: 1-6, 92-117 and 1993a, 1993b], Terrell [1978], Nash and Ogan [1990] (and also the publications referred to in their footnote 10) and Ogan [1992].

11. As recorded by Blackwood [1935: 44-5] and by Keil [this volume].

12. For example, in relation to the Siwai see Oliver [1993a: 25]; in relation to the Nasioi, see Ogan [1972: 97]. People who had to flee their home areas during the height of the Bougainville conflict commonly tell of being assisted in particular by members of their corresponding clan when living in areas belonging to other language groups. In particular, members of displaced groups in central Bougainville report being able to establish strong linkages to clan groupings 
that their clan migration histories indicated were related to the displaced groups.

13. However, one of the main ways of holding land among the Torau is through matrilineal lineages of persons from the same clan descended from a known maternal ancestor.

14. Members of particular Torau clans assert that during the conflict, 1988-1997, their clan members fought more bravely than those of other clans.

15. For example, occupying different ecological niches can result in significant differences in food and in material culture. Thus, among speakers of the Nasioi language, because of the altitude at which they live, the people of Kongara, high in the mountains south of Panguna, have access to few coconuts and other tree crops, but can grow many plants that coastal and valley people cannot. They also have different sources of protein from coastal and valley people, including more use of lizards and insects.

16. See endnote 15.

17. Bougainville, since 1998, has hosted numerous New Zealand and Australian personnel in the Truce Monitoring Group, the Peace Monitoring Group and numerous aid projects. Where relations between individuals from opposite sides of the Tasman have become strained, it has been far from uncommon for explanations proffered by people from either side for the offending behaviour of a person from the opposite side to be based in part at least on stereotypes of the kinds of negative qualities that tend to be attributed to the 'group' from the opposite side.

18. J.Griffin [1982: 113] suggests the term 'Daru' as the basis for the letters ' $\mathrm{Da}$ ', and just Koromira as the basis for the letters 'Ko'. My source of information for the derivation of the anagram is Damien Dameng, who was a member of the executive of Napidakoe Navitu.

19. In the case of the Bougainville People's Congress, constituency names in the Nasioi-speaking areas include Bava-Pirung, Apiatei, Kongara, Nasioi, and Kokoda (an anagram of the first two initials of Koromira, Koianu and Dantenai). In the case of Nagovisi, the constituency names used included Velepi, Lamane, Telepi and Tomau. In terms of demands for drawing of constituency boundaries for the new Autonomous Bougainville Government expected to be established through elections planned for mid-2005, at public meetings in 2002 and 2003 held to discuss development of the new Bougainville constitution, a 'chief' of a major Pirung village asked for a separate constituency for the Pirung on the basis that their kastom and interests were quite different from those of the neighbouring Apiatei, Bava, Nasioi and Dantenai groups.

20. This is not to say, however, that groups in remote areas necessarily want economic development at any cost. In 1966, Catholic Bishop, Leo Lemay, pointed out to the people of the mountainous areas around the Panguna mine that 'they would remain "bush", without roads, if CRA were told to leave, he was told in no uncertain terms: "We want our land; we do not want CRA; we want to remain bush; and if need be our children will remain bush"' [Laracy 1999: 586]. Laracy was quoting from a letter of 16 August 1966 from Lemay to the then retiring Administrator of the Territory of Papua New Guinea, Sir Donald Cleland.

21. This fact is reflected in patterns of voting among the Nasioi for candidates in elections for the colonial legislature, where they did not unite to support Nasioi candidates [Ogan: 1965].

22. Though not necessarily a universal tendency. Connell suggests that unlike the Bougainville groups that Friedlaender [1975] discussed '... Siwais did not conceive of their own physical uniqueness; they believed that it was generally impossible to distinguish Siwais from other Bougainvilleans in this way. Their uniqueness was a product of language and culture' [1978: 29].

23. While the term 'Buka' gradually came to be applied to any black-skinned person from 
Bougainville, in the late 19th century it was likely to be a relatively accurate description of the place of origin of workers recruited from what is now Bougainville, as they tended to come mainly from Buka Island and the far north of Bougainville Island.

24. Deputy commissioner for the Western Pacific and acting special commissioner for New Guinea.

25. See Oliver [1991: 21] and J. Griffin and Togolo [1997: 359] and the sources that they cite.

26. Similarly, 'Buka basket' came to be the term applied to baskets made in in the south of mainland Bougainville, in Siwai and Buin!

27. The Final Report of the Bougainville Constitutional Commission talks of a number of such groups, including 'the Solo-Mono movement originally based in Nagovisi and led by Johannes Avaroko, and more recently by King Tore, of Boku in the Baitsi, a group with support extending through Siwai and into Telei (Buin); the Johannes Kanis movement of Selau-Suir; the group led by Fabian Tonepa of the Avaipa area, in Eivo; the Sipapai movement, led by Clement Sipapai, of the Karato area, West Asikopan on the Western side of the Eivo-speaking area of Central Bougainville; the group led by Paul Mena of Pontona, in the Koromira/Koianu area; the Toiakingil movement led by Blasius Raring, on Nissan Island, north of Buka Island; the group led by Peter Chanel Kakapitai of the Keriaka area on the Northwest coast of Bougainville Island'. [Bougainville Constitutional Commission 2004: 32]

28. For the first election to the colonial legislature - the House of Assembly — in 1964, there was just one 'open' electorate and one regional electorate, both covering the whole of Bougainville. In the 1968 elections, there were two open electorates, one North and one South, as well as the regional electorate. For all elections to the Papua New Guinea national legislature since 1972 (House of Assembly to 1975, and from Independence in September 1975, the Papua New Guinea National Parliament) there have been three 'open' electorates (North, Central and South) and one regional.

29. That was a threat that was to be echoed many times by elements of the Buka leadership from 1988 until a common Bougainville negotiating position emerged in late 1999 as part of the Bougainville peace process.

30. Tanis [this volume] also provides insights into how resentments about compensation payments strained inter-group relations, in his case more local relations between original landowners in the lower tailings lease area and settlers from Lamane who had purchased land in the lower tailings area and so received compensation in relation to their blocks.

31. See endnote 28.

32. See section 49 of the Constitution of North Solomons Provincial Government, entitled 'Representation of Regions', and similar provisions in clause 81 of the Constitution of the Autonomous Region of Bougainville [Bougainville Constituent Assembly 2004].

33. The deputy premier was appointed by the premier from among the members of the legislature, while the speaker was elected by the members of the legislature from either among their members or from prominent persons outside the legislature who were qualified to stand for election.

34. Information from Melchior Togolo.

35. Information from Joseph Kabui. 


\section{NAGOVISI VILLAGES \\ AS A WINDOW ON \\ BOUGAINVILLE IN 1988}

by James Tanis

\section{INTRODUCTION}

Violent conflict between armed Bougainvilleans and the Papua New Guinea security forces erupted in November 1988, the armed Bougainvillean elements pursuing secession from Papua New Guinea. By March 1990, the Papua New Guinea National Government withdrew its forces from Bougainville, and on 17 May the leader of the secessionist Bougainville Revolutionary Army (BRA), Francis Ona, announced Bougainville's Unilateral Declaration of Independence (UDI). A few weeks later, the National Government suspended the North Solomons Provincial Government (NSPG), by which time it had become clear that the premier of the provincial government, Joseph Kabui, was working with the BRA.

Since 1990 the secessionist BRA and other pro-independence groups have held an annual celebration of the 1990 UDI every 17 May. After joining the peace process that began in mid-1997, one of the BRA responses to the changed political situation was to rename 17 May as 'Remembrance Day', to remember both the UDI and those who had died on all sides of the conflict. But Francis Ona and his supporters decided in early 1998 to remain outside the peace process, and instead announced the formation of a Government of the Republic of Me'ekamui, supported by former BRA elements that were now designated the Me'ekamui Defence Force. Francis Ona and his 'government' continued to observe the 17 May celebration of UDI in its original form.

Fridays are busy market days in Arawa, the former mining town and Bougainville's main administrative centre under the NSPG. In 2004 the market 
place was situated on what was - before it was burnt down during the conflict the concrete floor of the Arawa Community Hall. On 21 May 2004, Arawa Town was alive with stories of that year's 17 May Celebrations. Some stories were about the recently completed 17 May games organised in Arawa by former combatants. Others were about the quite different ceremonies held by Francis Ona and the Me'ekamui Government in Guava Village, Ona’s base in the mountains, adjacent to the derelict site of the huge mine once operated by Bougainville Copper Ltd (BCL).

One group in the market chewed betel nut and talked about how Francis Ona and the Me'ekamui announced that Queen Elizabeth II and other major public figures from all over the world were going to Guava Village to recognise the Me'ekamui Government, bringing planes and vehicles for Ona. Although the Queen and other figures did not come, on 17 May Francis Ona proclaimed himself to be the new king of Bougainville (King Francis Dominic Dateransi Ona Domanaa). On the same day, Ona's close associate of the previous two years, a Bougainvillean from Siwai called Noah Musingku, was proclaimed Prince David Noah Musingku Hokong Papala.

Musingku had been a key figure in U-Vistract, a pyramid scheme purporting to make quick money and based in Port Moresby from the late 1990s. When he failed to pay his 'investors' their promised 100 per cent interest per month, legal action was launched against him, and when he failed to appear an arrest warrant was issued. In the meantime, Noah had moved to Guava, which also happened to be in a 'no-go-zone' proclaimed by Ona around the Panguna mine area, where the Australian led Peace Monitoring Group and the United Nations Observer Mission on Bougainville (both supporting the then ongoing peace process) and the Papua New Guinea police did not venture. Late in 2002 Noah went to the Solomon Islands, announcing to great fanfare that he was giving the government there SI\$2.4 billion. He left the Solomon Islands just ahead of the arrival there in 2003 of the Regional Assistance Mission to the Solomon Islands, and returned to Francis Ona in Guava, which he apparently saw as a safe haven from possible arrest, and a base for seeking new investors in his latest schemes, which included a Royal Bank of Papala!

As I listened to the conversations in the market, one man said: Yumi bin gat Primia, yumi bin gat Supreme Commander, yumi bin gat President na nau yumi gat King na ino long taim wanpela man em bai kolim em yet olsem Pop ("We had Premiers, Supreme Commanders, Presidents and now a King and how soon will it be before someone else declares himself to be the Pope'). The group burst into laughter. Another swore loudly, saying: Mipela ino laik harim King mipela ilaikim indipendens ('We don't want to hear about Kings, we want to see 
independence'). A third joined in: Yes, mipela ilaikim moni bilong mipela tasol na mipela ino laik harim Prince ('We only want our money back from our investment and have nothing to do with Prince and such ...').

My mind drifted back to 1989 when there were few things associated with Francis Ona that could have been regarded as laughing matters. I remember having heard of how a woman in my village of Panam was fined K50 by local BRA members for calling Francis Ona a 'stupid pig' while she watched smoke rising from nearby Orami village as it was burnt by Papua New Guinea Defence Force (PNGDF) soldiers. I was not there at the time, but I could have killed her too in those days for saying anything critical of the BRA's Supreme Commander. How things have changed in 17 years.

My day in the market in 2004 was almost exactly 15 years from the 1990 UDI, and 17 years from 1988, the start of the conflict. I had been involved in this struggle for that whole period. But 2004 was the 17 th year of a conflict that many thought would last a week. How did all this start?

This chapter presents a brief survey of places, events and people that I saw and heard during the period when I was a young man, in my teens and early 20s, just before the Bougainville conflict began. They are things that I hope will shed some light on how and why the conflict started.

\section{MY TERRITORY}

\section{Nagovisi and Bana - the People, the Land and the Rivers}

My people are called the Nagovisi people. Different groups make up the Nagovisi society, identified mainly by the geographical areas they occupy, and the variations in pronunciation of our language.

The higher lands occupied by Nagovisi people close to the central mountains of Bougainville are called the Lamane area, which shares common borders with Kongara One and Ioro areas of the mainly Nasioi-speaking Kieta District. I was born and raised in Panam Village in Lamane.

The midlands, or valleys west of the mountains, are known to us as the Booga area. Sirakatau, where the Australian-led Peace Monitoring Group had its 'forward patrol base' during the Bougainville Peace Process, is in the Booga area. The other 'landmark' of the Booga area is the Boleuko Catholic Mission. To the north of Booga, and also in the midlands, is the Veripe area, and its major landmark is the former Bougainville Copper Agricultural Foundation at Mananau. The polluted Yaba (Jaba) River flows through the Veripe area, which shares part of its border with the Oune and Avaipa people of the Kieta District. 
To the south of Booga and also in the midlands is the Tomarasi area, for which the main landmarks are the Sovele Catholic Mission and Sovele District Office. Closer to the coast, on the plains between the Veripe and the Tomarasi areas, is the Toberaki area where the main landmark is the Morotona Health Centre. The Toberaki and Tomarasi areas share borders with the Banoni people, who live close to the west coast, and speak a language distinct from that of the Nagovisi.

The people of each of the Nagovisi areas are known by the name of their area, and are also identified by the specific accent of the area. We Nagovisi generally call our language Tobee, but in the Lamane area we speak it with an accent called Teleepi. But people from Tomarasi call the Nagovisi language the Sibee Language.

The Kawaro (Kawerong) River starts in the Panguna area in the mountains north-east of Lamane and flows through Ioro and Oune areas and meets what we call the Yaba (Jaba) River that starts in the mountains of Ioro, and flows down to the borders with Veripe, close to the Bougainville Pump Station (which formerly pumped the vast amounts of water to the Panguna mine site needed for the operations there). Two other rivers join with Yaba and the Kawaro rivers, the Nonopa and Pagaro rivers in the Booga area. The Pagara River starts in the Kongara One area of Kieta District and flows west between the borders of Lamane and Ioro, down through the Booga and Veripe areas, joining the Yaba River in the Toberaki area.

During the colonial era, the kiap (government field officer) patrolled Nagovisi from Boku Patrol Post in the Baitsi area (the Baitsi are a small sublanguage of the Motuna language of Siwai, whose territory is at the northern end of the Siwai area.) The same kiap administered the Banoni people along the coast and the Baitsi people around Boku. When cocoa was introduced to our people in the 1960s, the Nagovisi, Banoni and Baitsi people formed the Bana Society, the name being created by taking the 'Ba' from Banoni and Baitsi and the ' $\mathrm{Na}$ ' from Nagovisi. The Society built its cocoa dryer at Beretemba close to Sovele Mission. During the community government era (1978-90, under the NSPG) the name 'Bana' was not much used.

When Francis Ona was creating the command structure of the BRA, however, he and his senior commanders created a chain of command for operations in Nagovisi, Banoni and Baitsi Area, naming it the 'Bana Command'. The Foxtrot - or 'F' - Company of the BRA operated there. Use of the name Bana became common during the conflict and today is often mistakenly used as the name of the territory, the people and the languages of both Nagovisi and Banoni. I have used the name 'Bana District' in this chapter simply because it is the name many Bougainvilleans are now familiar with. 


\section{Community Governments of Bolave and Ioro}

Before the conflict there were three community governments that were either wholly or partially in what is now called the Bana District.

The name of the Bolave Community Government was created by combining the first two letters of the areas that the government covered, namely the Booga, Lamane and Veripe areas. This body had its offices in Sikolewa Village on the eastern edge of the Veripe area, the last village of Bana before heading east into the Ioro area of the Kieta District. Bolave was the closest community government in the Bana District to the Panguna area. In fact it was much closer to Panguna than the offices of the community government actually responsible for the Panguna area (Ioro Community Government), whose office was on the Birampa River, near Orami Village, close to the western edge of the Ioro area. This was a location inland of the main Siwai, Bana, Panguna Highway, at the end of a small feeder road that branched at Sikolewa Village. As a result, if Ioro officials wanted to go Panguna, they had to travel down to the main road at Sikolewa, and usually wait for a vehicle at the Bolave Community Government office. The leadership of these two community governments enjoyed a close relationship.

The other two community governments in Bana were Lato, based in Sovele, and covering southern parts of Lamane and Tomarasi and Toberaki, and Baba, based in Boku, and covering parts of Banoni and Baitsi areas. Both bodies borrowed the first two letters from the names of the areas under their jurisdiction to create the new names for their community governments.

Less than five kilometres away from the Ioro Community Government Office, up the Biampa River in Irang Village, there was a different kind of government led by Damien Dameng. The provincial government called it the 'Private Government', while some Church people called it a cargo cult, and still others called it the '50 Toea Gavman' (names that I shall explain later in this chapter). Dameng himself called his government the 'Me'ekamui Pontoku Onoring, Daita Karakeni'. In Nasioi one meaning would be the Parliament (Karakeni) of clans in Kieta District (Daita) to protect our autonomy (Onoring) over our land and cultures that we have possessed from time immemorial (Pontoku) to enhance wholeness, unity, peace and holiness (Méekamui) in the society. I will discuss his government further later in this chapter.

The Ioro Community Government did little in the areas supporting Dameng, and concentrated more on villages closer to the roads and of strong Christian influence. Support for Dameng's Me'ekamui Pontoku Onoring was strong higher up across the foot of the Crown Prince Ranges, in Irang, Pankaa, Mosinau and Poaru villages. These villages sit like an arc around Guava Village, the home of Francis Ona. But Dameng's support in Guava was limited. Similarly activities of the Ioro 
Community Government were almost non-existent in Guava Village, mainly because it was so far from the community government's offices. As a result, daily life in Guava was shaped mostly by the pressures of the Panguna mine and its associated activities.

\section{The Impacts of Mining in my Area}

The open-cut mine pit operated by Bougainville Copper Limited (BCL) was at Panguna, in the Ioro area of the Crown Prince Ranges. The mine pumped a slurry concentrate of copper, gold and silver through a pipeline to Loloho in the Anewa Bay on the east coast of Bougainville. To the west of Panguna, BCL dumped into the river system the tailings waste - crushed rock and chemicals from which the ore had been removed. It was dumped into the Kawaro (Kawerong) River at Panguna, from where it flowed into the Yaba River, which flowed on through the Toberaki area of Nagovisi and finally into the Empress Augusta Bay on the coast in the Banoni Area. The tailings did not affect just the Kawaro and Yaba Rivers but also the Pagala, Nonopa and Ore Rivers that flowed into the main Yaba River.

BCL dug at Panguna and pumped the concentrate east and dumped waste (tailings) to the west, 24 hours a day, seven days a week and 365 days a year. All the mining towns and infrastructure was built on the eastern side of the island a town at Panguna and another at Arawa on the east coast.

The area affected by the tailings was divided into two parts - the Upper Tailings area in Ioro, and the Lower Tailings area in the Bana District. While the most visible environmental damage caused by the mine is the giant hole in Panguna, the environmental damage caused to the fertile lands around the Lower Tailings area was probably much higher. The tailings killed all life in the river, especially the many species of fish that our people once ate. It raised the level of the riverbed, causing floods, and requiring a huge levy bank to be built on the southern side of the Yaba, in the Lower Tailings area. Guava Village, where Francis Ona comes from, is close to the mine pit, but sits well above it. The villages along the Yaba River, however, lie below the huge tailings dump, exposed not just to dust, but also the constant threat of being buried.

\section{Key Leaders and Influential Groups in Bana and Ioro}

Perhaps it is a coincidence that so many people deeply involved in the major political developments in Bougainville from the 1960s onwards have come from the Bolave, Ioro or Baba community government areas. But I think not. Together with parts of the east coast, these were the areas that felt the greatest impact on land, environment and society from BCL's mining and its associated activities. I think in particular of seven leaders from the area who played prominent roles in this turbulent period. 
The late Sir Paul Lapun, a member of Papua New Guinea's first House of Assembly (the colonial legislature), and Papua New Guinea's first knight, negotiated for the payment to the landowners of five per cent of the royalty payments that the Papua New Guinea government received from the Panguna Mine. He was from Mabesi Village in the Banoni Area of the Bana District.

Damien Dameng, the founder of Me'ekamui Pontoku Onoring, who became known for challenging the authority of the colonial administration, foreign religions and education systems as well as the mining operations in Panguna, is from Irang Village in Ioro Area.

Martin Bonai, the deputy to Dr Alexis Sarei, the Premier of the NSPG (premier from 1976 to 1980 and from 1984 to 1987) was from Lamane but resided in the Lower Tailings area, where he owned land bought from the local landowners (see below).

The late Patrick Bano, chairman of the Bana Pressure group (see below) was from Mariga Village in the Banoni Area of the Bana District. He was the deputy chairman of the New Panguna Landowners Association.

James Sinko, deputy supreme commander of the BRA and the first vice president of the Bougainville Interim Government in 1990, was originally from Lamane, but resided in Polamato Hamlet in the Lower Tailings area, near Kuneka Village in the Veripe area. Sinko owned a large cocoa plantation, living about two kilometres from Martin Bonai's house.

Francis Ona, secretary of the New Panguna Landowners Association (an organisation discussed below), the supreme commander of the BRA and the president of Bougainville Interim Government the political arm of the BRA, and from 17 May 2004 the self-declared King of Me'ekamui, is from Guava village in the Ioro Area. His father, Leo Dateransi, is from Orami Village along the Bana/Ioro border.

Joseph Kabui, the former premier of the NSPG (1987-90), the vice president of Bougainville Interim Government, and from 1999 to the present (2004) President of the Bougainville Peoples' Congress, is from Kawaronau in the Upper Tailings area.

\section{Landowners}

Groups owning land covered by mining-related leases belonged to at least six main territories. First were the Torau-speaking people of the land taken for mine port facilities at Loloho, on the east coast. Second were the Nasioi- and Eivo-speaking landowners along the port/mine access road. Third were the Nasioi-speaking landowners covered by the Mining Lease around Panguna itself. Fourth were the Nasioi-speaking landowners of the Upper Tailing Lease along the Yaba River. Fifth 
were the Bana landowners of the Lower Tailings Lease down to the coast. A sixth was called the river-owners, people who received fish compensation, and they were from both Nasioi- and Tobee-speaking villages along the Pagara and Nonopa rivers and other rivers that flowed into the main Yaba River. In one sense there were two groups - landowners and river-owners. I am a river-owner, and received fish compensation from BCL.

In the 1980s in the Bana District, landowners and other groups unhappy with BCL, organised themselves into the Bana Pressure Group, the chairman of which was the late Patrick Bano. After losing in the 1988 provincial elections to Martin Bonai, James Sinko took an active role in this group, ousting Bano as chairman and taking a more aggressive leadership stance than Bano.

\section{BCL, Land Transfers, and Social and Economic Change in Bana}

During the mid-1960s, when Conzinc Riotinto Australia (CRA) was beginning its development of the Panguna mine, an American Catholic priest, Father James Moore, was stationed at Moratona, along the Pagara River, close to where it meets the Yaba River, in the Toberaki area. At that time it had still not been decided where to situate the main town and port facilities for the Panguna mine. Because the land south of the Yaba was fertile, flat and sparsely populated, there was talk of the town being established there. Older people tell us that Father Moore advised the people of that area to sell most of their land to the Nagovisi people of the mountainous Lamane area, then much more densely populated than the Toberaki area. My father and his older brothers sharpened and sold axe handles to get money to buy some of this land. My father eventually decided to remain in Panam Village in Lamane, leaving his older brother to settle in the new land.

Father Moore told the Toberaki people that it was better to share the land with their mountain kin than to risk losing it to the mine or the government. The landowners obeyed him because in those days the priest had answers to life after death in heaven as well as much influence over life on earth through the material goods they handed out to their converts.

The Toberaki people sold their land for an average of A $\$ 60$ or less for large blocks of many hectares. Methods of payment depended on the personal relationships between the sellers and buyers, and basically involved use of customary means but using cash. The Toberaki landowners gave boundaries of these blocks to the Lamane settlers through verbal descriptions of landmarks (big trees, creeks and valleys) and instructed the Lamane settlers to cut the boundaries themselves. Some of these Toberaki landowners never actually knew how much they were selling. Transactions varied from person to person and were never recorded. I doubt they considered the future value of the land they were selling. 
In this way Lamane's new settlers ended up close to the lower Yaba River, adjacent to or in what was to become the Lower Tailings Lease (although many blocks were outside of the Tailings Lease area). The settlers did not buy all the land, so that the original landowners still held some land close to the Yaba River. The Lamane settlers built houses on their blocks and later established hamlets as their families multiplied.

The mountain people were in many cases very industrious, and established big cocoa gardens on the fertile flood plains, often becoming more economically secure than the original landowners.

When the first mine lease related payments began to be made by BCL, the largest amounts went to the Lower Tailings areas, because the areas affected on the Yaba flood plain were more extensive than other areas in the mine site lease areas. In some cases Lamane settlers received more land rents and compensation than original landowners. Some settlers became rich. Because we Nagovisi people do not have a sound for ' $r$ ' in our language many of our people confused the term 'lease' for the word 'rich'. As for me, I confused lease for 'dish', and so imagined a dish full of money given to the landowners. It became common for families in receipt of mine lease related payments to buy motor vehicles, something not too common before BCL. My father's brothers bought a new truck and called it Moalu (which to them meant something like 'if we had not come down to this land from the Lamane Mountains we would have never have been able to buy this truck').

The Lamane settlers tried to help those who remained in the mountains by organising business groups. My father's brothers were among them. Quite unused to the relatively large amounts of money never seen before in these areas, some involved in such activities became almost too kind. For example, my father's brothers donated about half the money needed to build a feeder road towards our village (though one that never actually reached the village). There was another stretch of road built by a New Zealand contractor known locally as 'Kiwi', resulting in that stretch of Road being called 'Kiwi Road'. The Nagovisi language does not have a sound for 'f', but only 'p', and so my father's brother, called Peter, was always proud when the road he spent his money on was called a 'feeder road' because he thought that the government was calling it the Peter Road. To him there was a Kiwi Road and a Peter Road.

The original Toberaki landowners resented the newly wealthy Lamane settlers who were getting thousands of kina in BCL annual lease payments, as well as significant incomes from big cocoa plantations on the land bought so cheaply in today's prices. The settlers later made some further payments to the original owners, but with a lot of reluctance, and to little satisfaction for the original landowners. 
The settlers from the mountains were not total strangers to the original landowners from the flat lands. They could associate themselves into common clan groupings with the Toberaki landowners. However, with new wealth from cocoa and lease payments the old clan ties became less strong. The land once valued at an average of $\mathrm{A} \$ 60$ for large blocks was transformed into a valuable commodity because of the new values set by the mine lease payments and the planting of cocoa.

\section{Cocoa and the Socio-economic Situation in the Village}

By the early 1980s, nearly every person in the Bolave area had one or more plots of cocoa. The ancient forests were devastated in order to clear land for cocoa gardens. Most family groups owned cocoa fermenteries and organised themselves into small cocoa buying units. By 1988, those who had moved faster with establishing fermenteries had made themselves mobile, using motor vehicles to buy wet cocoa beans to increase fermentery production. These and related developments had some important impacts, and also contributed to other social changes then occurring in our area.

First, cocoa growers now did not have to worry about carrying their cocoa beans to the nearest fermentery. They could sell it wet, directly from their cocoa gardens. But the fermenteries without vehicles lost their market. At the same time the market was competitive, resulting in a good price for growers.

Second, the growers now wanted feeder roads into the areas where their own cocoa gardens grew. They wanted such roads so much that donations for their construction were often collected from business groups, particularly cocoa buying groups. The balance of the budget for such a road would usually come from the local community government and the NSPG. The perception of the people was that these were the governments that looked after them. While the Papua New Guinea National Government took most of the revenue from BCL, it gave nothing back to the village people. It was instead the NSPG and the community governments that helped the people with the small share of mine revenue Bougainville received. As a result the National Government was seen by many as excess baggage for Bougainville, even an obstacle to its development.

Thirdly, the big 'line' villages, first established in the times of the German and early Australian colonists, disintegrated quickly, as families moved back to their traditional lands forming small Nalebo (clan) hamlets. For example, my village of origin may be seen as Panam village. However, I was not raised there, but grew up in a small hamlet called Kakaunasi (meaning cocoa garden).

Fourth, the aggressive cocoa growing and fermenting activity began to cause land problems. Previously land had been used mainly for food gardens and 
hunting and there was plenty for everyone. Now, for the first time, there was real competition for access to land for cocoa gardens. Nagovisi society is matrilineal, the women 'owning' the land. Traditionally all land is inherited by the Maniku (female). However land can also be given by mothers and sisters to the nugaa (male) to pass on to children of the males as vabui (son's land). The Maniku (women) now became stronger in pushing the nugaa (men) into living on their wives' land. Sisters did not want to give land to their brothers to be given to the paternal nieces or nephews. This was called voliwatawata (chasing off children of males). While this did not happen uniformly, it created resentment between the viumalo (father's clan) and the viulupo (children's clan). This weakened the strong family ties that had once held our communities together, from time immemorial.

Fifth, the family linkages, which had traditionally been maintained by local inter-marriage, were not as strong as they once were. The viulupo (children of the male) were now often seen as excess baggage to the viumalo (father's clan). Walomasinga pagopago (friendly chewing of betel nut with the sister-in-law) was not enjoyed as it used to be. Even within clans, problems caused by land disputes increased.

Clans now engaged in much activity of tracing back their own roots. In fact, very few could trace back far, because our people had lost so much knowledge of such things in their eagerness to learn new ways over the previous 50 years or so. Some clans deliberately 'corrupted' their family histories and clan lines to protect land that they had taken possession of through 'doubtful' means.

In the 1970s many people in my area started village-based 'micro-finance' schemes based on traditional shell money ownership. The schemes were called Veta, adopted from a name given to the women's bag made from coconut palm traditionally used for storing and carrying goods and valuables. The system encouraged the contribution of compulsory savings from cash earning activities by clan members to the Veta which would then be used to fund needs, such as compensation obligations, bride price, and so on. The idea was that even business needs could be met, so that there would be no poverty and crime to bring shame to the clan. The communal economic activity would in turn strengthen the unity within the clan and with other clans.

By 1988, however, social and economic conditions had changed. People had become much more independent of each other, more individualistic. Further, buyers of dry cocoa beans were paying by cheque, so that the bigger growers and cocoa-dryer owners were forced to depend on the banks. Banks quickly became seen as the better alternative because they could make money grow - magic that Veta did not posses. By the late 1980s bank agencies were opening in the villages and Veta was gone. 
However many of the older generation still cherished the idea of Veta and blamed each other for its failure. When Veta faded away there was no common economic interest and common ownership of clan or community wealth to maintain the social ties between one's Vomalo (father's clan), Volupo (children's clan), Wakaialo (grandfather's clan) and Wamaekoli (mother's clan). The people started seeing each other not as brothers and sisters and clan mates with common ownership of wealth, but more as business competitors, with only the fittest to survive. This contributed to inequality, to social gaps and to hatred. Suspicion of sorcery increased.

In the mountain areas of Lamane, despite the failure of the Veta system, the people managed to build permanent houses from savings from cocoa. In the Lower Tailings Lease and on the Yaba River, BCL built most permanent houses under their resettlement scheme. In my village, there were four such houses. To match that level of housing others had to dig into their cocoa income to build permanent houses.

In schools in my area a penalty fee of about K1.00 was imposed for those who were absent. It was common to skip school, especially on Wednesdays, when harvesting cocoa took place. Our parents would not chase us away because extra hands were always welcomed. Absentee fees were often described as lip bilong kakau (meaning mere leaves of cocoa).

For those in high schools, too, life in the village often seemed easier, perhaps partly because in the 1970s and 1980s there always seemed to be plenty of money at home, and because life in boarding school seemed a Spartan existence, full of boredom. Many ended up running away from school, as, for example, did my three brothers. My wife never went beyond the second grade. None of her brothers completed school. By 1988 as far as I know, I was the only student attending university from the whole of Bolave Community Government area. I survived the temptation of what seemed a better life in the village.

For those who endured schooling and continued on to higher secondary and tertiary institutions away from Bougainville, many did not return home. Most female students from my area did not marry people from Bana, and ended up elsewhere. For many clans, this development contributed to the beginnings of fear that their continuity, through the female line, was now threatened. Fear that our rare and beautiful black skin was now going to become Ulugasi (redskin) caused real insecurity.

Those living close to the established roads and cocoa plantations of the Tailings Lease witnessed the arrival of Ulugasi labourers (mainly from the Highlands and Sepik areas of the Papua New Guinea mainland). They came to work as truck drivers and plantation workers in the cocoa plantations owned by local people. Most of them got married to the locals and settled. When they married women they now became the Motainala (husband) with management 
responsibilities over the wife's resources. Often they confused their role as caretakers with the kind of authority they would have had in their patrilineal societies in their own provinces, thus wanting to be more powerful over the wives than is customary in Nagovisi society. At the same time they proved to be hard working and were soon controlling even the local food markets to the point that locals were buying food from them, and traveling in their PMVs (passenger motor vehicles).

As soon as they settled they seemed to bring in their wantoks (people from their home areas). As they grew in numbers they also grew in strength. In some cases they took over land without asking. This also threatened the security of the local people. By the end of 1988 most plantation owners were wishing that they had never recruited these laborers in the first place.

During the 1980s, the levels of mine lease payments declined. When landowners asked about this, BCL told them that they were not making as much profit as before.

Most of those who had bought vehicles in the late 1970s now had to ride in buses owned by Ulugasina (red skins).

\section{Kastom and Religion}

The old traditional values of the Nagovisi were nearly extinct by the 1980s. They were described as pasin temata — or paganism. By then we had experienced 50 years of our attention being shifted from our long-established cultural and environmental consciousness to a new home in the sky called heaven. But at the same time, there were challenges emerging in the 1980s to the long-established dominance of the three 'main' churches - Catholic, Uniting and Seventh-Day Adventist.

Christianity was, it sometimes seemed to me, already fast becoming just another public occasion to many churchgoers. At the road junction connecting the roads to the Catholic Mission, Panguna and Sirakatau Village, was a liquor outlet. It was not unusual for local catechists to join some Community Government members and BCL workers for a few drinks in a local black market after Sunday lotu (church service) at the Mission. Sometimes after such a drinking session they would end up in fights or going to weekend dances in the ' 6 to 6 disco' in the village. In the process, many church and government members lost their integrity in the eyes of the people.

It was in the 1980s too that there were significant movements of people away from the previously dominant Catholic Church and across to other denominations. There were also divisions within the Uniting and the Seventh-Day Adventist churches. Other denominations that came up under the name of the Pentecostal movements began to take hold. 
The extended family and clan ties that had previously been reinforced by the strong tendency for whole clan lineages and family groups to belong to the same church were undermined by the growing tendency for individuals to choose their own denomination from the many new Protestant churches coming into Bougainville.

Johannes Awarako of Kiripage Bakolam Village in the Lamane area did not agree with any of the churches or their supporters. He was not actually opposed to the concepts introduced by the Catholic Church, but rather believed that they could be satisfied within the indigenous beliefs of the people. He searched for how best to integrate the liturgy of the Catholic Church into what some would have regarded as the stone age culture of Nagovisi. His support quickly grew, and he formed the Solo Moma Movement. Solo was the name that Awarako claimed to be original for Bougainville and it comes from a legend that talks of how our ancestral mother commanded the sea to roll back shouting, 'Solo! Solo!'. The sea rolled back leaving a small piece of what is now known as Bougainville Island. The Solo Moma was the movement of leaders (Moma) of Solo (Bougainville).

A character from Nagovisi folklore figured prominently in Awaroko's beliefs. Boiru is a figure that rose again three days after dying. Before jumping into a swamp now know as Boiru Luma, he left us symbols of death, rebirth and eternal life. The symbol of death was what we call a sharp eye-browed frog (kantoko) which lies upside down when touched and the symbol of eternal life was a crayfish which, instead of dying, grows new skin to replace its old.

Awaroko's beliefs were also influenced by his limited knowledge of Christianity, one shaped mostly through experience of Catholic liturgy. His group also had some mystical beliefs about the Bougainvillean member of the then Papua New Guinea legislature, Sir Paul Lapun. He was believed to possess hidden powers and ideas about government and the future of Bougainville. Awarako's people saw him as an icon and worshipped him.

Awarako eventually opposed Christians as liars who had stolen our land and our culture. He opposed payment of taxes to government or contributions to the church, because he believed that they were working for the same master - the monokakata (whiteman). As he grew in strength Awarako formed his own government and militia. In early 1988 he recruited young men to be trained. There was an ex-soldier and one ex-policeman who trained them in basic military drills mainly for ceremonial marching. Most people disregarded Awarako as a cultist.

He built his parliament in the shape of Noah's Ark and there he burnt offerings. He ordered his followers to throw away whiteman's money and exchange it for shell money. He had many supporters in his own area, but only a few educated people and politicians joined him. I am unclear whether they did so for political purposes, or were really convinced by his beliefs, or were just interested to collect 
money that was now changed into traditional shell money and rejected as whiteman's rubbish.

Damien Dameng lived just over 20 kilometres away from the Bolave area, in Irang Village, on the western edge of the Nasioi-speaking area of Bougainville. I first heard his name when I was a small boy, before the establishment of the community government system. Paul Eki, a man from my village, who was a village councillor in the local government council established by the colonial Administration, took Dameng to court for setting up his own police force, supposedly to wipe out sorcerers. While Dameng consequently stopped his campaign against sorcerers, at the same time he realised that the local government councils were worried about his influence, making him feel stronger than the councils.

Dameng opposed church teachings as trickery, the colonial administrators as thieves, and CRA and BCL as destroyers of land and culture. In the early 1960s he established his own government (Me'ekamui Pontoku Onoring) and refused to pay taxes to the government, instead establishing his own tax regime which by the mid-1970s was set at 50 toea per person (resulting in his government often being referred to as the 50 toea Gavman - or 50 toea government, toea being the unit of Papua New Guinea currency roughly equivalent to a cent). Although he had initially supported Sir Paul Lapun, by the late 1960s he opposed him strongly for negotiating the payment to the mine lease landowners of five per cent of the government's royalties from the mining. To him Bougainvillean land was holy and agreement on payment of five per cent royalties was like giving the land away to the whiteman for next to nothing.

Dameng was involved in the leadership of more mainstream political developments from the late 1960s, including Napidakoe Navitu and the Bougainville Special Political Committee, and always maintained good relations with senior Bougainvillean leaders, such as the three premiers of the NSPG - Alexis Sarei, 1976-80, and 1984-87, Leo Hannett, 1980-84, and Joseph Kabui, 1987-90. Under Kabui, the NSPG recognised the legitimacy of Dameng's grievances and the values in his ideas about village-based government incorporating the best from traditional leadership, and recognised Me'ekamui Pontoku Onoring as a 'private government'.

\section{GOVERNMENT AND POLITICS}

So far I have focused on my memories of what was happening in the 1980s at the very local level of my village and in the wider Bolave Community Government area. But there were, of course, links between what was happening there and the wider politics of Bougainville. I want to now touch upon those linkages as I saw 
them, through mine lease landowner politics, aspects of the operation of the community government, aspects of the operation of the NSPG, and its difficulties in responding to the difficult problems such as illegal squatters from other parts of Papua New Guinea, the Bougainville Development Corporation (BDC) (a major company in which the NSPG was the majority shareholder), and the problems of mine workers. Finally I will contrast people's perceptions of community and provincial governments with their perceptions of the Papua New Guinea National Government.

\section{The 'Landowners'}

I first heard of the word 'landowners' (or as my father pronounced it, Len Oonas) when I was a schoolboy, in the late 1970s. I accompanied my father to Panguna. The Bolave Community Government Office was at the junction of the main road to Panguna and so was a convenient place to wait for a truck to give us a lift. There I saw two women and some men having a meeting with members of the Bolave Community Government. I could hear the two women nearly crying and begging the Bolave Community Government to help the 'landowners' with their problems.

Outside the office there was talk about a 'strike', a word that I did not know. My father explained that there was probably going to be a fight and that the Panguna supermarket would be looted. I liked the idea, and decided that if a fight started I wanted to be there with my father. The strike did take place and I did go. I could see a large man with a big beard talking. Some were saying that the supermarket was ours and others that it belonged to the whiteman. While they were still debating, some younger men went ahead and started breaking into the supermarket. We, the smaller ones, got away with items from the supermarket while adults became targets for policemen.

In 1979, around the time of the looting of the Panguna supermarket, as part of the struggle for improved compensation and land rents from BCL, the landowners established the Panguna Landowners Association (PLA). One of its main founders was Michael Pariu, a close relative of Joseph Kabui. Under Pariu's leadership the PLA initially took strong positions, beginning with demonstrations in 1979. Some say this activity also provided Pariu with a launching pad to be elected into the NSPG Assembly in 1980.

From 1980 many noticed a sharp decline in Pariu's aggressive opposition to BCL. Some suspected that his appointment as the Provincial Minister for Community Government and Liquor Licensing had softened him. There were also suspicions expressed that he had supported the establishment by BDC, in the first half of the 1980s, of the limestone production project at Manetai, just south 
of Arawa. (The product of the limestone project was sold to BCL for use in the copper ore concentration process.) There was particular concern about Pariu supporting the project because landowner funds were invested in the BDC. The landowners lost confidence in him and in the 1984 NSPG elections Joseph Kabui replaced him as the member for Eivo/Ioro Electorate.

In 1981 a meeting was organised at Dapera Village, close to the minesite, to discuss the dissatisfaction of the new generation of mine-lease landowners towards the older generation of landowner leaders on issues including royalties and the state of affairs of the Road Mine Tailings Trust Fund, which managed some of the money paid by BCL and invested it on behalf of the landowners. I understand that Francis Ona and his cousins were invited to attend and that they declined the invitation, preferring, apparently, to maintain their links with their relatives who were part of the older generation of leaders who ran the Trust Fund.

However, on 21 August 1987 at Panguna Gymnasium, the New Panguna Landowners Association (New PLA) was formed, a move reflecting the anger of the younger generation members of the landowner groups about the unfairness of the distribution of financial benefits of the mine and their complete loss of faith in the older generation of landowner leaders. The person chosen as chairperson of the New PLA was Francis Ona's cousin, Perpetua Serero. Patrick Bano, then chairman of the Bana Pressure Group, became the vice chairman, and Francis Ona was chosen as the secretary. Joseph Kabui, who had shortly before this become the premier of the NSPG, was also in attendance, as was Raphael Bele, the member for Central Bougainville in the National Parliament, who was also a landowner, from the Torau-speaking village of Rorovana.

The management of BCL refused to recognise the New PLA, and maintained its links with the long-established PLA, representing the older generation.

\section{The Bolave Community Government}

Sikolewa, where the Bolave Community Government Office was situated, was about a kilometre away from the retaining wall for the tailings and the big Yaba Pump Station. The Bolave Community Government had a chairman, a deputy and an executive body. There were peace officers and village court magistrates who were, as far as the villagers were concerned, associated with the Bolave Community Government, and who were responsible for maintaining peace and good order in the community. The Bolave Community Government was responsible for small-scale community projects in the villages in the area. Leadership at this level of government was attained more through saveikata (education) than through the traditional ways of sidokosidoi (heritage), kasikelo (hard work), and laguke (military effort), which were now largely forgotten. 
To the village people, although the community government system was foreign, it was nevertheless close to them. As a result they saw it as their own government. In their eyes, too, the NSPG was their national government. These governments provided something to the village, whereas the Papua New Guinea National Government was very remote, and the annual grant that it gave the NSPG was seen as little return on the revenue that Papua New Guinea derived from BCL and from Bougainville's cocoa production.

On the other hand the taxes imposed by the Bolave Community Government (especially the flat rate personal tax — 'head tax') were also rising in the 1980s. Some of those unable to pay community government taxes started to wish that they were part of Damien Dameng's Private Government, where they would pay only 50 toea in tax. (This is something that I learnt many years later when my father confided to me that he would have liked to join Dameng to avoid paying taxes so as to save money for my school fees. I am sure that there were other people thinking the same way, especially when the NSPG recognised Dameng.)

\section{The NSPG}

Among the reasons why the village people saw the NSPG as the true government of Bougainville was that on 1 September 1975 Bougainville leaders had declared Bougainville independent from the colonial Administration of the Territory of Papua and New Guinea (the Government of Australia). At that time, of course, Papua New Guinea was not yet born as a sovereign state, and the fact that Bougainville declared itself independent before the birth of Papua New Guinea was seen as a significant point, especially by the older generation.

For the village people in the Bolave area (and presumably elsewhere), the adoption of the name 'North Solomons' for Bougainville's provincial government identified Bougainvilleans as Solomon Islanders and not Papua New Guineans. This identity was also expressed in the Bougainville flag, adopted in the mid1970s, and its anthem. (As far as I know NSPG was the only provincial government to adopt a provincial anthem.)

For what we saw as the North Solomons Province, the main 'national' celebrations were held on 1 September, the date of the 1975 UDI and secession. However, officially these celebrations were called the North Solomons Provincial Day. The date of Papua New Guinea's independence - 16 September — was officially the day for Independence celebrations. To Bougainvilleans, however, this was just a public holiday. By 1987, feelings on Bougainville were changing. There was a young and energetic premier, standing firm to fight for the people's basic grievances against squatter settlements, and land issues involving BCL. He was clearly more active on these issues than the older generation of leaders. He was 
also indicating that he wanted to officially shift the independence celebrations from 16 September to 1 September. He had already recognised Dameng's 50 toea as a Private Government. People's confidence in the premier's stand against injustices was growing.

Through the 1980s, with the problems of landowners, squatters, land claims, and other social problems on the increase, the NSPG was increasingly in a difficult position. It did not have the legal, financial and administrative powers or capacity to address the basic grievances of the people and deal with their increasing problems. It had little or no influence on the review of the mining agreement between the National Government and BCL, the problems caused by squatters, and the many other social, religious and other divisive issues facing Bougainville. The NSPG was not moving in response to the people's grievances. At the grassroots level, impatience was beginning to grow and there was a gap between the hope that the premier had given the people and the capacity of the provincial government system through which the premier was expected to deliver. I believe that this was one gap that allowed the BRA leadership and the armed struggle to gain popularity among the people as the only option to defend Bougainvillean rights.

The Bolave area was in the Bagana constituency for the NSPG. In the 1988 provincial general elections there were three candidates for that seat. One was Ronald Agamo from Panam Village, the second was James Sinko, and the third was Martin Bonai. The campaign was bitter. One result was tension between Bonai and Sinko and a loss of unity among the Lamane Settlers in the Tailings Lease area. As it is with politics anywhere, when Bonai won, James Sinko then blamed him for government and mining related problems affecting our area.

\section{The Bougainville Development Corporation}

Bougainville Development Corporation (BDC), a corporation established in the 1970s, in which the NSPG held slightly more than 50 per cent of the shares, was generally referred to as the business arm of the NSPG. How the BDC operated was little known to village people. All that was known and expected was that it should support the financial autonomy of the NSPG.

Following the 1984 provincial elections, however, it became clear that the NSPG was losing control over BDC. The premier from 1980 to 1984 , Leo Hannett, was regarded as a Pangu Pati supporter, an opponent of the Melanesian Alliance Pati, whose candidate, Alexis Sarei, became premier. But although the NSPG was the majority shareholder of BDC, it did not have control of the special majority of shares needed to remove Hannett as chairman of the BDC board of directors after the elections. Tensions between the NSPG and elements of the 
BDC board were evident, and these became quite intense when the board organised an issue of new shares that diluted the NSPG shareholding below 50 per cent.

$\mathrm{BDC}$ was now seen in the village as a private business benefiting just a few individuals. It became an object of exactly the same kind of anger and resentment as the issues that divided the mine lease landowners in relation to the old PLA and the New PLA. Former premier, Leo Hannett, became a household name as part of the widespread public discussion of BDC affairs. The perception in the village, based on what the leaders were saying, was that Leo Hannett 'emi bagarapim BDC' (he was messing up BDC).

\section{The Squatter Settlements}

Attracted by the opportunities made available by economic prosperity in Bougainville, people from other parts of Papua New Guinea flooded into Bougainville in the 1970 s and 1980s to work in both the public and private sectors. Not all of them ended up in jobs, some settling on customary land to garden the fertile soil of Bougainville. By 1988 they were controlling markets, PMV (passenger motor vehicle) businesses and other small-scale business. They seemed to be taking over land everywhere.

Crime and other problems came to be blamed on 'redskins'. There was an 'Arawa phantom' who went on a raping spree. In the late 1980s a Siwai woman was harassed at Arawa in public. When her husband tried to protect her he was bashed up by the wantoks of the original assailant. In a matrilineal society where rape was minimal, this kind of action was seen as unacceptable. Women came to fear the 'redskins'. I remember the trouble our people used to go through in afternoons to make sure they that left town before 5.30 p.m. because of the dangers of the ulugasina ('redskins').

During the 1988 provincial government elections one ulugasi contested and won a seat in Arawa, where there was enough of a concentration of ulugasina to vote him in to office. This was a grave shock to most Bougainvilleans. In the villages people worried that the ulugasina were taking over government, and would control power, protect the squatter settlements and threaten customary land ownership.

Hopes rose among Bougainvilleans when the NSPG launched the operation Mekim Save (make them take notice) in 1988. It was intended to clear out illegal squatter settlements, and send back to their home provinces people who were not already employed. The exercise seemed to hit a brick wall in the face of assertions of the Papua New Guinea constitutional right to freedom of movement. To ordinary Bougainvilleans, however, this very right was now being exercised by outsiders at the expense of the rights of Bougainvilleans to the freedom to enjoy 
the use of their customary land. In the process, Bougainvillean landowners began to resent the Papua New Guinea Constitution as protecting the rights of others.

Squatter settlements were, of course, a widespread phenomenon, but centred mainly on the Arawa-Kieta-Toniva area. They were also beginning to appear, however, in the Tailings area of Bolave, and elsewhere. Therefore, almost all Bougainvilleans shared concern about what was happening. Whereas the category of 'threatened' landowners was once restricted to those living in mine-lease areas, increasingly there was a sense in which all Bougainvillean landowners felt threatened by, and had grievances against, outsiders.

\section{Dissatisfied Workforce}

In late 1988, I did some vacation employment for BCL at Panguna as a casual employee in the finance section at the head office administration building known as the 'Pink Palace'. I stayed at Karoona Haus with the apprentices and other tradesman. There was a separate Kawerong House that was more like the highclass expatriate accommodation. After work I would listen to workers talking about their frustrations over what they saw as their low levels of pay as compared to their Australian counterparts, disparities in salaries for the nationals and details of personal problems with their white bosses. In discussing pay rates and accommodation concerns, Bougainvillean and non-Bougainvillean workers were often in agreement. However within the Bougainvillean-only circles of discussion, there were also bitter complaints that BCL was favouring the non-Bougainvilleans and giving limited opportunities to Bougainvilleans. Today I look back and think that BCL should have provided more employment opportunities for Bougainvilleans.

Coincidentally, I was working there when the first destruction of BCL property and power pylons began in November 1988. Those doing the destruction were known as militants, or Rambos. One day an operator went missing. The next day he had joined the militants. Then a week later, a colleague warned me not to come back to work on Saturday because the pay office was going to be burnt. I caught a bus and went to my village and, true to his warnings, the office was burnt. We came back the next day to clear the mess wearing masks and overalls and looking more like aliens from outer space than pay officers of BCL.

Francis Ona was a BCL employee and so were many of his associates, while others involved in the militancy were contractors and landowners. To me, this illustrates the old saying that 'you cannot hate something that you have not known to love before'.

The important organisation handling the grievances of the mineworkers was the Mining Workers Union. One of its key personalities was the late Henry Moses. He introduced Joseph Kabui to the dynamics of unionism and sent him to study at 
the University of Papua New Guinea where he gained a Diploma in Industrial Relations. Not long after that Kabui entered politics, getting much of his support from his boss and mentor, Henry Moses, and from the Mine Workers Union.

\section{Papua New Guinea (Onadakata Gavamani)}

When I was a small boy in elementary school in the mid-1970s, I asked my dad where Papua New Guinea was. He replied: Anada kata, paused, and then added ulugasina vikano (meaning that it was the land in the west, that the 'redskins' belong to). Later, in 1988, when I was attending university in Lae that was still the phrase used by my family to describe where I went to 'school'. Those of us attending school and university on the mainland lived in continuous fear of harassment. I did not know why we had to be so scared in a country that was supposed to be ours. We never felt we were Papua New Guineans.

The increasing landowner problems, and problems caused by expanding squatter settlements, demanded a direct National Government response. That did not come, and increasingly NSPG leaders and the landowners no longer trusted the National Government.

Having worked to develop Bougainville to a large extent through their own initiative, by the late 1980s, the people's perception of the National Government was that it was a parasite, and a hindrance to the resolution of the people's grievances and the overall advancement of Bougainville. Increasingly people talked of wishing that they had succeeded with the attempted bruklus (secession) of 1975.

During the 1987 National Provincial Premier's Conference held in Lae, the main centre of Morobe Province, as a Bougainvillean student at the University of Technology, I attended a dinner hosted by the vice chancellor where Joseph Kabui spoke to the Bougainvillean students. He had a lasting effect on me when he said the following; 'I encourage you Bougainvilleans to study hard. I am young and have become a premier to now try to find solutions to the basic grievances and aspirations of our people. We have started the operation Mekim Save. We have also decided that North Solomons celebrates its Provincial Day on 1 September and as for the Papua New Guinea Independence on the 16th there will be no celebrations but a mere public holiday'. He ended by saying, laughing: 'You never know, we may be an independent nation one day'.

The premier did not implant the wish for independence in me, for it was already there. All he did was give strength to an existing wish.

\section{Bougainvillean Nationalism}

It is a common view amongst us Bougainvilleans that we are culturally and historically different, with our own ethnic identity. Aspirations for a separate identity for 
Bougainvilleans were just as strong in the late 1980s as they had been in the mid1970 s, especially in the villages, and probably stronger as a result of the experience of the grievances and problems that I have discussed. If there was any reduction in the strength of such aspirations, it would just have been the few living in towns and perhaps some leaders.

By 1987, in Bolave, it was seen as a time for change. When in 1988 people voted against the endorsed Melanesian Alliance Pati candidate for premier, pushing the young premier Kabui back into that position contrary to the wishes of the Pati, it was clear that people were no longer following party politics.

The urge to go their own way was further strengthened by the NSPG decision to have our independence celebration on the 1 st and only a public holiday on the 16th of September.

For many of us in schools and universities outside Bougainville we had begun to expect a change in Bougainville. When the premier visited us in Lae we knew that such a time was soon to be. We kept most of this in our hearts. But the talk of bruklus (secession) was household talk in the village long before Francis Ona started the revolution.

\section{CONCLUSIONS - PULLING THE THREADS TOGETHER}

In the 1970s and 1980s, Bougainville's main towns were among the most highly developed in Papua New Guinea, and the province as a whole was generally economically well off. Beneath its economic prosperity, however, there was trouble brewing. All of the threads that I am now identifying were also things that involved hazards for Bougainville, things that we can now see threatened us with grave danger in the late 1980s. They included:

1. Over an extended period new economic, social and religious needs had been undermining the strength of customary social ties that had held families and clans together from time immemorial;

2. What seems to me to have been a rise in the rate of 'dropouts' from school, which I think was caused by the gap between what seemed to many students the better or easier life in the village compared to the hard life of high schools rather than academic reasons. But as a result there was also a generation that could neither fit in well in the village nor secure employment in town.

3. There were both divisions within the landowner groups and a considerable gap between the landowners and BCL;

4. Bougainvilleans felt that their rights as customary landowners, and their freedom and security, were threatened by the increasing squatter settlements; 
5. Bougainvilleans had little or no sense of identity as Papua New Guineans, and their sense of Bougainvillean identity was increasing as a result of their feelings of fear and insecurity which they blamed in large part on finding themselves within Papua New Guinea's borders;

6. The limited presence of the Papua New Guinea National Government in Bougainville both symbolically and in terms of tangible projects such as infrastructure, led many Bougainvilleans to see the Papua New Guinea National Government as excess baggage;

7. There was disintegration of any unity in the Bougainvillean leadership those working at the Papua New Guinea national level and at the provincial level - due to party politics, and the divisive impact of the provincial elections of the 1980s on the leadership of groups in the Tailings Lease area. This division branched out into the local levels.

8. The NSPG and its administration were unable to provide solutions to landowner grievances and basic aspirations of the people for more development and identity, due to legal, financial and administrative limitations.

9. There was deep dissatisfaction among the BCL employees concerning the gap between national workers and the expatriate workers, and the limited opportunities for Bougainvillean workers;

10. As a result of the grievances and resentments discussed in this chapter, the long-standing sense of Bougainvillean identity was being expressed more and more in the form of demands for separate Bougainvillean statehood.

This is not an exhaustive list; there are many more issues that could be discussed. But these are among the most important.

I would describe these threads as combining into something like dynamite in 1988. All that was needed was a fuse and an ignition. And that is how it happened. While all these factors were combining to produce new heights of frustration among Bougainvilleans, a young nursing sister from Kongara was murdered. In matrilineal Bougainville, killing of women is unforgivable. The squatters were blamed, and local landowners went on a rampage in squatter settlements nearby. It is not known how many of the squatters lost their lives. The landowner issue may have been the dynamite - or the fuse — but to set the explosion the spark caused by the killing of the nurse was required.

The way I see it, much of the blame for what happened lay with the National Government, and with the external systems and ideas that were forced upon us. As the problems and concerns of our people grew, the National Government simply continued to fiddle with its fingers.

When conflict eventually exploded, its characteristics reflected, or were shaped by, the threads that I have described. Many different interest groups on 
Bougainville were pulled together by their common aspiration for Bougainville identity and their common blame of the Papua New Guinea National Government for causing their economic and social problems.

I cannot claim to have explained here the entire set of root causes of the conflict. Maybe some of what I have discussed might better be classified as symptoms rather causes - it is too early to say. I have just tried to remember how things were before the conflict, and the issues that contributed to the emergence of the conflict. It might even be said that it could be misleading to start painting any picture about Bougainville simply based on a snapshot of the Bolave area and its linkages with wider developments. My own idea, however, is that a focus on the local communities may provide a good start to understanding a complex conflict which began locally and very quickly became a widespread revolution. Perhaps the best way of improving our overall understanding of why and how the conflict began would be to continue getting more snapshots, including important ones like those that could come from just before the conflict from Guava, Moroni, and Dapera villages, near the Panguna minesite, and Pirurari. Or what about a snapshot of what Francis Ona was doing in the two years just before the conflict, who were his drinking and workmates, and so on?

Of course, the snapshots I have presented are only intended to shed light on how the conflict began. If we are also to shed some light on what happened after 1988, in complex events that changed Francis Ona from the heroic figure of 1988 and the early 1990 s to a figure who, in 2004 , is the subject of market place jokes about his coronation, many additional snapshots will also be needed.

A further limitation that I have encountered is that my own cultural background shapes me. So what I have described for Bolave area may not be true for other districts. It is also true that because my first language is not English, it is hard for me to explain in as much depth as I would like many of the threads I have discussed. But I want to talk to a wider audience than would be possible if I were to write in my Nagovisi language.

Last but not least these are only a few of what is, in many ways, just one side of the beginnings of the conflicts. There are other important sides, as becomes clear when I consider such big questions as:

- What interests did the Papua New Guinea Government have in Bougainville?

- What were Australia's interests, in terms of the political, economic and military influence that it had over Papua New Guinea in 1988?

- What role did global financial institutions play, and what pressures do they exert on third world nations?

- What were the global trends in the late 1980s in terms of economic, political, military and religious balance of power? 
I want to end my discussion by asking a question that I often ask myself. After gaining political independence from colonial masters, do all third world nations enjoy only brief periods of real independence? Must they all then experience civil wars and revolutions and go bankrupt and join the queue awaiting solutions from elsewhere? Is there any chance of real political independence? We must all continue to search for the answers to these questions. 


\section{HISTORICAL CHRONOLOGY}

29,000 years BP

(before present) Buka and Bougainville first populated, probably from the North (through the Bismarck Archipelago).

3,000 years BP New waves of settlement enter Buka and Bougainville from the North, associated with Lapita pottery.

1767 First European sighting of Buka/Bougainville (British vessel captained by Carteret).

1768 Bougainville Island sighted by French expedition under Louis de Bougainville.

(November) German flags of annexation raised in Bismarck Archipelago and on New Guinea mainland.

(May) Administrative authority granted to chartered German New Guinea Company.

(October) Solomon Islands north of a line of demarcation included in German New Guinea: Buka, Bougainville, Choiseul, Ysabel, Shortlands and Ongtong Java atoll. Solomon Islands (BSIP). 
1905

1914
1901-02

Line of demarcation between German New Guinea and BSIP changed so that Shortlands, Choiseul, Ysabel, and Ontong Java all come under BSIP. Buka and Bougainville remain part of German New Guinea.

Catholic Society of Mary (Marists) mission station established near Kieta.

German Administration post established at Kieta.

(September) German rule in New Guinea ends when Australian military forces take over.

(December) Australian forces occupy Kieta.

Methodist missionaries settle permanently in Siwai.

(May) Australia granted 'C' class Mandate over former German New Guinea by League of Nations.

Australian Administration established its district headquarters at Kieta, and sub-district headquarters at Sohano in Buka Passage and at Kangu on the Buin coast.

Seventh-Day Adventist mission in Bougainville.

American Fr Thomas Wade, SM, becomes bishop of Bougainville Diocese.

Sporadic gold mining from around 1930 at Kupei, near Panguna, becomes established by 1934, and continues until Japanese occupation of Bougainville begins in 1942.

(December) Japan declares war on the United States of America.

(January) Rabaul occupied by Japanese soldiers.

(March) Japanese occupation of Bougainville begins.

Administrative amalgamation of Papua and New Guinea under Australian military administration.

(August) United States forces land at Torokina. 
(October-December) Australian troops take over military operations on Bougainville.

(December) Australian military campaign to reconquer Bougainville begins.

(15 August) Japan surrenders.

(March) Australian civilian administration re-established. United Nations agrees to Australian trusteeship of the former Mandated Territory of New Guinea.

Sohano Island, in the Buka Passage, between Buka and Bougainville, becomes colonial district headquarters.

United Nations (UN) grants formal approval for joint administration of Papua and New Guinea (PNG).

Territory of Papua and New Guinea (TPNG) Legislative Council established.

Local Government Councils (LGC) proposed in TPNG but slow to be accepted in Bougainville.

Attempt to set up a LGC on Buka fails.

1954 Catholic teacher training for boys at Tarlena in north Bougainville.

UN Visiting Mission reports that some Buin people want the Shortland Islands included in the Trust Territory. School in North Bougainville. of North Bougainville. In spite of opposition, by 1963 others established throughout Bougainville.

UN Trusteeship Council calls on Australia to set targets for self-government Hahalis Welfare Society founded in Buka, with John Teosin as president/chairman. 
Government geological report confirms intensive low-grade copper mineralisation in Panguna/Kupei area of Central Bougainville.

1961

1962

1963

1964

1965

1966
Marist Brothers at St Joseph's School, Rigu, near Kieta, extend schooling for boys to secondary level.

Nasioi villagers in Kieta as well as villagers in other parts of Bougainville advise UN Visiting Mission of dissatisfaction with Australian rule.

Members of Hahalis and police skirmish on Buka beach. Ban on the drinking of alcohol by indigenes lifted throughout TPNG.

Conzinc Rio Tinto Australia Exploration Ltd (CRA) granted authority to prospect over area including Panguna deposit. First Bougainvilleans ordained as Catholic priests (Frs Aloysius Noga and Peter Tatamas).

(April 1st) CRA geologist, Ken Phillips, walks into Panguna Valley to conduct survey.

(May) Panguna villagers question presence of geologists in the area.

First general elections conducted for the TPNG House of Assembly. Paul Lapun represents the only Bougainville electorate. First government high school set up at Hutjena (Buka).

(January) Mining warden rejects objections from local villagers and grants additional prospecting licences to CRA.

Diamond drilling begins in Panguna area.

Confrontations between villagers and geologists continue throughout the year.

(January) five villagers get one month prison sentences for destroying exploration camp on their land. Australian Federal Minister for External Territories makes brief visit to Bougainville and tells disgruntled villagers a mine is not for their benefit alone but for the nation as a whole, and villagers will receive compensation but no special benefits. 
Motion by Bougainville Member of the House of Assembly, Paul Lapun, for amendment to Mining Ordinance to give 20\% or $5 \%$ royalty share to landowners defeated in House of Assembly.

Bougainvilleans at Holy Trinity Seminary, Madang, discuss secession for Bougainville.

(July) Villagers around Panguna force suspension of drilling, operations, but drilling later continues under police protection. (November) House of Assembly passes Lapun's 5\% royalty amendment despite Administration opposition.

(December) Lapun unable to persuade some local landowners to support further exploration even with promise of royalties.

Panguna Landowners protest strongly to mining warden's court re. renewal of CRA prosecting authorities.

(June) Negotiation of mining agreement between CRA and Administration, including offer of $20 \%$ equity to PNG if project Proceeds.

(August) Terms of the agreement between CRA and the colonial Administration incorporated in the Mining (Bougainville Copper Agreement) Ordinance.

Colonial Administration district headquarters moved from Sohano, in North Bougainville, to Kieta in Central Bougainville. in Port Moresby and calls for referendum on secession for Bougainvilleans.

CRA bulk sampling and pilot plant testing confirms Panguna ore reserves.

Second general election to the House of Assembly, conducted in three Bougainville electorates, South Open (won by Paul Lapun), North Open (won by Donatus Mola) and Regional (won by Joseph Lue). final feasibility study to Administration. Arawa plantation acquired compulsorily for town-site for mine and Administration. 
(April) 1,200 people from 25 villages attend public meeting in Kieta protesting against compulsory acquisition of Arawa. (June) Surveyors move in to work on Arawa land. (August) Bougainville villagers objections to Special Mining Lease taken up by the public solicitor in the Australian High Court without success.

Administration attempts to acquire land at Loloho for port mine facilities opposed strongly by Rorovana villagers. (July) Micro-nationalist Napidakoe Navitu movement is formed as part of widespread unrest about land acquisitions for the mine, and 1,500 people attend its first meeting. (August) Riot police expel forcibly Rorovana villagers from their land at Loloho which is required for the mine's port facilities. CRA negotiates with Rorovana villagers through Napidakoe Navitu on improved terms for the Port Lease, and Australian Administration is persuaded to offer improved terms. (November) Improved terms accepted by Rorovana landholders.

Napidakoe Navitu becomes more influential, and supports calls from various Bougainvilleans for a referendum on secession. (March) Secretary to Napidakoe Navitu conducts an unofficial referendum on Bougainville's secession through the monthly Bougainville News (which he ran) and claims to have distributed 16,000 voting papers, with over 11,000 supporting 'a complete break' with PNG. (August) People of Arawa Village agree to lease land for town development on terms similar to those agreed to by the Rorovana land-holders.

(September) BCL establishes a Village Relations Office to handle landowner compensation claims.

Motion in the House of Assembly by Bougainville representative, Paul Lapun, that a committee be appointed to tour Bougainville to determine if a referendum on secession should be held is defeated.

Construction worker labour force for Panguna mine and associated works peaks at over 10,000.

(April) BCL granted Tailings Lease over the whole Jaba River Valley. 

demand for secession by Mungkas Association members when attending UPNG graduation in Port Moresby. (April) Commercial production begins at the Panguna copper and gold mine.

Third general election for the House of Assembly, conducted in three open electorates in Bougainville (South, won by Paul Lapun who becomes Minister for Mines and Energy, North, won by Donatus Mola who becomes Minister for Buisness Development, and Central, won by Raphael Bele) and a regional electorate (won by Catholic priest, John Momis, who becomes Deputy Chairman and de facto chairman of the Constitutional Planning Committee established by the House of Assembly). (June) Constitutional Planning Committee established. (November) House of Assembly supports motion moved by Bougainville representative, John Momis, for review of mineral policy inclusive of a right to re-negotiate mining agreements. (December) Bougainville Awareness Seminar conducted by Mungkas Association at Rigu/Tubiana discusses future status of Bougainville.

(December) Pay-back killings of two prominent Bougainvillean public servants, Luke Rovin and Peter Moini, at Goroka in the Eastern Highlands sparks widespread anger in Bougainville and protests against future PNG rule.

1973 (February) Bougainville Special Political Committee (BSPC) established, and consults about, and prepares the case for, establishing a district government for Bougainville. (July) BSPC submits demand for a district government to the Constitutional Planning Committee. International copper prices rise to record levels and BCL profitability soars to unexpected $\$ 158$ million.

1974 (January) First meeting of the Bougainville Constituent Assembly held.

(July) Bougainville Provincial Government formally established, on an interim basis, under hastily passed TPNG legislation, Somare Government promises Bougainville will receive the state's $95 \%$ of mine royalties. 
(August to October) Re-negotiation by the National Government of the 1967 mining Agreement with CRA/BCL, and new Bougainville Copper Agreement signed, with terms more favourable to PNG, and provision for seven yearly reviews.

BCL agrees to a moratorium on exploration within existing prospecting authorities.

Fr Gregory Singkai from Bougainville becomes first indigenous bishop of Catholic diocese of Bougainville.

(May) Bougainville deleted Provincial Government votes to secede from PNG and adopts the name 'North Solomons'. (16 July) Regulation passed by national government providing for first elections for the Bougainville Provincial Government. (30 July) National Constituent Assembly votes to support Chief Minister Somare's motion to remove all provisions on provincial government from the independence PNG Constitution.

(August) Bougainville Provincial Assembly announces decision to declare independence of the Republic of North Solomons as from 1 September.

(1 September) Bougainville secessionist leaders announce the unilateral declaration of independence of Bougainville from PNG, and the flag of the North Solomons Republic is raised in the Arawa market.

John Momis and Raphael Bele resign from their seats in the PNG National Parliament.

John Momis and Hahalis Welfare Society leader, John Teosin, travel to New York to argue the case for recognition of Bougainville's secession at the UN.

(16 September) PNG's Independence is proclaimed.

(16 October) Bougainville Provincial Government is suspended by the PNG Parliament. PNG National Government seeking to resolve their differences. (April) Suspension of Bougainville Provincial Government revoked. (July) First election held for the Bougainville Provincial 
Government. Alexis Sarei elected unopposed as first premier of Bougainville.

(August) The Bougainville Agreement is signed between the PNG National Government and Bougainville leaders, ending Bougainville's bid to secede, and paving the way for provision on provincial government to be included in the PNG Constitution. (December) PNG Parliament passes amendments to the PNG Constitution providing for the provincial government system. By-elections held to fill the vacancies for the Central Open and Regional electorates created by resignations of Momis and Bele, and Paulus Harepa and Raphael Niniku elected.

Bougainville Development Corporation (BDC) founded with Leo Hannett as chairman of directors.

Constitution of the North Solomons Provincial Government (NSPG) adopted.

(April) Organic Law on Provincial Government comes into operation, and among other things provides the basis for the formal recognition of the NSPG, and as a body with enhanced powers as compared with the original 1974 legislation on provincial government.

(June-July) First general elections for the PNG National Parliament return John Momis (Regional), Raphael Bele (Central), Anthony Anugu (South), and Sam Tulo (North).

1978 Panguna Landowners' Association (PLA) organised to press BCL for increase in compensation payments.

1979 Villagers protest, and loot the Panguna supermarket, when BCL refuses their demands for increased compensation. Leo Hannett defeats Alexis Sarei in 'presidential' vote of whole of Bougainville.

(July) PLA representatives sign a new land compensation agreement with BCL, and the Road Mining Tailings Leases Trust (RMTL) is established under the terms of that agreement. Melanesian Alliance founded. 
Negotiations between the NSPG and the PNG National Government preparatory to renegotiation of the 1974 Bougainville Copper Agreement, with the Provincial Government and local leaders demanding transfer of National Government equity, a greater share of tax revenue, an increased rate of royalty and increase in the Non-renewable Resources Fund levy payable to Bougainville.

(September) Panguna landowner roadblock halts BCL production for some days.

National Government rejects Provincial Government demands and re-negotiation of the 1974 Agreement does not proceed.

(June-July) second general elections for the PNG National Parliament return John Momis (Regional), Raphael Bele (Central), Anthony Anugu (South), and Sam Tulo (North).

(May) General election for the NSPG. Alexis Sarei (Melanesian Alliance candidate) defeats Leo Hannett for premiership.

BCL study on tailings disposal options results in proposal to construct a pipeline to the west coast.

(May-June) Alexis Sarei resigns as Premier, and NSPG Constitution amended to allow the NSPG Assembly to elect a premier from among its own ranks when a vacancy in the position of Premier occurs shortly before a general election is due, and Joseph Kabui is elected Premier, as a Melanesian Alliance representative.

A New Panguna Landowners' Association (NPLA) is set up in opposition to PLA.

The 'Bougainville Initiative' is announced as a major plank of the Melanesian Alliance's campaign for the 1987 national elections, involving 3\% of total BCL revenue for the Province. Local landowners support it and add other demands for extra compensation, construction of housing, village electrification, and expatriates to replace Bougainvilleans in the Village Relations Office. (June-July) third general elections for the PNG National Parliament return John Momis (Regional), Raphael Bele 
(Central), Peter Kungka (South), and Michael Ogio (North). (August) New Panguna Landowners Association (New PLA) established (with executive members including Perpetua Serero as chairman, and her cousin Francis Ona as Secretary), which challenges the PLA leadership.

(March) Panguna landowners demonstrate in support of demand that National Government cancel the Mining Agreement with BCL.

(April) Landowners demand K10 billion compensation for past damage to land and environment, transfer of $50 \%$ of BCL profits and/or National Government tax revenues to the Provincial Government and transfer of ownership of BCL itself to Bougainvillean control within five years.

(17 May) Panguna landowners block three access roads to Panguna for 12 hours, halting BCL mining operations for six hours.

(26 May) Landowner demands discussed at meeting of Provincial Government and National Government representatives. (July) General election for the NSPG. Incumbent premier, Joseph Kabui (independent, but pro-Melanesian Alliance candidate) defeated Leo Hannett and Anthony Anugu, the official Melanesian Alliance candidate.

(July) PNG Minister for Minerals and Energy, Patterson Lowa, Fr. John Momis MP, Raphael Bele MP and NSPG leaders meet at Panguna with New PLA members and other villagers who express their frustration with the failure of $\mathrm{BCL}$ and government to deal with their concerns.

(August) PNG Cabinet commissions report on environmental and other impacts of the mine by New Zealand company, Applied Geology Associates Ltd. (August) New PLA members occupy RMTL offices claiming mismanagement by old PLA executive. (October) Francis Ona warns that landowner patience is running out.

(18 November) Meeting held with Panguna landowners to discuss report of an environmental impact study on the Panguna mine by Applied Geology Associates, a report which largely refutes landowner claims of chemical pollution, soil 
degradation, prevalence of diseases in adjacent areas etc., leading to angry rejection by landowner leaders, Francis Ona calling it a 'whitewash', and storming out of the meeting. (22 November) Theft of explosives from Panguna Mine magazine following police action to clear landowner roadblock.

(26-27 November) Series of attacks on BCL property, especially on power-lines.

(December) BCL mining operations halted for several periods by explosions.

(December) PNG Police riot squads brought to Bougainville from Lae and elsewhere to help contain violence.

(December) Raids by riot squads in Panguna area spark claims of brutality.

(December) Notice calling out PNG Defence Force in aid of the civil power published in the National Gazette, though troops not deployed until April 1989. 


\section{ACRONYMS AND ABBREVIATIONS}

$\begin{array}{ll}\text { AB } & \text { Amtsblatt für Neuguinea } \\ \text { AIB } & \text { Allied Intelligence Bureau } \\ \text { AIF } & \text { Australian Imperial Force } \\ \text { ANGAU } & \text { Australian New Guinea Administration Unit } \\ \text { ANU } & \begin{array}{l}\text { Australian National University } \\ \text { Australian and New Zealand Association for the Advancement } \\ \text { ANZAAS }\end{array} \\ \text { of Science } \\ \text { AOC } & \text { Assembly of Chiefs } \\ \text { AusAid } & \text { Australian Agency for International Aid } \\ \text { AWA } & \text { Australian Wireless Association } \\ \text { AWM } & \text { Australian War Memorial } \\ \text { BANA } & \text { Banoni and Nagovisi } \\ \text { BCA } & \text { Bougainville Copper Agreement } \\ \text { BCL } & \text { Bougainville Copper Limited (Ltd) } \\ \text { BCPL } & \text { Bougainville Copper Proprietary Limited (Pty Ltd) } \\ \text { BDC } & \text { Bougainville Development Corporation } \\ \text { BDPR } & \text { Bougainville District Patrol Reports } \\ \text { BIA } & \text { Buka Interim Authority } \\ \text { BIPG } & \text { Bougainville Interim Provincial Government } \\ \text { BLF } & \text { Buka Liberation Front } \\ \text { BLGC } & \text { Buka Local Government Council } \\ \text { BML } & \text { Bougainville Mining Limited } \\ \text { BP } & \text { Burns, Philp \& Co Ltd } \\ \text { BSPC } & \text { Bougainville Special Political Committee } \\ \text { BTG } & \text { Bougainville Transitional Government } \\ \text { BRA } & \text { Bougainville Revolutionary Army }\end{array}$


Burns Philp Burns, Philp \& Company Limited (Co Ltd)

CCEA Cocoa and Coconut Extension Agency

CLC Christian Life Centre

$\mathrm{CMB} \quad$ Copra Marketing Board

$\mathrm{CO} \quad$ Commanding Officer

COC Council of Chiefs

$\mathrm{CPC} \quad$ Constitutional Planning Committee

CPL Choiseul Plantations Limited (Ltd)

CRA Conzinc Riotinto of Australia Limited

CRAE Conzinc Riotinto Australia Exploration

CSIRO Commonwealth Scientific, Industrial and Research Organisation

DDA Department of District Administration

DDSNA Department of District Services (and Native Affairs)

DHPG Deutsche Handels und Plantagen Gesellschaft

DipEd Diploma of Education

DKB Deutsches Kolonialblatt

DO District Officer

GNG German New Guinea

GPNG Government of Papua New Guinea

HAD House of Assembly Debates

HMAS His Majesty's Australian Ship

LCOE Leitana Council of Elders

MSS manuscripts (in archives)

NAA National Archives of Australia

Napidakoe (Nasioi) Pi (Pirung) Da (Damara) Ko (Koromira/Konau (E (Eivo)

NavituNa

NAN Non-Austronesian

NBAC Noel Butlin Archives Centre

NBHC New Broken Hill Consolidated Ltd

NG New Guinea

NGIB New Guinea Infantry Battalion

NGO Non-Government Organisation 
NKW

NLA

NPLA

NSPG

NSP

NZ

PD

PEC

PIM

PLA

PMB

PMG

PMV

PNG

PNGDF

PP

RMTLTF Road Mine Tailings Lease Trust Fund

RNZAF

RTZ

SDA

SIL

SM

SML

SMS

SSGM

TNG

TPNG

UDI

UN

UPNG

WPHC

Nachrichten aus Kaiser Wilhelmsland

National Library of Australia

North Solomons Province

New Zealand

\section{Parliamentary Debates}

Provincial Executive Council

Pacific Islands Magazine

Panguna Landowners' Association

Pacific Manuscripts Bureau

Peace Monitoring Group

Passenger (or Public) Motor Vehicle

Papua New Guinea Defence Force

Parliamentary Papers

Royal New Zealand Air Force

Rio Tinto Zinc Corporation Limited

Seventh-Day Adventist

Society of Mary (Marists)

Special Mining Lease

Territory of New Guinea

Territory of Papua and New Guinea

United Nations

University of Papua New Guinea
New Panguna Landowners' Association

North Solomons Provincial Government

Papua New Guinea / Papua and New Guinea

Summer Institute of Languages, Goroka

German abbreviation for His Majesty's ship

State, Society and Governance in Melanesia Project at the ANU

Unilateral Declaration of Independence

West Pacific High Commission 



\section{GLOSSARY OF NON-ENGLISH WORDS AND PHRASES}

\begin{tabular}{|c|c|}
\hline \multirow{4}{*}{$\begin{array}{l}\text { Aaka(na) } \\
\text { Abacio }\end{array}$} & (Telei) clan matriliny \\
\hline & (Telei) chief's hall; \\
\hline & also kinsman of chief; \\
\hline & also women's carrying bag \\
\hline abaito & (Telei) Male clubhouse \\
\hline abuta & (Telei) coarse shell valuables \\
\hline anada & (Nagovisi) land \\
\hline beroana & (Haku) shell money \\
\hline big man/big men & anglicised version of Tok Pisin term, 'bikman' \\
\hline bikman/bik man & (Tok Pisin) leader, chief \\
\hline bilum/s & (Tok Pisin) string bag/s \\
\hline bogorogo & (Telei) referring to chiefs' men; his men \\
\hline bosboi & (Tok Pisin) indigenous supervisor or foreman \\
\hline bruklus & $\begin{array}{l}\text { (Tok Pisin) literally 'break free'; a term used } \\
\text { in Bougainville to describe secession }\end{array}$ \\
\hline burepi & (old Telei) a rich man \\
\hline butbutul & (Haku) chiefs' messengers \\
\hline calaboose & Anglicised version of the Tok Pisin word kalabus \\
\hline confrère & (French) colleague \\
\hline corvée & (French) unpaid tax in labour \\
\hline Daita Karakeni & $\begin{array}{l}\text { (Nasioi) Parliament of the clans in the Kieta } \\
\text { district }\end{array}$ \\
\hline didiman & (Tok Pisin) agricultural field officer \\
\hline doivent mourir & (French) ought to die \\
\hline
\end{tabular}




\begin{tabular}{|c|c|}
\hline dokta boi & (Tok Pisin) medical assistant \\
\hline draipela & (Tok Pisin) big, strong, extraordinary \\
\hline draipela masta & (Tok Pisin) important or senior (European) boss \\
\hline droit de seigneur & (French) right of the lord \\
\hline emi bagarapim & (Tok Pisin) [he, she, it] is/was messing it up \\
\hline feudalisch & (German) feudal \\
\hline Feuerholz & (German) tinder wood \\
\hline garamut & (Tok Pisin) slit gong (wooden signal drum) \\
\hline gavman/gavaman & (Tok Pisin) government \\
\hline goagono & (Haku) sacred \\
\hline gohus & $\begin{array}{l}\text { (Haku) literally the new shoot of the palm tree; a } \\
\text { senior chief, usually the head of new branches or } \\
\text { off-shoots of the main Haku sub-clans }\end{array}$ \\
\hline hahots & (Haku) taboo \\
\hline hamal & (Haku) curse imposed by a chief \\
\hline han & (Haku) settlement site \\
\hline haus & (Tok Pisin) dwelling, hut, shed \\
\hline haus kapa & (Tok Pisin) house with metal roof \\
\hline haus karamut & (Tok Pisin) men's club house containing a slit gong \\
\hline Imperium in Imperio & (Latin) an empire within an empire \\
\hline imo & (Telei; Siwai) my clanmate \\
\hline ioruhu & (Haku) original forest \\
\hline isu tetele & (Torau) straight nose \\
\hline juntun & (Haku) autochthonous spirits of masalai places \\
\hline kakao & (Tok Pisin) cocoa \\
\hline kakaunasi & (Nagovisi) cocoa garden \\
\hline kalabus & (Tok Pisin) prison \\
\hline kanaka(s) & (Tok Pisin) native \\
\hline kantoko & (Nagovisi) sharp eye-browed frog \\
\hline karamapim & (Tok Pisin) to cover something \\
\hline karamut & (Tok Pisin) alternative spelling of garamut \\
\hline kasikelo & (Nagovisi) hard work \\
\hline
\end{tabular}




$\begin{array}{ll}\text { kastom } & \text { (Tok Pisin) custom } \\ \text { kata } & \text { (Nagovisi) west } \\ \text { kaukau } & \text { (Tok Pisin) sweet potato } \\ \text { kepa } & \text { spouted bowls common to Mararing phase pottery } \\ \text { kiap } & \text { (Tok Pisin) government official; } \\ \text { patrol officer/field officer } & \text { (Haku) large feast/s } \\ \text { kinalala } & \text { (Telei) Chief's bonded male supporter } \\ \text { kitere } & \text { (Telei) elders' children } \\ \text { kitoria } & \text { (Haku) fowl } \\ \text { koa; kekeliou } & \text { (Haku) no longer fertile } \\ \text { kobkobul } & \text { (Tok Pisin) hornbill (and totemic symbol thereof) } \\ \text { kokomo } & \text { (German) colony } \\ \text { Kolonie } & \text { (Haku) sea hawk } \\ \text { kotoiana } & \text { (original Telei/recent Tok Pisin) a rooster; an } \\ \text { kukerai } & \text { Administration appointed headman; see also luluai } \\ & \\ \text { laki } & \text { (Tok Pisin) card game } \\ \text { laguke } & \text { (Nagovisi) military effort } \\ \text { laplap } & \text { (Tok Pisin) waistcloth; loincloth } \\ \text { lapun } & \text { (Tok Pisin) old person } \\ \text { liklik dokta } & \text { (Tok Pisin) medical assistant } \\ \text { lip bilong kakau } & \text { (Tok Pisin) literally, leaves of cocoa, but used in } \\ & \text { 1980s Nagovisi to describe the penalty fee payable } \\ \text { by a student absent from school } \\ \text { lopo } \\ \text { lotu } \\ \text { lucky } \\ \text { luluai } & \text { (Haku) newly chopped/cleared } \\ \text { (Tok Pisin) church service, faith } & \text { Anglicised version of Tok Pisin word, laki } \\ \text { luma } & \text { (Tok Pisin) village headman first appointed by the } \\ \text { German administration } \\ \text { mana } \\ \text { mangki/manki masta } \\ \text { maniku } \\ \text { man save } \\ \text { manugau }\end{array}$




\begin{tabular}{|c|c|}
\hline maru & (Siwai) 'growing-up' ritual; totem \\
\hline masalai & (Tok Pisin) spirit place \\
\hline masta & (Tok Pisin) foreign man or overlord \\
\hline mavo & (Nagovisi) ritual first occasions \\
\hline Me’ekamui & (Nasioi) sacred land \\
\hline Me’ekamui Pontoku Onoring & (Nasioi) an assembly to protect autonomy over \\
\hline & $\begin{array}{l}\text { land and culture, possessed from time immemorial, } \\
\text { to enhance wholeness, unity peace and holiness }\end{array}$ \\
\hline mekim save & (Tok Pisin) to punish severely, to be hard on \\
\hline & someone, to make (him/she/them) understand \\
\hline minei & (Telei) main pillar in chief's club house \\
\hline moma & (Nagovisi) leaders \\
\hline muns & see mona \\
\hline mona & (Haku) traditional plank canoe \\
\hline monokakata & (Nagovisi) whiteman \\
\hline monaruko & (Haku) Stem or source of the Ruko cult \\
\hline motainala & (Nagovisi) husband \\
\hline muki & (Haku) dog \\
\hline mumi & (Siwai) elder or leader of a descent group \\
\hline mumiana & (Telei) chief's wife \\
\hline mumira & (Telei) hereditary chief \\
\hline mungkas & (Telei) black \\
\hline munibil & (Haku) paramount chieftainship \\
\hline muniruko & (Halia) stem or source of Ruko cult \\
\hline mure & (Telei) totem-clan \\
\hline murkohiongo & $\begin{array}{l}\text { (Haku) God of tsunono's power /supreme spiritual } \\
\text { authority }\end{array}$ \\
\hline Napidakoe Navitu & $\begin{array}{l}\text { 'Napidakoe' is an anagram made up of the first } \\
\text { letters of names of language and other groups in } \\
\text { central Bougainville - Na (Nasioi), Pi (Pirung), } \\
\mathrm{Da} \text { (Damara), Ko (Koramira/Koianu) and E (Eivo), } \\
\text { while Navitu is a Nasioi word meaning 'together', } \\
\text { and the two words formed the name of a political } \\
\text { grouping established in central Bougainville in the } \\
\text { late 1960s. }\end{array}$ \\
\hline nalebo & (Nagovisi) clan \\
\hline namme & (Nagovisi) work basket \\
\hline nanaboko & (Telei) sexual partners for the mumira \\
\hline
\end{tabular}




\begin{tabular}{|c|c|}
\hline navitu & (Nasioi) together \\
\hline ngorere & (Haku) ranked unit of people within a ranked \\
\hline & sub-clan with a common female ancestor \\
\hline nitsunomo & $\begin{array}{l}\text { (Haku) divine potency, authority and power of } \\
\text { the chief }\end{array}$ \\
\hline nkorogo & (Telei) male members of other chiefs' group \\
\hline nomma & (Nagovisi) destruction of an erring couple's property \\
\hline nugaa & (Nagovisi) male, men \\
\hline nulla poena sine lege & (Latin) no punishment without a law \\
\hline oboring (pl. obontu) & (Nasioi) leader \\
\hline oping & (Haku) uninhabited \\
\hline oromrui & (Telei) chief's personal war god \\
\hline osikaiang & (Nasioi) original inhabitants \\
\hline paake & (Nagovisi) woman’s work basket \\
\hline paiou & (Haku) strings of porpoise or flying fox teeth \\
\hline pasin temata & (Tok Pisin) paganism \\
\hline pati & (Tok Pisin) secular celebration; party or celebration \\
\hline patu & $\begin{array}{l}\text { (Haku) head of highest lineage; literally seed of the } \\
\text { palm tree }\end{array}$ \\
\hline peits & $\begin{array}{l}\text { (Haku) lowest level of heritary chiefs; literally those } \\
\text { who sulk }\end{array}$ \\
\hline perekuba; perekupa & (Telei) bird \\
\hline perekuva & (Telei) clan \\
\hline pinaposa & (Haku) members of same clan or sub-clan \\
\hline pitpit & $\begin{array}{l}\text { (Tok Pisin) cane grass with edible head, and with } \\
\text { stems used for light fences and walls }\end{array}$ \\
\hline poket moni & (Tok Pisin) allowance money \\
\hline pokonopo & (Telei) elders'friends/companions \\
\hline potutu & (Haku) taro \\
\hline Protektorat & $\begin{array}{l}\text { (German) political term: area protected, cared for } \\
\text { by a government see also Schutzgebiet }\end{array}$ \\
\hline rausim & (Tok Pisin) destroy, get rid of \\
\hline Ruko & (Haku and Halia) initiation cult \\
\hline
\end{tabular}




$\begin{array}{ll}\text { saksak } & \text { (Tok Pisin) sago; material woven of dried vegetation } \\ \text { saveikata } & \text { (Nagovisi) education } \\ \text { save man } & \text { (Tok Pisin) educated man } \\ \text { Schutzgebiet } & \text { (German) protected area } \\ \text { sidokosidoi } & \text { (Nagovisi) heritage } \\ \text { singsing } & \text { (Tok Pisin) any festival involving dancing and } \\ \text { sira } & \text { singing, and sometimes feasting } \\ \text { spak } & \text { (Nagovisi) feast } \\ & \text { (Tok Pisin) drunk } \\ \text { tala tala } & \\ \text { taima } & \text { (Torau) shiny skin } \\ \text { tambu } & \text { (Nasioi) pudding made from starchy vegetables } \\ \text { taragau } & \text { and almonds } \\ \text { Tok Pisin, tokpisin } & \text { (Tok Pisin) traditional currency } \\ & \text { (Tok Pisin) eagle (or totemic symbol thereof) } \\ \text { Teo-Melanesian, or Melanesian Pidgin, or Pidgin } \\ \text { Tolo } & \text { English; a lingua franca spoken in Papua New } \\ \text { totemsippen } & \text { Guinea } \\ \text { tou } & \text { (Haku) island of vegetation } \\ \text { tripela (draipela) masta } & \text { (German) clans } \\ \text { tsigoro } & \text { (Telei) small bird } \\ \text { tsuhana } & \text { (Tok Pisin) important (European) boss } \\ \text { tsunaun } & \text { (Telei) stone arrangements found in Buin } \\ \text { tsunono } \\ \text { tubu } \\ \text { tubikau } \\ \text { tuiruma } \\ \text { tultul } & \text { (Haku) clubhouse } \\ \text { tulun } & \text { (Tinputz) person of rank / importance } \\ \text { tumbuna } & \text { (Haku) chiefs } \\ \text { uan } & \text { (Telei) clan } \\ \text { ugu } & \text { (Haku) chief's sister / woman of high rank } \\ \text { uhats } & \text { (Telei) slit-gongs } \\ \text { ulugasi } & \text { (Tok Pisin) colonial village officials below luluai } \\ \text { and their assistants; government chief's assistants } \\ \text { (Halia) horizon } \\ \text { (Tok Pisin) forebears } \\ \\ \text { (Telei) dove } \\ \text { (Telei) hornbill } \\ \text { (Haku) sacrifice } \\ \text { (Nagovisi) red skins, Papua new Guineans as } \\ \text { distinct from (black) Bougainvilleans } \\ \end{array}$




$\begin{array}{ll}\begin{array}{l}\text { uniari } \\ \text { unu }\end{array} & \text { (Torau) not too black and not too light skin colour } \\ \text { upi / upe } & \text { (Telei) a ritual feast for boys' initiation } \\ \text { urar } & \text { (Tinputz) lantern shaped hat worn by boys and } \\ \text { young men before initiation } \\ \text { (Tinputz) spirits of the dead } \\ \text { vabui } \\ \text { veta } \\ \text { (Nagovisi) a son's land } \\ \text { (Nagovisi) village micro finance scheme based on } \\ \text { traditional shell money ownership that operated in } \\ \text { parts of Nagovisi in the 1970s } \\ \text { vikano } \\ \text { viulupo, volupo } \\ \text { viumalo, vomalo } \\ \text { voliwatawata } \\ \text { (Nagovisi) children's clan; children of the male } \\ \text { (Nagovisi) father's clan } \\ \text { waitman } \\ \text { wakaiolo } \\ \text { walomasinga pagopago }\end{array}$




\section{BIBLIOGRAPHY}

\section{A: Identified Alphabetically by Authors and Authorising Agency for Ease of Location:}

[Please note: the inclusion here of unpublished texts by named authors is intended to guide the reader immediately to where they are held.]

Aerts, Theo ed.

1994 The Assembly Hall at Bomana. (Souvenir Brochure on the Occasion of its Official Opening, 22 May 1994.) Bomana, Papua New Guinea: Salt Press, $39 \mathrm{pp}$.

Allen, J. and Hurd, C.

1963 Languages of the Bougainville District. Ukarumpa: Papua New Guinea Summer Institute of Linguistics.

Allied Geographic Section. Allied Forces, Southwest Pacific Area.

1943 Terrain Study No. 41, Area Study of the Mandated Solomons. Map 13, 23 June. Allied Geographic Section, Southwest Pacific Area.

1944 Special Report No. 65, Bougainville, 21 November. Allied Geographic Section, Southwest Pacific Area.

Allied Intelligence Bureau

World War II Radio Reports. Canberra: Australian War Memorial, 423/9/35

Allotte, Francois

1912 Rapport sur la Prefecture des Salomons Septentrionales. MS. Rome: Archivio Padri Maristi, 5SS, 208, Epistolae.

1918 Letter to Broyer, 14 June. Apia: Archives of the Diocese of Samoa and Tokelau, D.9.4. 
1924 'Notice sur Buin'. MS in two exercise books. Rome: Archivio Padri Maristi, O’Reilly Papers; MS copies. Canberra: Pacific Manuscripts Bureau, Research School of Pacific and Asian Studies, Australian National University, 4 (MSS series).

ANGAU see Australian New Guinea Administration Unit

Anis, T.

1977 'Buka Local Government Council'. In Connell, J. ed. Local Government Councils in Bougainville, pp. 111-19. Bougainville Special Publications. Christchurch: Department of Geography, University of Canterbury.

Anis, T., Makis, E., Miriung, T. and Ogan, E.

1976 'Toward a New Politics?' In Stone, D. ed. Prelude to Self-Government, pp. 442-66. Canberra: Australian National University Press.

Anis, T., Dove, J., Miriung, T. and Ogan, E.

1977 'The Wakunai Local Government Council'. In Connell, J. ed. Local Government Councils in Bougainville, pp. 91-5. Bougainville Special Publications. Christchurch: Department of Geography, University of Canterbury.

Australia see below and also Commonwealth Government of Australia

\section{Australia. Parliament.}

Parliamentary Debates, 27 March, 1 April 1936, 6 April 1947.

Journals of the Senate, 1922, Session 1.

\section{Australian Army}

1945 Headquarters. 2nd Australian Corps Language Detachment. Canberra: Australian War Memorial.

\section{Australian New Guinea Administration Unit}

1944 'Interrogation of Natives, Lt R. Cambridge, Siwai, 27 Nov 1944'. Reports from Bougainville. Nov-Dec 1944. Canberra: Australian War Memorial, AWM 54, 80/6/14.

\section{Ballard, John}

1981 'Policy Making as Trauma: the Provincial Government Issue'. In Ballard, J. ed. Policy Making in a New State: Papua New Guinea 1972-77, pp. 95-132. Brisbane: University of Queensland Press. 
BCL see Bougainville Copper Limited

\section{Bedford, Richard and Mamak, Alexander}

1976 'Kieta, Arawa and Panguna: the towns of Bougainville'. In Jackson, R. T. ed. An Introductory Urban Geography of Papua New Guinea, pp. 444-82. Department of Geography Monograph. Port Moresby: University of Papua New Guinea.

1977 Compensation for Development: The Bougainville Case. Bougainville Special Publications, No. 2. Christchurch: Department of Geography, University of Canterbury.

\section{Behr, John}

1990 'Traeger, Alfred Hermann (1895-1980)', Australian Dictionary of Biography, Vol. 12: pp. 251-2. Melbourne: Melbourne University Press.

\section{Bellwood, P.}

1996 'Hierarchy, Founder Ideology and Austronesian Expansion'. In Fox, James and Sather, Clifford eds. Origins, Ancestry and Alliance: Explorations in Austronesian Ethnology I, pp. 18-40. Comparative Austronesian Project. Canberra: Department of Anthropology, Research School of Pacific and Asian Studies, Australian National University.

\section{Beniston, Daphne N.}

1994 The Call of the Solomons: the New Zealand Methodist Women's Response. Auckland: Wesley Historical Society.

\section{Bennett, Judith A.}

1987 Wealth of the Solomons: A History of a Pacific Archipelago, 1800-1978. Honolulu: University of Hawai'i Press.

2000 'Across the Bougainville Strait: commercial interests and colonial rivalry, c.1880-1930', Journal of Pacific History, 35, 1 (June): pp. 67-82.

Bettison, D., Hughes, C. and van der Veur, P. eds

1965 Papua New Guinea Elections 1964. Canberra: Australian National University Press.

\section{Black, S.}

1977 The Excavation at Teobebe, Teop Island. Reports of the Bougainville Archaeological Survey, No. 10. Chicago: Field Museum of Natural History. 
Blackwood, B.

1935 Both Sides of Buka Passage. An Ethnographic Study of Social, Sexual, and Economic Questions in the North-Western Solomon Islands, Oxford: Clarendon Press.

Blake, D. H. and Miezitis, Y.

1967 The Geology of Bougainville and Buka Islands, New Guinea. Bureau of Mineral Resources, Australia, Bulletin No. 93. Canberra: Bureau of Mineral Resources, 56 pp.

Bleeker, P. and Freyne, D. F.

1981 Areas Suitable for Cocoa Production in Papua New Guinea. Canberra: Commonwealth Scientific and Industrial Organsiation.

Boch, Maurice

1914 Letter to Forester, 18 September. Rome: Archivio Padri Maristi, O’Reilly Papers.

1935 Letter to O’Reilly, 5 February. Rome: Archivio Padri Maristi, O’Reilly Papers; MS copies. Canberra: Pacific Manuscripts Bureau, Research School of Pacific and Asian Studies, Australian National University.

Boniwell, B.

1972 'Bougainville copper project'. In Ryan, P. ed. Encyclopaedia of Papua New Guinea, Vol. 1: pp. 92-8. Melbourne: Melbourne University Press.

\section{Bougainville Constitutional Commission}

2004 Report on the Third and Final Draft of the Bougainville Constitution, prepared by the Bougainville Constitutional Commission. Transcript. Buka and Arawa: Bougainville Constitutional Commission.

\section{Bougainville Constituent Assembly}

2004 'The Constitution of the Autonomous Region of Bougainville. Adopted by the Bougainville Constituent Assembly at Buin on 12 November 2004'. Papua New Guinea National Gazette No.G138, Port Moresby, Friday, 10 December 2004, PNG Government Printer.

\section{Bougainville Copper Limited}

1978 Annual Report for 1978

1989 Annual Report for 1989 
Bougainville, L. A. Comte de

1772 A Voyage Round the World. Performed by Order of His Most Christian Majesty in the Years 1766, 1767, 1768 and 1769. London: J. Nourse and T. Davies.

1961 A Voyage Round the World. Reinhold, J. trans. New York: Da Cape Press.

Bougainville District Patrol Reports see Territory of New Guinea, Department of District Services and Native Affairs.

\section{Bougainville Transitional Government}

1996 Bougainville Council of Elders Act.

Bourke, R. M. and Betitis, T.

2003 Sustainability of Agriculture in Bougainville Province, Papua New Guinea. Land Management Group, Australian National University.

\section{Boyle, Valens}

1989 Sacrifice not Romance: the Marist Brothers in the Solomons. Sydney:

Macarthur Press for the Marist Brothers.

Brown, Paula

2001 'The Historical Context of Colonialism'. In McPherson, Naomi ed. In Colonial New Guinea: Anthropological Perspectives, pp. 15-26. Pittsburgh: University of Pittsburgh Press.

BTG see Bougainville Transitional Government

Buckley, K. and Klugman, K.

1983 The Australian Presence in the Pacific: Burns Philp, 1914-1946. Vol. 2. Sydney: Allen and Unwin.

\section{Bucknall, Graeme}

1981 'Flynn, John (1880-1951)', Australian Dictionary of Biography, Vol. 8: pp. 531-4. Melbourne: Melbourne University Press.

Budden, F. M.

1973 That Mob: The Story of the 55/53rd Australian Infantry Battalion. Privately published.

Buin Patrol Reports, see Territory of New Guinea, Department of District Services and Native Affairs 


\section{Butler, Alan comp.}

1984 A New Guinea Bibliography. Volume 1. Waigani, Port Moresby: University of Papua New Guinea Press.

\section{Butler, Alan and Cumings, Gary comps.}

1986 A New Guinea Bibliography. Volume 3. Waigani, Port Moresby: University of Papua New Guinea

\section{Burger, Friedrich}

1923 Unter den Kannibalen der Südsee. Dresden: Verlag Deutsche Buchwerkstätten.

Byrnes, G. M.

1989 A War History of the Papuan Infantry Battalion. Privately published.

Callan, Jay S.

1976 Settlement Patterns in Pre-War Siwai: An Application of Central Place Theory to a Horticultural Society. Chicago: Chicago Field Museum of Natural History.

Cann, H. M., de Toma, C., Cazes, L., Friedlaender, J. et al. (i.e. 34 other named members of project)

2002 'A human genome diversity cell line panel', Science, 296, 55-66: pp. 261-2.

Carter, George G.

1973 A Family Affair: A Brief Survey of New Zealand's Missionary Involvement in Missions Overseas 1822-1972. Auckland: Wesley Historical Society of New Zealand.

Cavidini, Fabio and King, Mandy

1999 An Evergreen Island. Videotape. Melbourne: Friends of the Earth.

Chaize, Leon

1925 Letter to Procurator, 8 March. Suva: Oceania Marist Province Archives, D.2.6.

Chambers, M. R.

1985 'Environmental management problems in Papua New Guinea'. The Environmental Professional, 7: pp. 178-85.

Charlton, Peter

1983 The Unnecessary War: Island Campaigns of the South-West Pacific, 1944-45. Melbourne: Macmillan. 


\section{Chinnery, E. W. Pearson}

1924 Notes on the Natives of South Bougainville and Mortlocks (Taku). Territory of New Guinea Anthropological Report No. 5. Canberra: Australian Government Publishing Service.

1926 see under Commonwealth Government of Australia.

1930 Anthropological Report (New Guinea Territory), No. 4. Canberra: Australian Government Publishing Service.

1932 'Presidential Address'. Australian and New Zealand Association for the Advancement of Science - Sydney Meeting, August 1932. Oceania, 3, no. 1: p. $88-100$.

Cilento, R. W.

1928 The Causes of Depopulation of the Western Islands of the Territory of New Guinea. Canberra: Australian Government Publishing Service.

Clark, G. H.

1990 'Panguna Copper-Gold Deposit'. In Hughes, F. E. ed. Geology of the Mineral Deposits of Australia and Papua New Guinea, pp. 1807-16. Melbourne: Australasian Institute of Mining and Metallurgy.

\section{Clarke, William C. and Ogan, Eugene}

1973 'Assumptions and Alternatives: Recent research by social scientists in Papua New Guinea'. In Fischer, J. ed. Foreign Values and Southeast Asian Scholarship. Research Monograph No. 11: pp. 264-90. Berkeley: Center for South and Southeast Asian Studies, University of California.

\section{Clifford, James}

1988 The Predicament of Culture: Twentieth Century Ethnography. Cambridge, Massachusetts: Harvard University Press.

Cocoa and Coconut Extension Agency of Papua New Guinea (now Cocoa and Coconut Institute at Tavilo, East New Britain)

1999 Report of the Bougainville Cocoa and Coconut Baseline Survey. Madang: Cocoa and Coconut Extension Agency of Papua New Guinea.

\section{Cocoa Board of Papua New Guinea}

1999 Annual Cocoa Statistics of Papua New Guinea. Kokopo, East New Britain: Cocoa Board of Papua New Guinea. 


\section{Commonwealth Government of Australia}

1917-20 Südsee-Handbuch. In English. Draft of a Guide to the South Seas:

Made by Direction of the German Imperial Admiralty. (Translated by direction of the Australian Naval Board, Melbourne, 1917-1920.)

1921; 1939-40

Report to the Council of the League of Nations on the Administration of the Territory of New Guinea, September 1914-30 June 1921. Melbourne.

1926 Report of the International Pacific Health Conference. Held at Melbourne, 15th to 22nd December, 1926. E. W. P Chinnery, auth. Melbourne:

Australian Government Publishing Service.

1940 Official Handbook of the Territory of New Guinea. Canberra: Australian Government Publishing Service.

Connell, John

1977 'The Decline of Local Government Councils and the Rise of Village Government'. In Connell, J. ed. Local Government Councils in

Bougainville, pp. 132-71. Bougainville Special Publications. Christchurch : Department of Geography, University of Canterbury.

1978 Taim Belong Mani: the Evolution of Agriculture in a Solomon Island Society. Canberra: Australian National University Press.

1991 'Competition and Conflict: the Bougainville Copper Mine, Papua New Guinea'. In Connell, John and Howitt, Richard eds. Mining and Indigenous Peoples in Autralasia, pp. 39-56. Melbourne: Oxford University Press.

\section{Connor, W.}

1972 'Nation-building or nation-destroying'. World Politics, 24 (April): pp. 319-55.

1973 'The politics of ethnonationalism'. Journal of International Relations, 27, 1: pp. 1-21.

\section{Conyers, D.}

1976 The Provincial Government Debate: Central Control Versus Local Participation in Papua New Guinea. Institute of Applied Social and Economic Research Monograph 2. Port Moresby: Institute of Applied Social and Economic Research.

\section{Copra Marketing Board of Papua New Guinea} $1999 / 2000$

Copra Statistics. Rabaul: Cocoa and Copra Research Institute of Papua New Guinea. 
Corris, P.

1973 Passage, Port and Plantation: A History of the Solomon Islands Labour Migration, 1870-1914. Melbourne: Melbourne University Press.

Cowen, Michael and MacWilliam, Scott

1996 Indigenous Capital in Kenya: the 'Indian' Dimension of Debate. Helsinki: Interkont Books and Helsinki Institute of Development Studies, University of Helsinki.

Cowen, Michael P. and Shenton, Robert W.

1996 Doctrines of Development. London: Routledge.

Davies, Hugh L.

1992 Mineral and Petroleum Resources of Papua New Guinea. University of Papua New Guinea Natural Resource Series. H. L. Davies, coord. Port Moresby: University of Papua New Guinea, 35 pp.

Decker, Charles ed.

1942 Saving the Solomons: From the Diary Account of (Rev. Mother) Mary Rose, S.M.S.M. Boston: Society for the Propagation of the Faith [also published 1947, Bedford, Massachusetts: Marist Mission].

\section{Denoon, Donald}

2000 Getting Under the Skin: The Bougainville Copper Agreement and the Creation of the Panguna Mine. Melbourne: Melbourne University Press.

Department of Anthropology and Sociology. Australian National University. 1968 An Ethnographic Bibliography of New Guinea. Volume 2. District Index. Canberra; Australian National University Press.

Diocese of Bougainville. Catholic Church

1989 Statement from the Diocesan Priests of Bougainville Diocese. Kieta:

Bougainville Diocese.

2001 Catholic Diocese of Bougainville Centenary 100 Years 1901-2001. Hahela Mission Station, Buka: Bougainville Diocese.

Department of District Services and Native Affairs

Annual Reports 


\section{Diploma in Library Science 2 Students.}

1980 North Solomons Bibliography. Multiple copies roneoed. Waigani, Port Moresby: Library Studies Section, Administrative College of Papua New Guinea. Copy held by J. and H. Griffin, Canberra.

\section{Dixon, Robert}

1985 'The Pacific Islands'. In Clapham, Noel, ed. Seventh-Day Adventists in the Pacific, 1885-1985: Australia, New Zealand, South-Sea Islands, pp. 198-232. Warburton: Signs Publishing.

Dobrich, J.

2004 Shovel Shape Incisor Distributions in Bougainville, Papua New Guinea. Philadelphia: Anthropology Department, Temple University.

\section{Docker, E. W.}

1970 The Blackbirders: The Recruiting of South Seas Labour for Queensland, 1863-1907. Sydney: Angus and Robertson.

\section{Dorsey, George A.}

1909 'A visit to the German Solomon Islands'. Putnam Anniversary Volume, pp. 521-44. New York: G. E. Stecher \& Company.

\section{Douglas, Bronwen}

1998 'Rank, Power, Authority: A reassessment of traditional leadership in South Pacific societies'. In Douglas, B., ed. Across the Great Divide. Journeys in History and Anthropology, pp. 29-67. Amsterdam: Harwood Academic Publishers.

Dove, J., Miriung, T. and Togolo, $M$.

1974 'Mining Bitterness'. In Sack, P. G., ed. Problem of Choice: Land in Papua New Guinea's Future, pp. 181-9. Canberra: Australian National University.

\section{Downer, Alexander}

2001 The Bougainville Crisis: An Australian Perspective. Canberra: Department of Foreign Affairs and Trade

\section{Downs, Ian}

1980 The Australian Trusteeship: Papua New Guinea 1945-75. Canberra: Australian Government Publishing Service. 
Doyle, Alban

1972 The Story of the Marist Brothers in Australia, 1872-1972. Sydney: E. Dwyer.

Durning, Francis

1985 Here I Am, a Failure: Emmet C. McHardy SM, Marist Missionary Priest in the Pacific. Wellington: Society of Mary, New Zealand Province.

Economic Consultants Ltd in association with Shankland Cox Partnership, Booker Agriculture International Ltd, Sea Fish Industry Authority

1982 North Solomons Provincial Development Study. Final Report, Vol. 2:

Background Papers, Pt. 1 and Pt. 2. Arawa: North Solomons Provincial Government.

Edridge, Sally comp.

1985 Solomon Islands Bibliography to 1980. Suva: Institute of Pacific Studies, University of the South Pacific; Wellington: Alexander Turnbull Library; Honiaria: Solomon Islands National Library.

Elkin, A. P.

1954 'Research development in the South-West Pacific', Sociologus, 4, 2: pp. 127-36.

\section{Ethnologue see Grimes, Barbara}

Everingham, I. B.

1977 Preliminary Catalogue of Tsunamis for the New Guinea/Solomon Islands Region, 1768-1972. Bureau of Mineral Resources, Australia, Report 180, 78 pp. Canberra: Bureau of Mineral Resources.

Everingham, I. B., Gaull, B. A. and Dent, V. F.

1977 The East Solomon Sea Earthquake of 20 July 1975; and Notes on Seismic Risk in Bougainville. Canberra: Bureau of Mineral Resources, Record 1977/31, 37 pp.

Feldt, Eric

1967 The Coast Watchers. Sydney: Angus and Robertson.

Feuer, A. B.

1992 Coast Watching in the Solomon Islands: The Bougainville Reports, December 1941-July 1943. New York: Praeger. 
Filer, C.

1990 'The Bougainville Rebellion, the Mining Industry and the Process of Social Disintegration in Papua New Guinea'. In May, R. J. and Spriggs, Matthew, eds. The Bougainville Crisis, pp. 112-40. Bathurst: Crawford House Press.

1992 'The Escalation of Disintegration and the Invention of Authority'. In Spriggs, Matthew and Denoon, Donald, eds. The Bougainville Crisis: 1991 Update, pp. 112-40. Canberra: Research School of Pacific and Asian Studies, Australian National University and Bathurst: Crawford House Press.

\section{Fingleton, Wally}

1970 'Bougainville: a chronicle of just grievances', New Guinea and Australia, the Pacific and South-East Asia, 5, 2 (June-July): pp. 13-20.

\section{Finney, Ben}

1973 Big-Men and Business: Entrepreneurship and Economic Growth in the New Guinea Highlands. Honolulu: University of Hawai' i Press.

Firth, R.

1967 'Analysis of Mana: an empirical approach'. In Firth, R., Tikopia Ritual and Beliefs, pp. 174-94. London: George Allen and Unwin.

Firth, S.

1973 German Recruitment and Employment of Labourers in the Western Pacific Before the First World War. Unpublished PhD thesis. University of Oxford. 1982 New Guinea Under the Germans. Melbourne: Melbourne University Press.

Fisher, N. H.

1973 'Geological Report Kupei Goldfields, Bougainville, T.N.G.' In Stephenson, H. H. ed. Bougainville - The Establishment of a Copper Mine, pp. 362-7. Melbourne: Construction, Mining, Engineering Publications.

Flannery, T., Kirch, P. V., Specht, J. and Spriggs, M.

1988 'Holocene mammal faunas from archaeological sites in island Melanesia', Archaeology in Oceania, 23, 3: pp. 89-94.

Flannery, T. and Wickler, S.

1990 'Quaternary murids (Rodentia: Muridae) from Buka Island, Papua New Guinea, with descriptions of two new species', Australian Mammalogy, 13: pp. 127-39. 


\section{Flaus, Karl}

1899a Letter to Broyer, 24 April. Apia: Archives of the Catholic Diocese of Samoa and Tokelau, D.9.3.

1899b Letter to Hervier, September. Rome: Archivio Padri Maristi, 5SS, 61, 208. Published in Annales des Missions de l'Oceanie, 10: pp. 289-91.

Foley, William A.

1986 The Papuan Languages of New Guinea. Cambridge: Cambridge University Press.

\section{Freeman, Colin}

1968 Bougainville Island Bibliography. Unpublished. TS. Copy held by J. and H. Griffin, Canberra.

Friedlaender, J. S.

1971a 'Isolation by distance in Bougainville', Proceedings of the National Academy of Science of the United States of America, 68, 4: pp. 704-07.

$1971 b$ 'The population structure of south-central Bougainville', American Journal of Physical Anthropology, 35, 1: pp. 13-25.

1975 Patterns of Human Variation: The Demography, Genetics, and Phenetics of Bougainville Islanders. Cambridge: Harvard University Press.

Friedlaender, J. S. coord.

1987 The Solomon Islands Project: A Long-term Study of Health, Human Biology and Culture Change. Oxford: Oxford Science Publications.

Friedlaender, J., Gentz, F., Thompson, F., Kaestle, F., Schurr, T., Koki, G., Mgone, C., McDonough, J., Smith, L. and Merriwether, D. A.

2005 Mitochondrial Genetic Diversity and its Determinants in Island

Melanesia. In Pawley, A., Attenborough, R., Golson, J. and Hide, R., eds. Papuan Pasts: Linguistic, Archaeological and Biological Relations of Papuan Peoples. Pacific Linguistics Series. Canberra: Research School of Pacific and Asian Studies, Australian National University. [In Press.]

Friedlaender, J. S., Sgaramella-Zonta, L.A. and Kidd, K. K.

1971 'Biological divergences in south-central Bougainville: an analysis of blood polymorphism, gene frequencies and anthropometric measurements utilizing tree models, and a comparison of these variables with linguistic, geographic, and migrational "distances", American Journal of Human Genetics, 23, 3: pp. 253-70. 
Friedlaender, J. S. and Steinberg A. G.

1970 'Anthropological significance of gamma globulin (Gm and Inv) antigens in Bougainville Island, Melanesia', Nature, 228: pp. 59-61.

\section{Frizzi, Ernst}

1914 Ein Beitrag zur Ethnologie von Bougainville and Buka mit Spezialler Berücksichtingung der Nasioi. Bässler Archiv, Supplement No. 6. Leipzig and Berlin: G.Teubner.

\section{Froehlich, J. W.}

1987 'Fingerprints as Phylogenetic Markers in the Solomon Islands'. In The Solomon Islands Project: A Long Term Study of Health, Human Biology, and Culture Change, pp. 175-214. Friedlaender J. S. coord. Oxford: Oxford Science Publications.

\section{Gailey, Harry}

1991 Bougainville 1943-1945: The forgotten campaign. Lexington: University of Kentucky.

\section{Galtung, J.}

1974 Structural Theory of Revolutions - Part II. Proceedings of the 1st International Working Conference on Violence and Non-Violent Action in Industrialized Societies: 27. Publications of The Polemological Center of the Free University Press (VUB), Vol. 5. Rotterdam: Rotterdam University Press.

Garrett, John

1997 Where Nets Were Cast: Christianity in Oceania since World War II. Suva: Institute of Pacific Studies.

Gawi, J., Ghai Y. and Paliwala, A.

1976 'National goals and law reform: a report on the Goroka Seminar', Melanesian Law Journal, 4: pp. 259-69.

Gentz, F., Friedlaender, J. S. and Merriwether, D. A.

2000 'New mtDNA Haplogroup Variation in Bougainville Island'. Paper read at American Association of Physical Anthropology, at San Antonio, Texas. (Copy held by J. S. Friedlaender, Temple University, Philadelphia.) 
Ghai, Yash

2000 'Ethnicity and Autonomy: a framework for analysis'. In Ghai, Yash, ed. Autonomy and Ethnicity: Negotiating Competing Claims in Multi-ethnic States, pp. 1-26. Cambridge: Cambridge University Press

Ghai, Yash and Regan, Anthony J.

2000 'Bougainville and the Dialectics of Ethnicity, Autonomy and Separation'. In Ghai, Yash, ed. Autonomy and Ethnicity: Negotiating Competing Claims in Multi-ethnic States, pp. 242-65. Cambridge: Cambridge University Press.

\section{Gillison, Douglas}

1962 Royal Australian Air Force 1939-1942. Canberra: Australian War Memorial.

GPNG see Government of Papua and New Guinea

\section{Goldman, I.}

1970 Ancient Polynesian Society. Chicago: Chicago University Press.

\section{Government of Papua and New Guinea}

1991 Bougainville Interim Authorities Act 1991.

\section{Griffin, Helga M.}

1990 'Auf der Suche nach der menschlichen Gesellschaft: Richard Thurnwald. [In Search of Human Society] By Marion Melk-Koch. Berlin, Dietrich Reimer Verlag, 1989. 352 pp. maps, illustrations, bibliography’. [Review], Journal of Pacific Pacific History, 3: pp. 57-8.

\section{Griffin, James}

1970 'Bougainville', Australia's Neighbours, 68 (January-February): pp. 7-12.

1972 'Bougainville — secession or just sentiment?' Current Affairs Bulletin, 48, 9 (1 February): pp. 259-80.

1973a 'Buka and Arawa: some black thoughts on a white history of Bougainville', Meanjin, 32, 4 (December): pp. 442-56.

1973 b 'Kivung Bougainville', New Guinea and Australia, the Pacific and Southeast Asia, 8, 2 (July): pp. 41-50.

1973 c 'Papua New Guinea and the British Solomon Islands Protectorate: fusion or transfusion?', Australian Outlook, 27, 3 (December): 319-28.

1973d 'Movements for Separatism and Secession'. In Clunies Ross, A. and Langmore, J., eds. Alternative Strategies for Papua New Guinea, pp. 99-130. Melbourne: Oxford University Press. 
1976 'Bougainville. Occultus sed non ignotus' [Kieta, Honiara and Port Moresby: hidden but not unknown], New Guinea and Australia, the Pacific and Southeast Asia, 10, 4: pp. 44-51.

1977 'Local Government Councils as an Instrument of Political Mobilisation in Bougainville'. In Connell, J. ed. Local Government Councils in Bougainville, pp. 29-57. Bougainville Special Publications. Christchurch : Department of Geography, University of Canterbury.

1978 'Paul Mason: planter and coastwatcher'. In Griffin, James ed. Papua New Guinea Portraits: The Expatriate Experience, pp. 126-68. Canberra: Australian National University Press.

1982 'Napidakoe Navitu'. In May, R. J. ed. Micronationalist Movements in Papua New Guinea, pp. 113-38. Political and Social Change Monograph No. 1. Canberra: Department of Social and Political Change, Research School of Pacific Studies, Australian National University.

1990 'Bougainville is a Special Case'. In May R. J. and Spriggs, M., eds. The Bougainville Crisis, pp. 1-15. Bathurst: Crawford House Press.

1995 Bougainville: a challenge for the churches. North Sydney: Catholic Commission for Peace and Justice.

Griffin, James and Griffin, Helga Maria

1975 Bougainville Artifacts. Conserved or Cookim Coffee? Occasional Paper No. 1. Boroko, Port Moresby: Institute of Papua New Guinea Studies. 14 pp.

Griffin, J., Nelson, H. and Firth, S.

1979 Papua New Guinea: A Political History. Melbourne: Heineman Educational Australia.

Griffin, James with Kawona, Sam

1989 'The Elections in North Solomons Province'. In Oliver, Michael, ed. Eleksin. The 1987 National Election in Papua New Guinea, pp. 225-243. Port Moresby: University of Papua New Guinea.

Griffin, James and Togolo, Mel

1997 'North Solomons Province, 1974-1990'. In May, R. J. and Regan, A. J. with Ley, Allison, eds. Political Decentralisation in a New State: the Experience of Provincial Government in Papua New Guinea, pp. 354-82. Bathurst: Crawford House Publishing.

Grimes, Barbara, ed.

2000 Ethnologue. Dallas: SIL International. 


\section{Grisward, P. Joseph}

1910 'Notes Grammaticales sur la Langue des Teleï, Bougainville, Iles Salomones', Anthropos, 5, 82-94: pp. 381-406.

1923 'Buin. Les Troubles Entre Morou et Bagui de 1912 a 1920'. MS. Rome: Archivio Padri Maristi, O’Reilly Papers; MS copies. Canberra: Pacific Manuscripts Bureau, Research School of Pacific and Asian Studies, Australian National University, 4 (MSS series).

HAD see Papua New Guinea Parliament. House of Assembly

\section{Hahl, Albert}

1937 Gouverneursjahre. Berlin: Frundsberg.

1980 Albert Hahl. Governor in New Guinea. Sack, Peter G. and Clark, Dymphna, trans. and eds. Canberra: National University Press.

\section{Hammett, Michael}

1977 Households on the Move: Settlement Patterns among a Group of Eivo and Simeku Speakers in Central Bougainville. Unpublished PhD thesis.

University of Hawai'i.

\section{Hannett, Leo}

1969 'Down Kieta Way, Independence of Bougainville'. New Guinea and Australia, the Pacific and Southeast Asia, 4, 1 (March-April): pp. 8-14.

Hanson, L. W., Allen, B. J., Bourke, R. M. and McCarthy, T. J.

2001 Papua New Guinea Rural Development Handbook. Canberra: Australian National University.

Harris, E. F. and Bailit, H. L.

1987 'Odontometric comparison among Solomon Islanders and other Oceanic peoples'. The Solomon Islands Project: A Long Term Study of Health, Human Biology, and Culture Change, pp. 215-64. Friedlaender J. S. coord. Oxford: Oxford Science Publications.

Harrisson, Tom,

1937 Savage Civilisation. London: V. Gollancz Ltd.

Hasluck, Paul

1976 A Time for Building. Melbourne: Melbourne University Press. 


\section{Hempenstall, Peter J.}

1978 Pacific Islanders under German Rule: A Study in the Meaning of Colonial Resistance. Canberra: Australian National University Press.

\section{Henshaw, David}

1989 Black Consequences of Australia's White New Guinea Policy. Melbourne.

\section{Hide, Robin comp.}

2005 A Personal Bibliography of Bougainville. Unpublished MS, 48 pp. Copy held by R. Hide, Research School of Pacific and Asian Studies, Australian National University.

Hirsch, Philip with Beck, A.

1991 Asia Pacific Focus - People and Environment in Change. Brisbane: Jacaranda Press.

\section{Hobsbawm, Eric}

1995 Age of Extremes: The Short Twentieth Century 1914-1991. London: Abacus.

Hookey, J. F.

1969 'The Establishment of a Plantation Economy in the British Solomon Islands Protectorate'. The History of Melanesia, pp. 229-38. Second Waigani Seminar. Canberra and Port Moresby: Research School of Pacific Studies, Australian National University and University of Papua New Guinea.

\section{Horner, David}

1998 Blamey: The Commander-in-Chief. Sydney: Allen and Unwin.

Hughes, P. J. and Sullivan, M. E.

1992 The Environmental Effects of Mining and Petroleum Production in Papua New Guinea. University of Papua New Guinea Natural Resource Series, H. L. Davies, coord. Port Moresby: University of Papua New Guinea, 28 pp.

Hungerford, T. A. G.

1950 'The nun's patrol', Stand-To, August September

1952 The Ridge and the River. Sydney: Angus and Robertson

1985 Knockabout with a Slouch: An Autobiographical Collection 1942-1951, Perth: Fremantle Arts Centre Press.

IBRD see International Bank for Reconstruction and Development 


\section{Ignace, Sister}

1924? 'Memoires', [1899-1922]. Transcript, 8pp. Lebel Papers held at Monoitu, Bougainville: Papua New Guinea. [Notes held by Hugh Laracy, Auckland.]

\section{International Bank for Reconstruction and Development}

1965 The Economic Development of the Territory of Papua and New Guinea. Baltimore: International Bank for Reconstruction and Development.

Irwin, $\mathrm{G}$.

1972 An Archaeological Survey in the Shortland Islands, B.S.I.P. Unpublished MA thesis. University of Auckland.

1973 'Man-land relationships in Melanesia: an investigation of prehistoric settlement in the islands of the Bougainville Strait', Archaeology and Physical Anthropology in Oceania, 8, 3: pp. 226-52.

\section{Iwamoto, Hiromitsu}

1999 Nanshin: Japanese Settlers in Papua and New Guinea 1890-49. Canberra: Journal of Pacific History.

Jackson, Donald

1989 Torokina: A Wartime Memoir 1941-1945. Ames: Iowa State University.

Jobes, D. V., Friedlaender, J. S., Mgone, C. S., Koki, G., Alpers, M. P., Ryschkevitsch, C. F. and Stoner, G. L.

1999 'A novel JC virus variant found in the Highlands of Papua New Guinea has a 21-base pair deletion in the agnoprotein gene', J Hum Virology, 2, 6: pp. 350-8.

Jones, R. and Spriggs, M.

2002 'Theatrum Oceani: themes and arguments concerning the prehistory of Australia and the Pacific'. In Cunliffe, B., Davies, W. and Renfrew, C., eds. Archaeology: the Widening Debate, pp. $\mathrm{xx}-\mathrm{xxx}$. London: British Academy.

Journals of the Senate, see Australia. Parliament.

Kamboh, M. I., Friedlaender, J. S., Ahn, Y. I., Ferrell, R. E.

1994 'A common deletion polymorphism in the Apolipoprotein A4 gene and its significance in lipid metabolism', Arteriosclerosis and Thrombosis, 14, 5: pp. 656-62. 


\section{Kaplan, S.}

1976 'Ethnological and biographical significance of pottery sherds from Nissan Island, Papua New Guinea', Anthropology, 66, 3: pp. 35-89.

\section{Keil, Jared}

1975 Local Group Composition and Leadership in Buin. Unpublished PhD thesis. Harvard University, Boston.

1980 'Prescription and improper marriage: kin category, social group, and relationship terminology usage in Buin', Journal of Anthropological Research 36, 4 (Winter): pp. 501-16.

\section{Kenneth, Roselyne}

1994 Economic Development and Matrilineal Kinship among the Haku of Buka Island. Unpublished BA Hons minor thesis. University of Papua New Guinea.

\section{Kettle, Ellen}

1989 That They Might Live. Sydney: F.P. Leonard.

Kieta Patrol Reports, see Territory of New Guinea, Department of District Services and Native Affairs

\section{Kirch, P. V.}

1997 The Lapita Peoples: Ancestors of the Oceanic World. Oxford: Blackwell.

\section{Koch, Klaus-Friederich}

1983 (1979)

'Epilogue: Pacification: perspectives from conflict theory'. In Rodman, Margaret and Cooper, Matthew eds. The Pacification of Melanesia, pp. 199-207. Ann Arbor: University of Michigan Press.

\section{Krause, F.}

1906 'Zur Ethnologie der Insel Nissan', Jahrbuch des Stadtischen Museum für Völkerkunde zu Leipzig, 1: pp. 44-159.

\section{Laracy, $\mathrm{H}$.}

1976 Marists and Melanesians: A History of the Catholic Missions in the Solomon Islands. Canberra: Australian National University Press.

1991 'Bougainville secessionism', Journal de la Société des Océanistes, 92-93: pp. 53-59. 
1996 'James Hannan', Australian Dictionary of Biography, Vol. 14: p. 377.

Melbourne: Melbourne University Press.

1998a 'Emmet McHardy', Dictionary of New Zealand Biography, Vol. 4: p. 311.

Wellington: Allen \& Unwin, Department of Internal Affairs.

1998b 'Oceania: Centennial Thoughts' ('L'Oceanie: Cent Ans d'Histoire')

[published in both languages]. In Koster, Theo ed. Oceania Marist

Province, 1898-1998, pp. 17-22. Suva: Society of Mary, Oceania

Province.

1999 'Maine, Massachusetts and the Marists: American Catholic missionaries in the South Pacific', Catholic Historical Review, 85, 4 (October): pp. 566-90.

2000 'Saint-making: the case of Pierre Chanel of Futuna', New Zealand Journal of History, 34, 1 (April): pp. 145-61.

2002 'John Strasburg: a Plain Sailor'. Unpublished chapter held by Hugh Laracy, Auckland.

2005 'Patrick O’Reilly: bibliographer of the Pacific'. In Cropp, Glynnis ed. Pacific Journeys: essay in honour of John Dunmore. Wellington: [In Press.]

Lātūkefu, Sione ed.

1982. 'Triumph and Defeat at Roreinang — a Tonga mission in New Guinea'. In Crocombe, Ron and Marjorie eds. Polynesian Missions in Melanesia from Samoa, Cook Islands and Tonga to Papua New Guinea and New Caledonia, pp. 39-53. Suva: Institute of Pacific Studies, University of the South Pacific.

1989 Papua New Guinea: A Century of Colonial Impact 1884-1984, Port Moresby: National Research Institute and University of Papua New Guinea.

\section{Laycock, Donald C.}

1968 'Tiperau Unites the Tribes'. Transcipt. Story told by Raukai at Paarino Village, April 1968. Copy in possession of Hugh Laracy, Auckland, by courtesy of the late Donald C. Laycock.

1969 Sublanguages in Buin: Play, Poetry, and Preservation. Pacific Linguistics Series A - Occasional Papers. Papers in New Guinea Linguistics No. 10. Canberra: Research School of Pacific and Asian Studies, Australian National University.

2003 A Dictionary of Buin, a Language of Bougainville. Pacific Linguistics 537. Onishi, Masayuki, ed. Canberra: Research School of Pacific and Asian Studies, Australian National University. 


\section{Lemay, Leo}

1966a 'Catholic mission and present day problems of leases', Catholic News, Special Issue (September), pp. 1-3.

1966bLetter to Cleland, 16 August 1966. Reproduced in Laracy, H. 'Maine, Massachusetts and the Marists: American Catholic missionaries in the South Pacific', pp. 585-8, Catholic Historical Review, 85, 4 (October): pp. 566-90.

Levine, Hal B.

1999 'Reconstructing ethnicity', The Journal of the Royal Anthropological Institute, 5, 2: pp. 165-80.

\section{L'Estrange, T.}

n.d. 'The Marist Medical Mission League'. Transcript. In possession of H. Laracy, Auckland.

1956 Letter, T. L'Estrange to G. T. Roscoe, 24 January. Copy in possession of H. Laracy, Auckland.

1957 'Gallant educational efforts in the North Solomons', Harvest, October, pp. 36-9.

1958 'Education in the Northern Solomons', Catholic Missions, April: pp. 16-17.

\section{Lincoln, Peter}

1978 'Reef-Santa Cruz as Austronesian'. In Wurm, S. A. and Carrington, Lois eds. Second International Conference on Austronesian Linguistics: Proceedings, pp. 929-67. Pacific Linguistics, Series C, No.61. Canberra: Research School of Pacific and Asian Studies, Australian National University.

Little Sisters of Nazareth, Bougainville

2001 Constitution of the Sisters of Nazareth.

\section{Long, Gavin}

1963 The Final Campaigns. Australia in the War of 1939-1945. Canberra: Australian War Memorial.

\section{Lord, Walter A.}

1977 Lonely Vigil: Coastwatchers of the Solomons. New York: Viking.

\section{Lowie, Richard}

1954 'Richard Thurnwald, 18.9.1869 - 19.1.1954', Sociologus, 4, 1, pp. 2-5. 


\section{Loy, T. H., Spriggs M. and Wickler, S.}

1992 'Direct evidence for human use of plants 28,000 years ago: starch residues on stone artefacts from the Northern Solomon Islands', Antiquity, 66: pp. 898-912.

\section{Luxton, C. T. J.}

1955 Isles of Solomon: A Tale of Missionary Adventure. Auckland: Methodist Foreign Missionary Society of New Zealand.

\section{Lynch, John D.}

1981 'Melanesian diversity and Polynesian homogeneity: the other side of the coin', Oceanic Linguistics, 20: pp. 95-129.

Lyng, Jens,

1925 Island Films: Reminiscences of 'German New Guinea'. Sydney: Cornstalk Publishing Co.

\section{Maalouf, Amin}

2001 In the Name of Identity: Violence and the Need to Belong. New York: Arcade Publishing.

\section{McAlpine, J. R.}

1967 'Population and land use of Bougainville and Buka islands'. In Lands of Bougainville and Buka Islands, Papua-New Guinea. CSIRO Land Research Series No. 20: pp. 157-67. Canberra: CSIRO.

\section{McAlpine, J. R., and Quigley, J.}

n.d. 'Natural Resources, Land Use and Population Distribution of Papua New Guinea: Summary Statistics from PNGRIS’. PNGRIS Report No. 7. Canberra: Commonwealth Scientific and Industrial Research Organisation.

\section{Mackenzie, S. S.}

1927 The Australians at Rabaul: The Capture and Administration of the German Possessions in the Southern Pacific. The Official History of Australia in the War of 1914-1918, Vol. 10. Sydney: Angus and Robertson.

1987 The Australians at Rabaul: The Capture and Administration of the German Possessions in the Southern Pacific. O'Neill, Robert, Series ed. Foreword by Hank Nelson. Brisbane: University of Queensland Press in association with the Australian War Memorial. 


\section{MacWilliam, Scott}

1996 'Papua New Guinea in the 1940s: empire and legend'. In Lowe, David ed. Australia and the End of Empires: The Impact of Decolonisation in Australia's Near North, 1945-65, pp. 25-42. Geelong: Deakin University Press.

McCarthy, J. K.

1944 Appendix to Australian New Guinea Administration Unit War Diary, September. MS. Canberra: Australian War Memorial, AWM 52. 1/10/1.

1963 Patrol into Yesterday: My New Guinea Years. Melbourne: Cheshire.

McHardy, E.

1935 Blazing the Trail in the Solomons: Letters from the North Solomons. Sydney: Dominion.

\section{$\mathrm{McNab}$, Alexander}

1998 We Were the First: The Unit History of No. 1 Independent Company. Loftus: Australian Military History Publications.

\section{McPherson, Naomi M.}

2001 'Introduction'. In McPherson, Naomi M., ed. In Colonial New Guinea: Anthropological Perspectives, pp. 1-14. Pittsburgh: University of Pittsburgh Press.

Mair, L. P.

1948, 1970

Australia in New Guinea. London: Christophers; Melbourne: Melbourne University Press.

\section{Malinowski, Bronislaw}

1926 Crime and Custom in Savage Society. London: Routledge \& Kegan Paul.

Mamak, Alexander and Bedford, Richard with Hannett, Leo and Havini, Moses

1974 Bougainvillean Nationalism: Aspects of Unity and Discord. Bougainville Special Publication No.1, 88 pp. Christchurch: University of Canterbury.

\section{Mamak, Alexander and Bedford, Richard}

1979 'Bougainville Copper Mineworkers Strike, 1975'. In Mamak, Alexander and Ali, Ahmed eds. Race Class and Rebellion in the South Pacific, pp. 76-85. Sydney: George Allen and Unwin. 


\section{Mandated Territory of New Guinea}

1921-1940 Annual Reports.

\section{Mann, Max}

n.d. Account of Civilians Leaving Kieta. Canberra: Australian War Memorial, AWM 54, 183/5/2.

\section{Mason, Paul}

$1941-43$

Coastwatching in Bougainville 1941-43. Report. MS. National Archives of Australia, Victorian Office.

\section{Mathews, Russell}

1961 Militia Battalion at War: The History of the 58/59th Australian Infantry Battalion in the Second World War. Sydney: 58/59th Battalion Association.

\section{Mauro-Miraku, Joseph}

n.d. During My Time (Taim Bilong Mi). Privately published.

\section{May, R. J.}

1990 'Introduction: The ethnic factor in politics', Pacific Viewpoint, 31, 2: pp. $1-9$

1997 (Re?)Discovering Chiefs: Traditional Authority and the Restructuring of Locallevel Government in Papua New Guinea. Regime Change and Regime Maintenance in Asia and the Pacific. Discussion Paper No. 18, 36 pp. Canberra: Department of Political and Social Change, Research School of Pacific and Asian Studies, Australian National University.

\section{Medcalf, Peter}

1986 War in the Shadows: Bougainville 1944-45. Canberra: Australian War Memorial.

\section{Melk-Koch, Marion}

1989 Auf der Suche nach der Menschlichen Gesellschaft: Richard Thurnwald. Berlin: Dietrich Reimer Verlag.

1992 'Don Laycock - corrector antiquorum'. In Dutton, Tom, Ross, Malcolm and Tryon, Darrell eds. The Language Game: Papers in Memory of Donald C. Laycock, pp. 257-62. Pacific Linguistics Series C-110. Canberra: Research School of Pacific Studies, Australian National University. 
Merriwether, D. A., Friedlaender, J. S., Mediavilla, J., Mgone, C., Gentz, F., Ferrell, R. E.

1999 'Mitochondrial DNA variation as an indicator of Austronesian influence in Island Melanesia', American Journal of Physical Anthropology. Vol. 110: pp. 243-70.

Middlemiss, B. J. A.

1970 'Napidakoe Navitu'. In Ward, M. ed. The Politics of Melanesia, pp. 100-104. Papers of the Fourth Waigani Seminar. Canberra and Port Moresby: Australian National University and University of Papua New Guinea.

Miller, D.

1979 National Sites Survey. Summary Report. Honiara: National Museum.

\section{Miller, John Jnr}

1959 Cartwheel: The Reduction of Rabaul. United States Army in World War II. The War in the Pacific. Washington: Office of the Chief of Military History, Department of the Army.

\section{Mitchell, Donald D.}

1971 Gardening for Money and Agriculture in Nagovisi. Unpublished PhD thesis. Harvard University, Boston.

1976 Land and Agriculture in Nagovisi. Papua New Guinea Institute for Applied Social and Economic Research Monograph 3. Port Moresby and Canberra: Institute of Applied Social and Economic Research and Australian National University.

1982 'Frozen assets in Nagovisi', Oceania: 53, 1: pp. 57-65.

Mitchell, Jill see Nash, Jill

\section{Momis, John}

1989 'PNG's aim for increased finances on the run involves "Taming the Dragon"', International Times, 12 July: p. 19.

\section{Morauta, L.}

1974 Beyond the Village: Local Politics in Madang, Papua New Guinea. London: Athlone. 
Morison, S. E.

1975 History of the United States Naval Operations in World War II: Breaking the Bismarcks Barrier 22 July 1942-1 May 1944. Boston: Little Brown and Company.

\section{Mosko, M.}

1985 Quadripartite Structures: Categories, Relations, and Homologies in Bush Mekeo Culture. Cambridge: Cambridge University Press.

Mueller, A.

1972 'Notes on the Tulun or Carteret Islands', Journal of the Papua New Guinea Society, 6, 1: p. 78.

Nash, J.

1972 Aspects of Matriliny in Nagovisi Society. Unpublished PhD thesis. Harvard University, Boston.

1974 Matriliny and Modernisation: The Nagovisi of South Bougainville. New Guinea Research Bulletin No 55. Port Moresby and Canberra: New Guinea Research Unit and Australian National University.

1981 'Sex, money and the status of women in aboriginal South Bougainville', American Ethnologist, 8: pp. 107-26.

2001 'Paternalism, Progress, Paranoia: patrol reports and colonial history in south Bougainville'. In McPherson, Naomi ed. In Colonial New Guinea: Anthropological Perspectives, pp. 111-124. Pittsburgh: University of Pittsburgh Press.

\section{Nash, J. and Mitchell, D.}

1973 'A note on some chipped stone objects from South Bougainville', Journal of the Polynesian Society, 82, 2: pp. 209-12.

Nash, J., and Ogan, E.

1990 'The red and the black: Bougainville perceptions of other Papua New Guineans', Pacific Studies, 13, 2: pp. 1-17.

\section{National Government of Papua New Guinea}

1991 Bougainville Interim Authorities Act 1991.

\section{National Statistical Office, Port Moresby}

Census 2000. Rural Census Unit Register: North Solomons Province. Waigani, Port Moresby: National Statistics Office. 


\section{Nelson, Hank}

1978 'The swinging index: capital punishment and British and Australian administrations in Papua and New Guinea, 1888-1945', Journal of Pacific History, 13, 3: pp. 130-52.

1982 'The Japanese 1942-1945: A Note on the Scale of the Dying'. In May, R. and Nelson, H., eds. Melanesia Beyond Diversity, pp. 174-8. Canberra: Research School of Pacific Studies, Australian National University.

1992a 'Nelson - Tokidoro interview, 29 April' [transcript with H. Nelson, Canberra].

1992 b'The troops, the town and the battle: Rabaul 1942', Journal of Pacific History, 27, 2: pp. 198-216.

\section{Newbury, Colin}

1989 'Land, Labour, Capital and Colonial Government in New Guinea'. In Lātūkefu, Sione ed. Papua New Guinea: A Century of Colonial Impact 1884-1984, Port Moresby: National Research Institute and University of Papua New Guinea.

\section{New Guinea Infantry Battalion}

1 New Guinea Infantry Battalion records. Canberra: Australian War Memorial, AWM 54, 8/4/5.

NGPNG see National Government of Papua New Guinea.

\section{North Solomons Provincial Government}

1982 see Economic Consultants Ltd.

1988a North Solomons Provincial Government, 1988 Law and Order Report.

Arawa: North Solomons Provincial Government.

1988b Research Into the Establishment of Councils of Chiefs in the North Solomons Province. Arawa: North Solomons Provincial Government.

Norton, H. L., Friedlaender, J. S., Merriwether, D. A., Koki, G., Mgone, C. S., and Shriver M. D.

2004 Pigmentation Variation in Island Melanesia and Associated Candidate Gene Variation. 73rd Annual Meeting of the American Association of Physical Anthropologists, Tampa, Florida: American Journal of Physical Anthropology Special Meeting Issue. Abstracts. Held by the Association.

2005 'Skin and hair pigmentation variation in Island Melanesia', American Journal of Physical Anthropology. In Press. 
NSO see Papua New Guinea National Statistical Office, Port Moresby

NSPG see North Solomons Provincial Government

O'Callaghan, Mary-Louise

2002 'The Origins of the Conflict'. In Carl, Andy and Garasu, Sister Lorraine eds. 'Weaving consensus — The Papua New Guinea-Bougainville peace process', Accord: An International Review of Peace Initiatives, 12: pp. 6-11.

\section{Ogan, Eugene}

1965 'An election in Bougainville', Ethnology, 4, 4: pp. 397-407.

1970a 'The Nasioi vote again', Human Organization, 29: pp. 178-89.

1970b 'Nasioi pottery making', Journal of the Polynesian Society, 79, 1: pp. 86-90.

1972 Business and Cargo: Socio-Economic Change Among the Nasioi of

Bougainville. New Guinea Research Bulletin No. 44. Port Moresby and

Canberra: New Guinea Research Institute and Australian National

University.

1974 'Cargoism and politics in Bougainville 1962-74', Journal of Pacific History, 9: pp. 117-27.

1975 'Decolonising anthropology?' Meanjin Quarterly, 34, 3: pp. 328-36.

1986 'Taim bilong Sipak: Nasioi alcohol use 1962-78', Ethnology, 25, 1: pp. $21-3$

1992 'The cultural background to the Bougainville crisis', Journal de la Société des Océanistes, 92-93: pp. 61-7.

1996 'Copra came before copper: the Nasioi of Bougainville and plantation colonialism 1902-1964', Pacific Studies, 19, 1: pp. 31-51.

2001 'Afterword. An Anthropology of Colonialism of the "Last Unknown"'. In McPherson, Naomi ed. In Colonial New Guinea: Anthropological Perspectives, pp. 194-200. Pittsburgh: University of Pittsburgh Press.

Ogan, Eugene, Nash, Jill and Mitchell, Donald

1976 'Culture Change and Fertility in Two Bougainville Populations'. In Giles, E. and Friedlaender, J., eds. Measures of Man, pp. 533-49. Cambridge: Harvard University Press.

\section{Ogilvy, Harry Lord Spencer Balfour}

1917 Letter to Administrator, 7 June 1917. Western Pacific High Commission held at Auckland University, New Zealand. 


\section{Okole, Henry}

1990 'The Politics of the Panguna Landowners' Organization'. In May, R. J and Spriggs, Matthew eds. The Bougainville Crisis, pp. 16-24. Bathurst: Crawford House.

\section{Oliver, Douglas Lewellyn}

1943 'The Horomorum Concepts of Southern Bougainville: a study in comparative religion'. In Coon, C. S. and Andrews, J. M. eds. Studies in the Anthropology of Oceania and Asia, pp. 50-65. Peabody Museum Papers No. 20. Cambridge: Peabody Museum of American Archaeology and Ethnology, Harvard University.

1949 'The Peabody Museum expedition to Bougainville, Solomon Islands, 1938-39'. Studies in the Anthropology of Bougainville, Solomon Islands' Peabody Museum Papers Vol. xxix, No. 2: pp. 1-38, 'Human Relations and Language in a Papuan-speaking tribe of Southern Bougainville, Solomon Islands - an essay'. Cambridge: Peabody Museum of American Archaeology and Ethnology, Harvard University.

1955 A Solomon Island Society: Kinship and Leadership Among the Siuai of Bougainville. Cambridge: Harvard University Press.

1962; 1989

The Pacific Islands. Cambridge: Harvard University Press.

1968 'Southern Bougainville', Anthropological Forum, 2, 2 (November): pp. 158-179.

1971 'Southern Bougainville'. In Berndt, Ronald M. and Lawrence, Peter eds. Politics in New Guinea. Traditional and in the Context of Change: Some Anthropological Perspectives, pp. 276-97. Perth: University of Western Australia Press.

1973 Bougainville: A Personal History. Melbourne: Melbourne University Press.

1989 The Pacific Islands. 3rd edition. Hawai' i: University of Hawai'i Press.

1991 Black Islanders: A Personal Perspective of Bougainville 1937-1991. Melbourne: Hyland Press.

1993a 'Rivers (W. H. R.) revisited: matriliny in southern Bougainville. Part 1: Introduction, The Siwai, The Nagovisi', Pacific Studies 16, 3 (September): pp. $1-54$.

1993b 'Rivers (W. H. R.) revisited: matriliny in southern Bougainville. Part 2: The Nasioi, The Buin, Discussion', Pacific Studies, 16, 4 (December): pp. $1-40$. 
Omuru, E., Nailina, R., and Fleming, E. comps. and eds.

2001 A Socioeconomic Baseline Survey of Cocoa and Copra Smallholders in East New Britain. Occasional Paper 1, Understanding the Smallholder Cocoa and Coconut Sector in Papua New Guinea. Port Moresby: Papua New Guinea Cocoa and Coconut Research Institute and Armidale: University of New England.

Onishi, Masayuki, ed.

2003 'Preface' comp. and ed. of Laycock, Donald [deceased]. A Dictionary of Buin, a Language of Bougainville, pp. viii-ix. Pacific Linguistics, 537. Canberra: Research School of Pacific and Asian Studies, Australian National University.

O'Reilly, Patrick and Sédès, Jean-Marie

1949 Jaunes, Noirs et Blancs: Trois Annees de Guerre aux Iles Salomon. Paris: Monde Nouveau.

\section{Oruka, H. Odera}

1981 'Rawl's Ideological Affinity and Justice as Egalitarian Fairness'. In Ericsson, Lars, O. et al., eds. Justice, Social and Global. Papers Presented at the Stockholm International Symposium on Justice, 1978: pp. 80-7. Stockholm: Akademilitteratur.

Page, R. W., and McDougall, I.

1972 'Geochronology of the Panguna porphyry copper deposit, Bougainville Island, Papua New Guinea', Economic Geology, 67: pp. 1065-74.

\section{Papua and New Guinea Parliament}

House of Assembly Debates, 1 August 1965, 4, 14 June 1966.

House of Assembly, Parliamentary Papers, November 1966, June 1969.

\section{Papua New Guinea National Statistical Office}

2000 National Population Census 2000. Port Moresby: Papua New Guinea National Statistical Office.

\section{Papuan Infantry Battalion}

1945 War Diary, 4 June, 9 August. MS. Canberra: Australian War Memorial. 
Parker, R. S.

1971 'Economics before politics, a colonial phantasy', Australian Journal of Politics and History, 17, 2: pp. 202-14.

\section{Parkinson, R.}

1907 Dreißig Jahre in der Südsee. Stuttgart: Strecker and Schröder

1999 Dreißig Jahre in der Südsee: Thirty Years in the South Seas: Land and People, Customs and Traditions in the Bismarck Archipelago and on the German Solomon Islands. Dennison, John trans. Bathurst: Crawford House Publications.

Parliamentary Papers, see Papua New Guinea Parliament, House of Assembly.

Parliament of Australia, see Australia

Patrol Reports, Bougainville District, see Territory of New Guinea, Department of District Services and Native Affairs.

\section{Pawley, Andrew}

1981 'Melanesian Diversity and Polynesian Homogeneity: a unified explanation for language'. In Hollyman, Jim and Pawley, Andrew eds, Studies in Pacific Languages and Cultures in Honour of Bruce Biggs, pp. 269-309. Auckland: Linguistic Society of New Zealand.

1998 'The Trans New Guinea Phylum Hypothesis: a reassessment'. In Miedema, Jelle, Odé, Cecilia and Dam, Rien A. C. eds. Perspectives on the Bird's Head of Irian Jaya, Indonesia, pp. 655-90. Amsterdam and Atlanta: GA; Rodopi.

Pels, Peter and Salemink, Oscar eds

2000 Colonial Subjects: Essays on the Practical History of Anthropology. Ann Arbor: University of Michigan Press.

Perry, W. J.

1914 'An analysis of the genealogical tables collected by Dr Richard Thurnwald in Buin', Anthropos, 9: pp. 801-11.

Petersen, G.

1999 'Sociopolitical rank and conical clanship in the Caroline Islands', Journal of the Polynesian Society, 108, 4: pp. 367-410. 
Phillips, [Judge] B. M.

1929 Report of the Commissioner Appointed to Inquire into Mission Policies and Activities Affecting the Maintenance of Peace and Good Order in the District of Kieta. Canberra; National Archives of Australia.

\section{Pinney, Peter}

1952 Road in the Wilderness. Brisbane: University of Queensland Press.

1990 The Glass Cannon: A Bougainville Diary 1944-45. Brisbane: Univesity of Queensland Press.

1992 The Devil's Garden: Solomon Islands War Diary, 1945. Brisbane: University of Queensland Press.

\section{Poncelet, Jean-Baptiste}

1918-24

Journal, MS. Copy in H. Laracy's possession, Auckland.

1924 'Notes sur la Station de Buin', 12 September. MS. Rome: Archivio Padri Maristi, O’Reilly Papers; MS copies. Canberra: Pacific Manuscripts Bureau, Research School of Pacific and Asian Studies, The Australian National University, 4 (MSS series).

\section{Pourhosseini, S. M.}

1995 Economic Activity, Jobs and Incomes in Bougainville. Unpublished report sponsored by Department of Finance, Port Moresby, with support of International Labor Organization and United Nations Development Project.

\section{Quodling, Paul}

1991 Bougainville, the mine and the people. Pacific Papers 3. Sydney: Centre for Independent Studies.

\section{Ravuvu, Asesela}

1974 Fijians at War. Suva: South Pacific Social Sciences Association.

Read, W. J.

1941-43

Report on Coastwatching Bougainville Island 1941-43. MS. Melbourne: National Archives of Australia, Victorian Office.

\section{Rechinger, Karl and Rechinger, Lily}

1908 Streifzüge in Deutsch-Neuguinea und auf den Salomons Inseln. Berlin:

Dietrich Reimer. 


\section{Regan, Anthony J.}

1995 Strengthening Traditional Authority and the Struggle for Power in Bougainville, Papua New Guinea. Unpublished MS. Held by the author, Canberra.

1998 'Causes and course of the Bougainville conflict', Journal of Pacific History, 33, 3, pp. 269-85.

1999 'Bougainville: the peace process and beyond'. Submission to the Foreign Affairs Sub-Committee of the Joint Standing Committee of Foreign Affairs, Defence and Trade Inquiry. http://rspas.anu.edu.au/melanesia/ajregan2.htm

2000 'Traditional Leaders and Conflict Resolution in Bougainville: reforming the present by rewriting the past?' In Dinnen, S. and Ley, A., eds. Reflections on Violence in Melanesia, pp. 290-304. Sydney: Hawkins Press and Canberra: Asia and Pacific Press.

2002a 'Why a Neutral Peace Monitoring Force?' The Bougainville conflict and the peace process'. In Wehner, Monica and Denoon, Donald eds. Without a Gun: Australia's Experience of Monitoring Peace in Bougainville, 1997-2001, pp. 1-18. Canberra: Pandanus Books.

2002b 'Bougainville: beyond survival', Cultural Survival Quarterly, 26, 3: pp. 20-4.

2003 'The Bougainville conflict: political and economic agendas'. In Ballentine, Karen and Sherman, Jake eds, The Political Economy of Armed Conflict: Beyond Greed \& Grievance, pp. 133-66. Boulder: Lynne Rienner Publishers.

\section{Reuter, T.}

1993 'Precedence in Sumatra: an analysis of the construction of status in affinal relations and origin groups', Bijdragen tot de Taal-Land-en-Volkenkunde, 148, pp. 489-520.

Rhoads, J. G.

1987 'Anthropometry'. The Solomon Islands Project: A Long Term Study of Health, Human Biology, and Culture Change, pp. 155-74. Friedlaender J. S. coord. Oxford: Oxford Science Publications.

Rhoads, J. G. and Friedlaender, J. S.

1975 'Language boundaries and biological differentiation of Bougainville: multivariate analysis of variance', Proceedings of the National Academy of Science of the USA, 72, 6: pp. 2247-50.

\section{Ribbe, Carl}

1903 Zwei Jahre unter den Kannibalen der Salomo-Inseln. Reiseerlebnisse und Schilderungen von Land und Leuten. Dresden: Hermann Beyer. 


\section{Riddell, Jack}

1992 Catalina Squadrons First and Furthest: Recounting the Operations of RAAF Catalinas May 1941 to March 1943. Privately published.

\section{Rimoldi, M.}

1971 The Hahalis Welfare Society of Buka. Unpublished PhD thesis. Australian National University, Canberra.

Rimoldi, M. and Rimoldi, E.

1992 Hahalis and the Labour of Love: A Social Movement on Buka Island. Oxford: Berg.

Robertson, John and McCarthy, John

1985 Australian War Strategy 1939-1945: A Documentary History. Brisbane: University of Queensland Press.

Robledo, R., Scheinfeldt, L., Merriwether, D. A., Thompson, F., and Friedlaender, $\mathrm{J}$.

2003 'A $9.1 \mathrm{~kb}$ insertion/deletion polymorphism suggests a common pattern of genetic diversity in island Melanesia', Human Biology. December.

Rogerson, R. J., Hilyard, D. B., Finlayson, E. J., Johnson, R. W., McKee C. O. and other contributors

1989 The Geology and Mineral Resources of Bougainville and Buka Islands, Papua New Guinea. Memoir 16. Geological Survey of Papua New Guinea, 217 pp. Port Moresby.

\section{Romilly, Hugh Hastings}

1887 The Western Pacific and New Guinea. London: J. Murray.

\section{Ross, J. M. S.}

1955 Official History of New Zealand in the Second World War 1939-45: Royal New Zealand Air Force, pp. 180-217. Wellington: War History Branch, Department of Internal Affairs.

\section{Ross, Malcolm D.}

1988 Proto Oceanic and the Austronesian Languages of Western Melanesia. Pacific Linguistics, Series C, No. 98. Canberra: Research School of Pacific and Asian Studies, Australian National University. 
1994 'Areal Phonological Features in North-Central New Ireland'. In Dutton, T. E. and Tryon, D. T. eds. Language Contact and Change in the Austronesian World, pp. 551-72. Berlin: Mouton de Gruyter.

1996 'Contact-Induced Change and the Comparative Method: cases from Papua New Guinea'. In Durie, Mark and Ross, Malcolm D., eds, The Comparative Method Reviewed: Irregularity and Regularity in Linguistic Change, pp. 180-217. New York: Oxford University Press.

2000 'Is there an East Papuan Phylum? Evidence from pronouns'. In Pawley, Andrew, Ross, Malcolm and Tryon, Darrell eds, The Boy from Bundaberg: Studies in Melanesian Linguistics in Honour of Tom Dutton, pp. 301-21. Canberra: Pacific Linguistics, Research School of Pacific and Asian Studies, Australian National University.

Rowley, C. D.

1958 The Australians in German New Guinea, 1914-1921. Melbourne: Melbourne University Press.

\section{Ryan, John}

1970 The Hot Land: Focus on New Guinea. Melbourne: Macmillan.

Ryschkewitsch, C. F. and Friedlaender, J. S. Mgone, C. S., Jobes, D. Agostini, H., Chima, M. P., Koki, G., Yanagihara, R., and Stoner, G. L.

2000 'Human polyomavirus JC variants in Papua New Guinea and Guam reflect ancient population settlement and viral evolution', Microbes Infect, 2, 9: pp. 987-96.

\section{Sabin, E. M.}

1988 Traditions and Customary Law and the Council of Chiefs System: Research into the Establishment of Councils of Chiefs and the Traditions and Customary Law. Port Moresby: University of Papua New Guinea.

\section{Sack, Peter}

1973 Land Between Two Laws. Canberra: Australian National University Press.

2000 'German Administration in Bougainville and Bougainville in the German records'. Paper presented at Bougainville: change and identities, division and integration; The Australian National University, 10-12 August, 2004.

2001 Phantom History, the Rule of Law and the Colonial State: The Case of German New Guinea. Canberra: Research School of Pacific and Asian History, Australian National University. 
2004 'Who Wants to Know What "Really" Happened? "King" Gorai and the Population Decline in the Shortland Islands?' Unpublished paper held by the author, Canberra.

Sack, Peter ed.

1980 German New Guinea. A Bibliography. Canberra: Department of Law and Social Sciences, Research School of Pacific and Asian Studies, Australian National University.

Sack, Peter and Sack Bridget compilers, eds and trans

1975 The Land Law in German New Guinea. A Collection of Documents. Canberra: Department of Law and Social Sciences, Research School of Pacific and Asian Studies, Australian National University.

Sack, P. and Clark, D., eds. and trans. [official govt. reports published under the editors' names; so also 1979, 1980 below]

1979 German New Guinea: The Annual Reports. Canberra: Australian National University Press.

1980 German New Guinea: The Draft Annual Report for 1913-14, Canberra: Australian National University Press.

Sahlins, M. D.

1963 'Poor man, rich man, big-man, chief: political types in Melanesia and Polynesia', Comparative Studies in Society and History, 5: pp. 285-303.

\section{Saovana-Spriggs, Ruth}

2003 'Bougainville Women's Role in Conflict Resolution'. In Dinnen, Sinclair ed. A Kind of Mending. Restorative Justice in the Pacific Islands, pp. 195-213. Canberra: Pandanus Books.

\section{Sarei, Alexis}

1974 Traditional Marriage and the Impact of Christianity on the Solos of Buka Island. New Guinea Research Bulletin, No. 57. Port Moresby and Canberra: Papua New Guinea Research Unit and Australian National University.

\section{Scaglion, R.}

1979 'Formal and informal operations of a village court in Maprik', Melanesian Law Journal, 7: pp. 116-29. 


\section{Schacht, Ted}

1990 My War on Bougainville: Under the Southern Cross. Loftus: Military History Publications.

\section{Schnee, Heinrich}

1904 Bilder der Südsee. Unter den Kannibalischen Stämmen des Bismarck-Archipel. Berlin: D. Reimer.

\section{Scott, R.M.}

1967 Lands of Bougainville and Buka Islands, Territory of Papua and New Guinea. Lands Research Series, No. 20. Canberra: Commonwealth Scientific and Industrial Research Organisation. 184 pp.

Scragg, R. F. R.

1957 Depopulation in New Ireland: A Study of Demography and Fertility. Port Moresby: Administration of Territory of Papua and New Guinea.

Senate, Parliament of Australia

1922 'Report on the claims of Captain J. Strasburg for a war gratuity', Journals of the Senate, Parliament of Australia, S.1.

Service, E. R.

1975 Origins of the State and Civilization: the Process of Cultural Evolution. New York: Norton.

\section{Sharp, Andrew}

1960 The Discovery of the Pacific Islands. Oxford: Oxford University Press.

\section{Sharp, Andrew ed.}

1968 The Voyages of Abel Janszoon Tasman. London: Clarendon Press.

Shaw, H. I. and Kane, D. T.

1963 Isolation of Rabaul. History of U.S. Marine Corps Operations in World War II, Vol. 2. Washington: Historical Branch, G-3 Division, Headquarters, United States Marine Corps.

Shoffner, R. K.

1976 The Economic and Cultural Ecology of Teop: An Analysis of the Fishing, Gardening, and Cash-cropping System in a Melaneisan Society. Unpublished $\mathrm{PhD}$ thesis, University of Hawai'i. 


\section{Sillitoe, Paul}

1998 An Introductiion to the Anthropology of Melanesia: Culture and Tradition, Cambridge: Cambridge University Press.

\section{Sinclair, James}

1984 Uniting a Nation: the Postal and Telecommunication Services of Papua New Guinea. Melbourne: Oxford University Press.

\section{Smith, Adam}

1978 The Wealth of Nations. Harmondsworth, England: Penguin Books.

\section{Smith, Tony}

2004 Development and Indigenous Accumulation in the Kimberley Region, Western Australia. Unpublished PhD thesis. Nepean: School of Economics and Finance, University of Western Sydney.

Smith, W. H. F and Sandwell, D. T.

1997 'Global seafloor topography from satellite altimetry and ship depth soundings', Science, 277 (26 September): pp. 1957-62.

Sokal, R. and Friedlaender, J.

1982 'Spatial Autocorrelation Analysis of Biological Variation on Bougainville Island'. In Crawford, M. H. and Mileke, J. H., eds. Current Developments in Anthropological Genetics. Plenum. 2: pp. 205-28.

\section{Somare, M.}

1975 Sana: An Autobiography. Port Moresby: Niugini Press.

1991 'Melanesian leadership'. In Proceedings of the XVII Pacific Science Congress, May 27-June 2. Honolulu: University of Hawaìi Press.

\section{Souter, Gavin}

1963 New Guinea: the Last Unknown. New York: Taplinger.

\section{Specht, J. R.}

1969 Prehistoric and Modern Pottery Industries of Buka Island, T.P.N.G. Unpublished PhD thesis. Australian National University, Canberra.

1974 'Of menak and men: trade and the distribution of resources on Buka Island, Papua New Guinea', Ethnology, 13, 3: pp. 225-37. 


\section{Spriggs, M.}

1991 'Nissan: the Island in the Middle'. In Allen, J. and Gosden, C. eds. Report of the Lapita Homeland Project. Occasional Papers in Prehistory, pp. 222-43. No. 20. Canberra: Department of Prehistory, Research School of Pacific and Asian Studies, Australian National University.

1992a 'Archaeological and Linguistic Prehistory in the North Solomons'. In Dutton, Tom, Ross, Malcolm and Tryon, Darrell eds. The Language Game: Papers in Memory of Donald C. Laycock, pp. 417-26. Canberra:

Department of Linguistics, Research School of Asian and Pacific Studies, Australian National University.

1992b 'Alternative prehistories for Bougainville: regional, national or micronational', Contemporary Pacific, 4, 2: pp. 269-98.

1997 The Island Melanesians. Oxford and Cambridge: Blackwell.

Spriggs, Ruth see Saovana-Spriggs

\section{Stuart, Robert}

1977 Nuts to You! Sydney: Wentworth Books.

Südsee Handbuch, in English, see Commonwealth Government of Australia.

Summerhayes, G. R.

2001a 'Defining the Chronology of Lapita in the Bismarck Archipelago'. In Clark, G. R., Anderson, A. J. and Vunidilo, T., eds. The Archaeology of Lapita Dispersal in Oceania, pp. 25-38. Terra Australis 17. Canberra: Pandanus Books.

2001b 'Lapita in the far west: recent developments', Archaeology in Oceania, 36: pp. 53-64.

\section{Swainson, Nicola}

1980 The Development of Corporate Capitalism in Kenya 1918-1977. London: Heinemann.

Sweeting, A. J.

1970 'Civilian Wartime Experience in the Territories of Papua and New Guinea'. Appendix in Hasluck, P., ed. The Government and the People 1942-1945. Appendix 2, Vol. 2 in Series Four (Civil) of Australia in the War of 1939-1945. Canberra: Australian War Memorial.

\section{Tappenbeck, Ernst}

1901 Deutsch Neu-Guinea. Berlin: Wilhelm Süsserot. 
Tatsiua, Elizabeth comp.

1984 Bibliography of North Solomons Province. Multiple copies printed by North Solomons Provincial Government Library. Copy held by A. J. Regan and J. and H. Griffin, Canberra.

\section{Terrell, John}

1976 Perspectives on the Prehistory of Bougainville Island, Papua New Guinea: a Study in the Human Biogeography of the Southwestern Pacific. Unpublished $\mathrm{PhD}$ thesis. Harvard University, Boston.

1978a 'Archaeology and the origins of stratification in southern Bougainville'.

Publications de la Société des Océanistes, 39: pp. 23-43.

1978b 'A microcosm of diversity', Australian Natural History, 19, 7: pp. 246-9.

1986 Prehistory in the Pacific Islands. Cambridge: Cambridge University Press.

Terrell, J. and Irwin, G.

1972 'History and tradition in the Northern Solomons: an analytical study of the Torau migration to southern Bougainville in the 1860s', Journal of the Polynesian Society, 81: pp. 317-49.

\section{Territory of New Guinea}

1923-40

Annual Report. Melbourne: Australian Government Publishing Service. $1947-56$

Bougainville District Patrol Reports (Department of District Services and Native Affairs), held in Port Moresby: Papua New Guinea National Archives and Records Service; Canberra: Australian National Archives; Australian National Library; Menzies Library, The Australian National University.

\section{Thomas, E. L. Gordon}

1914 Letter to Colonial Office, 16 January. Auckland: Western Pacific High Commission Archives (University of Auckland).

\section{Thomson, H. A. trans.}

1901-13

German New Guinea Annual Reports. Transcript. Canberra: National Library of Australia.

Thompson, Herb and MacWilliam, Scott

1992 The Political Economy of Papua New Guinea: Critical Essays. Manila and Wollongong: Journal of Contemporary Asia Press. 
Thompson, J. E.

1962 The Pumkuna Copper-Gold Prospect, Bougainville Island, TPNG. Bureau of Mineral Resources, Australia, Record 1962/39.

Thorne, A. and Raymond, R.

1989 Man on the Rim: the Peopling of the Pacific. Sydney: Angus and Robertson.

\section{Thorpe, Ken}

1996 My Wartime Story, Gundaroo, New South Wales: Brolga Press.

\section{Thurnwald, Hilde}

1934 'Woman's status in Buin society', Oceania 5, 2 (December): pp. 142-70.

1937 Menschen der Südsee. Stuttgart: Ferdinand Enke.

1938 'Ehe und Mutterschaft in Buin (Bougainville, Salomo-Archipel)' [Marriage and Motherhood in Buin. (Solomons Archipelago)] Archiv für Anthropologie und Völkerforschung, 24: pp. 214-46.

Thurnwald, Richard C.

1908 'Nachrichten aus Nissan und von den Karolinen', Zeitschrift für Ethnologie, 42: pp. 106-15.

1909 'Reisebericht aus Buin und Kieta', Zeitschrift für Ethnologie, 41: pp. 512-31.

1910a 'Im Bismarck Archipel und auf den Salomo-Inseln 1906-1909', Zeitschrift für Ethnologie, 42: pp. 100-47.

1910b 'Die eingeborenen Arbeitskräfte im Südseeschutzgebiet' [The Indigenous Labour Force in the South Seas Protectorate], Koloniale Rundschau: pp. 607-32.

1912 Forschungen auf den Salomo-Inseln und dem Bismarck-Archipel. Band I: Lieder und Sagen aus Buin. Band 3: Volk, Staat und Wirtschaft. Berlin: Dietrich Reimer.

1934a 'Some traits of Society in Melanesia'. Proceedings of the Fifth Pacific Science Congress Volume IV (Canada, 1933), pp. 2805-14. Toronto: University of Toronto Press.

1934 b 'Pigs and currency in Buin', Oceania, 5, 2 (December): pp. 119-41.

1936a 'Studying savages in Melanesia', The Yale Review, 26, 2 (December): pp. 313-32.

1936b 'The price of the White Man's peace', Pacific Affairs, 9, 3 (September): pp. 347-57.

1936c 'Profane literature of Buin, Solomon Islands', Yale University Publications in Anthropology, 8: pp. 3-15.

1951 'Historical sequences on Bougainville', American Anthropologist, 53: pp. 137-9. 
TNG see Territory of New Guinea

Toborua, A.

1967 'Memories of J. H. L. Waterhouse', Papua and New Guinea Journal of Education, 5, 1 (May): pp. 9-42.

Tryon, D. T., ed.

1995 Comparative Austronesian Dictionary. Berlin: Mouton de Gruyter.

Tsibin, D.

1966 'The Bougainville affair', New Guinea, December-January: pp. 33-5.

United States Geological Survey: http://neic.usgs.gov. [Used by Davies this volume.]

Van de Veur, Paul W.

1966 Search for New Guinea's Boundaries. From Torres Strait to the Pacific.

Canberra: Australian National University Press.

Vedder, J. G. and Bruns, T. R.

1989 The Geology and Offshore Resources of Pacific Islands Arcs. Earth Science Series 12 - Solomon Islands and Bougainville. Tulsa: The Circum-Pacific Council for Energy and Mineral Resources.

Waddell, J. R. E.

1975 Local Government Councils in Papua New Guinea: Policy and Practice, with Particular Reference to the Mount Hagen and Sumgilbar Local Government Councils. Unpublished PhD thesis. University of Papua New Guinea.

Wade, Thomas

1931 Saints and Savages [Marist Mission film, produced by Thomas Wade, filmed by Emmett McHardy, copy in New Zealand Film Archives, Wellington and Marist Fathers, New Zealand Province, Wellington].

Wallis, H., ed.

1965 Carteret's Voyage Round the World, 1766-1769. Cambridge: Cambridge University Press, for the Hakluyt Society.

War Cabinet. Commonwealth Government of Australia

1941 Evacuation of Women and Children. Decision 13 March and June. Canberra: National Archives of Australia. 


\section{Wassman, Jurg,}

1995 Historical Atlas of Ethnic and Linguistic Groups in Papua New Guinea. Basel: University of Basel

Waterhouse, J. H. L.

1931 'The Kazukurul language of New Georgia' (sounds communicated in notes by S. H. Ray), Man, 31, 131-158: pp. 123-6.

\section{Wendland, Wilhelm}

1939 Im Wunderland der Papua: ein deutscher Kolonialarzt erlebt die Sudsee. Berlin.

\section{Wesley-Smith, Terence}

1992 'Development and crisis in Bougainville: a bibliographic essay', Contemporary Pacific, 4, 2: pp. 408-32.

\section{West, Francis J.}

1966 'The Historical Background'. In Fisk, E. K., ed. New Guinea on the Threshold. Aspects of Social, Political and Economic Development. Canberra: The Australian National University.

Westermark, G.

1914 Letter to Western Pacific High Commission, 2 July 1914. Auckland: Western Pacific High Commission, University of Auckland.

\section{Wheeler, Gerald Camden}

1914 'Totemismus in Buim (Süd-Bougainville)', Zeitschrift für Ethnologie, 46: pp. $41-4$.

1926 Mono-Alu Folklore (Bougainville Strait, Western Solomon Islands). London: Routledge.

\section{White, Geoffrey M.}

1992 'The discourse of chiefs: notes on a Melanesian society', Contemporary Pacific, 4: pp. 73-108.

Whittaker, J. L., Gash, N. G., Hookey, J. F. and Lacey, R. J.

1975 Documents and Readings in New Guinea Histor: Prehistory to 1889. Brisbane: Jacaranda Press. 


\section{Wickler, S.}

1990. 'Prehistoric Melanesian exchange and interaction: recent evidence from the northern Solomon Islands', Asian Perspectives, 29: pp. 135-54.

1995 Thirty Thousand Years on Buka. Unpublished PhD thesis. University of Hawai'i.

2001 'The Prehistory of Buka: A Stepping Stone Island in the Northern Solomons. In Department of Archaeology and Natural History, Research School of Pacific Studies, and Centre for Archaeological Research, Australian National University, Terra Australis, 16

2003 The Prehistory of Buka: A Stepping Stone Island in the Northern Solomons. Department of Archaeology and Natural History, Research School of Pacific Studies, and Centre for Archaeological Research, Australian National University, Terra Australis Series, 16.

Wickler, S. and Spriggs, M.

1988 'Pleistocene human occupation of the Solomon Islands, Melanesia', Antiquity, 62: pp. 703-06.

\section{Wigmore, Lionel}

1963 They Dared Mightily. Canberra: Australian War Memorial.

\section{Williams, Ronald}

1972 The United Church in Papua, New Guinea and the Solomon Islands. Rabaul: Trinity Press.

\section{Woodford, Charles}

1913 Letter to Colonial Office, 16 May 1913. Auckland: Western Pacific High Commission, University of Auckland, CO222/119 (2), microfilm reel 2938, p. 534.

1914 Letter to Western Pacific High Commission, 2 July 1914, Auckland: Western Pacific High Commission archives, University of Auckland, WPHC 4, 1911/1914.

\section{Worsley, Peter}

1968 The Trumpet Shall Sound: A Study of 'Cargo Cults' in Melanesia. London: McGibbon and Kee. 


\section{Wright, Huntley}

1999 State Practice and Rural Smallholder Production: Late-Colonialism and the Agrarian Doctrine of Development in Papua New Guinea, 1942-69.

Unpublished $\mathrm{PhD}$ thesis. Palmerston: Massey University.

\section{Wurm, Stephen A.}

1975 'New Guinea Area Languages and Language Study'. In Wurm, S., ed. New Guinea Area Languages and Languages Study pp. 299-322. Vol. 1. Papuan Languages and the New Guinea Linguistic Scene. Pacific Linguistics, Series C, No. 38. Canberra: Research School of Pacific and Asian Studies, Australian National University.

1978 'Reefs-Santa Cruz: Austronesian'. In Wurm, S. A. and Carrington, Lois eds. Second International Conference on Austronesian Linguistics: Proceedings, pp. 969-1010. Pacific Linguistics, Series C, No.61. Canberra: Research School of Pacific and Asian Studies, Australian National University.

\section{Wurm, Stephen and Shiro Hattori}

1981-83

Language Atlas of the Pacific Area. Pacific Linguistics, Series C, Nos. 66-67. Canberra: The Australian Academy of the Humanities in collaboration with the Japan Academy.

Wurm, S. Voorhoeven, C. L. and McElhanon, K.

1975 'The Trans-New Guinea Phylum in General'. In Wurm, S., ed. New Guinea Area Languages and Language Study. Vol. 1. Papuan Languages and the New Guinea Linguistic Scene. Pacific Linguistics, Series C, No. 38. Canberra: Research School of Pacific and Asian Studies, Australian National University.

Yanagihara, R., Nerurkar, V. R., Scheirich, I., Agostini, H. T., Mgone, C. S., Cui, X,. Jobes, D. V., Cubitt, C. L., Ryschkewitsch, C. F., Hrdy, D. B., Friedlaender, J. S., and Stoner, G.

2002 'JC virus genotypes in the western Pacific suggest Asian mainland relationships and virus association with early population movements', Human Biology, 74, 3: pp. 473-88. 


\section{B: Newspapers and Journals in General}

Acta [Societatis Mariae] (Rome)

Advocate (Melbourne).

AB: Amstblatt für Neuguinea

Australian Financial Review

Catholic Leader (Brisbane)

Catholic Missions (Sydney); see also Sol Mons

Catholic News (North Solomons Catholic Vicariate/Diocese)

CRA Gazette

Deutsches Kolonialblatt (DKB)

Dialogue

Government Gazette (British Administration — German New Guinea)

Hamburger Echo

Kreuz und Charitas [German Marist Mission Journal]

Link (Honiara)

Nachrichten aus Kaiser Wilhelmsland (NKW)

National (Port Moresby)

Official Handbook of the Territory of New Guinea

Pacific Islands Year Book

PIM: Pacific Islands Monthly 
Post Courier (Port Moresby)

Sol Mons [acronym for Services of Lay Missionaries on North Solomons] 1965-66. A quarterly publication, its first issue (March 1965) was titled Bougainville News and the last (September 1966), a special issue, was titled Catholic News. There were seven issues in all.

\section{Archives and Repositories}

\section{AWM: Australian War Memorial [Archives]}

\section{NAA: National Archives of Australia}

1915-21 includes CRS, A457, 710/3/-. The account of Australian activity in Bougainville is drawn mainly from documents in this file, complemented from others in Western Pacific High Commission, 1916-17; and Prime Minister's Department A452

National Archives and Records Service of Papua New Guinea, Port Moresby 1946-55 BDPR (Bougainville District Patrol Reports) 1947-48 DDA (Department of District Administration) Annual Report

NLA: National Library of Australia

E. W. P. Chinnery Papers, MS 766.

NBAC: Noel Butlin Archives Centre. Acton, Canberra Burns Philp Papers, NM 115/156

PMB: Pacific Manuscripts Bureau Canberra: Department of South East Asian and Pacific History, Research School of Pacific and Asian Studies, Australian National University PMB 4 Roman Catholic Church, North Solomon Islands, 1900-40 includes Patrick O’Reilly Papers PMB 600 Gordon Thomas Papers PMB 1184 Fred Archer Papers PMB 1210 Deutsche Handels-Und-Plantagen Gesellschaft

WPHC: Western Pacific High Commission records Auckland University 1916-17 includes WPHC 4, 3251/1917. Documents in this file complement those in NAA 1915-21. 


\section{THE AUTHORS}

\section{Davies, Hugh}

Hugh Davies earned his first degrees at the University of Western Australia and a $\mathrm{PhD}$ from Stanford University, California. He has worked in Papua New Guinea since 1957 as a government geologist and since late 1989 as Professor of Geology at the University of Papua New Guinea. He has published on various aspects of Papua New Guinea and southwest Pacific geology and in the last decade has become increasingly involved in natural disaster research and response.

\section{Elder, Peter}

Peter Elder is a visiting fellow in the Department of Political and Social Change, Research School of Pacific and Asian Studies, The Australian National University, Canberra. Since 2000 he has been engaged in the collection of press reports made during the Bougainville conflict from 1988 and peace process from 1997. $\mathrm{He}$ is a graduate of the ANU (1979) and has a PhD from the Northern Territory University (now Charles Darwin University) (1999).

\section{Friedlaender, Jonathan}

Beginning in 1966, Jonathan Friedlaender has been involved in numerous surveys of genetic diversity that focus on Bougainville, but also include the Bismarcks and Solomon Islands. His work has emphasised both the ancient distinctiveness of Bougainville people, as well as the unexpected diversity among different Bougainville groups. He was educated at Harvard University, and teaches at Temple University.

\section{Griffin, Helga}

Helga Griffin graduated BA at the University of Papua New Guinea (1975) and in the Honours History program of James Cook University of North Queensland (1984) and obtained a graduate Dip. Ed. at the Canberra College of Advanced Education (1987). She was on the research and editorial staff of the Australian Dictionary of Biography at The Australian National University (1979-98). Her interest in Bougainville's history and ethnography spans 33 years.

\section{Griffin, James}

James Griffin, a graduate of the University of Melbourne, was appointed to the University of Papua New Guinea's History Department (1968-75). He returned to that university as Professor of Extension Studies (1981-4) and Professor of 
History (1988-90) and was appointed Emeritus Professor (1991). In 1980-1 and 1984-6 he was Senior Research Fellow in Pacific History at the Australian National University. He has published widely on Papua New Guinea and Australian history, politics and education.

\section{Keil, Jared}

Jared Keil is an Associate Professor in the Department of Sociology and Anthropology and the Institute of Political Economy at Carleton University, Ottawa, Canada. He is an anthropologist who has carried out fieldwork among the Buin of southern Bougainville Island, beginning in 1971.

\section{Kenneth, Roselyn}

Roselyn Kenneth comes from Lontis Village, Haku, in Buka. She graduated BA (with Honours in Anthropology) from the University of Papua New Guinea (1989) and did course work and research for a Master's qualification at Monash University, Melbourne, in 1995-6, obtaining a graduate Diploma in Social Anthropology when circumstances obliged her to return to University of Papua New Guinea without completing the writing of her thesis. She has since completed her Masters Degree. From 2000 to 2004 she worked in Buka with the United Nations Office of Project Services and from mid-2005 she is employed with AusAID in Port Moresby.

\section{Laracy, Hugh}

Hugh Laracy obtained a PhD from The Australian National University in 1970. He was subsequently appointed to an academic post in New Zealand from where he has since continued to teach and to carry out research on the Pacific from a wide range of overseas archives, and has published extensively on a range of issues. $\mathrm{He}$ is a regular news media commentator on Pacific affairs and literature.

\section{Lummani, Joachim}

Joachim Lummani is from Iamaru Village, Muguai, Buin District, Bougainville. He graduated from the University of Papua New Guinea in 1997 with a combined BEc and BA degree (majoring in Philosophy). He then worked with the National Research Institute, Port Moresby, and the Cocoa Coconut [Research] Institute of Papua New Guinea in Rabaul. He is presently studying for his Masters degree in agricultural research at Curtin University of Technology, Western Australia. 


\section{McWillliam, Scott}

Scott MacWilliam is a Centre Associate at the Asia Pacific School of Economics and Government, The Australian National University. He teaches and writes on development, international and indigenous capital, and poverty, with particular reference to Kenya, Papua New Guinea, Fiji and Australia. He taught at the University of Papua New Guinea from 1983 to 1985, when his research on Bougainville began.

\section{Momis, Elizabeth Ibua}

Born in Buin and named Ibua, in 1969 she joined the Sisters of Nazareth in Bougainville and was professed as Sister Therese Marie in 1972. She obtained her diploma in secondary teaching from the Goroka Teacher's College, her BEd from the University of Papua New Guinea, and a graduate diploma in ministry from the Sydney College of Divinity. She has published on Bougainville Copper Ltd company-related problems and on the role of women in the Bougainville 'conflict'. She is married to John Momis.

\section{Momis, John}

John Momis was born in 1942 at Salamaua, and grew up in Morou Village, Buin, in South Bougainville, where his father was a mumira - an hereditary chief. He received his secondary education in Australia. After training in Papua New Guinea and Australia he was ordained a Catholic priest in 1970, in Bougainville. He has been elected to the Papua New Guinea National Parliament as a Bougainville representative seven times (1972-2002). From 1999 he was governor of Bougainville, a parliamentary position, but in April 2005 resigned to contest the election for President of the first Autonomous Bougainville Government. He is married to Elizabeth Ibua Momis.

\section{Nash, Jill}

Jill Nash graduated BA from the University of Minnesota and PhD from Harvard University. During her longterm research of the Nagovisi of Bougainville, her major interests have been kinship, gender and ethnicity. She is currently Professor and Chair, Department of Anthropology, State University College of New York at Buffalo.

\section{Nelson, Hank}

Hank Nelson was born in Boort, rural Victoria, in 1937. He went to Port Moresby in 1966 to teach at the Administrative College and the University of Papua New Guinea. He holds a PhD from UPNG. From 1972 he has held various positions at The Australian National University, including Pro-Vice-Chancellor. He is now 
Professor Emeritus. His publications, films and radio documentaries have been concerned with the histories of Australia and Papua New Guinea.

\section{Ogan, Eugene}

Eugene Ogan received a BA from the University of California and a PhD from Harvard University. In 1962 he began ethnographic studies of Nasioi speakers in Bougainville, and has continued his research for more than 40 years, expanding his focus to include the Solomon Islands and other parts of Papua New Guinea.

\section{Regan, Anthony}

Anthony Regan is a Fellow in the State, Society and Governance in Melanesia Project in the Research School of Pacific and Asian Studies at The Australian National University, Canberra. His main field of research is the law and politics of constitutions, conflict and reconciliation, and has worked in Papua New Guinea, Uganda, East Timor and Solomon Islands. He was an adviser to the Bougainville parties in the Bougainville peace process, 1997 to 2005.

\section{Sack, Peter}

Peter Sack studied law in Germany where he was born. After obtaining a PhD from The Australian National University in 1971 with a thesis on early European land acquisitions in German New Guinea, he continued to study the colonial as well as the pre and postcolonial law and history of Melanesia and Micronesia. He is a visiting fellow at the Research School of Pacific and Asian Studies, The Australian National University.

\section{Sagir, Bill}

Bill Sagir teaches at the University of Papua New Guinea. He is from Madang Province and his wife is from Haku, in Buka. He studied sociology at the University of Papua New Guinea and Victoria University of Wellington, New Zealand, and in 2003 obtained a PhD in Anthropology from The Australian National University.

\section{Spriggs, Matthew}

Matthew Spriggs is Professor of Archaeology in the School of Archaeology and Anthropology at the Australian National University. He has worked in the field of Island Southeast Asian and Pacific Island archaeology since 1975, obtaining his PhD from The Australian National University in 1981 on traditional Pacific irrigation technologies. He carried out archaeological research on Bougainville and Nissan between 1985 and 1987. 


\section{Tanis, James}

James Tanis is from Nagovisi in Bougainville. His undergraduate studies at the University of Technology in Lae were interrupted in 1988 by the Bougainville conflict. He held senior positions in the Bougainville Revolutionary Army and the Bougainville Interim Government and was actively involved in most aspects of the Bougainville peace process. From 2003 to 2005 he was Minister for Peace and Autonomy in the Bougainville Interim Provincial Government.

\section{Togolo, Melchior}

Mel Togolo was born at Rorovana Village in Bougainville. He graduated in Economics with honours from the University of Papua New Guinea in 1974, obtained his Masters Degree in Economics from the University of Leeds in England in 1976, and a Master's degree in Geography from the University of Hawaii in 1989. He held a series of senior positions with the North Solomons Provincial Government, in Bougainville, from 1978 to 1990. He has been a consultant and a general manager in several mining companies, responsible for corporate affairs and for issues dealing with the environment, sustainable development, government interests and regulations, the private sector and NGOs.

\section{Tryon, Darrell}

Darrell Tryon is a Professor of Linguistics in the Research School of Pacific and Asian Studies at The Australian National University. He specialises in the indigenous languages of Oceania, particularly Island Melanesia, having worked extensively in every island group, from Bougainville to New Caledonia, for nearly 40 years. 


\section{INDEX}

\section{A}

agriculture, subsistence gardening, xxxi, 9, 44, 48, 56, 80, 148, 153, 154, 162, 215, 229, 233,

234, 236, 238, 242, 243, 250-2, 254, 276-8, 338, 352, 375, 376, 377, 389, 392, 401, 408, 412,426

Aita and its people, 57, 60, 62-3, 64, 65, 204, 240, 243; Fred Archer posted there as coastwatcher, 182; Jack Read at Aita, 184

alcohol, 389, 393, 397; law forbidding use by Bougainvilleans dismantled, 476

Allied Geographic Section, 168, 171, 175, 437

Allied Intelligence Bureau (AIB), 189-90, 198

Alu, 35, 50, 109, 115, 121, 335-6, 344

Amalgamated Wireless (Australasia) Ltd (AWA), 176

Anglo-German Convention 1899-1900, 75

Anglo-German Declaration of 1886, 74-5, 77

annexation, 73-8

Apiatei, 428, 430, 445

Applied Geology Association (APG), 270

Arawa people, 162, 290, 296; plantation, 156, 157, 167, 173, 261, 295, 389, 390; resumption of land 1969, 295; township, 101, 140, 244, 261, 262, 268, 277, 286, 287, 297, 298, 299, 366, 391-4, 395, 396, 397, 404, 408, 412, 413, 415, 425, 426, 428, 431, 436, 437, 442, 447, 448, 452, 463, 466, 467; village, 277, 296

Arawa Enterprises Ltd, 272

archaeological excavations, 1; Kilu Cave, 1, 2, 4-6, 8, 11, 46; Palandraku, 8, 10-11; Sohano and Hangan pottery phases, 11-12; on Nissan, map of sites, 7; Lebang Takoroi, 6, 7, 9; Lebang Tatale, 6, 7, 9; Lebang Halika, 6, 7, 8, 9; Yomining pottery phase on Nissan, 10, 11, 145 central Bougainville, Sivu rock shelter, 12; Sivu, Asio and Pidia pottery phases, 12, 15, 17

Archer, Fred, planter, 143, 147, 148, 156, 157, 158, 159, 160, 165, 167, 182

Aropa Valley, 57, 90, 155, 156, 273, 389, 391, 393, 395, 396

artefacts / artifacts see also material culture, 164, 203, 212, 216-18

Asitavi, St Mary's [Girls] High School, 134, 319, 320, 321, 390, 432, 432

Assembly of Chiefs (AOC), 367-8, 370

Auna, Joseph L., 129

Australian Agency for International Aid (AusAid), 373, 395

Australian and New Zealand Association for the Advancement of Science (ANZAAS), 219

Australian colonial Administration personnel: Ashton, Des, 292; Bridge, Ken, 179, 190; Brown, 
David, 282; Cardew, Captain H.C. 117, 138-9; Charlton, Captain R. 138; Cleland, Sir Donald, Administrator, 131-2, 294, 304, 445; Cole, R.R, 195; Denehy, Max, 292;

Dougherty, H., 180; Ellis, Tom, 292; Guthrie, Eric, 179, 197; Green, Frank, 179, 197;

Humphries, A.J, 195; Hunter, Lt. A.J., 115-16, 138; Mackie, Lt. John, 177, 180, 183-4, 186, 197; Mann, Max, 197; McAdam, Major T.L., 145, 152, 153; McCarthy, Keith, 176; McGregor, A.R., 115, 138; Maughan, J.M., 137; Merrylees, J.I., 179, 180, 181; Ogilvy, Captain H.B., 113, 114, 137; Pethebridge, Brigadier S.A.,115; Simcocks, Captain George, 138; Somerset, Captain, 116, 138; Stevenson, George, 179, 185, 186; Slattery, C.W., 195; Bougainvilleans in Australian Administration employment: Tamti, Amos 176; Tokidoro, Nelson, 176

Australian Imperial Force (AIF), 162, 193, 198

Australian military administration of Bougainville, 137-9, 144, 145, 146, 155, 176

Australian New Guinea Aministration Unit (ANGAU), 189-91, 195, 301

Austronesian, evidence of pre-historic immigration, 1, 17, 350

Austronesian languages in Bougainville, 31-7, 39, 44-45, 46, 48

autonomy, 143, 296, 312, 314-6, 324, 413, 451, 465, see also secession

Avaipa, 428, 430, 431, 434, 443, 444, 446, 449

Avaroko, Johannes, 446, 460

\section{B}

Babala, 112, 114, 117, 119

Bagui Village, 110-17, 124, 126

Baitsi area, 163, 406, 446, 450-1

balance as a social ideal, xxv, 52-3, 211, 251, 258, 289, 419-20, 431, 434, 440-2, 456, 471, see also reciprocity

Bana district and people, 321, 404, 449-54, 450-4, 458, 463

BANA (Banoni and Nagovisi), 409

BANA Cocoa Marketing Society, 403

Bana High School, 321, 404

BANA Pressure Group, 242, 453, 454, 463

banking, 288, 395, 415, 457; Commonwealth Bank, 198

Bano, Patrick, 453, 454, 463

Banoni, 35, 48, 52, 123, 260, 263, 290, 321, 409, 450, 451-3

Barnes, Charles, 291, 292, 293, 296

Bava, 109, 428, 430, 431, 442, 445

Bedford, Richard, 362, 392, 393, 444

Bele, Raphael, 281, 290, 463

Bennigsen, von, 87-8, 105

bibliographies on Bougainville, 200-1, 208, 220, 221

'big man' concept of leadership, 16, 17, 51, 206, 281, 332, 338, 402

Bika, John, 314

Biro/Biroi Village, 128, 150, 400, 402, 404

'blackbirding', 146, 435, 436, see also labour recruiting

'Black Dogs' of Kieta, 185

black skin, xxv, xxvii, 57, 434; DermaSpectrometer readings, 58, 60; Melanin Index, 59, 60, 61

Blackwood, Beatrice, 54, 149, 161, 164, 166, 204, 206, 216, 357-8 
Blamey, Sir Thomas, 193

Boku Patrol Post, 400, 402, 450, 451

Bolave area and Community Government, 451-2, 456, 458, 461-4, 465, 467, 469, 471

Bonai, Martin, deputy NSPG, 453, 454, 465

bosbois / bossboys, Kerosene, 174, 175, 185; Siarua, 156; Tukan, 156

Booga, 429, 430, 442, 449-50, 451

Bougainville [Provincial Government] Agreement 1976, 314-16

Bougainville Christian Farmers' Association, 320

Bougainville Combined Councils Conference, 297, 308, 440

Bougainville Copper Agreement 1976, 265-6, 309-10

Bougainville Copper Foundation (BCF), 272

Bougainville Copper Limited (BCL), xx-xxi, xxii, 27-8, 132, 201, 224, 258-73, 275, 276, 290, 295, 314, 316, 326, 327, 391, 392, 426, 440, 448, 452, 454-63, 464, 465, 467, 469

Bougainville Copper Proprietary Limited (BCPL), xxi, 294-6

Bougainville Council of Elders Act 1996, 370

Bougainville Development Corporation (BDC), xxxii, 224-5, 462-3, 465-6

Bougainville Development Foundation (BDF), 272

Bougainville District Patrol Reports, 133, 143, 146, 195, 227-9, 230, 235, 236, 238, 278

Bougainville flag, 464 raised, 298

Bougainville identities, in precolonial times, $423-4$, in the colonial and post-colonial era, 424-42

Bougainville Independence, Declaration in 1975, 209

Bougainville Interim Provincial Government (BIPG), 297, 298

Bougainville, Louis de, 18

Bougainville Peace Agreement 2002, 143

Bougainville People’s Congress, 371, 373, 430, 445, 453

Bougainville Resistance Forces, 395, 196

Bougainville Revolutionary Army (BRA), 132, 252, 270, 287, 314, 324, 349, 366, 368, 369, 373 , 395, 396, 398, 404, 406, 408, 413, 443, 447, 449, 450, 453, 465

Bougainville Special Political Committee (BSPC), 297, 362-3, 461

Bougainville Transitional Government, xix, 370

Bowu, 114, 148, 166

Brothers of St Joseph, 308, 318, 320, 323

boundaries, 74-6, 77-8

bruklus, see secession

Buin, 204, 212, 410, 204, 205, 339-42, see also Telei

Buka, 203, 204, 206, 207, 216, 218, 219, 240, 241, 242, 244, 247; identity, 435-8, perceived superiority as labourers, 436

Buka Interim Authority (BIA), 369-8

Buka Liberation Front (BLF), 368

Buka Local Government Council (BLGC), 359-60,

Bundesamt für Gewissenschaften und Rohstoffe (BGR), 25

Burger, Friedrich, 107, 217

Burns, Philp \& Co. Ltd, trading company, 101, 102, 114, 145-6, 147, 148, 150, 157, 158, 159, $163,165,166,167,174,197,231-3,236,238$ 


\section{C}

Cambridge, Rolf, 191, 197

Canarium almonds, 8, 53, 397

capital and capitalism, xxviii, xxxii, 101, 157, 165, 225, 226, 227, 230, 232, 234, 236, 237,

$271,295,403$

cargo cults, 131, 145, 152, 200, 209, 264, 291, 389, 451; leaders, Pako, Terasin, Muling, Sanop, $172-3$

Carteret, Philip, 18, 169

Carteret Islands, 169-70

cash income, 175, 240, 245, 375, 378, 393

cash cropping, 240, 241, 243, 244, 245, 248, 249, 250, 252, 257, 260-2, 276, 278, 327, 357, $376,377,378,383,384,385,391,392,393,403,407,408$

Catholic Church, statistics, 1966-7, 134-5; education and health services, 319-22; training for religious life, 322-23; leadership roles, 323-5; concern for social justice, 325-7; socio-economic innovations, 327-8

'C'- class Mandate of League of Nations, 75, 139, 142

Chan, (Sir) Julius, 310

chiefs, xxxi, 16, 51, 81, 82, 89, 96, 97, 106, 109, 110, 112, 113, 114, 116, 117, 234, 334, 336, 337, 356, 360, 361, 365, see also luluai, mumira, rank, tsunono, tubikau

'Chinatown' at Buka Passage, 171, 177, at Kieta, 393

Chinese presence, 170, 178, 185, 289; indentured labourers, 157; Chin Yung, 177; Laurie Chan, 177; Mack Lee, trader, 185; Wong You, storekeeper at Buka Passage, 158, 174, 177, 180, 185

Chinnery, E.W.P. 122, 141, 142, 145, 146, 147, 151, 161-4, 166, 167, 344

Christian Life Centre (CLC), 406, 408

Ciperau, see Tsiperau

civil war, see the 'conflict'

clans and sub-clans, 49, 52, 54-5, 214, 251, 261, 276, 278, 281-2, 286. 341-2, 344, 345, 347-9, $352-4,356,364,367,368,372,372,375,380,382,427,429,445,451,457,458,469$, see also lineages

Clarke, Bill, 388

Clark, Dymphna, 208, 219, 221

cocoa (cacao), xxxi, xxxii, 131, 173, 224, 230, 233, 234, 237, 239-40, 245-7, 248, 249, 250-1, $254,255,256,262,306,327,328,357,378,389,391,393,395,401,403,405,407,408$, $443,450,453,455-8,464$

Cocoa and Copra Marketing Board, 393

colonialism, xxxiv e.g and the Haku, 355-60

'conflict' ['the conflict'], contributing factors, xxviii-xxix, 202, 224, 245, 248, 250, 252, 285,

$318,319,394,395,396,442,448,450,451,471$; see also 'crisis'

Connell, John, 153, 204, 359, 360, 445

Constitutional Planning Committe of Papua New Guinea (CPC), 297, 310-13, 363, 411

Constitution of North Solomons Provincial Government, xix-xxi

Conzinc Riotinto Australia (CRA), xx-xxi, 27, 224, 258-9, 263, 273, 293, 294, 295, 309, 326, 445, 454; see also Bougainville Copper Ltd

Conzinc Riotinto Australia Exploration (CRAE), xx-xxi, 275, 291, 292, 293, 294

copra, 80, 85, 87-8, 106, 125, 138, 147, 151, 152, 154, 156-7, 159, 160, 165, 167, 168, 173-4, 
$224,227-8,231,232,234,236,239,240,245,246,247--50,256,261,262,275,328$,

$378,389,391,393,395,393,399,410,412,413,414$

Council of Chiefs (COC), 365-8, 369, 370, 372; not in Mogoroi, 413

Council of Elders, Leitana [and Haku], 370-2, not in Mogoroi, 413

'crisis', the, 210, 218, 274, 285, 286, 288, 289, 297, 306, 310, 322, 324, 326, 328, 365, 368, 370,

$372,382,385,397,398,400,404,407,408,412,413,414$ see also the conflict

cult movements and leaders, 446

\section{D}

Damara, 428, 430, 431, 439, 443

Dameng, Damien, 439, 444, 445, 451, 453, 461, 464-5; see also 50 Toea Gavman

Dantenai, 428, 430, 443

Denoon, Donald, historian, 209, 392

Department of Agriculture, Stock and Fisheries, 179, 229, 405-6

Department of District Administration (DDA), 292

Department of District Services and Native Affairs (DDSNA), 172, 264

Deutsche Handels und Plantagen Gesellschaft (DHPG), 96-7, 107, 154, 155,

Dialogue broadsheet, 130, 306

Dodoko, see Loloho

Doellinger, Dr August, 90, 91, 136, 137

Dove, John, 130

\section{E}

earthquake activity, 28-9

ecology, 50

Eivo, 62, 63, 35, 204, 275, 278, 426, 428, 446, 463

Elkin, A.P., 201-2, 205, 210

Espie, (Sir) Frank, 275, 276, 293, 296, 299

ethnonational sentiment, 361-2

Expropriation Board, 144, 147, 156, 157, 158, 159, 167

\section{$\mathbf{F}$}

Feldt, Eric, 185

fertility (human) control, xxxii, 401

feuds, 110-19, 213

50 Toea Gavman, 451, 461, 464, 465

Fijians, 186

Filer, Colin, 274, 277

Firth, Stewart, 93, 95-100, 107, 208, 357, 372

flag of province raised, 298-90

Friedlaender, Jonathan, 422, 445

Frizzi, Ernst, 161, 203 


\section{G}

gardens and gardening, xxxi, see agriculture

Gausu, 281

genetic research: blood genetics, 63-4; influence from migration, 65, 67-9; mitochondrial genetics, 64-5; mtDNA analysis, 65-7; reasons for genetic variation, 1, 19, 61, 68

geological map (1989), 23; topography, 21

geological studies and surveys (1965), 24; (1987-88), 24-6

German New Guinea, colonial rule, 74, 84-103, 106, 107; legislative framework, 78-82; administrative framework, 82-4; administration personnel, 84-91; Protectorates Act, 78, 79; Native Penal Ordinance, 79; Protectorates Act, 79; Colonial Service Act, 81; economic developments, 100-3; commercial landholdings registered 1912-14, 140

Gorai, ('King') of Alu (Shortlands) 'big man', 85, 343

Government schools, 391

'Greater Bougainville' (archaeological term), 2, maps of, 3, 5, 19

Green, Frank, 179, 197

Griffin, Helga, 343, 444

Griffin, James, 143, 152, 197, 215, 217, 219, 221, 265, 273, 444, 445

Gris, Gabriel, 313

Guava census division and Village, 264, 391, 404, 448, 451-3, 471

\section{$\mathbf{H}$}

Hahalis Welfare Society, defection by Catholics, 131, 204, 207, 292, 293, 298, 313, 359, 439

Hahl, Albert, 85-6, 88-91, 98, 101, 105, 106, 107, 110-11, 217, 219, 436

Haku, 346-73, 374-87

Haku Community Government, 364

Halsey, Admiral, 188, 189,

Hammet, Michael, 204

Hannett, Leo, 129, 130, 204, 265, 296, 297, 298, 306, 313, 319, 362-3, 412, 461, 465, 466

Hasluck, (Sir) Paul, 226, 232, 291

headhunting, 16-17, 53, 69, 148, 149, 150, 166, 333, 335, 340, 422

head tax, xxxi, 102, 151, 165, 175, 356-7, 464

Hide, Robin, 221

Hobsbawn, Eric, 226

Holocene, 4, 5, 6, 11, 13

Holy Spirit Seminary, Madang, 129, 130, 305, 307

House of Assembly, 291-3, 301, 309, 310, 312, 313, 327, 359, 401, 415, 446, 453

Hughes, Philip J., 28

human diversity, xxvi, xxviii

human occupation, evidence of years, xxv

\section{I}

identitiy and identities, xxvi, xxvii, xxviii, xxix, xxxii, xxxiii, xxxiv, xxxv, 31, 128, 129, 153, 170, 237 , 267, 277, 288, 292, 306, 315, 318, 321, 346, 367, 371, 418-46, 464, 468, 470, 471

Ignace, Sister, 116, 117

Ioro and Ioro Community Government, 428, 439, 443, 449, 450, 451-3, 463 


\section{$\mathbf{J}$}

Jaba / Yaba River, 28, 240, 259, 262, 269, 290, 297, 449; environmental impact studies (1985, 1992), 28; pollution and compensation to villagers, $452,453,454,455,458$

Japanese, jurisdiction for, 157-8; residents in Bougainville, 170; Ikeda, 178, 179; Ishibashi, 178, 179; Osaki, 178; Usaia Sotutu, 176, 183, 186, 189; Tashiro Tsunesuke, 178, 185

Japanese military presence, World War I, 75, 141; World War II, 49, 108, 121, 128, 142, 150, 159, $165,176,179,180,181,182-194,195,197,198$

\section{$\mathbf{K}$}

Kabui, Joseph, 453, 460, 461, 462, 463, 467, 468, 469, 444, 446, 447

Kakapitai, Peter Chanel, 446

Kakata, Joseph, 300

Kangu police post and government station, 145, 172, 176, 176, 179, 185, 195, 303, 304, 305

Kanis, Johannes, 446

Kearei, Anton, 129

Keil, Jared, 203, 204, 205, 211, 214, 221

Kenneth, Roselyne, 207, 373, 444

Keriaka Plateau of limestone, 22

Kiau, Chilion, 122

Kieta, government post, 83-4, 89, 91, 93, 94, 95, 97, 101, 111, 217; capture in World War I, 136-9, 155; World War II, 180-2; European settlement, 109; Kieta Club, 389; Kieta Hotel, township, 278

Kieta District, 151, 169, 172, 173, 176, 178, 197, 449, 450, 451; sub-districts, 172, 234, 235

'King' Gorai see Gorai

'King' Tore see Tore

Kilage, Ignatius, 306, 313

kinship determination, 50, 51

Kitu, 301

Koikei, 413, 415

Koianu, 429, 430, 445, 446

Komoro, Andrew, 413, 415

Kongara, 52, 286, 287, 391, 392, 393, 395, 396, 397, 428, 429, 431, 434, 445, 449, 450

Kopana, Telei, 109, 113, 115, 116, 119

Koromira, 109, 152, 163, 190, 191, 227-8, 235-6, 240, 324, 328, 393, 428-9, 430, 445, 446

Korp, 186, 187

Krause, Fritz, 203

Kröning, Dr B., 101, 137, 181, 182

kukurai (government appointed village head), 151, 167, 358

Kunkei / Kungkei, 112-14, 116, 119, 301

Kupei gold mining, beginning of in 1930, 26, 175; in 1940, 175; decline of in 1941, 175; examined in 1961, 27

Kurai, 327

Kurongku, Peter, 129, 306, 319, 324 


\section{L}

Lamane, 429, 430, 442, 445, 449, 450, 451, 453-5, 458, 460, 465

land use among the Haku, 376-8; disputes, 50; pressures, 242; rights to, 50; systems in Bougainville, 241

languages, 50, see groups: Austronesian and Papuan, interrelation, 34, distribution maps, 32, 34

Lapapiri, 114, 148, 166

Lapita pottery, illustration [xxxvi], 1, distribution map, 2, 9-10, expansion, 18

Lapun, (Sir) Paul, 129, 293-4, 296-7, 306, 322

Laracy, Hugh, 163, 208, 209, 359, 445

Latukefu, Sione, 431

Lavelai in Buin, Methodist base, 119, 121

Laycock, Don, 118, 214, 221, 343, 344, 345

leadership, 51

leadership code, 311

'line' villages, 116, 145, 146, 150, 151, 344, 358, 405, 421, 456

lineages, 50, 54, 251, 341, 345, 353, 354, 367, 372, 375, 379, 381, 383, 387, 420, 423, 424, 425, $426,438,445,460$

localised groupings among Nasioi and Nagovisi, 429-30, map 430

Loloho / Dodoko, 28, 244, 261, 265, 270, 276, 277, 282, 295, 309, 390, 395, 396, 452, 453

Lower Tailings Lease Area, xxxii, 290, 446, 452, 453, 454, 455, 458

Lowie, Robert, 210, 211

Loy, Tom, 5

Lucas, W.H., 140, 147-8, 157-9, 167

Lue, Joseph, 129

luluai (government appointed chief), 81, 144, 151, 195, 301, 303, 357-8, 367

Luluai River, 195

Lummani, Joachim, xxxi, 408

\section{M}

Mackenzie, Seaforth, 146, 147, 148, 149, 151, 152, 166

MacWilliam, Scott, 238

Magara, 356

Magic and sorcery, 52, 53, 54, 211, 218, 352, 355-6, 375, 379, 458

Makis Paramountcy, 229, 230

Malinowski, Bronislaw, 210

Mamak, Alexander, 362, 392, 393

Marist Brothers, 127

Marists, 172, 361; their initiatives, Bougainville Diocese, Marist statistics, 1939, 126, 1966-7, 125, 134-4, chapels and schools constructed in 1920-21, 119, economic developments projects, 135, social justice support, 131-2

Marist Medical Mission League, Sydney based, 127

Marist priests, arrival in Bougainville, 152; some priests: Allotte, Fr Francois, 109-10, 111, 112, 120; Binois, Fr Albert, 152, 166; Boch, Fr Maurice, 120, 138-9, 145, 152; Fingleton, Fr Wally, 129, 130, 131, 265, 328; Flaus, Pater 98, 99, 107, 120; Forestier, Fr, 121; Grisward, Fr Joseph, 110, 111, 112, 113, 114, 116, 117, 118, 119, 121, 122, 344; Hannan (Monsignor) James, 127, 128; Lebel, Fr, 186; Lemay, (Bishop) Leo, 130, 131, 132, 265 , 
309, 323, 326, 327, 445; Lemers, Fr Paul, 360; McHardy, Fr Emmett, 127, 278, 290, 432, 436, 434, 437; Meyer, Fr Pierre, 109; Miltrup, Fr of Piano in Buin, 187, 198; Montauban, Fr Paul, 126; O'Reilly, Fr Patrick, 123, 124, 126, 163; Sarei, Dr Alexis, 129, 206; Seiler, Fr, 166; Wade, (Bishop) Thomas, 126, 127, 130, 164, 171, 302, 317, 322; Wiley, Fr Robert, 132

Mason, Paul, planter, 143, 159, 165, 176, 186, 187, 190, 191, 197, 215, 304

matrilineal descent and organisation, 49, 341-2, 375; among the Nagovisi, 401-2, 407, 457; usurpation of women's rights, 282; role of maternal uncles among the Haku, 374-87

Matzunitsi, Emma (Sr Catherine), 320

Me'ekamui Defence Force, 413, 447

Me'ekamui Pontoku Onoring Republic, 439, 440, 451, 453, 461

Me'ekamui, Republic of, 404, 447

Mekim Save, 468, 466, 468

Melanesian Alliance, 225, 465, 469

Melanesian, (in $\mathrm{R}$ and $\mathrm{H}$ Thurnwald) read Papuan

Melk-Koch, Marion, 210, 211-12, 345

Mena, Paul, 445

Mesiamo, 128, 150, 152, 153, 402

Methodists and their missionaries, 120-2, 126, 133, 151, 152, 163, 164, 166, 171, 172, 186, 319, 389; indigenous Methodist teachers, Devita, 121; Alley, Don, 133, 171, 181; Cropp, Allan, 121; Luxton, Clarence, 133, 171, 180, 181; Roreinang Mission Station, in Kongara area, 431; Voyce, Allan, 121; Alf 163, 164, 171; A.H. 167; Sister Ada Lee, 171, Fijian missionaries, 186

Methodist Missionary Society of New Zealand, 152, 171

Middlemiss, Barry, 297

Mining Workers Union, 467

Miriung, Theo, 265, 306, 319, 444

Mitchell, Donald, 204, 409, 242, 249, 250

Mogoroi Village, Buin, pen portrait, 339-45, 410-15

Moini, Peter, 403; murder of, 411

Mola, Donatus, 129, 296, 359

Momis, Elizabeth Ibua, 215, 221

Momis, Fr John, 112, 130, 296, 297, 298, 319, 326, 394, 411, 412, 415

Morauta, Mekere, 266

Morgan, Leo, 129, 412

Moro/Morou Village, 110-19, massacre, 301

Moro-Bagui feud, 110-19, 126

Moroko, Isaiha, 444

Moses, Henry, 467, 468

mumira (Telei chiefs), 109, 110, 118, 301, 302, 339, 340-1, 342, 343, 343, 344, see also chiefs

Mungkas Society, 296, 394

munibil (Haku, paramount chief), 348, 350, 356, 358-9, 367

Musingku [Musungku] Hokong Papala, 'Prince David', Noah of Siwai, 112, 448

$\mathbf{N}$

Nachman, Stephen, 204

Nagovisi, 204, 290, 400-9 
Namaliu, Rabbi, 302

Napidakoe Navitu, 296, 297, 362, 394, 429, 430, 440, 445

Narakobi, Bernard, 309, 313

Naruke, 278, 290

Nash, Jill, 51, 145, 150, 163, 204, 206, 400-9, 432

Nasioi people, 278, 284; ethnography, 203, 204, 260, 388-409, 428; language, 51-3, 287

National Constituent Assembly, 312, 313

National Provincial Premier's Conference, 468

Nebot, chief on Buka, 356

Nelson, Hank, 133, 166

Newbury, Colin, 154

New Guinea Infantry Battalion (NGIB), 190, 192

Neu Guinea Kompagnie, 77, 79, 80, 82, 86

New Panguna Landowners Association (NPLA), 290, 453, 463

Nikora at Bagana, 236

Nissan, xv, 6-19; archaeological sites map, 7, 47, 48, 50, 88, 105, 106, 157, 169, 184, 188, 190 , 194, 203, 204, 424, 446

North Solomons Agricultural Foundation, 272

North Solomons Cultural Centre, 218

North Solomons Medical Foundation, 272

North Solomons Provincial Government (NSPG), 305, 314, 316, 364, 411, 415, 430, 440; Constitution, drafted 1972, 441, Provincial Executive Council (PEC), 441, suspended by National Government, 447, dilemma, 470 (point 8)

Northern Solomons, 19, 77, 78, 83, 84, 85, 87, 88, 90, 91, 92, 93, 94, 95, 96, 97, 98, 99, 100, $101,102,103,104,105,106,107$,

Numa Numa (Numanuma) people and plantation), 13, 14, 85, 102, 109, 111, 167, 173, 176, $192,198,290$

\section{$\mathrm{O}$}

obsidian, trade in, 12,14

Ogan, Eugene, 149, 150, 155, 156, 160, 166, 204, 205, 206, 210, 215, 260, 265, 273, 388-409, $418,419,423,432$

Ona, Francis, 252, 270, 326, 368, 404, 447, 448, 449, 450, 451, 452, 453, 463, 467, 469, 471; as 'King' Francis Dominic Dateransi Ona Domanaa, 448

Oliver, Douglas, 16, 18, 51, 53, 56, 57, 58, 150, 161, 163, 164, 199, 200, 201-2, 203, 204, 205, $206,210,260,265,332,338,342,343,344,345,358,410,420,444,446$

ombudsman, 264, 306, 311

Oni, leader from Moroni village, 293

$\mathbf{P}$

Pako, 172-3, 183

Pangu Party (Pati), 297, 465

Panguna Development Foundation (PDF), 272, 295

Panguna Landowners' Association (PLA), 225, 264, 285, 290, 453, 462, 463, 466

Panguna mine and people, xxviii, xxix, xxxii, xxxiv, 25, 26, 27, 133, 201, 224, 237, 245, 258-73, 
259 (map), 274, 284, 286, 288, 290, 295, 308, 309, 313, 315, 403, 410, 425, 440, 443, 445 , 448, 450-4, 471; closure of the mine in 1989, 27; economic benefits, 27; negative effects, 27; examined 1961, 27; feasibility study 1969, 27; full production, 27

Papala, 301-2

Papuan (non-Austronesian) languages in Bougainville, Buin (Telei), Eivo, Keriaka, Kunua (Konua),

Nasioi (Kieta), Nagovisi, Rotokas, Siwai (Motuna), 39-45

Papua New Guinea Constitution, 314, 467

Papua New Guinea Defence Force (PNGDF), 286, 306, 368, 369, 394, 396, 449

Papua New Guinea National Parliament / government, 313-16, 443, 447, 456, 462, 464, 470, 471

Parkinson, Richard, 53, 85, 86, 95, 96, 97, 101, 107, 169, 203, 204, 420

Pariu, Michael, 462-3

Partridge, Frank, 194, 198

Patriliny, 407

patrol officers, 146

Patupatuai Marist mission, Buin coast, 109, 113, 116, 117, 126, 171; closed 119

Peace Monitoring Group (PMG), 395, 445, 448, 449

peace process, xxvi, xxxv, 329, 395, 398, 443, 446, 447, 448, 449

Pentanu, Simon, 444

'phantom' history, 124, 220

Phillips, Ken, 291-2, 293

Piering, 219, 221

pigs, 48, 49, 53, 113, 114, 117, 149, 150, 151, 164, 185, 190, 194, 228-9, 235, 302-3, 332, 333, 334, 335, 336, 338, 340, 341, 350, 352, 402, 409, 420; prehistoric evidence of presence on Bougainville, 8, 9, 11

Pirung, 428, 429, 430, 431, 433, 434, 442, 445

plantation colonialism, 388, 392, 398, 418

plantation economy, xxxi, 376-8, 382-6

plantation labourers, 160 see also bosbois

plantation managers and owners, 167; Archer, Fred at Jame, 147, 156, 157, 158, 160, 165, 167, 182; Burns, Frank at Teopasina, 184; Cambridge, Rolf of Soraken, 177, 191, 197, 198; Campbell, Claude of Raua, 143, 159, 160; Ebery, Thomas at Toimanapu, 167, 176, 180, 181, 185, 190; Falkner, Mrs Eve, at Tearouki,173 178, 187; Good, Percy at Kessa, 176, 181, 182; Huson, Mrs C. at Haramon on Buka, 173, 178, 187; Kröning at Toberoi, 181-2; Mason, Paul at Inus, 165, 176, 304; Scott, John, at Inus, 115, 121, 174; Stuart, Robert, at Inus, 155, also at Tenakau, 167, 174, 178, 179, 181; Arigua, Kurwina and Mabiri, 185, 197; Thomson, Drummond at Numa Numa, 176, Urban, Fred at Hakau, 159, 196

plantations, 145, 154-161, map 155, 167, 184, 197, see also Trading Companies

Pleistocene, 4, 5, 6, 11, 44, 48

police, New Guinea Police Force, 172; riot squad, 209, 296; posts, 146

Pomalate Village, pen portrait, 400-9

population (demography) estimates or census, Bougainville (or Northern Solomons) District, 1914, 170 , non-indigenous $102 ; 1921,144 ; 1924,151 ; 1931,170 ; 1935,170 ; 1939,242 ; 1940$, 196; 1941, 160-1; 1943, 196; 1950, 196; 1966, 125; 1967, 242; 1970, 130; 1980, 242, (rural) 243; 1988, 242; 1995, 242; 2000 (by rural villages) 244; 2005, xxv; Kieta District, 1924, 151; sub-districts, 1995, 242; 160-61; Nissan 1900, 88; Buka, 1921, 196, Buka 1940, 196, Buka 2000, 350; Nissan and Killinailu, 1900, 87-8; Kieta District, 1924, 151; District 
populations, 1941, 1960-1; 1951, 160-1, 1955, 242; Haku, 2000, 351; Haku by villages 2000, 351, Lontis Village 1999 and 2000, 351, urban south-east Bougainville 1970, 391, Nasioi villages 1960s and 2000, 275; Rorovana comparison 1960s and 2000, 275, in general, xxii, xxxii, 1, 13, 14, 68, 104, 170-1, 195-6, 196, 241-4, 246-7, 248, 250, 256, 257, 268, $269,273,278,287,324,340.382,390,392,396,398,405,408,427$

Poraka, 277, 290, see also Uruava

pottery, Buka, 1, 10, 11, 12, 13, 15; Nissan, 11; central Bougainville, 12, 15, 17; south

Bougainville, $15,17-18$

Prince David, see Musingku

principle of subsidiarity, see subsidiarity

Protestant evangelical sects, 397, 414

Provincial Executive Council (PEC), 441

provincial government system, 314-16

punitive expeditions, 81-2, 86-7, 92, 109, 111, 148, 149, 150, 437

Q

Queen Elizabeth II, 448

'Queen' Emma Forsayth, 87, 88, 100, 101, 104, 105

\section{$\mathbf{R}$}

Radio Bougainville, 314

radios introduced, $176,182,375$

Rainbow Centre, 328

Rambos, or militants, 467

Ranga and Opia's first coast to coast crossing of PNG, 219, 221

rank, xxxi, 51, 117, 334, 344, 346, 347, 348, 349, 350, 353-4, 358, 368, 371, 372, 375, 376,

$379,381,384,398,414,431$, see also tsunaun and tuhikau

Raring, Blasius of Nissan, 446

Read, Jack, 165, 167, 179, 180, 181, 182, 183, 184, 186, 187, 196, 197, 198

Rechinger, Karl and Lily, 217

reciprocity, xxvi, 210-11, 419, see also balance

records of German colonialism, 207-8

Regan, Anthony, 112, 211, 221

Regional Assistance Mission 2003, 448

Rememberance Day, 17 May, 447

Resistance Forces, 287, 395, 396

Ribbe, Carl, 203

right of eminent domain over land, 131

Rigu, St Joseph's Marist Brothers High School, 308, 309, 320, 321, 390, 394

Rimoldi, Max, 204, 207, 350, 356, 359, 372

Road Mine Tailings Leases Trust Fund (RMTLTF), 225, 263, 290, 463

Roche, Frank, 185

Rotokas, 57, 62-3, 65, 163, 164, 240, 290

Rovin, Luke, murder of, 403, 411 
Rorovana villages and people, 17, 58, 62, 137, 156, 209, 275, 276, 277, 278, 284, 286, 287, 288, 289, 290, 295-6, 309, 327, 391, 425, 426, 428, 463

Royal New Zealand Air Force (RNZAF), 189, 194

Rumba Village, 17, 172

Rutherford, John, anthropologist, 204

\section{$S$}

Sack, Bridget, 208

Sack, Peter, 140, 208, 219, 220, 221, 444

Sagir, Bill, 206, 207, 373

Sanop, 172, 183

Saposa, 48, 58, 69, 183

Sarei, Alexis Holyweek, priest, 129, 204, 207; premier of Bougainville, 265, 305, 313, 319, 453, 461, 465; Chairman of BIG, 298

Saovana-Spriggs, Ruth, 46, 207, 208

Schnee, 86-7, 105

Schutzgebiet (Protected Area), 75, 77, 104

secession, xvi, 291-9, 313, 362, 363, 447

Serero, Perpetua, 463

Seventh-Day Adventist (SDA) missions and missionaries, 121, 152, 163, 171-2, 186, 389, 438;

Pascoe, Cyril at Rumba, 172, 181

Shoffner, Robert, 204

Shortland Islands, 212, 277, relationship with Bougainville, 335-6

Siau, John, 444

Simeku, 42, 57, 65, 428, 430

Singkai, Gregory, 129, 306, 319, 323, 324, 325, 326

Sinko, James, 453, 454, 465

Sisiou, Peter, 130

Siwai (also Siuai), 204, cultural affinity with neighbours, 338, pacification, 119-123

Siwai Local Government Council, 433

smallholder, xxxi, 227-31, 233, 234, 236, 237, 239, 240-1, 245-9, 254-5, 276, 391

social and economic conditions 1940, 175

social change, 49

Society of Mary (SM) see Marists

Sohano (Buka Passage), 10-11, 170, 172, 180, 229, 389, 440

Solo Moma movement, 460, 446

Somare, (Sir) Michael, 258, 296, 297, 298, 303, 306, 310, 312, 313, 314, 370, 411

Specht, Jim , 11,14

spirit world, 49

Spriggs, Matthew, 43, 46, 47, 48, 49, 56

St Joseph's Marist High School, Rigu, see Rigu

Strasburg, Captain Lt. John, 137, 139

subsidiarity, principle of, 309, 311, 312, 316

Sullivan, Marjorie E., 28

sweet potato (kaukau), 229, 241, 299, 303, 377, 404 


\section{T}

Tabago Mission, 215, 323, 328, 414, 415

Takera, Clement, 402

Tamti, kiap's right hand man at Buka Passage, 176

Tamuka (Noga), Aloysius, 129, 215, 319, 322, 323

Tanis, James, 367, 429, 430, 446, 444

Tappenbeck, Ernst, 219, 221

Tarara Village of Torau speakers, 245, 282, 425, 426

taro, 5, 48, 49, 54, 122, 151, 241, 303, 350, 351, 377, 378

Tatamus, Peter, 129

Tatsiua, Elizabeth, 200

Tato, Hamao, 313, 367

Taukang, Philip, 132

tax, 27, 28, 81, 84, 92, 102, 116, 145, 148, 151, 160, 271, 295, 356, 357, 359, 439, 460, 461, 464; see also head tax

Telei (Terei) people, 110, 163, 203, 212; language, 213, 214, 302, 303, 434, 446; social structure, 215

Telipe, 429, 430

Teop Island and plantation, 12, 15, 48, 58, 69, 157, 171, 172, 204, 207, 208, 240

Teosin, John, 298, 313, 322, 360

Terrell, John, 13, 15-17, 51

Territory of Papua and New Guinea established 1949, 75

'the conflict' see also crisis, civil war

Thompson, Jack Errol, 27

Thurnwald, Hilde, 205, 211, 213, 214, 215, 216, 332-45

Thurnwald, Richard, 49, 51, 90, 106, 111, 149, 164, 204, 221, 150, 161-2, 203, 205, 210-16, $332-45,444$

Tinputz, 48, 51, 54-6, 86-7, 110, 137, 156, 159, 171, 173, 232, 240, 244, 245

Tiperau, see Tsiperau

Toberaki, 429, 430, 450, 451, 452, 454, 455, 456

Togel, James, 265

Togolo, Melchior, 265, 319, 362, 444, 446

Toiakingil movement, see Raring, Blasius, 446

Tomarasi, 429, 430, 450, 451

Tonepa, Fabian, 446

Tonnaku, Joseph, 129

topography, land map 21; seafloor map, 21

Torau people, 155, 17, 274-90, 420, 424, 425, 432, 434, 443, 444, 445

Torau villages, Rorovana, Vito and Tarara, 17, 426, 427, 463

Tore, ('King'), 446

Torokina, 29, 108, 129, 240, 244, 253, 301, 319, 322, 323, 327; development during World War II, 182, 187, 188-9, 190, 191, 194, 195, 198

totemic clans, 341-2, 344, 347

totems, 278, 341-2, 344, 345-6

traders and trading companies (foreign), Bismarck Archipel Gesellschaft, 101; Burns, Philp \& Co., 101, 102, 114, 146, 147, 148, 157, 158, 159, 160, 164, 166, 167, 174, 197, 231-3, 236, 238; Carpenter, W. R., 116, 159, 231, 233; Choiseul Plantations Ltd, 101, 114, 140, 145 , 
166, 174, 197, 231-2; Deutsche Handels-und-Plantagen Gesellschaft, 96, 154; Forsayth, 96, 97, 105; German New Guinea Company, 153; Hernsheim, 73, 101, 105; Lever Brothers,

101, 'Queen' Emma Forsayth, 87, 100, 101, 104; Watson, Colyer, 159

translations between languages, problems encountered, 213

Tsibin, Daniel, 129, 297

Tsiperao, 118, 343, 345

tsunamis, 28, 29

tsunaun (Tinputz person of rank or importance), 54-5, 358

tsunono (Haku chief) 346, 347, 349, 350, 351-2, 354, 356, 357, 358, 359, 360, 361, 364-72, 372, 373 , see also chiefs and mumira

Tubiana Mission, 109, 394

tubikau (Haku chief's sister, woman of high status), 351, 353, 354, 361, 372

tultul, 81, 151, 281, 357

Tunim, Marcelline, 444

Tunuru Catholic mission, 131, 265, 278, 436

Turiboiru Catholic mission, 116, 119, 121, 302

Tye, 116, 121

\section{$\mathbf{U}$}

Unilateral Declaration of Independence (UDI), 209, 313, 447

United (Uniting) Church and its affiliates, 321, 397, 400, 438

United Nations, 75, 266, 296, 298, 309, 313

United Nations Commission, visiting Bougainville 1962, 388-9

United Nations Decolonisation Committee, 313

United Nations Observer Mission, 306, 448

University of Papua New Guinea (UNPG), 129, 130, 200, 297, 391, 468

unu, Telei initiation feasts, 205, 333, 337, 340

upe (also upi) headgear, vii, 55

Uruava, 58, 275, 276, 277, 282, 286; people, 17; extinct language, 17, 35, 46, 290

U-Vistract pyramid money scheme, 448

\section{V}

Veripe, 429, 449, 450, 451, 453

Vernon, Don, 290

Village Courts in Haku, 364-6, 373

Vito, village of Torau speakers, 425, 275, 282, 426

volcanic activity, 12, 20, 22, 28-30, 43, 420

volcanoes, Bagana, 12, 24; active, 13, 30; Balbi, 12, 13, 22, 24, 30; Billy Mitchell, 13, 30; eruption, 13, 15, 17; Loloru, 13, 24, 30

\section{W}

Walllis, Samuel, 18

Wakunai, 57, 172, 240, 245, 245, 286, 287, 290, 395, 426

war damages compensation, 230

Ward, Eddie, 226 
Warwick Smith, George, 291, 292, 296

Wau, 281

Western Pacific High Commission (WPHC), 116, 124

White Australia policy, 157

Wickler, Stephen, 1, 2, 10, 46

Wolfers, Ted, 265, 273

World Bank Report 1965, 291

World War II on Bougainville, air war, 187; total deaths estimated, 194-6; effect on Bougainville population, 195-6; evacuation of civilians, 187, 196, 197

$\mathbf{Y}$

Yaba River see Jaba 



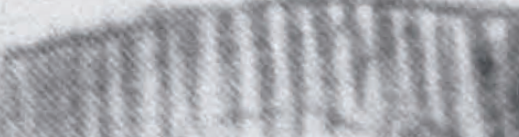
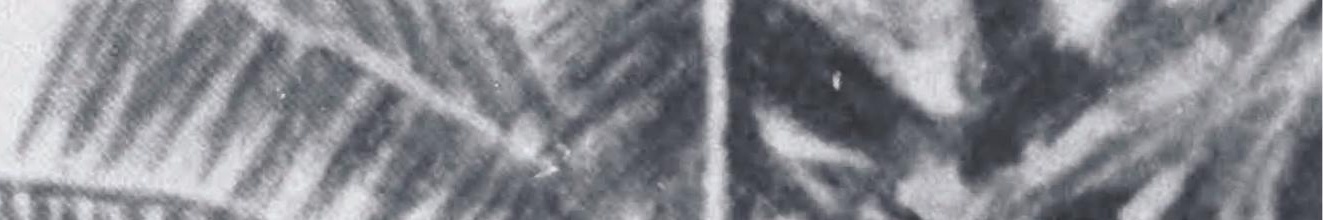

18
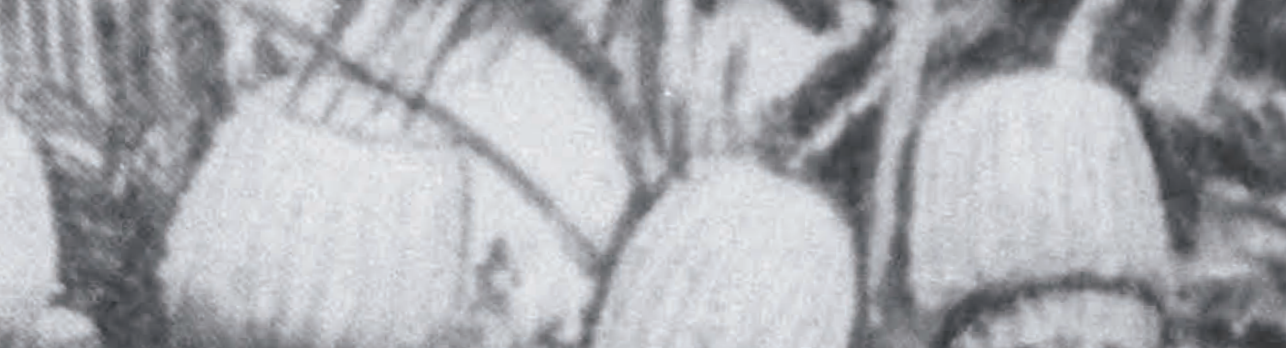

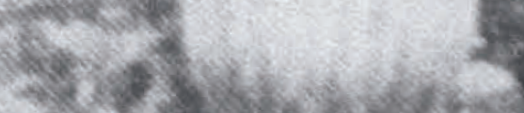

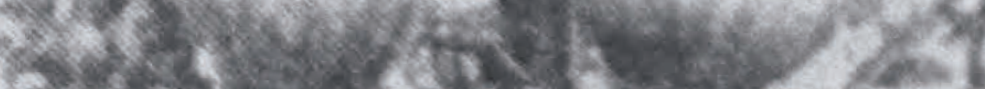

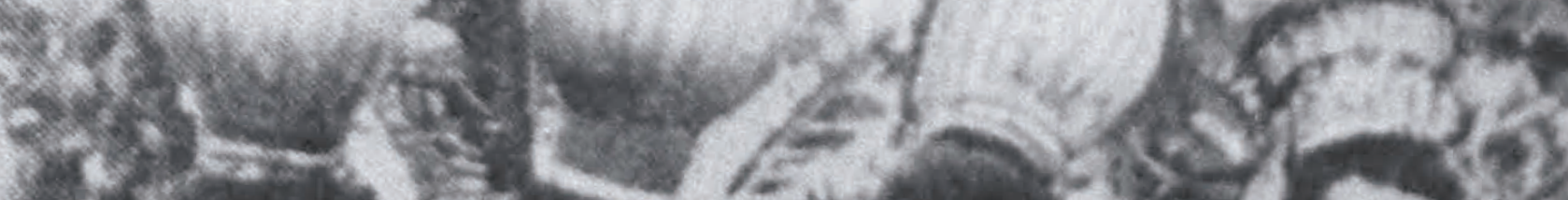

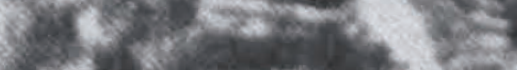
( 38

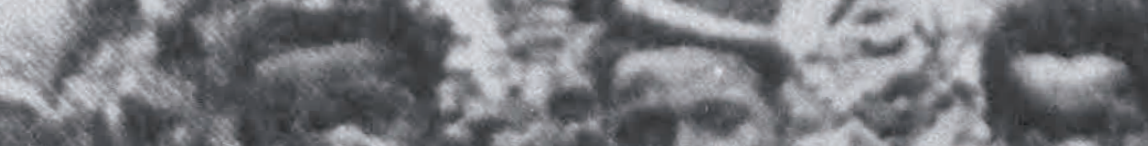

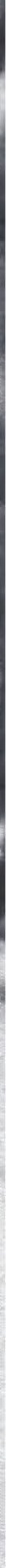

Boy initiates in 1911 with their characteristic Upe head covers. [Frizzi, 1914: Figure 18] 
